\title{
Light effects on fruiting body development of wildtype in comparison to light-insensitive mutant strains of the basidiomycete Coprinopsis cinerea, grazing of mites (Tyrophagus putrescentiae) on the strains and production of volatile organic compounds during fruiting body development
}

\author{
Dissertation \\ In Partial Fulfillment of the Requirements for the Degree \\ Doctor of Philosophy $(\mathrm{PhD})$ \\ of the Faculty of Forest Sciences and Forest Ecology \\ Georg-August-University Göttingen
}

Submitted by

Wassana Chaisaena

born in Bangkok, Thailand 
$1^{\text {st }}$ Referee: $\quad$ Prof. Dr. Ursula Kües

$2^{\text {nd }}$ Referee: $\quad$ Prof. Dr. Stefan Schütz

$3^{\text {rd }}$ Referee: $\quad$ Prof. Dr. Reiner Finkeldey

Date of Oral Examination: 17.07.2008 


\section{Zusammenfassung}

Coprinopsis cinerea gilt in Thailand als ein spezieller Speisepilz (Hed-cone-noi), der von kleinen Familienbetrieben auf landwirtschaftlichen Abfallstoffen, wie z.B. auf Wasserhyazinthe und Stroh produziert und in eingelegter Form vermarktet wird. In der Wissenschaft wird er als Modelorganismus zu Fruktifizierungsstudien bei Homobasidiomyzeten (Agaricomycotina) eingesetzt. C. cinerea ist ein heterothallischer Pilz, in dessen Lebenszyklus das Myzel abwechselnd zwei Stadien einnimmt: das unfruchtbare, kreuzungsfähige monokaryotische Myzel (Monkaryon) und das fruchtbare dikaryotische Myzel (Dikaryon), die sich im zweiwöchigem Lebenszyklus abwechseln. Dikaryonten mit zwei verschiedenen haploiden Zellkernen entstehen durch Verschmelzen zweier kompatibler Monokaryoten mit unterschiedlichen haploiden Zellkernen. Die Paarung zwischen den beiden Monokaryoten wird über unterschiedliche Allele an den beiden Kreuzungstypgenorte $A$ und $B$ kontrolliert. Diese werden auch für die Induktion der Fruchtkörperbildung des Pilzes benötigt. Gewisse Mutationen in diesen Genen bewirken eine Selbstkompatibilität von monokaryontischen Myzelien, die es diesen Mutanten wie z.B. dem Stamm AmutBmut erlauben, ohne vorherige Kreuzung mit einem anderen Monokaryon Fruchtkörper auszubilden. Solche Mutanten sind bevorzugte Stämme für Mutagenesen zur Suche von Entwicklungsdefekten in Fruchtkörperbildung, da sie nur einen Typ von haploiden Kernen besitzen.

In dieser Dissertation wurde der morphologische Prozess der Fruchtkörperentwicklung des Stammes AmutBmut hinsichtlich der Lichtregulierung untersucht. Die Fruchtkörperentwicklung dauert insgesamt sieben Tage. Zuerst werden kleine Hyphenaggregate gebildet, in denen sich Gewebe für Hut und Stiele der Pilze differenzieren. In den reifen Primordien findet Karyogamie, Meiose und sexuelle Basidiosporenbildung in bzw. an spezifischen Zellen (Basidien) statt. Die Prozesse der Gewebeentwicklung, Karyogamie und Meiose, sowie die Bildung von Basidiosporen werden durch den Tag/Nacht-Rhythmus kontrolliert, d.h. durch Zeiten mit und Zeiten ohne Licht. In dieser Arbeit wurden bis zur vollständigen Entwicklung von Primordien sechs verschiedene Zeitpunkte definiert, bei denen ein Lichtsignal für den korrekten Fortgang des Prozesses nötig ist. Sollten Lichtsignale während der Entwicklung z.B. durch Transfer von Strukturen verschiedenen Alters (1 Tag alt, 2 Tage alt, etc.) in konstante Dunkelheit fehlen, werden anstelle von Fruchtkörpern elongierte Strukturen 
(,etiolierte Stiele“) gebildet mit langen Stielen und unterentwickelten Hüten. Je nach Alter beim Transfer sind die erreichten Entwicklungsstadien der Hutgewebe verschieden weit, aber bis zu einem Alter von 5 Tagen wird jeweils eine Weiterentwicklung des Hutgewebes durch Transfer ins Dunkle blockiert. Gewebe einzelner Stadien der Fruchtkörperentwicklung und der Entwicklung etiolierte Stiele bei Wildtyp und Mutanten wurden eingebettet, geschnitten und die Struktur unter dem Mikroskop beobachtet.

Vier verschiedene Mutanten wurden untersucht, die in Licht etiolierte Stiele bildeten. Alle Mutationen waren rezessiv und traten in verschiedenen Genen ( $d s t 1$, dst2, dst3 bzw. dst4) auf. Zwei der Mutanten wurden direkt aus AmutBmut produziert. Zwei weitere kamen aus Japan mit einem anderen genetischen Hintergrund. In einem umfangreichen co-isogenem Prozess (sieben Generationen, wobei die erste Kreuzung mit dem Homokaryon AmutBmut und die weiteren Rückkreuzungen mit dem zu AmutBmut co-isogenen Monokaryon PS001-1 durchgeführt wurden) wurden neue Stämme mit dem gleichen genetischen Hintergrund wie AmutBmut produziert mit jeweils einem Gendefekt einer etiolotierten Stielausbildung aus den japanischen Stämmen. Bildung etiolierter Stiele in co-isogene Mutanten der vier verschiedenen $d s t$-Gene wurden morphologisch untersucht und verglichen. Zwei Mutanten $(d s t 1, d s t 2)$ waren defekt in ersten Schritten der Gewebeentwicklung. Sie waren zudem defekt in Lichtkontrollierter Bildung asexueller Sporen (Oidien) am Myzelium. Die dst2 Mutante war zudem defekt in der Unterdrückung von Fruchtkörperbildung im konstanten Licht und sie bildete auch etiolierte Stiele, wenn sie vollkommen im Dunkeln angezogen wurde im Gengensatz zum AmutBmut Wildtyp und anderen Mutanten, die mindestens ein Lichtsignal zur ersten Induktion einer Entwicklung benötigen. Aufgrund einer einfacheren Handhabung ist diese Mutante daher besonders interessant für Pilzzüchter für die Produktion essbarer Pilze, da sie etolierte Stiele under allen Bedingungen (im Licht, im Dunkeln, bei höheren und bei niedrigeren Temperaturen) macht. Alle anderen Stämme formen etiolierte Stiele nur bei $28^{\circ} \mathrm{C}$. Im Gegesatz zu anderen Stämmen, bei denen die kurzlebigen Fruchtkörper schnell degenerieren, wenn sie nicht gleich geerntet und weiter in Lake eingelegt werden, sind etiolierte Stiele langlebig und können daher frisch an Kunden verkauft werden.

Pilze werden aus verschiedenen Gründen gegessen, u.a. wegen ihres guten Geschmacks und Geruchs. In Kooperation mit Forschern der Abteilung Forstzoologie 
und Waldschutz, insbesondere Dr. Prodpran Thakeow, wurden Odorabgaben während der Fruchtkörperentwicklung gemessen. Typische flüchtige Pilzgerüche (1-Octen-3-ol, 3-Octanon) wurden in größeren Mengen während der frühen Phasen der Fruchtkörperentwicklung entdeckt. Ebenso konnten flüchtige Sesquiterpene ( $\beta$ Himachalen und Cuparen) während der Reifung nachgewiesen werden. Auch wenn diese Gerüche angenehm für den Verbraucher sind, können sie doch Probleme bei der Lagerung bereiten. Staubmilben wie z.B. Tyrophagus putrescentiae (Acari: Acaridida) lassen sich einfach durch diese Düfte anlocken und können dann Lebensmittel verderben. Labortests mit T. putrescentiae belegten, dass die beiden C8-Komponenten 1-Octen-3-ol und 3-Octanon die Arthropoden anlocken. Folglich werden Milben auch von C. cinerea Kulturen angelockt, die dann als Nahrungsmittel genutzt wurden. Milbenfraß bewirkt am angegriffenen Myzel eine immense Erhöhung an den vier volatilen Substanzen (VOCs, ,volatile organic compounds“). Dies erklärt auch die Milebnaggregation an den Fraßstellen in Pilzkulturen, da hier im vegetativen Myzelium vermutlich eine erhöhte Produktion an VOCs stattfindet.

Das Verhalten von Milben gegenüber Myzelkulturen und Fruchtkörpern wurde untersucht. Milben fressen das vegetative Myzel, aber nicht Primordien, Fruchtkörperstiele und etiolierte Stiele und auch nicht die multizellulären Sklerotien, melanisierte aggregierte Strukturen, die zum Fortbestehen der Pilze dienen. Allerdings werden die Milben von den Hüten reifer Fruchtkörper angelockt, wo sie die Lamellen beweiden und die reifen Basidiosporen in sich aufnehmen. Die Tiere verbreiten Basidiosporen äußerlich durch Anheften der Sporen an ihren Körpern, sowie gefressene Sporen nach Passieren der Verdauungstrakte durch Ausscheiden von Fäkalien. Ausgeschiedene intakte Basidiosporen in Faekalien können auskeimen. Wie hier gezeigt, dienen Milben daneben auch als Vektoren von Bakterien und, wie in der Literarur berichtet, auch von anderen Pilzen. Probleme, die bei der kommerziellen Pilzkultivierung durch Milbenbefall auftreten, sind somit die Kontaminierung des Materials durch die Fäkalien der Milben, sowie die Einbringung anderer schädlicher Mikroorganismen in die Pilzkulturen. In der kommerziellen Pilzkultivierung müssen daher gute hygienische Bedingungen herrschen, um einen Milbenbefall zu vermeiden. 


\section{Summary}

Coprinopsis cinerea in Thailand is a speciality mushroom (hed-cone-noi) that is grown in small family businesses on agricultural wastes, e.g. on water hyacinths and straw, and the fungi are offered in pickled form to the customers. In research, it is used as a model organism to study fruiting body development in the homobasidiomycete fungi (Agaricomycotina). C. cinerea is a heterothallic species with two distinct types of mycelia alternating in its life cycle, i.e. the infertile monokaryon and the fertile dikaryon. Dikaryons with two distinct haploid nuclei in their cells form by fusion of two compatible monokaryons having different haploid nuclei. Mating between two monokaryons is controlled by the two mating type loci $A$ and $B$. For a compatible mating, two monokaryons need to have different alleles at both loci. These are also needed for induction of fruiting body (mushroom) development. Certain mutations in the mating type genes cause self-compatibility of monokaryons, allowing such mutants (e.g. strain AmutBmut) to develop fruiting bodies without prior mating to a compatible monokaryon. Because strains like AmutBmut contain only one type of haploid nuclei and developmental mutants are easy to obtain from them, they are preferred strains for genetic studies in fruiting body development.

In this thesis, the morphological processes of fruiting body development of strain AmutBmut were followed up with respect to light regulation. Fruiting body development from start to end takes seven days in which first small hyphal aggregates will be formed, in which tissues for mushroom cap and stipe will then differentiate. Once all tissues are fully developed in the fruiting body primordia, nuclear fusion and meiosis will occur in specific cells (basidia) for the formation of the sexual basidiospores. The process of tissue development, karyogamy and meiosis and basidiospore formation is strictly controlled by the day/night rhythm, i.e. by periods with light and by periods without light. In total, six time points up to primordia maturation were defined where a light signal is required for progress in development. When transferring developing structures of different age (1 day-old, 2 days-old, ...) into constant dark, so-called etiolated, respectively dark stipes are formed, structures with long stipes and underdeveloped caps. Depending on the age of transfer, the developmental stage of the cap differs but up to day 5 of development, there will always be an arrest in development. Structures and tissues were observed under the microscope after embedding and sectioning them. Structures of etiolated stipes were compared with 
similar structures formed by specific mutants in fruiting body development in the normal day-night rhythm.

Four different mutants forming etiolated stipes under light illumination were analyzed. Genetic crosses showed that they had all recessive mutations and that the mutants were defective in different genes ( $d s t 1, d s t 2, d s t 3$ and $d s t 4$, respectively). Two of the mutants were directly produced in the AmutBmut background. Two others were obtained from Japan and had a different genetic background. In an extensive coisogenisation process (seven generations including a first cross with homokaryon AmutBmut and subsequent backcrosses to the AmutBmut co-isogenic monokaryon PS001-1), new strains were produced having the same genetic background of strain AmutBmut but carrying the defective etiolated stipes genes from the Japanese strains. Four co-isogenic mutants were compared in more detail in etiolated stipe development. Two of the mutants were defective in early development in light control of tissue differentiation. These two mutants $(d s t 1, d s t 2)$ were also defective in the light-induced production of asexual spores (oidia) in the mycelium. The $d s t 2$ mutant furthermore was defective in repression of fruiting body development in constant light and it formed etiolated stipes in constant dark unlike all other mutants and strain AmutBmut that require at least one light signal or alternatively a nutritional signal to induce hyphal aggregation. This latter $d s t 2$ mutant is particularly interesting for mushroom production as it will produce etiolated stipes under all environmental conditions (light, dark, lower and higher temperature) unlike the other mutants and also the AmutBmut strain that develop etiolated stipes only in a strict temperature regime at $28^{\circ} \mathrm{C}$. For farmers, cultivation will thus become easier when less restrictive culture conditions are tolerated. As a further advantage, unlike the wildtype mushrooms that will degenerate within a day unless boiled and pickled, the etiolated stipes are long lasting and can thus be sold also as fresh food to the customers.

Mushrooms are eaten by several reasons - one of it is their pleasant taste and odour. In further experiments performed in cooperation with members of the Forest Zoology and Forest Conservation, in particular Dr. Prodpran Thakeow, odour development during fruiting body development was followed up. Typical volatile mushroom odours (1-octen- 3-ol, 3-octanone) were detected in higher amounts during the earlier stages of fruiting body development as well as certain volatile sesquiterpenes ( $\beta$-himachalene and cuparene) at mushroom maturation. Whilst these odours are pleasant and attractive to the human consumer, they also may give a problem for hygienic storage of mushrooms. 
Storage mites also called grain or food mites such as Tyrophagus putrescentiae (Acari: Acaridida) are easily attracted by these odours and may spoil the food. Laboratory tests with T. putrescentiae proofed that both C8-compounds 1-octen-3-ol and 3-octanone attracted the arthropods. In consequence, mites were easily attracted to cultures of $C$. cinerea which were used as food sources by the animals. Wounding of the mycelium was shown to dramatically increase the production of the four VOCs (volatile organic compounds). Mites in fungal cultures were found clustering together in the vegetative mycelium at places of grazing, possibly due to an increase in the production of VOCs by possibly the damage caused through the grazing.

The behaviour of mites towards fungal cultures and mushrooms were further observed. Mites grazed on the vegetative mycelium but they did not attack the fruiting body primordia, fruiting body stipes and neither etiolated stipes and they also left aside the multicellular sclerotia, melanized aggregated structures serving for duration. However, mites were attracted to the caps of maturing fruiting bodies where they graze on the gills including ingesting the mature basidiospores. Basidiospores were distributed by the animals externally when attached to their bodies. Basidiospores were however also internally distributed by the mites. After passing the digestion track of the mites, faecal pellets were excreted containing many intact basidiospores able to germinate. In addition, mites were seen to distribute the asexually formed oidia from the vegetative mycelium to new places. In conclusion, mites act in three different ways in distributing in fungus. In addition, they are vectors of bacteria as shown in this work as well as of other fungi as reported in the literature. Major problems in commercial mushroom cultivation given with mite infestation are thus the contamination of the material with the abundant faeces that the mites produce as well as the bringing in of unwanted other micro-organisms that spoil the mushroom cultures. In practice for commercial mushroom production, good hygienic conditions have to be provided in order to avoid mite infestation. 


\section{Acknowledgements}

I would like to express my sincere thanks to all those who were involved in one or other way in the successful completion of this $\mathrm{PhD}$ studies. Without the support, encouragement, patience and intellectual guidance of my supervisor Prof. Ursula Kües and her hard help particularly during writing the thesis and editing that requires in depth knowledge of the subject, exceptional writing skills, and professionalism this study would not have been possible.

I would like to thank Prof. Stefan Schütz for giving me the opportunity to learn the analysis of volatile organic compounds in Coprinopsis cinerea at the section Forest Zoology and Forest Conservation of the Büsgen-Institute of the Georg-AugustUniversity of Göttingen for his comments and suggestions to my thesis and being the second supervisor and examiner of my PhD defense. I am also thankful to Prof. Reiner Finkeldey for readily accepting to be the co-examiner and for his kind suggestions and support all the way.

I express my deep gratitude to Assist. Prof. Manoon Mekaroonkamol, President of the University of Technology Lanna Phitsanulok Campus, Thailand, for his encouragement and providing the financial support throughout my $\mathrm{PhD}$. I would like also to thank my master's supervisors, Assoc. Prof. Sumonta Promboon from the Srinakharinwirot University and Assoc. Prof. Arunee Ingkakul from the Kasetsart University, Thailand for creating a true interest in me to study for a $\mathrm{PhD}$.

I sincerely thank Dr. Andrzej Majcherczyk and Dr. Patrik Hoegger for giving instructions in a fungal biotechnology course and their help and supervision in the laboratory techniques and scientific discussion in our group-meetings.

Especially I am obliged to Mojtaba Zomorrodi, Karin Lange, Alexandra Dolynska and Gisbert Langer-Kettner, not only for their kind technical help but also being friendly during my PhD studies. Special thanks to Monica Navarro-González for giving kind advice on microscope techniques and work in the laboratory, her friendly help, discussions and sharing experiences, to Martin Rühl, Banyat Cherdchim, Dong-Sheng Wei and Sudhakar Peddireddi for the continuous motivation and their suggestions and criticism on my thesis. I thank Prayook Srivilai for introducing me into genetics of $C$. cinerea, Rajesh Velagapudi, Dorothea Fragner, Jhansi Kalyani Pemmasani, Sreedhar Kilaru, Ravi Chandra Dwiredi and Ihtzaz Malik and for their friendly support and also 
Dr. Annette Naumann and Dr. Katerina Svobodova for friendship, help and the scientific discussions.

Special thanks to Dr. Rosemarie Heyser for teaching me photographing cultures and fruiting bodies with a digital camera, and to Dr. Andrea Olbrich for kindly teaching me the sectioning of samples with the microtome.

I would like to express my sincere appreciation to Prodpran Thakeow and Ulrike Eisenwiener for their kind co-operation in working on identification of volatile organic compounds in Coprinopsis cinerea and for friendship, help and nice discussions. I would like to thank Dr. Pavel Plašil, Dr. Oliver Eikel and Olivia Sánchez-Hernández for their kind cooperation in working with mites.

I would like to thank Dr. Ernst Kürsten and Dr. Gerhard Büttner for their kind coordination of the $\mathrm{PhD}$ program in Wood Biology and Technology.

I am really grateful to all Thai people in Göttingen who always took care of my feelings for my mother land, for their suggestions and help to lead a happy life during my stay in Germany. Special thanks to Martin Rühl and Pitipong Thobunluepop for their discussion of the statistical data analysis.

My sincere thanks to Christof Köhler and his family for their help in data analysis and support during my stay in Göttingen.

Finally my gratitude to my parents Mr. Tawin Singhadaung and Mrs. Rampai Sitornkul, my step-mother Mrs. Wannee Singhadaung, my mother and father in-law Mrs. Malee Chaisaena and Mr. Bunoorn Chaisaena and also my brother Mr. Rittiron Singhadaung, Mrs. Kanlayanee Supadit, Mrs. Autcharawan Oumyam and Piyarat Singhadaung for their continuous support, encouragement and taking care of my children with their love. I would like to express my deepest special thank to my husband for his continuous support, encouragement and taking care of my children with love and patience in Thailand during my stay in Germany. 


\section{Table of Contents}

\section{Page}

ZUSAMMENFASSUNG

TABLE OF CONTENTS

ix

\section{CHAPTER 1 INTRODUCTION, AIM OF THE THESIS ANA GENERAL} DISCUSSION

1.1 Abstract

1.2 Introduction to the subject mushroom cultivation 4

1.2.1 Production of edible mushrooms 5

$\begin{array}{ll}\text { 1.2.2 Edible mushroom as resource of nutrition } & 10\end{array}$

1.2.3 Cultivation techniques of the mushrooms Pleurotus, Volvariella and Coprinopsis in Thailand

1.3 Aims of the Thesis

1.4 Summarizing major results of this thesis and their general discussion

1.4.1 The process of fruiting body development in C. cinerea

1.4.2 Genetic analysis of C. cinerea mutants with defects in fruiting body development

1.4.3 Pests in fungal cultures

1.4.4 Volatile organic compounds (VOCs) in mushroom cultures

\section{CHAPTER 2 EFFECTS OF LIGHT IN FRUITING BODY}

DEVELOPMENT OF THE BASIDIOMYCETE Coprinopsis cinerea

2.1 Abstract

2.2 Introduction

2.3 Materials and methods

2.3.1 Strains and growth conditions

2.3.2 Tissue fixation, dehydration and infiltration with Roti-Plast and microscopy 
2.4 Results and discussion

2.4.1 Fruiting body development of homokaryon AmutBmut under a normal day-night rhythm

2.4.2 Progress in development after transfer of different stages of the fruiting body pathway of homokaryon AmutBmut into constant darkness

2.4.3 Transfer of etiolated stipes into normal fruiting conditions with a $12 \mathrm{~h}$ light $/ 12 \mathrm{~h}$ dark regime

2.4.4 Fruiting body development of $C$. cinerea homokaryon AmutBmut under periods of constant light illumination

2.4.5 Growth and fruiting body development of homokaryon AmutBmut under incubation at constant light at $28^{\circ} \mathrm{C}$ and $37^{\circ} \mathrm{C}$, respectively 99

2.5 Conclusions

2.6 References

\section{CHAPTER 3 DEFECTS IN LIGHT-REGULATION OF}

\section{DEVELOPMENT IN THE BASIDIOMYCETE Coprinopsis cinerea}

3.1 Abstract

3.2 Introduction

3.3 Materials and methods

3.3.1 Strains and culture conditions

3.3.2 Morphological analysis of etiolated stipes by hand-sectioning with a sharp razor blade

3.3.3 Photographing

3.4 Results and discussion

3.4.1 Mutations leading to etiolated stipes occurred in four different genes 115

3.4.2 Bringing the $d s t 1$ and $d s t 2$ defects into the genetic background of homokaryon AmutBmut

3.4.3 Co-isogenisation of self-compatible homokaryons carrying defective $d s t$ genes with the self-compatible homokaryon AmutBmut and characterization of the different $d s t$ defects in formation of etiolated stipes under standard fruiting conditions 
3.4.4 Analysis of the fruiting behaviour of mutant homokaryons under conditions differing from standard fruiting conditions

3.4.5 Other phenotypes influenced by the $d s t$ mutations 145

$\begin{array}{ll}3.5 \text { Conclusions } & 151\end{array}$

3.6 References 153

CHAPTER 4 GRAZING OF THE MITE Tyrophagus putrescentiae IN CULTURES OF THE BASIDIOMYCETE Coprinopsis cinerea 157

$\begin{array}{ll}4.1 \text { Abstract } & 158\end{array}$

$\begin{array}{ll}4.2 \text { Introduction } & 159\end{array}$

$\begin{array}{ll}\text { 4.3 Materials and methods } & 160\end{array}$

4.3.1 Organisms and culture conditions used in this study 160

4.3.2 Competition test between different types of $C$. cinerea mycelia 162

4.3.3 Testing effects of volatile organic compounds (VOCs ) on mites 163

$\begin{array}{ll}4.4 \text { Results and discussion } & 164\end{array}$

4.4.1 The origin of mites used in this study and their experimental handling and cultivation $\quad 164$

4.4.2 Grazing of mites in mycelial cultures of C. cinerea 165

4.4.3 Grazing of mites in mycelial cultures of C. cinerea with fruiting bodies 167

4.4.4 Further observations on behaviour of the mites in young $\begin{array}{ll}\text { mycelial cultures } & 171\end{array}$

4.4.5 Further observations on grazing preferences and behaviour $\begin{array}{ll}\text { of the mites } & 175\end{array}$

4.4.6 Consumption of basidiospores by the mites 178

4.4.7 Competition tests between different types of $C$. cinerea mycelia in attraction of mites 179

4.4.8 Fungal odour compounds, 1-octen-3-ol and 3-octanone, in attraction of mites 195

4.4.9 Reproduction of mites in fungal cultures 198

4.4.10 Death of mites in fungal cultures 202

$\begin{array}{ll}4.5 \text { Conclusions } & 204\end{array}$

$\begin{array}{ll}4.6 \text { References } & 208\end{array}$ 


\section{CHAPTER 5 VOLATILE PRODUCTION DURING DEVELOPMENT}

$\begin{array}{ll}\text { OF Coprinopsis cinerea } & 216\end{array}$

$\begin{array}{ll}5.1 \text { Abstract } & 217\end{array}$

$\begin{array}{ll}5.2 \text { Introduction } & 218\end{array}$

$\begin{array}{ll}\text { 5.3 Materials and methods } & 219\end{array}$

5.3.1 Strains and growth conditions $\quad 219$

5.3.2 Volatile organic compounds (VOCs) sampling by solid phase micro-extraction (SPME) and gas chromatography/mass spectrometry (GC/MS) 221

5.4 Results and discussion 223

5.4.1 Defining best conditions for fruiting of C. cinerea on glass vials 223

5.4.2 Identification of VOCs of homokaryon AmutBmut emitted during fruiting body development in glass vial cultures 230

5.4.3 Comparison of VOCs emissions by mycelia of $C$. cinerea cultures with respect to wounding

5.4.4 Wounding effect emissions of VOCs from fruiting body stipes of C. cinerea

$\begin{array}{ll}5.5 \text { Conclusions } & 247\end{array}$

$\begin{array}{ll}5.6 \text { References } & 250\end{array}$

$\begin{array}{ll}\text { CURRICULUM VITAE } & 257\end{array}$ 
CHAPTER 1

\section{Introduction, Aim of the Thesis and General Discussion}




\subsection{Abstract}

Cultivation of edible and medicinal mushrooms is worldwide an increasing business. In Thailand, mushroom cultivation on agricultural wastes and fast growing pest plants such as water hyacinth can help to establish small family businesses giving farmers a good extra income. Next to well-known edible mushrooms such as the oyster fungi (Pleurotus species, particularly Pleurotus ostreatus) and the paddy-straw fungus (Volvariella volvaceae), the inkcap Coprinopsis cinerea as a fungus adapted to higher temperatures by using composts as ecological niches grows well in this tropical country and was therefore introduced to the market in Thailand by governmental and royal support and by support of the FAO (Food and Agriculture Organization of the United Nations). The fungus easily accepts various kinds of agricultural wastes such as straws as well as the pest plant water hyacinth as substrate. Within short time, it reliably produces mushrooms that however need to quickly be harvested, boiled and pickled because mushrooms of $C$. cinerea are only short lasting. In this thesis, effects on light and dark periods on the developmental process of fruiting body development are analyzed to define growth conditions that help to make the fruiting structures longer lasting. Incubation in constant dark of early structures of fruiting body development leads by proliferation of tissue at the base of the normal stipe to the formation of special elongated stipes whereas at the same time cap development arrests. These elongated structures known as etiolated stipes or dark stipes will not directly autolyse as the normal mushroom does upon maturation. Production conditions promoting the formation of etiolated stipes could therefore very much ease for farmers the cultivation and promotion of $C$. cinerea on the market. However, since normally fully dark conditions are required for etiolated stipe production, this in practice is difficult to achieve. Luckily, mutants are available that by genetic defects produce long-lasting etiolated stipes also under conditions of light illumination. Four such mutants are presented in this thesis and their morphological and physiological properties are compared. Another focus in this thesis with potential effects on commercial mushroom production lies on mites that may infest fungal cultures and cause loss of yield by grazing on the mycelium and present hygienic problems by contaminating the potential food with their faeces. Mites of the species Tyrophagus putrescentiae attracted in the laboratory to $C$. cinerea cultures were therefore observed in this thesis in their behaviour with the fungus. Attraction of the mites to the fungus is likely mediated by volatile organic compounds (VOCs). Production of VOCs during vegetative and sexual 
reproductive development of the fungus was followed up and potential functions of certain groups of VOCs (eight carbon compounds, in particular 1-octen-3-ol and 3-octanone; sesquiterpenes, in particular cuparene and $\beta$-himachalene) are discussed. For the success of commercial production of edible mushrooms and their acceptance by the consumers, the compositions of VOCs emitted by the fruiting bodies play an important role since they determine the odor of the mushrooms and contribute to the flavor of the mushrooms.

Key words: Coprinopsis cinerea, Pleurotus ostreatus, Volvariella volvacea, Tyrophagus putrescentiae, homokaryon AmutBmut, dikaryon, fruiting body, mushroom, mushroom cultivation, pests, nutrition value, volatile organic compounds, 1-octen-3-ol, 3-octanone, Hed-cone-noi, water hyacinth, etiolated stipe 


\subsection{Introduction to the subject mushroom cultivation}

Higher basidiomycetes (Agaricomycotina) have various ecological functions. Many of them are degraders of complex organic materials including the difficult to decompose plant litter and specially also wood. After breaking down the complex organic material, saprophytic fungi take up the nutritients from the surrounding resources through absorption (Fett et al. 1995, Baeza et al. 2000, Mshandete and Cuff 2007). Distinguished are white-rot fungi that degrade the lignin in the wood and brownrot fungi that in contrast attack the celluloses and the hemicelluloses in the lignified plant cell walls (Schwarze et al. 2000, Schmidt 2007, Hoegger et al. 2008). Wood degraders might be saprotrophic or, less often, pathogenic. Amongst the pathogenic basidiomycetes are economical important species causing root, butt rot and stem rot to standing trees ultimately resulting in the death of the trees (Shaw and Kile 1991, Woodward et al. 1998, Kharazipour et al. 2007, Kües et al. 2007). Other higher basidiomycetes known as ectomycorrhizal species undergo positive symbiotic interactions with plants. In the symbiotic ectomycorrhizal situation, the fungi supply nutrients and water to the plant roots and benefit in the situation by obtaining carbonrich metabolites from the plants being prerequisite for fungal sexual reproduction (Martin et al. 2008). Sexual reproduction in higher basidiomycetes occurs in the fruiting bodies, commonly referred to as mushrooms, which are the most complex and largest structures occurring in the fungal kingdom (Moore 1998, Kües 2000, Kües and Liu 2000; http://www.ipm.ucdavis.edu/ PMG/PESTNOTES/ pn74100.html).

Many mushrooms are edible and/or of medical interest (Borchers et al. 1999, Chang 1999, Rühl and Kües 2007) and therefore are collected from the forests. However, yields of these non-wood forest products are unpredictable since very much influenced by the prevailing environmental conditions, e.g. temperature, light and humidity (Pilz and Molina 2002). Mushroom cultivation under defined conditions can overcome such problems. However, cultivation conditions for commercial production have so far been established only for a limited group of easy to handle saprotrophs that grow on plant wastes from agriculture and forestry (Rühl et al. 2007). Mushroom production by myorrhizal species being dependent on their hosts for mushroom production might be promoted in the forests by targeted inoculation of trees as much as the natural competitions with other species and the unpredictable climatic conditions allow (Alexander et al. 2002, Rühl et al. 2007). 


\subsubsection{Production of edible mushrooms}

Edible mushrooms present a source of human food for better nutrition in terms of health. For example, the overall protein concentration in mushrooms is favourable as well as the relative distribution of the different amino acids in the total protein content. In particular, mushrooms are rich in essential amino acids. In contrast, mushrooms are low in fat and cholesterol. Furthermore, many mushrooms are attributed as medicinal mushrooms by their content of many known and probably even more unknown secondary metabolites with positive effects on health, either in treatment of illnesses or in the prevention of bad health conditions (Wasser and Weis 1999, Schmit 2001, 2002, Wasser 2002; see below). Positive health effects are not only restricted to the edible species that for millenia are consumed by humans (Rühl and Kües 2007) but also toxic species such as the fly agaric (Michelot and Melendez-Howell 2003, Biziulevicius 2007). In addition, edible mushrooms are very tasty and have very pleasant aromas. Flavors from mushrooms as aroma compounds have thus apparent value for the food industry (Dijkstra 1976, Okamoto et al. 2002, De Pinho et al. 2008).

The substrates used for commercial mushroom cultivation are derived mainly from vast amounts of agricultural, forestral and sometimes industrial organic waste materials since such waste products are cheap and their usage in mushroom cultivation is a good solution to the problem of an environmental-friendly disposal with the extra result of a high value product. The variety of agro-forestry wastes reach from straw (wheat, rice, oat, ...), reed grass, sawdust of different species (spruce, pine, beech, birch, pine, gum wood, ...), banana and bamboo leaves, tree bark and stems, several husk types, some scrubs, weedy plant such as water hyacinth and others (reviewed by Poppe 2000). Cultivation of speciality mushrooms (i.e. less often cultivated and thus unusual mushrooms not regularly found in supermarkets) on lignocellulosic wastes represents one of the most economically and cost-effective organic recycling processes (Poppe 2000, Philippoussis et al. 2001, Obodai et al. 2003, Mandeel et al. 2005). Furthermore for economical mushroom cultivation with highest profit and reliable yields, easy to handle, low cost technologies are required. The basic knowledge for this comes nowadays mostly from scientific information from mushroom research to which the mushroom industries have been giving increased attention in the recent decades (Rühl and Kües 2007).

Worldwide, mushroom cultivation focuses on about a dozen species of basidiomycetes (Chang 1999, Kües and Liu 2000). Agaricus bisporus and allies (button 
mushrooms, champignon de Paris) are the most often cultivated species, followed by oyster mushrooms (Pleurotus species) and hiratake (Lentinula edodes) (Rühl and Kües 2007). Worldwide, mushroom production of the most important species is still increasing (Table 1) as well as the number of species that were so far successfully taken into cultivation (Rühl and Kües 2007). Particularly in China, occupying a leading position in mushroom production and consumption (Chang 2005; Table 2) and being a country of a strong traditional usage of many different species as medicinal mushrooms (Chang 1999, Mayell 2001, Chu et al. 2002, Shen and Royse 2002, Zhou et al. 2007), cultivation techniques for many new species were developed in the last years adding up to about a hundred different species that can nowadays be grown in commercial cultivation (Chang 2005, Rühl and Kües 2007). Amongst the quickly increasing number of speciality mushrooms are species from the traditional genus Coprinus (nowadays divided into the four different genera Coprinus, Coprinopsis, Coprinellus and Parasola; Redhead et al. 2001). Of the coprini, the shaggy mane fungus or lawyers' wig Coprinus comatus is best known as a delicious speciality mushroom (Navarro-González 2008; Table 2). For example in Taiwan, the fungus is grown for the formulation of nutraceuticals and functional foods (Ho and Peng 2006, Tsai et al. 2007) - i.e. food that is not only giving nutrients to the consumer but will also contribute to keep good health and well-being (Chang and Buswell 1996). Coprinopsis cinerea [formerly Coprinus cinereus; also known under other names e.g. Coprinus fimetarius and Coprinus lagopus sensu Buller; common name ink cap mushroom (Redhead et al. 2001); Thai names: Hed-cone-noi or Hed-thoua], the model species of the higher basidiomycetes for laboratory research (Kües 2000), is another edible species that is easy to cultivate (Navarro-González 2008). This species (Fig. 1) is eaten in Tanzania, Thailand, Sri Lanka and other developing countries (Mshandete and Cuff 2007, NavarroGonzález 2008). In some of the developing countries, young fruiting bodies are regularly collected as a welcome addition to their lunches by farm workers from waste heaps that accumulate on farms growing for example sisal and sugar canes (NavarroGonzález 2008) whilst e.g. in Thailand, it is purposely cultivated by small farmers as an extra income for the family on agricultural wastes and in particular on water hyacinths being a fast growing pest plant in Thai rivers (Polprasert et al. 1980, Mahujchariyawong 2001, Buranachonbot 2004, Jantarasri 2004, Rühl and Kües 2007). Since mature fruiting bodies quickly autolyse (Kües 2000, Navarro-González 2008), the fungus is harvested prior to full fruiting body maturation (see below). The harvested maturating 
Table 1 Estimated worldwide mushroom production of the most important species in tons/year (Chang 1999, Kües and Liu 2000)

\begin{tabular}{|l|l|l|l|l|l|}
\hline \multirow{2}{*}{ Species } & \multicolumn{5}{|l|}{ Worldwide production in tons in the year } \\
\cline { 2 - 6 } & $\mathbf{1 9 8 1}$ & $\mathbf{1 9 8 6}$ & $\mathbf{1 9 9 0}$ & $\mathbf{1 9 9 4}$ & $\mathbf{1 9 9 7}$ \\
\hline Agaricus bisporus & 900.0 & $1,227.0$ & $1,420.0$ & $1,846.0$ & $1,955.9$ \\
\hline Lentinula edodes & 180.0 & 314.0 & 393.0 & 826.2 & $1,564.4$ \\
\hline Pleurotus spp. & 35.0 & 169.0 & 900.0 & 797.4 & 875.6 \\
\hline Auricularia spp. & 10.0 & 119.0 & 400.0 & 420.1 & 485.3 \\
\hline Volvariella volvacea & 54.0 & 178.0 & 207.0 & 298.8 & 180.8 \\
\hline Flammulina velutipes & 60.0 & 100.0 & 143.0 & 229.8 & 284.7 \\
\hline
\end{tabular}

Table 2 The twelve mostly produced mushrooms in China (Chang 2005)

\begin{tabular}{|l|l|l|l|l|l|l|}
\hline \multirow{2}{*}{ Species } & \multicolumn{6}{l}{ Production in tons/year } \\
\cline { 2 - 7 } & $\mathbf{1 9 8 6}$ & $\mathbf{1 9 9 8}$ & $\mathbf{2 0 0 0}$ & $\mathbf{2 0 0 1}$ & $\mathbf{2 0 0 2}$ & $\mathbf{2 0 0 3}$ \\
\hline Pleurotus spp. & 100 & 1,020 & 1,700 & 2,590 & 2,647 & 2,488 \\
\hline Lentinula edodes & 120 & 1,388 & 2,205 & 2,072 & 2,214 & 2,228 \\
\hline Agaricus bisporus & 185 & 426 & 637 & 743 & 923 & 1,330 \\
\hline Auricularia spp. & 80 & 491 & 968 & 1,124 & 1,242 & 1,655 \\
\hline Volvariella volvacea & 100 & 32 & 112 & 116 & 151 & 197 \\
\hline Flammulina velutipes & 10 & 189 & 299 & 389 & 506 & 558 \\
\hline Tremella spp. & 50 & 100 & 103 & 114 & 138 & 184 \\
\hline Hericium erinaceus & 50 & 28 & 6 & 9,5 & 13 & 31 \\
\hline Hypsizygus spp. & - & 21 & 84 & 120 & 190 & 243 \\
\hline Pholiota nameko & 1 & 31 & 48 & 51 & 85 & 172 \\
\hline Grifola frondosa & - & 10 & 6 & 15 & 37 & 25 \\
\hline Coprinus comatus & - & - & - & 39 & 157 & 178 \\
\hline Others* & - & 664 & 470 & 371 & 464 & 1,100 \\
\hline
\end{tabular}

*Others include Pleurotus nebrodensis, Pleurotus eryngii, Agrocybe chaxinggu, Dictyophora spp., Agaricus brasiliensis, Ganoderma spp., Wolfiporia cocos, Lepista nuda, Agrocybe aegerita, Tricholoma gigangteum, Auricularia fuscossuccinea, Tremella cinnabarina, Pleurotus citrinopileatus, Pleurotus sapidus, Stropharia rugoso-annulata and Lentinus giganteus

mushrooms are cleaned, blanched in hot water, pickled in a salt brine and offered in supermarkets in preserving glasses (Fig. 2).

Next to C. cinerea, other speciality mushrooms cultivated in Thailand include a temperature-tolerant variety of the oyster mushroom Pleurotus ostreatus (Thai name: Hed-gnangrom) and temperature tolerant strains of other Pleurotus species that grow at $25^{\circ} \mathrm{C}$ (Molloy et al. 2003, Keshri et al. 2003, Vetayasuporn 2006, Villaceran et al. 2006), the tropical mushroom Volvariella volvacea (common name: paddy straw mushroom; Thai name: Hed-fang). They are grown in Thailand in small family businesses on agricultural wastes (Buranachonbot 2004; Fig. 3 and Fig. 4). Own farm wastes such as cotton wastes, dried corn stalks and crushed corn cobs and other wastes from local industries e.g. spent brewers grains, bagasse and sawdust can be also used 


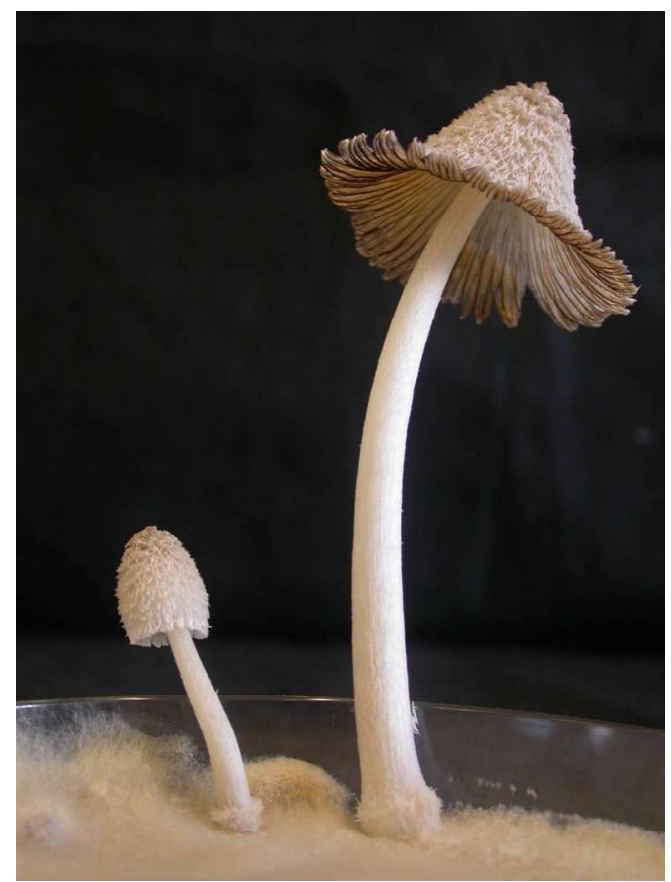

Fig. 1 A dikaryotic strain of Coprinopsis cinerea (Hed-cone-noi, Thailand; photograph by W. Chaisaena). The culture was grown in a $9 \mathrm{~cm}$ in $\varnothing$ Petri-dish on artificial agar medium (YMG/T; Granado et al. 1997). After mycelial growth for 5 days at $37^{\circ} \mathrm{C}$ in the dark, fruiting bodies appeared when cultures were transferred for 7 days at $28^{\circ} \mathrm{C}$ into standard fruiting conditions (12 h light/12 h dark and 85-90\% humidity; Granado et al. 1997).

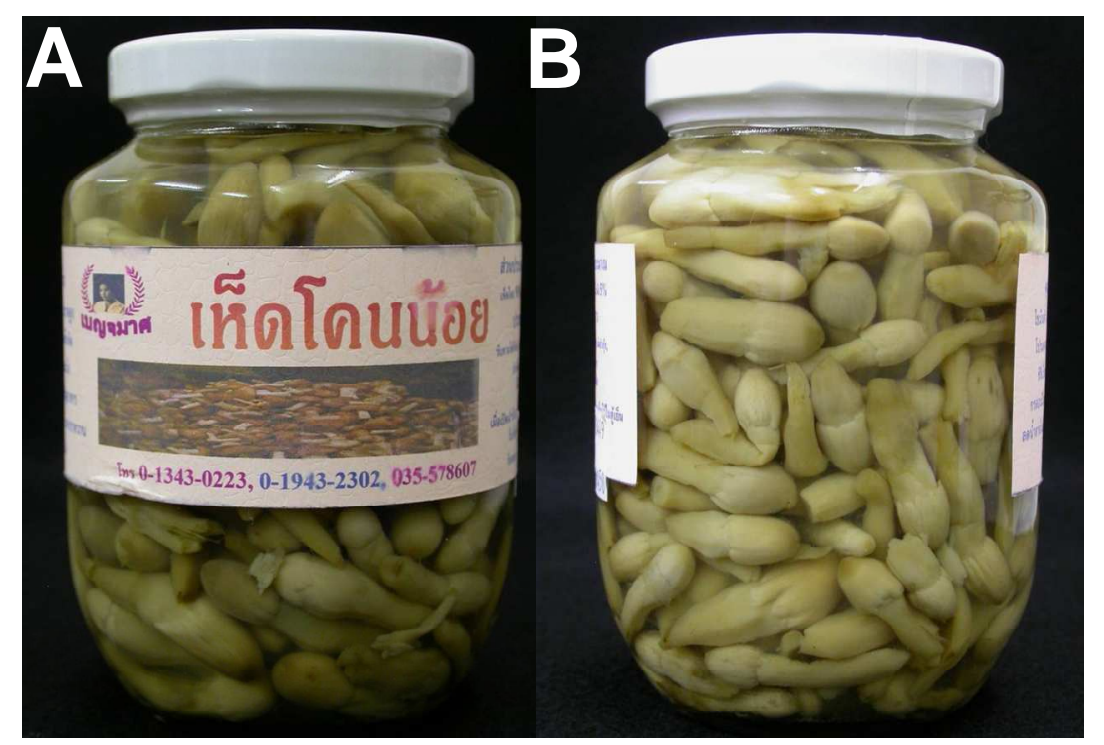

Fig. 2 Young maturating mushrooms from a commercial dikaryotic strain of Hed-cone-noi (Coprinopsis cinerea) pickled in a 50\% salt solution in a glass jar as a product from the Benjamagh company in Thailand sold in a Thai food store; photograph by W. Chaisaena. Note that the pickled Hed-cone-noi structures are immature primordia as likely obtained under partially exclusion of light. The inscription on the glass states as values for nutrition that the product has low fat, no cholesterol, high mineral content and potassium and promises the consumers a decrease of blood pressure, protection against cancer cells by selenium, improvement of the appetite by glutamic acid, and decrease of blood sugar as a preventive action in diabetes. 

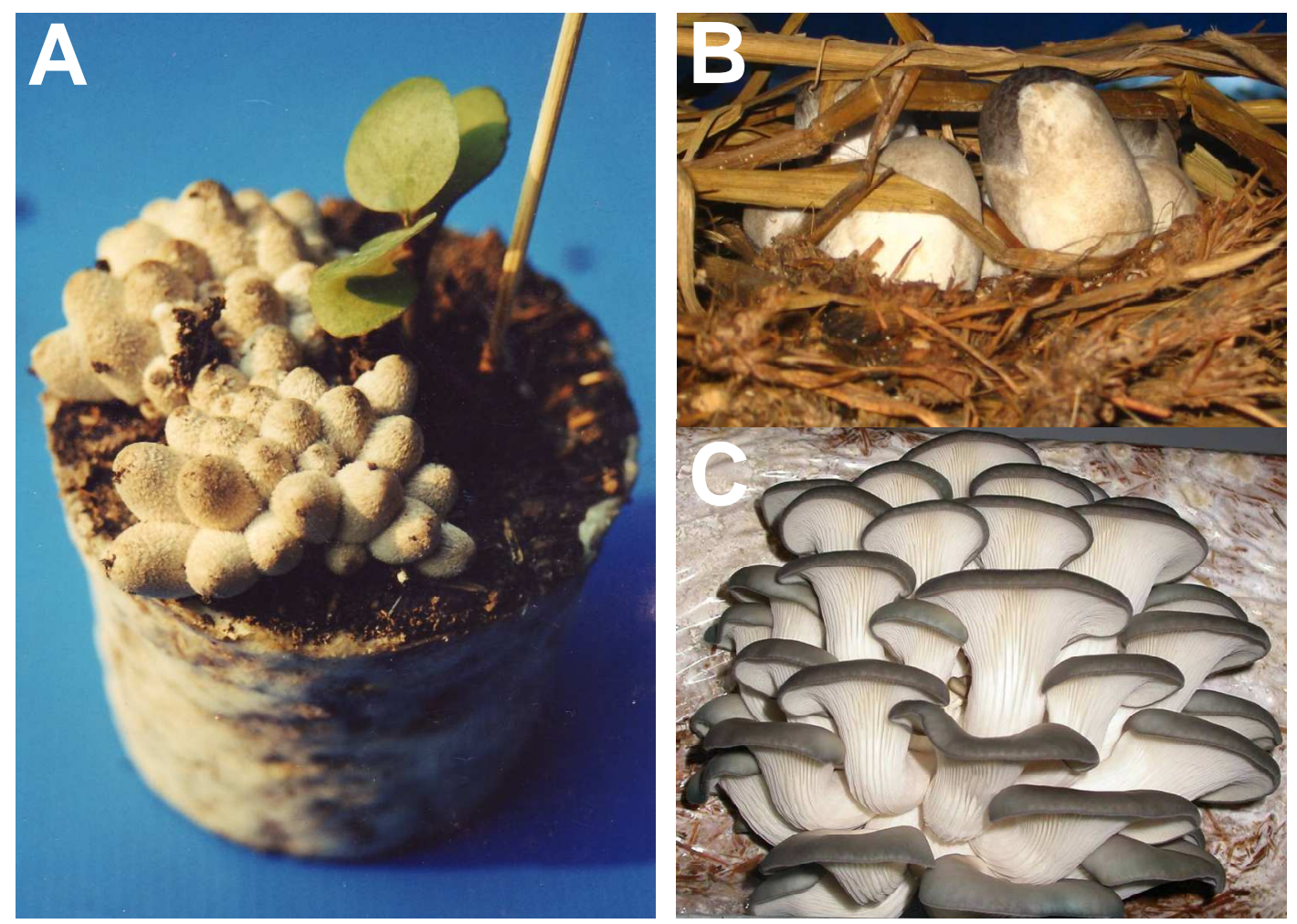

Fig. 3 Cultivation of edible mushrooms on lignocellulosic wastes in Thailand. (A) Coprinopsis sp., Hed-cone-noi, Thailand (likely Coprinopsis cinerea) was coincidentally grown on a mixture of bean skins and rice straw in pot plant container $10 \mathrm{~cm}$ in $\varnothing$ and $9 \mathrm{~cm}$ in height which was made of a mixture of banana fibers and recycled paper and coated with a 1:3 solution of paraffin and glycerol (for details in production of pot plant containers see Kharazipour et al. 2007). Prior to filling into the container, the bean skin-rice straw mixture was watered by $100 \mathrm{ml}$ of a $2 \%$ urea solution and a Kalanchoe was planted into the material (Chaisaena et al. 2003). (B) Volvariella volvacea (Hed-fang) grown on rice straw in a Thai mushroom farm of Tanapon Bunme and (C) Pleurotus spp. (Hed-gnangrom) grown on a mixture of water hyacinth and rice straw in a culture chamber at the Büsgen-Institute in Göttingen. Photos by W. Chaisaena taken in Thailand (A) and (B) and in the laboratory in Göttingen (C).

offering an efficient recycling of the materials with an added-value (htt://www.angkor.com/cityrain/Ron/ff/Water\%20hyacinths\%20turning\%20a\%20weed \%20into\%20a\%20winwin\%20situation.htm; Vetayasuporn 2006). Compared to temperate countries where without high energy costs $V$. volvacea and $C$. cinerea may be grown only seasonally, these species are particular well adopted to the tropical countries since preferring high growth temperatures up to $37^{\circ} \mathrm{C}$ and more and high fruiting temperatures at $25-28^{\circ} \mathrm{C}$. Mushroom cultivation on small scale with successful low-tech methods and minimal investment is possible for the species why cultivation is so attractive for small family businesses (Samarawira and Fernando 1973, Mau et al. 1997, Chiu and Moore 1999, Villaceran et al. 2006). 

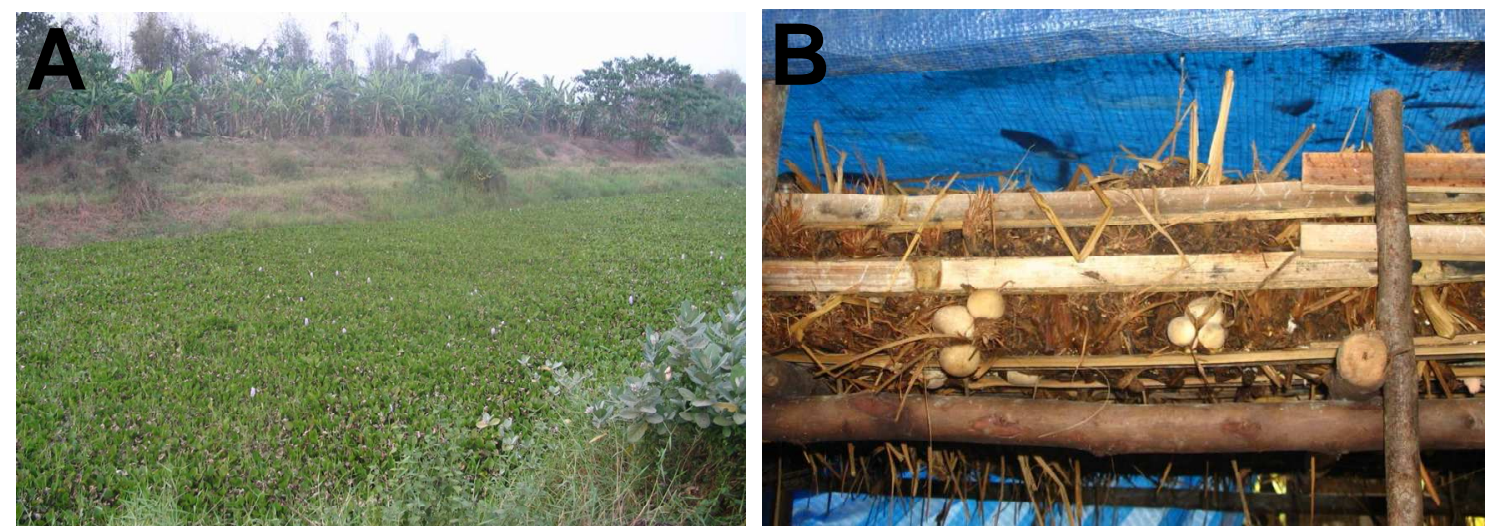

Fig. 4 Water hyacinth as cheap, quickly renewable substrate for mushroom cultivation. (A) This weedy plant abundantly grows in and thereby blocks waterways in Thailand. The waterways have constantly to be freed from the material which as a very efficient way of recycling can be used for preparing at low costs an excellent substrate for growing mushrooms. (B) Cultivation of Volvariella volvacea in a mushroom bed filled with a mixture of water hyacinth and rice straw serving as a substrates for growing mushrooms. Photos by W. Chaisaena taken in Thailand.

\subsubsection{Edible mushroom as resource of nutrition}

The nutritional potential of the edible mushrooms C. cinerea, Pleurotus flabellatus and $V$. volvacea grown in Tanzania as domesticated indigenous wild species on composted solid sisal decortication residues were analyzed by standard procedures such as atomic absorption spectrophotometry in order to determine the proximate chemical composition of dried fruiting bodies. The results showed that the overall nutritional potential of the three mushroom species are quite good (Table 3, 4 and 5). The overall results indicated that the fruiting bodies of three native mushrooms from Tanzania have nutritious qualities similar to other cultivated exotic edible mushrooms and a much higher protein content than many cereals and vegetables. The three mushrooms offer therefore to Tanzania and other tropical developing countries a good diet of high nutritional value by a highest protein content and a favourable mineral content (Mshandete and Cuff 2007). 
Table 3. Proximate composition of the three domesticated edible wild mushrooms in Tanzania (after Mshandete and Cuff 2007)

\begin{tabular}{|c|c|c|c|}
\hline & $\begin{array}{l}\text { Coprinopsis } \\
\text { cinerea* }\end{array}$ & \begin{tabular}{|l|} 
Pleurotus \\
flabellatus*
\end{tabular} & $\begin{array}{l}\text { Volvariella } \\
\text { volvaceae* }\end{array}$ \\
\hline Moisture (\% of wet weight) & $92 \pm 0.84$ & $93 \pm 1.93$ & $91 \pm 0.64$ \\
\hline Dry matter (\% of wet weight) & $8 \pm 0.16$ & $7 \pm 1.07$ & $9 \pm 0.36$ \\
\hline Total nitrogen (\% of dry weight) & $4 \pm 0.06$ & $4.48 \pm 0.29$ & $6.5 \pm 0.04$ \\
\hline Crude protein (\% of dry weight) & $17 \pm 0.25$ & $21 \pm 0.09$ & $28 \pm 0.16$ \\
\hline Crude fat (\% of dry weight) & $1.0 \pm 0.03$ & $1.3 \pm 0.53$ & $3.3 \pm 0.01$ \\
\hline Crude fibre (\% of dry weight) & $6.6 \pm 0.32$ & $11 \pm 0.89$ & $9.8 \pm 0.41$ \\
\hline Ash (\% of dry weight) & $13 \pm 0.62$ & $6.1 \pm 0.27$ & $10 \pm 0.12$ \\
\hline Total carbohydrate (\% of dry weight) & $62 \pm 0.58$ & $60 \pm 0.25$ & $50 \pm 3.15$ \\
\hline $\begin{array}{l}\text { NFE (nitrogen-free extract) } \\
\text { weight) }\end{array}$ & $56 \pm 0.85$ & $49 \pm 1.12$ & $41 \pm 2.9$ \\
\hline Energy (K cal) & $313 \pm 4.34$ & $302 \pm 8.65$ & $305 \pm 12.58$ \\
\hline Ascorbic acid (mg/100 g dry weight) & $55 \pm 1.91$ & $33 \pm 1.19$ & $48 \pm 1.55$ \\
\hline
\end{tabular}

$*$ Values are means \pm SD from nine determinations

Table 4. Major mineral content of the three domesticated edible wild mushrooms in Tanzania (after Mshandete and Cuff 2007)

\begin{tabular}{|l|c|c|c|}
\hline Mineral (mg/100 g dry matter) & $\begin{array}{l}\text { Coprinopsis } \\
\text { cinerea }^{*}\end{array}$ & $\begin{array}{l}\text { Pleurotus } \\
\text { flabellatus* }\end{array}$ & $\begin{array}{l}\text { Volvariella } \\
\text { volvaceae* }\end{array}$ \\
\hline Sodium (Na) & $338 \pm 2.30$ & $686 \pm 3.00$ & $258 \pm 2.20$ \\
\hline Potassium (K) & $3232 \pm 2.60$ & $1537 \pm 2.40$ & $1324 \pm 2.50$ \\
\hline Phosphorus (P) & $1142 \pm 3.00$ & $1616 \pm 2.97$ & $1699 \pm 2.57$ \\
\hline Magnesium (Mg) & $36 \pm 2.10$ & $40 \pm 1.90$ & $57 \pm 2.30$ \\
\hline Calcium (Ca) & $214 \pm 2.60$ & $120 \pm 2.50$ & $446 \pm 19.00$ \\
\hline
\end{tabular}

$*$ Values are means \pm SD from three different analyses

Table 5 Trace mineral content of three domesticated edible wild mushrooms in Tanzania (after Mshandete and Cuff 2007)

\begin{tabular}{|l|l|l|c|}
\hline Mineral (mg/100 g dry matter) & $\begin{array}{l}\text { Coprinopsis } \\
\text { cinerea }\end{array}$ & $\begin{array}{l}\text { Pleurotus } \\
\text { flabellatus }\end{array}$ & $\begin{array}{l}\text { Volvariella } \\
\text { volvaceae* }\end{array}$ \\
\hline Zinc (Zn) & $141 \pm 3.40$ & $145 \pm 2.30$ & $68 \pm 2.20$ \\
\hline Iron (Fe) & $248 \pm 2.20$ & $209 \pm 2.50$ & $426 \pm 2.40$ \\
\hline Manganese (Mn) & $14 \pm 3.10$ & $10 \pm 1.80$ & $5.2 \pm 1.70$ \\
\hline Copper $(\mathbf{C u})$ & $23 \pm 0.10$ & $22 \pm 0.20$ & $16 \pm 0.42$ \\
\hline Cobalt $(\mathbf{C o})$ & Not detected & Not detected & Not detected \\
\hline
\end{tabular}

$*$ Values are means \pm SD of three different analyses 


\subsubsection{Cultivation techniques of the mushrooms Pleurotus, Volvariella and}

\section{Coprinopsis in Thailand}

Throughout growth of mushroom species on the substrates, the fungi must be capable to break down the prevalent organic materials and to convert them into necessary nutrients. Therefore, the success of commercial cultivation of mushrooms very much depends on the growth materials (substrates) chosen. Generally, a mushroom species might prefer a particular limited range of growth media, although some species can grow on a wide range of materials (http://www.attra.org/attra-pub/mushroom.html). Mushroom production is basically the end of the fungal life cycle (Kües 2000, Kües and Liu 2000, Rühl and Kües 2007). Thus, knowledge about the individual specifics of the life cycle (Fig. 5), the detailed steps in mushroom development (Fig. 6 and Fig. 7) and the growth requirements for each species (Table 6) are prerequisites for successful commercial mushroom cultivation. The continuous monitoring of mushroom cultivation conditions and timely manipulation of the respective environmental conditions are considered an important part of marketing mushrooms by commercial production (Sánchez 2004, Kitamoto 2006, Rühl and Kües 2007).

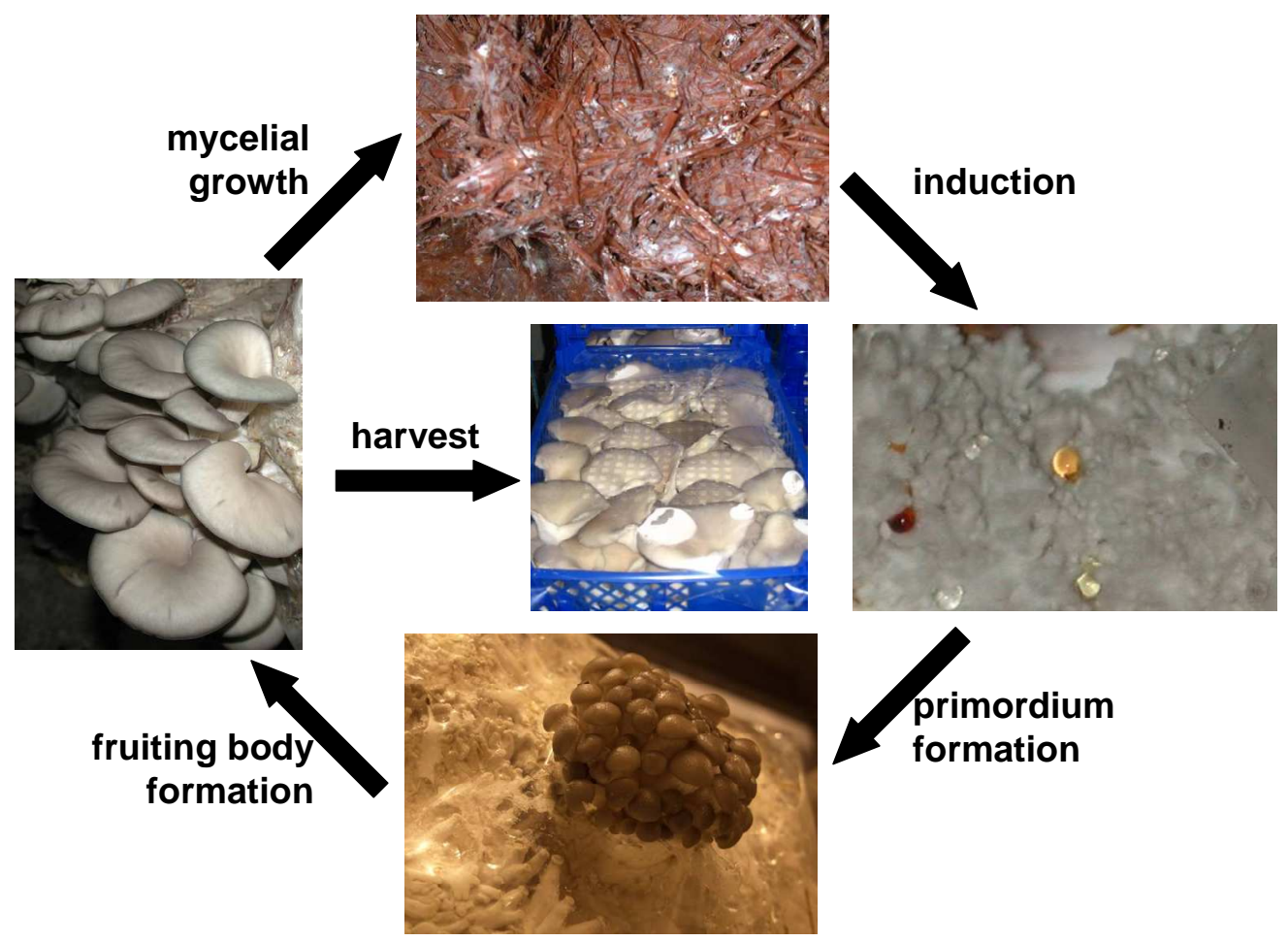

Fig. 5 The basic steps in the life cycle and, accordingly, the main steps in mushroom cultivation as documented for Pleurotus ostreatus on pasteurized wheat straw (Rühl et al. 2007; courtesy of M. Rühl). 


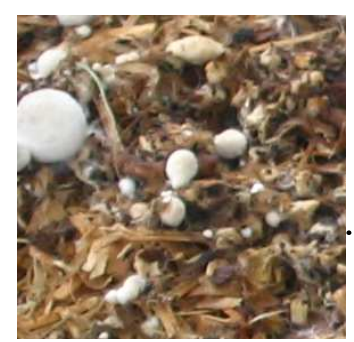

Pin and button stage

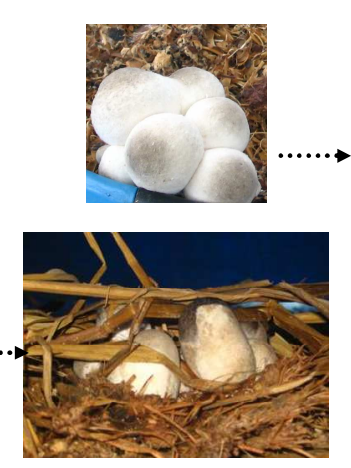

Egg stage

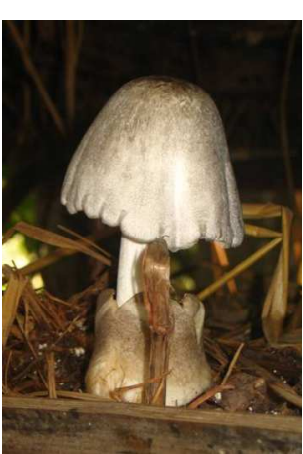

Elongation stage

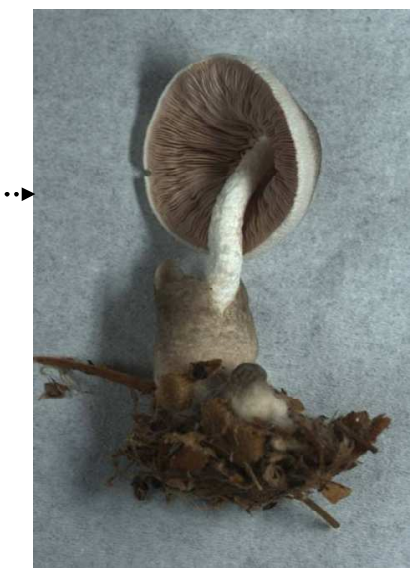

Cap expansion

Fig. 6 The main stages of mushroom development of Volvariella volvacea. The fungus grew on a mixture of dried water hyacinth and rice straw. After mycelial growth on the substrate from the added solid spawn sunlight stimulated the production of small nodules (hyphal aggregates) called pin-heads that further develop into the pin and the button stage (young structures being of white color) and then to the egg stage (being of dark brown color). From the egg, at the elongation stage the mature fruiting body arises through stipe elongation and cap opening. Mature mushrooms have a height of about 6 to $10 \mathrm{~cm}$. The originally white gills turn brown due to production of mature basidiospores. The photos were taken by W. Chaisaena in a Thai mushroom farm.

A number of different species of mushrooms has been commercially grown in tropical areas which cover also some areas of Thailand. In this country, Pleurotus spp. and $V$. volvaceae are cultivated for large scale sale on the central market and $C$. cinerea for small scale sale on local markets. The market for mushroom production in Thailand continues to grow due to the environmental-friendly potential of waste management and due to the benefits of the nutrition by mushrooms for obtaining better and keeping good health (Buranachonbot 2004, Mshandete and Cuff 2007). In 1998-2000, there were governmental and royal Thai programs that successfully supported in collaboration with the FAO (Food and Agriculture Organization of the United Nations) programs of mushroom production in rural areas particularly by disabled persons for sustainable food production (http://www.fao.org/sd/PPdirect/PPre0072.htm; ftp://ftp.fao.org/SD/ SDA/SDAR/sard/Mushroom_training_Thailand1.pdf;http://www.miusa.org/publication s/freeresources/mti/chapter14).

In some villages in Thailand, growing mushrooms on agricultural wastes is the only income that allows the villagers to stay in their home places and not to migrate for work into any of the big towns (http://www.gsid.nagoya-u.ac.jp/project/fieldwork/ofw/ OFW_Report/1999/OFW\%20Report\%20WG4.pdf). There is however still much potential to improve rural mushroom production by teaching more persons the 
knowledge required for successful cultivation, by further improving techniques (http://www.gsid.nagoya-u.ac.jp/project/fieldwork/ofw/OFW_Report/ 1999/OFW\%/ 20 Report\%20WG4.pdf) and possible also by selecting further species and better strains (Rühl and Kües 2007). As in other countries (Kües and Liu 2000, Rühl and Kües 2007) with learning better cultivation procedures, a boom of mushroom cultivation started in Thailand in the late 1980ies that since the start of this century raised slightly further (Fig. 7), possibly as the result of the governmental and royal promotion programmes on mushroom cultivation. Another major increase in mushroom cultivation may come with new or better establishment of speciality mushrooms such as $C$. cinerea that currently is grown only on some farms in Northern Thailand (Buranachonbot 2004).

Mushroom cultivation techniques divide into the general processes of substrate selection and preparation, substrate inoculation, incubation for mycelial growth and incubation for fruiting. The conditions for mycelial growth and for fruiting can be quite distinct. Fruiting occurs often better at lower temperatures than the optimal growth and light is particularly important for proceeding in the right developmental patterns (Buranachonbot 2004, Rühl and Kües 2007; http://www.fungifun.org/English/Pftek; Table 6 and Fig. 8). Nutrients are other important factors that are decisive for the entry into mushroom development. Nutrients need to be low (Moore 1998, Kües 2000) and

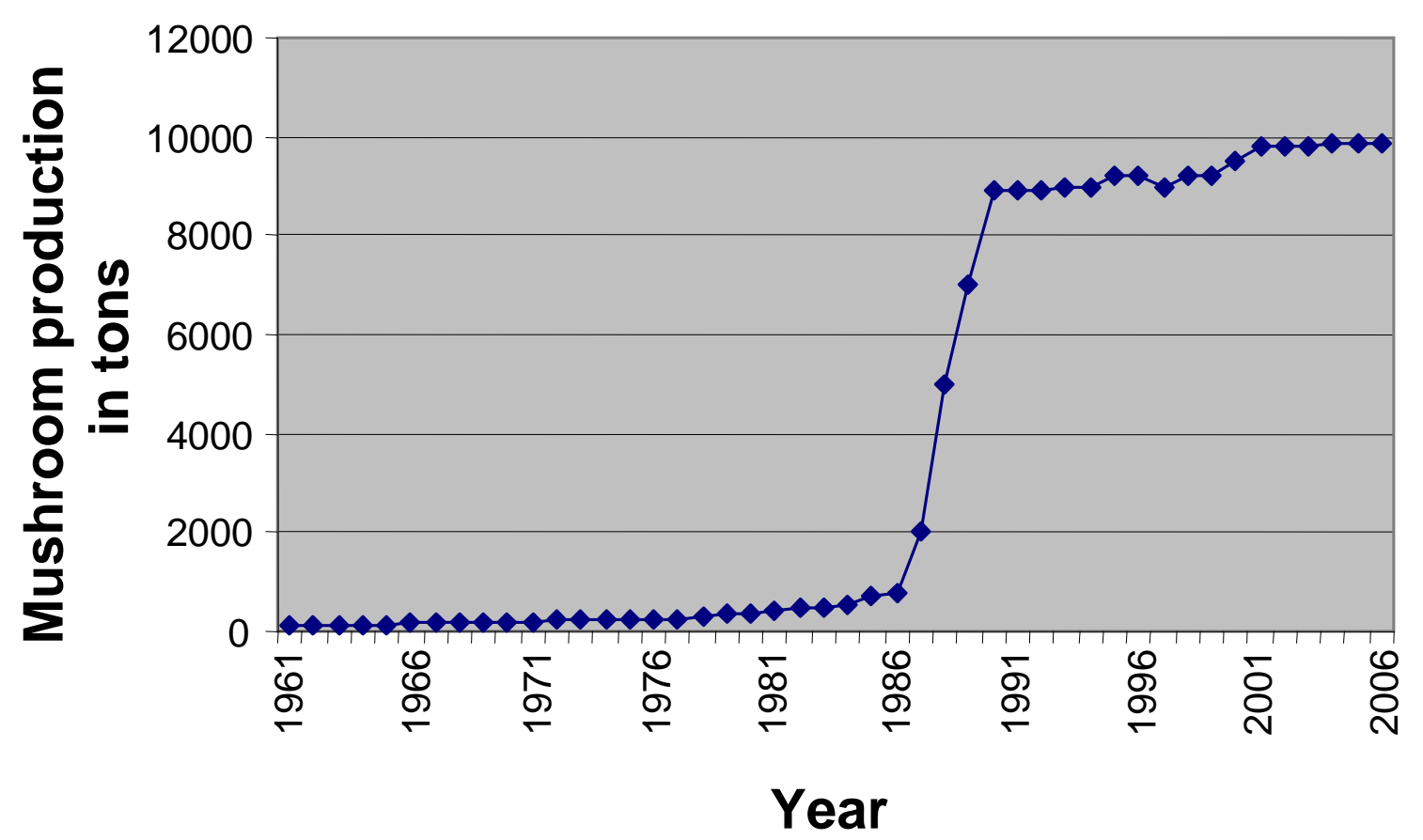

Fig. 7 Mushroom production in Thailand according to FAO (http://faostat.fao.org/site/567 /DesktopDefault.aspx?PageID=567) 


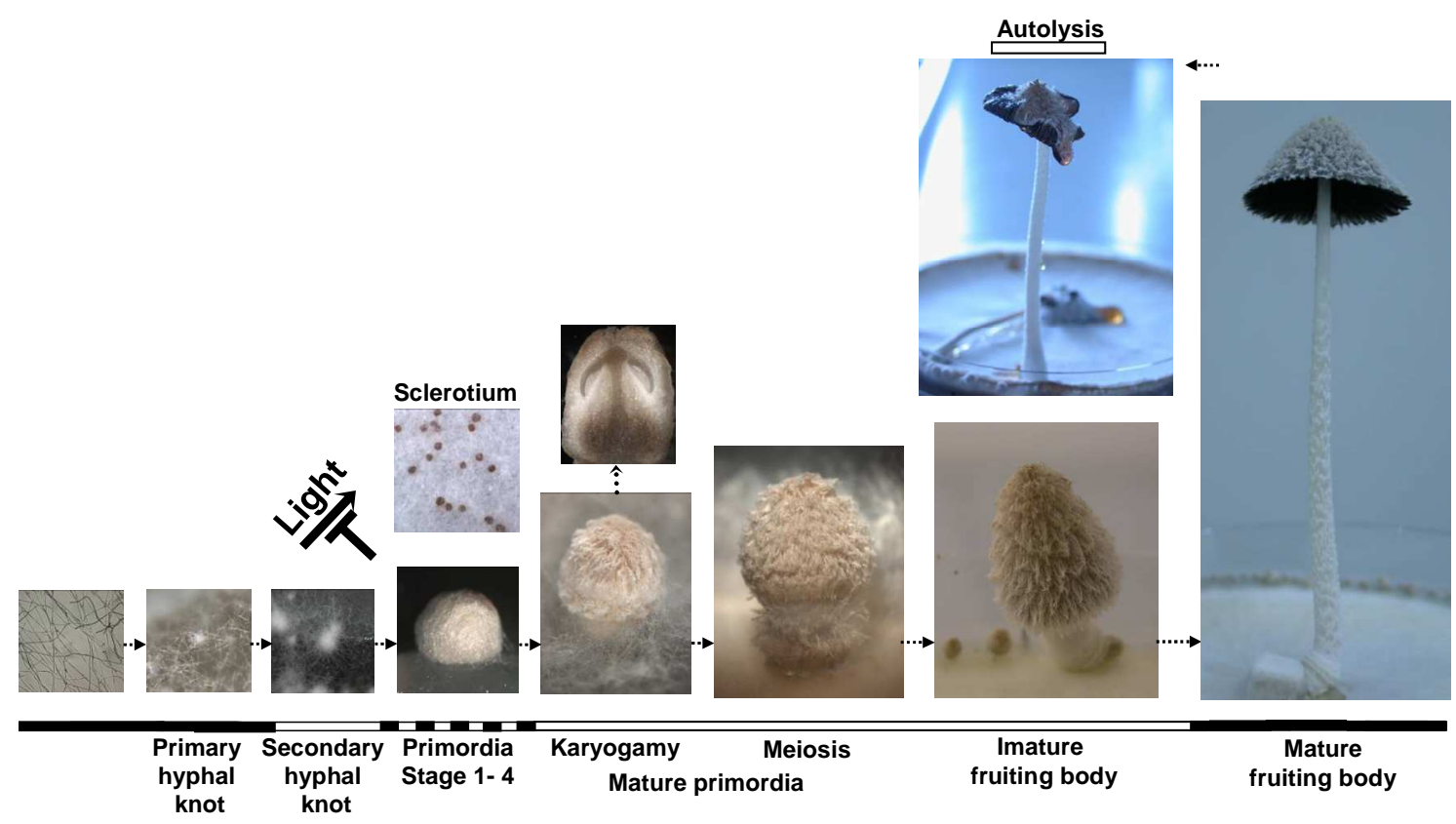

Fig. 8 Stages of mushroom development in Coprinopsis cinerea on artificial medium (Granado et al. 1997) as described by Boulianne et al. (2000) and Navarro-González (2008). After mycelial growth at $37^{\circ} \mathrm{C}$ in the dark, cultures of the mating type-defective, selfcompatible homokaryon AmutBmut were transferred into $28^{\circ} \mathrm{C}$ standard fruiting conditions (12 h light/12 h dark rhythm; 85-90\% humidity) at the beginning of a first light phase. Fruiting body development starts in the dark by intense branching at single or a few hyphae of the vegetative mycelium in order to form loose hyphal aggregates (primary hyphal knots; Liu 2001). If these structures stay further in the dark, they will transform into small compact sclerotia, brown colored duration structures with a melanized rind of small compactly aggregated cells and an inner medulla of larger more or less round uncoloured cells. Upon receipt of a light signal, hyphal cells aggregate firmly into small round bodies (secondary hyphal knots). Within these bodies, tissue development of stipe and cap starts in order to give rise to the fruiting body primordia. When kept further in the dark, long structures (dark stipes or etiolated stipes) form with extended stipes and underdeveloped caps. To progress properly in tissue formation within the fruiting body primordia, at least three dark-light changes are required particularly also for progress in primary and secondary gill formation. On the outer surfaces of the gills within the hymenial layer, specific cells will differentiate to the basidia in which karyogamy and meiosis take place. With a new day, another light signal induces karyogamy within the basidia within the basidia with the fully established tissues. In parallel to karyogamy and the directly following meiosis and the subsequent basidiospore formation, within a few hours (from the early evening to midnight) the stipe elongates and the cap expands. However, soon after maturation the cap autolyses to release the majority of basidiospores in liquid droplet. Within about 8 to $12 \mathrm{~h}$ after cap opening, the mushroom fully collapses (Iten 1970, Moore et al. 1979, Boulianne et al. 2000, Walser et al. 2003, Kües et al. 2004, NavarroGonzález 2008, further information in Chapter 2 of this thesis). The photos were taken by W. Chaisaena from cultures a self-compatible strain Coprinopsis cinerea AmutBmut from cultures grown in the laboratory. 
Table 6 Cultivation conditions for some selected mushrooms (after Lelley 1991, Stamets 1993; adopted from Rühl and Kües 2007)

\begin{tabular}{|l|l|l|l|}
\hline & $\begin{array}{l}\text { Volvariella } \\
\text { volvaceae }\end{array}$ & $\begin{array}{l}\text { Pleurotus } \\
\text { eryngii }\end{array}$ & $\begin{array}{l}\text { Pleurotus } \\
\text { ostreatus }\end{array}$ \\
\hline Mycelial growth & \multicolumn{3}{|l|}{} \\
\hline Temperature $\left[{ }^{\circ} \mathrm{C}\right]$ & $24-35$ & $25-28$ & 24 \\
\hline Relative air humidity [\%] & $80-95$ & $55-95$ & $85-95$ \\
\hline Duration [days] & $5-10$ & $28-56$ & $12-21$ \\
\hline Primordia formation & \multicolumn{3}{|l|}{} \\
\hline Temperature $\left[{ }^{\circ} \mathrm{C}\right]$ & $27-32$ & $10-17$ & $10-16$ \\
\hline Relative air humidity [\%] & $90-100$ & $90-100$ & $95-100$ \\
\hline Duration [days] & $4-6$ & $4-5$ & $3-5$ \\
\hline Fruiting body maturation & \multicolumn{3}{|l|}{} \\
\hline Temperature $\left[{ }^{\circ} \mathrm{C}\right]$ & $27-32$ & $12-26$ & $10-21$ \\
\hline Relative air humidity [\%] & $85-95$ & $80-90$ & $85-90$ \\
\hline Duration [days] & $6-10$ & $21-35$ & $4-7$ \\
& $(7-12$ days $)$ & $7-14$ days $)$ \\
\hline Harvest & \multicolumn{3}{|l}{} \\
\hline Flushes & $>2$ & 2 & $3-4$ \\
\hline
\end{tabular}

come from substrates of specific types, often from wastes (Fig. 5, Fig. 6, Fig. 8). Other environmental factors influencing fruiting are a high humidity and ventilation conditions affecting oxygen and carbon dioxide concentrations (Kües 2000, Rühl and Kües 2007).

Mushroom cultivation from agricultural by-products and waste materials such as palm fibers, banana leaves, water hyacinth, sawdust, sugar cane cotton waste, rice hull, rice bran, soybean skin straw and shells is most economical particular in tropical countries where various types of such wastes accumulate in local regions. Mixing the substrates can be a good solution to overcome on the one hand variations in the supply of the different wastes over the time and on the other hand to balance out the different $\mathrm{C}$ to $\mathrm{N}$ ratios of the substrates in optimal nutrients concentrations for most efficient mushroom production. Substrates for mushroom cultivation needs carefully be prepared. For example, in case of application of straw, the material needs to be milled to a length of about 2 to $6 \mathrm{~cm}$. The straw needs to be watered to gradually give the substrate the required water content. While in operation, during fungal growth and mushroom production, the humidity of the substrates needs to be observed and eventually be adjusted. Straw is particularly useful for the growth of $V$. volvariella and Pleurotus species but it can also be mixed with other wastes (Rühl and Kües 2007; Fig. 6 and Fig. 9). 

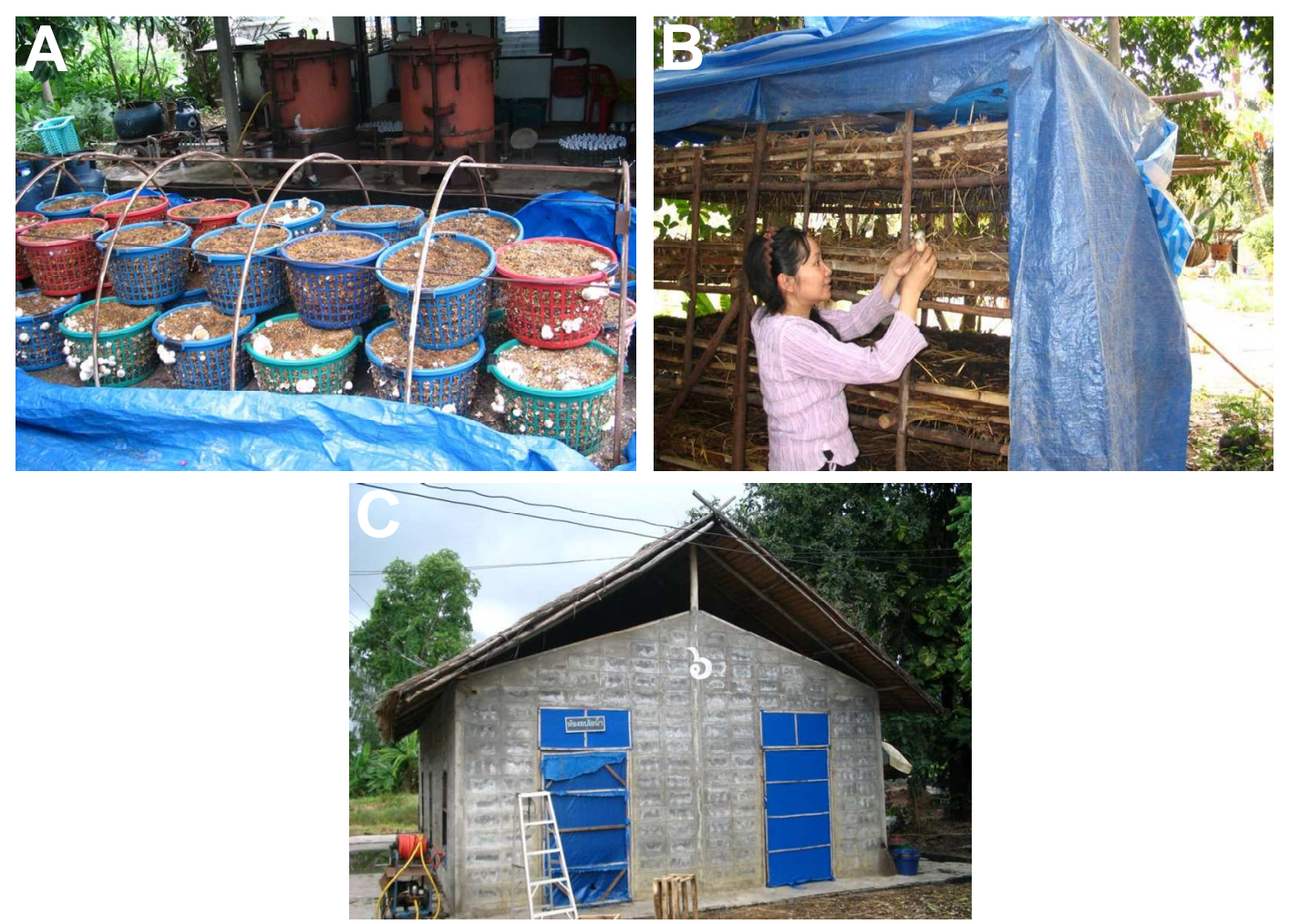

Fig. 9 Cultivation of Volvariella volvacea on small scale family businesses in Thailand.

(A) Plastic baskets filled with a substrate of hackled rice straw and hyacinth waste on which the fungus was grown and in which young mushrooms developed. Note the plastic foil that will be used to cover the pile of plastic baskets in order to regulate light, temperature and humidity conditions for best mushroom production. (B) A wooden self-made mushroom bed as another easy way to cultivate on small scale mushrooms. Again a plastic foil is used to regulate light, temperature and humidity conditions. (C) A shelter for mushroom growth. Photos (A) and (C) were taken by W. Chaisaena, the photo (B) was taken by T. Bunme.

C. cinerea cultivated as a local mushroom especially in the Northern parts of Thailand (mushroom farms locate at the Banthungpha district Lampang province in Northern Thailand) received its local names Hed-cone-noi from the characteristics of stipes and cap differentiation or Hed-thoua from the substrates used for growing the fungus. Growth substrates are based on a variety of bean peels (enriching the protein value) and mixed with dried water hyacinth waste (water hyacinth leafs, water hyacinth leaf stems and water hyacinth roots) for agriculture waste recycling (Abo-Bakr et al. 1983, Mahmood et al. 2005, Gunnarsson and Petersen 2007). A special advantage of this mushroom is that it easily grows on many different types of agriculture wastes available in the tropical zone (Fig. 10), combined with a relatively short life cycle (Kües 2000) and a very high percent yield of mushroom production (Buranachonbot 2004). The potential of advanced laboratory research on $C$. cinerea - being commonly used as 

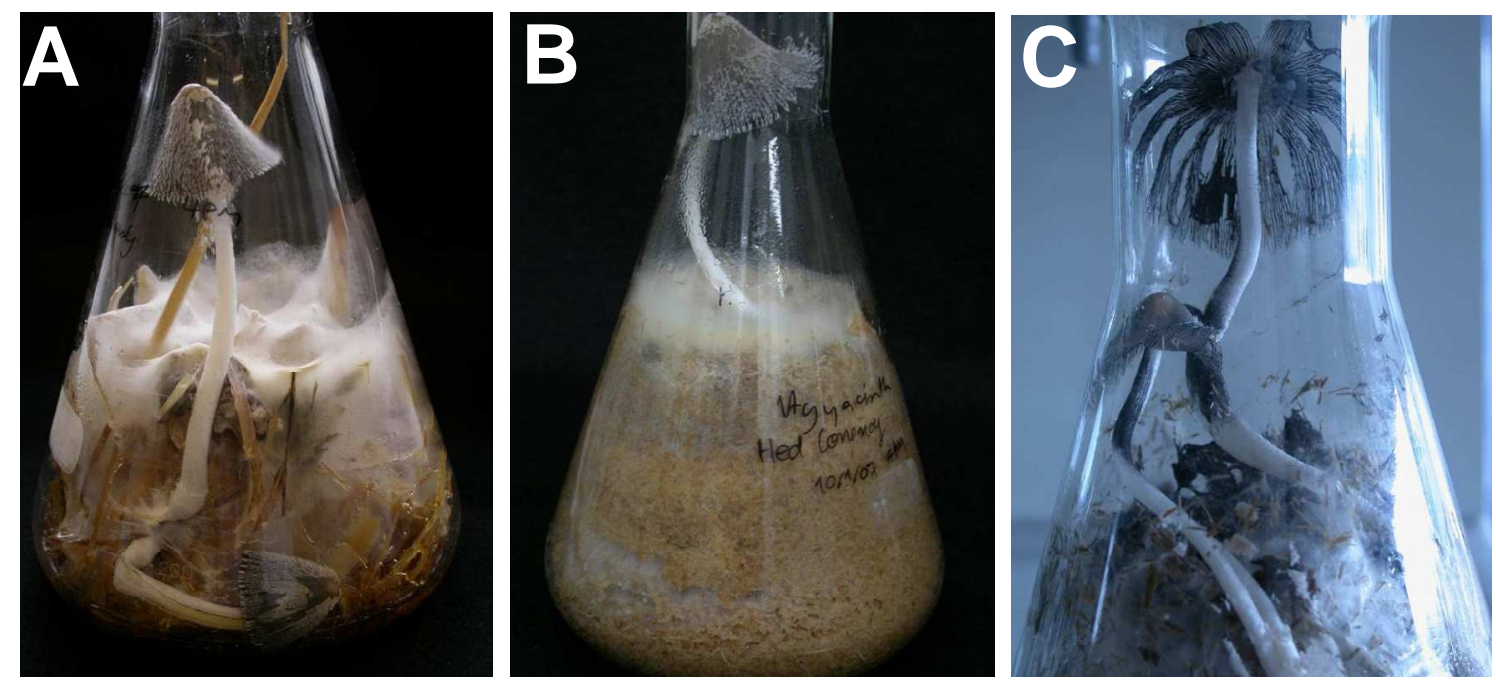

Fig. 10 A commercial Coprinopsis cinerea (Hed-cone-noi) strain from Thailand was grown at $28^{\circ} \mathrm{C}$ in a $12 \mathrm{~h}$ light/12 $\mathrm{h}$ dark cycle in the laboratory in flasks on different wetted substrates. (A) Hackled wheat straw, (B) hackled water hyacinth and (C) on horse dung, the natural substrate of the fungus (Kües 2000). Photographs were taken by W. Chaisaena in Göttingen.

genetic model species to which classical (crossings between different strains) and modern molecular gene transfer technologies (transformation) can be applied (Kües et al. 2007) - might direct improvements in mushroom cultivation in the future.

Easy to obtain resources for $C$. cinerea cultivation in Thailand are agriculture wastes such as bean skins, bean plant residues, banana leafs, type of straws, saw dusts, rice husks, water hyacinth and other wastes. Handbooks for Hed-cone-noi cultivation are available in Thai language (Buranachonbot 2004, Jantarasri 2004), information on the method of cultivation was introduced to farmers by the teachers Anon Euatrakul and Twach Tapinkgae and a successful mushroom farm is handled for example by the farmer Panuwat Chulaotrakul in the Lampang Province in the North of Thailand (Buranachonbot 2004). The cultivation requires only small investments (Buranachonbot 2004, Jantarasri 2004), e.g. for plastic baskets such as shown in Fig. 9A in which the fungus can be grown on the agricultural wastes in simple dark shelters (see Fig. 9 for different types - the simple ones using plastic foils as covers as shown in Fig. 8A and Fig. 9B or more solid build hoods as in Fig. 9C) at the prevailing temperatures of around $25^{\circ} \mathrm{C}$. Altogether the different steps of handling of substrate preparation, fungal cultivation and mushroom harvest are quite easy:

i. Substrate preparation: The respective materials for $C$. cinerea cultivation are crushed into pieces of appropriate sizes and are filled into plastic containers or pressed 
into a wooden mushroom bed frame (sized approximately $30 \mathrm{~cm}$ x $30 \mathrm{~cm}$ x $60 \mathrm{~cm}$ ). The matter can be fixed in such a wooden frame simply by strings. Since for optimal fruiting in C. cinerea, a certain C-N ratio is crucial (Savoie et al. 1992, Kües 2000, Kües and Liu 2000), the prepared material will be soaked in a liquid fertilizer solution at $85^{\circ} \mathrm{C}$. The high temperature will help the soaking but also to reduce contaminations in the substrate with other microbes due to pasteurizing effects. After soaking, the substrate block needs to cool down below $40^{\circ} \mathrm{C}$ before fully grown $C$. cinerea spawn can be added.

ii. Inoculation: $C$. cinerea spawn is usually prepared by inoculation and incubation of cereal grains (usually rye, cotton seed hulls or millet) that had previously been steamtreated for pasteurization of the material. The spawn is added to the freshly prepared substrate blocks by putting aliquots of the pre-cultures $2-3 \mathrm{~cm}$ from the surface deep into the substrate blocks.

iii. Incubation: After inoculation, under the climate in Northern Thailand, the spawn develops a thread-like network, the mycelium growing throughout the substrate blocks. For optimal growth, cultures in the wooden mushroom beds or in plastic containers will be covered with the plastic sheets to protect the substrate blocks from dehydration by sun and wind and to keep an optimal high growth temperature and low amounts of light. Cultures are incubated in such way for 3-4 days until the mycelia completely cover the surface of substrate blocks. At this time of cultivation, the substrate blocks should be moved into a cultivation room under controlled temperature, humidity and light conditions. If not available, a darkened garage might be used or the mycelium-overgrown substrate blocks might be moved into shadow underneath trees.

iv. Fruiting: For induction of fruiting body formation, the plastic cover should be opened. For better mushroom yields, after opening the plastic cover a pure liquid fertilizer solution may be sprinkled onto the cultures. When incubating in a controlled cultivation room, for optimal yields the temperature should be kept for 2-3 days still high at $37-40{ }^{\circ} \mathrm{C}$ and at a humidity of $75-90 \%$. The required high moisture in the substrate block is maintained by spraying water mixed with liquid fertilizers (40 liter of water: $100 \mathrm{ml}$ of fertilizer) onto the substrate blocks. Once fruiting structures start to appear, young immature mushrooms as shown in Fig. 2 might be picked on daily basis for up to a month. 


\subsection{Aims of the thesis}

C. cinerea as an easy to grow fungus with a very short life cycle of about two weeks which can be genetically manipulated both by classical and by molecular genetics (Walser et al. 2001) is study object of this thesis. C. cinerea served for over hundred years as a model fungus to study developmental processes in the higher basidiomycetes and is thus of all mushrooms scientifically best understood (Kües 2000). Nevertheless, the knowledge we currently have on the fruiting behaviour of the fungus is still not too extensive (Kües et al. 2007, Navarro-González 2008). As reported above, an economical importance of the fungus is lately rising in countries with tropicalsubtropical climates with cheap labor and vast amounts of agricultural wastes (Kües et al. 2007, Rühl and Kües 2007). This thesis addresses questions that should help to further establish commercial mushroom production of $C$. cinerea in the future in countries like Thailand.

Major research tasks addressed in this thesis were:

i. Observations on tissue formation during the process of fruiting body development in the $C$. cinerea wildtype situation under standard fruiting conditions in a $12 \mathrm{~h}$ light/ $12 \mathrm{~h}$ dark regime and under incubation in constant light or in contanst dark (described in Chapter 2 of this thesis)

ii. Linking these observation to tissue development in a set of $C$. cinerea mutants forming abnormal fruiting structures during incubation under standard fruiting conditions in the $12 \mathrm{~h}$ light/12 $\mathrm{h}$ dark regime (described in Chapter 3 of this thesis)

iii. Studying the effects of small animals, here specifically mites, grazing on C. cinerea cultures endangering as potential pests commercial mushroom production (Chapter 4 of this thesis)

iv. Studying the production of volatiles by $C$. cinerea cultures acting as odour and flavor components for a good taste of the mushrooms but possibly serving also as attractants to mites being unwanted in mushroom cultures (Chapter 5 of this thesis) 


\subsection{Summarizing major results of this thesis and their general discussion}

\subsubsection{The process of fruiting body development in $C$. cinerea}

The process of fruiting body development of the specific strain AmutBmut of C. cinerea under standard fruiting conditions $\left(12 \mathrm{~h}\right.$ light $/ 12 \mathrm{~h}$ dark regime at $28^{\circ} \mathrm{C}$ ) over the time has recently been described by Navarro-González (2008) and see Fig. 8. Strain AmutBmut is a homokaryon that has defects in the two mating type loci (Swamy et al. 1984) that control mating and fruiting body development (Kües et al. 1998, 2001, Casselton and Kües 2007).
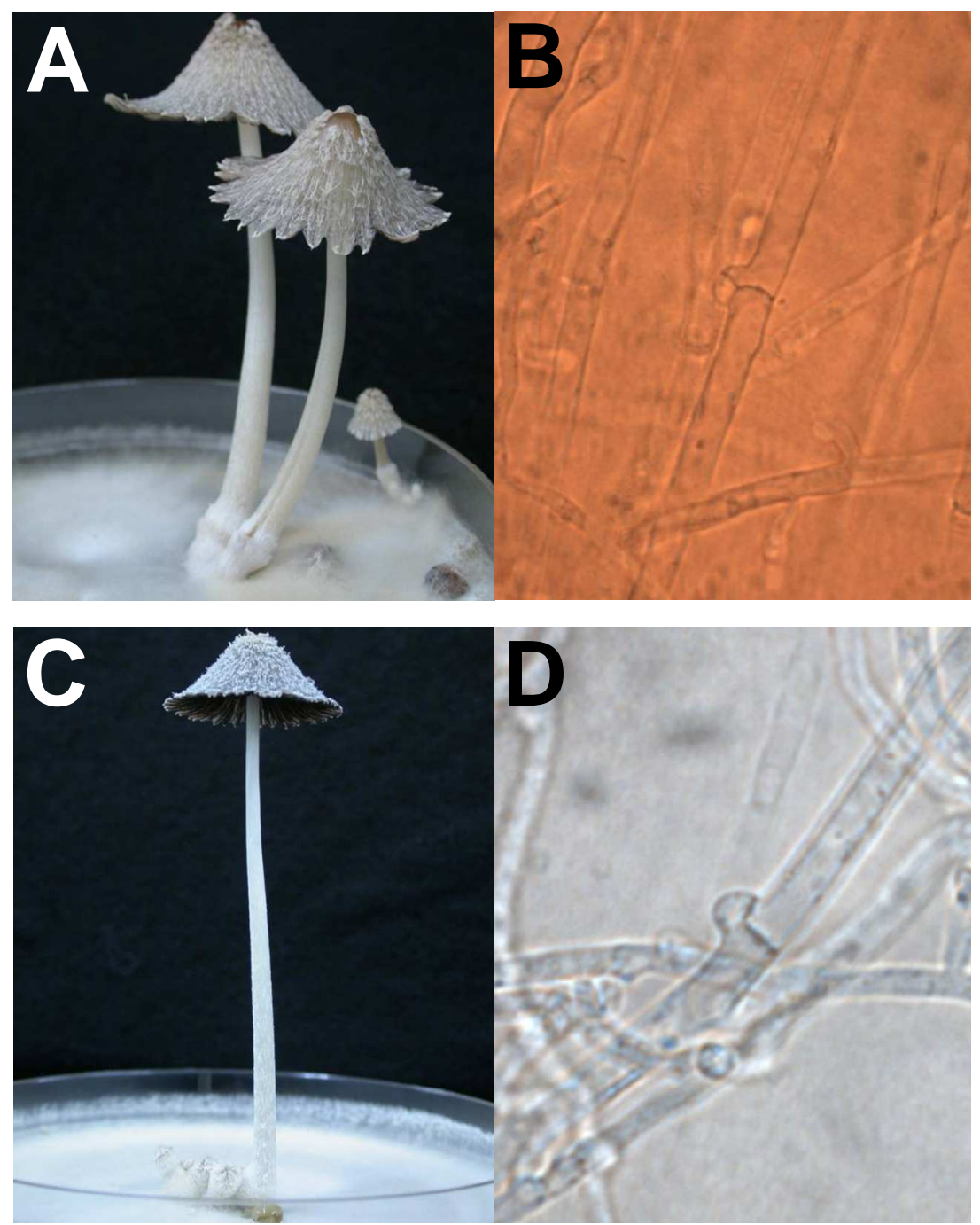

Fig. 11 Mushrooms developed (A) on a commercial Coprinopsis cinerea (Hed-cone-noi) strain from Thailand and (C) on dikaryon PS001-1 x PS002-1 (obtained by mating from monokaryons PS001-2 and PS002-1; see Srivilai 2006 and Chapter 3 of this thesis) that were grown as described in the legend of Fig. 1 on artificial YMG/T medium (Granado et al. 1997) and (B) and (D) microscopic pictures of hyphae of the strains Hed-cone-noi and PS001-1 x PS002-1, respectively, with clamps cells at the hyphal septa indicating them to be dikaryons. The photos were taken by W. Chaisaena in Göttingen. 
The defects in the mating type loci allow the strain to fruit without the need of mating to another compatible strain (Boulianne et al. 2000, Kües et al. 2007; Fig. 8). In the normal condition, it is only the dikaryon - the secondary mycelium with two genetically distinct haploid nuclei in its cells formed after mating of two compatible, i.e. mating type-different primary mycelia called monokaryons by having only one type of haploid nuclei in their cells - that can form fruiting bodies (Kües 2000, Rühl and Kües 2007; Fig. 11).

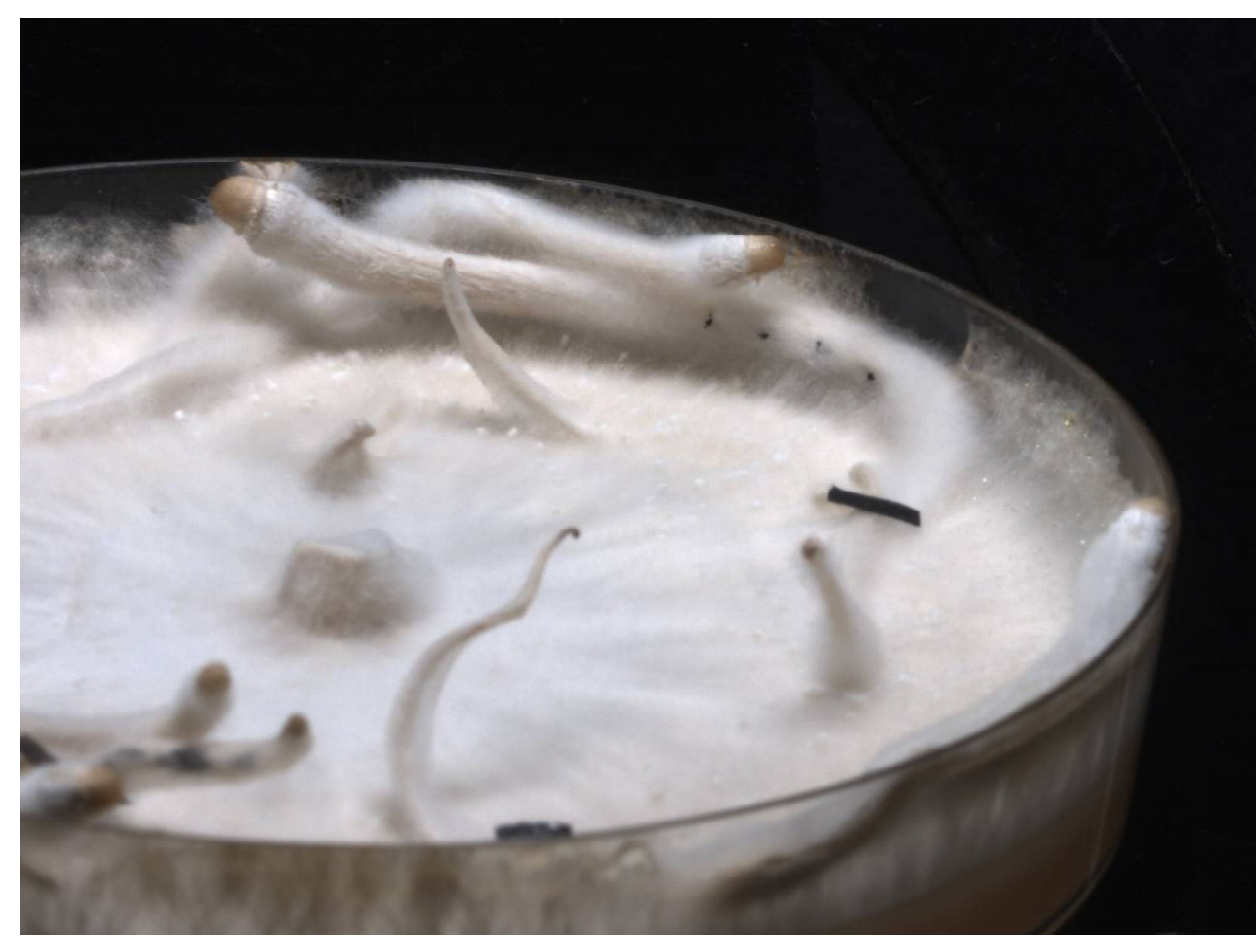

Fig. 12 Etiolated stipes formed on a culture of Coprinopsis cinerea homokaryon AmutBmut. After 5 days growth at $37^{\circ} \mathrm{C}$ in the dark on artificial YMG/T medium (Granado et al. 1997), made up with tap water from Göttingen, the plate was transferred to $28^{\circ} \mathrm{C}$ and first illuminated for $3 \mathrm{~h}$ and then kept for seven days in constant dark (photographed by W. Chaisaena in Göttingen).

Fruiting body development in $C$. cinerea is adapted to the light-dark changes in the normal day-night rhythm and strictly controlled by light and by dark phases that are required to be given at specific time points in the process of development (Kües 2000, Lu 2000, Navarro-González 2008, see Chapter 2 of this thesis). If not followed in the right order, mushroom development might be delayed or arrest (Kües 2000, Lu 2000) or unusual long structures with an underdeveloped cap might be formed known as dark stipes or etiolated stipes (Borriss 1934, Tsusué 1969, Lu 1974, Elliott 1994, Muraguchi 
and Kamada 1998). Such structures appear in the cultures when after the light-induced initiation of fruiting body development cultures are kept in the dark (Fig. 12). These long structures are formed by an unusual growth of tissue material localized at the primordial shaft beneath the cells forming the stipe of a normal mushroom under the rhythmic light-dark chances in a day-night regime (Terashima et al. 2005).

Unlike normal fruiting bodies that upon maturation quickly autolyse within a few hours (Iten 1970, Iten and Matile 1970, Navarro-González 2008; Fig. 13 and Fig. 14), etiolated stipes are long lasting (see Fig. 12 and Chapter 2 and 3 of this thesis). Such a feature can be quite useful for mushroom cultivation - on the one hand, it prolongs the shelf life of the food and overcomes for $C$. cinerea the need for boiling and pickling the immature fruiting bodies directly after their harvest and, on the other hand, it can help to develop mechanical harvesting devices such as known e.g. for commercial picking of

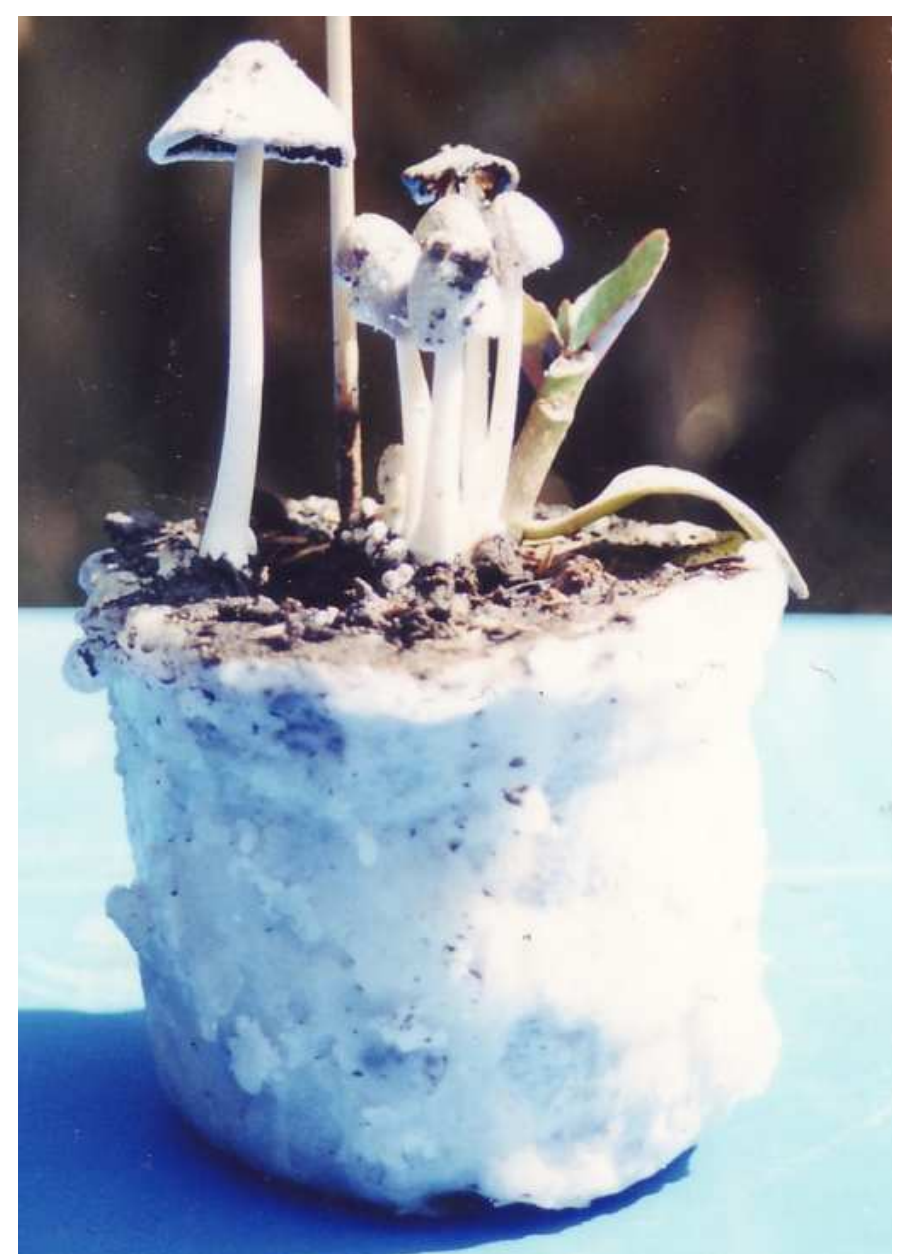

Fig. 13 Fruiting bodies of Coprinopsis cinerea quickly deteriorate upon maturation. A similar pot plant container as shown in Fig. 3A (photographed in Thailand by W. Chaisaena at an early morning) infested coincidently by a Coprinopsis strain was photographed by W. Chaisaena in the later afternoon when the mature fruiting bodies undergo autolysis. 

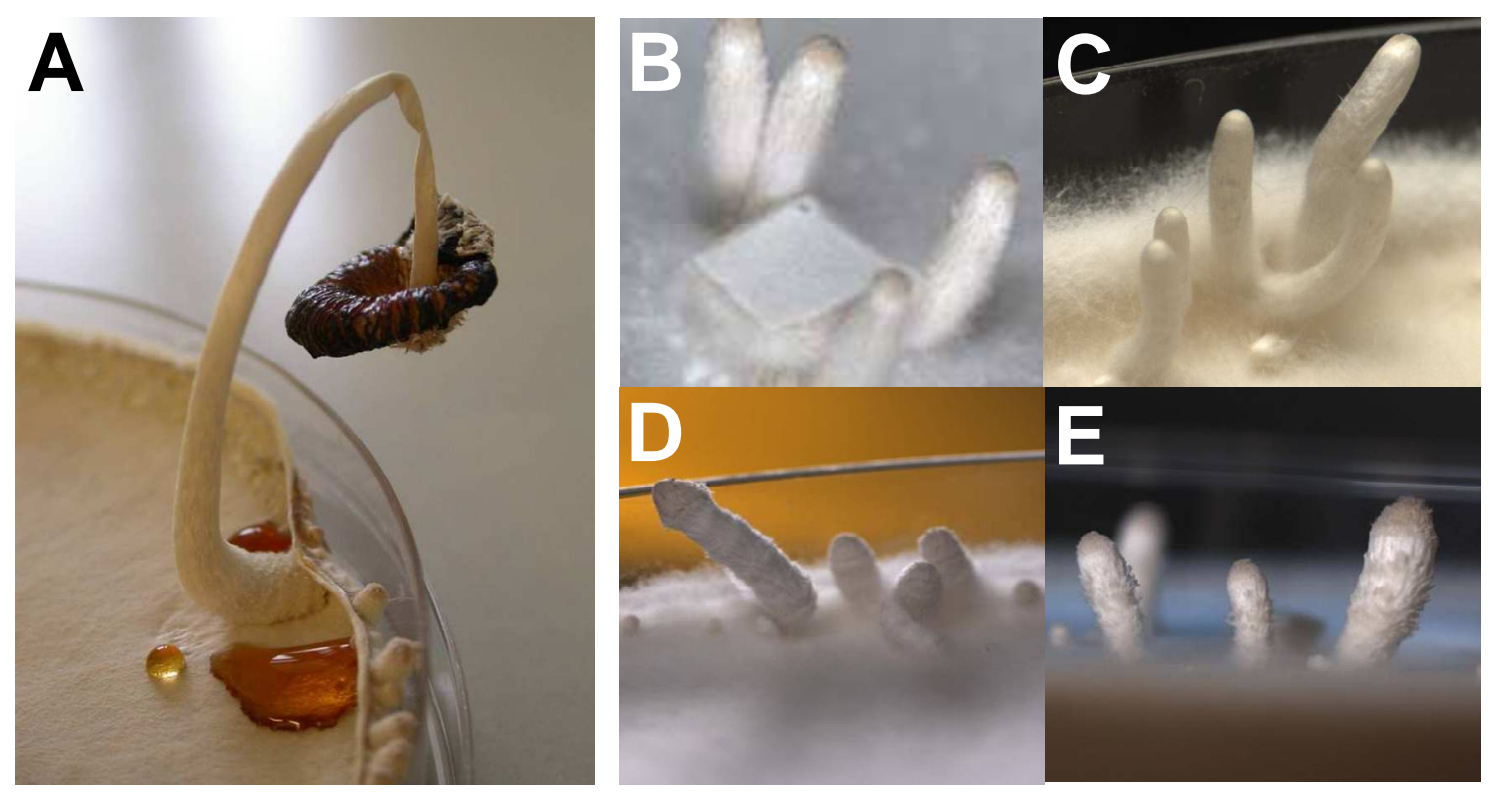

Fig. 14 Autolysing fruiting body of the mating type-defective Coprinopsis cinerea homokaryon AmutBmut cultivated on artificial YMG/T medium (Granado et al. 1997) under standard growth and fruiting conditions as described in the legend of Fig. 1 (A) and etiolated stipes formed by mutant homokaryons PUK1-6 (B), PUK2-6 (C), PUK3 (D) and PUK4 (E) under the same conditions of cultivation. Note that Fig. B to E are also shown and further explained in Chapter 3 of this thesis. The photos were taken by W. Chaisaena in Göttingen.

A. bisporus mushrooms (Chang and Hayes 1978, Sánchez 2004). Indeed, Flammulina velutipes (Enoki, Enokitake, golden needle mushroom; Fig. 15) is commercially grown in plastic bottles or vinyl bags under dark conditions favouring the production of elongated stipes with small immature pale caps (Redhead and Petersen 1999). Also in this species as in $C$. cinerea, missing light is responsible for the phenomenon of formation of elongated stipes (Chang and Hayes 1978, Stamets and Chilton 1983, Chang et al. 1993, Sakamoto et al. 2002, 2004, 2007). The customers buying the mushroom are used to this look of $F$. velutipes in the supermarkets determined by technical reasons and thus economical interests, although the etiolated-stipe-form does not represent for the fungus the ideal situation required for spore production, i.e. for sexual reproduction (Mcknight and Estabrook 1990, Mcknight 1992, Haindl and Monzer 1994, Monzer et al. 1994, Sakamoto et al. 2002). In harvesting strong structures of $C$. cinerea from sisal waste heaps, African sisal farm workers probably unconscientiously make use of the characteristic of the fungus that, when kept in the dark, young fruiting body primordia will transfer into such more stable elongated stipes. The sisal wastes heaps are every day feed with new loads of sisal waste being placed 
upon the old loads into which mushroom development was previously initiated by light signals. In their need to grow to the surface for cap maturation, the young primordia therefore change their developmental program to etiolated stipe formation resulting in the growth of a type of root-like structure within the sisal waste (Härkönen et al. 1993). In the Thai $C$. cinerea cultivation, the feature of formation of etiolated stipes is also to some extend made use of as can be deduced from the relatively thick and long stipe structure beneath an underdeveloped mushroom cap in the jar with pickled C. cinerea (Fig. 2), although the mushroom growers are advised by the respective

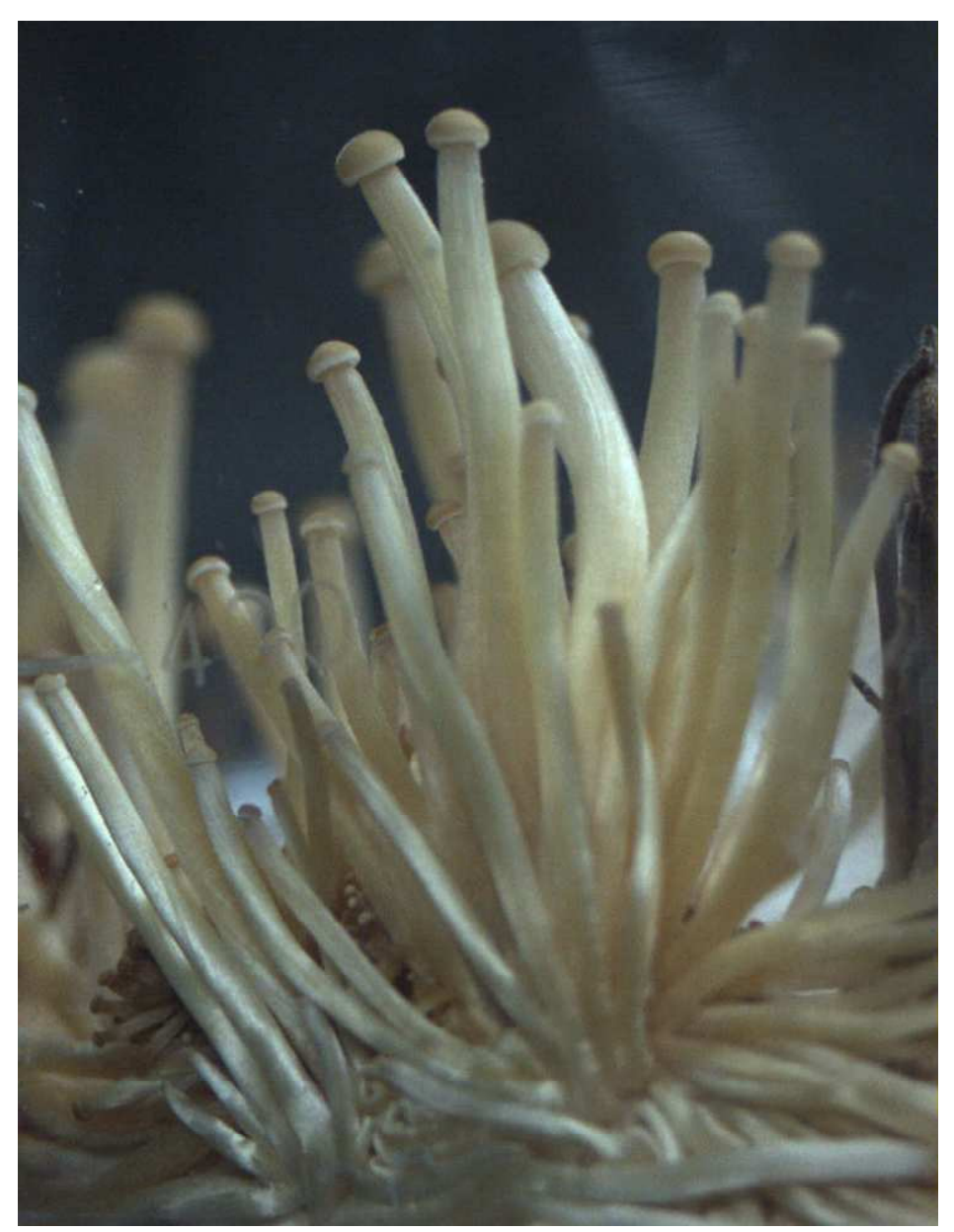

Fig. 15 Slender mushroom structures with small caps formed by a commercial strain of Flammulina velutipes from Thailand. The strain was inoculated on approximately $50 \mathrm{~g}$ millet that was immersed overnight in tap water in order to swell after which the material was autoclaved. The fungal culture was incubated at $25^{\circ} \mathrm{C}$ under constant light illumination for about two weeks until the millet was fully overgrown by mycelium. Then, the culture was transferred into a cold room $\left(4^{\circ} \mathrm{C}\right.$ and $60 \%$ humidity) into the dark (interrupted occasionally by short light periods by people entering the cold room). Approximately one month after storing in the cold room, the fresh fruiting structures shown in the photo were noted in the culture. Within 5 further months of incubation within the cold room, the fruiting structures eventually dried out and collapsed (not shown). The photo was taken by W. Chaisaena in Göttingen. 
handbooks in $C$. cinerea cultivation to take the plastic foil of the substrate to allow fruiting body development (Buranachonbot 2004). A more defined light regime could indeed result in better to handle structures. Thus, it was important in this study to define for the first time all light and all dark sensitive phases during the seven day lasting process of fruiting body development (Chapter 2 of this thesis). It was found that there were at least six different phases where a light signal needs to be given in order to suppress etiolated stipe formation. When cultures were transferred in early development into constant dark, resulting etiolated stipes were relatively thin and weak compared to etiolated stipes that formed when cultures were transferred at later time in development into constant dark. In terms of harvesting biggest and strongest etiolated stipes, it appears best to transfer cultures at day 5 of fruiting development (containing primordia of developmental stage 4; compare Chapter 2 of this thesis and Navarro-González 2008) into constant dark. Moreover, cultivation with tap water from Göttingen made structures longer and stronger (Fig. 12), indicating that alteration of nutritional conditions can further improve growth of etiolated stipes (see Chapter 2 of this thesis). Likewise, Navarro-González (2008) reports that prevalence of certain metal ions (e.g. copper) can help in the formation of strong etiolated stipes and that this can happen even in the presence of light and at higher temperatures than normally. Japanese researchers reported previously that addition of nitrogen can overcome partially the need for light in induction of fruiting body formation although the respective authors did not describe whether the structures formed were in the shape of etiolated stipes (Morimoto et al. 1981). In another study, Tsusué (1969) differentiated between the type of structures suggesting together with the results of Morimoto et al. (1981) that media with higher nitrogen content might favour the formation of etiolated stipes. These results might relate to the advice to the Thai farmers to sprinkle the mycelial-grown substrate in $C$. cinerea cultivation with fertilizer (see above).

\subsubsection{Genetic analysis of $C$. cinerea mutants with defects in fruiting body development}

An alternative with a great practical use to influencing the formation of etiolated stipes during $C$. cinerea cultivation by environmental conditions are given by mutants that are defective in the normal light-regulation of fruiting body development and therefore form etiolated stipes normally under standard fruiting conditions with a rhythmic 
light-night change of the typical day-night rhythm (Fig. 14 and Fig. 16). Two different types of mutants of this type have been reported in the literature. The responsible gene of the first mutant group, dst l, has been cloned and found to encode a protein with high similarity of the blue-light receptor WC1 of the ascomycete Neurospora crassa (Terashima et al. 2005). The gene of the second group of mutants, $d s t 2$, has also been cloned (reported by T. Kamada on the XXIV Fungal Genetic Conference in Asilomar/Pacific Grove, CA, March 20-25, 2007 in a talk entitled "Two genes, dst 1 and $d s t 2$, essential for photomorphogenesis during fruiting body development of Coprinus cinereus"; U. Kües, personal communication) but the function of the product has not yet been described in the literature.

Monokaryons containing either a defect in the gene $d s t 1$ (A8, B7 strain R1428F1\#74 with allele $d s t 1-2)$ or a defect in the gene $d s t 2$ (A91, B92 strain H1-1280F1\#5 with allele $d s t 2-1)$ were kindly provided for this work by Prof. T. Kamada. These strains were of different genetic background hampering clear-cut genetics since other genes in the genetic background of the strains might influence morphological characteristic of the etiolated stipes formed by the mutants in the light, e.g. the length, width and strength of the structures (Walser et al. 2001, Srivilai 2006). Moreover, since the genes
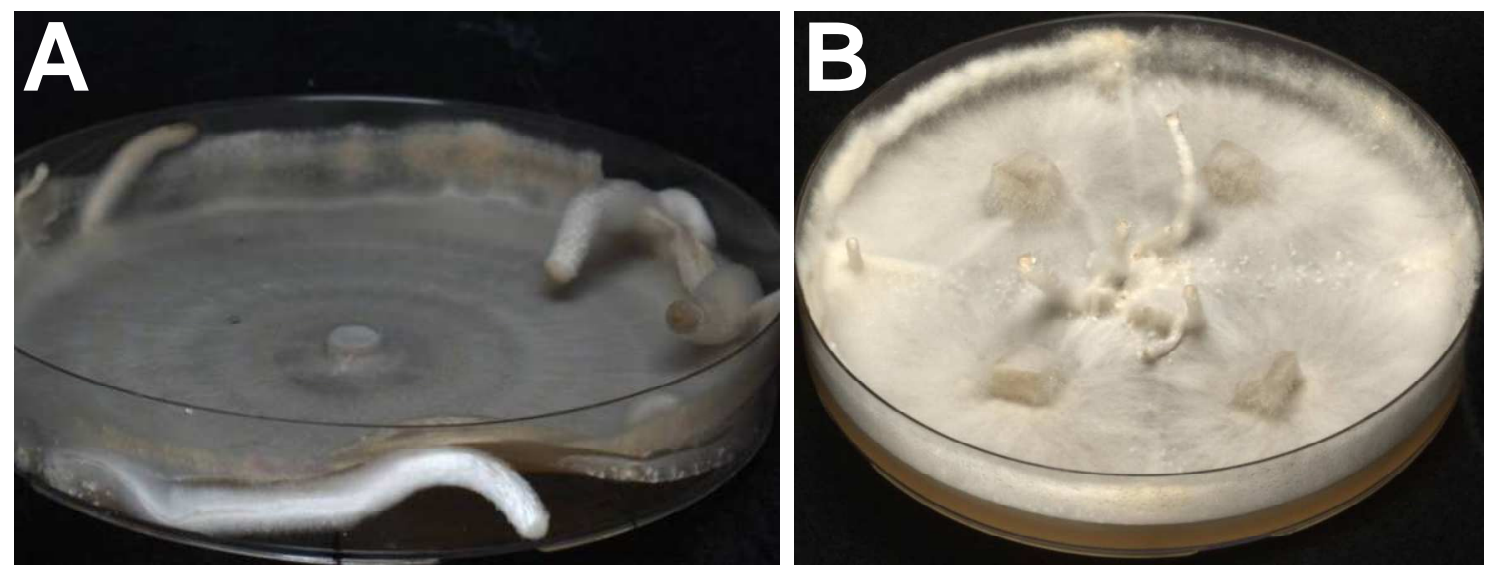

Fig. 16 The Coprinopsis cinerea homokaryotic mutants PUK2-6 carrying gene dst1-2 (see Chapter 3 of this thesis) and PUK3 carrying gene dst3-1 (see Chapter 3 of this thesis) form etiolated stipes under standard fruiting conditions (Granado et al. 1997). The strains were grown for 5 days at $37^{\circ} \mathrm{C}$ in the dark, after which they were transferred into $28^{\circ} \mathrm{C}$ at a humidity of $85-90 \%$ into a repeating regime of $12 \mathrm{~h}$ light/12 h dark. The plate shown in (A) was incubated for three days at $28^{\circ} \mathrm{C}$ in normal position and then for 7 days in up-side-down position. The plate shown in (B) was incubated for three days at $28^{\circ} \mathrm{C}$. The medium on which the strains were grown were artificial YMG/T medium (Granado et al. 1997) made up with deionized water. 
are only functional in fruiting and the gene defects are recessive (Terashima et al. 2005), mating them to another monokaryon will not bring a noticeable phenotypic effect to the fruiting body unless the partner monokaryon would carry also a defect in the respective gene. Thus, it was necessary to bring the mutated genes by suitable crosses into a homokaryon situation where defects in the two mating type loci allow fruiting body formation without mating to another strain and, thereby, the phenotypic expression of recessive genes (Kües et al. 2007). Accordingly, the C. cinerea A43mut B43mut homokaryon AmutBmut (Swamy et al. 1984) was used in this study for crosses with the two mutants obtained from Japan and respective mating type-defective homokaryons were obtained (Chapter 3 of this thesis). In order to overcome any negative effects from genes from the background of the two Japanese mutant monokaryons, six rounds of backcrosses were performed in this work with selected $d s t 1$ - or $d s t 2$-defective homokaryons against the AmutBmut co-isogenic monokaryon PS001-1 obtained from P. Srivilai (Srivilai 2006) in order to have co-isogenic strains that distinguish as much as possible only in the alleles of the defective genes (Walser et al. 2001, Srivilai 2006). From the last cross, the mating type-defective mutant homokaryons PUK1-6 (Fig. 14B) and PUK2-6 (Fig. 14C) were obtained with either gene $d s t 1-2$ or $d s t 2-1$. The developmental defects in these mutants were studied and the results are described in Chapter 3 of this thesis.

Two other mutants (7K17 and B-1918) forming etiolated stipes under standard fruiting conditions were obtained by mutagenesis directly in the AmutBmut background (Liu et al. 1999; J.D. Granado and U. Kües, unpublished). The defects in these two mutants leading to the etiolated stipe phenotype differed by the genes that were affected. Complementation tests showed that the defective genes also differed from defects in the genes $d s t 1$ and $d s t 2$. In conclusion, there are at least four different genes in $C$. cinerea that control etiolated stipe phenotypes. Crosses were performed with the homokaryotic mutant strains with the $d s t 3-1$ and the $d s t 4-1$ defects, respectively, against the AmutBmut co-isogenic monokaryon PS00-1-1 in order to eliminate any extra mutations that might have been generated during the mutagenesis procedure - the effect of obtaining multiple mutations during a round of mutagenesis has been noticed before in $C$. cinerea (Liu et al. 2006). The developmental defects in the resulting mating-type defective homokaryons PUK3 (Fig. 14D) and PUK4 (Fig. 14E) carrying either gene $d s t 3-1$ or gene $d s t 4-1$ in these mutants were studied and the results are described in Chapter 3 of this thesis. 
Genes $d s t 1-2$ and $d s t 2-1$ were found to be active at the very early time of development directly after the formation of round hyphal aggregates, known as the secondary hyphal knots in which tissue differentiation of cap and stipe is initiated (Moore 1998, Boulianne et al. 2000, Liu 2001, Velagapudi 2006, Navarro-González 2008; see Chapter 2 of this thesis). In contrast, genes $d s t 3-1$ and $d s t 4-1$ act later in development at the primordia stages P4 and P5 (see Chapter 3 of this thesis), when all tissues within the structures are developed (see Chapter 2 of this thesis). Primordia stage P4 is a prekaryogamy stage and primordia stage P5 is a stage in which karyogamy happens that will later during the day lead into meiosis (Navarro-González 2008). On artificial YMG/T medium containing yeast and malt extract, glucose and tryptophan (Granado et al. 1997), mutant PUK4 (Fig. 14E) made the strongest and largest structures in high numbers which means that this strain may have advantages for commercial mushroom production (compare Fig. 14B to E). Structures made by mutant PUK3 were also relatively strong (Fig. 14D) but the numbers of total structures per plate were generally lower than the numbers achieved with mutant PUK4 (own observation; however, note that numbers of structures per plate were not analyzed in detail in this study). In contrast, mutant PUK2-6 (Fig. 14C) also formed high numbers of etiolated stipes per plate (not analyzed in detail). These structures were usually longer than those formed by mutant PUK4 but, at the same time, they were more slender and softer (see Fig. 14C and E; not analyzed in detail) why cultivation of PUK2-6 for commercial mushroom production might be only second choice. However, the mutant has the other advantage that etiolated stipes are formed under all types of light conditions (see Chapter 3 of this thesis) which could ease the handling of the fungus by farmers in practice. Finally, mutant PUK1-6 (Fig. 14B) is of all the less favourable strain for mushroom cultivation because of the low number of etiolated stipes made by the strain per plate (not analyzed in detail). Experiments with media made up with tap water from Göttingen instead of de-ionized water showed that also the etiolated stipes of the mutant homokaryons will be influenced in structure by media composition. Tap water lead to larger and stronger structures on all four mutants (see Chapter 3 of this thesis), an effect which should be more suitable for a commercial market. Thus, in the future more efforts need to be given to nutrient conditions to find the best production schemes for the mushroom growers when using these types of mutants. Regarding the usage of tap water, it has to be noted that there will be local differences in the compositions and not all tap water sources might have the same positive effect on strengthening and enlarging the structure 
of the etiolated stipes. In Zurich, for example, water effects on development were never noted when growing mutant B-1918 but different agar sources and cultivation conditions (free in the air or in touch with agar) were observed to have an effect (J.D. Granado and U. Kües, unpublished). The effect of agar touching on induction of fruiting body maturation was also seen in this study for all four types of mutants (experimental set-up with incubating plates upside down; see Chapter 3 of this thesis). Water and/or agar effects were probably also responsible for a late induction of maturation of fruiting body development in mutant B-1918 when the strain was grown in Canada and the USA, respectively (Liu et al. 1999, Money and Ravishankar 2005). Induction of maturation of fruiting body development by turning plates up-side down takes different times with mutants PUK3 and PUK4 reacting comparably fast, mutant PUK2-6 only after longer periods such as a month when the etiolated stipes stopped to elongate and mutant PUK1-6 reacting only in exceptional cases (see Chapter 3 of this thesis). These observations on the stability of the phenotype under various environmental conditions argue also for mutant PUK2-6 for being best in commercial mushroom production. Studying the physiology of etiolated stipe formation in the future will help to set up best conditions for obtaining high numbers of strong, longlasting structure in commercial mushroom production (Sánchez and Moore 1999, Sánchez 2006). For production of long, slender and long-lasting etiolated stipes in Thailand, the suitability of local agricultural wastes including weedy plant such as the water hyacinths for commercial production will have to be tested (Morris 2001). If successful in high mushroom yields, appropriate advertising of the unusually shaped structures with their small caps for the commercial market is required in order to raise the acceptance as a new type of food. Since introduction of $C$. cinerea in Thailand as such has been achieved successfully in the 1980ies, one can expect that also the new shape of $C$. cinerea food will be considered by the population for consumption.

\subsubsection{Pests in fungal cultures}

Commercial mushroom cultivation is in constant danger to fail by various types of pests, microbial infections and viruses that might infest the fungal substrate, the mycelium and/or the fruiting bodies growing on the substrate. As pests to name, there are larvae and adults of certain flies and gnats (Wu and Zhang 1993, Gao and Zou 2001, Zou et al. 1993, Mohan et al. 1995, Scheepmaker et al. 1997a, Heard 1998, Jess and 
Kilpatrick 2000, White and Czajkowska 2000, Bae et al. 2001, Liu et al. 2002, Jess and Bingham 2004, Kim et al. 2004, Smith et al. 2006a,b, Freire et al. 2007, Jess et al. 2007), beetles and other insects (Bhattacharyya et al. 1993, Sato et al. 1998, 1999, Sato 2003), and there are mites (Mukherje and Choudher 1974, Cross and Kaliszweski 1988, Okabe 1993a,b, Wu and Zhang 1993, Zou et al. 1993, Gao and Zou 2001, Okabe et al. 2001, Bussaman et al. 2006, Kheradmand et al. 2007a,b), springtails (Bhattacharyya et al. 1993) and nematodes (Tsuda et al. 1996, Okada and Kadota 2003, Tsuda and Futai 2005, Okada et al. 2005). Numerous microbial diseases on mushrooms can be caused by bacteria (Tsukamoto et al. 2002, Sokovic and van Griensven 2006), yeasts and molds (Tsuneda et al. 1997, Chen et al. 1999, Umar and van Griensven 1999, Krupke et al. 2003, Guthrie and Castle 2006, Largeteau et al. 2006, Amey et al. 2007, KomonZelazowska et al. 2007) and viruses (Revill et al. 1999, Rao et al. 2007, Kim et al. 2008). Avoidance of any of these harmful organisms and viruses is a command for any successful commercial mushroom production. In some instances, resistant strains may be available (Tokimoto and Komatsu 1995, Olivier et al. 1997, Smith et al. 2006a) or be obtained by breeding efforts through performance of suitable genetic crosses between strains of good quality. However, often such high quality strains are not at hand or breeding is a long lasting process (Kües and Liu 2000, Sánchez 2004, Fan et al. 2006, Kitamoto 2006). Thus, most importantly, highest hygienic standards are required in order to avoid any contamination, to be verified by general mushroom cultivation techniques. Amongst other measures, a high hygienic standard can be achieved by disposing at once all used up material such as spent mushroom compost, cleaning all facilities before starting a new round of mushroom cultivation and pasteurizing all new incoming material (Sánchez 2004, Rühl and Kües 2007). Another important issue is the inoculum used for the new round of mushroom cultivation. Spent mushroom substrate which still will have much living fungal material should not be taken by the danger of bringing in a contamination from the previous cultivation into the fresh substrate. Instead, fresh spawn needs to be prepared in sterile way. Most spawn is made with mycelium from a stock culture, rather than from mycelium obtained by basidiospore germination. Basidiospores harvested from mushrooms as a product of meiosis present a large heterogeneity of the genetic material which will result in the generation of a variety of different mushroom strains with different fruiting qualities (Quimio et al. 1990; http://pubs.cas.psu.edu/freepubs/pdfs/UL207.pdf). 
So far, few mushroom pests and diseases have been studied in thorough detail. Accordingly, our knowledge on prevention measures and treatments once a problem arises in a mushroom culture is very limited. Pesticides and fungizides might be applied (Freeman 1974, Clift and Terras 1991, Savoie et al. 1992, Ali et al. 1999, Gandhi 1999, Gandhi et al. 2001, Arora et al. 2003, Bernardo et al. 2004, Gea et al. 2005, ChrysayiTokousbalides 2006, Grogan 2006, Royse et al. 2008) or in times of growing ecological and health concerns, biocontrol methods might be developed (Alamidi et al. 1991, Okabe 1993 a,b, Wu and Zhang 1993, Narasimhan and Mohan 1995, Koning et al. 1996, Enkegaard et al. 1997, Scheepmaker et al. 1997a,b, Ali et al. 1999, Jess and Kilpatrick 2000, Gao and Zou 2001, Berndt et al. 2003, Jess and Bingham 2004, Freire et al. 2007, Hubert 2004, Smrž 2004, Smrž and Norton 2004). In order to better protect mushroom cultures and in order to develop better biological measures against pests, microbes and the various types of mushroom diseases, the nature and characteristics of the relationships between potential threats and mushrooms of interest should be studied. In this work, after an infestation of $C$. cinerea cultures with mites identified to belong to the species Tyrophagus putrescentiae (Fig. 17), the chance was taken to look into the interaction of this ubiquitous food and house dust mite and the fungus. The observations in this study. together with additional observations made by Navarro-González (2008), revealed that the animal is specifically attracted to the fungal cultures where it grazes on the vegetative mycelium and on the basidiospores, the latter of which however are only ingested but not digested (see Chapter 4 of this thesis). Fruiting structures, regardless of being young developing primordia or stipes of mature fruiting bodies or etiolated stipes are avoided by the animals as were the dark-stained, melanized sclerotia, round small bodies serving in duration of the fungus (see Chapter 4 of this thesis). From this, one might conclude that in commercial mushroom cultivation the damage by the mites might not be too severe. However, by the consumption of the vegetative mycelium supporting the fruiting structures with water, nutrients and energy (Moore 1998, Kües 2000) less material will be available for the fungus to build up fruiting structures. Thus, mushroom yields have to be expected to decline. Furthermore, mites invading a mushroom culture will bring in various types of bacteria and molds (Fermor et al. 1991, Tsukamoto et al. 2002, Hubert et al. 2003, Foster et al. 2004, Smrž 2004, Bussaman et al. 2006, see also Chapter 4 of this thesis) that usually will be harmful to the mushroom production, e.g. by competing for nutrients, by suppressing the growth of the 

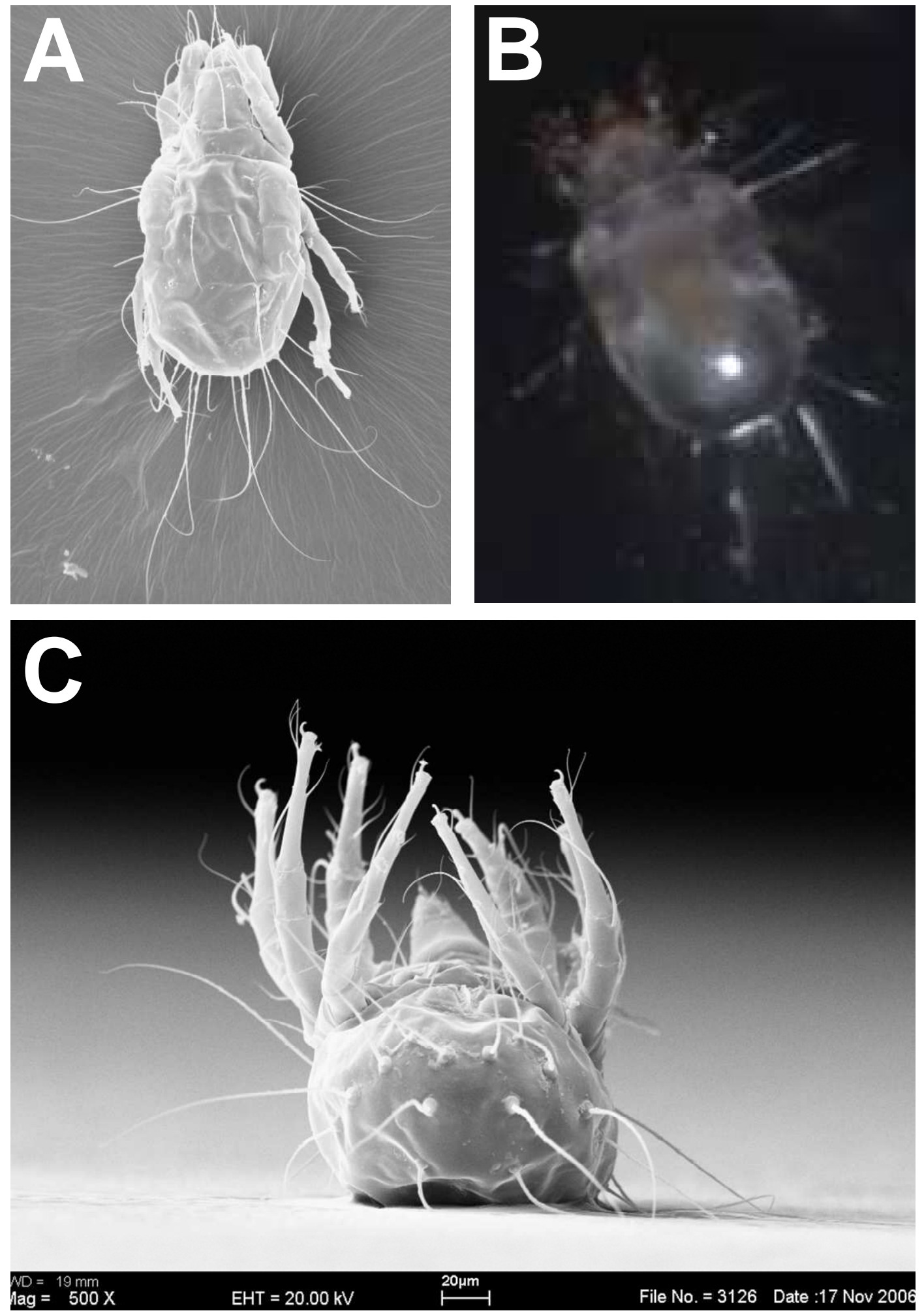

Fig. 17 Electron-microscopic pictures (A), (C) and a picture taken with a binocular (B) of mites that invaded cultures of Coprinopsis cinerea in the laboratory (see Chapter 4 of this thesis). The mites were identified from the electron-microscopic pictures as Tyrophagus putrescentiae by Dr. Pavel Plašil from the Forest Zoology and Forest Conservation group of the Büsgen-Institute. Mites were prepared for the electron-microscopic analysis by Ulrike Eisenwiener from the same group and the photos were taken by Dr. Oliver Eikel. The picture in (B) was taken by W. Chaisaena with a Stemi 2000-C binocular, Carl Zeiss, Göttingen, Germany (see Chapter 4 of this thesis). 
cultivated species and its fruiting body production and by befouling the mushrooms (Mohan et al. 1995, Okabe 1999, Revill et al. 1999, Hatvani et al. 2007, KomonZelazowska et al. 2007). Moreover, mites themselves will pollute the mushrooms by the multitude of faeces they excrete all over the fungal material, both the vegetative mycelium and the mushrooms (see Chapter 4 of this thesis) making the mushrooms and etiolated stipes uneatable as food. Faeces of mites are well-known causes of allergies (Munhbayarlah et al. 1998, Eriksson et al. 1999, Arlian and Platts-Mills 2001, Hashimoto et al. 2001, Yasuhara et al. 2001, Ortego et al. 2004, Ramos et al. 2004, Hubert et al. 2005, Jeong et al. 2005, Morgan and Arlian 2006, Jeong et al. 2007, Huang and Liu 2007) and other diseases (Roche et al. 1997, Jones 1998, Knight et al. 2000, Asokananthan et al. 2002). Currently, there is no biological measure of how to keep the mites away from the fungal cultures during commercial mushroom production. However, in some cultures of $C$. cinerea infested with mites and kept unlocked in the greenhouse, a second species of mites occurred that nourished from the first species T. prudescentiae (P. Plašil, personal communication). The predatory mite has not yet been identified but it might be the base for developing an efficient method of biological control of the spoilage mite. In the literature, there are already some reports on establishing a biocontrol of mites by predators (Collings 1994, Rasmy and Ellaithy 1988, Asselt 1999, Koveos and Broufas 1999, Kim and Seo 2001, Maeda and Takabayashi 2001, Okabe et al. 2001, Kishimoto 2003, Skirvin and Fenlon 2003, Bussaman et al. 2006, Edgington et al. 2008, Mineiro et al. 2008), amongst also some reporting on T. putrescentiae (Vanhaelen et al. 1978, Smrž 1991, Enkegaard et al. 1997, Franzolin 1999, Duek et al. 2001, Okabe et al. 2001, Lee et al. 2005, Palyvos et al. 2006, Idder and Pintureau 2008). Observations on the mites described in Chapter 4 of this thesis suggested that they were attracted by the mycelium of the fungus C. cinerea. Attraction will have been mediated by some kind of volatile organic compound (VOC) or a mixture of VOCs. In the literature, there are reports stating that the organic compounds cis- and trans-octa-1,5-dien-3-ol and some methyl ketones will attract the species T. putrescentiae (Yoshizawa et al. 1970, Vanhaelen et al. 1978, 1980). These compounds are present in cheese (Delahunty and Piggott 1995, Urbach 1997) and can also be detected amongst the VOCs released by fungi (Vanhaelen et al. 1978, 1980). Moreover, predatory mites are attracted by VOCs to places that are infested by other kinds of mites that they use as food (Asselt 1999, Hubert et al. 2004, Skelton et al. 2007). Such VOCs might be generated by the organisms the first group of 
mites grazes on, most likely indirectly as a response of the mycelium to the unwanted grazing (Kuwahara et al. 1987, Morino et al. 1997, Ruther and Steidl 2000) or by the faeces that the mites excrete (Ortego et al. 2000, Sánchez-Ramos et al. 2004). Semiochemicals are certainly important to bring unwanted arthropods and other small animals into a mushroom culture but they might also be used in intelligent way in protection of a fungal culture, for example by attracting predators. VOCs might be applied to a to be protected food (Vanhaelen et al. 1978, Lee et al. 2005, Sung et al. 2006, Tak et al. 2006, Hubert et al. 2008), particularly also if being a substance reacting as a repellent to the unwanted invaders. Recently, the fungal volatiles 1-octen-3-ol and methyl cinnamate have been described to act as repellent in cultures of Tricholoma matsutake (Matsutake) against springtails (Sawahata et al. 2008).

\subsubsection{Volatile organic compounds (VOCs) in mushroom cultures}

The obviously strong attraction of mites to cultures of $C$. cinerea described in Chapter 4 of this thesis was one reason to study the emission of VOCs from C. cinerea cultures with vegetative mycelium and from cultures with developing fruiting structures. The mite $T$. putrescentiae is known to be attracted by cis-and trans-octa-1,5dien-3-ols, eight carbon compounds known to be produced by mushrooms (Vanhaelen et al. 1978, 1980; see Chapter 4 of this thesis). Not surprising therefore, T. putrescentiae is a known mushrooms pests (Okabe et al. 2001, Kheradmand et al. 2007a,b). The involvement of compounds like cis-and trans-octa-1,5-dien-3-ols in the fungal aroma in interactions with pests and in reproductive events are reviewed, as well as the enzymatic system involved in their biosynthesis (Chiron and Michelot 2005, Combet et al. 2006). Mushrooms of different species might differ in VOC production (Ohta 1983, Rapior et al. 2002, Fons et al. 2006) and, very interesting, at different developmental stages, odour production within a given species can undergo strong chances (Cho et al. 2006, 2007, 2008, Wood and Levevre 2007). VOCs specific for discrete developmental stages of the fungus might yield odours specifically attractive for mites or also insects leading them to food sources whilst VOCs can also act as repellents helping to protect the mushrooms from consumptions by animals (Wood et al. 2001, Chiron and Michelot 2005, Sawahata et al. 2008). Since grazing preferences of $T$. putrescentiae discriminated between vegetative mycelium and higher order structures such as fruiting body primordia, fruiting body stipes, etiolated stipes and sclerotia (see Chapter 4 of this 
thesis), it was an obvious task to follow up VOC production during vegetative and sexual reproductive development of the fungus (see Chapter 5 of this thesis). Furthermore, VOCs contribute to the attractive odour and also the pleasant flavor of mushrooms making them a delicacy for human consumption (Kińderlerer 1989, Vandamme 2003, Cho et al. 2007, 2008) which was another reason to follow up in this thesis odour production and composition by C. cinerea. Flavor compounds from basidiomycetes as well as from ascomycetes include amongst other types of VOCs various kinds of alcohols, terpenes, aldehydes, ketones, sesquiterpenes and aromatic compounds (Sunesson et al. 1995, Wheatley et al. 1997, Korpi et al. 1999, Rösecke and König 2000, Rösecke et al. 2000, Abraham 2001, Okamoto et al. 2002, Wheatley 2002). By health and food safety concerns, a choice of natural flavor (bioflavor) is nowadays increasingly considered rather than usage of chemosynthetic products. Volatile compounds as secondary metabolites produced by fungi have not only been studied in their role in food flavors, but they have also been taken advantage of, e.g. in chemotaxonomic studies, in mild methods of food preservation and as indicators of food spoilage (Gatfield 1988, Schnürer et al. 1999). For example, the eight-carbon compound 1-octen-3-ol has repellent activity to certain animals (e.g. slugs and collembolas; Wood et al. 2001, Chiron and Michelot 2005, Sawahata et al. 2008), helping therefore in longer storation of goods by preventing the spoilage of food by bringing in contaminating bacteria and fungi. 1-Octen-3-ol at lower concentrations has been defined to be an attractant to certain mites but at higher concentrations, the 1octen-3-ol acts repellent (Jiang et al. 1997). Moreover, as demonstrated with Penicillium paneum that produces 1-octen-3-ol as a volatile self-inhibitor, the compound has an inhibitory effect on asexual spore (conidia) germination at high spore concentrations $\left(10^{9}\right.$ conidia $\left.\mathrm{ml}^{-1}\right)$. However, the negative effect on germination must be only transient and reversible, why an eventually fully evaporating volatile is an ideal solution to the function of a self-inhibitor acting in spore germination (Chitarra et al. 2005).

The most typical fungal odours (FOs) are indeed certain eight-carbon compounds such as 1-octen-3-ol and 3-octanone (Thakeow et al. 2007), particularly also in mushrooms (Ohta 1983, Rapior et al. 2002, Fons et al. 2006, Cho et al. 2006, 2007, 2008, Wood and Lefevre 2007). As 1-octen-3-ol, 3-octanone has been shown to serve as an attractant to certain mites whereas higher concentrations can lead to repellency (Jiang et al. 1997, Ridsdill-Smith et al. 2002). 1-octen-3-ol and 3-octanone have been 
also identified to be major odour compounds in $C$. cinerea. These two compounds have been detected to increase in production at the different developmental stages of fruiting body development, such as at the developmental transition of from the vegetative mycelium to the hyphal knots (Thakeow 2008 and see Chapter 5 of this thesis), being the first aggregated structures in the process of fruiting body development (see Chapter 2 of this thesis). In primordia development, i.e. during stipe and cap tissues differentiation, at maturation of fruiting body development and during fruiting body autolysis, these compounds are also produced by at different concentrations (Thakeow 2008 and see Chapter 5 of this thesis). Moreover, as shown in this thesis, increased amounts of eight-carbon compounds are produced as a stress reaction upon mycelial wounding (see Chapter 5 of this thesis).

Also in many other basidiomycete fungi, 1-octen-3-ol was recognised as the mediator of the mushroom-like aroma (Tressl et al. 1982, Chen and Wu 1984, Mau et al. 1997, Nidiry 2001, Cho et al. 2008, Thakeow 2008; see Chapter 5 of this thesis). There have been various reports on the 1-octen-3-ol formation in mushrooms, e.g. in Agaricus campestris (Tressl et al. 1982), in Agaricus bisporus (Venkateshwarlu et al. 1999), in Pleurotus pulmonarius (Assaf et al. 1997), in Pleurotus florida (Venkateshwarlu et al. 1999), in Volvariella volvacea (Mau et al. 1997), in Lentinus decadetes (Matsui et al. 2003, Akakabe et al. 2005) and in Lentinula edodes and in Tricholoma matsutake (Akakabe et al. 2005, Cho et al. 2008). In some instances, 1-octen-3-ol was found to be abundantly released in the mycelium stage and then gradually reduced in abundance during fruiting body formation (Venkateshwarlu et al. 1999, Wood et al. 2001, Cho et al. 2007, 2008, De Pinho et al. 2007, Wood and Lefevre 2007, Sawahata 2007). A similar phenomenon was observed in these species regarding the abundance of fungal 3-octanone production (Venkateshwarlu et al. 1999, Cho et al. 2007, 2008, De Pinho et al. 2007). Volatile compounds are detected and identified by analytical techniques, such as gas chromatography and mass spectrometry (GC/MS) (Thakeow et al. 2007, Thakeow 2008; see also Chapter 5 of this thesis). Using such techniques, VOCs have not only been determined in fresh mushrooms but also in canned and dried edible mushroom and in mushroom products (Dijkstra 1976, Kińderlerer 1989, Venkateshwarlu et al. 1999, Hiraide 2005, Cho et al. 2007, De Pinho et al. 2008). 1-Octen-3-ol as a volatile compound being one of the most important flavor components found in mushrooms is a product of the oxidative breakdown of linoleic acid (Holtz and Schisler 1971, Assaf et al. 1997, Cruz et al. 1997, Kuribayashi 
et al. 2002). Different pathways from linoleic acid to 1-octen-3-ol have been proposed. Those are, for example, via an enzymatic hydroperoxide lyase reaction on (10E,12Z)-9hydroperoxyoctadeca-10,12-dienoic acid (9-HPOD) (Tressl et al. 1982) and on (8E,12Z)-9-hydroperoxyoctadeca-8,12-dienoic acid (10-HPOD) (Wurzenber and Grosch 1982) and a homolytic cleavage of 10-HPOD (Combet et al. 2006). Also other eight-carbon volatiles are reported to be important products of the oxidation and cleavage of the fatty acid linoleic acid and these products are classified as molecules taking part in a wide range of biological processes (Combet et al. 2006). Interesting for industrial flavor production, adding linoleic acid and other fatty acids such as hexanoic acid, octanoic acid, decanoic acid, lauric acid and linolenic acid to cultures of basidiomycetes can therefore enhance the production of volatile organic compounds. For example, adding fatty acids into liquid culture of Piptoporus soloniensis enhanced the production of $\gamma$-decalactone as a sweet flavor smell similar to tropical fruits of peach or apricot (Okamoto et al. 2002).

Other volatile compounds also play a role as flavor components in the food industry. The fungus Penicillium roqueforti is for example widely used to produce blue veined Roquefort, Stilton, Gorgonzola and other cheeses by its ability to convert medium-chain fatty acids to their corresponding methyl ketones. Despite, this fungus is also a widespread contaminant of various food products and feeds (Fan et al. 1976, Kinsella and Hwang 1976). The biosynthesis of specific volatile compounds by $P$. roqueforti correlates with the formation of PR toxin, particularly the production of some sesquiterpenes, amongst $\beta$-himachalene whose presence therefore can be taken as volatile biomarker for PR toxin production (Jelen 2002). In C. cinerea, the sesquiterepenes cuparene and $\beta$-himachalene were detected at late stages of fruiting body development during which spores are produced and released to the environment (Thakeow 2008; see Chapter 5 of this thesis). Sesquiterpenes can have toxic including antimicrobial effects and Thakeow (2008) therefore proposed the protection of the basidiospores by the compounds as a potential function of the $C$. cinerea sesquiterpenes cuparene and $\beta$-himachalene, for example a protection against microbial attack. However, since microbial attacks are unlikely restricted to the short time of the very fast proceeding fruiting body maturation when the sesquiterpenes are specifically produced (Thakeow 2008; see Chapter 5 of this thesis), a protection against microbes may not be a primary target of the occurrence of cuparene and $\beta$-himachalene during $C$. cinerea mushroom development. 
Many sesquiterpenes have also cytotoxic effects (Wasser and Weis 1999) and certain sesquiterpenes in plant essential oils are even known to have acaricidal effects (Teles et al. 2007). However, mites are specifically attracted to the gills of the C. cinerea mushrooms and they consume the mature basidiospores without visible negative effects on the animals (Navarro-González 2008; see Chapter 4 of this thesis). Biologically, the mature basidiospores unlikely need a major protection by volatile compounds since the melanisation of the very thick fungal spore walls protects them very well against any physical and biological threats (Heintz and Niederpruem 1970, 1971, McLaughlin and Beckett 1987, Kües 2000). Moreover, if, as suggested by the work of Navarro-González (2008) and the results presented in Chapter 4 of this thesis, mites have a function in spore distribution, certainly at or after fruiting body maturation there should not be a production of volatile compounds being harmful to the animal vectors when consuming the spores. There is however a small window in the developmental pathway of fruiting body development during the basidiospore development where a protection by volatiles could be very useful: After the transfer of large amounts of nutrients (glycogen, oils and fatty acids) occurring prior to incorporation of melanin into the young spore cell wall layers (Ji and Moore 1993, Kües 2000), the nutrient-rich immature spores might be a welcome food for grazing small animals such as the mites. Very likely, due to the lacking protection in the fungal cell walls, the immature spores would not only be ingested by the mites as seen with the mature spores (Navarro-González 2008; see Chapter 4 of this thesis) but the immature spores would likely also be digested. Transient production of volatiles with toxic and repellent properties against mites during the therefore very sensitive period of basidiospore development would be an efficient strategy to ensure spore survival by promoting avoidance of grazing by the mites. Strikingly, cuparene and $\beta$-himachalene are only produced at a very small period of time at the late stage of fruiting body formation that covers this oversensitive development stage in basidiospore production (Thakeow 2008; see Chapter 5 of this thesis). Currently, release of VOCs was measured in time periods of $24 \mathrm{~h}$ (Thakeow 2008, see Chapter 5 of this thesis). In the future, such measurements should be performed at shorter times adjusted to the lengths of the different specific events occuring during fruiting body development (Navarro-González 2008; see Chapter 2 of this thesis). 


\subsection{References}

Abo-Bakr TM, El-Shemi NM and Mesallam AS (1983) Isolation and chemical evaluation of protein from water hyacinth. Plant Foods for Human Nutrition 34:67-73.

Abraham WR (2001) Bioactive sesquiterpenes produced by fungi: Are they useful for humans as well? Curr Med Chem 8:583-606.

Akakabe Y, Matsui K and Kaiiwara T (2005) Stereochemical correlation between 10-hydroperoxyoctadecadienoic acid and 1-octen-3-ol in Lentinula edodes and Tricholoma matsutake mushrooms. Biosci Biotech Biochem 69:1539-1544.

Alamidi AHK, Dunne R and Downes MJ (1991) Parasitus Bituberosus (Acari: Parasitidae) - an agent for control of Lycoriella solani (Diptera: Sciaridae) in mushroom crops. Exp Appl Acarol 11:159-166.

Alexander SJ, Pliz D, Weber NS, Brown E and Rockwell VA (2002) Mushrooms, trees, and money: Value estimates of commercial mushrooms and timber in the Pacific Northwest. Environ Manag 30:129-141.

Ali O, Dunne R and Brennan P (1999) Effectiveness of the predatory mite Hypoaspis miles (Acari: Mesostigmata: Hypospadias) in conjunction with pesticides for control of the mushroom fly Lycoriella solani (Diptera: Sciaridae). Exp App Acarol 23:65-77.

Amey RC, Athey-Pollard A, Mills PR, Foster GD and Bailey A (2007) Investigations into the taxonomy of the mushroom pathogen Verticillium fungicola and its relatives based on sequence analysis of nitrate reductase and ITS regions. Microbiology 76:757-768.

Arlian LG and Platts-Mills TAE (2001) The biology of dust mites and the remediation of mite allergens in allergic disease. J Aller Clin Immunol 107:406-413.

Arora C, Kaushik RD, Kumar A and Garg GK (2003) Fungicidal potential of Kumaon and Tarai region plants against mushroom fungal pathogens. Allelopath $\mathrm{J}$ 11:63-69.

Asokananthan N, Graham PT, Stewart DJ, Bakker AJ, Eidne KA, Thompson PJ and Stewart GA (2002) House dust mite allergens induce proinflammatory cytokines from respiratory epithelial cells: The cysteine protease allergen, Der p1, activates protease-activated receptor (PAR)-2 and inactivates PAR-1. J Immunol 169:4572-4578. 
Assaf S, Hadar Y and Dosoretz CG (1997) 1-Octen-3-ol and 13-hydroperoxylinoleate are products of distinct pathways in the oxidative brake down of linoleic acid by Pleurotus pulmonarius. Enz Microb Technol 21:484-490.

Asselt LV (1999) Interactions between domestic mites and fungi. Indoor Built Environ 8:216-220.

Bae JS, Kim I, Kim SR, Jin BR and Sohn HD (2001) Mitochondrial DNA sequence variation of the mushroom pest flies, Lycoriella mali (Diptera: Sciaridae) and Coboldia fuscipes (Diptera: Scatopsidae), in Korea. Appl Entomol Zool 36:451-457.

Baeza A, Guillen J and Paniagua JM (2000) Radiocaesium and radiostrontium uptake by fruit bodies of Pleurotus eryngii via mycelium, soil and aerial absorption. Appl Radiat Isot 53:455-462.

Bernardo D, Cabo AP, Novaes-Ledieu M, Pardo J and Mendoza CG (2004) Comparative effect of the fungicide Prochloraz-Mn on Agaricus bisporus vegetative-mycelium and fruit-body cell walls. Int Microbiol 7:277-281.

Berndt O, Meyhofer R and Poehling HM (2003) Propensity towards cannibalism among Hypoaspis aculeifer and H. miles, two soil-dwelling predatory mite species. Exp App Acarol 31:1-14.

Bhattacharyya PR, Adhikary RK and Bordoloi DN (1993) Population-dynamics of insect pests and damage of the white button mushroom in the environment of north eastern India. J Food Sci Tech Mys 30:377-379.

Biziulevicius GA (2007) Taking advantage of the experience in ethnomedicinal use of mushrooms: Antiinflammatory and related pharmacological activities of fly agaric (Amanita muscaria) ethanolic extract deserve a modern evaluation. Med Hypoth 69:946-947.

Borchers AT, Stern JS, Hackman RM, Keen CL and Gershin ME (1999) Mushroom, tumor and immunity. Proceed Soc Exp Bio Med 221:281-293.

Borriss H (1934) Beiträge zur Wachstums- und Entwicklungsphysiologie der Fruchtkörper von Coprinus lagopus. Planta 22:28-69.

Boulianne RP, Liu Y, Aebi M, Lu BC and Kües U (2000) Fruiting body development in Coprinus cinereus: regulated expression of two galectins secreted by a nonclassical pathway. Microbiol 146:1841-1853.

Buranachonbot B (2004) Hed-Thoua (hed-cone-noi). In: Mushroom Handbook (B Buranachonbot, ed.) Tappitak, Bangkok, Thailand, pp. 135-138. 
Bussaman P, Sermswan RW and Grewal PS (2006) Toxicity of the entomopathogenic bacteria Photorhabdus and Xenorhabdus to the mushroom mite (Luciaphorus sp; Acari: Pygmephoridae ). Biocont Sci Tech 16:245-256.

Casselton LA and Kües U (2007) The origin of multiple mating types in the model mushrooms Coprinopsis cinerea and Schizophyllum commune. In: Sex in fungi: Molecular determination and evolutionary implications (J Heitman et al., eds.), ASM Press, Herndon, VA, USA, pp. 283-301.

Chaisaena P, Suksawat M, Chaisaena W and Singhadaung R (2003) The study on recycled paper to pot plant container of Kalanchoe which was coated with substance and without coated substance. Research report to the Rajamangala University of Technology, Lanna Phitsanulok Campus Thailand (in Thai), pp. 1-28.

Chang ST (2005) Witnessing the development of the mushroom industry in China. Proc. 5th International conference on mushroom biology and mushroom products. Acta Edulis Fungi 12:3-19.

Chang ST and Buswell JA (1996) Mushroom nutriceuticals. World J Microbiol Biotechnol 12:473-476.

Chang ST and Hayes WA (1978) Cultivation in Western countries: Growing in house; X. Harvesting. In: The biology and cultivation of edible mushrooms (ST Chang and WA Hayes, ed.), Academic Press, Inc, London, UK, pp. 331-333.

Chang ST and Hayes WA (1978) Flammulina velutipes. In: The biology and cultivation of edible mushrooms. (ST Chang and WA Hayes, ed.), Academic Press, Inc, London, UK, pp. 409-422.

Chang ST, Buswell JA and Miles PG (1993) Chapter 5; Physiology and the breeding of Flammulina velutipes. In: Genetics and breeding of edible mushrooms (ST Chang, JA Buswell and PG Miles, eds.) OPA, Amsterdam, Netherlands, pp. 87-108.

Chang ST (1999) World production of cultivated edible and medicinal mushrooms in 1997 with emphasis on Lentinus edodes (Berk.) Sing. in China. International J Med Mush 1:291-300.

Chen CC and Wu CM (1984) Volatile components of mushroom (Agaricus subrufecens). J Food Sci 49:1203-1209.

Chen X, Romaine CP, Ospina-Giraldo MD and Royse DJ (1999) A polymerase chain reaction-based test for the identification of Trichoderma harzianum biotypes 2 
and 4, responsible for the worldwide green mold epidemic in cultivated Agaricus bisporus. Appl Microbiol Biotechol 52:246-250.

Chiron N and Michelot D (2005) Mushrooms odors, chemistry and role in the biotic interactions - a review. Crypt Mycol 26:299-364.

Chitarra GS, Abee T, Rombouts FM and Dijksterhuis J (2005) 1-Octen-3-ol inhibits conidia germination of Penicillium paneum despite of mild effects on membrane permeability, respiration, intracellular $\mathrm{pH}$, and changes the protein composition. FEMS Microbiol Ecol 54: 67-75.

Chiu SW and Moore D (1999) Segregation of genotypically diverse progeny from selffertiöized haploids of the Chinese straw mushroom, Volvariella volvacea. Mycol Res 103:1335-1345.

Cho IH, Choi HK and Kim YS (2006) Difference in the volatile composition of pinemushrooms (Tricholoma matsutake Sing.) according to their grades. J Agric Food Chem 54:4820-4825.

Cho IH, Lee SM, Kim SY, Choi HK, Kim KO and Kim YS (2007) Differentiation of aroma characteristics of pine-mushrooms (Tricholoma matsutake Sing.) of different grades using gas chromatography-olfactometry and sensory analysis. J Agric Food Chem 55:2323-2328.

Cho IH, Namgung HJ, Choi HK and Kim YS (2008) Volatiles and key odorants in the pileus and stipe of pine-mushroom (Tricholoma matsutake Sing.). Food Chem 106:71-76.

Chrysayi-Tokousbalides M, Kastanias MA, Coward S, Philippoussis A and Diamantopoulou P (2006) Residue evaluation of famoxadone and trifloxystrobin in cultivated mushrooms. Environ Sci Health Part B Pestic Food Contam Agric Wastes 41:571-583.

Chu KK, Ho SS and Chow AH (2002) Coriolus versicolor: a medicinal mushroom with promising immunotherapeutic values. J Clin Pharmacol 42:976-984.

Clift AD and Terras MA (1991) Effects of pesticides on the yield and production patterns of 3 standard and 6 hybrid strains of cultivated mushrooms in NewSouth-Wales. Aust J Exp Agric 31:427-430.

Collings JB (1994) Bifurcation and stability analysis of a temperature-dependent mite predator-prey interaction model incorporating a prey refuge. Bullet Math Biol 57:63-76. 
Combet E, Burton KS, Eastwood DC, Griffiths G and Henderson J (2006) Eigth-carbon volatiles in mushrooms and fungi: properties, analysis, and biosynthesis. Mycosci 47:317-326.

Cross EA and Kaliszewski MJ (1988) The life-history of a mushroom pest mite, Pediculaster flechtmanni (Wicht) (Acari: Pygmephoroidea), with studies of alternate morph formation. Environ Entomol 17:309-315.

Cruz C, Noel-Suberville C and Montury M (1997) Fatty acids content and some flavour compounds release in two strain of Agaricus bisporus, according to three stages of development. J Agric Food Chem 45:64-67.

De Pinho PG, Ribeiro B, Goņalves RF, Baptista P, Valentao P, Reabra RM and Andrade PB (2008) Correlation between the pattern volatiles and the overall aroma of wild edible mushrooms. J Agric Food Chem 56:1704-1712.

Delahunty CM and Piggott JR (1995) Current methods to evaluate contribution and interactions of components to flavour of solid foods using hard cheese as an example. Int J Food Sci Tech 30:555-570.

Dijkstra FY (1976) Studies on mushroom flavour 3. Some flavour compounds in fresh, canned and dried edible mushrooms. Zeit Lebensmit Forsch 160:401-405.

Duek L, Kaufman G, Palevsky E and Berdicevsky I (2001) Mites in fungal cultures. Mycoses 44:390-394.

Edgington S, Fernando LCP and Jones K (2008) Natural incidence and environmental profiling of the mite-pathogenic fungus Hirsutella thompsonii Fisher for control of the coconut mite in Sri Lanka. Int J Pest Manag 54:123-127.

Elliott CG (1994) Reproduction in fungi. Genetical and physiological aspects. Chapman and Hall, London, UK.

Enkegaard A, Sardar MA and Brodsgaard HF (1997) The predatory mite Hypoaspis miles: Biological and demographic characteristics on two prey species, the mushroom sciarid fly, Lycoriella solani, and the mould mite, Tyrophagus putrescentiae. Entomol Experiment Appl 82:135-146.

Eriksson TLJ, Whitley P, Johansson E, Van Hage-Hamsten M and Gafvelin G (1999) Identification and characterisation of two allergens from the dust mite Acarus siro, homologous with fatty acid-binding proteins. Int Archiv Aller Immunol 119:275-281.

Fan LF, Pan HJ, Soccol AT, Pandey A and Soccol CR (2006) Advances in mushroom research in the last decade. Food Technol Biotechnol 44:303-311. 
Fan TY, Hwang DH and Kinsella JE (1976) Methyl ketone formation during germination of Penicillium roqueforti. J Agric Food Chem 24:443-447.

Fermor TR, Henry MB, Fenlon JS, Glenister MJ, Lincoln SP and Lynch JM (1991) Development and application of a biocontrol system for bacterial blotch of the cultivated mushroom. Crop Protec 10:271-278.

Fett WF, Wells JM, Cescutti P and Wijey C (1995) Identification of exopolysaccharides produced by fluorescent Pseudomonas associated with commercial mushroom (Agaricus bisporus) production. Appl Environ Microbiol 61:513-517.

Fons F, Rapior S, Fruchier A, Saviuc P and Bessiere JM (2006) Volatile composition of Clitocybe amoenolens, Tricholoma caligatum and Hebeloma radicosum. Crypt Mycol 27:45-55.

Foster GD, Amey RC, Bailey A and Mills PR (2004) Investigation of the interaction between Verticillium fungicola and Agaricus bisporus. Mush Sci 16:479-487.

Franzolin MR, Gambale W, Cuero RG and Correa B (1999) Interaction between toxigenic Aspergillus flavus Link and mites (Tyrophagus putrescentiae Schrank) on maize grains: effects on fungal growth and aflatoxin production. J Stored Prod Res 35:215-224.

Freeman JA (1974) Research in progress at the pest infestation control laboratory. EPPO Bulletin 4:291-294.

Freire RAP, De Moraes GJ, Silva ES, Vaz AC and Castiho RD (2007) Biological control of Bradysia matogrossensis (Diptera: Sciaridae) in mushroom cultivation with predatory mites. Exp App Acarol 42:87-93.

Gandhi KJK (1999) The importance of fire-skips as biotic refugia and the influence of habitat heterogeneity on epigaeic beetles in pyrogenic stands of the northern Rocky Mountains. MSc Thesis, University of Alberta, Edmonton, Alta.

Gandhi KJK, Spence JR, Langor DW and Morgantini LE (2001) Fire residuals as habitat reserves for epigaeic beetles (Coleoptera: Carabidae and Staphylinidae). Biol Conserv 102:131-41.

Gao JR and Zou P (2001) Biology, life table and host specificity of the mushroom pest, Brennandania lambi (Acari: Pygmephoroidea). Exp App Acarol 25:187-202.

Gatfield IL (1988) Production of flavor and aroma compounds by biotechnology. Food Technol. 42:110-122. 
Gea FJ, Navarro MJ and Tello JC (2005) Reduced sensitivity of the mushroom pathogen Verticillium fungicola to prochloraz-manganese in vitro. Mycol Res 109:741-745.

Granado JD, Kertesz-Chaloupková K, Aebi M and Kües U (1997) Restriction enzymemediated DNA integration in Coprinus cinereus. Mol Gen Genet 256:28-36.

Grogan HM (2006) Fungicide control of mushroom cobweb disease caused by Cladobotryum strains with different benzimidazole resistance profiles. Pest Manag Sci 62:153-161.

Gunnarsson CC and Peterson CM (2007) Water hyacinths as a resource in agriculture and energy production: A literature review. Waste Manag 27:117-129.

Guthrie JL and Castle AJ (2006) Chitinase production during interaction of Trichoderma aggressivum and Agaricus bisporus. Can J Microbiol 52:961-967.

Haindl E and Monzer J (1994) Elongation growth abd gravitropic curvature in the Flammulina velutipes (Agaricales) fruiting body. Exp Mycology 18:150-158.

Härkönen M, Saarimäki T and Mwasumbi L (1993) Tanzanian mushrooms and their uses 2. An edible species of Coprinus section Lanatuli. Karstenia 33:51-59.

Hashimoto T, Takada N and Motoyama N (2001) ATPase activities of acarid mite, Tyrophagus putrescentiae (Schrank) (Acari: Acaridae), and their inhibition by several acaricides. Med Entomol Zool 52:195-200.

Hatvani L, Antal Z, Manczinger L, Szekeres A, Druzhinina IS, Kubicek CP, Nagy A, Nagy E, Vagvolgvi C and Kredics L (2007) Green mold diseases of Agaricus and Pleurotus spp. are caused by related but phylogenetically different Trichoderma species. Phytopathol 97:532-537.

Heard SB (1998) Resource patch density and larval aggregation in mushroom-breeding flies. OIKOS 81:187-195.

Heintz CE and Niederpruem (1970) Ultrastructure and respiration of oidia and basidiospores of Coprinus lagopus (sensu Buller). Can J Microbiol 16:481-484.

Heintz CE and Niederpruem (1971) Ultrastructure of quiescent and germinated basidiospores and oidia of Coprinus lagopus. Mycologia 63:745-766.

Hiraide M (2005) The smell and adorous components of dried shiitake mushroom, Lentinula edodes III: substances that increase the odorous compound content. J Wood Sci 52:265-269. 
Ho MS and Peng JT (2006) Edible mushroom production in Taiwan. In: Mushrooms international: the newsletter of the International Society for Mushroom Science (T Biggs and F Biggs, eds.), North Richmond, Australia, pp. 7-9.

Hoegger PJ, Majcherczyk A, Dwivedi RC, Svobodova K, Kilaru S and Kües U (2008) Enzymes in wood degradation. In: Wood production, wood technology and biotechnological impacts (U Kües, ed.), Universitätsverlag, Göttingen, Germany, pp. 383-432.

Holtz RB and Schisler LC (1971) Lipid metabolism of Agaricus bisporus (Lange) Sing: I. Analysis of sporophore and mycelial lipids. Lipids 6:176-180.

Huang ZJ and Liu ZG (2007) Identification and purification of Tyrophagus putrescentiae allergens. Aller Immunol Inst, 25:483-487.

Hubert J, Stejskal V, Kubatova A, Munzbergova Z, Vanova M and Žd'árková E (2003) Mites as selective fungal carriers in stored grain habitats. Exp App Acarol 29:69-87.

Hubert J, Jarošík V, Mourek J, Kubátovát A and Žd'árková E (2004) Astigmatid mite growth and fungi preference (Acari: Acaridida): Comparisons in laboratory experiments. Pedobiologia 48:205-214.

Hubert J, Dolečková-Marešová L, Hýblová J, Kudlíková I, Stejskal V and Mareš M (2005) In vitro and in vivo inhibition of $\alpha$-amylases of stored-product mite Acarus siro. Exp App Acarol 35:281-291.

Hubert J, Muenzbergova Z, Nesvorna M, Poltronieri P and Santino A (2008) Acaricidal effects of natural six-carbon and nine-carbon aldehydes on stored-product mites. Exp App Acarol 44:315-321.

Idder MA and Pintureau B (2008) Effectiveness of the ladybird Stethorus punctillum (Weise) as a predator of the mite Oligonychus afrasiaticus (McGregor) in the palm plantations of the area of Wargla in Algeria. Fruits 63:85-92.

Iten W (1970) Zur Funktion hydrolytischer Enzyme bei der Autolysate von Coprinus. Ber Schweiz Bot Ges 79:175-198.

Iten W and Matile P (1970) Role of chitinase other lysosomal enzymes of Coprinus lagopus in the autolysis of fruiting bodies. J Gen Microbiol 61:301-309.

Jantarasri P (2004) Growing Coprinus fimetarius. In Thai language, Format: HTML/CD-ROM,Compatibility:All O/S, Table of CD-ROM. In: Chapters; Background information on Coprinus fimetarius, Basic Coprinus fimetarius plantation and interesting factors. Published by Regional Information Service 
Centre for South East Asia on Appropriate Technology (ed.), Inst Sci Tech Res Devel, Chiang Mai,Thailand.

Jelen HH (2002) Volatile sesquiterpene hydrocarbons characteristic for Penicillium roqueforti strains producing PR Toxin. J Agric Food Chem 50:6569-6574.

Jeong KY, Kim WK, Lee JK, Lee JS, Lee J, Lee IY, Kim KE, Park JW, Hong CS, Ree HI and Yong TS (2005) Immunoglobulin E reactivity of recombinant allergen Tyr p 13 from Tyrophagus putrescentiae homologous to fatty acid binding protein. Clin Diag Lab Immunol 12:581-585.

Jeong KY, Lee H, Lee JS, Lee J, Lee IY, Ree HI, Hong CS and Yong TS (2007) Molecular cloning and the allergenic characterization of Tyrophagus putrescentiae. Protein Pept Lett 14:431-436.

Jess S and Bingham JFW (2004) The spectral specific responses of Lycoriella ingénue and Megaselia halterata during mushroom cultivation. J Agric Sci 142:421-430.

Jess S and Kilpatrick M (2000) An integrated approach to the control of Lycoriella solani (Diptera: Sciaridae) during production of the cultivated mushroom (Agaricus bisporus ). Pest Manag Sci 56:477-485.

Jess S, Murchie AK and Bingham JFW (2007) Potential sources of sciarid and phorid infestations and implications for centralised phases I and II mushroom compost production. Crop Protec 26:455-464.

Ji J and Moore D (1993) Glycogen etabolism in relation to fruit body maturation in Coprinus cinereus. Mycol Res 97:283-289.

Jiang Y, Ridsdill-Smith TJ and Ghisalberti EL (1997) The effect of volatile metabolites of lipid peroxidation on the aggregation of redlegged earth mites Halotydeus destructor (Acarina: Penthaleidae) on damaged cotyledons of subterranean clover. J Chem Ecol 23:163-174.

Jones AP (1998) Asthma and domestic air quality. Soc Sci Med 47:755-764.

Keshri G, Challen M, Elliott T and Magan N (2003) Differentiation of Agaricus species and other homobasidiomycetes based on volatile production patterns using an electronic nose system. Mycol Res 107:609-613.

Kharazipour A, Ludwig K, Chaisaena W, Polle A and Kües U (2007) Wood and other plant fibres in the production of peat substitutes and pot plant containers. In: Wood production, wood technology and biotechnological impacts (U Kües, ed.), Universitatsverlag, Göttingen, Germany, pp. 609-635. 
Kheradmand K, Kamali K, Fathipour Y, Goltapeh EM and Ueckermann EA (2007a) Thermal requirement for development of Sancassania rodionovi (Acari: Acaridae) on mushrooms. J Econ Entomol 100:1098-1103.

Kheradmand K, Kamali K, Fathipour Y, Goltapeh EM and Ueckermann EA (2007b) Development, life table and thermal requirement of Tyrophagus putrescentiae (Astigmata: Acaridae) on mushrooms. J Stored Prod Res 43:276-281.

Kidon MI, Chiang WC, Liew WK, Lim SH, See Y, Goh A, Tan JPL, Chay OM and Balakrishnan A (2005) Sensitization to dust mites in children with allergic rhinitis in Singapore: does it matter if you scratch while you sneeze? Clin Exp Aller 35:434-440.

Kim HH, Choo HY, Kaya HK, Lee SM and Jeon HY (2004) Steinernema carpocapsae (Rhabditida: Steinernematidae) as a biological control agent against the fungus gnat Bradysia agrestis (Diptera: Sciaridae) in propagation houses. Biocont Sci Tech 14:171-183.

Kim SS and Seo SG (2001) Relative toxicity of some acaricides toz he predatory mite, Amblyseius womersleyi and the twospotted spider mite, Tetranychus urticae (Acari: Phytoseiidae, Tetranychidae). App Ent Zool 36:4509-4514.

Kim SW, Kim MG, Kim J, Lee HS and Ro HS (2008) Detection of the mycovirus OMSV in the edible mushroom, Pleurotus ostreatus, using an SPR biosensor chip. J Virol Meth 148:120-124.

Kińderlerer JL (1989) Volatile metabolites of filamentous fungi and their role in food flavour. J Appl Bacteriol Symp Suppl 133-144.

Kinsella JE and Hwang DH (1976) Enzymes of Penicillium roqueforti involved in the biosynthesis of cheese flavour. CRC Crit Rev Food Sci Nutr 8:191-228.

Kishimoto H (2003) Development and oviposition of predacious insects, Stethorus japonicus (Coleoptera: Coccinellidae), Oligota kashmirica benefica (Coleoptera: Staphylinidae), and Scolothrips takahashii (Thysanoptera: Thripidae) reared on different spider mite species (Acari: Tetranychidae). App Ent Zool 38:15-21.

Kitamoto Y (2006) Current progress in breeding of edible and pharmaceutical mushrooms. Mokuz Gakkai 52:1-7.

Knight DA, Asokananthan N, Watkins DN, Misso NLA, Thompson PJ and Stewart GA (2000) Oncostatin M synergises with house dust mite proteases to induce the production of $\mathrm{PGE}_{2}$ from cultured lung epithelial cells. $\mathrm{Br} \mathrm{J}$ Pharmacol 131:465-472. 
Komon-Zelazowska M, Bissett J, Zafari D, Hatvani L, Manczinger L, Woo S, Lorito M, Kredics L, Kubicek CP and Druzhinina IS (2007) Genetically closely related but phenotypically divergent Trichoderam species cause green mold disease in oyster mushroom farmsworldwide. Appl Environ Mycobiol 73:7415-7426.

Koning G, Hamman B and Eicker A (1996) The efficacy of nematophagous fungi on predaceous nematodes in soil compared with saprophagous nematodes in mushroom compost. S Afr J Bot 62:49-53.

Korpi A, Pasanen AL and Vitanen H (1999) Volatile metaboilites of Serpula acrymans, Coniophora puteana, Poria placenta, Stachybotrys chartarum and Chaetomium globosum. Build Environ 34:205-211.

Koveos DS and Broufas GD (1999) Feeding history affects the response of the predatory mite Typhlodromus kerkirae (Acari: Phytoseiidae) to volatiles of plants infested with spider mites. Exp App Acarol 23:429-436.

Krupke OA, Castle AJ and Rinker DL (2003) Mushroom compost that inhibit mycelial growth of the commercial mushroom Agaricus bisporus. Mycol Res 107:1467-1475.

Kües U (2000) Life history and developmental processs in the basidiomycete Coprinus cinereus. Microbiol Mol Biol Rev 64:316-353.

Kües U and Liu Y (2000) Fruiting body production in basidiomycetes. Appl Microbiol Biotechnol 54:141-152.

Kües U, Granado JD, Hermann R, Boulianne RP, Kertesz-Chaloupková K and Aebi M (1998) The $A$ mating type and blue light regulate all known differentiation processes in the basidiomycete Coprinus cinereus. Mol Gen Genet 260:81-91.

Kües U, James TY,Vilgalys R and Challen MP (2001) The chromosomal region containing pab-1, mip, and the $A$ mating type locus of the secondarily homothallic homobasidiomycete Coprinus bilanatus. Curr Genet 39:16-24.

Kües U, Künzler M, Bottoli APF, Walser PJ, Granado JD, Liu Y, Bertossa RC, Ciardo D, Clergeot PH, Loos S, Ruprich-Robert G and Aebi M (2004) Mushroom development in higher basidiomycetes. Implications for human and animal health. In: Fungi in Human and Animal Health Scientific Publishers (RKS Kushwaha, ed.), Jodhpur, India, pp. 431-470.

Kües U, Mai C and Militz H (2007) Biological wood protection against decay, microbial staining, fungal moulding and insect pests. In: Wood production, 
wood technology and biotechnological impacts (U Kües, ed.), Universitätsverlag, Göttingen, Germany, pp. 273-294.

Kuribayashi T, Kaise H, Uno C, Hara T Hayahawa T and Joh T (2002) Purification and characterization of lipoxygenase from Pleurotus ostreatus. J Agric Food Chem 50:1247-1253.

Kuwahara Y, Akimoto K and Leal WS (1987) Pheromone study on acarid mites 9 syntheses of alarm pheromone analogs of the mold mite, Tyrophagus putrescentiae, and their biological activities. Agric Biol Chem 51:3441-3442.

Largeteau ML, Baars JPP, Regnault-Roger C and Savoie JM (2006) Molecular and physiological diversity among Verticillium fungicola var. fungicola. Mycol Res 110:431-440.

Lee CH, Sung BK and Lee HS (2005) Acaricidal activity of fennel seed oils and their main components against Tyrophagus putrescentiae, a stored-food mite. J Stored Prod Res 42:8-14.

Lee HS (2005) Food protective effect of acaricidal components isolated from anise seeds against the stored food mite, Tyrophagus putrescentiae (Schrank). J Food Protec 68:1208-1210.

Lelley J (1991) Pilzanbau: Biotechnologie der Kulturspeisepilze. Ulmer, Stuttgart, Germany, pp. 1-404.

Liu Y (2001) Fruiting body initiation in the basidiomycete Coprinus cinereus. PhD Thesis, University of ETH Zurich, Zurich, Switzerland.

Liu Y, Granado JD, Polak E and Kües U (1999) Crosses with AmutBmut homokaryons of Coprinus cinereus. Fungal Genet Newslet 46:16-20.

Liu Y, Srivilai P, Loos S, Aebi M and Kües U (2006) An essential gene for fruiting body initiation in the basidiomycete Coprinopsis cinerea is homologous to bacterial cyclopropane fatty acid synthase genes. Genetics 172: 873-884.

Liu YN, Honda H and Kohno Y (2002) Mating behavior and its regulatory factors in the black fungus gnat, Bradysia paupera (Diptera: Sciaridae). Jpn J Appl Entomol Zool 46:23-30.

Lu BC (1974) Meiosis in Coprinus. V. The role of light on basidiocarp initiation, mitosis and hymenium differentiation in Coprinus lagopus. Can J Bot 52:299-305.

Lu BC (2000) The control of meiosis progression in the fungus Coprinus cinereus by light/dark cycles. Fungal Genet Biol 31:33-41. 
Maeda T and Takabayashi J (2001) Production of herbivore-induced plant volatiles and their attractiveness to Phytoseius persimilis (Acari: Phytoseiidae) with changes of Tetranychus urticae (Acari: Tetranychidae) density on a plant. App Ent Zool 36:47-52.

Mahmood Q, Zheng P, Siddiqi MR, Islam E, Azim R and Hayat Y (2005) Anatomical studies on water hyacinth (Eichhornia crassipes (Mart.) Solms) under the influence of textile wastewater. J Zhejiang Univ Sci B 6:991-998.

Mahujchariyawong J (2001) Modelling sustainable water quality improvement using water hyacinth and its application in Thailand. Int J Sustain Dev World Ecol 8:221-231.

Mandeel QA, Al-Laith AA and Mohamed SA (2005) Cultivation of oyster mushrooms (Pleurotus spp.) on various lignocellulosic wastes. World J Microbiol Biotechnol 21:601-907.

Martin F, Aerts A, Ahren D, Brun A, Danchin EGJ, Duchaussoy F, Gibon J, Kohler A, Lindquist E, Pereda V, Salamov A, Shapiro HJ, Wuyts J, Blaudez D, Buee M, Brokstein P, Canback B, Cohen D, Courty PE, Coutinho PM Delaruelle C, Detter JC, Deveau A, DiFazio S, Duplessis S, Fraissinet-Tachet L, Lucic E, Frey-Klett P, Fourrey C, Feussner I, Gay G, Grimwood J, Hoegger PJ, Jain P, Kilaru S, Labbe J, Lin YC, Legue V, Le Tacon F, Marmeisse R, Melayah D, Montanini B, Muratet M, Nehls U, Niculita-Hirzel H, Oudot-Le Secq MP, Peter M, Quesneville H, Rajashekar B, Reich M, Rouhier N, Schmutz J, Yin T, Chalot M, Henrissat B, Kües U, Lucas S, de Peer YV, Podila GK, Polle A, Pukkila PJ, Richardson PM, Rouze P, Sanders IR, Stajich JE, Tunlid A, Tuskan G and Grigoriev IV (2008) The genome of Laccaria bicolor provides insights into mycorrhizal symbiosis. Nature 452:88-92.

Matsui K, Sasahara S, Akakabe Y and Kaiiwara T (2003) Linoleic acid 10-hydroperoxide as an intermediate during formation of 1-octen-3-ol from linoleic acid in Lentinus decadetes. Biosci Biotech Biochem 67:2280-2282.

Mau JL, Chyau CC, Li JY and Tseng YH (1997) Flavor compounds in straw mushrooms Volvariella volvacea harvested at different stages of maturity. J Agric Food Chem 45:4726-4729.

Mayell M (2001) Maitake extracts and their therapeutic potential. Altern Med Rev 6:48-60. 
Mcknight KB (1992) Evolution of Flammulina velutipes basidiocarp size with respect to relative-humidity. Mycologia 84:219-228.

Mcknight KB and Estabrook GF (1990) Adaptations of sporocarps of the basidiomycete Flammulina velutipes (Agaricales) to lower humidity. Botanical Gazette 151:528-537.

McLaughlin DC and Beckett A (1987) Low scanning electron microscopy of discharged basidiospores of Coprinopsis cinereus. Mycologia 79:158-161.

Michelot D and Melendez-Howell LM (2003) Amanita muscaria: chemistry, biology, toxicology, and ethnomycology. Mycol Res 107:131-146.

Mineiro DC, Luiz J, Eidi SM, Adalton R and Valter A (2008) Population dynamics of phytophagous and predaceous mites on coffee in Brazil, with emphasis on Brevipalpus phoenicis (Acari: Tenuipalpidae). Exp Appl Acarol 44:277-291.

Mohan S, Mohan S and Disney RHL (1995) A new species of scuttle fly (Diptera: Phoridae) that is a pest of oyster mushrooms (Agaricales: Pleurotaceae) in India. Bullet Entomol Res 85:515-518.

Molloy FJ, Critchley AT, Kandjengo L and Mshigeni KE (2003) The use of the valuable oyster mushroom, Pleurotus sajor-caju, for conversion of waste materials produced from seaweed and brewing industries: Preliminary investigations. AMBIO 32:76-78.

Money NP and Ravishankar JP (2005) Biomechanics of stipe elongation in the basidiomycete Coprinopsis cinerea. Mycol Res 109:627-634.

Monzer J, Haindl E, Kern V and Dressel K (1994) Gravitropism of the basidiomycete Flammulina velutipes morphological and physiological aspects of the graviresponse. Exper Mycol 18:7-19.

Moore D (1998) Fungal morphogenesis. Cambridge University Press, Cambridge, UK, pp. 1-469.

Moore D, Elhiti MMY and Butler RD (1979) Morphogenesis of the carpophore of Coprinus cinereus. New Phytol 83:695-722.

Morgan MS and Arlian LG (2006) Enzymatic activity in extracts of allergy-causing astigmatid mites. J Med Entomol 43:1200-1207.

Morimoto N, Suda S and Sagara N (1981) Effect of ammonia on fruit-body induction of Coprinus cinereus in darkness. Plant Cell Physiol 22:247-254.

Morino A, Kuwahara Y, Matsuyama S and Suzuki T (1997) (E)-2-(4'-methyl-3'penteny lidene)-4-butanolide, named beta-acariolide: A new monoterpene 
lactone from the mold mite, Tyrophagus putrescentiae (Acarina: Acaridae). Behav Ecol 10:422-427.

Morris R (2001) Water hyacinths: turning a weed into a win-win situation. Future frame articles Zeitgeist, Morgenwelt e.V., Hamburg, Germany, pp.1

Mshandete AM and Cuff J (2007) Proximate and nutrient composition of three types of indigenous edible wildmushrooms grown in Tanzania and their utilization prospects. Africa J Food Agric Nutr Devel 7:1-16.

Mukherje AB and Choudhur AK (1974) Mites pest on mushroom. FAO plant protection Bulletin 22:51-52.

Munhbayarlah S, Park JW, Ko SH, Ree HI and Hong CS (1998) Identification of Tyrophagus putrescentiae allergens and evaluation of cross-reactivity with Dermatophagoides pteronyssinus. Yonsei Med J 39:109-115.

Muraguchi H and Kamada T (1998) The ichl gene of the mushroom Coprinus cinereus is essential for pileus formation in fruiting. Development 125:3133-3141.

Narasimhan S and Mohan H (1995) A new method for the synthesis of (z)-9hexadecen-1-al, an important pheromone component of heliothis-armigera and many other pests. Indian J Chem, Section $\beta$ : Org Chem Incl Med Chem 34:950-953.

Navarro-González M (2008) Growth fruiting body development and laccase production of selected coprini. PhD Thesis. Georg-August University of Göttingen, Göttingen, Germany.

Nidiry ESJ (2001) Structure-fungitoxicity relationships of some volatile flavour constituents os the edible mushrooms Agaricus bisporus and Pleurotas florida. Flavour Fragr J 16:245-248.

Obodai M, Cleland-Okine J and Vowotor KA (2003) Comparative study on the growth and yield of Pleurotus ostreatus mushroom on different lignocellulosics byproducts. J Ind Microbiol Biotechnol 30:146-149.

Ohta A (1983) Quantitative-analysis of odorous compounds in the fruit bodies of Tricholoma-matsutake. Trans Mycol Soc Jpn 24:185-190.

Okabe K (1993a) Population-growth and dispersal behavior of Histiogaster sp (Acari: Acaridae) on several economically important fungi. Appl Entomol Zool 28:11-18.

Okabe K (1993b) Developmental period and fecundity of Histiogaster sp. (Acari: Acaridae) on 3 Fungi. Appl Entomol Zool 28:479-487. 
Okabe K (1999) Vectoring of Hypocrea nigricans (Hypocreales: Hypocreaceae) by three fungivorous mite species (Acari: Acaridae). Exp Appl Acarol 23:653-658.

Okabe K, Miyazaki K and Yamamoto H (2001) Population increase in mushroom pest mites on cultivated Hypsozygus marmoreus and their vectoring of weed fungi between mushroom cultivation media. Jpn J Appl Entomol Zool 45:75-81.

Okada H and Kadota I (2003) Host status of 10 fungal isolates for two nematode species, Filenchus misellus and Aphelenchus avenae. Soil Biol Biochem 35:1601-1607.

Okada H, Harada H and Kadota I (2005) Fungal-feeding habits of six nematode isolates in the genus Filenchus. Soil Biol Biochem 37:1113-1120.

Okamoto K, Narayama S, Katsuo A, Shigematsu L and Yanase H (2002) Biosynthesis of $p$-anisaldehyde by the white-rot basidiomycete Pleurotus ostreatus. J Biosci Bioeng 93:207-210.

Olivier JM, Mamoun M and Munsch P (1997) Standardization of a method to assess mushroom blotch resistance in cultivated and wild Agaricus bisporus strains. Can J Plant Pathol 19:36-42.

Ortego F, Sánchez-Ramos I, Ruiz M and Castañera P (2000) Characterization of proteases from a stored product mite, Tyrophagus putrescentiae. Arch Insect Biochem Physiol 43:116-124.

Palyvos NE, Athanassiou CG and Kavallieratos NG (2006) Acaricidal effect of a diatomaceous earth formulation against Tyrophagus putrescentiae (Astigmata: Acaridae) and its predator Cheyletus malaccensis (Prostigmata: Cheyletidae) in four grain commodities. J Econ Ent 99:229-236.

Philippoussis A, Zervakis G and Diamantopoulou P (2001) Bioconversion of agricultural lignocellulosic wastes through the cultivation of the edible mushrooms Agrocybe aegerita, Volvariella volacea and Pleurotus spp. World J Microbiol Biotechnol 17:191-200.

Pilz D and Molina R (2002) Commercial harvests of edible mushrooms from the forests of the Pacific Northwest United States: issues, management, and monitoring for sustainability. Forest Ecol Manag 155:3-16.

Polprasert C, Wangsuphachart S and Muttamara S (1980) Composting nightsoil and water hyacinth in the tropics. Compost Sci Land Utiliz 22:25-27.

Poppe J (2000) Use of agricultural waste materials in the cultivation of mushrooms. Mush Sci 15:3-23. 
Quimio TH, Chang ST and Royse DJ (1990) Technical guidelines for mushroom growing in the tropics. FAO Plant Production and Protection Paper 106, Rome, Italy.

Rao JR, Nelson DWA and McClean S (2007) The enigma of double-stranded RNA (dsRNA) associate with mushroom virus $\mathrm{X}$ (MVX). Curr Iss Mol Biol 9:103-121.

Rapior S, Breheret S, Talou T, Pelissier Y and Bessiere JM (2002) The anise-like odor of Clitocybe odora, Lentinellus cochleatus and Agaricus essettei. Mycologia 94:373-376.

Rasmy AH and Ellaithy AYM (1988) Introduction of Phytoseiulus persimilis for two-spotted spider mite controlin greenhouse in Egypt (Acari: Phytoseiidae, tetranychidae). Biocontrol 33:435-438.

Redhead SA and Petersen RH (1999) New species, varieties and combinations in the genus Flammulina. Mycotaxon 71:285-294.

Redhead SA, Vilgalys R, Moncalvo JM, Johnson J and Hopple JS (2001) Coprinus Persoon and the disposition of Coprinus species sensu lato. Taxon 50:203-241.

Revill PA, Davidson AD and Wright PJ (1999) Identification of a subgenomic mRNA encoding the capsid protein of mushroom bacilliform virus, a single-stranded RNA mycovirus. Virology 260:23-276.

Ridsdill-Smith J, Ghisalberti E and Jianq Y (2002) Induced responses in clover to an herbaceous mite. Arch Insect Biochem Physiol 51:170-181.

Roche N, Chinet TC and Huchon GJ (1997) Allergic and nonallergic interactions between house dust mite allergens and airway mucosa. Eur Respi J 10:719-726.

Rösecke J and König WA (2000) Constituents of various wood-rotting basidiomycetes. Phytochemistry 54:603-610.

Rösecke J, Pietsch M and König WA (2000) Volatile constituents of wood-rotting Basidiomycetes. Phytochemistry 54:747-750.

Royse DJ, Sánchez JE, Beelman RB and Davidson J (2008) Re-supplementing and re-casing mushroom (Agaricus bisporus) compost for a second crop. World $\mathbf{J}$ Microbiol Biotech 24:319-325.

Rühl M and Kües U (2007) Mushroom production. In: Wood production, wood technology and biotechnological impacts (U Kües, ed.), Universitätsverlag, Göttingen, Germany, pp. 555-585. 
Rühl M, Kilaru S, Hoegger P, Kharazipour A and Kües U (2007) Production of laccases and other enzymes for the wood industry. In: Wood production, wood technology and biotechnological impacts (U Kües, ed.), Universitätsverlag, Göttingen, Germany, pp. 469-507.

Ruther J and Steidle JLM (2000) Mites as matchmakers: Semiochemicals from hostassociated mites attract both sexes of the parasitoid Lariophagus distinguendus. J Chem Ecol 26:1205-1217.

Sakamoto Y, Ando A, Tamai Y and Takashi Y (2004) Pileus differentiation and pileusspecific protein expression in Flammulina velutipes. Mycoscience 45:333-339.

Sakamoto Y, Ando A, Tamai Y, Miura K and Yajima T (2002) Protein expressions during fruit body induction of Flammulina velutipes under reduced temperature. Mycol Res 106:222-227.

Sakamoto Y, Ando A, Tamai Y, Tamai Y and Yajima T (2007) Pileus differentiation and pileus-specific protein expression in Flammulina velutipes. Fungal Genet Biol 44:14-24.

Samarawira I and Fernando ST (1973) Antigen analysis of the cultivated paddy straw mushroom of Thailand, Philippines and Ceylon. Ann Bot 37:371-374.

Sánchez C (2004) Modern aspects of mushroom culture technology. Appl Microbiol Biotechnol 64:756-762.

Sánchez C (2006) Microscopic observations of the early development of Pleurotus pulmonarius. Mycologia 98:682-689.

Sánchez C and Moore D (1999) Conventional histological stains selectively stain fruit body initials of basidiomycetes. Mycol Res 103:315-318.

Sánchez-Ramos I, Hernández CA, Castañera P and Ortego F (2004) Proteolytic activities in body and faecal extracts of the storage mite, Acarus farris. Med Vet Entomol 18:378-386.

Sato T (2003) Effects of photoperiod and temperature on development and larval diapause of Dacne picta (Coleoptera: Erotylidae). Appl Entomol Zool 38:117-123.

Sato T, Nakamuta K and Nakashima T (1998) Behavioral response of Dacne picta (Coleoptera: Erotylidae) to different growing stages of the shiitake mushroom, Lentinula edodes. Appl Entomol Zool 33:223-226.

Sato T, Shinkaii N and Amano H (1999) Selective oviposition by adult females and larval growth of Dacne picta Crotch (Coleoptera: Erotylidae) on different 
growing stages of the shiitake mushroom, Lentinula edodes. Appl Entomol Zool $34: 1-7$

Savoie JM, Chalaux N and Oliver JM (1992) Variability in straw quality and mushroom production-importance of fungicide schedules on chemical composition and potential degradability of wheat straw. Biores Tech 41:161-166.

Sawahata T, Shimano S and Suzuki M (2008) Tricholoma matsutake 1-octen-3-ol and methyl cinnamate repel mycophagous Proisotoma minuta (Collembola: Insecta). Mycorrhiza 18:111-114.

Scheepmaker JWA, Geels FP, Smits PH and Van Griensven LJLD (1997a) Location of immature stages of the mushroom insect pest Megaselia halterata in mushroomgrowing medium. Entomol Exper Appl 83:323-327.

Scheepmaker JWA, Geels FP, Smits PH and Van Griensven LJLD (1997b) Control of the mushroom pests Lycoriella auripila (Diptera:Phoridae) by Steinernema feltiae (Nematoda: Steinernematidae) in field experiments. Ann Appl Biol 131:359-368.

Schmidt O (2007) Indoor wood-decay basidiomycetes: damage, causal fungi, physiology, identification and characterization, prevention and control. Mycol Prog 6:261-279.

Schmit JP (2001) Intraspecific competition in two unit-restricted fungal decomposers, Coprinus cinereus and Coprius congregatus. Mycol Res 105:112-118.

Schmit JP (2002) Tradeoffs between reproduction and mycelium production in the unitrestricted decomposer Coprinus cinereus. Mycologia 94:40-48.

Schnürer J, Olsson J and Börjesson T (1999) Fungal volatiles as indicators of food and feeds spoilage. Fungal Gen Biol 27:209-217.

Schwarze FWMR, Baum S and Frink S (2000) Resistance of fibre regions in wood of Acer pseudoplatanus degraded by Armillaria mellea. Mycol Res 104:1126-1132.

Shaw CG and Kile GA (1991) Armillaria root disease. Agriculture Handbook No. 691. Forest Service United States Department of Agriculture, Washington, DC USA, pp. 1-231.

Shen Q and Royse DJ (2002) Effects of genotypes of maitake (Grifola frondosa) on biological efficiency, quality and crop cycle time. Appl Microbiol Biotechnol 58:178-182. 
Skelton AC, Birkett MA, Pickett JA and Cameron MM (2007) Olfactory responses of medically and economically important mites (Acari: Epidermoptidae and Acaridae) to volatile chemicals. Med Entomol 44:367-371.

Skirvin D and Fenlon J (2003) Of mites and movement: the effects of plant connectedness and temperature on movement of Phytoseiulus persimilis. Biol Cont 27:242-250.

Smith JE, Challen MP, White PF, Edmondson RN and Chandler D (2006b) Diffential effect of Aaricus host species on the population development of Megaselia halterata (Diptera: Phoridae). Bullet Entomol Res 96:565-571.

Smith JE, White PF, Edmondson RN and Chandler D (2006a) Effect of different Agaricus species on the development o the mushroom sciarid fly Lycoriella ingénue. Entomol Experim Applica 120:63-69.

Smrž J (2004) Microanatomical and biological aspects of bacterial associations in Tyrophagus putrescentiae (Acari: Acaridida). Exp App Acarol 31:105-113.

Smrž J and Norton RA (2004) Food selection and internal processing in Archegozetes longisetosus ( Acari: Oribatida). Pedobiologia 48:111-120.

Smrž J, Svobodová J and Čatská V (1991) Synergetic participation of Tyrophagus putrescentiae (Schrank) (Acari: Acaridida) and its associated bacteria on the destruction of some soil micromycetes. J Appl Ent 111:206-210.

Sokovic M and Van Griensven LJLD (2006) Antimicrobial activity of essential oils and their components against the three major pathogens of the cultivated button mushroom, Agaricus bisporus. European J Plant Path 116:211-224.

Srivilai P (2006) Molecular analysis of genes acting in fruiting body development in basidiomycetes. PhD Thesis. Georg-August University of Göttingen, Göttingen, Germany.

Stamets P (1993) Constituents of various wood-rotting basidiomycetes. Phytochemistry. In: Growing gourmet and medicinal mushrooms (P Stamets, ed.), Ten Speed Press, Berkely, CA, USA, pp. 603-610.

Stamets P and Chilton JS (1983) Growing parameters for various mushroom species (Flammulina velutipes). In: The mushroom cultivator: A practical guide to growing mushrooms at home (P Stamets and JS Chilton, eds.), Olympia: Agaricon Press, Washington, Hong Kong, pp. 172-175. 
Sunesson AL, Vaes WHJ, Nilsson CA, Blomquist G, Andersson B and Carlson R (1995) Identification of volatile metabolites from 5 fungal species cultivated on 2 media. Appl Environ Microbiol 61: 2911-2918.

Sung BK, Lim JH and Lee HS (2006) Food protective and color alteration effects of acaricidal aldehydes on Tyrophagus putrescentiae (Schrank). J Food Protec 69:1728-1731.

Swamy S, Uno I and Ishikawa T (1984) Morphogenic effects of mutations at the $A$ and $B$ inconpatability factors in Coprinopsis cinereus. J Gen Microbiol 130:3219-3224.

Tak JH, Kim HK, Lee SH and Ahn YJ (2006) Acaricidal activities of paeonol and benzoic acid from Paeonia suffruticosa root bark and monoterpenoids against Tyrophagus putrescentiale (Acari: Acaridae). Pest Manag Sci 62:551-557.

Teles Pontes WJ, Selva de Oliveira JC, Gomes da Camara CA, Correia Gondim MG, Vargas de Oliveira J and Schwartz MO (2007) Acaricidal activity of the essential oils of leaves and fruits of Xylopia sericea St. Hill. On the two spotted spide mite (Tetranychus urticae Koch). Quimica Nova 30:838-841.

Terashima K, Yuki K, Muraguchi H, Akiyama M and Kamada T (2005) The dst1 gene involved in mushroom photomorphogenesis of Coprinus cinereus encodes a putative photoreceptor for blue light. Genetics 171:101-108.

Thakeow P (2008) Development of a basic biosensor system for wood degradation using volatile organic compounds. PhD Thesis. Georg-August University of Göttingen, Germany.

Thakeow P, Holighaus G and Schütz S (2007) Volatile compounds for wood assessment. In: Wood production, wood technology and biotechnology impacts (U Kües, ed), Universitätsverlag Göttingen, Germany, pp. 197-228.

Tokimoto K and Komatsu M (1995) Selection and breeding of Shiitake strains resistant to Trichoderma spp. Can J Bot 73:S962-S966.

Tressl R, Bahri D and Engel KH (1982) Formation of 8-carbon and 10-carbon components in mushroom (Agaricus campestris). J Agric Food Chem 30:89-93.

Tsai SY, Tsai HL and Mau JL (2007) Nonvolatile taste components of fruit bodies and mycelia of shaggy ink cap mushroom Coprinus comatus (OF Mull: Fr.) pers. (Agaricomycetideae). Int J M Mush 9:47-55.

Tsuda K and Futai K (2005) Description of two new species of Iotonchium Cobb, 1920 (Tylenchida: Iotonchiidae) from Japan. Nematology 7:789-801. 
Tsuda K, Kosaka H and Futai K (1996) The tripartile relationship in gill-knot disease of the oyster mushroom, Pleurotus ostreatus (Jacq: Fr) Kummer. Can J Zool 74:1402-1408.

Tsukamoto T, Murata H and Shirata A (2002) Identification of non-pseudomonad bacteria from fruit bodies of wild Agaricales fungi that detoxify tolaasin produced by Pseudomonas tolaasii. Biosci Biotechnol Biochem 66:2201-2208.

Tsuneda A, Murakami S, Gill WM and Maekawa N (1997) Black spot disease of Lentinula edodes caused by the Hyphozyma synanamorph of Eleutheomyces subulatus. Mycologia 89:867-875.

Tsusué YM (1969) Experimental control of fruit-body formation in Coprinus macrorhizus. Dev Growth Differ 11:164-178.

Umar MH and Van Griensven LJLD (1999) Studies on the morphogenesis of Agaricus bisporus: the dilemma of normal versus abnormal fruit body development. Mycol Res 103:1235-1244.

Urbach G (1997) The flavour of milk and dairy products: II. Cheese: contribution of volatile compounds. Int J Dairy Tech 50:79-89.

Vandamme EJ (2003) Bioflavours and fragrances via fungi and their enzymes. Fungal Divers 13:153-166.

Vanhaelen M, Vanhaelen-Fastre R and Greeraerts J (1978a) Volatile constituents of Trichothecium roseum. Sabouraudia 16:141-150.

Vanhaelen M, Vanhaelen-Fastre R, Geeraerts J and Wirthlin T (1978b) Cis- and transocta-1,5-dien-3-ol, new attractants to the cheese mite Tyrophasus putrescentiae (Schrank) (Acarina: Acaridae) identified in Trichothecium roseum (Fungi Imperfecti). Microbios 23: 199-212.

Vanhaelen M, Vanhaelen-Fastré R and Geeraerts J (1980) Occurrence in mushrooms (Homobasidiomycetes) of cis- and trans-octa-1,5-dien-3-ol, attractants to the cheese mite Tyrophagus putrescentiae (Schrank) (Acarina, Acaridae). Cell Mol Life Sci 36:406-407.

Velagapudi R (2006) Extracellular matrix proteins in growth and fruiting body development of straw and wood degrading basidiomycetes. PhD Thesis. GeorgAugust University of Göttingen, Göttingen, Germany.

Venkateshwarlu G, Chandravadana MV and Tewari RP (1999) Volatile flavour components of some edible mushrooms (Basidiomycetes). Flav Frag J 14:191-194. 
Vetayasuporn S (2006) Oyster mushroom cultivation on different cellulosic substrates. Res J Agric Bio Sci 2:548-551.

Villaceran AB, Kalaw SP, Natural PS, Abella EA and Reyes RG (2006) Cultivation of Thai and Japanese strains of Pleurotus sajor-caju on rice straw-based Volvariella volvacea mushroom spent and composted rice straw in Central Luzon Region, Philippines. J Agric Technol 2:69-75.

Walser PJ, Hollenstein M, Klaus MJ and Kües U (2001) Genetic analysis of basidiomycete fungi. In: Molecular and cell biology of filamentous fungi: a practical approach (NJ Talbot, ed.), Practical Approach Series, IRL Press, Oxford, England, pp. 59-90.

Walser PJ, Velagapudi R, Aebi M, Kües U (2003) Extracellular matrix proteins in mushroom development. Recent Res Devel Microbiol 7:381-415.

Wasser SP (2002) Medicinal mushrooms as a source of antitumor and immunomodulating polysaccharides. Appl Microbiol Biotechnol 60:258-274.

Wasser SP and Weis AL (1999) Therapeutic effects of substances occurring in higher basidiomycetes mushrooms: A modern perspective. Crit Rev Immunol 19:65-96.

Wheatley RE (2002) The consequences of volatile organic compound mediated bacterial and fungal interactions. Anton Van Leeuwen 81:357-364.

Wheatley RE, Hackett C, Bruce A and Kundzewicz A (1997) Effect of substrate composition on production of volatile organic compounds from Trichoderma spp. Inhibitory to wood decay fungi. Int Biodeterior Biodegrad 39:199-205.

White PF and Czajkowska M (2000) Effects of methoprene and permethrin on paedogenetic larvae of Heteropeza pygmaea and Mycophila speyeri (Diptera: Cecidomyiidae). J Econ Entomol 93:1222-1226.

Wood WF and Lefevre CK (2007) Changing volatile compounds from mycelium and sporocarp of American matsutake mushroom, Tricholoma magnivelare. Biochem System Ecol 35:634-636.

Wood WF, Archer CL and Largent DL (2001) 1-Octen-3-ol, a banana slug antifeedant from mushrooms. Biochem System Ecol 29:531-533.

Woodward S, Stenlid J, Karjalainen R and Hüttermann A (1998) Heterobaidium annosum biology, ecology, impact and control. University Press, Cambridge, UK, pp. 1-589. 
Wu JF and Zhang ZQ (1993) Host feeding, damage and control of the mushroom pest, Brennandania lambi (Acari, Pygmephoroidea) in China. Exp App Acarol $17: 233-240$.

Wurzenberger M and Grosch W (1982) The enzymic oxidative breakdown of linoleic acid in mushroom (Psalliota bispora). Zeit Lebensmit Forsch 175:186-190.

Yasuhara T, Takai T, Yuuki T, Okudaira H and Okumura Y (2001) Biologically active recombinant forms of a major house dust mite group 1 allergen Der $\mathrm{f} 1$ with full activities of both cysteine protease and IgE binding. Clin Exp Aller 31:116-12.

Yoshizawa T, Yamamoto I and Yamamoto R (1970) Attractancy of some methyl ketones isolated from Cheddarcheese for cheese mites. Botyu-Kagaku 35:43-45.

Zhou XW, Lin J, Yin YZ, Zhao JY, Sun XF and Tang KX (2007) Ganodermataceae: Natural products and their related pharmacological functions. Am J Chin Med 35:559-574.

Zou P, Gao JR and Ma EP (1993) Preliminary studies on the biology pest mite Luciaphorus auriculariae (Acari: Pygmephoridae) infesting jew's ear mushroom Auricularia polytricha in China. Exp App Acarol 17:225-232. 
CHAPTER 2

\section{Effects of light in fruiting body development of the basidiomycete Coprinopsis cinerea}

I am very much thankful to Dr. Mónica Navarro-González for her input in this chapter by helping to define the different developmental stages during fruiting courses, by supplying photos for Fig. 1, by training me in sectioning of fruiting structures by razor blades and by careful tissue analysis of sections of primordia produced by myself in hand cuts with razor blades and by microtome sections and by introducing me to photographing at the microscope. Dr. Andrea Olbrich kindly taught me the techniques of microtome sectioning and of sample preparation for it. Dr. Rosemarie Heyser is thanked for teaching me photographing cultures and fruiting bodies with a digital camera. 


\subsection{Abstract}

Fruiting body formation in the basidiomycete fungi is studied with the model fungus Coprinopsis cinerea. This developmental event in the life cycle of $C$. cinerea occurs after mating of two compatible monokaryons at the resulting dikaryon in a normal daynight rhythm at temperatures around $25^{\circ} \mathrm{C}$. The self-compatible homokaryon AmutBmut with mutations in the $A$ and $B$ mating type loci develops fruiting bodies without mating and is thus a genetically attractive strain to study since it allows easy production of mutants in the developmental pathway of fruiting body development (for further information see Chapter 3). In total from the first step of fruiting body development (hyphal knot formation) over primordia stages 1 to 5 to fruiting body maturation and basidiospore formation and release, the fungus needs seven days. In order to clarify the general fruiting pattern, fruiting of this self-compatible strain was investigated in time courses of alternating dark and light periods reflecting the normal day and night chances and in time course where cultures were transferred at different points of development into constant dark or into constant light. Both light and dark phases were found to influence fruiting development but at different stages in the routine of fruiting body development. Dark is needed for the formation of the primary hyphal knots. Light is then needed for induction of formation of secondary hyphal knots, small hyphal aggregates in which tissue differentiation initiates. Light is also required for tissue differentiation. If light is lacking, etiolated stipes will be formed by elongating the primordial shafts of the young primordia structures that try to push their underdeveloped caps towards a light source. In total, six time points up to primordia maturation were found where in the process of fruiting a light signal is required. The timings in between these light signals represent one day-night cycle. Up to completing tissue development at primordia stage 4, dark phases can be lacking. When cultures were kept in constant light, development still continued. When reaching primordia stage 5, there was an arrest in development prior to karyogamy. Induction of karyogamy itself is long known to be a light-depending process that needs to happen before fruiting bodies can mature by stipe elongation and cap opening. If one allows the structures to undergo karyogamy before keeping in constant light, a second essential dark phase becomes visible during or at the end of meiosis I. If this dark phase is given to the fungus, incubation afterwards in constant light has no further negative influence. Fruiting bodies will form basidiospores, their caps will fully open and stipes fully 
elongate before spores are released by autolysis. In conclusion, the day/night rhythm is required to undergo the developmental process of fruiting body development in the appropriate morphological sequence. Structures formed during the normal light/dark rhythm as well as structures formed upon incubation for periods in constant dark and structures formed upon incubation periods in constant light were morphological analyzed.

Key words: Coprinopsis cinerea, fruiting body development, tissue formation, timecourse, light phases, dark phases, primary and secondary hyphal knots, primordia, normal stipe development, etiolated stipes, primordial shaft, gills 


\subsection{Introduction}

Coprinopsis cinerea is used as a model organism for studying fruiting body (mushroom) development in the higher basidiomyetes. C. cinerea has two main types of mycelia, the asexual monokaryon and the sexual dikaryon, formed by fusion of two compatible monokaryons. Fruiting bodies normally develop on the dikaryon (Kües 2000). The cytological processes of fruiting-body development have been described in its main steps. Fruiting takes place over a period of 7 days from the start of localized hyphal aggregation in the vegetative mycelium to fruiting body maturation and autolysis (Moore 1998, Kües et al. 2007, Navarro-González 2008). Fruiting body development occurs at $25-28^{\circ} \mathrm{C}$ and is adapted to the light-dark changes of the normal day-night rhythms. Within dark, only primary hyphal knots form, small loosely hyphal aggregates. Light has been described to be an important signal for regulation of the developmental and physiological processes during fruiting body development. Blue light is required for production of a compact round hyphal aggregate (secondary hyphal knot) in which differentiation of cap and stipe tissues of the mushrooms initiate. Also tissue differentiation in progressing of fruiting body primordia development requires light signals as well as karyogamy and meiosis that take place in the basidia on the gills of the fully established primordia in parallel to fruiting body maturation through stipe elongation and cap expansion. When blue light is missing upon hyphal aggregate formation, slender elongated structures are formed with underdeveloped caps and extended primordial shafts ( $\mathrm{Lu}$ 1974, 2000, Kamada et al. 1978, Kamada and Tsuji 1979, Kües et al. 1998). These slender structures are variously known under the names etiolated stipes (Kües 2000), dark stipes (Tsusué 1969, Terashima et al. 2005), pseudorhizal stipes (Blayney and Marchant 1977), oversized stipes (Lu 1974) or long slender stalks (Morimoto and Oda 1973).

Development of etiolated stipes has however so far little been studied. In screenings for defects in fruiting body development, some mutant strains were detected that form etiolated stipes also under a normal dark-light regime (Liu et al.1999b, Terashima et al. 2005, Kües et al. 2007). In order to understand their developmental defects, it is essential to first study the behavior of a wildtype strain under distorted light-dark regimes.

Homokaryon AmutBmut is a special strain of $C$. cinerea used for induction of mutants in fruiting body development (Granado et al. 1997). The strain has one type of haploid nuclei in its cells like a monokaryon (Swamy et al. 1984, Kües et al. 2002b). 
However, due to specific mutations in both mating-type loci (A43mut, B43mut), it shows characteristics typical of the dikaryon such as formation of fused clamp cells at hyphal septa. Furthermore, the strain is self-compatible and gives rise to fruiting bodies without prior mating to another compatible monokaryon (Swamy et al. 1984, Boulianne et al. 2000, Walser et al. 2003). This special feature together with the ability to form unicellular haploid spores (oidia) provides us with an easily accessible genetic system. Oidia can easily be mutagenized and, upon their germination, will form mycelia on which defects in fruiting are easily detected due to the single type of haploid nuclei that is present in those mutated mycelia (Granado et al. 1997, Kües et al. 2004, Walser et al. 2001). Some of the available etiolated stipe mutations have been induced in this strain by UV- and by REMI (restriction-enzyme-mediated insertion) mutagenesis (Liu et al.1999a, Kües et al. 2007). Therefore, homokaryon AmutBmut is used in this study to define the process of fruiting body development, in particular the light regulated steps in tissue development within developing primordia, respectively to define the alternate processes that happen when an essential light signal is missing.

\subsection{Materials and methods}

\subsubsection{Strains and growth conditions}

The self-compatible $C$. cinerea homokaryon AmutBmut (A43mut, B43mut, pab1) forms fruiting bodies without prior mating to another strain and produces oidia in a light-regulated manner (Swamy et al. 1984, May et al. 1991, Kertesz-Chaloupková et al. 1998). After placing small pieces of mycelium $(4 \times 4 \mathrm{~mm})$ in the middle of $9 \mathrm{~cm} \varnothing$ Petri-dishes, the strain was routinely grown on YMG/T complete medium at $37^{\circ} \mathrm{C}$ in the dark in ventilated black boxes sized 27x37x13 cm (Granado et al. 1997). After 5 days at $37^{\circ} \mathrm{C}$, cultures were fully grown and transferred for induction of fruiting body development into at $28^{\circ} \mathrm{C}$ at a high humidity (about 90\%) in a $12 \mathrm{~h}$ light- $12 \mathrm{~h}$ dark cycle into a climate chamber (Vötsch Industrietechnik $\mathrm{GmbH}$, Balingen, Germany). To determine developmental processes in constant dark, every day when light switches on, a subset of 10 cultures were transferred into ventilated boxes for further incubation under constant darkness. To determine development in constant light in an other series of experiment, also every day subsets of 10 plates were transferred into an incubator Model CU-36L5 (CLF Plant Climatics, Emersacker, Germany) providing constant light at a humidity of $85 \%$. In an other set of experiments, plates were incubated directly 
upon inoculation for 16 days under constant light either at $28^{\circ} \mathrm{C}$ or at $37^{\circ} \mathrm{C}$ in the incubator at a humidity of 85\%. The light sources were in all instances Osram L36W67 white fluorescent tubes covering also the effective blue light range (KerteszChaloupková et al. 1998, Kües et al. 1998) and plates obtained in all cases light intensities of $30-40 \mu \mathrm{E} \mathrm{m}^{-2} \mathrm{~s}^{-1}$. Development on plates incubated within dark was checked daily under red-light since it is blue light that affects development in C. cinerea (Kertesz-Chalopková et al. 1998). Regarding incubation in dark boxes in constant dark see also the note at the end of the legend of Fig. 3.

The fungus was further grown in flasks on fresh loosened horse dung (Granado et al. 1997) for 5 days at $37^{\circ} \mathrm{C}$ in the dark before moving into standard fruiting conditions at $28^{\circ} \mathrm{C}$.

\subsubsection{Tissue fixation, dehydration and infiltration with Roti-Plast and microscopy}

Fruiting structures of homokaryon AmutBmut were collected from Petri-dishes for tissue fixation by paraffin according to Crockett et al. (2005). First, structures were incubated at room temperature (RT) for fixation for $2 \mathrm{~h}$ in FAE (per 1: $50 \mathrm{ml} 40 \%$ formaldehyde, $50 \mathrm{ml} 99 \%$ acetic acid and $900 \mathrm{ml} 70 \%$ ethanol), followed by dehydration in $70 \%(\mathrm{v} / \mathrm{v})$ ethanol for $2 \mathrm{~h}$, and then for each $30 \mathrm{~min}$ at RT in $80 \%(\mathrm{v} / \mathrm{v})$ ethanol, 90\% (v/v) ethanol, 96\% (v/v) ethanol, 96\% (v/v) ethanol/isopropanol 1:1 and isopropanol, respectively. Subsequently, samples were incubated for each $30 \mathrm{~min}$ at RT in isopropanol/Roti-Histol 3:1, isopropanol/Roti-Histol 1:1, in isopropanol/ Roti-Histol 1:3 and 3 time in pure Roti-Histol solution (Carl Roth, Karlsruhe, Germany). In the next steps for infiltration of paraffin, samples were incubated each two hours in a saturated solution of Roti-Plast in Roti-Histol (Carl Roth) at RT and at $40^{\circ} \mathrm{C}$, respectively. The final two steps were incubations in melted Roti-Plast at $60^{\circ} \mathrm{C}$ for $2 \mathrm{~h}$ and $12 \mathrm{~h}$, respectively. Samples were subsequently given into metallic frames which were filled up with melted saturated paraffin Roti-Plast. Samples were cooled down and fixed onto wood blocks using melted paraffin as glue. Afterwards, the paraffin-embedded samples were sectioned using a rotation microtome (R. Jung GmbH, Heidelberg, Germany) at a section sickness of $12 \mu \mathrm{m}$. Sections were fixed on microscope slides by adding a drop of water to make the sample planar before fixing for $2 \mathrm{~min}$ at $40^{\circ} \mathrm{C}$ on a hot plate. Then, the paraffin was removed from the sections by each $30 \mathrm{~min}$ incubation in isopropanol/Roti-Histol 1:3, isopropanol/Roti-Histol 1:1, isopropanol/Roti-Histol 3:1, 
and pure isopropanol, respecttively. Subsequently, the samples were incubated on the microscope slides at $40^{\circ} \mathrm{C}$ over night in an incubator. Afterwards, samples were stained for 3 min with $0.1 \%$ toluidine blue in $0.2 \mathrm{M}$ phosphate buffer, $\mathrm{pH} 7.0$ followed by $2 \mathrm{~min}$ incubation at $40^{\circ} \mathrm{C}$ on a hot plate. A drop of glycerine was added onto the samples which were then covered by a cover slip. Stone weights were given onto the cover slips over night to make the sample plane and to remove air bubbles. Subsequently, samples were observed by light microscopy (Carl Zeiss Mikroskopie, Göttingen, Germany, Axioplan 2 imaging). Digital photographs were taken using a color chilled 3CCD camera (colorview soft imaging system) for image processing (analysis®, Soft Imaging System GmbH, Münster, Germany).

Other samples of etiolated stipes were cut longitudinal into halves with a sharp razor blade or vertical to produce cross-sections from primordial shafts, stipes and caps. These cuttings were observed under a Stemi 2000-C binocular (Carl Zeiss Mikroskopie, Göttingen, Germany).

\subsection{Results and discussion}

\subsubsection{Fruiting body development of homokaryon AmutBmut under a normal day-night rhythm}

Fig. 1 shows an overview of the fruiting process of homokaryon AmutBmut. A first steps towards fruiting, primary hyphal knot formation, occurs in the dark (Fig. 1A). Within the aerial mycelium, intense hyphal branching occurs at defined places yielding a loose aggregated structure of a diameter of about $0.03 \mathrm{~mm}$ known as the primary hyphal knot (Boulianne et al. 2000). When kept further in the dark, these will transform into compact dark-stained duration bodies called sclerotia (Kües et al. 2002a, Velagapudi 2006). Genetic evidences suggest that alternatively these primary hyphal knots will further develop into secondary hyphal knots (Liu et al. 2006, Moore 1998), compact up to $0.2 \mathrm{~mm}$-sized round hyphal aggregates of plectenchymatic interwoven hyphae (Fig. 1A and B) in which tissue development starts (Matthews and Niederpruem 1972, Fig. 1C). Induction of secondary hyphal knot formation requires a light signal at day 0 , the day before their appearance within the aerial mycelium (day 1 in development). Secondary hyphal knots are the first developmental structures defined to the fruiting pathway (Boulianne et al. 2000). At the start of day 1 of development, no tissue differentiation is visible within the secondary hyphal knot (Fig. 1B). 
A
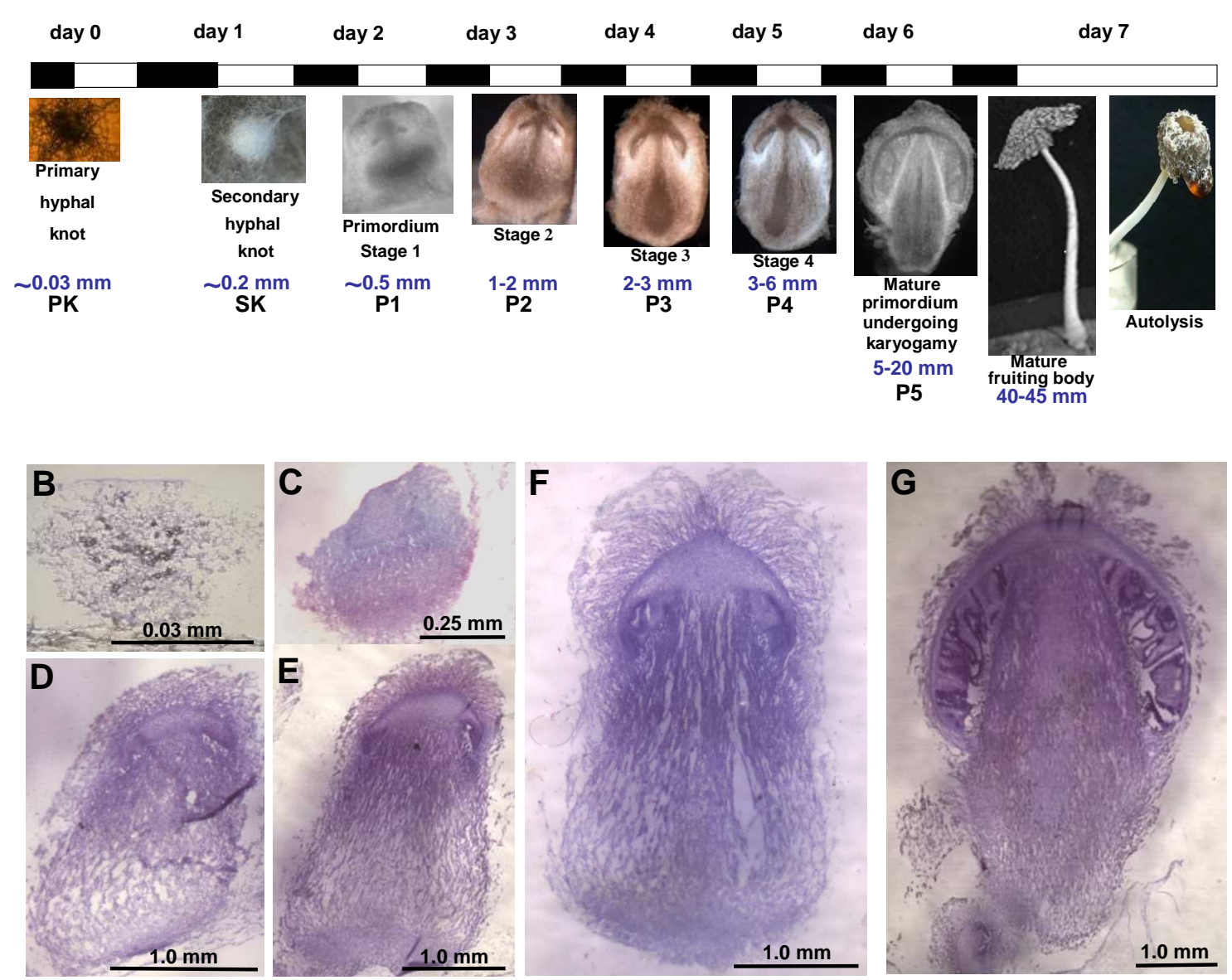

Fig. 1 The process of fruiting body development in homokaryon AmutBmut. (A) Overview on the 7 day long developmental pathway. Up to day 5, structures shown are as being typical for the morning when light switches on. The mature primordium undergoing karyogamy has been harvested shortly before light at day 6 switches on, the mature fruiting body is from the middle of the night phase of day 5, and the autolysing mushroom from the morning of day 7 (pictures were kindly provided by M. Navarro-González). (B) to (G) Sections through a secondary hyphal knot (SK), developing primordia of stage 1 (P1), stage 2 (P2), stage 3 (P3), and stage 4 (P4) and a mature primordium (P5) at the stage of karyogamy, respectively. $\mathbf{P K}=$ primary hyphal knot.

In the morning on day 2 of development when the light period starts, the now about $0.5 \mathrm{~mm}$ sized structure in its interior (see the cut of primordium stage 1 in Fig. 1A) is clearly demarcated into a zone with the developing cap and a zone with the developing stipe (see also Fig. 1C). At the lower edges of the cap, gills start to develop as it is indicated by the darker stained lower cap border in Fig. 1A and C. A day later at the same time (day 3 of development), the 1 to $2 \mathrm{~mm}$ long structure is more oblong by stipe growth and, on the cap, gills are now clearly to be recognized (Fig. 1A, primordium 
stage 2; Fig. 1D). It takes two further days for all tissues in the primordium to mature (primordium stage 3 and stage 4; see Fig. 1A, E and F) until at day 5 of development, when light induces karyogamy in the basidia in the now fully developed gills (not shown here, but see Navarro-González 2008). In the morning of day 6 of development (Fig. 1A and G), karyogamy is nearly completed and meiosis will start

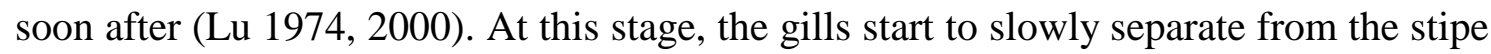
that starts to elongate by hyphal cell extension growth (Fig. 1G). Meiosis and basidiospore production and maturation follows over the day along with first slow and then rapid stipe elongation and cap expansion to give a mature fruiting body in the middle of the night period (Lu 2000, Navarro-González 2008; see Fig. 1A). Soon after, cap autolysis starts (Iten 1970, Iten and Matile 1970), and in the early morning on day 7 of development, after light was turned on, the deliquescent mushroom releases its black basidiospores in liquid drops to the ground (Fig. 1A).

\subsubsection{Progress in development after transfer of different stages of the fruiting body pathway of homokaryon AmutBmut into constant darkness}

Fig. 2 shows a mature fruiting body of homokaryon AmutBmut on a Petri-dish with YMG/T agar in comparison with a slender structure that developed on the same medium after growth for 5 days at $37^{\circ} \mathrm{C}$ and transfer of the plate to $28^{\circ} \mathrm{C}$ for $3 \mathrm{~h}$ into light followed by 5 days of incubation in ventilated dark boxes in constant dark. The slender structure had a poorly developed cap and an elongated stipe-like shaft as described in the literature for etiolated stipes, respectively dark stipes (Tsusué 1969, Lu 1974, Kamada et al. 1978, Terashima et al. 2005).

Tests with control plates that were incubated for 5 days at $37^{\circ} \mathrm{C}$ in the dark followed by transfer into $28^{\circ} \mathrm{C}$ in the dark without being exposed to any light signal demonstrated that the light signal given for $3 \mathrm{~h}$ directly upon transfer into $28^{\circ} \mathrm{C}$ was required to induce etiolated stipes (Fig. 3). Cultures at day 5 after transfer into constant darkness also contained secondary hyphal knots, indicating that these were induced by the first light signal given to the culture (Fig. 4A). Obviously, only a selection of structures continued development into etiolated stipes, possibly on expense of the others. Similar effects have been described before in normal fruiting body development (Kües 2000). A few hundreds of secondary hyphal knots are normally induced by light on freshly grown cultures of homokaryon AmutBmut, most of which soon after abort 


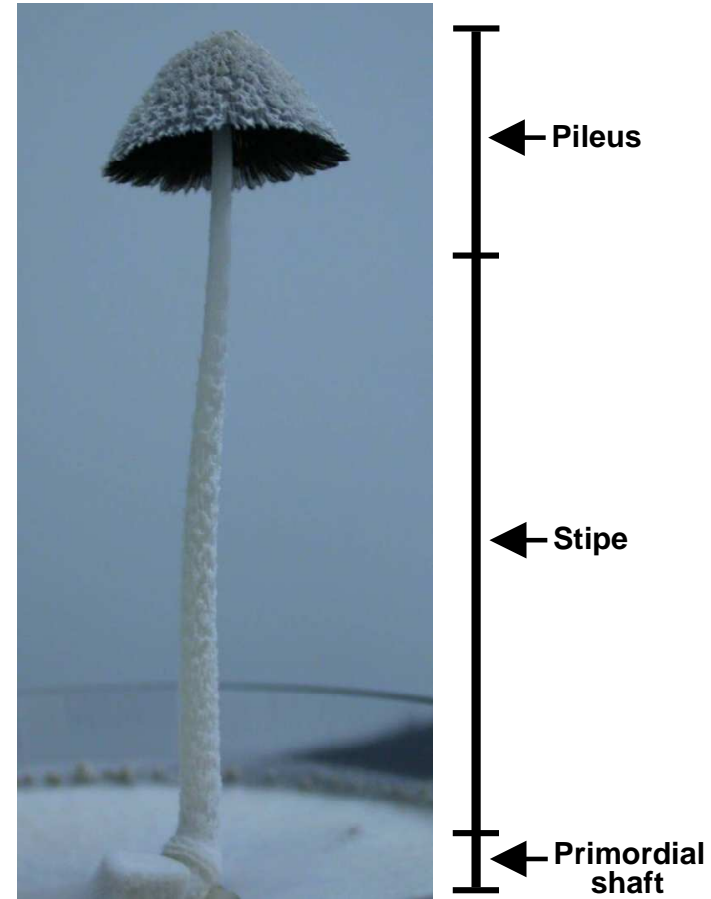

Fruiting body

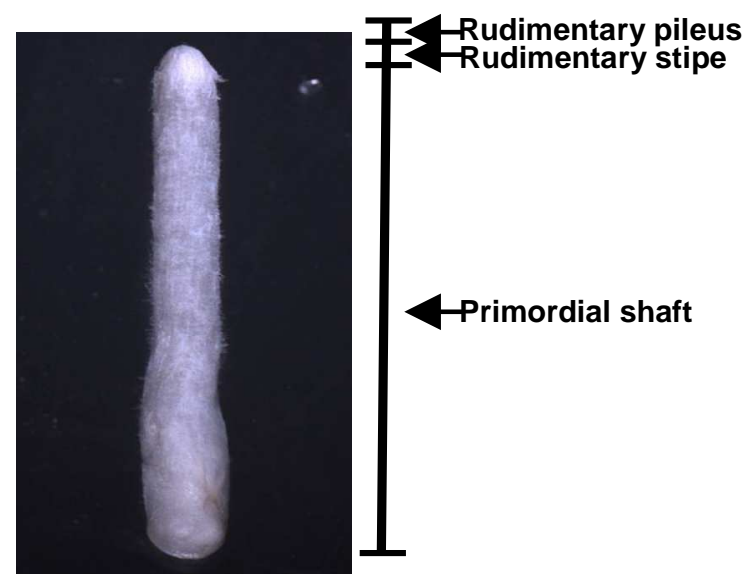

Etiolated stipe (Dark stipe)

Fig. 2 Comparison of a normal mature fruiting body of homokaryon AmutBmut developed in a $12 \mathrm{~h}$ light/12 $\mathrm{h}$ dark regime at $28^{\circ} \mathrm{C}$ with an etiolated stipe (dark stipe) formed after setting a short pulse in a culture kept at $28^{\circ} \mathrm{C}$ in constant dark. According to Terashima et al. (2005), in the etiolated stipes the primordial shaft, serving in the mature fruiting body as base holding the structure erected on the substrate, elongates whilst cap and stipe remain rudimentary.

development. Only in exceptional cases (usually in less than $1 \%$ of fruiting initiation events), a structure will mature into a fruiting body with basidiospores (Fig. 4B).

Light signals are known to be required for induction of tissue formation within secondary hyphal knots (Lu 1974, 2000, Kamada et al. 1978, Kamada and Tsuji 1979). At times, when primary hyphal knots (day 0) or also secondary hyphal knots (day 1) were transferred into constant dark (Fig. 3), no tissue development are to be recognized in the young caps of the structure differently to the mornings of the following days of incubation under standard fruiting conditions (Fig. 1). It was thus an interesting question to observe what will happen when cultures at later stages of development would be transferred into constant darkness at $28^{\circ} \mathrm{C}$ (Fig. 3). Up to day 5 of incubation, transfer of structures into the dark caused etiolated stipe development of a selection of structures grown in the transferred plates (Fig. 5). In conclusion, there are at least six light-sensitive phases during hyphal knot and primordia formation. 


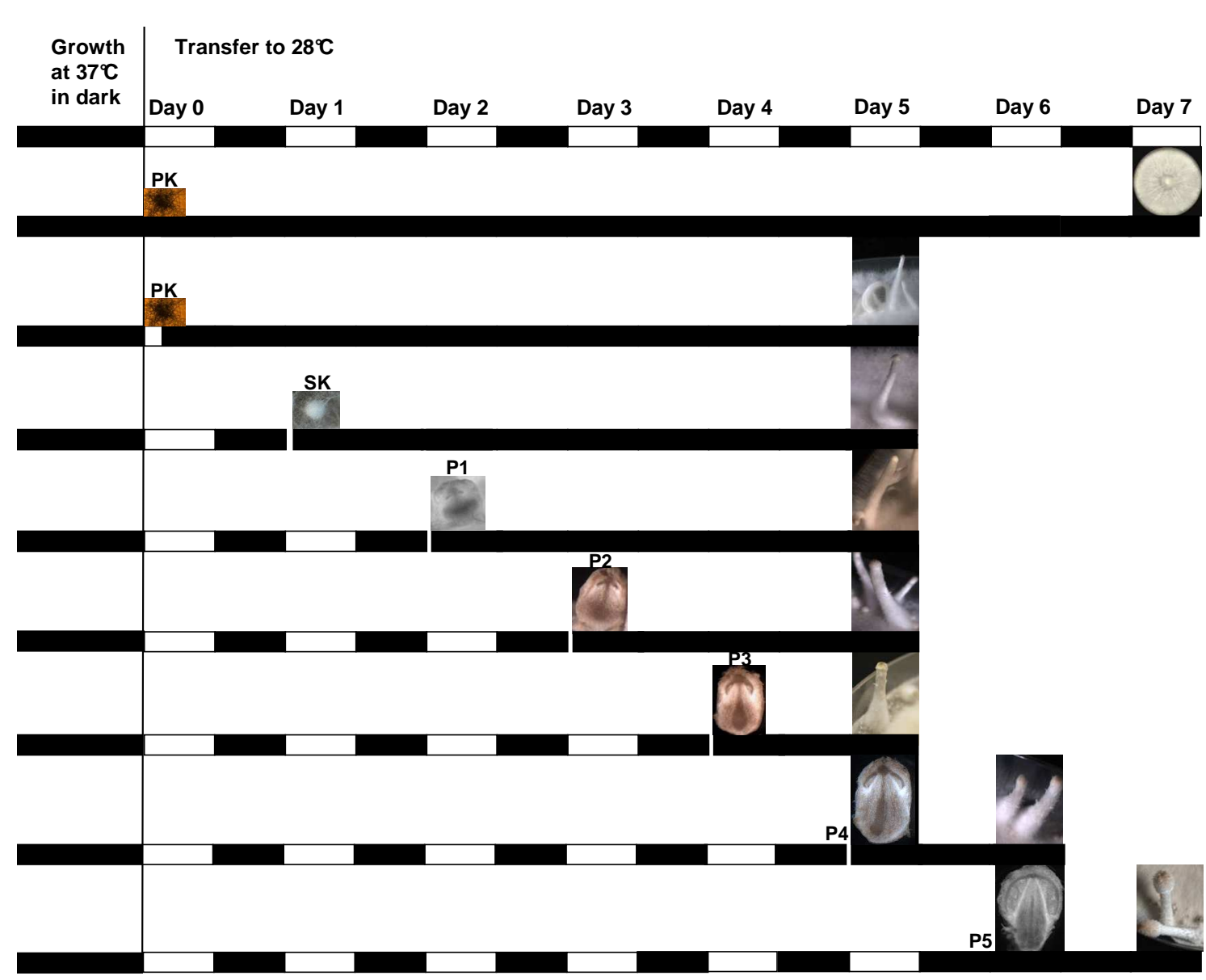

Fig. 3 Experimental setup of transferring YMG/T plates of homokaryon AmutBmut at different time points of the normal fruiting pathway into constant dark. All plates were incubated for $5 \mathrm{~d}$ at $37^{\circ} \mathrm{C}$ to allow growth of the fungus before transferring it to $28^{\circ} \mathrm{C}$. A subset of 10 plates was kept in constant darkness without any exposure to light. Another subset of 10 plates was incubated for $3 \mathrm{~h}$ at light before transferring them into constant dark. Other subsets of each 10 plates were kept through full periods of $12 \mathrm{~h}$ light exposure before transferring them at the beginning of a new light period (about $5 \mathrm{~min}$ after light switches on) into ventilated boxes into constant dark. A white box labelled with a day in the upper line of the figure denotes a $12 \mathrm{~h}$ light period and the following black box the dark period on a $24 \mathrm{~h}$ scale under standard fruiting conditions. The times of transfer and the maximum developmental stage reached by cultures at the point of transfer into constant dark are indicated by the photos above. Plates were further incubated at $28^{\circ} \mathrm{C}$ until day 5 , day 6 or day 7, respectively, after transfer into constant dark for evaluation of developmental structures. In between the transfer into boxes and the end of the experiment, each morning plates were evaluated under red light. Larger structures of etiolated stipes were first seen on sets of plates on day 5 , respectively day 6 and day 7 , after transfer into constant dark. Structures were photographed as shown in the figure, which finished the incubation of different subsets of plates in the experiment.Thereby, PK denotes primary hyphal knot, SK secondary hyphal knot, P1 up to P5 primordia stage 1 to 5 as defined in Fig. 1 (P5 = mature primordium). Note to this experiment and the following that it is not fully excluded that very low levels of light might occasionally have reached the fungus. Due to own fear, that the fungus might not reach enough oxygen, the lid of the dark boxes used for incubation were never fully pushed into the fixed close position. 

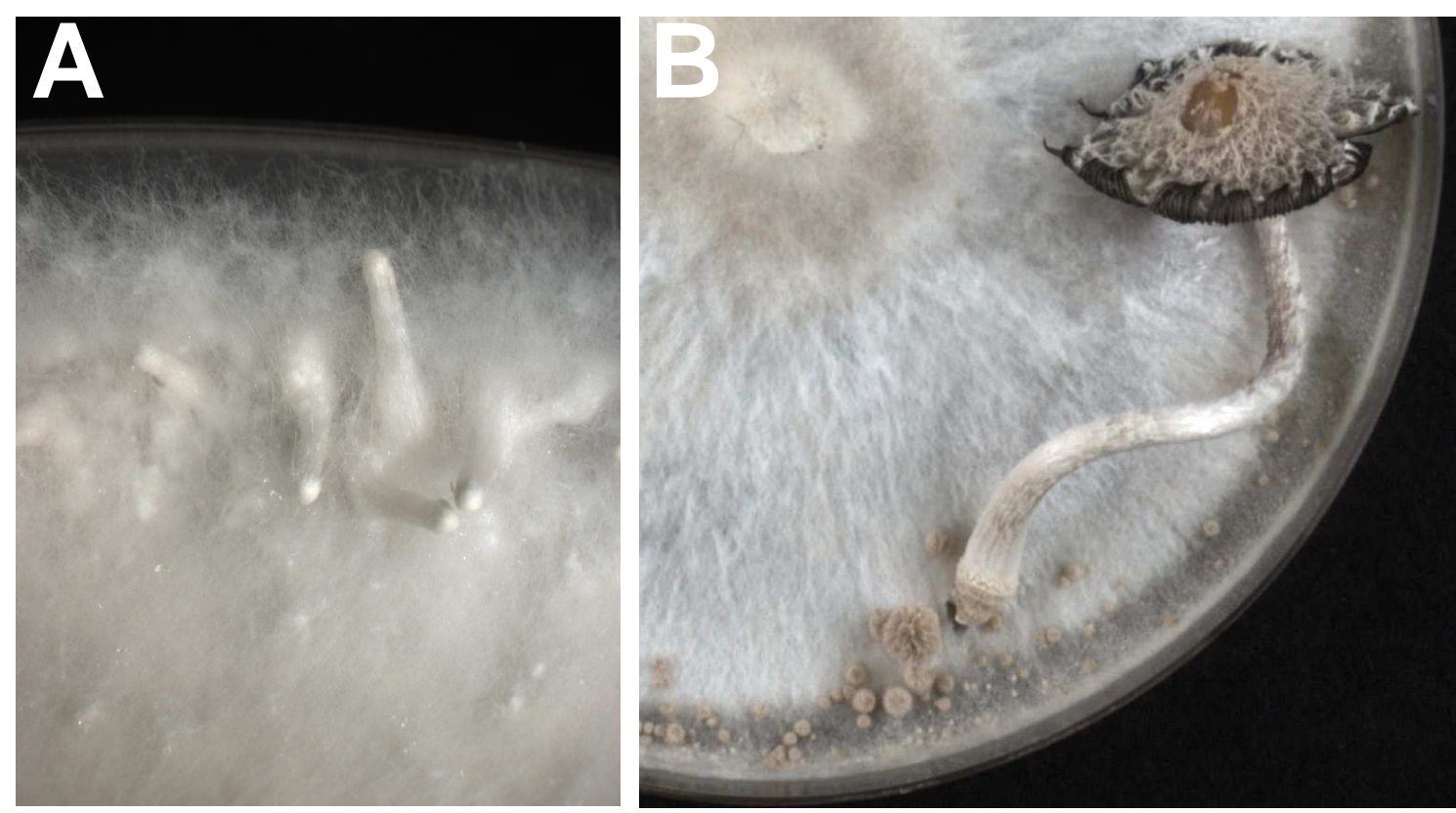

Fig. 4 (A) Etiolated stipes amongst secondary hyphal knots in a YMG/T plate of homokaryon AmutBmut grown for 5 days at $37^{\circ} \mathrm{C}$ in constant dark before transfer to $28^{\circ} \mathrm{C}$ with $3 \mathrm{~h}$ light illumination and subsequent incubation up till day 5 at $28^{\circ} \mathrm{C}$ in constant dark. (B) A mature fruiting body of homokaryon AmutBmut amongst many smaller abortive structures (secondary hyphal knots and primordia of different age) in the morning on day 7 of total incubation at $28^{\circ} \mathrm{C}$ after growth for 5 days at $37^{\circ} \mathrm{C}$ in the dark and transfer into standard fruiting conditions.

Etiolated stipes were harvested from the plates (see Fig. 5), their average length at the point of harvest determined and outer morphologies compared (Table 1). The results show that up to a transfer of day 5 of incubation at $28^{\circ} \mathrm{C}$ into the dark, fruiting structures are still susceptible to etiolated stipe production, i.e. up to day 5 of development after transfer to standard fruiting conditions at $28^{\circ} \mathrm{C}$, a light signal is required to suppress etiolated stipe formation and to continue normal tissue development (see also Fig. 6). In the morning of day 6 of incubation at $28^{\circ} \mathrm{C}$ under standard fruiting conditions, structures are undergoing karyogamy (Navarro-González 2008), a light induced event that will only occur once tissue development in the primordia was completed (Lu 1974, 2000). Simultaneously, onset of karyogamy is required to initiate cap maturation and stipe elongation (Kües 2000, Kües et al. 2004). Furthermore, although light still influences the speed of subsequent events (particularly the different steps in meiosis) upon karyogamy, normal fruiting body development can continue in the dark (Lu 1974, 2000). The results presented here in Fig. 5G show that a transfer into constant dark after day 5 of incubation at $28^{\circ} \mathrm{C}$ at standard fruiting conditions does not cause anymore etiolated stipe formation. Instead, normal stipe elongation was observed 

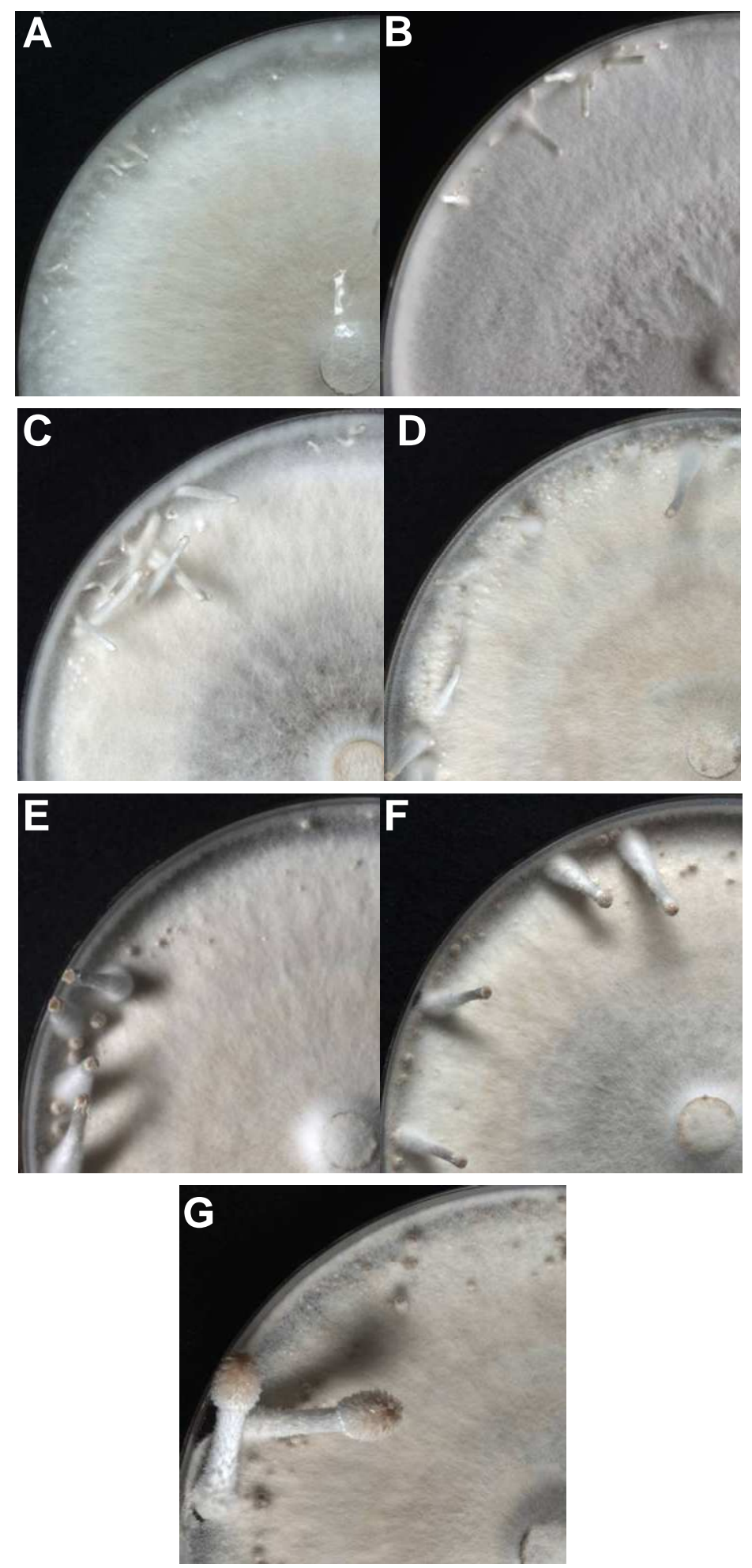

Fig. 5 Overview of structures present on YMG/T plates of homokaryon AmutBmut grown for 5 days in constant dark at $37^{\circ} \mathrm{C}$ in the dark before transferring into standard fruiting conditions at $28^{\circ} \mathbf{C}$. Plates were transferred at day 0 after $3 \mathrm{~h}$ illumination at $28^{\circ} \mathrm{C}$ under standard fruiting conditions into constant dark (A), or on the morning of day $1(\mathbf{B})$, day $2(\mathbf{C})$, day $3(\mathbf{D})$, day $4(\mathbf{E})$, day $5(\mathbf{F})$ or day $6(\mathbf{G})$, respectively, of incubation at $28^{\circ} \mathrm{C}$ under standard fruiting conditions (compare the scheme in Fig. 3). Plates shown under (A) to (D) were analyzed on day 5 of total incubation at $28^{\circ} \mathrm{C}$, the plates shown under $(\mathbf{E})$ and $(\mathbf{F})$ at day 6 and day 7 of total incubation at $28^{\circ} \mathrm{C}$, respectively. 
Table 1 Characteristics of etiolated stipes

\begin{tabular}{|c|c|c|c|}
\hline \multicolumn{2}{|c|}{ Day of } & \multirow{2}{*}{$\begin{array}{c}\text { Size } \\
\text { in } \mathbf{c m}^{*}\end{array}$} & \multirow[t]{2}{*}{ Outer morphological description $^{+}$} \\
\hline transfer of plates & evaluation & & \\
\hline Day 0 & Day 5 & $1.02 \pm 0.17$ & $\begin{array}{l}\text { Thin, soft, white structures with minute } \\
\text { cap, single hyphae stand up like hairs at } \\
\text { the lower half of the structure, structure is } \\
\text { difficult to section }\end{array}$ \\
\hline Day 1 & Day 5 & $1.02 \pm 0.28$ & $\begin{array}{l}\text { Slightly stronger and wider than } \\
\text { structures from day } 0 \text {, white in color, cap } \\
\text { slightly more pronounced, single hyphae } \\
\text { stand up like hairs at the lower half of the } \\
\text { structure, sectioning is easier }\end{array}$ \\
\hline Day 2 & Day 5 & $1.08 \pm 0.27$ & $\begin{array}{l}\text { Again stronger and more stiff in structure, } \\
\text { tissue more compact, white in color, cap } \\
\text { with outer veil clearly distinguishable, } \\
\text { single hyphae stand up like hairs at the } \\
\text { lower half of the structure, sectioning is } \\
\text { easy }\end{array}$ \\
\hline Day 3 & Day 5 & $1.18 \pm 0.24$ & $\begin{array}{l}\text { Similar as structures on day } 2 \text {, but again } \\
\text { more strong and wide in diameter and the } \\
\text { cap is further developed and pinkish in } \\
\text { color, more hairy like hyphae on the } \\
\text { lower half of the structure, easy to section }\end{array}$ \\
\hline Day 4 & Day 5 & $1.42 \pm 0.31$ & $\begin{array}{l}\text { Similar to structures of day } 3 \text { but with an } \\
\text { increase in width diameter and cap further } \\
\text { developed and more intense in color, easy } \\
\text { to section }\end{array}$ \\
\hline Day 5 & Day 6 & $1.44 \pm 0.27$ & $\begin{array}{l}\text { Similar to structures of day } 4 \text { but with an } \\
\text { increase in width diameter and cap further } \\
\text { developed, easy to section }\end{array}$ \\
\hline Day 6 & Day 7 & $2.61 \pm 0.50$ & $\begin{array}{l}\text { Abortive fruiting body partially elongated } \\
\text { normal stipe and a normal developed but } \\
\text { unopened cap }\end{array}$ \\
\hline
\end{tabular}

* Between 8 and 20 structures were analyzed

${ }^{+}$Compare Fig. 5 and Fig. 6

(Fig. 5G) although mature fruiting bodies never occurred in the experiments reported here. These results are well in accordance with the earlier observations by Lu (1974, 2000) and Kamada et al. (1978).

Sectionings of etiolated stipes were performed to determine the inner tissue structures of the etiolated stipes. In accordance with the outer observations, structures on plates transferred on day 0 of incubation at $28^{\circ} \mathrm{C}$ into the dark started only cap tissue development (Fig. 6), whereas structures transferred at day 1 of incubation at $28^{\circ} \mathrm{C}$ formed already primary gills within the cap (Fig. 6). Structures transferred on day 2 of incubation into constant dark possessed secondary gills (Fig. 6) that in the normal time 

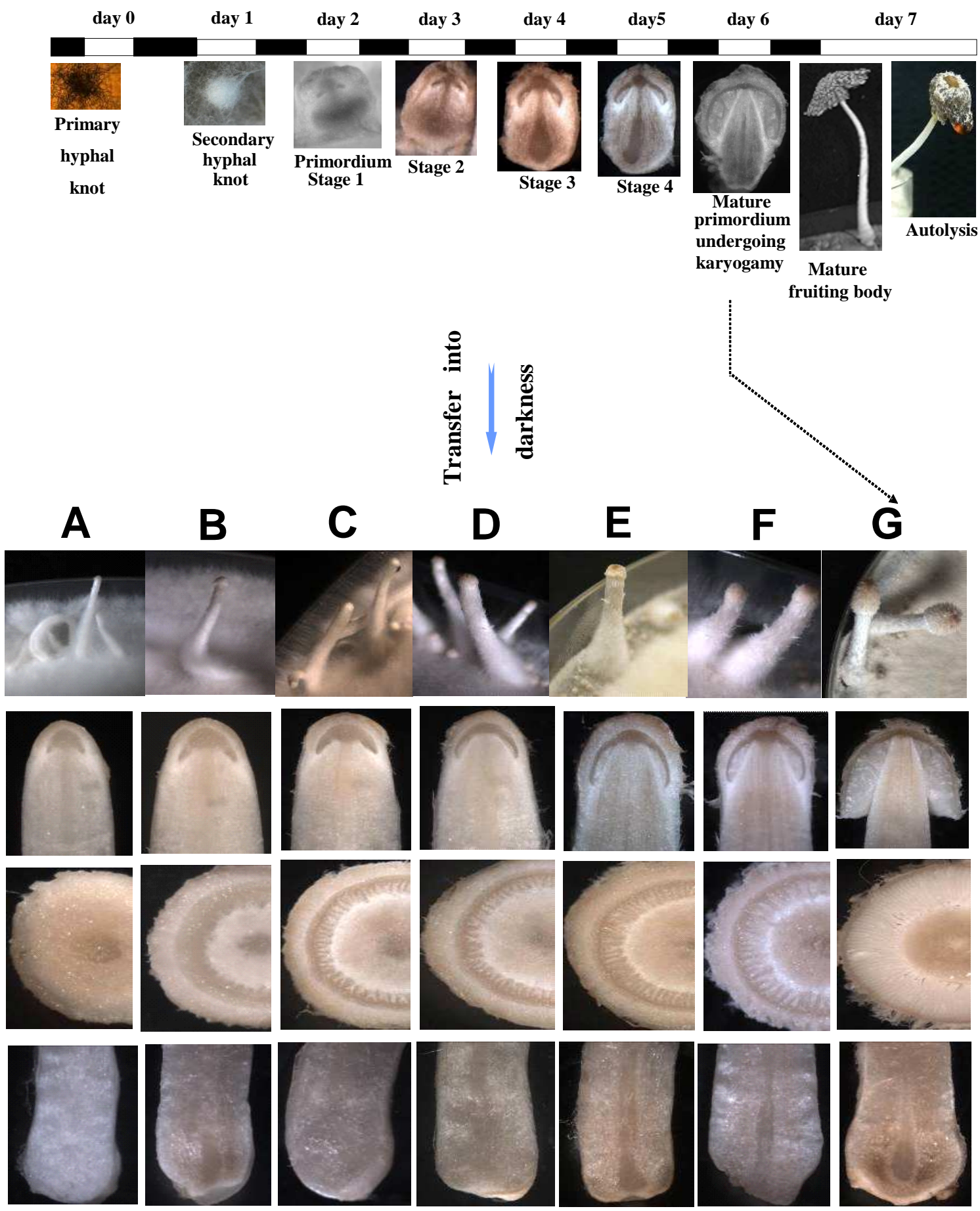

Fig. 6 Etiolated stipe formation upon transfer of cultures of homokaryon AmutBmut into constant dark. Plates were transferred at day 0 after $3 \mathrm{~h}$ illumination at $28^{\circ} \mathrm{C}$ under standard fruiting conditions into constant dark, or on the morning of day 1, day 2, etc. up to day 6 of incubation at $28^{\circ} \mathrm{C}$ under standard fruiting conditions (compare the scheme in Fig. 3). On top of the figure, the normal fruiting scheme of Coprinopsis cinerea is shown (compare Fig. 1). Below structures are shown on day $5(\mathbf{A})$ to $(\mathbf{E})$, referring to a transfer at day 1 to 4 after transfer to standard fruiting conditions, respectively), respectively day $6(\mathbf{F})$, transfer into constant dark at day 5 of incubation at $28^{\circ} \mathrm{C}$ ) and day $7(\mathbf{G})$, transfer into constant dark at day 6 of incubation at $28^{\circ} \mathrm{C}$ ) of total incubation at $28^{\circ} \mathrm{C}$ after first growing under standard fruiting conditions and then for defined periods in constant dark. Structures are shown still growing on plates (upper row), and beneath as longitudinal sections of the upper and the lower part of the structures (second and third row) and cross-sections through the caps of the structures (lower row), respectively. 
course of fruiting body development are visible in the morning at the time point (Fig. 1) and Navarro-González (2008) when in the experiments reported here the structures were transferred into dark. In conclusion, normal development did not continue but arrested at this stage whereas etiolated stipe growth initiated in the more basic parts of the primordia. Similarly for structures transferred on day 4 and day 5 of incubation at $28^{\circ} \mathrm{C}$ into constant darkness, there was no further development of cap tissues in the structures of that what was performed to the point of transfer from light into the dark (compare Fig. 6 with Fig. 1 and Navarro-González 2008).

Looking at the bases of the various structures, there appears to be a difference between all the etiolated stipe structures and the base of the arrested fruiting body structure obtained after transfer at day 6 of incubation at $28^{\circ} \mathrm{C}$ into constant dark (Fig. 6). The latter has a darker core within the middle of the stipe base whereas in etiolated stipes this core extends evenly along the length of the structures (Fig. 6 and Fig. 7). Moreover, the base of the aborted fruiting body from day 7 is more round and broader in diameter as the stipe. This is because the primordia including the base are circumvented by a veil (Fig. 6, Navarro-González 2008) that upon maturation will rupture above the base of the stipe resulting in slender veil less stipes with a larger base. The pictures suggest that the lower part of the stipe tissue in secondary hyphal knots and in developing primordia will give rise to etiolated stipe formation by continuous growth. When following up the inside of an etiolated stipe over its whole length, nowhere a compact base tissue is obvious (Fig. 7A,B). The stipe tissue underneath the cap appears to continue without obvious interruption into etiolated stipe tissue
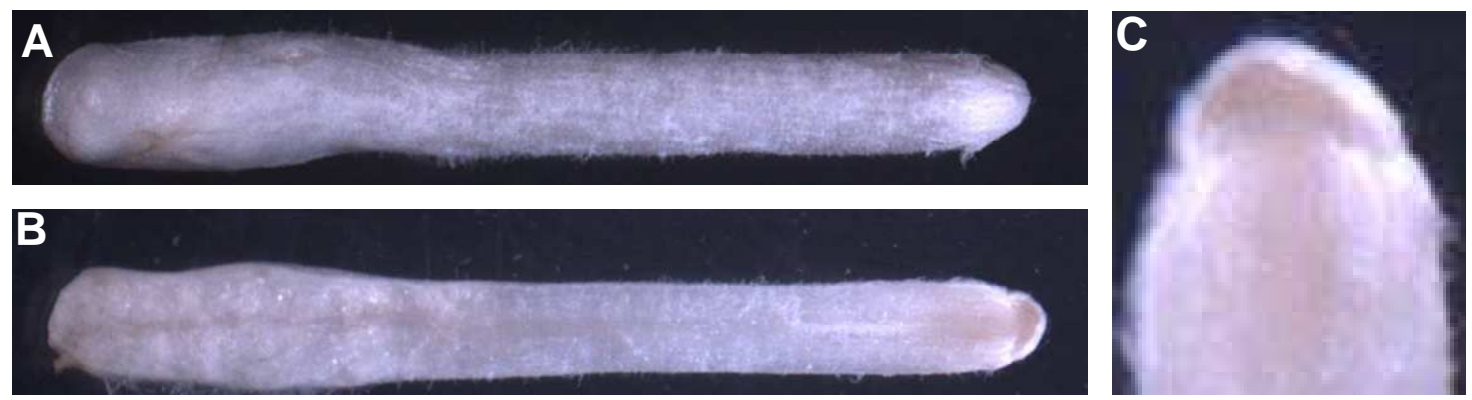

Fig. 7 An etiolated stipe from an AmutBmut culture grown for 5 days at $37^{\circ} \mathrm{C}$ before transfer to $28^{\circ} \mathrm{C}$ for first $3 \mathrm{~h}$ in light and afterwards till day 5 of incubation at $28^{\circ} \mathrm{C}$ into constant dark. (A) Overview of the etiolated stipe before sectioning. Note the veil cells covering the tip of the etiolated stipe. (B) Longitudinal section of the etiolated stipe shown in (A), (C) Enlarged view of the cap, stipe and upper tissues of the etiolated stipe. 

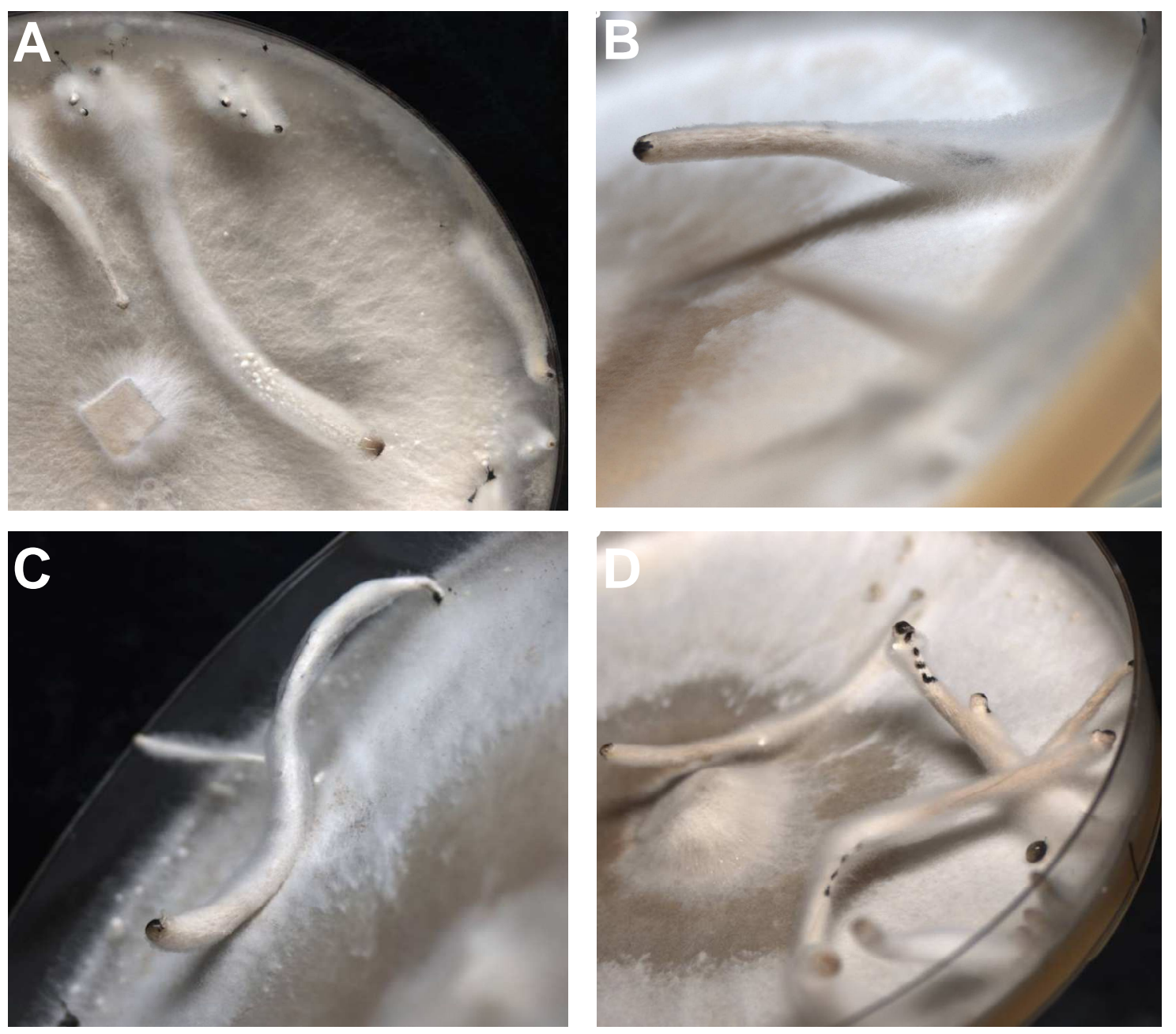

Fig. 8 Etiolated stipe formation upon transfer of YMG/T cultures of homokaryon AmutBmut at $28^{\circ} \mathrm{C}$ after light illumination for periods longer than 5 days into constant dark. Exact cultivation periods in dark and overall cultivation conditions of these plates were not recorded in a respective protocol of the experiment. Pictures were taken and are only shown here since they demonstrate nicely that only a subset of structures will develop over the time into very long structures. Cultivation in the dark of the plates over the time was likely incomplete since fresh formation of secondary hyphal knots was observed indicating reception of a new light signal that is known to be required for fresh secondary hpyhal knots. Pictures are shown to demonstrate that new secondary hyphal knots form at the younger end of etiolated stipes rather than inducing further cap development of the already established structure.

(Fig. 7C). Etiolated stipe formation does not stop at a size of about 1 to $2 \mathrm{~cm}$ as might be deduced from Table 1 . When cultures after setting a light pulse at $28^{\circ} \mathrm{C}$ and transfer into dark were kept for further days in constant dark at $28^{\circ} \mathrm{C}$, a subset but not all of the structures further elongate by several $\mathrm{cm}$ in length. Fig. 8 shows a set of plates after longer periods of incubation in dark boxes documenting that not all structure develop further. This is comparable to the behaviour in formation of large numbers of secondary hyphal knots and young primordia in cultures under standard fruiting conditions, most 
of which will abort in development in favour of a few structures that eventually will mature. The likely reason for such behaviour is the restricted amount of nutrients which will be not enough to nourish all structures to fully develop over the time (Kües 2000). It is further interesting to note that upon receiving another light signal, etiolated stipes appear not to mature further but serve as places of induction for the development of fresh secondary hyphal knots (Fig. 8A, Elliott 1994, Kües 2000 and see blow). There appears to be sense in this when most nutrients of a culture are collected in the long etiolated stipes, thus being at the places were subsequently required for formation of proper mushrooms when sufficient light is given to the cultures. Furthermore, light reacts only at defined places in the cultures, i.e. at young cell such as found at the edge of actively growing cultures (Kües 2000). In older cultures, the freshly grown parts of etiolated stipes obviously present also such young cells that can be reactive on light.

To follow the growth of elongated stipe over the time, in further series of experiments at day 5 of incubation in dark after a short light impulse on the day of transfer to $28^{\circ} \mathrm{C}$ (day 0), using red-light for handling etiolated stipes were size-marked with ink in equal steps starting at the cap according to the scheme shown in Fig. 9. Experiments were first performed with etiolated stipes grown in standard YMG/T cultures but structures were relatively weak and thus not easy to handle. By chance, it was noticed that YMG/T made up with tap water were much stronger and thus, YMG/T tap water medium was subsequently used in growth studies of etiolated stipes. Structures on plates made with tap water could be marked earlier already on day 3 or day 4 of cultivation in constant dark after transfer of fully grown plates to $28^{\circ} \mathrm{C}$ and a $3 \mathrm{~h}$ light illumination. First attempts of following up the daily growth of etiolated stipes (performed on etiolated stipes grown on YMG/T agar plates made up with distilled water) were restricted on marking the newly developed part under red light to finally consider after two to four days further incubation in constant dark to increase in growth. However, in several instances a difficulty was encountered by the fact that ink marks were not anymore or only poorly visible due to strong hair-like hyphal growth at the older parts of the structures (for examples see Fig. 8 and also Fig. 10 indicating the same phenomenon for structures grown on YMG/T agar plates made up with tap water). In consequence of this, in a final experiment using YMG/T tap water agar plates both marking and measuring increase in daily length was done under red light. Starting with a total of 99 different young etiolated stipes, seven individual structures were so observed on a daily basis up to day 6 . The average increase of the etiolated stipes from 
day 3 to day 4 was $0.79 \pm 0.32 \mathrm{~cm}$, from day 4 to day $51.45 \pm 0.30 \mathrm{~cm}$, and from day 5 to day $61.78 \pm 0.70 \mathrm{~cm}$, respectively. From these limited data, it appears that with raising length of the etiolated stipes, also the total increase in length per day raises. Growth of other etiolated stipes could only be followed up till day 3 (8 individual structures), day 4 (68 individual structures), or day 5 (16 individual structures) of incubation in constant darkness since they arrested in growth on the respective days (see Fig. 11) supporting the above suggestion that some structures give up their development in favour of others. When taking also these structures into calculations on average daily length increases of etiolated stipes, an increase in length of $1.39 \pm 0.57 \mathrm{~cm}$ was observed from day 3 to day 4 (from a total of 91 analyzed structures) and an increase in length of $1.58 \pm 0.64 \mathrm{~cm}$ from day 4 to day 5 (from a total of 23 analyzed structures), respectively. Possibly, the somewhat larger extend in length upon longer incubation relates to an overall rise in strength of the structures (for this point of discussion, compare also Table 1).
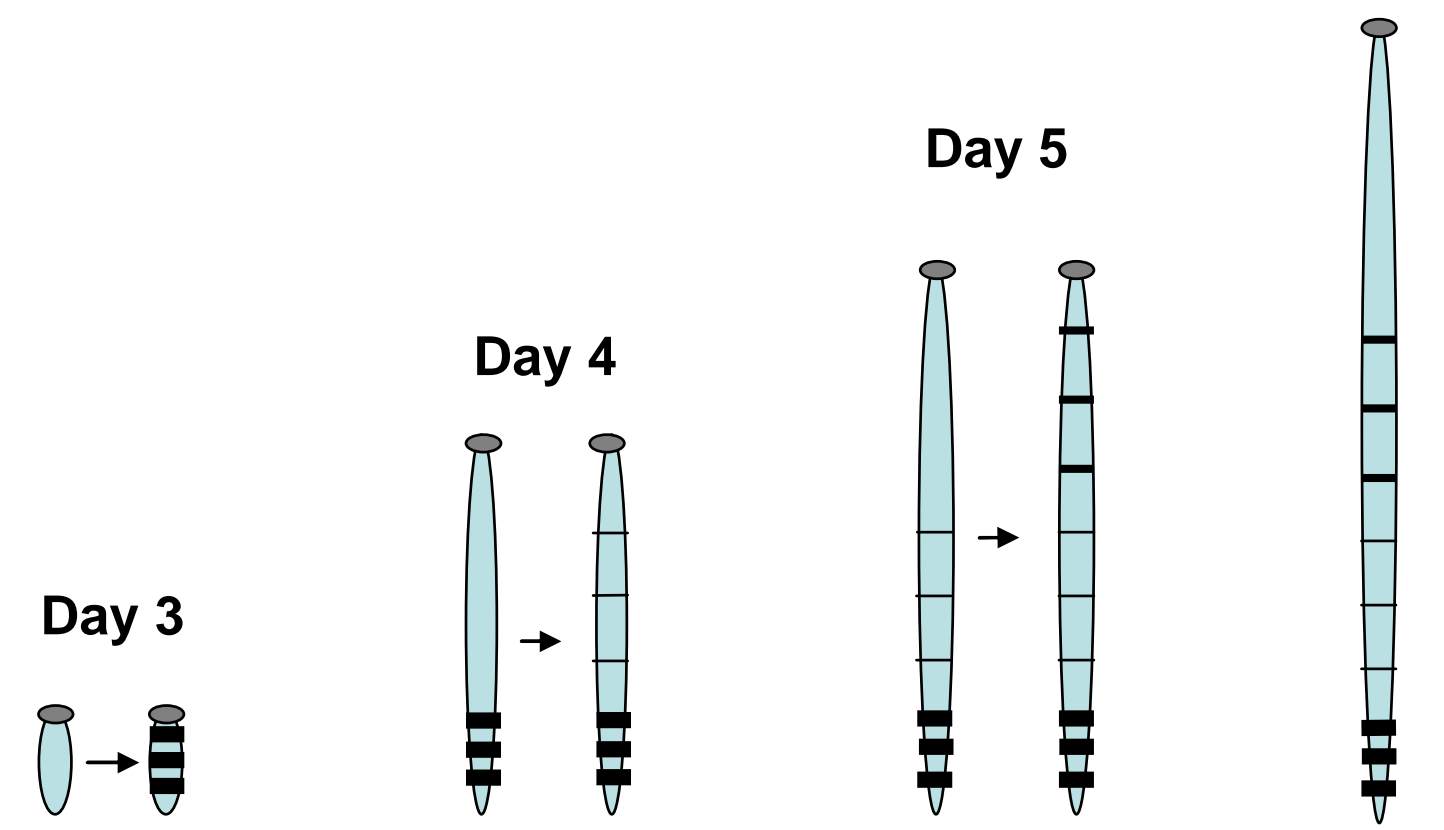

\section{Day 6}

Fig. 9 Scheme for marking etiolated stipes. After growth for 5 days at $37^{\circ} \mathrm{C}$ on $\mathrm{YMG} / \mathrm{T}$ tap water agar plates, Petri dishes were transferred for $3 \mathrm{~h}$ into light at $28^{\circ} \mathrm{C}$ and subsequently for further incubation into constant dark. After three days, etiolated stipes were measured in size and marked under red light on the cap (indicated in grey) and at three further equally spaced positions on the shaft of the etiolated stipes (light blue). Structures were further incubated at $28^{\circ} \mathrm{C}$ in constant dark and measured and marked again after $24 \mathrm{~h}$ (day 4 ) and $48 \mathrm{~h}$ (day 5), respectively, and finally evaluated at day 6 of total incubation at $28^{\circ} \mathrm{C}$. 
In all cases where further growth of etiolated stipes was observed, the section marked at the cap to the next neighboured mark increased by several $\mathrm{cm}$, whereas distances between other marks did not noticeably change (Fig. 10). The observations suggest that etiolated stipes grow by proliferation of tissues above the older parts of etiolated stipes but below the cap. Terashima et al. (2005) previously reported that etiolated or dark stipes develop by elongating the base (nicely termed by these authors the primordial shaft) underneath the stipe tissue that elongates during normal fruiting body development (compare Fig. 2) although they did not give proof for this statement.
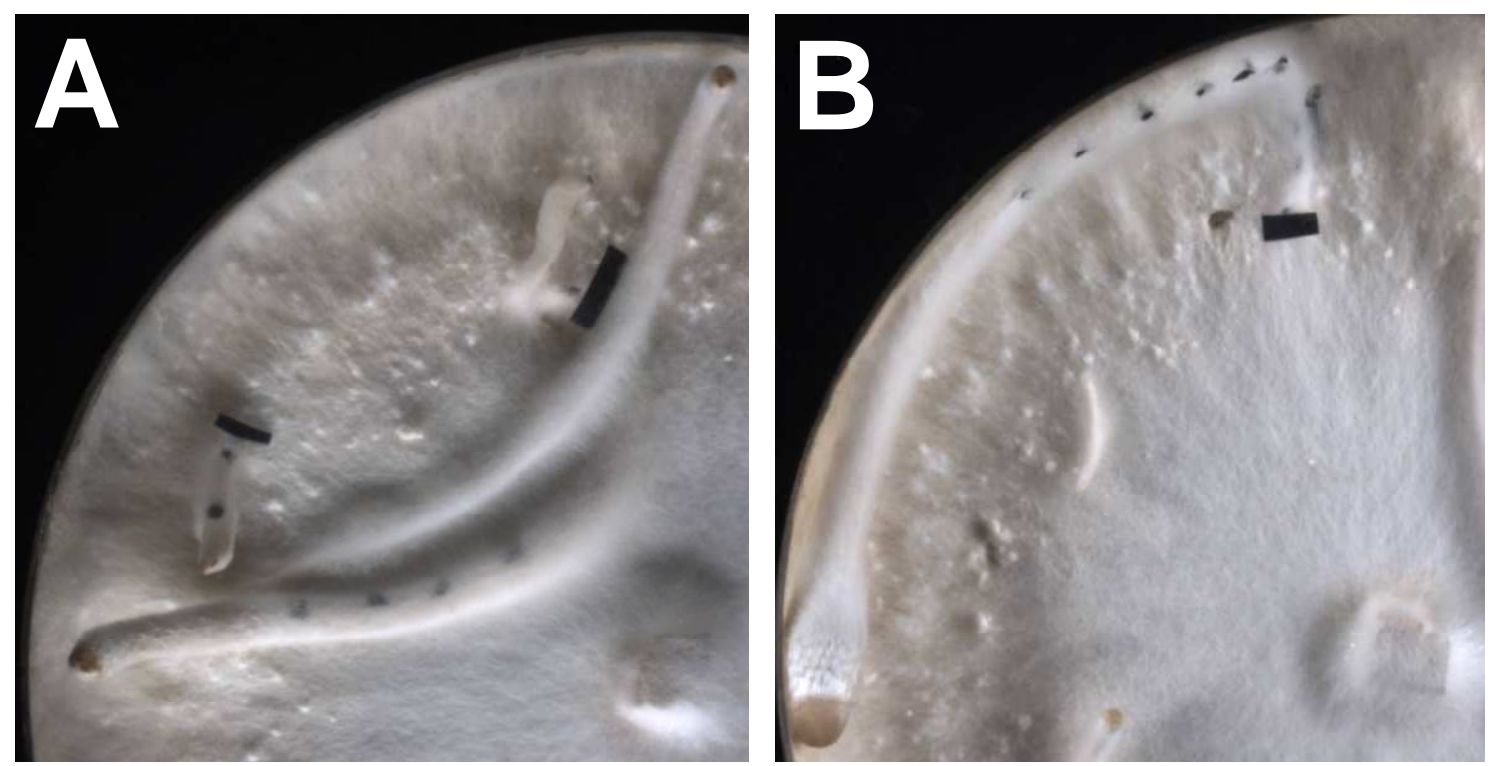

Fig. 10 Growth of etiolated stipes of homokaryon AmutBmut over the time. The strain was grown for 5 days at $37^{\circ} \mathrm{C}$ in constant dark on YMG/T medium (made up with tap water) upon which plates were transferred to standard fruiting conditions at $28^{\circ} \mathrm{C}$ (day 0) and upon $3 \mathrm{~h}$ illumination into constant dark at $28^{\circ} \mathrm{C}$ into ventilated boxes. At day 3 of incubation at constant dark, a first set of marks was set by ink under red-light, upon which the plates were transferred back for $24 \mathrm{~h}$ into constant dark. Marking was repeated on day 4 and 5 of incubation with a final length evaluation of day 6 of incubation. Etiolated stipes were finally photographed at day 7 of incubation $(\mathbf{A}),(\mathbf{B})$. Note in the left plate (A), that the first marks from day 5 and some from day 6 are not anymore visible due to extensive hairy-like hyphal growth. Note also in both plates the many very small etiolated stipes within the aerial mycelium that appeared to have arrested in development.

The results shown in Fig. 10 clearly indicate that older tissues of etiolated stipes will not proliferate for extension growth. Since the cap is only pushed forward by newly established shaft tissue without obvious further development (compare also Fig. 7), also tissues of the cap is not responsible for forward growth of the etiolated stipes. Most likely the growth zone will be just below the cap, probably at the place where the veil stops (compare Fig. 7A and C). The marking in the experiments shown did not 
encompass this region. In future studies, marking should therefore present a continuous line from the tip of the cap down the shaft over a defined length of the etiolated stipe. The point of tearing apart of the line should tell us than where the growth zone exactly lies.
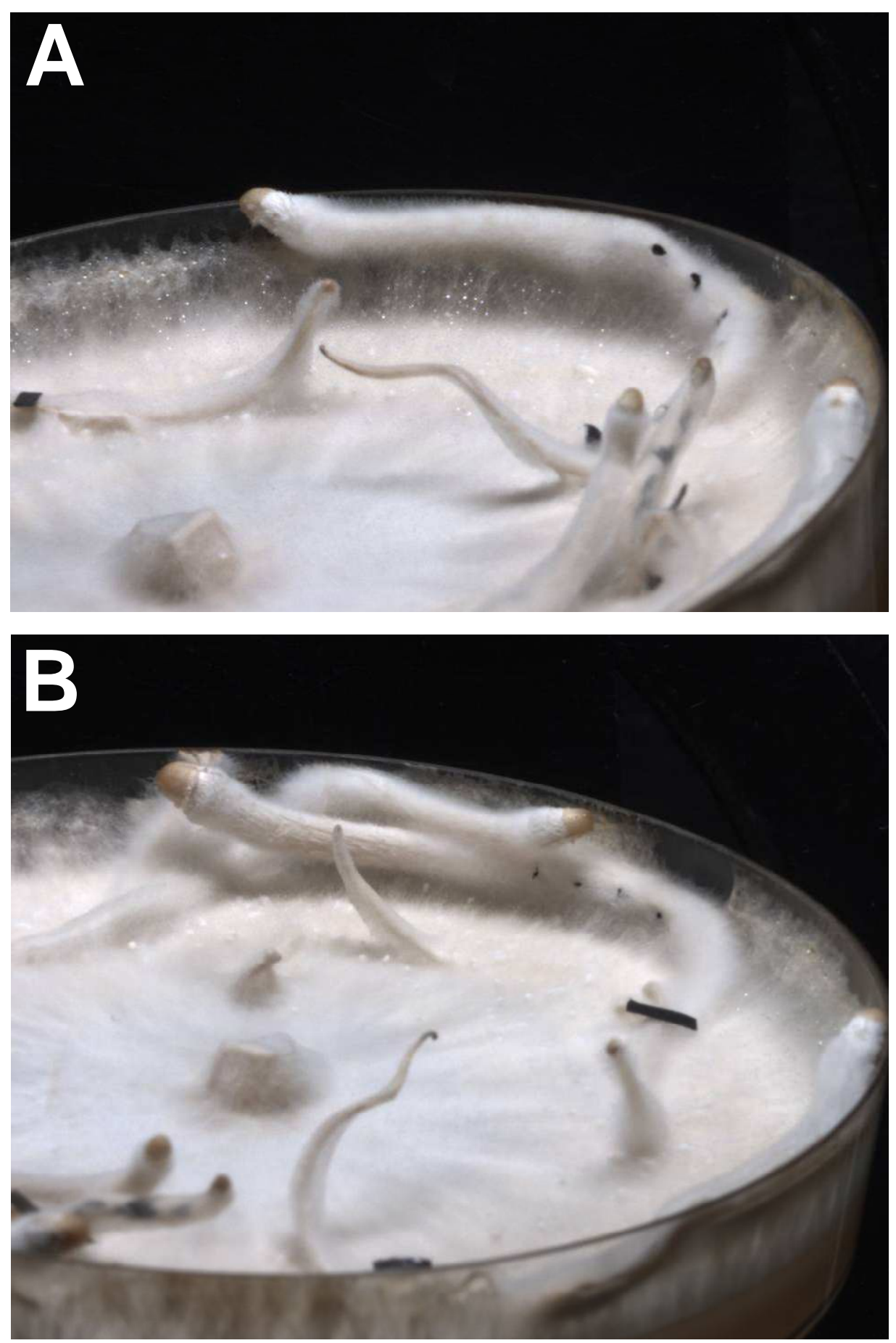

Fig. 11 The majority of young etiolated stipes arrest early in development over the time in favor of one or two structures that develop further. The plates shown are from the same experiment than those given in Fig. 10 and they were also photographed on day 7 after transfer of plates at $28^{\circ} \mathrm{C}$ into constant darkness. 


\subsubsection{Transfer of etiolated stipes into normal fruiting conditions with a $12 \mathrm{~h}$ light/12 h dark regime}

Upon development of etiolated stipes, an obvious question is whether these develop further into mature fruiting bodies when returned into a normal $12 \mathrm{~h}$ light/12 h dark regime. As shown in Fig. 8 and supported by literature data (Elliott 1994), it appears that transfer of etiolated stipes back into normal light conditions will not cause maturation of the cap of the etiolated stipes. Rather, new secondary hyphal knots develop that eventually might develop into normal fruiting bodies (Fig. 12).

To elucidate this question further, subsets of each 10 standard YMG/T agar plates of AmutBmut cultures grown for 5 days at $37^{\circ} \mathrm{C}$ before transfer into $28^{\circ} \mathrm{C}$ and incubating them for distinct phases under normal fruiting conditions and in constant darkness according to the different cases shown the scheme in Fig. 3 were transferred at day 5 (Fig. 13A to 13E, respectively day 6 (Fig. 13F) or day 7 (Fig. 13G) of total cultivation at $28^{\circ} \mathrm{C}$ from constant darkness back into the normal $12 \mathrm{~h}$ light $/ 12 \mathrm{~h}$ dark regime. In all instances when transfer into constant darkness occurred on day 0 , day 1 , day 2 or day 3 of total incubation at $28^{\circ} \mathrm{C}$, etiolated stipes aborted in development and fresh hyphal knots were produced developing into normal primordia and at day 7 of normal mushroom development maturating into the typical C. cinerea fruiting bodies (Fig. 13A to $13 \mathrm{D})$. Also in the other three sets of plates that were transferred later into constant darkness such freshly induced primordia occurred some of which subsequently resulted in normal matured fruiting bodies (Fig. 13E to G). From later stages in development [day 5 and day 6 of normal fruiting body development (see Fig. 1) corresponding to primordia in the pre-karyogamy stage with fully developed tissues, respectively to primordia undergoing karyogamy (Navarro-González 2008)] one might have guessed that an interruption of normal fruiting conditions by transfer of plates for a defined time into constant dark would not have had as severe effects on aborting fruiting structures, particularly not when a transfer was performed at day 6 of normal fruiting body development. However, judging from the plates shown in Fig. 13E and 13G, on the plates shown there were no such primordia structures on the plates shown that could have been followed up in development of etiolated stipes after their transfer back into standard fruiting conditions.

In plates that were transferred at day 4 of total incubation at $28^{\circ} \mathrm{C}$ into constant darkness and at day 5 of incubation at $28^{\circ} \mathrm{C}$ back into the standard fruiting conditions 


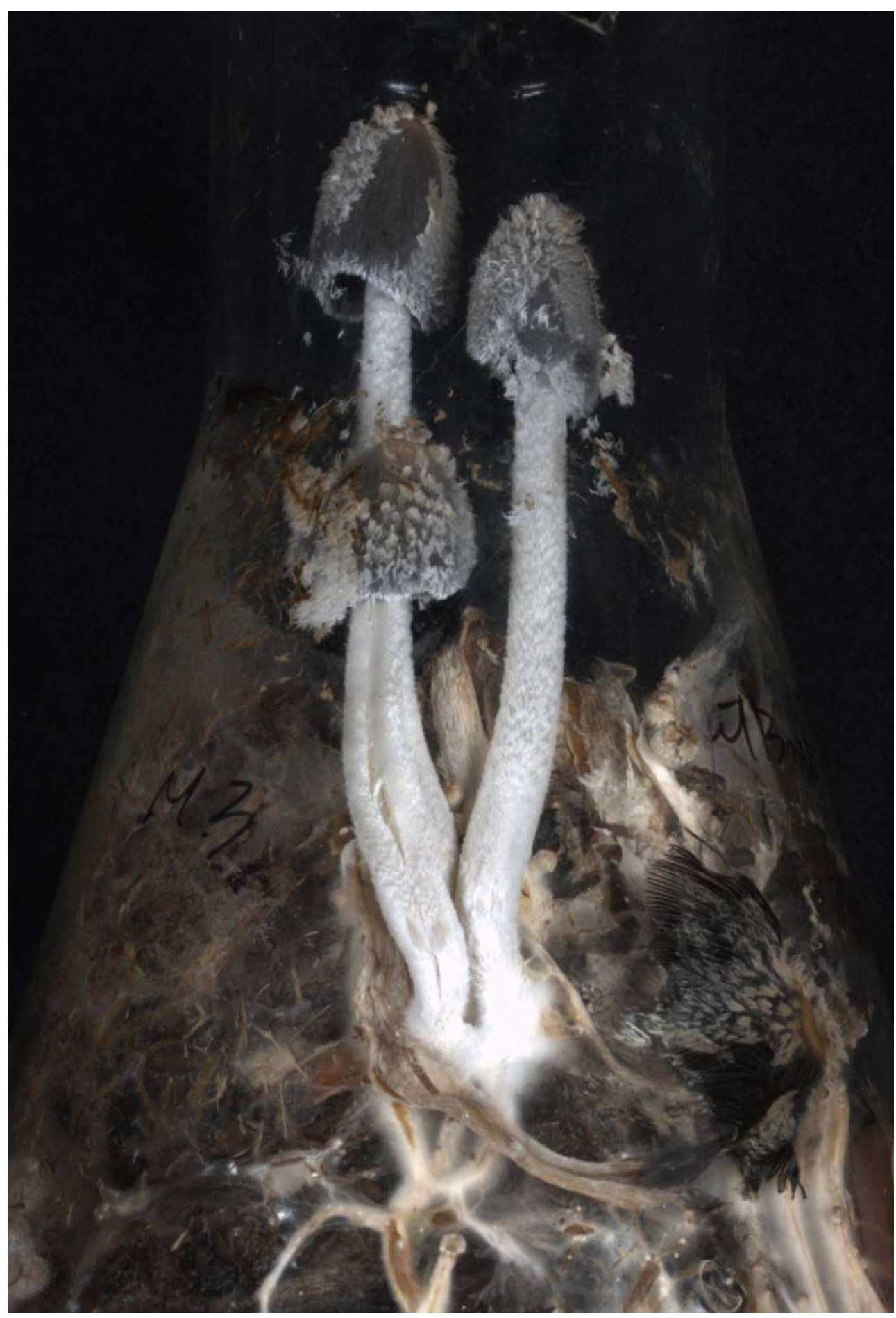

Fig. 12 Fruiting bodies developed on aborted etiolated stipes of Coprinopsis cinerea AmutBmut in a horse dung culture. Strain AmutBmut was inoculated by transferring six agar pieces (about $2 \mathrm{~mm} \times 2 \mathrm{~mm}$ in size) with mycelium from a fresh YMG/T preculture into a $500 \mathrm{ml}$ flask containing sterilized horse dung. The culture was incubated for 5 days at $37^{\circ} \mathrm{C}$ in the dark before transferring into standard fruiting conditions at $28^{\circ} \mathrm{C}$. Etiolated stipes developed deeply within the horse dung at the bottom of the flask. These stipes pushed forward to the surface of the horse dung to obtain enough light for formation of proper fruiting bodies. The fruiting bodies shown here initiated development as new structures on aging etiolated stipes. When fruiting body maturation started, the culture was transferred over night to room temperature in the lab to reduce the speed of fruiting body maturation so that at the next morning, the structures could be photographed before fully maturation and fast autolysis. 

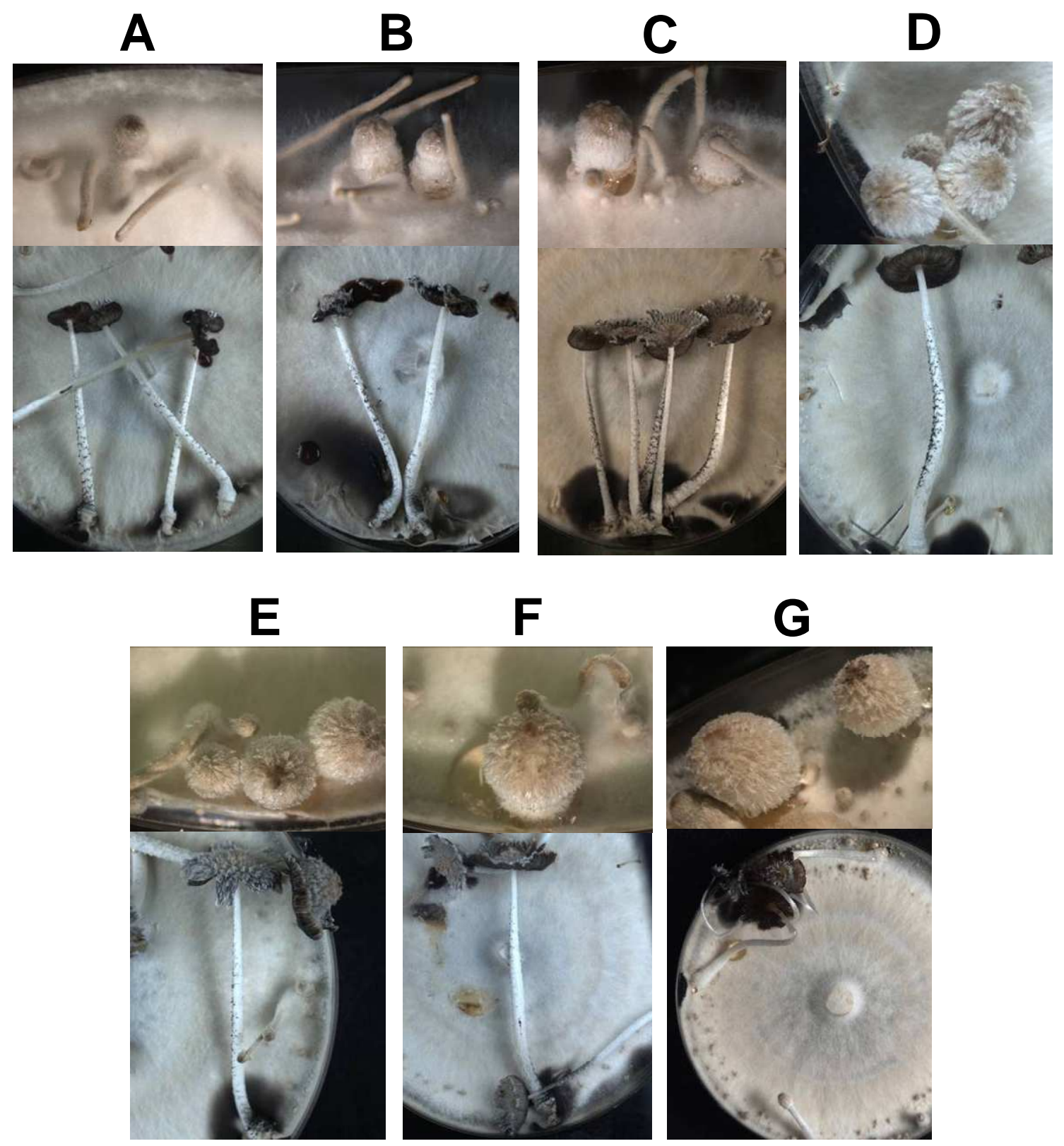

Fig. 13 Fruiting body development of homokaryon AmutBmut after transfer of plates kept at $28^{\circ} \mathrm{C}$ for defined periods in constant dark for etiolated stipe production back into standard fruiting conditions. Standard YMG/T plates of homokaryon AmutBmut were grown for 5 days in constant dark at $37^{\circ} \mathrm{C}$ and then transferred for defined times into standard fruiting conditions before incubating them in constant dark at $28^{\circ} \mathrm{C}$ (compare scheme in Fig. 3; per case 10 different plates were incubated) to develop dark stipes. Subsequently, all cultures were moved from constant dark back into standard fruiting conditions [at day 5 those cultures that were transferred on day $0(\mathbf{A})$, day $1(\mathbf{B})$, day $2(\mathbf{C})$, day $3(\mathbf{D})$ and day $4(\mathbf{E})$ of incubation at $28^{\circ} \mathrm{C}$ into constant dark; at day 6 the cultures that were transferred at day $5(\mathbf{F})$ of incubation at $28^{\circ} \mathrm{C}$ into constant dark; at day 7 the cultures that were transferred at day $6(\mathbf{G})$ of incubation at $28^{\circ} \mathrm{C}$ into constant dark]. Three days after transfer back into standard fruiting conditions, representative plates from the sets of plates transferred at day 0,1 or 2 of incubation at $28^{\circ} \mathrm{C}$ into constant dark (cases (A) to $(\mathbf{C})$ were first photographed (in each case the upper of the respective two pictures shown). Five days after transfer back into standard fruiting conditions, a representative plate from the sets of plates transferred at 3 of incubation at $28^{\circ} \mathrm{C}$ into constant dark [case (D)], were first photographed (the upper of the respective two pictures shown). Six 
days after transfer back into standard fruiting conditions, representative plates from the sets of plates transferred at day 4,5 or 6 of incubation at $28^{\circ} \mathrm{C}$ into constant dark [cases (E) to $(\mathbf{G})$ ] were first photographed (in each case the upper of the respective two pictures shown). Amongst the formerly grown etiolated stipes, normally developed primordia were observed [at least in cases (A) to (E)], some of which matured into fully developed fruiting body (in each case the lower of the respective two pictures; photos taken on day 7 after transfer back into standard fruiting conditions). In the plates shown in $(\mathbf{E})$ and $(\mathbf{G})$, no etiolated stipes were seen that would correspond to the expected developmental age to be achieved at the point of transfer. Thus, from these plates no definite conclusions should be drawn.

with $12 \mathrm{~h}$ light illumination, an exceptional structure was able to continue tissue development of the cap of the etiolated stipe to a fully established cap with basidiospores (shown in Fig. 14B in comparison to a normally developed mushroom in 14C). This exceptional event correlated with transfer of primordia that in the normal course of fruiting body development mostly completed tissue development in the cap (see Fig. 1A and F and Fig. 3). To describe the available results of the experiment completely, one further unusual structure should be mentioned that occurred on a plate transferred at day 0 into constant dark and at day 5 of total incubation at $28^{\circ} \mathrm{C}$ back into standard fruiting conditions (Fig. 14A). This special structure had a further developed cap but never matured into a fully developed fruiting body (Fig. 14A).

In conclusion from the presented data of the experiment, it appears that etiolated stipes developing from hyphal knots or from very young primordia have not the potential to turn back into the normal developmental routine of fruiting body development. For etiolated stipes carrying primordial caps with fully established tissues, this question unfortunately is left open. Observations from other unfortunately not well documented photos suggest that the situation of a transfer into constant darkness at day 6 of normal fruiting body development followed by a transfer back into standard fruiting conditions at day 7 might be quite different (Fig. 15). It appears that maturation of fully established primordia undergoing already karyogamy (compare Navarro-González 2008) will be delayed by one day by such treatment and that fully developed mushrooms will finally be obtained at day 8 of incubation. Such mushrooms from delayed maturation distinguish from normal fruiting bodies maturing at day 7 under standard fruiting conditions by extended etiolated stipe tissue present beneath a normal looking primordial shaft (Fig. 15). Such extended shafts are known from horse dung cultures where they are thought to help pushing the cap through the material towards the surface and light and they were the reason why in Japan the fungus 


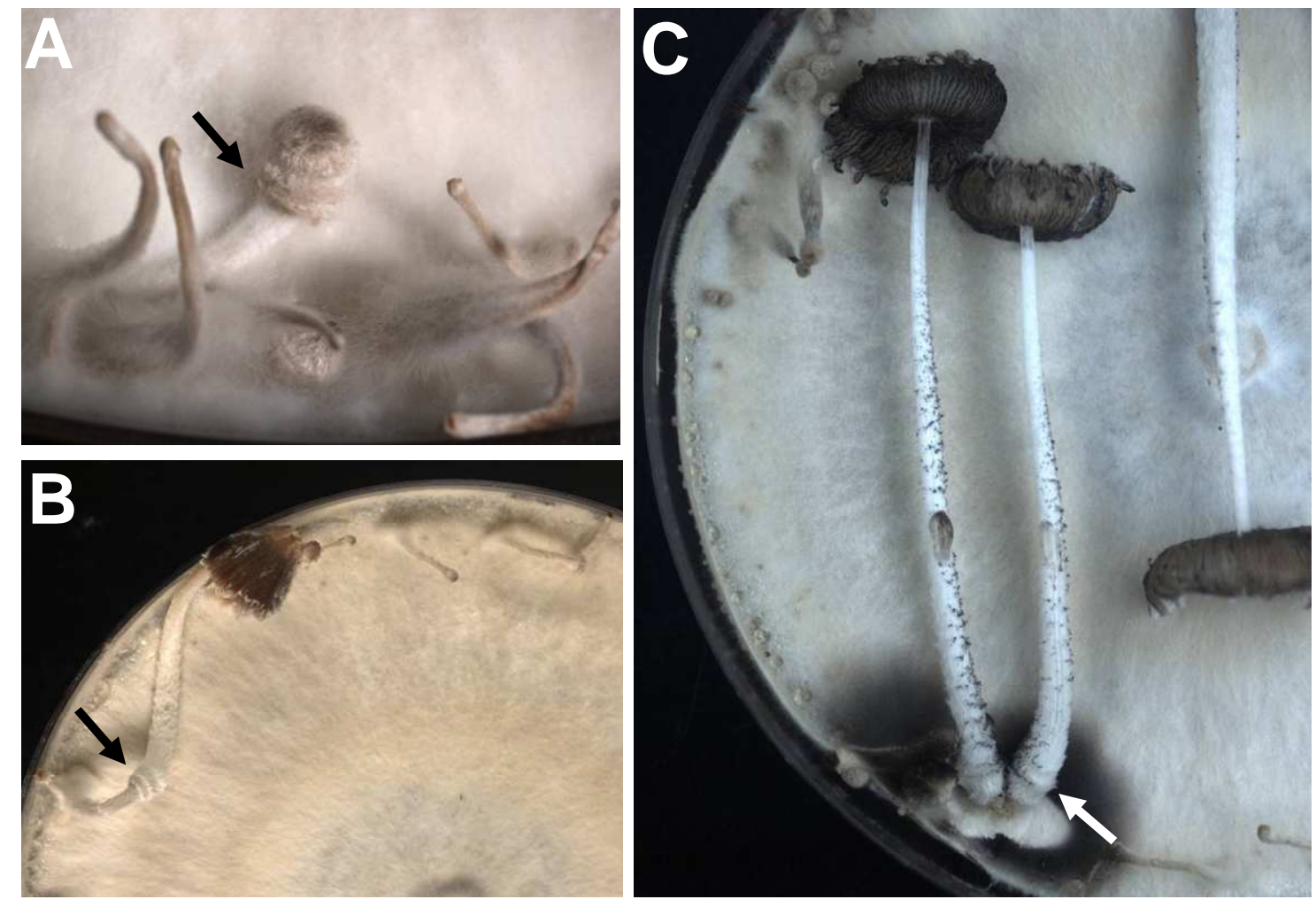

Fig. 14 Fruiting body development of homokaryon AmutBmut after transfer of plates kept at $28^{\circ} \mathrm{C}$ for defined periods in constant dark for etiolated stipe production back into standard fruiting conditions. (A) An etiolated stipe with a cap with an unusual progressed tissue development observed in a culture that was transferred after $3 \mathrm{~h}$ light illumination into constant dark up to day 5 of total incubation at $28^{\circ} \mathrm{C}$ before shifting the plate back into standard fruiting conditions. The photo was made 3 days after the shift back into the normal fruiting conditions. Size and structure of the cap corresponds well with the normal primordium size and structure at day 3 of fruiting body development observed under standard fruiting conditions (see Fig. 1, Navarro-González 2008). (B) A fruiting body with spores observed at day 3 after transfer of a plate back into standard fruiting conditions that previously were kept for 4 days in standard fruiting conditions at $28^{\circ} \mathrm{C}$ and then for one day up to day 5 of total incubation at $28^{\circ} \mathrm{C}$ in constant dark. The arrow points at the extended shaft underneath the normal formed stipe of the fruiting body. (C) For comparison of the fruiting structure, another plate of the same treatment is shown, where fruiting body development initiated newly upon transfer back into standard fruiting conditions and completed at day 7 after transfer back into standard fruiting conditions. The arrow points at the normally looking primordial shaft of the fruiting bodies.

was originally called Coprinus macrorhizus (Kües 2000; MycoBank Fungal Databases, Databases,http: //www. mycobank.org). In future, the developmental processes that happen upon transfer of etiolated stipes of different age back into normal fruiting conditions need still to be studied more thoroughly to verify the impressions on etiolated stipe development in dark and in standard fruiting conditions as presented here. 

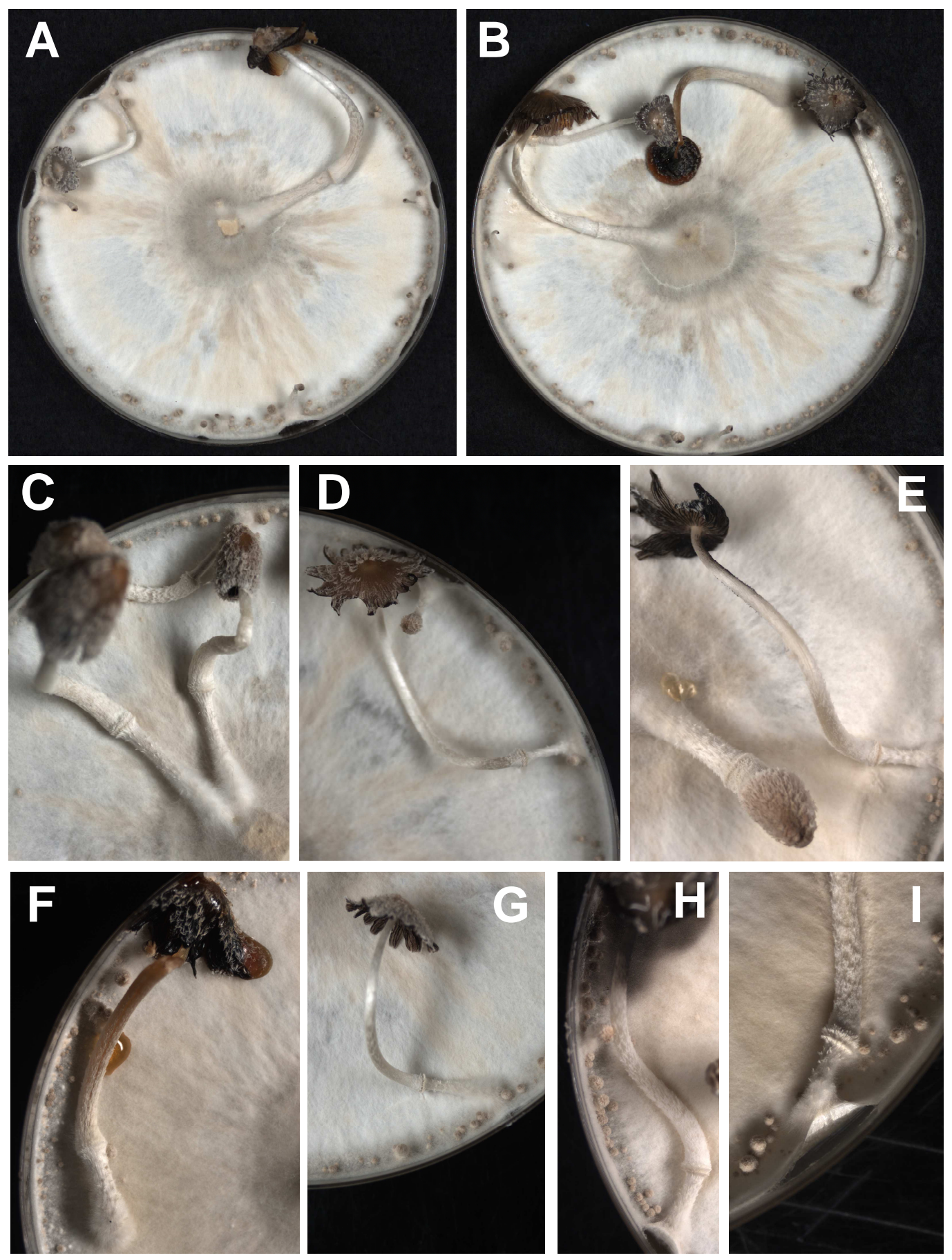

Fig. 15 Views on fruiting bodies of Coprinopsis cinerea homokaryon AmutBmut that maturated on YMG/T plates after growth for $5 \mathrm{~d}$ at $37^{\circ} \mathrm{C}$ in the dark, transfer into standard fruiting conditions at $28^{\circ} \mathrm{C}$ (day 0 to day 6, compare Fig. 1), transfer early at day 6 for $1 \mathrm{~d}$ into constant dark at $28^{\circ} \mathrm{C}$, and transfer early at day 7 back into standard fruiting conditions on day 8 of development. (A) and (B) Views on complete plates, (C) to (H) views on single fruiting bodies with elongated shafts beneath the normally looking primordial shaft and fruiting body stipe, and (I). enlarged view on a primordial shaft developed above an etiolated stipe. Note, the cultures shown are believed to be from the same experiment shown in Fig. 13 and Fig. 14. However, the original files documenting the course of the experiment were lost due to the unfortunate failure of a computer hard disc. In the future, the experiment has therefore to be repeated in order to proof the results of the experiment as interpreted here. 


\subsubsection{Fruiting body development of $C$. cinerea homokaryon AmutBmut under periods of constant light illumination}

Fruiting body development of $C$. cinerea homokaryon AmutBmut is adapted to the light and dark periods in the normal day/night rhythm (Fig. 1, Kües et al. 2004, 2007, Navarro-González 2008). The experiments presented so far in this chapter showed that the length of the dark periods have a decisive influence on the progress of normal fruiting body development. In the following, experiments are described designed to detect effects of prolonged light periods on fruiting body development.

Homokaryon AmutBmut was grown on standard YMG/T plates for 5 days at $37^{\circ} \mathrm{C}$ and subsequently transferred to $28^{\circ} \mathrm{C}$ under standard fruiting conditions into a climate chamber with $85-90 \%$ humidity for further incubation. At the morning of day 0 of incubation, a subset of 10 plates was transferred into constant light illumination at $28^{\circ} \mathrm{C}$ into an incubator with $85 \%$ humidity. Similarly, at day 1 of incubation at $28^{\circ} \mathrm{C}$, at day 2 of incubation at $28^{\circ} \mathrm{C}$, at day 3 of incubation at $28^{\circ} \mathrm{C}$, and at day 4 of incubation at $28^{\circ} \mathrm{C}$, subsets of each ten plates were transferred from standard fruiting conditions into constant light illumination at $28^{\circ} \mathrm{C}$ and $85 \%$ humidity into the incubator. All these plates were evaluated at day 5 of total incubation at $28^{\circ} \mathrm{C}$. Another set of 10 plates was transferred at day 5 of incubation under standard fruiting conditions for $24 \mathrm{~h}$ into constant light illumination at $28^{\circ} \mathrm{C}$ and $85 \%$ humidity into the incubator to be evaluated at day 6 of total incubation at $28^{\circ} \mathrm{C}$. A further set of 10 plates was transferred at day 6 of incubation under standard fruiting conditions for $24 \mathrm{~h}$ into constant light illumination at $28^{\circ} \mathrm{C}$ and $85 \%$ humidity into the incubator to be evaluated at day 7 of total incubation at $28^{\circ} \mathrm{C}$. This principal experimental set-up is documented in Fig. 16. After the first evaluation at day 5, day 6 or day 7 , respectively, all plates were incubated further in constant light up to day 16 of total incubation at $28^{\circ} \mathrm{C}$. The light intensity of all light incubation periods applied was $30-40 \mu \mathrm{E} \mathrm{m}^{-2} \mathrm{~s}^{-1}$. After growth at $37^{\circ} \mathrm{C}$ in constant dark at the time of transfer into $28^{\circ} \mathrm{C}$ (day 0 ), primary hyphal knots were noted in the cultures. The next morning at day 1 , all plates had secondary hyphal knots. On the plates that had no dark phase and were kept directly in constant light, young primordia of 1-2 $\mathrm{mm}$ in size were also seen (Fig. 16) suggesting that the lack of a dark period speeded somewhat up the normal development. Primordia of a similar developmental stage were seen in the plates with a dark incubation phase at the morning of day 2 of 


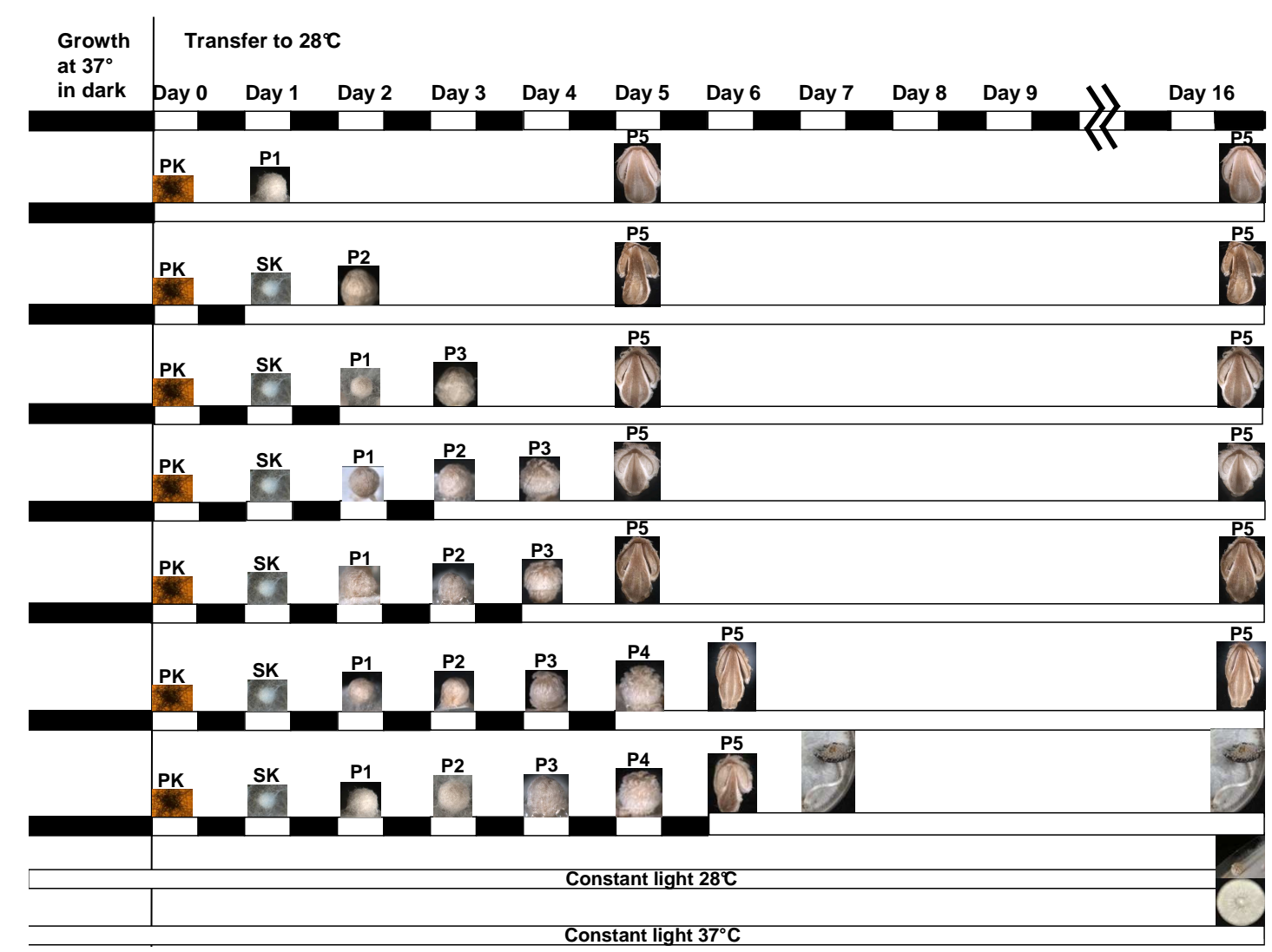

Fig. 16 Experimental setup of transferring YMG/T plates of homokaryon AmutBmut at different time points of the normal fruiting pathway into constant light. All plates were incubated for $5 \mathrm{~d}$ at $37^{\circ} \mathrm{C}$ to allow growth of the fungus before transferring it to $28^{\circ} \mathrm{C}$. A subset of 10 plates was kept in constant light in an incubator with $85 \%$ humidity without any further incubation periods in the dark (day $0=$ day of transfer). Another subset of 10 plates was incubated for $1 \mathrm{~d}$ under standard fruiting conditions in a climate chamber at $90 \%$ humidity before transferring them into constant light into the incubator with $85 \%$ humidity. Other subsets of each 10 plates were kept through more full $12 \mathrm{~h}$ light $/ 12 \mathrm{~h}$ dark periods in the climate chamber before transferring them at the beginning of a new light period (about $5 \mathrm{~min}$ after light switches on in the climate chamber) into constant light into the incubator with $85 \%$ humidity. A white box labelled with a day in the upper line of the figure denotes a $12 \mathrm{~h}$ light period and the following black box the $12 \mathrm{~h}$ dark period on a $24 \mathrm{~h}$ scale under standard fruiting conditions. The times of transfer and the maximum developmental stage reached by cultures at the point of transfer into constant light are indicated by the photos above. In addition, on each day of incubation under standard fruiting

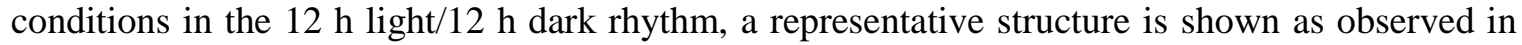
the mornings at the start of a $12 \mathrm{~h}$ light period. Thereby, PK denotes primary hyphal knot, SK secondary hyphal knot, P1 up to P5 primordial stages 1 to 5 as defined in Fig. 1 (P5 = mature primordium). Upon a shift from standard fruiting conditions into incubation in constant light, plates were further incubated at $28^{\circ} \mathrm{C}$ in the incubator at $85 \%$ humidity until day 5 , day 6 or day 7 , respectively, for evaluation of developmental structures after transfer into constant light at $28^{\circ} \mathrm{C}$. In between the transfer into constant light and the end of the experiment, each morning plates were also evaluated. Structures were photographed as shown in the figure and in Fig. 19 and 20 on days of evaluation. In addition to growing the fungus as it is standard in the laboratory for 5 days at $37^{\circ} \mathrm{C}$ in constant dark, effects of growth of the vegetative mycelium directly in constant light at the two different temperatures $28^{\circ} \mathrm{C}$ and $37^{\circ} \mathrm{C}$ were also tested as indicated by the two lines at the bottom of the figure. Only when grown in constant light at $28^{\circ} \mathrm{C}$, the fungus was able to induce fruiting body development whereas on plates incubated under continuous illumination in constant light at $37^{\circ} \mathrm{C}$ not even primary or secondary hyphal knots appeared (for further information, see text). 


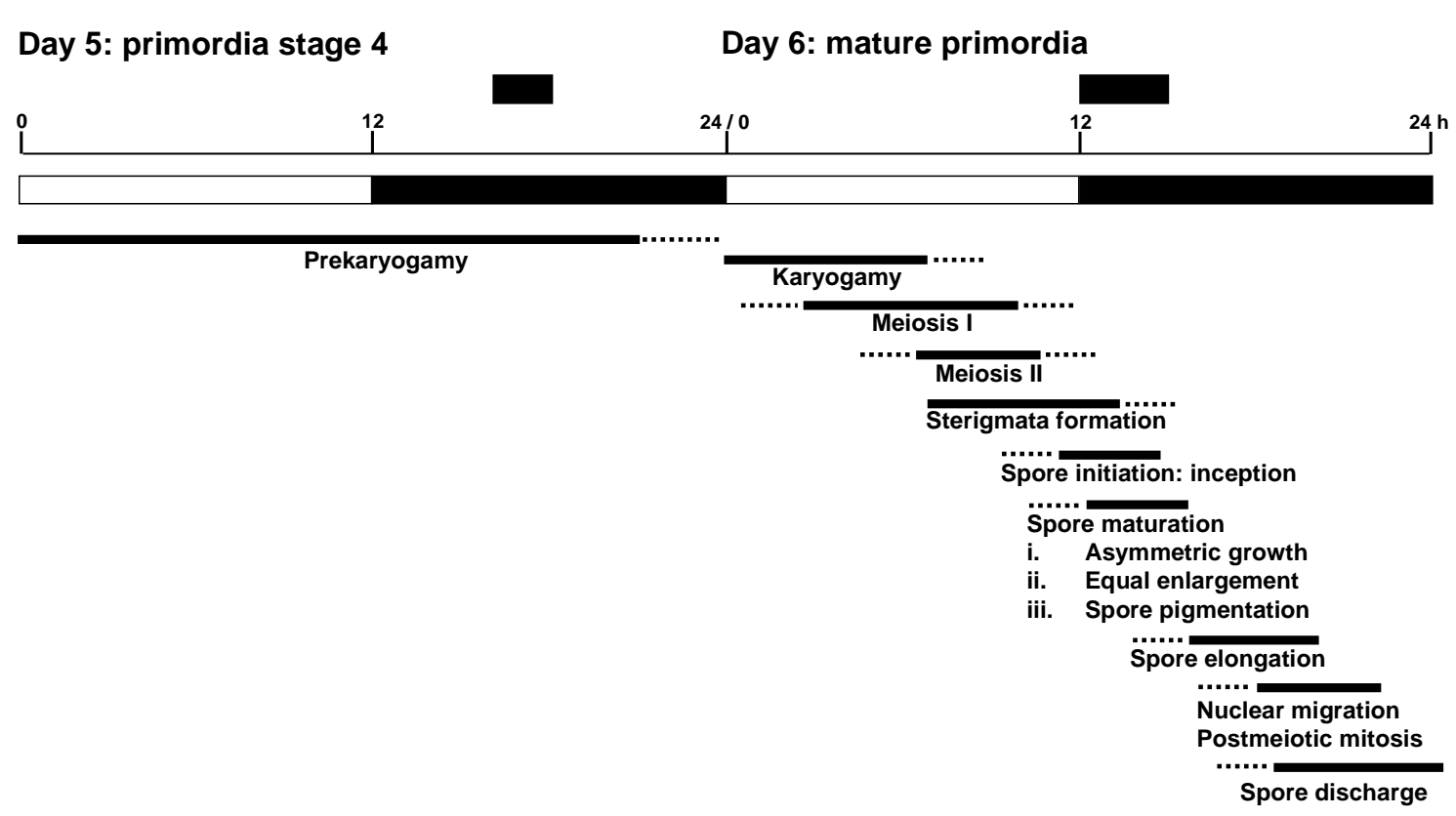

Fig. 17 Scheme explaining the processes occurring in basidia over the time in fully established primordia from the prekarogamy stage up to spore formation according to observations under the microscope made by Navarro-González (2008). Primordia stage 4 (prekaryogamy stage) with fully established cap and stipe tissues are obtained under standard fruiting conditions on day 5 of incubation whereas under standard fruiting conditions karyogamy, meiosis and spore formation mostly happen in primordia stage 5 on day 6 of incubation. White and black boxes in the time scale represent light and dark phases, respectively. The smaller dark boxes above indicate a period of minimum $2 \mathrm{~h}$, respectively a $3 \mathrm{~h}$ where arrest in fruiting body development induced by cultivation in constant light can be released through transferring cultures into constant dark (after Lu 1974, 2000 and Lu and Jeng 1975).

incubation at $28^{\circ} \mathrm{C}$ (Fig. 16). Likewise, transfer in constant light at later days of incubation seems to have a somewhat positive effect on the speed of development (Fig. 16). Once started, incubation in constant light did not block tissue formation in developing primordia. However, regardless on which day the transfer into constant light was done up to day 5 (inclusive), development eventually arrested at a stage when the gills started to separate from the stipe and when the stipe slowly elongated. These morphological processes are observed under standard fruiting conditions on day 6 of development when meiosis occurs in the basidia (Fig. 17, Navarro-González 2008). Prolonged incubation under constant illumination up to day 16 of total incubation at $28^{\circ} \mathrm{C}$ did not further improve development-under such conditions, the arrest was permanent in those plates shifted before or at day 5 of incubation under standard fruiting conditions into constant light (Fig. 16 and Fig. 18). Only plates incubated for 6 days under standard 
fruiting complete the full fruiting body pathway including formation of basidiospores (Fig. 16 and Fig. 18).

Lu (1974) and Lu and Jeng (1975) described for C. cinerea strains a 2 h-long darkdependent period at the meiotic S-phase occurring in the fungus prior to karyogamy. Fruiting cultures kept at the required time phase in fully dark before changing incubation conditions to constant light illumination were able to develop pre-karyogamy primordia (compare Fig. 17). When this dark period was missing, there was a permanent arrest in fruiting body development ( $\mathrm{Lu} \mathrm{1974,} \mathrm{Lu} \mathrm{and} \mathrm{Jeng} \mathrm{1975).} \mathrm{Lu} \mathrm{(2000)} \mathrm{further} \mathrm{described} \mathrm{that}$ another $3 \mathrm{~h}$ long dark period is required for some strains including homokaryon AmutBmut to overcome a light-induced arrest after diplotene in meiosis I (compare Fig. 17). If the dark period is not given at the appropriate time point at meiosis, development arrests permanently. Generally, with $16 \mathrm{~h}$ light/ $8 \mathrm{~h}$ dark $\mathrm{Lu}$ in his experiments used another light/dark rhythm (Lu 1974, 1982, 2000, Lu and Jeng 1975) than many other researchers (Kamada et al. 1978, Kües 2000, Liu 2001, Navarro-González 2008, this study). Thus, the observations by $\mathrm{Lu}$ and colleagues are not easy to transfer to the observations of the experiment described here. However, the phenomenon of lightinduced arrests are also recognised in the experiments documented in Fig. 16. Primordia stage 4 (P4) at day 5 in the normal $12 \mathrm{~h}$ light/12 h dark rhythm receive the light signal inducing karyogamy and, subsequently, the mature primordia should be on day 6 in meiosis I which finishes towards the end of the normal $12 \mathrm{~h}$ light phase of incubation at day 6 (compare Fig. 17, Navarro-González 2008). If however subsequently to induction of karyogamy in primordia stage 4 on day 5 no dark phase at the end of meiosis I on day 6 is given, permanent arrest in development happens which is seen on day 6 in the experiment described here (Fig. 16 and Fig. 20G, H) - incubation for several further days in constant light did not result in fruiting body maturation (Fig. 16 and Fig. 18 upper row). In conclusion, the experiment described here confirms Lu's earlier reports on two dark-dependent, i.e. light-sensitive steps during the process of fruiting body development in C. cinerea. As described in the study by $\mathrm{Lu}$ (2000), transfer of structures into constant light after the second dark-dependent light-sensitive phase had no negative effect on fruiting body maturation (Fig. 16 and Fig. 18 lower row). In addition to the experiments described here, future studies could test whether primordia that developed under constant illumination in light to stage 4 or stage 5 will be able to complete fruiting body development when transferred back into darkness. 

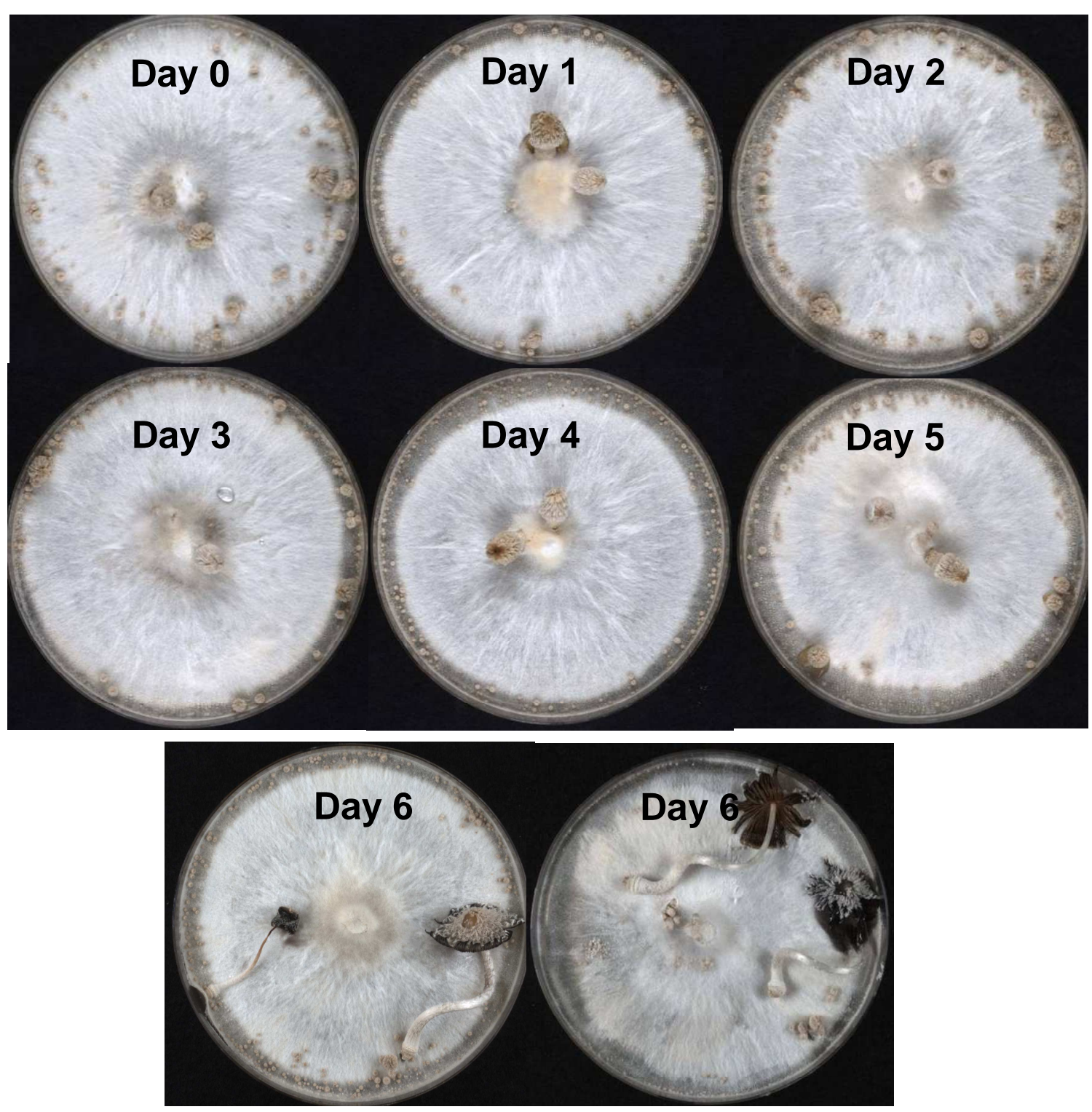

Fig. 18 Plates from the experimental set-up shown in Fig. 16 photographed at day 16 of incubation at $28^{\circ} \mathrm{C}$ (upper rows) respectively at day 7 of incubation at $28^{\circ} \mathrm{C}$ (bottom row). The number of the day indicated on the plates refer to the day of incubation at $28^{\circ} \mathrm{C}$ at which a plate was transferred into constant light illumination. Note that plates transferred before day 6 of incubation under standard fruiting conditions at $28^{\circ} \mathrm{C}$ developed only mature primordia (see upper rows) whereas on the plates transferred at day 6 of incubation into constant light illumination formed fruiting bodies that were fully developed and autolysing on day 7 of incubation at $28^{\circ} \mathrm{C}$ (see lower row). 


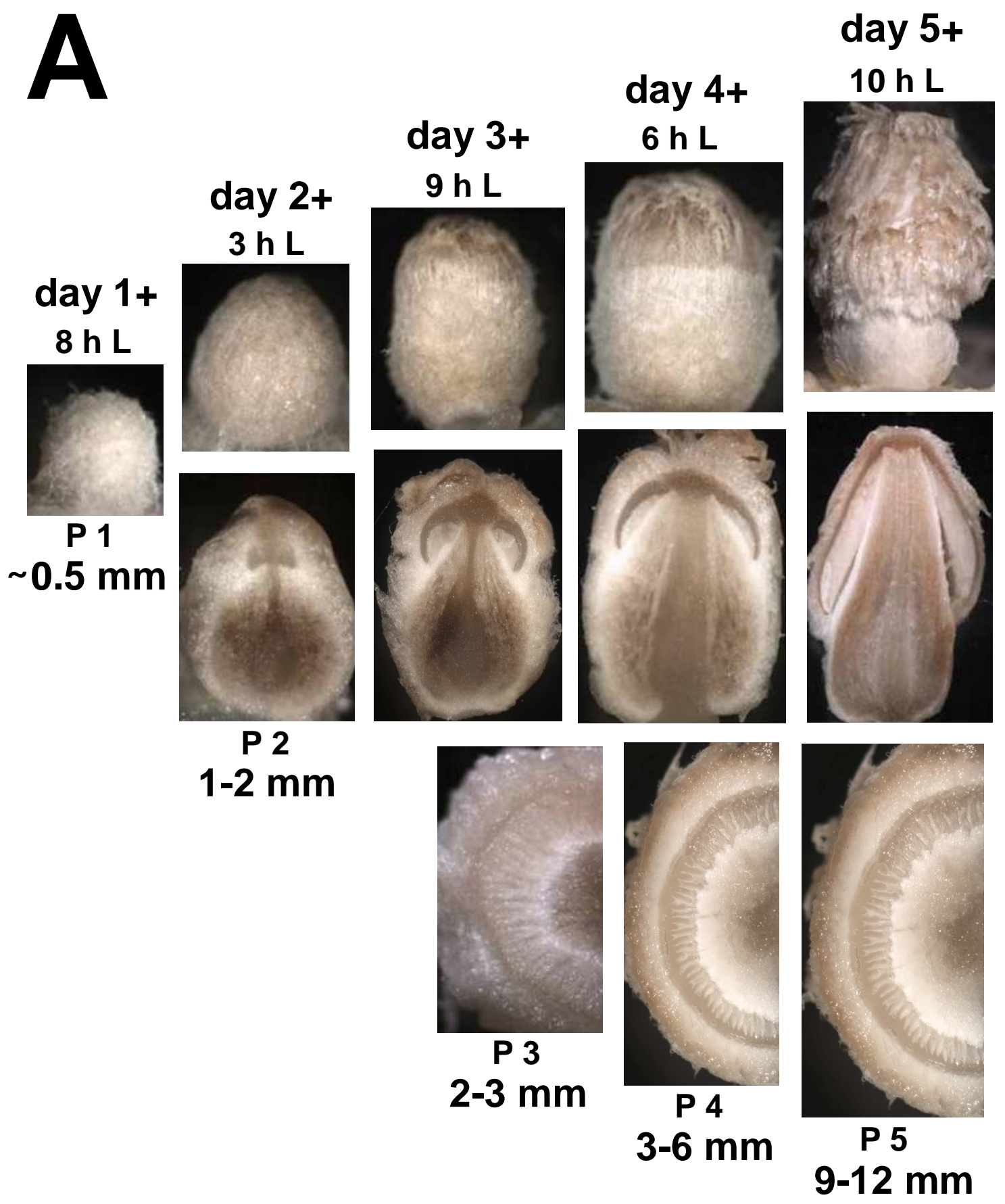

Fig. 19 Developmental progress of primordia formation in AmutBmut cultures that were transferred directly after 5 days of growth at $37^{\circ} \mathrm{C}$ into constant light at $28^{\circ} \mathrm{C}$ [transfer at day 0 of incubation at $28^{\circ} \mathrm{C}$; see (A)] and after one day incubation under standard fruiting conditions [transfer at day 1 of incubation at $28^{\circ} \mathrm{C}$; shown in (B)]. Time points of morphological analysis are given above the photos and the developmental stages reached at these time points and structure sizes below the photos. P1 to P5 denote primordia stage 1 to 4 and the mature primordium as defined in Fig. 1 ( $\mathrm{P} 5=$ mature primordium), the letter $\mathrm{L}$ the length of a light phase applied on the day of harvest before sectioning a respective structure. Note that the outer structure of the primordia (upper rows), the inner tissue distribution (middle rows) and the development of primary and secondary gills (bottom rows) are as in primordia developing under standard fruiting conditions (compare Fig.1). 


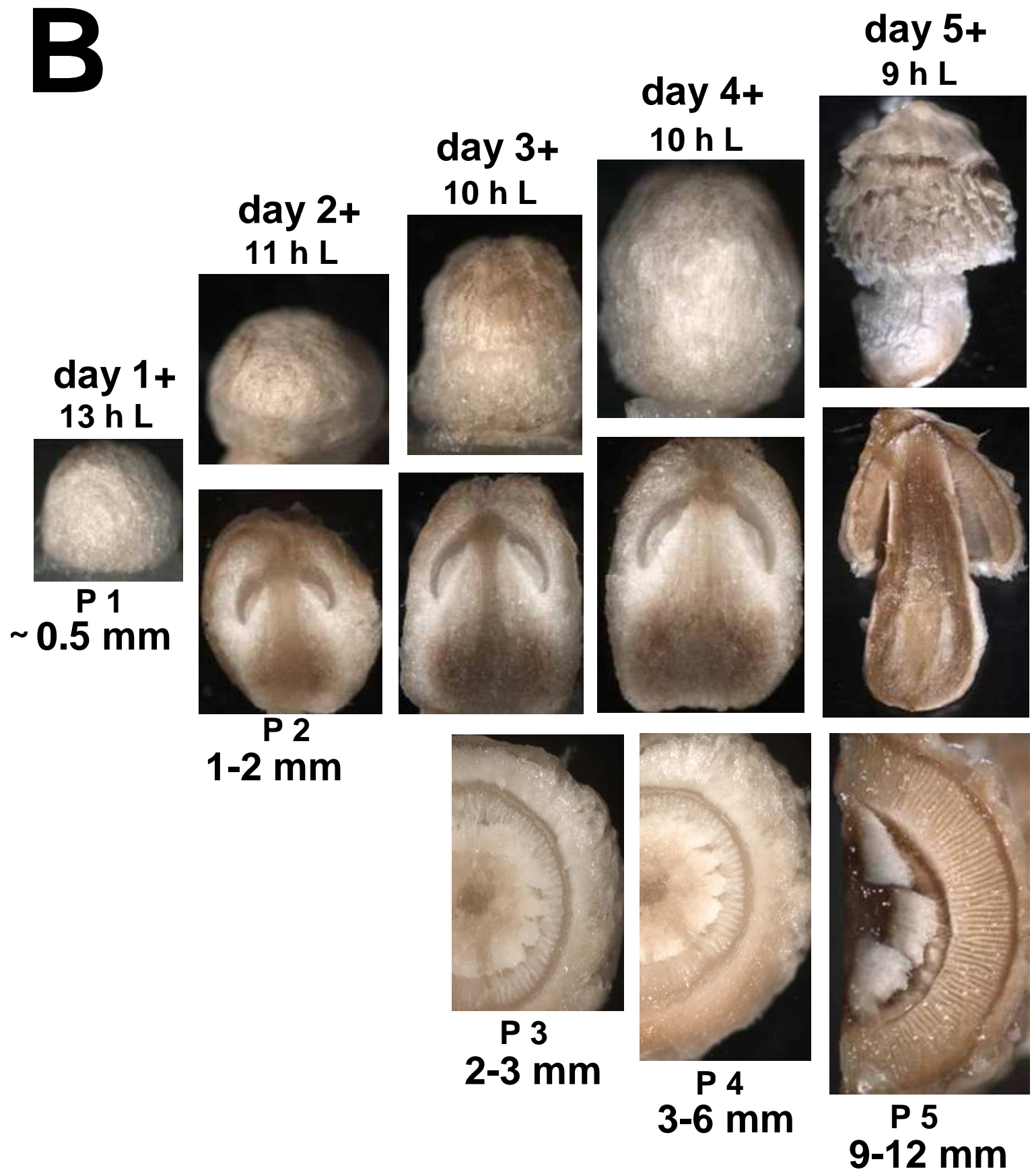

Most importantly, however note also that developmental stages occurred about 1 day earlier in this series of experiments compared to what happens under standard fruiting conditions (see Fig. 1), an effect caused by longer illumination by light noted also before by Lu (1982). This effect could have contributed to the confusion in description of time courses of fruiting body development in Coprinopsis cinerea found in the literature which makes understanding the process for readers of the literature difficult and comparisons of different reports often impossible (Kües 2000, Liu 2001, Navarro-González 2008). Finally, note that arrest in development occurred at primordia stage 5 at a time point of first slow stipe elongation (Moore et al. 1979, Liu 2001, Navarro-González 2008). 


\section{Arrest at a pre-karyogamy stage}

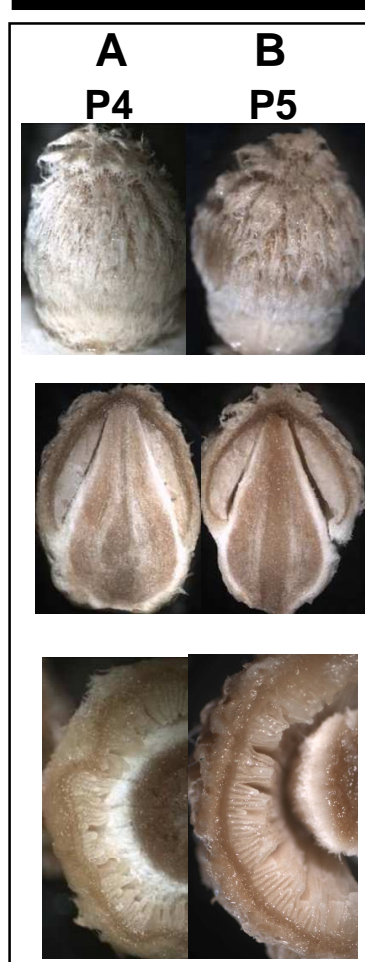

day2+3h $L$ day2+3h $L$
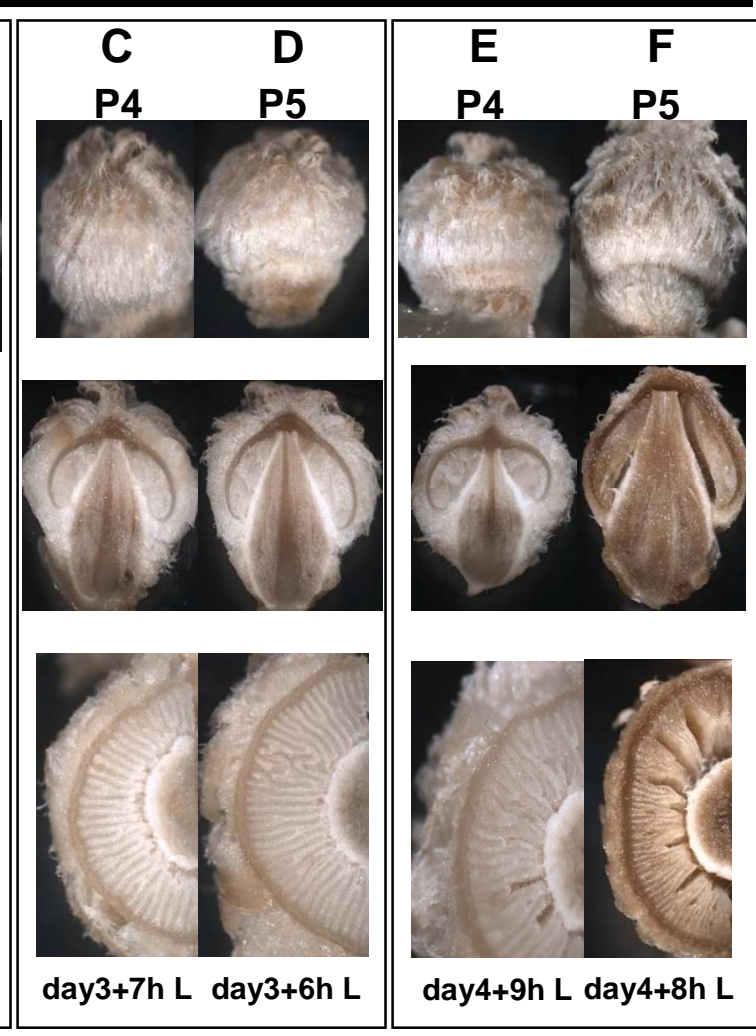

Arrest in meiosis

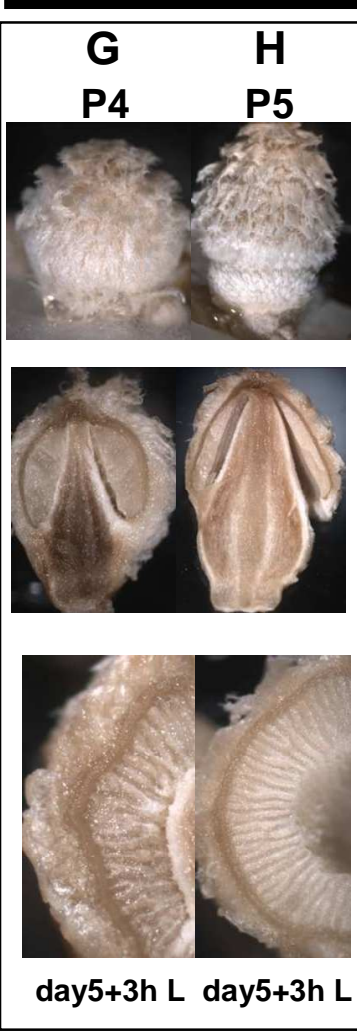

Fig. 20 Sections through primordia harvested on day 4 and day 5 of incubation at $28^{\circ} \mathrm{C}$ after transfer of fully grown AmutBmut plates from $37^{\circ} \mathrm{C}$ according to the scheme shown in Fig. 16. Sections of primordia harvested on day $4(\mathbf{A})$ and day $5(\mathbf{B})$, respectively from plates that were transferred at day 2 of incubation at $28^{\circ} \mathrm{C}$ into constant light. Sections of primordia harvested on day $4(\mathbf{C})$ and day $5(\mathbf{D})$, respectively from plates that were transferred at day 3 of incubation at $28^{\circ} \mathrm{C}$ into constant light. Sections of primordia harvested on day 4 (E) and day 5 $(\mathbf{F})$, respectively from plates that were transferred at day 4 of incubation at $28^{\circ} \mathrm{C}$ into constant light. Sections of primordia harvested on day $4(\mathbf{G})$ and day $5(\mathbf{H})$, respectively from plates that were transferred at day 5 of incubation at $28^{\circ} \mathrm{C}$ into constant light. $\mathrm{P} 4$ and $\mathrm{P} 5$ denote primordia stages 4 to 5 as defined in Fig. 1 (P5 = mature primordium), the letter $L$ the length of a light phase on the day of harvest applied before sectioning a respective structure. Note that the outer structure of the primordia (upper rows), the inner tissue distribution (middle rows) and the development of primary and secondary gills (bottom rows) are as in primordia developing under standard fruiting conditions (compare Fig. 1 and Fig. 19 A and B). Note also that arrest in development occurred at primordia stage 5 at a time point of first slow stipe elongation [see $(\mathbf{B}),(\mathbf{D})$, and $(\mathbf{F})$ ] at a time point of first slow stipe elongation by cell proliferation observed in a pre-karyogamy stage, respectively at meiois I at a stage of initial stipe elongation by cell inflammation and by first gill separation from the stipe and tearing the veil from the stipe $(\mathbf{H})$, [for more detailed description of the processes see Moore et al. 1979, Liu 2001, and Navarro-González 2008 and compare also Fig. 19]. 


\subsubsection{Growth and fruiting body development of homokaryon AmutBmut under incubation at constant light at $28^{\circ} \mathrm{C}$ and $37^{\circ} \mathrm{C}$, respectively}

When homokaryon AmutBmut was grown under constant light illumination at $28^{\circ} \mathrm{C}$, fruiting body development initiated (Fig. 21A). Small numbers of primordia (up to 10) were formed per plate but development did never complete. Primordia development arrested after secondary gill formation at primordia stage 4 (Fig. 22). This arrest is again congruent with a need of a dark phase prior to induction of karyogamy in the stage of meiotic S-phase as reported by Lu and colleagues (see above). Whether the arrest can be released by transfer into darkness at an appropriate time point directly after establishing primordia stage 4 can be tested in the future, respectively whether the long continuous

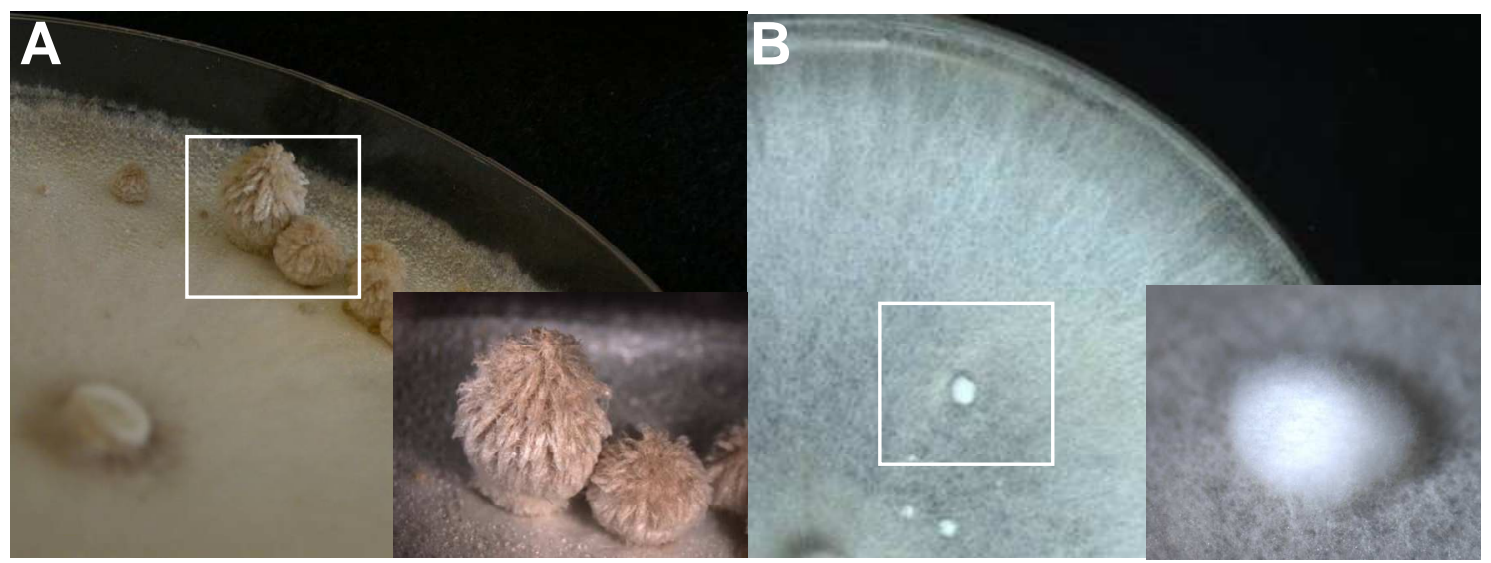

Fig. 21 Fruiting body development initiates in homokaryon AmutBmut when grown under constant light illumination at $28^{\circ} \mathrm{C}(\mathbf{A})$ but not when grown under constant light illumination at $37^{\circ} \mathrm{C}(\mathbf{B})$.

illumination by light is a too strong stress factor for the structures from which they cannot recover. The low number of primordia per plate indicates that the vegetative mycelium is sensitive to light signals but growth at $28^{\circ} \mathrm{C}$ under constant light illumination is not too favourable for fruiting since plates grown previously in the dark tend to form several hundreds of secondary hyphal knots of which an estimated 50 to 100 will start tissue differentiation for further primordia development (NavarroGonzález (2008).

When homokaryon AmutBmut was grown under constant light illumination at $37^{\circ} \mathrm{C}$, fruiting body development never initiated. However, white cottony hyphal tufts regularly appeared in the cultures (Fig. 21B). The function or importance of these 

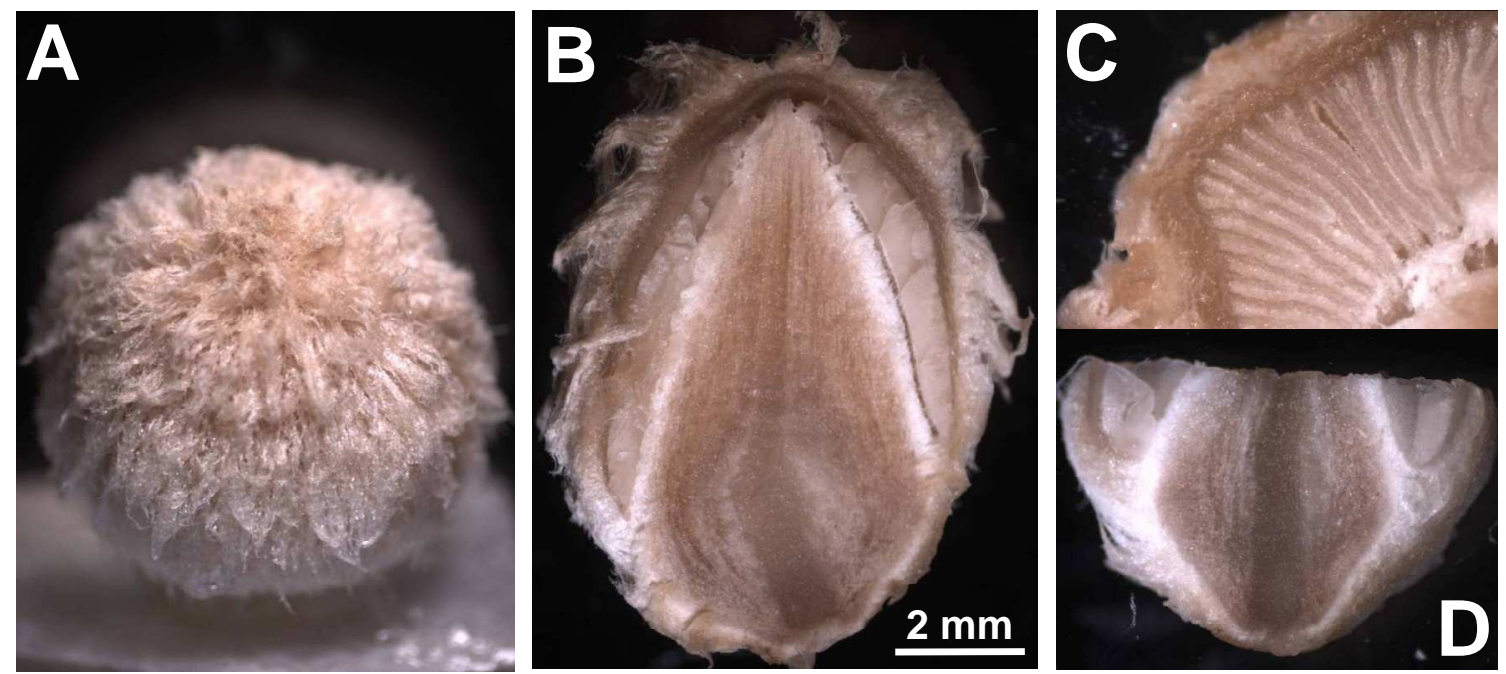

Fig. 22 Fruiting body primordia of homokaryon AmutBmut grown under constant light illumination at $28^{\circ} \mathbf{C}$. (A) View on the cap of a primordium stage 4, (B) transversal section through a primordium stage 4 showing complete cap and stipe tissue formation, (C) crosssection through the cap showing that primary and secondary gills are formed and (D) enlargement of the transversal section showing the primordial shaft.

hyphal tufts for the fungus is not known but might be considered as a kind of stress reaction. This idea is supported by observations that similar hyphal tufts appear in very old cultures of homokaryon AmutBmut but also on various monokaryons (e.g. PS002-1 which is co-isogenic to AmutBmut; see Srivilai 2006) at room temperature when the agar aged and became dry (own observations and observations by U. Kües, not further documented). Such structures occur also in cultures stressed by grazing mites (for further information see Chapter 5). 


\subsection{Conclusions}

Experiments presented in this chapter show that the process of fruiting body development in $C$. cinerea underlies a complex pattern of light and dark control. Light is needed to induce secondary hyphal knot formation but can also be a stress factor when given too much, particularly when applying at higher temperature $\left(37^{\circ} \mathrm{C}\right.$ which is an extra stress factor suppressing fruiting body initiation; Lu 1972, 1982, Kües 2000, Navarro-González 2008). Dark phases are not required to undergo most of the tissue differentiation in the primordia. However, light is needed for proper continuation of tissue formation during hyphal knot and primordia development at six different time points. If any one of these are missing, the secondary hyphal knots and the developing primordia will undergo etiolated stipe formation by outgrowth of the primordial shaft underneath the young stipe and cap tissues. Etiolated stipe formation can be interpreted as a mechanism of the fungus to search for and to grow towards a light source in order to finally obtain enough light to successfully initiate and complete fruiting body development. Later fruiting body development however needs two dark phases - one at the meiotic S-phase prior to the light-induced karyogamy and one during or shortly after meiosis I. Bringing the different light- and dark-sensitive phases together, it is obvious that the fungus adopted a control in progress of development that followed exactly the normal day-night phases as it occurs in nature. Thus, the day/night rhythm synchronizes development to finally finish with fruiting body maturation around mid-night and spore release by autolysis in the early morning hours at day 7 (compare also NavarroGonzález 2008). It is tempting to think about a connection of this time schedule with small animals, insects or mites that tend to be most active in the early morning hours before the dew will evaporate by wind blow and raising temperatures (for examples of the extensive literature on mites' and insects' activities in morning hours and in relation to environmental conditions such as humidity, wind blow and temperature e.g. see references Bergh 2001, Hemmati et al. 2001, Oliveira et al. 2006, Onzo et al. 2003, Edington et al. 2007). In this way, the fungal life cycle can connect to the life style of small mobile animals. Interrelations of $C$. cinerea and mites are described in Chapter 4. 


\section{6 References}

Bergh JC (2001) Ecology and aerobiology of dispersing citrus rust mites (Acari: Eriophyidae) in central Florida. Environ Entomol 30:318-326.

Blayney P and Marchant R (1977) Glycogen and protein inclusions in elongating stipe of Coprinus cinereus. J Gen Microb 98:467-476.

Boulianne RP, Liu Y, Aebi M, Lu BC and Kües U (2000) Fruiting body development in Coprinus cinereus: regulated expression of two galectins secreted by a nonclassical pathway. Microbiol 146:1841-1853.

Crockett DK, Lin Z, Vaughn CP, Lim MS and Elenitioba-Johnson KS (2005) Identification of proteins from formalin-fixed paraffin-embedded cells by LCMS/MS. Lab Invest 85:1405-1415.

Edgington S, Moore D, El Bouhssini M and Sayyadi Z (2007) Beauveria bassiana for the control of sunn pest (Eurygaster integriceps) (Hemiptera: Scutelleridae) and aspects of the insect's daily activity relevant to a mycoinsecticide. Bioc Sci Tech 17:63-79.

Elliott CG (1994) Reproduction in fungi. Genetical and physiological aspects. Chapman and Hall, London, UK, pp. 5-36.

Granado JD, Kertesz-Chaloupková K, Aebi M and Kües U (1997) Restriction enzymemediated DNA intergration in Coprinus cinereus. Mol Gen Genet 256:28-36.

Hemmati F, Pell JK, McCartney HA and Deadman ML (2001) Airborne concentrations of conidia of Erynia neoaphidis above ceral fields. Mycol Res 105:485-489. Iten W (1970) Zur Funktion hydrolytischer Enzyme bei der Autolyse von Coprinus. Ber Schweiz Bot Ges 79:175-198.

Iten W and Matile P (1970) Role of chitinase and other lysosomal enzymes of Coprinus lagopus in the autolysis of fruiting bodies. J Gen Microbiol 61:301-309.

Kamada T and Tsuji M (1979) Darkness-induced factor affecting basidiocarp maturation in Coprinus macrorhizus. Plant Cell Physiol 20:1445-1448.

Kamada T, Kurita R and Takemaru T (1978) Effects of light on basidiocarp maturation in Coprinus macrorhizus. Plant Cell Physiol 19:263-275.

Kertesz-Chaloupková K, Walter PJ, Granado JD, Aebi M and Kües U (1998) Blue light overrides repression of asexual sporulation by mating type genes in the basidiomycete Coprinus cinereus. Fungal Genet Biol 23:95-109. 
Kües U (2000) Life history and developmental processs in the basidiomycete Coprinus cinereus. Microbiol Mol Biol Rev 64:316-353.

Kües U, Granado JD, Hermann R, Boulianne RP, Kertesz-Chaloupková K and Aebi M (1998) The $A$ mating type and blue light regulate all known differentiation processes in the basidiomycete Coprinopsis cinereus. Mol Gen Genet 260:81-91.

Kües U, Künzler M, Bottoli APF, Walser PJ, Granado JD, Liu Y, Bertossa RC, Ciardo D, Clergeot P-H, Loos S, Ruprich-Robert G and Aebi M (2004) Mushroom development in higher basidiomycetes. Implications for human and animal health. In: Fungi in human and animal health (RKS Kushwaha, ed.), Scientific Publishers, Jodhpur, India, pp. 431-470.

Kües U, Navarro-González M, Srivilai P, Chaisaena W and Velagapudi R (2007) Mushroom biology and genetics. In: Wood production, wood technology and biotechnological impacts (U Kües, ed.), Universitätsverlag, Göttingen, Germany, pp. 396-414.

Kües U, Polak E, Bottoli APF, Hollenstein M, Walser PJ, Boulianne RP, Hermann R and Aebi M (2002a) Vegetative development in Coprinus cinereus. In: Mol Biol Fungal Devel (HD Osiewacz, ed.), Marcel Dekker, New York, USA, pp. 133-164.

Kües U, Walser P, Klaus M and Aebi M (2002b) Influence of activated $A$ and $B$ mating type pathways on developmental processes in the basidiomycete Coprinus cinereus. Mol Gen Genom 268:262-271.

Liu L, Tewari RP and Williamson PR (1999a) Laccase protects Cryptococcus neoformans from antifungal activity of alveolar macrophages. Infect Immun 67:6034-6039.

Liu Y (2001) Fruiting body initiation in the basidiomycete Coprinus cinereus. PhD thesis, University of ETH Zurich, Zurich, Switzerland.

Liu Y, Granado JD, Polak E and Kües U (1999b) Genetic crosses with Amut Bmut homokaryons of Coprinus cinereus. Fungal Genet Newsl 46:16-20.

Liu Y, Srivilai P, Loos S, Aebi M and Kües U (2006) An essential gene for fruiting body initiation in the basidiomycete Coprinopsis cinerea is homologous to bacterial cyclopropane fatty acid synthase genes. Genetics 172:873-884.

Lu BC (1972) Dark dependence of meiosis at elevated temperatures in the basidiomycete Coprinus cinereus. J Bacteriol 111:833-834. 
Lu BC (1974) Meiosis in Coprinus. V. The role of light on basidiocarp initiation, mitosis and hymenium differentiation in Coprinus lagopus. Can $\mathrm{J}$ Bot 52:299-305.

Lu BC (1982) Replication of deoxyribonucleic acid and crossing over in Coprinus. In: Basidium and basidiocarp. Evolution, cytology, function and development (K Wells and EK Wells, eds.), Springer-Verlag, New York, NY, pp. 93-112.

Lu BC (2000) The control of meiosis progression in the fungus Coprinus cinereus by light/dark cycles. Fungal Genet Biol 31:33-41.

Lu BC and Jeng DY(1975) Meiosis in Coprinus. VII The prekaryogrammy S-phase and the postkaryogammy DNA replication in C. lagopus. J Cell Sci 17:461-470. Matthews TR and Niederpruem DJ (1972) Differentiation in Coprinus lagopus. I. Control of fruiting and cytology of initial events. Arch Mikrobiol 87:257-268.

May G, Le Chevanton L and Pukkila PJ (1991) Molecular analysis of the Coprinus cinereus mating type $A$ factor demonstarated an unexpectedly complex structure. Genetics 128:529-538.

Moore D (1998) Fungal morphogenesis. Cambridge University Press, Cambridge, UK, pp. 1-469.

Moore D, Elhiti MMY and Butler RD (1979) Morphogenesis of the carpophore of Coprinus cinereus. New Phytol 66:377-382.

Morimoto N and Oda Y (1973) Effects of light on fruit-body formation in a basidiomycete, Coprinus macrorhizus. Plant Cell Physiol 14:217-225.

Navarro-González M (2008) Growth fruiting body development and laccase production of selected coprini. PhD thesis. Georg-August University of Göttingen, Göttingen, Germany.

Oliveira CRF, Faroni LRA, Guedes RNC, Pallini A and Gonçalves JR (2006) Parasitism of the mite Acarophenax lacunatus on Tribolium castaneum. Pesq Agropec Bras 41:1059-1061.

Onzo A, Hanna R, Zannou I, Sabelis MW and Yaninek JS (2003) Dynamics of refuge use: diurnal, vertical migration by predatory and herbivorous mites within cassava plants. Oikos 101:59-69.

Srivilai P (2006) Molecular analysis of genes acting in fruiting body development in basidiomycetes. PhD thesis. Georg-August University of Göttingen, Göttingen, Germany. 
Swamy S, Uno I and Ishikawa T (1984) Morphogenic effects of mutations at the $A$ and $B$ inconpatability factors in Coprinopsis cinereus. J Gen Microbiol 130: 3219-3224.

Terashima K, Yuki K, Muraguchi H, Akiyama M and Kamada T (2005) The dst1 gene involved in mushroom photomorphogenesis of Coprinus cinereus encodes a putative photoreceptor for blue light. Genetics 171:101-108.

Tsusué YM (1969) Experimental control of fruit-body formation in Coprinus macrorhizus. Dev Growth Differ 11:164-178.

Velagapudi R (2006) Extracellular matrix proteins in growth and fruiting body development of straw and wood degrading basidiomycetes. PhD thesis, GeorgAugust University of Göttingen, Göttingen, Germany.

Walser PJ, Hollenstein M, Klaus MJ and Kües U (2001) Genetic analysis of basidiomycete fungi. In: Molecular and cell biology of filamentous fungi: A practical approach (NJ Talbot, ed.), Practical Approach Series, IRL Press, Oxford, England, pp. 59-90.

Walser PJ, Velagapudi R, Aebi M and Kües U (2003) Extracellular matrix proteins in mushroom development. Recent Res Devel Microbiol 7:381-415. 


\section{Defects in light-regulation of development in the basidiomycete Coprinopsis cinerea}

* This work is dedicated to the memory of Katharina Kertesz-Chaloupková. Without her, mutant 7K17 would not have been identified.

I am very thankful to Dr. Prayook Srivilai`s contribution of his suggestion and training me the basic laboratory techniques in genetic of Coprinopsis cinerea. I wish to thank Martin Rühl for his kind discussion on how to analyse the number of oidias with a heamatocytometer. 


\subsection{Abstract}

Coprinopsis cinerea is an excellent model fungus to study fruiting body development in the higher basidiomycetes. Due to specific mutations in their mating type genes, self-fertile homokaryons such as strain AmutBmut (A43mut, B43mut) exist in which recessive mutations in the pathway of fruiting body development can be studied. Homokaryon AmutBmut initiates and completes fruiting body development in the normal day/night rhythm at temperatures around $28^{\circ} \mathrm{C}$ (standard fruiting conditions). Light as well as defined dark phases are very important regulators for an accurate proceeding in the pathway of fruiting body development including karyogamy, meiosis and basidiospore formation. As described in Chapter 2 of this thesis, when light is missing, normal cap and stipe tissue development arrests in the wild-type homokaryon AmutBmut in favour of formation of etiolated stipes, also called dark stipes. Here, four mutant genes are presented in which recessive defects cause in A43mut, B43mut mutant homokaryons production of etiolated stipes under normal fruiting conditions. The four analyzed defects occurred in four different genes that react at different time points in the progress of fruiting body development: genes $d s t 1$ and $d s t 2$ are early acting at the stages of hyphal knot formation up to formation of young primordia (primordia stage 1) whereas genes $d s t 3$ and $d s t 4$ act later in development at primordia stages 3 and 4, respectively. Cross-sections through matured etiolated stipe showed that gill development in $d s t 3$ and $d s t 4$ mutants was generally more advanced than that in $d s t-1$ and $d s t-2$ mutants. Unlike genes $d s t 3$ and $d s t 4$, gene $d s t 1$ and particularly gene $d s t 2$ cause pleiotrophic effects also on various other light-regulated phenotypes, such as production of asexual spores (oidia) and production of sclerotia, which are multicellular pigmented resting structures. A43mut, B43mut homokaryons co-isogenic to the wildtype homokaryon AmutBmut were created with each one of the four $d s t$ defects to study further the effects by these genes in best defined conditions.

Key words: Coprinopsis cinerea, fruiting body development, etiolated stipes, dark stipes, mutants, $d s t$ genes, co-isogenic self-fertile homokaryons, asexual spore, sclerotia, day/night rhythm 


\subsection{Introduction}

Coprinopsis cinerea is used as a model organism to study fruiting body development in the homobasidiomycete fungi. C. cinerea is a heterothallic species with two distinct types of mycelia alternating in its life cycle, i.e. the infertile monokaryon and the fertile dikaryon (Kües 2000). Monokaryons germinate from haploid binucleate basidiospores, the sexual spores forming in the fruiting bodies, or from the uninucleate haploid oidia, vegetative spores arising on aerial hyphae of vegetative mycelium (Kertesz-Chaloupková et al. 1998, Kües 2000). Dikaryons form by fusion of two compatible monokaryons. Mating between two monokaryons is controlled by the two mating type loci $A$ and $B$. For a compatible mating, two monokaryons need to have different alleles at both loci (Casselton and Olesnicki 1998, Casselton and Kües 2007).

Little is know about regulation of production of the asexual oidia. The monokaryon produces oidia in high numbers independently of light (Brodie 1931), whereas in dikaryons, blue light induces oidia production (Kertesz-Chaloupková et al. 1998). Similarly to the dikaryons, homokaryons being self-compatible by mutations in the mating type loci (Amut, Bmut) do not form notable numbers of spores in the dark but upon light induction high numbers of oidia arise in the aerial mycelium. The products of the $A$ mating type locus are responsible for the repression of oidia formation in the dark (Kertesz-Chaloupková et al. 1998, Kües et al. 1998, 2000). As dikaryons, such Amut Bmut homokaryons are also able to perform the sexual cycle with fruiting bodies in which karyogamy, meiosis and basidiospore development takes place (Swamy et al. 1984).

Fruiting body development of $C$. cinerea is a process involving various hyphalhyphal (cell-cell) interactions and it occurs as response of the mycelium to environmental conditions such as light, temperature, humidity and depletion of nutrients (Moore 1998, Kües 2000). The process of fruiting body development is adapted to the day-night rhythm. Both, the dark and the light periods are necessary for development to proceed in the correct manner. Neither in constant light nor in constant dark, fruiting bodies will develop. The process appears to start with minute loose hyphal aggregates, primary hyphal knots that develop on the mycelium of homokaryons and dikaryons in the dark. These primary hyphal knots will transform into sclerotia, small compact bodies with a melanized rind serving for duration, when cultures are further kept in the dark (Moore 1981, Boulianne et al. 2000, Kües et al. 1998). Upon a light signal, overnight somewhat larger secondary hyphal knots $(0.5 \mathrm{~mm}$ in diameter) (Muraguchi 
and Kamada 1998) are generated but normally only in the dikaryons. Within these fruiting body initials, tissue development for cap and stipe structures initiates to give rise to fruiting body primordia. This process takes at least three days till tissues are fully established (Boulianne et al. 2000, Kües 2000, Walser et al. 2003) but this was up till recently only poorly described (Buller 1910, Moore et al. 1979). Under proper light and dark conditions, some steps in tissue formation and differentiation within primordia to obtain the mature fruiting bodies have been described by Buller (1910), Matthews and Niederpruem (1973), Reijnders (1979), and Moore and co-workers (1979, 1998). Picture catalogs over the whole series of the events in fruiting body development were now given by Navarro-González (2008) and in Chapter 2 of this thesis for the homokaryon AmutBmut that mimics a dikaryon by defects in the two mating type loci.

From transfer experiments of cultures from a typical day-night rhythm into constant dark it has been shown before that cap tissue and normal stipe development arrests in the dark. Instead, long structures are formed obviously from tissue proliferation in the lower stipe area, the primordial shaft (Terashima et al. 2005, Chapter 2 of this thesis). These structures with elongated shafts and rudimentary stipes and pileus are variously referred to as dark-stipes (Tsusué 1969, Muraguchi and Kamada 1998) or etiolated stipes (Borriss 1934, Elliott 1994). Etiolated stipes will be formed when either cultures that had a light signal for induction of secondary hyphal knot formation, or cultures that had a light signal for regulation in tissue differentiation in secondary hyphal knots or in primordia stage 1 to stage 3 or in cultures that had a light signal to induce karyogamy in primordia stage 4 were transferred into constant dark (compare Chapter 2 of this thesis ). This later step in fruiting body development is thus also under light control. Once a fruiting body primordium is fully established with gills and on the gills the basidia at day 4 of development, a light signal is required to induce karyogamy without, the primordia eventually abort (see also Lu 1974, Kamada et al. 1978, Chapter 2 of this thesis). In the normal fruiting body pathway, parallel to karyogamy, directly or indirectly dependent on light, the stipe slowly begins to elongate and the cap to open (Borriss 1934, Cox and Niederpruem 1975, Gooday 1974, Gruen 1982, Kamada 1994, Navarro-González 2008). Transfer of cultures into constant dark that had a light signal to continue development in primordia stage 5 has no further consequence and the structures will undergo normal stipe development up to fruiting body maturation (Chapter 2 of this thesis). 
Further light signals control the progress of meiosis that follows directly upon karyogamy. Light can delay development of basidiospore formation ( $\mathrm{Lu}$ and Jeng 1975, Miyake et al. 1980) although there are strain-specific differences (Lu 2000). Subsequent basidiospore production occurs in the dark whilst stipes rapidly elongate and the cap expands to give a fully developed mushroom in the middle of a night period (Hammad et al. 1993, Kamada et al. 1976). However, if cultures are kept in constant light at this stage, fruiting body development and basidiospore formation will also complete (Chapter 2 of this thesis).

A few mutants in light control have been described in $C$. cinerea that form etiolated stipes in constant light. Mutants were obtained either by conventional UV or chemical mutagenesis or by modern REMI (restriction enzyme-mediated integration, a technique involving transformation to integrate plasmids into a genome at places opened up by the action of externally added restriction enzymes). Mutations described by Japanese researchers occurred in two independent genes ( $d s t 1$ and $d s t 2 ; d s t=$ dark stipe). Gene $d s t 1$ has been cloned and found to encode a protein related to the white-collar I type of blue light photoreceptors (Terashima et al. 2005). Using strain AmutBmut, the above mentioned homokaryon with defects in the two mating type loci, Kües et al. generated a mutant collection in fruiting body development (Granado et al. 1997, Kües, Granado and Aebi, unpublished). Two mutants were detected with an etiolated stipe-phenotype, one created by conventional UV mutagenesis and one by REMI (Liu et al. 1999). A preliminary comparison of these mutants with strains defective in dst1 or $d s t 2$ suggested them to contain mutations in other genes (T. Kamada, personal communication). Here, we analyse the effect of these mutations on light regulation and sexual and asexual morphological processes in comparison to the wild type and to the effects of mutations in genes $d s t 1$ and $d s t 2$.

\subsection{Materials and methods}

\subsubsection{Strains and culture conditions}

All strains used in this study are listed for a quick overview in Table 1. 
Table 1 List of Coprinopsis cinerea strains used in this study

\begin{tabular}{|c|c|c|c|}
\hline Strain & Genotype & $\begin{array}{l}\text { Type of mycelium, } \\
\text { mutagenesis }\end{array}$ & Source/reference \\
\hline R1428F1\#74 & $A 8, B 7, d s t 1-2$ & $\begin{array}{l}\text { monokaryon, progeny of } \\
\text { REMI-mutant R1428 x } 5337\end{array}$ & $\begin{array}{l}\text { Terashima et al. } \\
(2005) ; \text { T. Kamada }\end{array}$ \\
\hline H1-1280F1\#5 & A91, B92, dst2-1 & $\begin{array}{l}\text { monokaryon, progeny of REMI } \\
\text { mutant H1-1280 x KF2\#1 }\end{array}$ & $\begin{array}{l}\text { Terashima et al. } \\
\text { (2005); T. Kamada }\end{array}$ \\
\hline $7 \mathrm{~K} 17$ & $\begin{array}{l}\text { A43mut, B43mut, } \\
\text { pab1-1, dst } 3-1\end{array}$ & $\begin{array}{l}\text { self-compatible AmutBmut } \\
\text { mutant obtained by UV } \\
\text { mutagenesis }\end{array}$ & $\begin{array}{l}\text { Granado et al. } \\
\text { unpublished; } \\
\text { K. Kertesz- } \\
\text { Chaloupková }\end{array}$ \\
\hline B-1918 & $\begin{array}{l}\text { A43mut, B43mut, } \\
\text { pab1-1, ::pab1 } \\
\text { dst4-1 }\end{array}$ & $\begin{array}{l}\text { self-compatible AmutBmut } \\
\text { mutant obtained by REMI } \\
\text { mutagenesis }\end{array}$ & $\begin{array}{l}\text { Liu et al. (1999); } \\
\text { JD. Granado }\end{array}$ \\
\hline AmutBmut & $\begin{array}{l}\text { A43mut, B43mut, } \\
\text { pabl }\end{array}$ & self-compatible homokaryon & $\begin{array}{l}\text { Swamy et al. (1984); } \\
\text { P. Pukkila }\end{array}$ \\
\hline Okayama 7 & $A 43, B 43$ & monokaryon & $\begin{array}{l}\text { May et al. (1991); } \\
\text { P. Pukkila }\end{array}$ \\
\hline GAU1 & $A 42, B 42, p a b l-2$ & $\begin{array}{l}\text { monokaryon co-isogenic to } \\
\text { homokaryon AmutBmut }\end{array}$ & Srivilai (2006) \\
\hline PS001-1 & $A 42, B 42$ & $\begin{array}{l}\text { monokaryon co-isogenic to } \\
\text { homokaryon AmutBmut }\end{array}$ & Srivilai (2006) \\
\hline PS002-1 & $A 3, B 1$ & $\begin{array}{l}\text { monokaryon co-isogenic to } \\
\text { homokaryon AmutBmut }\end{array}$ & Srivilai (2006) \\
\hline PUK1 & $\begin{array}{l}\text { A43mut, B43mut, } \\
\text { pab1-1, dst1-2 }\end{array}$ & self-compatible homokaryon & this study \\
\hline PUK1-2 & $\begin{array}{l}\text { A43mut, B43mut, } \\
\text { pab1-1, dst1-2 }\end{array}$ & $\begin{array}{l}\text { self-compatible homokaryon } \\
\text { co-isogenic to AmutBmut }\end{array}$ & this study \\
\hline PUK1-4 & $\begin{array}{l}\text { A43mut, B43mut, } \\
\text { pab1-1, dst1-2 }\end{array}$ & $\begin{array}{l}\text { self-compatible homokaryon } \\
\text { co-isogenic to AmutBmut }\end{array}$ & this study \\
\hline PUK1-6 & $\begin{array}{l}\text { A43mut, B43mut, } \\
\text { pab1-1, dst1-2 }\end{array}$ & $\begin{array}{l}\text { self-compatible homokaryon } \\
\text { co-isogenic to AmutBmut }\end{array}$ & this study \\
\hline PUK2 & $\begin{array}{l}\text { A43mut, B43mut, } \\
\text { pab1-1,dst2-1 }\end{array}$ & self-compatible homokaryon & this study \\
\hline PUK2-2 & $\begin{array}{l}\text { A43mut, B43mut, } \\
\text { pab1-1,dst2-1 }\end{array}$ & $\begin{array}{l}\text { self-compatible homokaryon } \\
\text { co-isogenic to AmutBmut }\end{array}$ & this study \\
\hline PUK2-3 & $\begin{array}{l}\text { A43mut, B43mut, } \\
\text { pab1-1, dst2-1 }\end{array}$ & $\begin{array}{l}\text { self-compatible homokaryon } \\
\text { co-isogenic to AmutBmut }\end{array}$ & this study \\
\hline PUK2-6 & $\begin{array}{l}\text { A43mut, B43mut, } \\
\text { pab1-1, dst2-1 }\end{array}$ & $\begin{array}{l}\text { self-compatible homokaryon } \\
\text { co-isogenic to AmutBmut }\end{array}$ & this study \\
\hline PUK3 & $\begin{array}{l}\text { A43mut, B43mut, } \\
\text { pab1-1, dst3-1 }\end{array}$ & $\begin{array}{l}\text { self-compatible homokaryon } \\
\text { co-isogenic to AmutBmut }\end{array}$ & this study \\
\hline PUK4 & $\begin{array}{l}\text { A43mut, B43mut, } \\
\text { pab1-1, dst4-1 }\end{array}$ & $\begin{array}{l}\text { self-compatible homokaryon } \\
\text { co-isogenic to AmutBmut }\end{array}$ & this study \\
\hline
\end{tabular}


C. cinerea strain AmutBmut (A43mut, B43mut, pab1) is a self-compatible homokaryon that forms fruiting bodies without prior mating to another strain and produces oidia in a light-regulated manner (Swamy et al.1984, May et al. 1991, Kertesz-Chaloupková et al. 1998). Mutant B-1918 (A43mut, B43mut, pabl, ::pab1 ${ }^{+}$) is a BamHI REMI-mutant of homokaryon AmutBmut (Granado et al. 1997, Liu et al. 1999), mutant 7K17 (A43mut, B43mut, pab1) an UV-mutant of homokaryon AmutBmut (Liu et al. 1999, Granado et al., unpublished), GAU1 (A42, B42, pab1-2), PS001-1 (A42, B42) and PS002-1 (A3, B1) are co-isogenic monokaryons to homokaryon AmutBmut (Srivilai 2006), monokaryons R1428F1\#74 (A8, B7, dst1-2) and H1-1280F1\#5 (A91, B92, dst2-1) were kindly provided by T. Kamada (Terashima et. al 2005) and monokaryon Okayama 7 (May et al. 1991) by P. Pukkila. Strains newly constructed in this work by crosses described in the results section are PUK1 (A43mut, B43mut, pab1-1, dst1-2) and PUK2 (A43mut, B43mut, pab1-1, dst2-1) came from the F1 generation of the crosses R1428F1\#74 x AmutBmut and H1-1280F1\#5. PUK1-2 (A43mut, B43mut, pab1-1, dst12), PUK1-4 (A43mut, B43mut, pab1-1, dst1-2), PUK1-6 (A43mut, B43mut, pab1-1, dst1-2) are strains related to homokaryon AmutBmut and were obtained in a co-isogenisation process with monokaryon PS00-1 of crosses F2, F4 and F6. Similarly, PUK2-2 (A43mut, B43mut, pab1-1, dst2-1), PUK2-3 (A43mut, B43mut, pab1-1, dst2-1) and PUK2-6 (A43mut, B43mut, pab1-1, dst2-1) were produced in a co-isogenisation process by backcrossing to monokaryon PS00-2. PUK3 (A43mut, B43mut, pab1-1, dst3-1) and PUK4 (A43mut, B43mut, pab1-1, dst4-11) are also co-isogenic strains to homokaryon AmutBmut. All the strains of the PUK-series are self-compatible homokaryons with defects in the mating type genes that as homokaryon AmutBmut can still mate like normal monokaryons with strains of other mating type specificity (Swamy et al. 1984).

Strains were routinely grown at $37^{\circ} \mathrm{C}$ on $\mathrm{YMG} / \mathrm{T}$ complete medium with agar from Serva (Heidelberg, Germany) or on minimal medium MM in ventilated black boxes sized 27x37x13 cm (Granado et al. 1997). Mycelial growth rates were determined by inoculating mycelial pieces in the middle of agar plates and measuring every day the increase of the colony radius at 8 different positions on the growing colonies by determining the distance from the middle of the inoculum to the edge of the colony. Daily increase was calculated by subtracting the values from day 2 from the values from day 5 and dividing the result by 3 for the number of days considered. Averages with standard deviations were calculated from the 8 different values obtained. 
Matings were performed at $37^{\circ} \mathrm{C}$ according to Walser et al. (2001) by placing two agar plugs (ca. $4 \times 4 \mathrm{~mm}$ ) with mycelium of two different strains in close vicinity in the middle of $9 \mathrm{~cm} \varnothing$ Petri-dishes onto agar (usually YMG/T medium). The formation of the dikaryon in a genetic cross typically results in vigorous growth from the margins of the paired monokaryons with clamp cells formed at the outgrowing hyphae (Casselton and Olesnicky 1998, Kües 2000, Walser et al. 2001). Accordingly, clamp cell formation was observed under a light microscope (Axioplan 2 imaging, Carl Zeiss, Göttingen, Germany) with squeezed agar samples with mycelium from the margin of the colonies.

For testing fruiting abilities, strains were cultivated for 5 days at $37^{\circ} \mathrm{C}$ in the dark before transferring the plates into standard fruiting conditions at a high humidity (about

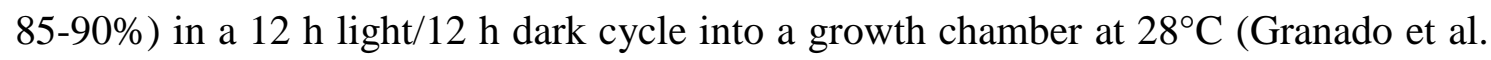
1997). The light sources were in all instances Osram L36W67 white fluorescent tubes covering also the effective blue light range (Kertesz-Chaloupková et al. 1997, Kües et al. 1998) and plates obtained in all cases light intensities of $30-40 \mu \mathrm{E} \mathrm{m} \mathrm{m}^{-1}$. As indicated in the results section, in some instances fruiting body development was observed on cultures grown directly after inoculation at $28^{\circ} \mathrm{C}$ in a $12 \mathrm{~h} \mathrm{light} / 12 \mathrm{~d}$ rhythm under $85-90 \%$ humidity and a light intensity of $30-40 \mu \mathrm{E} \mathrm{m}^{-2} \mathrm{~s}^{-1}$.

Basidiospores were harvested by placing fruiting body caps into sterile $1.5 \mathrm{ml}$ Eppendorf-tubes filled with $1 \mathrm{ml}$ sterile $\mathrm{H}_{2} \mathrm{O}$. The numbers of basidiospores per fruiting body cap were determined with a hematocytometer (type Thoma-chamber: $0.100 \mathrm{~mm}$ in deepness and $0.0025 \mathrm{~mm}^{2}$ per 1 small square of the hematocytometer counting area). Appropriate dilutions of the resulting spore suspension (about $10^{3}$ to $10^{4}$ spores $/ \mathrm{ml}$ ) were plated onto YMG/T or MM agar for germination at $37^{\circ} \mathrm{C}$ in the dark. After 2 days of incubation, germinated colonies were transferred onto fresh agar plates for further cultivation at $37^{\circ} \mathrm{C}$ in the dark. If required, auxotrophies of germinated clones were tested by growing them on MM agar plates. Mutant mating types of clones were detected through microscopy in order to detect the A43mut phenotype formation of clamp cells or the A43mut, B43mut phenotype formation of fused clamp cells (KerteszChaloupková et al. 1998, Kües et al. 1998). Wildtype mating type specificities were determined by crosses with appropriate strains of different mating types. Strains carrying a wild type $A$ mating type locus and the B43mut mutant locus were detected through crossings with monokaryon Okayama 7 possessing the wildtype $B 43$ specificity from which B43mut was originally obtained (Swamy et al. 1984, May et al. 1991) such strains were recognised by the fact that the $B 43 m u t$ mutation does not lead to a perfect 
look of a dikaryon with fused clamp cells at every septum and that the $B$-mating-typecontrolled phenotypes nuclear exchange and migration through the mating partner will not or, if, only poorly occur (Swamy et al. 1984, Kertesz-Chaloupková et al. 1998, Kües et al. 2001, P. Srivilai and U. Kües, unpublished observations).

Formation of etiolated stipes was observed under standard fruiting conditions (Granado et al. 1997, see Chapter 2 of this thesis) usually with the upper face of the Petri-dish (lid) localized to the top. In some experiments, Petri-dishes with etiolated stipes were turned up-side down for further incubation for 7 days at $28^{\circ} \mathrm{C}$ under standard fruiting conditions.

Presence of sclerotia, dark-pigmented (melanized) round, compact resting bodies about 0.1-0.2 mm in size (Kües et al. 1998, 2001; see also Chapter 4 of this thesis) were observed under different cultivation conditions (on YMG/T at $37^{\circ} \mathrm{C}$ in constant dark and in constant light) 25 days after inoculation of strains. For estimates of numbers of sclerotia per plate, a pie slice corresponding to an eighth of the overall surface was observed at two different places (at the outside of the plate $3.0 \mathrm{~cm}$ apart from the centre of the pie slice, and at the inside of the plate $1.5 \mathrm{~cm}$ apart from the centre). The two different places represented each a circle of $0.5 \mathrm{~mm}$ in $\varnothing$ under a binocular (Stemi 2000-C binocular, Carl Zeiss, Göttingen, Germany) in which all sclerotia present were counted. Differentiation in two circles was done since in most cultures, the density of sclerotia was very high at the outer edges of colonies and the density of sclerotia decreased dramatically with decreasing distance to the centre of the plate. From the numbers of sclerotia calculated in the small observed circles, total numbers per complete outer and per complete inner mycelia rings corresponding to the width and positions of the small observed circles on the Petri-dishes were calculated. Per analyzed strain, 5 replications were done and average values with standard deviations calculated.

Oidia formation in the aerial vegetative mycelium by mutants with $d s t$ defects were tested according to Kertesz- Chaloupková et al. (1998), Clones were grown on YMG/T at $37^{\circ} \mathrm{C}$ in constant dark. After 5 days of incubation, one set of fully grown plates (5 per each clone) were further incubated at $37^{\circ} \mathrm{C}$ in constant dark whereas a parallel set of fully grown plates ( 5 per each clone) was transferred for 4 days into constant light (light intensity of $\left.20-25 \mu \mathrm{E} \mathrm{m}^{-2} \mathrm{~s}^{-1}\right)$. Subsequently, the asexual spores from the aerial mycelium were scraped with a spatular from the agar surface into $10 \mathrm{ml}$ of sterile $\mathrm{H}_{2} \mathrm{O}$. Oidia were separated from mycelial fragment by filtration through glass wool placed in a bell shaped funnel. The number of oidia in the solution was then determined with a 
hematocytometer (type Thoma-chamber: $0.100 \mathrm{~mm}$ in deepness and $0.0025 \mathrm{~mm}^{2}$ per 1 small square of the hematocytometer counting area). The number of oidia was expressed per culture (Petri-dish, $9 \mathrm{~cm}$ in $\varnothing$ ).

\subsubsection{Morphological analysis of etiolated stipes by hand-sectioning with a sharp razor blade}

The inner morphological structure of etiolated stipes was observed after sectioning the structures with a sharp razor blade as described in Chapter 2 of this thesis.

\subsubsection{Photographing}

Photographing of cultures, of structures underneath the Stemi 2000-C binocular and under the Axioplan 2 imaging light microscope was done as described in Chapter 2 of this thesis. Photographs were digitalized for image processing (analysis ${ }^{\text {, Soft Imaging }}$ System GmbH, Münster, Germany) via a color chilled 3CCD camera (colorview soft imaging system).

\subsection{Results and discussion}

\subsubsection{Mutations leading to etiolated stipes occurred in four different genes}

The self-compatible homokaryons 7K17 and B-1918 carry recessive defective genes leading to the formation of etiolated stipes under normal fruiting conditions with changing light and dark phases following the day/night rhythm (Fig. 1A and B). Monokaryons R1428F1\#74 and H1-1280F1\#5 known to carry the recessive defects $d s t$-2 and $d s t 2-1$, respectively (Terashima et al. 2005, T. Kamada, personal communication) have different mating type specificities from the other two strains and, consequently, dikaryons could be formed through mating. Dikaryons resulting from these crosses as well as dikaryons formed between H1-1280F1\#5 and R1428F1\#74 gave rise to fruiting bodies with basidiospores (Fig. 2) indicating that all gene defects are recessive and that neither homokaryon 7K17 nor homokaryon B-1918 are defective in genes $d s t 1$ and $d s t 2$.

In order to determine whether 7K17 and B-1918 carry defects in the same or in different $d s t$ genes, the strains were crossed to the co-isogenic, pab1-1 defective 


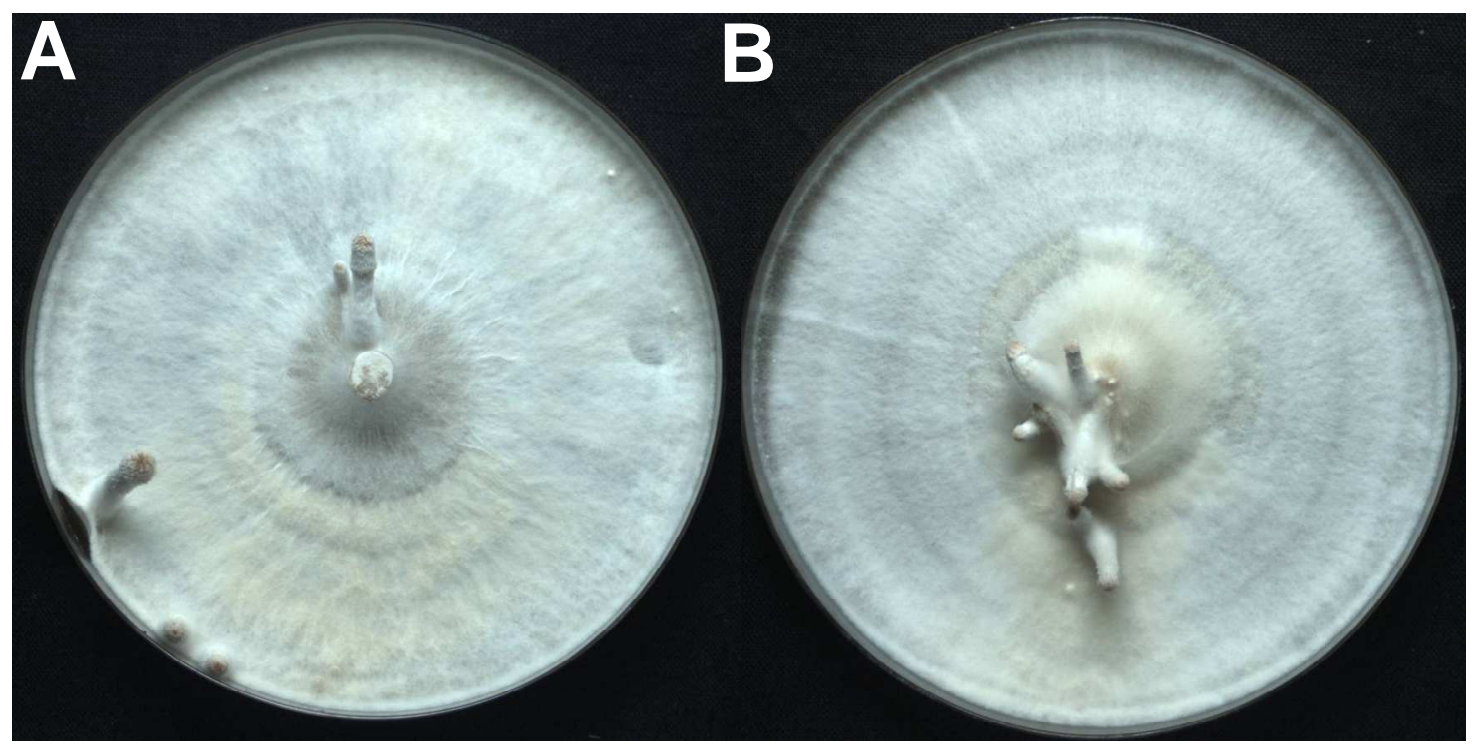

Fig. 1 Etiolated stipes formed on YMG/T agar plates by homokaryon AmutBmut mutants 7K17 (A) and B-1918 (B) under standard fruiting conditions.
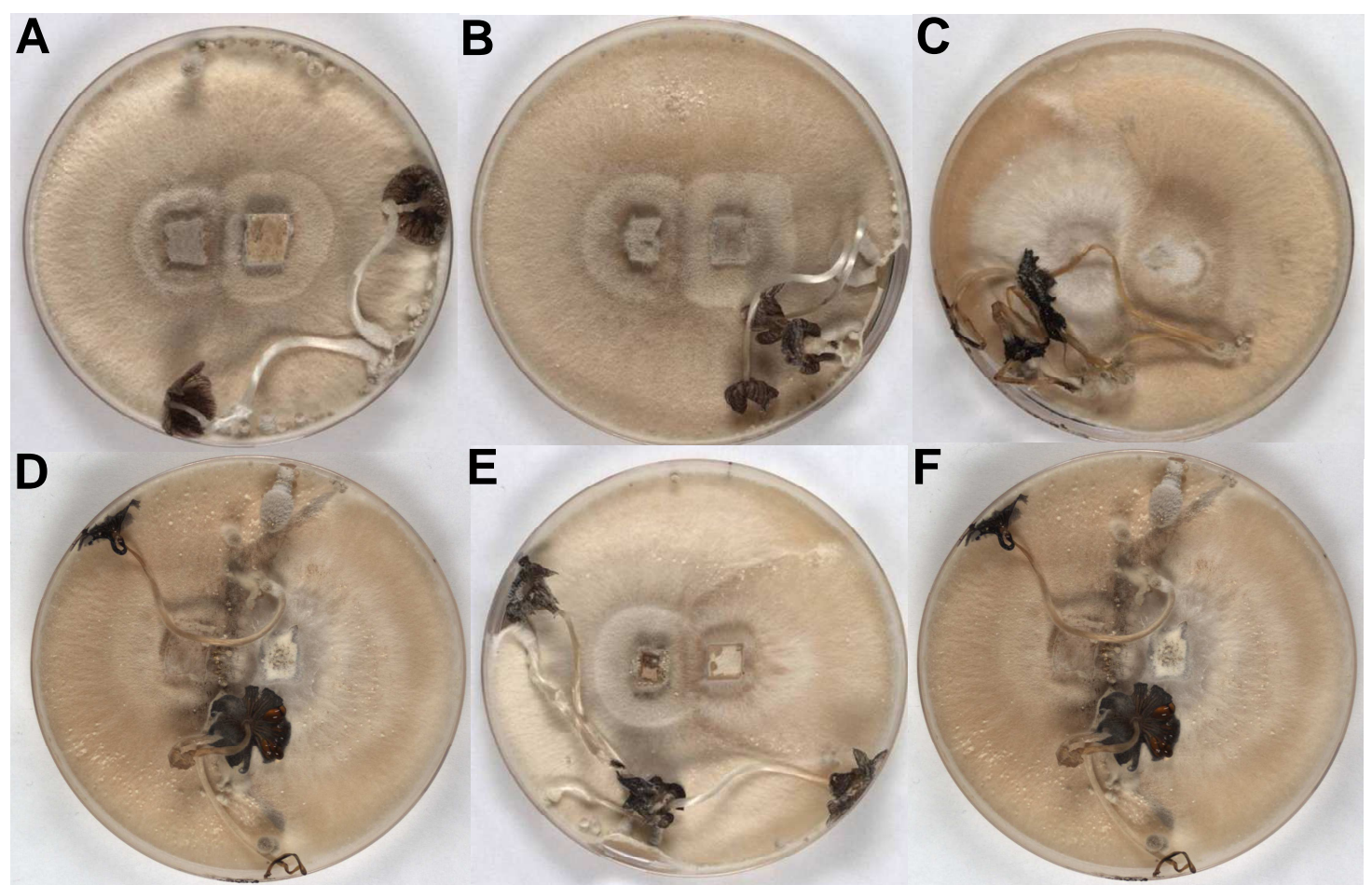

E
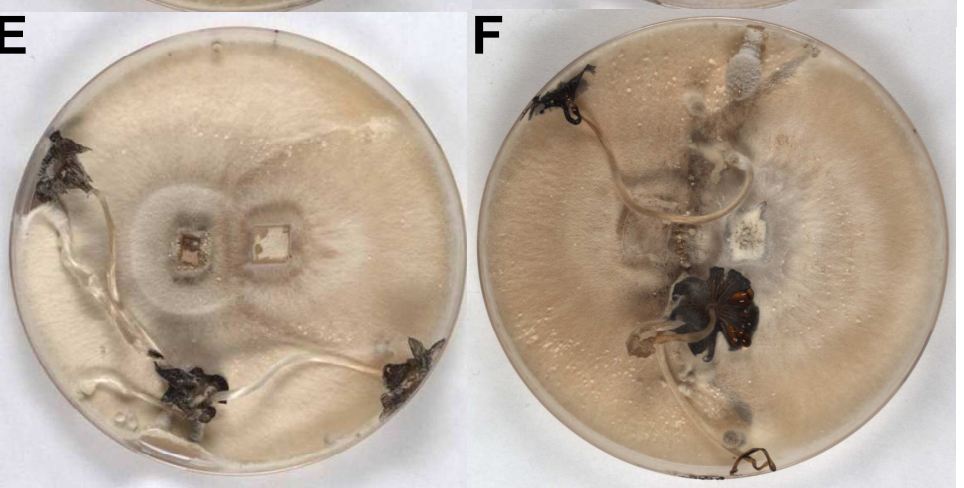

Fig. 2 Fruiting body development in crosses of strains with $d s t$ defects show genetic complementation indicating that gene defects are recessive and that defects occur in different genes. (A) and (B) Cross of strain H1-1280F1\#5 x R1428F1\#74, (C) cross of strain H1-1280F1\#5 x 7K17, (D) cross of strain H1-1280F1\#5 x B-1819, (E) cross of strain R1428F1\#74 x 7K17, and (F) cross of strain R1428F1\#74 x B-1819. Fruiting body development occurred on YMG/T plates under standard fruiting conditions. 
$A 42, B 42$ monokaryon GAU1 in order to isolate pabl-1 defective $A 42, B 42$ monokaryons carrying $d s t$ defects.

Basidiospores from fruiting bodies formed at a respective 7K17 x GAU1 dikaryon were germinated on YMG/T complete medium. Colonies with typical monokaryon appearance (i.e. containing the 42 wildtype locus from GAU1 and not the clamp cellinducing A43 mutant locus from 7K17; see Swamy et al. 1984 for mycelial phenotypes caused by A43mut) were crossed with the A43, B43 monokaryon Okayama 7 to determine their $B$ locus specificity by dikaryon formation that can easily happen when a clone carries the B42 locus but not when a clone carries the B43mut locus. Of finally tested 101 clones, only 25 gave rise to a dikaryon, different to the $1: 1$ distribution expected by an equal 1:1 distribution of the $B$ mating type specificities in the progeny. This unexpected 1:3 distribution of dikaryon formation versus a lack of a mating reaction indicates that in UV-mutant $7 \mathrm{~K} 17$ further to the $d s t$ defect there is possibly another gene defective which acts in the mating reaction or in germination causing an under-representation of $B 42$ clones in the progeny of cross $7 \mathrm{~K} 17$ x GAU1 (not further analyzed in this study). The 25 A42, B42 monokaryons that mated with monokaryon Okayama 7 were subsequently crossed to both homokaryon $7 \mathrm{~K} 17$ and homokaryon B-1918. In total, eight clones carried the $d s t$ defect of homokaryon 7K17 since only etiolated stipes and no normal fruiting bodies were formed on the respective dikaryons under standard fruiting conditions. In crosses of these clones with homokaryon B-1918, normal fruiting bodies appeared (Table 2) indicating that the $d s t$ defects in $7 \mathrm{~K} 17$ and B-1918 were in different genes. The defective dst gene in 7K17 was subsequently called $d s t 3$ (specific allele $d s t 3-1$ ) and the defective $d s t$ gene in B-1918 $d s t 4$ (specific allele $d s t 4-1)$.

Basidiospores from fruiting bodies formed by a respective B-1918 x GAU1 dikaryon were germinated on YMG/T complete medium to subsequently transfer colonies with typical monokaryon appearance (i.e. containing the 42 wildtype locus from GAU1 and not the clamp cell-inducing A43 mutant locus from B-1918) onto MM medium. In a normal 1:1 distribution, a total of 55 colonies from the progeny grow on MM and a total of 53 colonies did not grow, suggesting that in the REMI-mutant B1918 the pabl wildtpye gene present in the vector used in REMI-transformation (Granado et al. 1997) has been inserted only once into the genome of homokaryon AmutBmut. All pabl auxotrophic colonies were subsequently mated to the $A 43, B 43$ monokaryon Okayama 7 to determine their $B$ locus specificity by dikaryon formation. 
In total, 27 of the clones formed a dikaryon with monokaryon Okayama 7, indicating these carried the $B 42$ mating type allele. These clones were subsequently crossed with homokaryons B-1918 and with 7K17 (Table 2). In total, seven clones carried the dst 4-1 defect of homokaryon B-1918 since only etiolated stipes were formed on the respective dikaryons under standard fruiting conditions. In crosses of these clones with homokaryon $7 \mathrm{~K} 17$, normal fruiting bodies appeared (Table 2) indicating again that the $d s t$ defects in 7K17 and B-1918 were in different genes.

Table 2 Crosses performed to determine the distribution of defective $d s t$ genes in progenies of cross B-1918 x GAU1 and of cross $7 \mathrm{~K} 17$ x GAU1, respectively.

\begin{tabular}{|c|c|c|c|c|}
\hline $\begin{array}{c}A 42, B 42 \\
\text { progeny from } \\
\text { cross }\end{array}$ & $\begin{array}{l}\text { Cross } \\
\text { with }\end{array}$ & $\begin{array}{l}A 42, B 42 \text { progeny } \\
\text { analyzed in total }\end{array}$ & $\begin{array}{c}\text { Wildtype fruiting } \\
\text { bodies on the } \\
\text { dikaryon }\end{array}$ & $\begin{array}{l}\text { Etiolated stipes } \\
\text { on the dikaryon }\end{array}$ \\
\hline \multirow[t]{2}{*}{ 7K17 x GAU1 } & $7 \mathrm{~K} 17$ & $25(100 \%)$ & $17(68 \%)$ & $8(32 \%)$ \\
\hline & B-1918 & $25(100 \%)$ & $25(100 \%)$ & $0(0 \%)$ \\
\hline \multirow[t]{2}{*}{ B-1918 x GAU1 } & B-1918 & $27(100 \%)$ & $20(74 \%)$ & $7(26 \%)$ \\
\hline & $7 \mathrm{~K} 17$ & $27(100 \%)$ & $27(100 \%)$ & $0(0 \%)$ \\
\hline
\end{tabular}

A second approach was chosen to confirm that defects in four different genes can lead in $C$. cinerea to etiolated stipe formation under standard fruiting conditions. The four strains R1428F1\#74, H1-1280F1\#5, 7K17 and B-1918 were all crossed to the AmutBmut co-isogenic monokaryons PS001-1 (A42, B42) and PS002-1 (A3, B1), respectively. From these crosses, $A 42, B 42$ and $A 3, B 1$ monokaryons were isolated carrying either the $d s t 1-2$ defect from R1428F1\#74, the dst2-1 defect from H1-1280F1\#5, the dst3-1 defect from 7K17 or the dst4-1 defect from B-1918 (Table 3 and Table 4). In the crosses with monokaryon PS001-1, the A42, B42 progeny was always identified by dikaryon formation upon crossing them with the other parental strain used in the first mating. Likewise in the crosses with monokaryon PS002-1, the $A 3, B 1$ progeny was always identified by dikaryon formation upon crossing them with the other parental strain used in the first mating. The resulting dikaryons were incubated under standard fruiting conditions to observe fruiting body or etiolated stipe formation (Fig. 3). Since all the defects in the four different $d s t$ genes were all shown to be recessive, dikaryons forming fruiting bodies should carry one wildtype gene whereas 
dikaryons forming etiolated stipes must have two alleles of a defective $d s t$ gene. In most instances, only subsets of the dikaryons initiated fruiting (Table 3 and Table 4) indicating that there were genes in the background of the strains that negatively influenced fruiting.

Table 3 Crosses performed to generate $A 42, B 42$ monokaryons carrying defective $d s t$ genes

\begin{tabular}{|l|c|c|c|c|c|}
\hline \multicolumn{1}{|c|}{$\begin{array}{c}\text { A42, B42 } \\
\text { progeny of } \\
\text { cross }\end{array}$} & Cross with & $\begin{array}{c}\text { A42, B42 } \\
\text { progeny } \\
\text { analyzed in } \\
\text { total }\end{array}$ & $\begin{array}{c}\text { Pildtype } \\
\text { fruiting } \\
\text { bodies }\end{array}$ & $\begin{array}{c}\text { Etiolated } \\
\text { stipes }\end{array}$ & $\begin{array}{c}\text { No } \\
\text { initiation of } \\
\text { fruiting }\end{array}$ \\
\hline $\begin{array}{l}\text { R1428F1\#74 x } \\
\text { PS001-1 }\end{array}$ & R1428F1\#74 & $29(100 \%)$ & $14(48 \%)$ & $2(7 \%)$ & $13(45 \%)$ \\
\hline $\begin{array}{l}\text { H1-1280F1\#5 } \\
\text { x PS001-1 }\end{array}$ & H1- & $22(100 \%)$ & $13(59 \%)$ & $9(41 \%)$ & $0(0 \%)$ \\
\hline 7K17 x & $7280 F 1 \# 5$ & & & & \\
PS001-1 & & $37(100 \%)$ & $17(46 \%)$ & $6(16 \%)$ & $14(38 \%)$ \\
\hline $\begin{array}{l}\text { B-1918 x } \\
\text { PS001-1 }\end{array}$ & B-1918 & $34(100 \%)$ & $11(32 \%)$ & $19(56 \%)$ & $4(12 \%)$ \\
\hline
\end{tabular}

Table 4 Crosses performed to generate $A 3, B 1$ monokaryons carrying defective $d s t$ genes

\begin{tabular}{|l|c|c|c|c|c|}
\hline \multirow{2}{*}{$\begin{array}{c}\text { A3, B1 } \\
\text { progeny of } \\
\text { cross }\end{array}$} & Cross with & \multirow{2}{*}{$\begin{array}{c}\text { A42, B42 } \\
\text { progeny } \\
\text { analyzed in } \\
\text { total }\end{array}$} & $\begin{array}{c}\text { Wildtype } \\
\text { fruiting } \\
\text { bodies }\end{array}$ & $\begin{array}{c}\text { Etiolated } \\
\text { stipes }\end{array}$ & $\begin{array}{c}\text { No } \\
\text { initiation of } \\
\text { fruiting }\end{array}$ \\
\hline R1428F1\#74 x & R1428F1\#74 & $53(100 \%)$ & $18(34 \%)$ & $4(8 \%)$ & $31(58 \%)$ \\
PS002-1 & & & & & \\
\hline $\begin{array}{l}\text { H1-1280F1\#5 } \\
\text { x PS002-1 }\end{array}$ & H1- & $41(100 \%)$ & $21(51 \%)$ & $19(46 \%)$ & $1(3 \%)$ \\
\hline $\begin{array}{l}\text { 7K17 x } \\
\text { PS002-1 }\end{array}$ & $7 \mathrm{~K} 17$ & $51(100 \%)$ & $2(4 \%)$ & $10(20 \%)$ & $39(76 \%)$ \\
\hline $\begin{array}{l}\text { B-1918 x } \\
\text { PS002-1 }\end{array}$ & B-1918 & $57(100 \%)$ & $6(10 \%)$ & $21(37 \%)$ & $30(53 \%)$ \\
\hline
\end{tabular}


This observation supports previous observations by other researchers (Moore 1981, Liu et al. 1999, Srivilai 2006) that mixing of different genetic backgrounds by meiosis in C. cinerea can bring new combinations of genes together that will hinder initiation of fruiting body development of progenies (see also another case below). Accordingly, from all the results shown in Tables 3 and 4, only the data of the crosses with strain H1-1280F1\#5 do allow a further interpretation on linkages according to the Mendelian rules. Since in both the crosses with monokaryon PS001-1 and with PS002-1, there was a clear 1:1 distribution in the tested progeny of normal fruiting body development and etiolated stipe development (Table 3 and Table 4) it is clear that defect $d s t 2-1$ is neither linked to the $A$ mating type locus nor to the $B$ mating type locus.

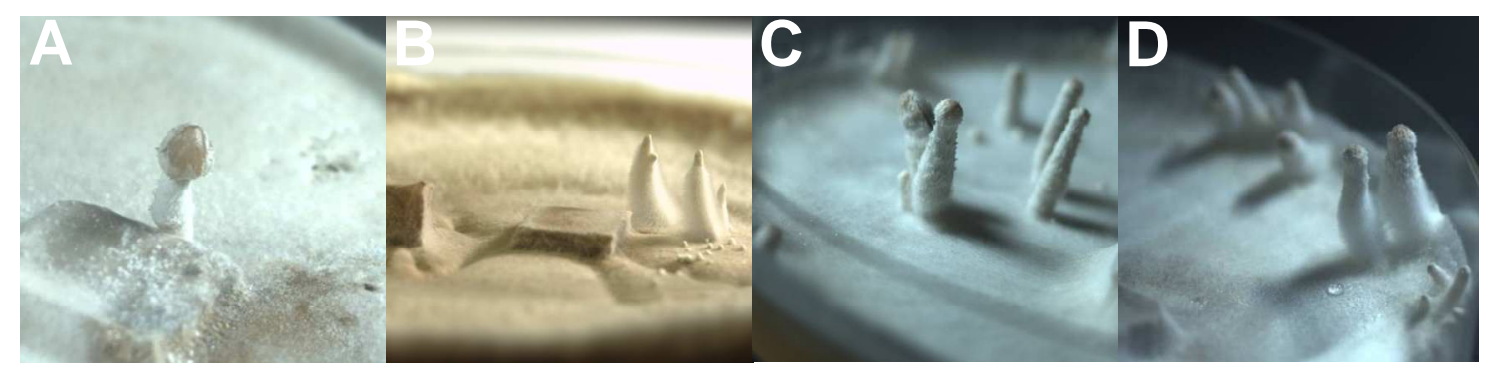

Fig. 3 Formation of etiolated stipes under standard fruiting conditions of dikaryons being homoallelic for one defective $\boldsymbol{d s t}$ gene. (A) A dikaryon formed by an $A 3, B 1$, dst1-2 monokaryon (from cross PS002-1 x R1428F1\#74) x the A8, B7, dst1-2 monokaryon $\mathrm{R} 1428 \mathrm{~F} 1 \# 74,(\mathbf{B})$ a dikaryon formed by an $A 42, B 42$, dst2-1 monokaryon (from cross PS001-1 $\mathrm{x}$ H1-1280F1\#5) x the $A 91, B 92$, dst2-1 monokaryon H1-1280F1\#5, (C) a dikaryon formed by an $A 3, B 1$, dst3-1 monokaryon (from cross PS002-1 x 7K17) $\mathrm{x}$ the A43mut, B43mut, dst3-1 homokaryon $7 \mathrm{~K} 17$, and (D) a dikaryon formed by an $A 3, B 1$, dst4-1 monokaryon (from cross PS002-1 x B-1918) x the A43mut, B43mut, dst4-1 homokaryon B-1918.

Subsequently from each of the crosses documented in Tables 3 and 4, 2 to 5 clones from the $A 42, B 42$ progeny, respectively from the $A 3, B 1$ progeny with a defect $d s t$ gene were selected for performing crosses in all possible combinations between these strains (Table 5). Resulting dikaryons were tested for their morphological behaviour under standard fruiting conditions. In all instances where mated clones carried different $d s t$ defects, normal fruiting body development occurred (Table 5) whereas in all instances where mated clones carried the identical $d s t$ defect, etiolated stipes were formed (Table 5). In conclusion, also this experiment verifies that there are four 
different genes (dst1, dst2, dst3 and $d s t 4)$ causing etiolated stipe formation when defective and that the isolated defects in the four genes are recessive.

Table 5 Phenotypes in fruiting of dikaryons formed by crosses between $A 3, B 1$ and $A 42$, B42 monokaryons carrying defective $d s t$ genes

\begin{tabular}{|c|c|c|c|c|}
\hline Genotype & $\begin{array}{l}\mathbf{A 4 2 ,}, \mathbf{B 4 2}, \boldsymbol{d s t 1 - 2} \\
(2 \text { clones tested) }\end{array}$ & $\begin{array}{l}\text { A42, B42, } \boldsymbol{d s t 2 - 1} \\
(5 \text { clones tested) }\end{array}$ & $\begin{array}{l}\text { A42, B42, } \boldsymbol{d s t 3 - 1} \\
\text { (7 clones tested) }\end{array}$ & $\begin{array}{l}\mathbf{A 4 2}, \mathbf{B 4 2}, \boldsymbol{d s t 4 - 1} \\
(5 \text { clones tested })\end{array}$ \\
\hline $\begin{array}{l}\text { A3, B1, } \boldsymbol{d s t 1 - 2} \\
\text { (2 clones tested) }\end{array}$ & Etiolate & Fruiting bodies & Fruiting bodies & Fruiting bodies \\
\hline $\begin{array}{c}\text { A3, B1, } \text { dst2-1 } \\
\text { (5 clones tested) }\end{array}$ & Fruiting bodies & Etiolated stipes & Fruiting bodies & Fruiting bodies \\
\hline $\begin{array}{c}\text { A3, B1, } \boldsymbol{d s t 3 - 1} \\
\text { (6 clones tested) }\end{array}$ & Fruiting bodies & Fruiting bodies & Etiolated stipes & Fruiting bodies \\
\hline $\begin{array}{l}\text { A3, B1, } \mathbf{d s t 4 - 1} \\
\text { (6 clones tested) }\end{array}$ & Fruiting bodies & Fruiting bodies & Fruiting bodies & Etiolated stipes \\
\hline
\end{tabular}

\subsubsection{Bringing the $d s t 1$ and $d s t 2$ defects into the genetic background of homokaryon AmutBmut}

The dst1-2 and dst2-1 genes were obtained from Prof. T. Kamada within two different monokaryons. For an easy comparison of the morphological effects of these defects with those of $d s t 3-1$ and $d s t 4-1$, it was decided to transfer the $d s t 1-2$ and $d s t 2-1$ alleles into an A43mut, B43mut background by crossing R1428F1\#74 and H1-1280F1\#5 with homokaryon AmutBmut. Basidiospores from fruiting bodies formed on these dikaryons were germinated on YMG/T plates. A43mut, B43mut clones were identified in the progeny by checking for fused clamp cell at the hyphal septa (A43mut induces clamp cell formation at the apical cells at places of new septa formations, B43mut fusion of the clamp cells with the subapical hyphal cells; Swamy et al. 1984). 44 A43mut, B43mut clones from cross R1428F1\#74 x AmutBmut and 50 A43mut, B43mut clones from cross H1-1280F1\#5 x AmutBmut were identified. Of the clones of the R1428F1\#74 x AmutBmut progeny, 7 and 14 formed fruiting bodies and etiolated stipes, respectively, when cultivated under standard fruiting conditions after growth on 
Table 6 Crosses performed to transfer $d s t 1-2$ and $d s t 2-1$ into the genetic background of homokaryon AmutBmut

\begin{tabular}{|c|c|c|c|c|c|}
\hline \multirow{2}{*}{$\begin{array}{c}\text { A43mut, } \\
\text { B43mut } \\
\text { progeny from } \\
\text { cross }\end{array}$} & \multirow[t]{2}{*}{ Cross with } & \multirow{2}{*}{$\begin{array}{c}\text { A43mut, } \\
\text { B43mut } \\
\text { progeny in } \\
\text { total }\end{array}$} & \multicolumn{3}{|c|}{ Phenotype of the dikaryons } \\
\hline & & & $\begin{array}{l}\text { Wildtype } \\
\text { fruiting } \\
\text { bodies }\end{array}$ & $\begin{array}{c}\text { Etiolated } \\
\text { stipes }\end{array}$ & $\begin{array}{c}\text { No } \\
\text { initiation } \\
\text { of fruiting }\end{array}$ \\
\hline $\begin{array}{l}\text { R1428F1\#74 x } \\
\text { AmutBmut }\end{array}$ & R1428F1\#74 & $44(100 \%)$ & $\begin{array}{c}7(16 \%) \\
(\text { day } 14 \pm 2)^{*}\end{array}$ & $\begin{array}{c}14(32 \%) \\
(\text { day } 22 \pm 4)^{*}\end{array}$ & $23(52 \%)$ \\
\hline $\begin{array}{l}\text { H1-1280F1\#5 x } \\
\text { AmutBmut }\end{array}$ & H1-1280F1\#5 & $50(100 \%)$ & $\begin{array}{c}20(40 \%) \\
\text { (day } 16 \pm 2)^{*}\end{array}$ & $\begin{array}{c}22(44 \%) \\
\text { (day } 19 \pm 3)^{*}\end{array}$ & $8(16 \%)$ \\
\hline
\end{tabular}

$*$ day refers to the period from the start of experiment (inoculation) over 5 days incubation at $37^{\circ} \mathrm{C}$ in the dark followed by transfer to standard fruiting conditions at $28^{\circ} \mathrm{C}$ till appearance of the structures.

YMG/T plates for 5 days at $37^{\circ} \mathrm{C}$ (Table 6), and of the clones of the H1-1280F1\#5 $\mathrm{x}$ AmutBmut progeny, 20 and 22 formed fruiting bodies and etiolated stipes, respectively (Table 6). Other clones did not initiate any fruiting body development (Table 6), an effect which is quite commonly observed in progenies of $C$. cinerea strains of very different genetic background and is explained by incompatible gene combinations brought together by mating from different monokaryotic parents (Moore 1981, Liu et al. 1999, Srivilai 2006, see above). From this experiment it is further interesting to note that clones undergoing normal fruiting body development complete fruiting body development in times comparable or only slightly later than the reference strain AmutBmut (see Chapter 2) whereas development of etiolated stipes occurs in comparison delayed. This effect was further studied in progenies (Table 6).

Fig. 4 and Fig. 5 show as examples for the successful transfer of genes $d s t 1-2$ and dst2-1 into an A43mut, B43mut background clones PUK1 (A43mut, B43mut, pab1-1, dst1-2) and PUK2 (A43mut, B43mut, pab1-1, dst2-1) forming on YMG/T plates under standard fruiting conditions etiolated stipes. Etiolated stipes are formed under standard fruiting conditions by the newly created strains PUK1 and PUK2 as well as by the mutant homokaryons 7K17 and B-1918. From the outer appearance it seems that there are morphological differences in the formation of etiolated strains by the different isolates (Fig. 5). Previously in Chapter 2 it was shown that etiolated stipes can show morphological differences depending on when a wildtype strain (defined here by homokaryon AmutBmut) is transferred during the pathway of fruiting body 


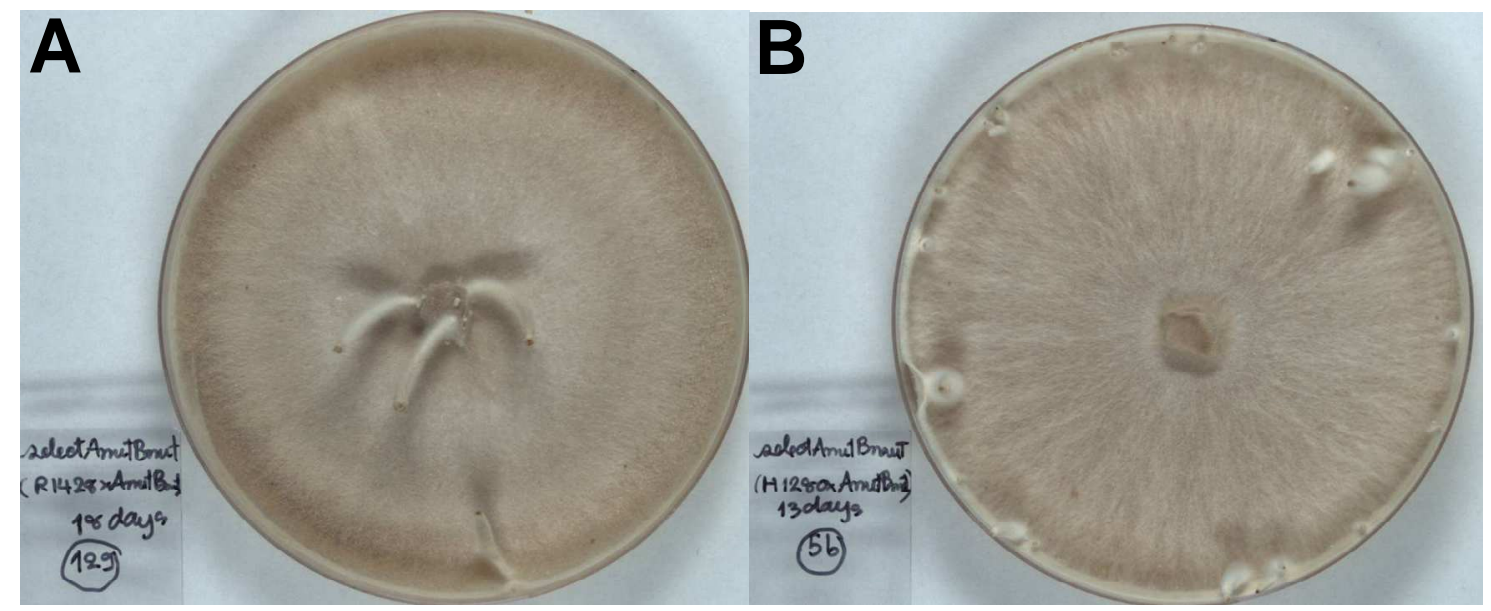

Fig. 4 Etiolated stipes formed on YMG/T agar plates under standard fruiting conditions by clones PUK1 obtained from cross R1428F1\#74 x AmutBmut (A) and by PUK2 obtained from cross H1-1280F1\#5 x AmutBmut (B).

development into constant dark. Therefore, the stage at which a block in normal development under standard fruiting conditions occurs changing it to etiolated stipe development could differ by the defects in the different genes $d s t 1, d s t 2, d s t 3$ and $d s t 4$.

\subsubsection{Co-isogenisation of self-compatible homokaryons carrying defective $d s t$ genes with the self-compatible homokaryon AmutBmut and characterisation of the different $d s t$ defects in formation of etiolated stipes under standard fruiting conditions}

Mutations $d s t 3-1$ and $d s t 4-1$ have been generated in the self-compatible homokaryon AmutBmut through UV- and REMI-mutagenesis, respectively (Granado et al. 1997, Granado et al., unpublished). Thus, the two mutations are already from the beginning onwards in same genetic background. However, since during mutagenesis procedures often more than one mutation is generated (for AmutBmut mutants e.g. see Liu et al. 1999, 2006, Srivilai 2006 and also this work), new A43mut, B43mut clones were selected from the F1 progeny of cross 7K17 x PS001-1 and from the cross B-1918 x PS001-1 that had either the defective gene dst3-1 (homokaryon PUK3) or the defective gene dst4-1 (homokaryon PUK4). Strains were identified within the progeny first by a vigorous growth and fused clamp cells at their hyphal septa and then through a fruiting test under standard fruiting conditions by the formation of etiolated stipes. 

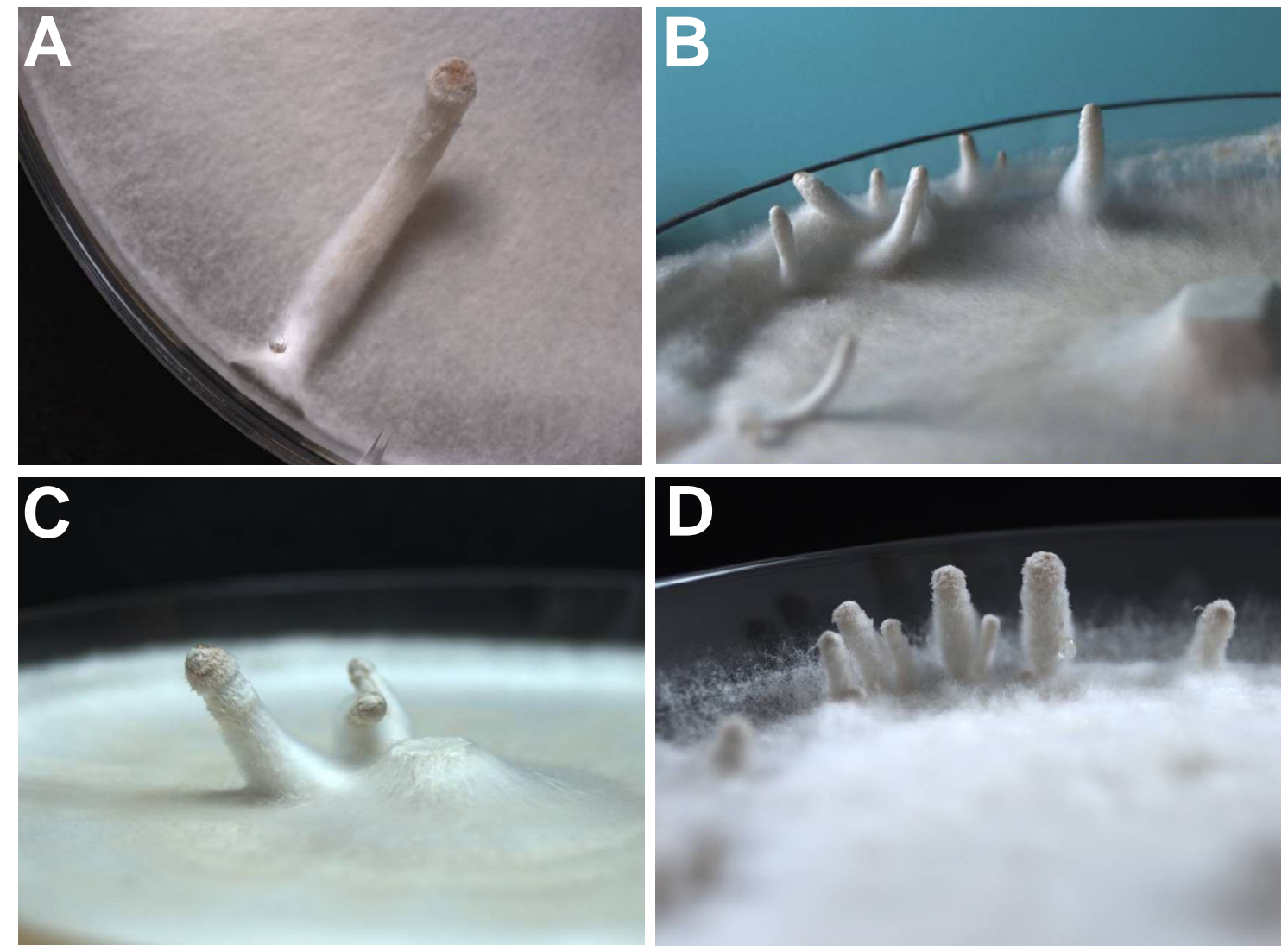

Fig. 5 Enlarged views on etiolated stipes formed by the self-fertile homokaryotic strains PUK1 (A), PUK2 (B), 7K17 (C) and B-1918 (D) on YMG/T agar plates under standard fruiting conditions. Note that the length of structures and the stage of cap development appear to be different between some of the strains.

Homokaryons PUK3 and PUK 4 were cultivated in parallel to homokaryons PUK1 and PUK2 for 5 days at $37^{\circ} \mathrm{C}$ on YMG/T medium and subsequently transferred into standard fruiting conditions at $28^{\circ} \mathrm{C}$. All cultures produced etiolated stipes but the time of appearance and the general look of the structures differed between different strains (Fig. 6).

Since the $d s t 1-2$ and the $d s t 2-1$ mutations came from another genetic background than homokaryon AmutBmut, it was possible that the differences encountered in development of homokaryons PUK1 and PUK2 compared to homokaryons PUK3 and PUK4 based on genetic differences in genes other than the mutated $d s t$ genes. In order to exclude this genetic possibility, co-isogenisation procedures were performed with the AmutBmut co-isogenic monokaryon PS001-1 and mutants PUK1 and PUK2 in order to 

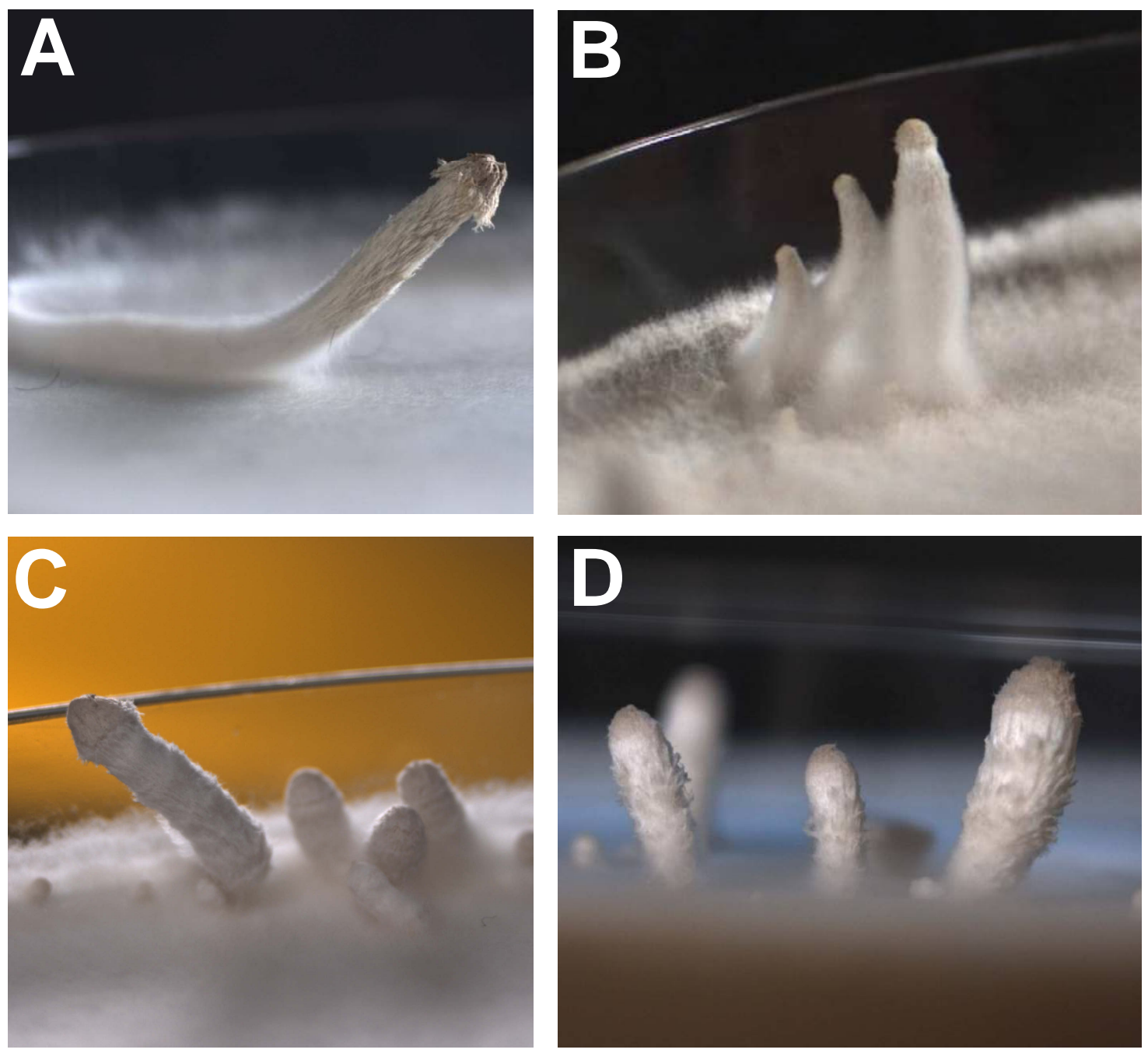

Fig. 6 Etiolated stipes formed under standard fruiting conditions by homokaryons PUK1 (A), PUK2 (B), PUK3 (C) and PUK 4 (D). Note that after five days of growth at $37^{\circ} \mathrm{C}$ in the dark, the PUK1 structure was photographed 11 days after transfer into standard fruiting conditions, the PUK2 structures 6 days after transfer into standard fruiting conditions, the PUK3 structures 11 days days after standard fruiting conditions and the PUK4 structures after 9 days of transfer into standard fruiting conditions.

obtain $d s t$-2 and $d s t 2-1$ homokaryons, respectively, being as closely related to homokaryon AmutBmut as possible.

PUK1 and PUK2 came originally from the F1 generation of the crosses R1428F1\#74 x AmutBmut and H1-1280F1\#5. Subsequently six further generations were created by backcrossing to monokaryon PS001-1 (Table 7 and Table 8). In all cases, A43mut, B43mut progeny was selected by microscoping for fused clamp cells formed at hyphal septa and by subsequent crosses with monokaryon PS001-1 and testing for fruiting body development of the resulting dikaryons. From each generation up to filial generation F6, suitable A43mut, B43mut homokaryons forming etiolated 
stipes under standard fruiting conditions were chosen for back-crosses with monokaryon PS001-1 in order to select further A43mut, B43mut homokaryons forming etiolated stipes under standard fruiting conditions. Finally, PUK1-6 (A43mut, B43mut, pab1-1, dst3-1) and PUK2-6 (A43mut, B43mut, pab1-1, dst4-1) were obtained.

Growth rates of strains were determined (Fig. 7). The wildtype homokaryon AmutBmut and mutants PUK3 and PUK4 grew faster than the co-isogenic monokaryons PS001-1 and PS002-1 and showed similar growth rates comparable to the dikaryon PS001-1 x PS002-1 in accordance to the fact that dikaryons of $C$. cinerea grow faster than monokaryons and that homokaryons with defects in the mating type loci behave in growth behaviour like dikaryons (Swamy et al. 1984, Kües 2000,

Table 7 Co-isogenisation process to introduce gene dst1-2 into the homokaryon AmutBmut background by using crosses with its co-isogenic monokaryon PS001-1

\begin{tabular}{|c|c|c|c|c|}
\hline \multirow{2}{*}{$\begin{array}{l}\text { A43mut, B43mut progeny } \\
\text { from cross }\end{array}$} & \multirow{2}{*}{$\begin{array}{c}\text { A43mut, } \\
\text { B43mut } \\
\text { progeny in } \\
\text { total }\end{array}$} & \multicolumn{3}{|c|}{ Phenotype of the dikaryons } \\
\hline & & $\begin{array}{c}\text { Wildtype fruiting } \\
\text { bodies }\end{array}$ & $\begin{array}{l}\text { Etiolated } \\
\text { stipes }\end{array}$ & $\begin{array}{c}\text { No initiation } \\
\text { of fruiting }\end{array}$ \\
\hline PUK1 (F1 clone) x PS001-1 & $38(100 \%)$ & $15(39 \%)$ & $19(50 \%)$ & $4(11 \%)$ \\
\hline PUK1-1 (F2 clone) x PS001-1 & $47(100 \%)$ & $8(17 \%)$ & $35(74 \%)$ & $4(9 \%)$ \\
\hline PUK1-2 (F3 clone) x PS001-1 & $23(100 \%)$ & $3(13 \%)$ & $10(43.5 \%)$ & $10(43.5 \%)$ \\
\hline PUK1-3 (F4 clone) x PS001-1 & $32(100 \%)$ & $1(3 \%)$ & $15(47 \%)$ & $16(50 \%)$ \\
\hline PUK1-4 (F5 clone) x PS001-1 & $38(100 \%)$ & $3(8 \%)$ & $15(39 \%)$ & $20(53 \%)$ \\
\hline PUK1-5 (F6 clone) x PS001-1 & $62(100 \%)$ & $21(34 \%)$ & $41(66 \%)$ & $0(0 \%)$ \\
\hline
\end{tabular}

Table 8 Co-isogenisation process to introduce gene dst2-1 into the homokaryon AmutBmut background by using crosses with its co-isogenic monokaryon PS001-1

\begin{tabular}{|c|c|c|c|c|}
\hline \multirow{2}{*}{$\begin{array}{l}\text { A43mut, B43mut progeny } \\
\text { from cross }\end{array}$} & \multirow{2}{*}{$\begin{array}{c}\text { A43mut, } \\
\text { B43mut } \\
\text { progeny in } \\
\text { total }\end{array}$} & \multicolumn{3}{|c|}{ Phenotype of the dikaryons } \\
\hline & & $\begin{array}{c}\text { Wildtype fruiting } \\
\text { bodies }\end{array}$ & $\begin{array}{l}\text { Etiolated } \\
\text { stipes }\end{array}$ & $\begin{array}{c}\text { No initiation } \\
\text { of fruiting }\end{array}$ \\
\hline PUK2 (F1 clone) x PS001-1 & $44(100 \%)$ & $3(7 \%)$ & $14(32 \%)$ & $27(61 \%)$ \\
\hline PUK2-1 (F2 clone) x PS001-1 & $42(100 \%)$ & $16(38 \%)$ & $25(60 \%)$ & $1(2 \%)$ \\
\hline PUK2-2 (F3 clone) x PS001-1 & $35(100 \%)$ & $10(28.5 \%)$ & $17(48.5 \%)$ & $8(23 \%)$ \\
\hline PUK2-3 (F4 clone) x PS001-1 & $21(100 \%)$ & $2(9.5 \%)$ & $10(47.5 \%)$ & $9(43 \%)$ \\
\hline PUK2-4 (F5 clone) x PS001-1 & $22(100 \%)$ & $7(32 \%)$ & $8(36 \%)$ & $7(32 \%)$ \\
\hline PUK2-5 (F6 clone) x PS001-1 & $71(100 \%)$ & $20(28 \%)$ & $51(72 \%)$ & $0(0 \%)$ \\
\hline
\end{tabular}


Kües et al. 2001). Mutants PUK1-6 and PUK2-6 grow in this test slightly less per day than homokaryon AmutBmut and mutants PUK3 and PUK4 but they were both still faster than the monokaryons PS001-1 and PS002-2 ( Fig. 7). The mycelium of PUK1-6 had a slightly altered appearance compared to homokaryon AmutBmut and the other three mutant homokaryons by forming a more dense but finer aerial mycelium (not shown). Since the co-isogenisation with six backcrosses to PS001-1 has proceeded very far, it is possible that the deviations in growth behaviour are due to effects of the $d s t 1-2$ and the $d s t 2-1$ mutations, respectively.

With in total 7 different generations of crossing to the AmutBmut background (one time directly to homokaryon AmutBmut, each six times via PS001-1), according to the equation of Leslie $(1981)$ : $C(n)=2 c(1 / 2)^{n}=c(1 / 2)^{n-1}$ with $n$ being the number of backcrosses performed, $\mathrm{C}(\mathrm{n})$ being the average number of chromosome tips remaining allogenic, $\mathrm{c}$ the haploid chromosome number of an organism which in C. cinerea is 13 (Pukkila and Lu 1985) representing thus 26 chromosal tips, the strains should differ from homokaryon AmutBmut by 0.203 chromosome tips which corresponds to only $1.0 \%$ of gene difference. Considering that each time a positive selection was carried out for the AmutBmut chromosome I carrying the A43mut locus and AmutBmut chromosome X carrying the B43mut type locus (Muraguchi et al. 2003), an even smaller number of 0.172 chromosome tips remaining allogenic in PUK1-6 and PUK2-6

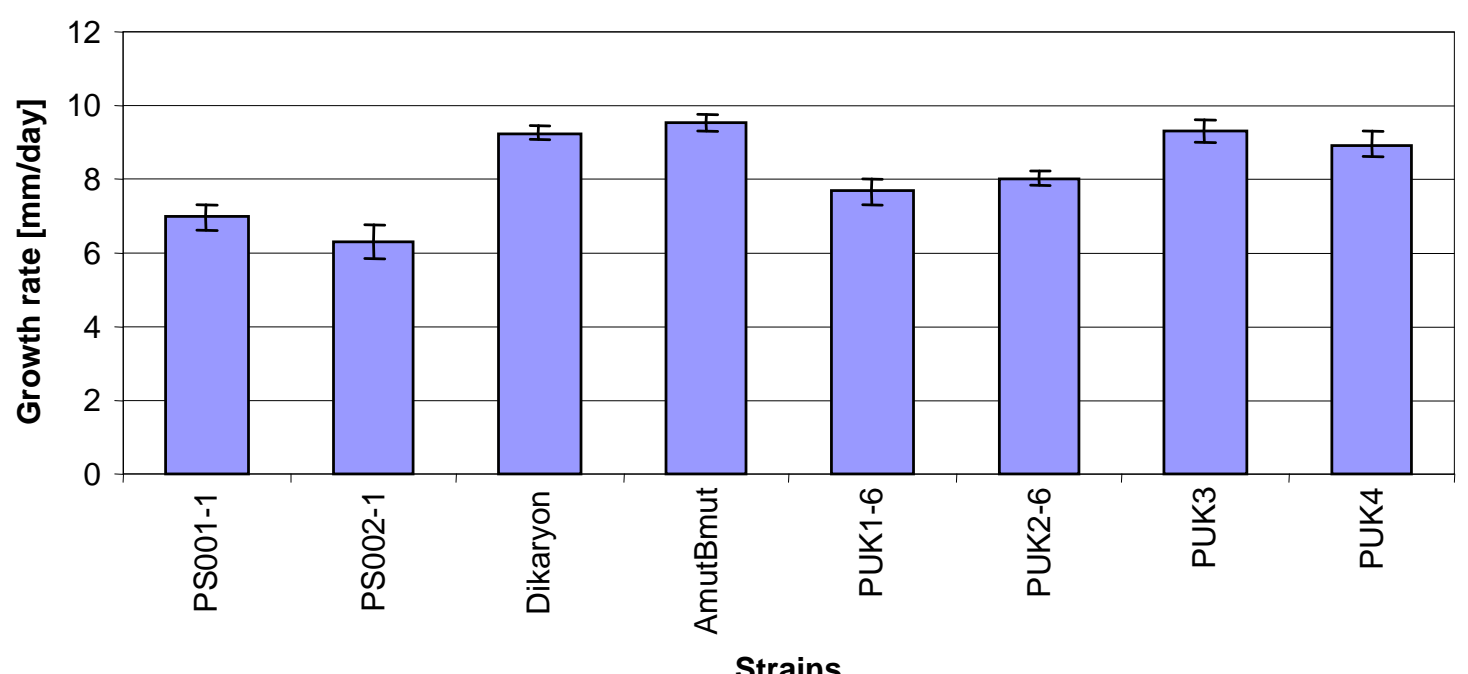

Fig. 7 Determination of growth rates on YMG/T medium at $37^{\circ} \mathrm{C}$. Growth rates were measured as described in the material and method sections. Further to the wildtype homokaryon AmutBmut and the mutant homokaryons PUK1-6, PUK2-6, PUK3 and PUK4 included for comparison are the two AmutBmut co-isogenic, mating-compatible monokaryons PS001-1 and PS002-1 and the dikaryon resulting from mating of these monokaryons. 
are predicted which corresponds to $0.86 \%$ of gene difference to homokaryon AmutBmut. The increase in clones able to initiate fruiting and the increase towards an even 1:1 distribution in normal fruiting phenotype versus mutant phenotype "etiolated stipes" in the higher filial generations (Table 7 and Table 8) supports the positive effect of backcrosses on homogenisation of the genetic material towards the AmutBmut genome.

During the co-isogenisation process, in order to obtain a first impression on its success, PUK1-2 and PUK2-2 from the filial generation F3 were chosen for morphological analysis in comparison to PUK3 and PUK4 (Fig. 8). From different sets of experiments, structures were harvested from the four homokaryons after different periods of cultivation at those time points that were believed to mark the maximum course of development the strains could undergo, the structures were sectioned for morphological comparisons (Fig. 8 and Fig. 9). Although all structures elongated the primordial shaft as typical for the formation of etiolated stipes on the wildtype homokaryon AmutBmut in the dark (compare Fig. 7 in Chapter 2 of this thesis), the sections appeared to indicate that the morphological events in cap tissue formation in PUK1-2 and PUK2-2 proceeded less far than that in PUK3 and PUK4.

The tissue development in the PUK1-2 and the PUK2-2 structures corresponded to the development of primordia stage 2 in the normal fruiting body development (compare Fig. 1 in Chapter 2 of this thesis and Navarro-González 2008) and the tissue development in the PUK3 and PUK4 structures to the development of primordia stages 3 and 4, respectively, in the normal fruiting body development (compare Fig. 1 in Chapter 2 of this thesis and Navarro-González 2008). When comparing the cap structures (Fig. 8 and Fig. 9) with those of etiolated stipes formed at the AmutBmut wildtype strain in the dark, the developmental progress of the etiolated stipes formed in light in cultures of PUK1-2 and PUK2-2 were found to be comparable to structures transferred at day 2 of the normal fruiting body development into constant dark (compare Fig. 6 in Chapter 2 of this thesis), the developmental progress of the etiolated stipes formed in light in cultures of PUK3 to be comparable to structures transferred at day 3 of the normal fruiting body development into constant dark (compare Fig. 6 in Chapter 2 of this thesis) and the developmental progress of the etiolated stipes formed in light in cultures of PUK4 to be comparable to structures transferred at day 4 of the normal fruiting body development into constant dark (compare Fig. 6 in Chapter 2 of this thesis). 

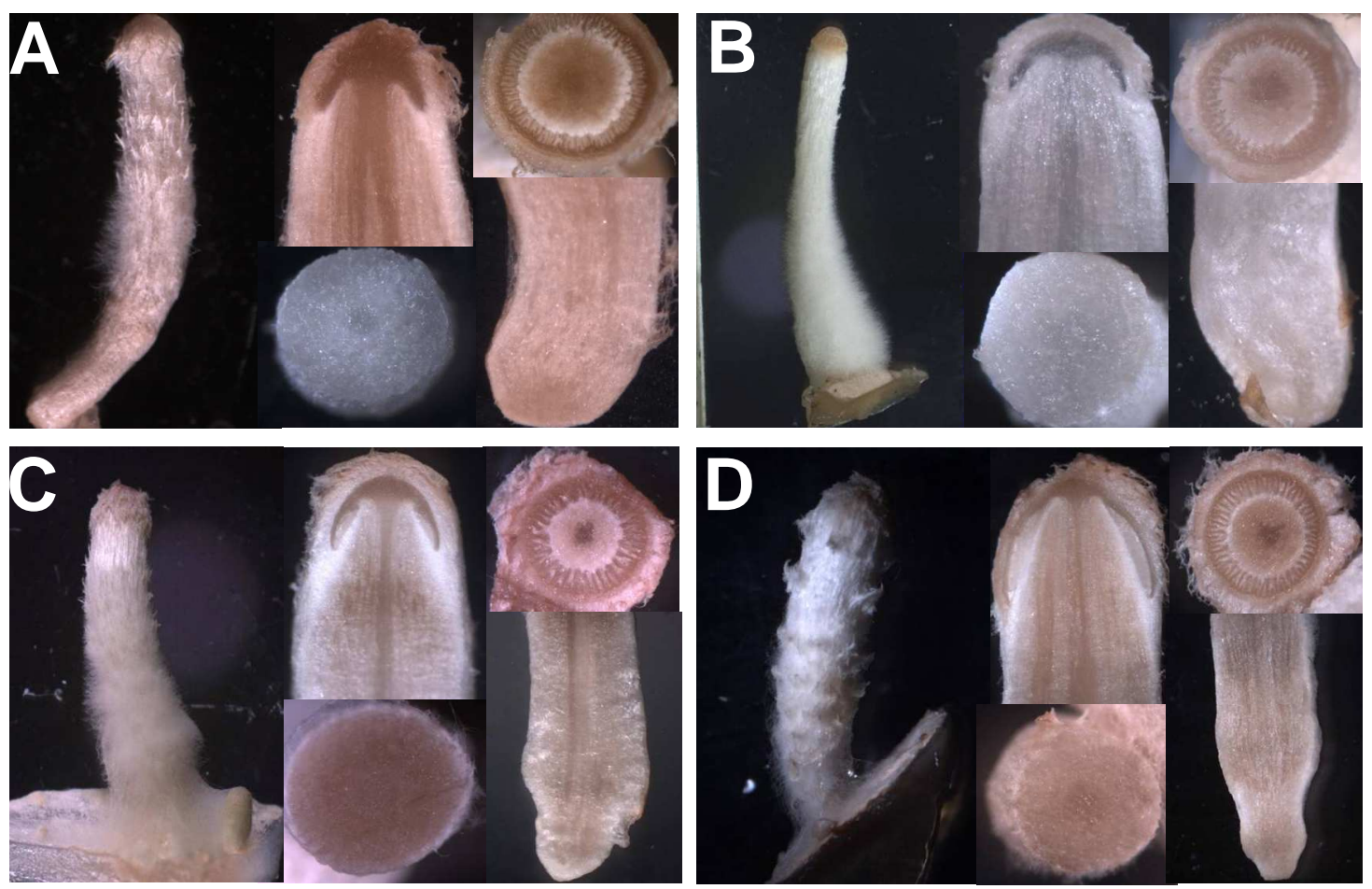

Fig. 8 Etiolated stipes formed under standard fruiting conditions by homokaryons PUK1-2 (A), PUK2-2 (B), PUK3 (C) and PUK 4 (D). Strains were inoculated onto YMG/T medium and incubated for five days at $37^{\circ} \mathrm{C}$ before transferring into standard fruiting conditions at $28^{\circ} \mathrm{C}$. The structure of PUK1-2 was harvested 7 days after transfer of cultures into standard fruiting conditions, the structure of PUK2-2 4 days after transfer of cultures into standard fruiting conditions, the structure of PUK3 5 days after transfer into standard fruiting conditions and the structure of PUK4 6 days after transfer into standard fruiting conditions. Examples of etiolated stipes are shown before sectioning as well as transversal sections and cross-sections through the caps and the base of the primordial shafts, respectively. From the sections of the cap, it is clear that the gill formation in the structures of PUK3 and PUK4 was further progressed than in structures shown for PUK1-2 and PUK2-2. Also, the base of the primordial shafts of structures from PUK3 and PUK4 differed from those of PUK1-2 and PUK2-2 by an indentation that is typical for older structures in fruiting body development (mature primordia that are shortly before or in stipe elongation) and in etiolated stipes formed on the wildtype when structures were transferred at day 5 or day 6 of development into constant dark. These indentations appear to mark the former localisation of attachment of the veil from the cap to the stipe (see Fig. 1 and Fig. 6 in Chapter 2 of this thesis). Very important for the correct interpretation of the pictures, one has however to note that the structures originated from different sets of experiments performed either in the year 2004 or in the year 2005 when the details of the whole developmental progress were little known. It is thus possible that the pictures do mark interims stages in development and not the end point of maximum development as believed at the time of harvest.

Since morphological differences were encountered between etiolated stipes formed by the four homokaryons under standard fruiting conditions (Fig. 6, Fig. 8, Fig. 9), it was also interesting to observe what would happen when fresh fully grown plates of the four mutant strains were transferred after a short light impulse at $28^{\circ}$ into constant dark. 
As shown in Fig. 10, compared to structures developing under standard fruiting conditions, progress in tissue development was less advanced in the etiolated stipes produced in cultures of all mutant homokaryons after their transfer into the dark. In all cases, development of etiolated stipes in constant dark was comparable to development of etiolated stipes formed in cultures of homokaryon AmutBmut treated in the same way (Fig. 10 and Fig. 11 and Fig. 1 in Chapter 2 of this thesis). In conclusion from this study, all four $d s t$ defects appear to act in development under normal fruiting body conditions at a stage later than primary and secondary hyphal knot formation (compare text and Fig. 1 in Chapter 2 of this thesis for further information on these structures formed early in the pathway of fruiting body development).

To perform a more defined study by growing and observing strains of nearly identical genetic background at the same time, the morphology of etiolated stipes formed by homokaryons PUK1-6 and PUK2-6 were subsequently compared with their co-isogenic homokaryons PUK3 and PUK4 (Fig. 11). Etiolated stipes formed by homokaryons PUK1-6 and PUK2-6 under standard fruiting conditions differed in similar way from those of homokaryons PUK3 and PUK4 (Fig. 12 and Fig. 13) as previously seen in the analysis of homokaryons PUK1-2 and PUK2-2 (compare Fig. 6 and Fig. 7 to 10). In summary, on YMG/T medium under standard fruiting conditions etiolated stipes from mutant homokaryon PUK1-6 had an average length of $1.4 \pm$ $0.6 \mathrm{~cm}$, etiolated stipes from strain PUK2-6 an average length of $1.2 \pm 0.3 \mathrm{~cm}$, etiolated stipes from strain PUK3 an average length of $1.2 \pm 0.2 \mathrm{~cm}$ and etiolated stipes from
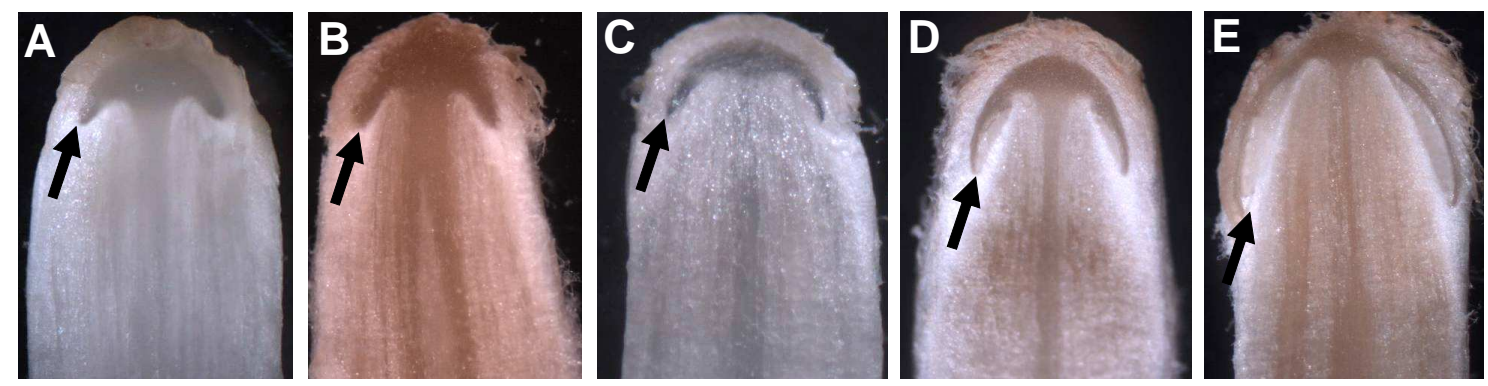

Fig. 9 Comparison of the underdeveloped caps on etiolated stipes formed by fresh, fully grown cultures of homokaryon AmutBmut when transferred after a short light pulse (30 min) for further incubation at $28^{\circ} \mathrm{C}$ into constant dark (A) with underdeveloped caps developed on etiolated stipes formed by PUK1-2 (B), PUK2-2 (C), PUK3 (D) and PUK4 (E) in YMG/T cultures incubated under standard fruiting conditions. The arrows in the photos point to the outer tips of the gills. Structures from PUK1-2, PUK2-2, PUK3 and PUK4 shown in this figure originated from the same sets of experiments than those shown in Fig. 8 and structures were harvested from plates at the same cultural age than the respective structures of the same strain shown in Fig. 8. 


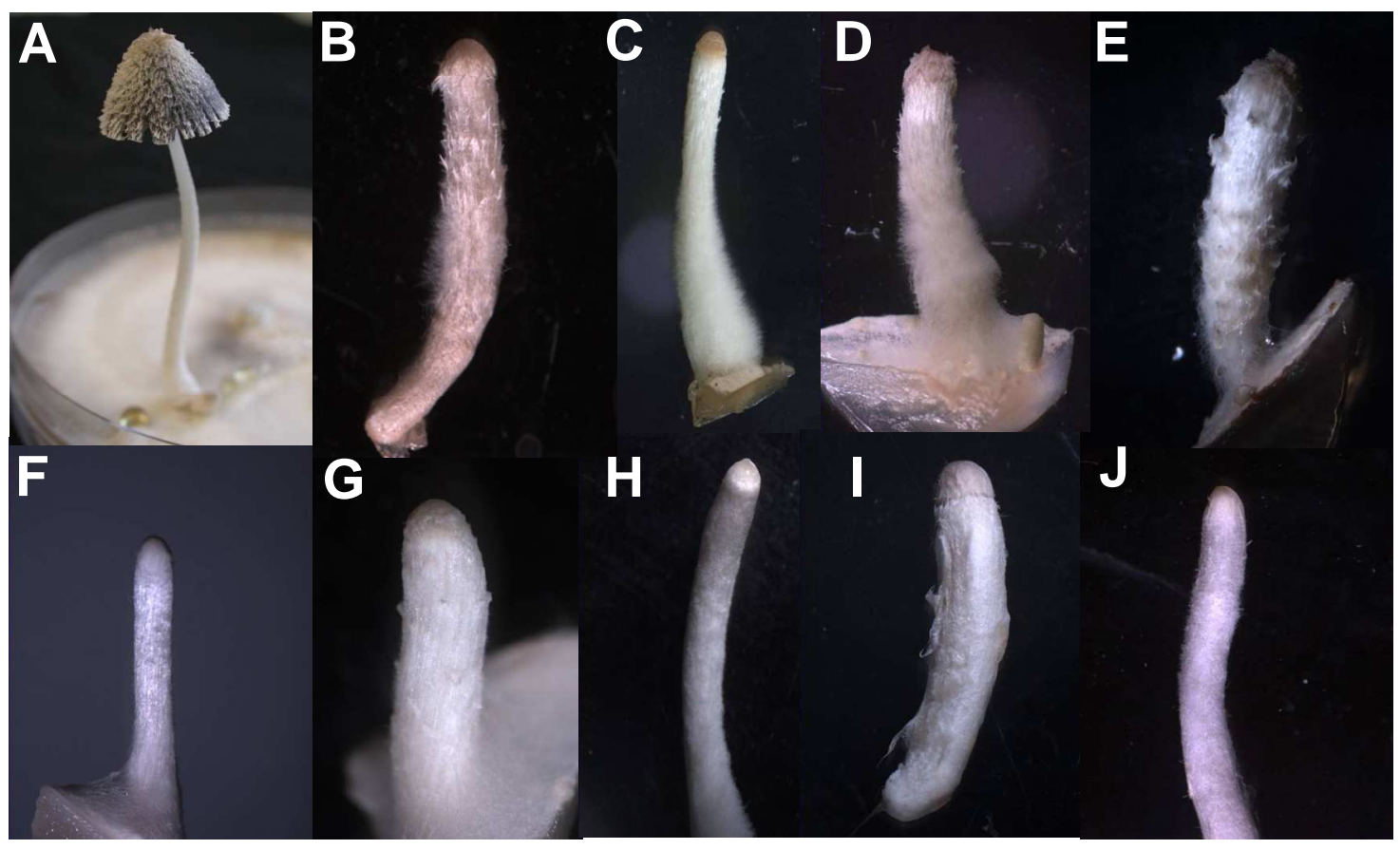

Fig. 10 Comparison of structures formed by homokaryon AmutBmut (A), (F), by mutant homokaryon PUK1-2 (B), (G), by mutant homokaryon PUK2-2 (C), (H), mutant homokaryon PUK3 (D), (I), and mutant homokaryon PUK4 (E), (J) in YMG/T cultures transferred after 5 day growth at $37^{\circ} \mathrm{C}$ in constant dark into standard fruiting conditions at $28^{\circ} \mathrm{C}(\mathrm{A})$ to $(\mathrm{E})$ or after a short light pulse $(30 \mathrm{~min})$ into constant dark at $28^{\circ} \mathrm{C}(\mathrm{F})$ to $(\mathrm{J})$. The mature fruiting body of homokaryon AmutBmut shown in (A) was obtained 8 days after transfer into standard fruiting conditions and the etiolated stipe shown in $(\mathbf{F})$ after five days of incubation at $28^{\circ} \mathrm{C}$ in constant dark. The structures shown in $(\mathbf{B})$ to $(\mathbf{E})$ were from the same set of experiments harvested at the same time points as those shown in Fig. 8 and 9. The pictures shown under $(\mathbf{F})$ to $(\mathbf{J})$ were from different sets of experiments. The etiolated stipe of homokaryon AmutBmut shown in $\mathrm{F}$ was harvested five days after transfer into constant dark at $28^{\circ} \mathrm{C}$, the structure of mutant homokaryon PUK1-2 6 days after transfer into constant dark at $28^{\circ} \mathrm{C}$, the structures of mutant homokaryon PUK2-2 3 days and PUK3 8 days after transfer into constant dark at $28^{\circ} \mathrm{C}$, and the structure of mutant homokaryon PUK4 7 days after transfer into constant dark at $28^{\circ} \mathrm{C}$. Also in this comparison of different structures, it has therefore to be noted that harvested structures did possibly not reach the maximum point of development. Judging from the outer morphology, the structures shown in $(\mathbf{B})$ and $(\mathbf{C})$ correspond in cap development to fully developed etiolated stipes formed when primary hyphal knots, secondary hyphal knots or primordia of stage 1 were transferred into constant dark, whereas the structures shown in (D) and (E) correspond in cap development to fully etiolated stipes formed when primordia of stage 3 were transferred into constant dark (compare Fig. 6 in Chapter 2). When comparing the structure shown in $(\mathbf{B})$ to $(\mathbf{E})$ with those shown in $(\mathbf{G})$ to $(\mathbf{J})$, it is to be noted that at least the cap development of etiolated stipes by mutant homokaryons PUK3 and PUK4 upon early transfer of cultures into constant were less advanced than cap development of etiolated stipes formed in cultures under normal fruiting conditions. Judging from the outer morphology, the structures shown in $(\mathbf{G})$ to $(\mathbf{H})$ for the four different mutant homokaryons appear to be about the same in cap development as the structure as shown in $(\mathbf{F})$ for the wildtype homokaryon AmutBmut. The same structures shown under $(\mathbf{G})$ to $(\mathbf{H})$ were subsequently sectioned and presented in Fig. 11. 

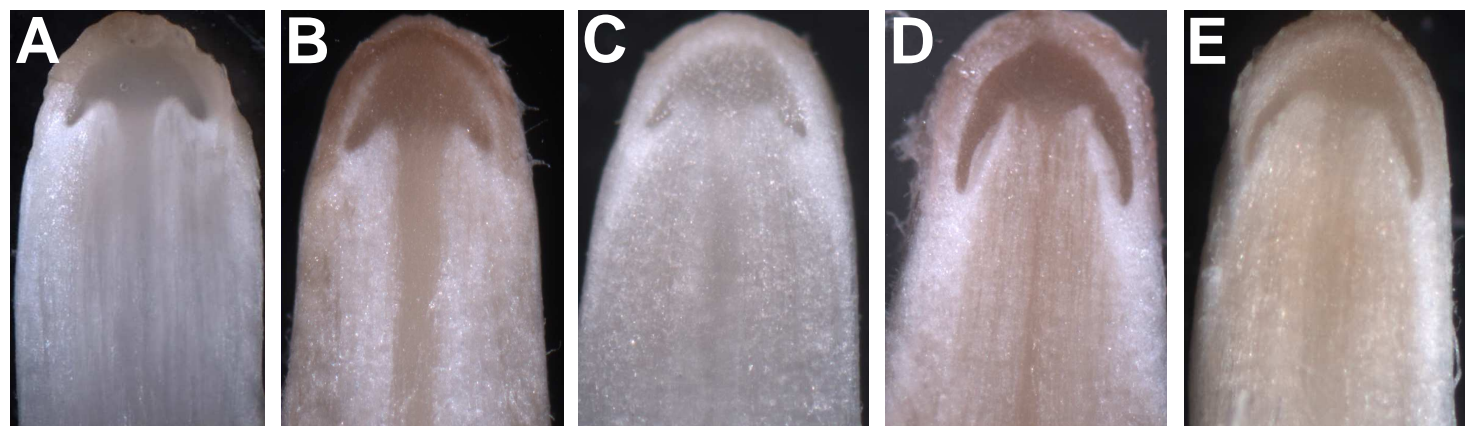

Fig. 11 Transversal sections of etiolated stipes formed by homokaryons PUK1-2 (A), PUK2-2 (B), PUK3 (C) and PUK 4 (D) on YMG/T cultures transferred after 5 day growth in constant dark at $37^{\circ} \mathrm{C}$ after a short light pulse $\left(30\right.$ min) into constant dark at $28^{\circ} \mathrm{C}$. Structures shown are identical to the structures shown in Fig. $10(\mathbf{F})$ to $(\mathbf{J})$. Cap development in the structures shown in (A) to $(\mathbf{C})$ correspond to etiolated stipes formed when primary hyphal knots, secondary hyphal knots or primordia of stage 1 of wildtype homokaryon AmutBmut were transferred into constant dark (compare Fig. 6 in Chapter 2 of this thesis), whereas the structures shown in (D) and (E) appear to be further developed since they correspond to etiolated stipes formed when primordia stage 2 were transferred into constant dark (compare Fig. 6 in Chapter 2 of this thesis).

strain PUK4 an average length of $0.9 \pm 0.2 \mathrm{~cm}$. Furthermore, etiolated stipes from homokaryons PUK1-6 and from PUK2-6 had a less advanced cap than etiolated stipes from homokaryons PUK3 and PUK4 and their stipes were more equally shaped without an indentation at the base of the stipes as seen in the structures coming from PUK3 and PUK4 (Fig. 13). As documented in the legends of Fig. 12 and Fig. 13, the analysed

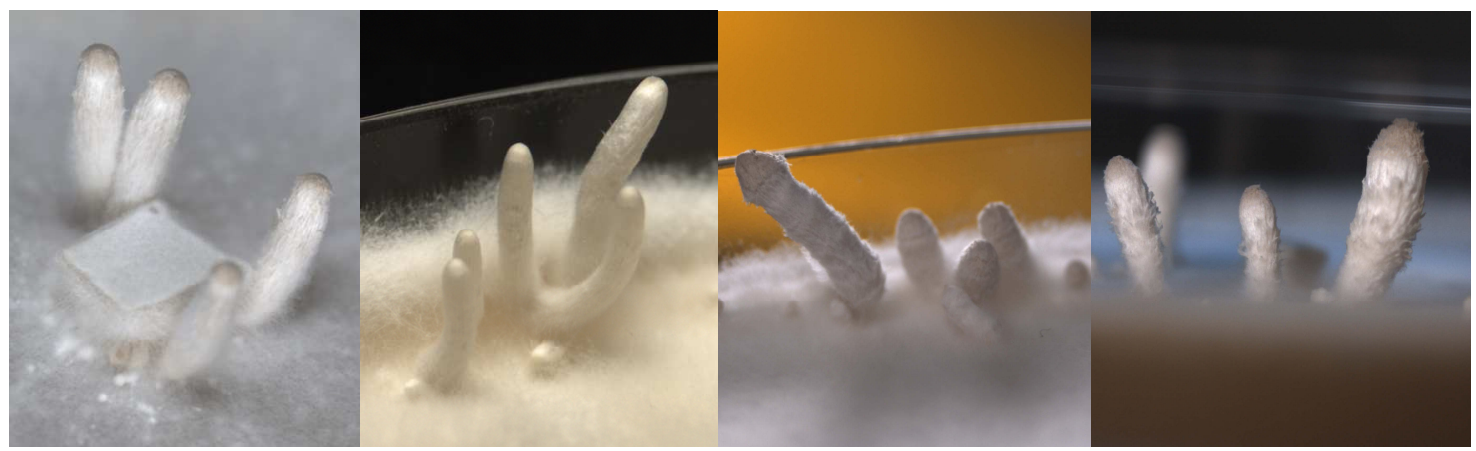

Fig. 12 Etiolated stipes formed under standard fruiting conditions by homokaryons PUK1-6 (A), PUK2-6 (B), PUK3 (C) and PUK 4 (D). Cultures of the different mutant homokaryons were grown for five days at $37^{\circ} \mathrm{C}$ in constant dark, after which plates were transferred into $28^{\circ} \mathrm{C}$ into standard fruiting conditions. Photos of etiolated stipes in the cultures were taken 14 days (PUK1-6), 3 days (PUK2-6), 8 days (PUK3) and 9 days (PUK4), respectively, after the transfer of cultures into standard fruiting conditions. Note that he photos taken for PUK1-6 and PUK2-6 were from the one set of experiments, and the photos taken for PUK3 and PUK4 from another set of experiments. Sections of etiolated stipes from the same sets of experiments as presented here are shown in Fig. 13. 

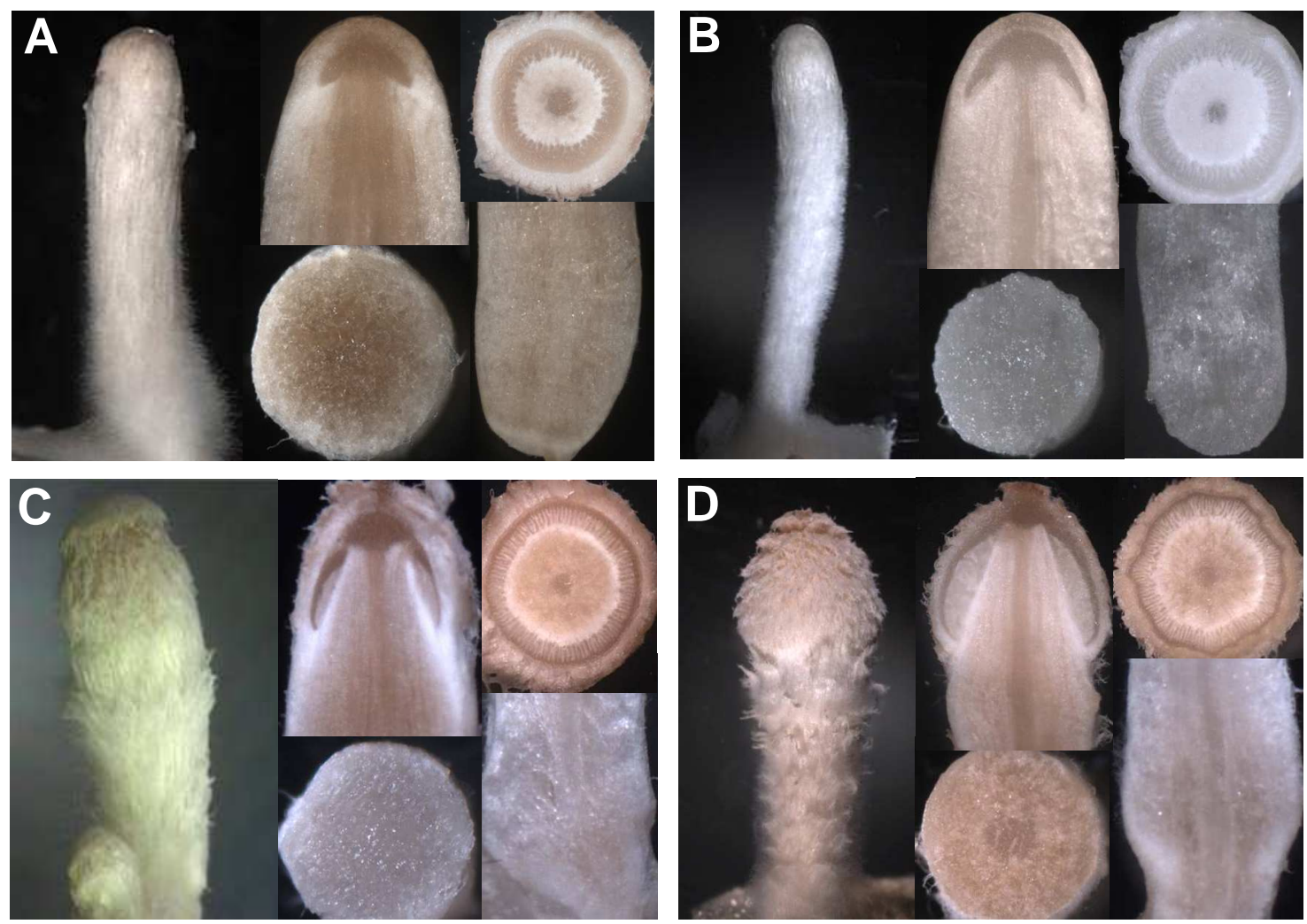

Fig. 13 Etiolated stipes formed under standard fruiting conditions by homokaryons PUK1-6 (A), PUK2-6 (B), PUK3 (C) and PUK4 (D). Strains were inoculated onto YMG/T medium and incubated for 5 days at $37^{\circ} \mathrm{C}$ before transferring into standard fruiting conditions at $28^{\circ} \mathrm{C}$. The structures shown were from the same sets of experiments than those shown in Fig. 12. The structure of PUK1-6 was harvested 14 days after transfer of cultures into standard fruiting conditions, the structure of PUK2-6 3 days after transfer of cultures into standard fruiting conditions, the structure of PUK3 8 days after transfer into standard fruiting conditions and the structure of PUK4 7 days after transfer into standard fruiting conditions. Examples of etiolated stipes are shown before sectioning as well as transversal sections and cross-sections through the caps and the base of the primordial shafts, respectively. From the sections of the cap, it is clear that the gill formation in the structures of PUK3 and PUK4 is further progressed than in structures of PUK1-6 and PUK2-6. Also, the base of the primordial shafts of structures from PUK3 and PUK4 differ from those of PUK1-6 and PUK2-6 by an indentation that is typical for older structures in fruiting body development (mature primordia that are shortly before or in stipe elongation) and in etiolated stipes formed on the wildtype when structures were transferred at day 5 or day 6 of development into constant dark. These indentations appear to mark the former localisation of attachment of the veil from the cap to the stipe (see Fig. 1 and Fig. 6 in Chapter 2 of this thesis)

etiolated stipes from PUK1-6, PUK2-6, PUK3 and PUK4 came from plates of different cultural ages. This was because etiolated stipes were formed at different days of development, suggesting again that the different defects in light-regulated development occur at different stages within the pathway of fruiting body formation. To document this further, 20 different plates per mutant homokaryon as well as 20 plates from the wildtype homokaryon AmutBmut were observed on daily basis after their transfer into 
standard fruiting conditions. Formation of etiolated stipes and/or fruiting bodies was noted and the average day at which a phenotype "etiolated stipe", respectively a phenotype "mature fruiting body" occurred (Table 9). As described in Chapter 2 of this thesis, homokaryon AmutBmut formed mature fruiting bodies at day $7 \pm 0$ of cultivation at $28^{\circ} \mathrm{C}$ under standard fruiting conditions, homokaryon PUK1-6 etiolated stipes at day $14 \pm 2$ at $28^{\circ} \mathrm{C}$ under standard fruiting conditions, homokaryon PUK2-6 etiolated stipes at day $3 \pm 1$ at $28^{\circ} \mathrm{C}$ under standard fruiting conditions, homokaryon PUK3 etiolated stipes at day $9 \pm 1$ at $28^{\circ} \mathrm{C}$ under standard fruiting conditions and homokaryon PUK4 etiolated stipes at day $8 \pm 1$ at $28^{\circ} \mathrm{C}$ under standard fruiting conditions. Accordingly, in PUK2-6, PUK3 and PUK4, the initiation of fruiting body development was normal and the day of appearance of the etiolated stipe phenotype correlated well with a normal tissue development in their cap up to the time point at which the defect interfere (compare Fig. 13 and Fig. 1 in Chapter 2 of this thesis). In contrast, in cultures of PUK1-6, initiation of fruiting body development was delayed by $10 \pm 2$ days as well as the process of etiolated stipe formation from secondary hyphal knots that appeared normal in look. It took $5 \pm 2$ days upon secondary hyphal knot formation to give etiolated stipes with a cap showing a stage of tissue development that correspond to stage day 2 in the normal primordia development (compare Fig. 13 and Fig. 1 in Chapter 2 of this thesis). Furthermore, also homokaryon PUK4 was special in behaviour. Although etiolated stipes occurred on day 6 of development (Table 9), some structures finally transferred into fruiting bodies of abnormal shapes (Fig. 14). The base of the stipes of these fruiting bodies corresponding to the etiolated stipe differed from the primordial shaft of fruiting bodies from the wildtype homokaryon AmutBmut (Fig. 14B) in addition to that fruiting bodies of PUK4 produced only few spores of slightly smaller length (Fig. 15, Table 10). This behaviour was also sometimes observed with the parental strain B-1918 during the performance of this thesis as well in published work by Lu (2000) and Money and Ravishankar (2005). Previous unpublished work by J.D. Granado and U. Kües in Zurich showed in contrast that the phenotype of B-1918 in the laboratory of Microbiology at the ETH Zurich was 100\% stable under standard fruiting conditions. Only when agar sources were changed from Serva to other suppliers, when tap water was used (observation by the project student 
Table 9 Time-course of development of etiolated stipes and/or fruiting bodies in YMG/T cultures of different mutant homokaryons and the wildtype homokaryon AmutBmut after transfer of 5 days-old fully grown plates from $37^{\circ} \mathrm{C}$ into standard fruiting conditions.

\begin{tabular}{|c|c|c|c|c|c|c|c|c|c|c|c|c|c|c|c|c|}
\hline \multirow[t]{2}{*}{ Strains } & \multicolumn{16}{|c|}{ Day of development in standard fruiting condition at $28^{\circ} \mathrm{C}$} \\
\hline & $\mathbf{0}$ & $\mathbf{1}$ & 2 & 3 & 4 & 5 & 6 & 7 & 8 & 9 & 10 & 11 & 12 & 13 & 14 & 15 \\
\hline AmutBmut & - & & & & & & $\rightarrow$ & $\mathbf{f}$ & & & & & & & & \\
\hline PUK1-6 & & & & & & & & & & & & & & & d & \\
\hline PUK2-6 & & & $\rightarrow$ & d & & & & & & & & & & & & \\
\hline PUK3 & & & & & & & & & & d & & & & & & \\
\hline PUK4 & & & & & & & & & d & af & & & & & & \\
\hline
\end{tabular}

$\mathrm{f}=$ normal fruiting body with abundant numbers of black spores

af $=$ abnormal fruiting body with few spores

$\mathrm{d}=$ etiolated stipes with an elongated primordial shaft and a rudimentary cap

$\longrightarrow$ start of development up to final stage of development
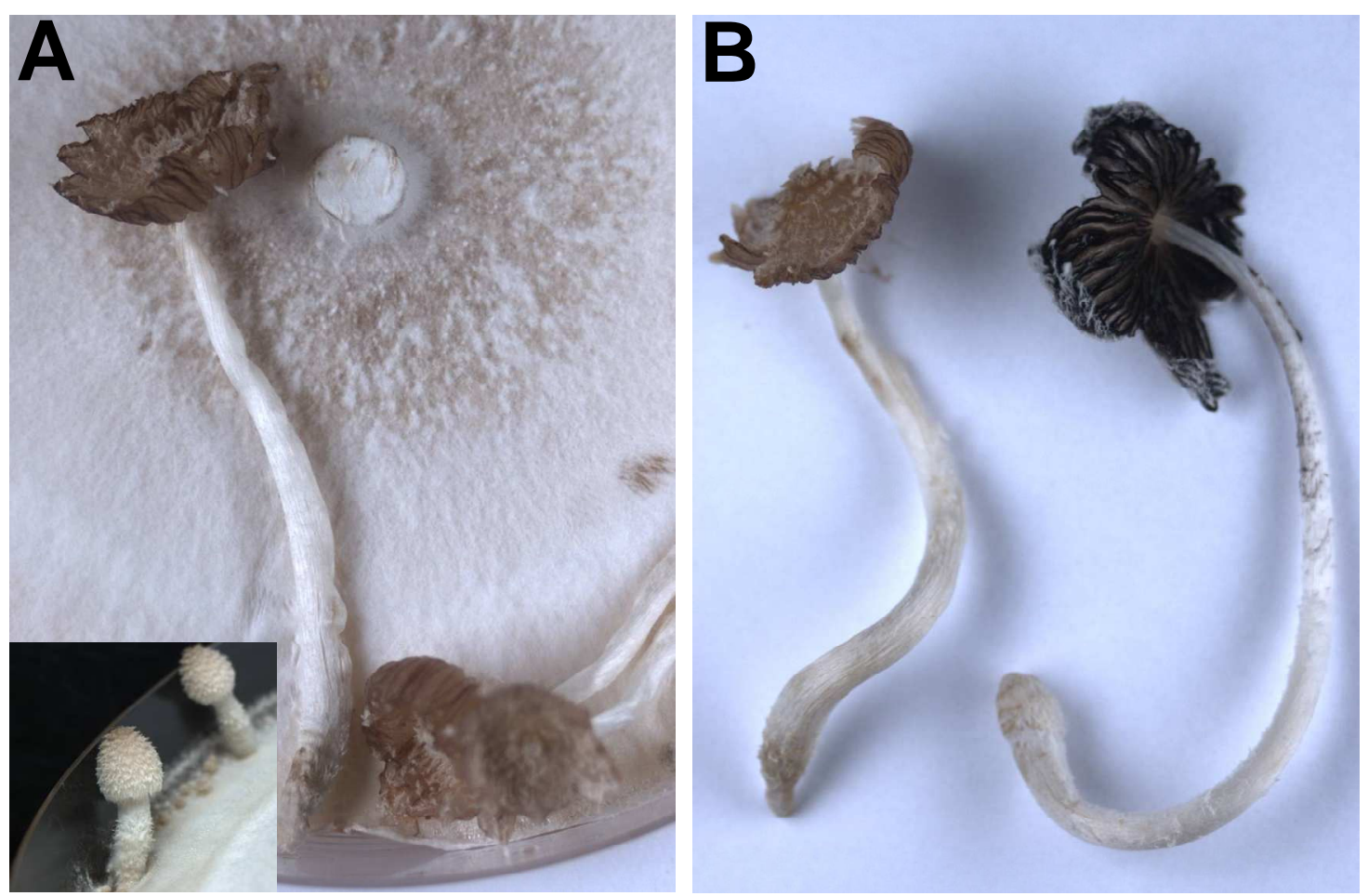

Fig. 14 Under standard fruiting conditions, the dst4 -1 mutant homokaryon PUK4 can form one day upon the occurrence of the etiolated stipes abnormal fruiting bodies with an altered primordial shaft due to the previous etiolated stipe formation. In (A), maturing and mature fruiting bodies of homokaryon PUK4 on Petri dishes are shown and in (B) at the left a fruiting body of homokaryon PUK4 is shown and at the right a normal fruiting body of homokaryon AmutBmut for comparison. Note that the PUK4 mushrooms form only few basidiospores (compare also Fig. 15). 


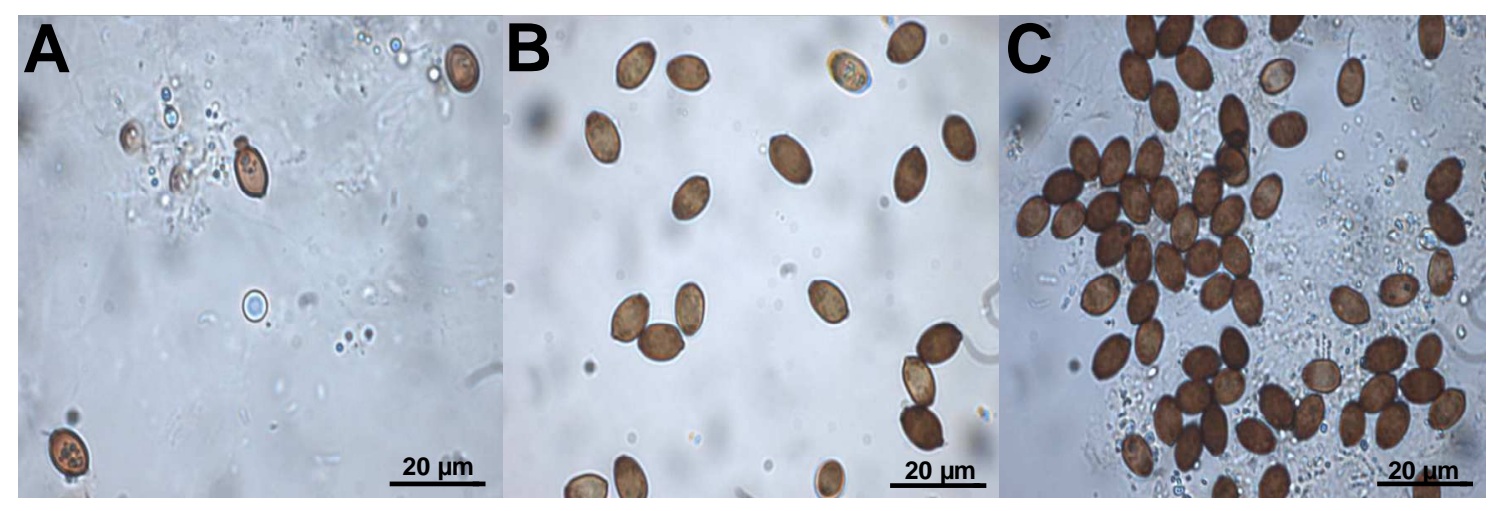

Fig. 15 PUK4 fruiting bodies produce abnormal low numbers of basidiospores that in addition have only a pale colour. Caps of fruiting bodies were transferred into $1 \mathrm{ml}$ of sterile water, mixed with the water and a drop of the spore solutions were observed under the microscope. (A) Spores from a cap of PUK4, (B) spores from a cap of homokaryon AmutBmut and $(\mathbf{C})$ spores from a cap of the dikaryon PS001-1 X PS002-1. Note that the colour of basidiospores from mutant PUK4 and from homokaryon AmutBmut was paler than basidiospores coming from the dikaryon.

Tina Schäfer in Göttingen) or when Petri dishes upon formation of etiolated stipes were turned upside down making the cap touching to the surface of the culture, cultures gave rise to completion of fruiting body development. In contrast, washing positiveacting agars several times with distilled water prior to addition to the YMG/T medium blocked completion of fruiting body formation upon etiolated stipe production. The data suggested that some kind of metal or mineral effect might contribute to the phenomenon (U. Kües, personal communication).

Table 10 Basidiospores formed on abnormal fruiting bodies of mutant homokaryon PUK4 compared to its parental homokaryon AmutBmut and a co-isogenic dikaryon PS001-1 $x$ PSO02-1

\begin{tabular}{|l|c|c|c|}
\hline \multirow{2}{*}{ Strain } & \multirow{2}{*}{$\begin{array}{c}\text { Amount of } \\
\text { basidiospores }\end{array}$} & \multicolumn{2}{c|}{ Size of basidiospores * } \\
\cline { 3 - 4 } & & Width $(\boldsymbol{\mu m})$ & Length $(\boldsymbol{\mu m})$ \\
\hline AmutBmut & $2.0 \times 10^{8}$ & $6.86 \pm 0.36$ & $10.43 \pm 0.62$ \\
\hline Dikaroyn PS001-1 x PS002-1 & $2.37 \times 10^{8}$ & $6.19 \pm 0.28$ & $9.28 \pm 0.67$ \\
\hline PUK4 (dst4 mutant) & $1.43 \times 10^{7}$ & $6.34 \pm 0.55$ & $8.10 \pm 1.08$ \\
\hline
\end{tabular}

* Each 20 basidiospores were analysed 


\subsubsection{Analysis of the fruiting behaviour of mutant homokaryons under conditions differing from standard fruiting conditions}

Due to the previous observations by other researchers, tap water experiments as well as experiments with turning cultures upside-down were performed also in this thesis using mutant homokaryons 7K17, B-1918, PUK1-4 and PUK2-3, PUK3, and PUK4 and, as a control, homokaryon AmutBmut.

The $d s t 4-1$ mutant B-1918 and dst3-1 mutant 7K17 both did grow more vigorously on YMG/T medium made up with tap water (Fig. 16B, E) than on medium made up with distilled water (Fig. 16A, D). Both strains completed fruiting body formation under standard fruiting conditions on medium made up with tap water (Fig. 16C, F). Fruiting bodies had however an abnormal shape with a long and thick etiolated stipe underneath the normally elongated stipe. Caps were filled with black spores that upon cap opening were released by autolysis. Similar results were obtained with the $d s t 3-1$ mutant PUK3 (not documented) and the dst4-1 mutant PUK4 (Fig. 17).

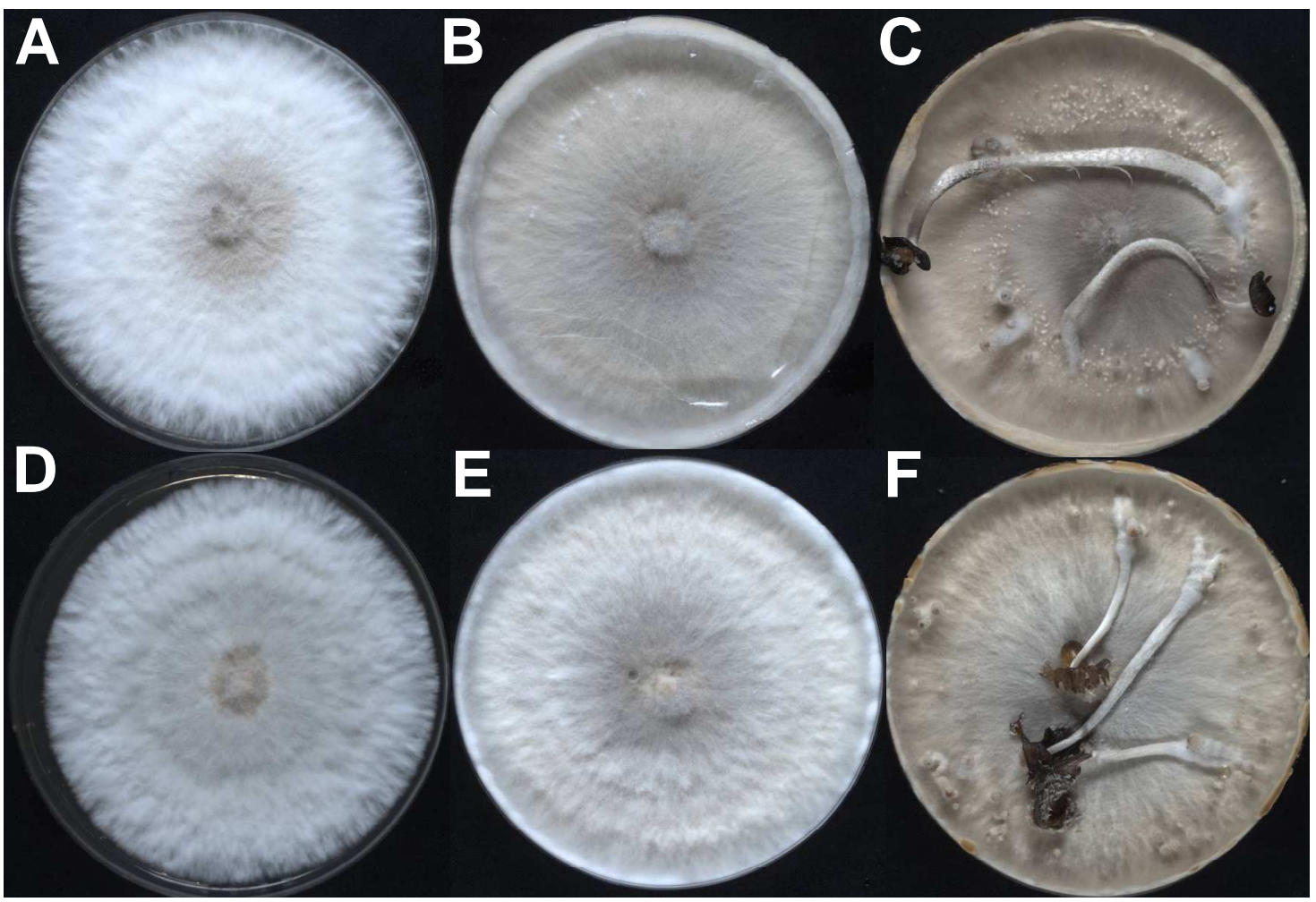

Fig. 16 Mutant homokaryon B-1918 (A) to (C) and mutant homokaryon 7K17 (D) to (F) on YMG/T medium made up with distilled water (A), (D), respectively with tap water (B), (E) after six days of growth at $37^{\circ} \mathrm{C}$ in the dark and seven days after transfer of six-day old plates into standard fruiting conditions at $28^{\circ} \mathrm{C}(\mathrm{C}),(\mathrm{F})$. 

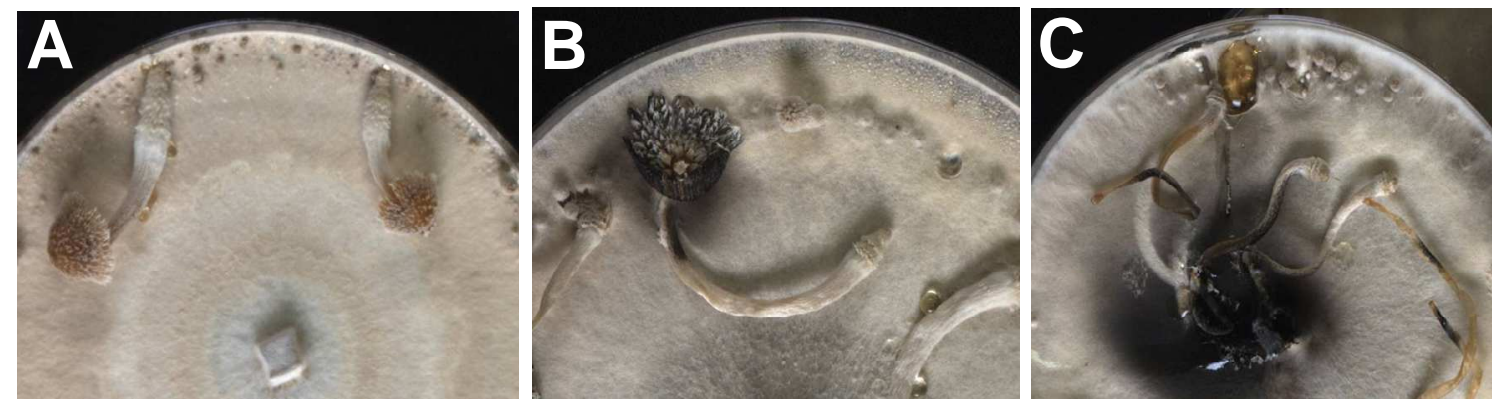

Fig. 17 Mutant homokaryon PUK4 grown for five days at $37^{\circ} \mathrm{C}$ in constant dark on YMG/T medium made up with distilled water $(A)$ and tap water $(B)$, respectively, upon which plates were transferred for 8 days into standard fruiting conditions at $28^{\circ} \mathrm{C}$ and wildtype homokaryon AmutBmut on YMG/T medium made up with tap water (C) incubated in parallel under the same conditions. Note that on medium made up with distilled water, mutant PUK4 has an etiolated stipe underneath its normal shaped stipe and it opened up its light-coloured cap only partially. On medium made up with tap water, mushrooms were stronger with only a very short etiolated stipe and a fully opened cap being black by abundant spore production. For comparison, on tap water $\mathrm{YMG} / \mathrm{T}$ agar plates inoculated with homokaryon AmutBmut, normal shaped fruiting bodies with many black spores appeared that autolysed already at the time point of photographing (5 1/5 after the light was switched on at day 7 of development) unlike the PUK4 structures of the same age shown in (A) and (B).

Also in the case of mutants carrying a $d s t 1-2$ or a dst2-1 defect [tested: homokaryons PUK1-4 from the fifth filial generation of the AmutBmut co-isogenisation process performed with PS001-1 (see Table 7) and PUK2-3 from the fourth filial generation of the AmutBmut co-isogenisation process performed with PS001-1 (see Table 8)] the etiolated stipes were much stronger, longer and more thick on YMG/T medium made up with tap water than on medium made up with distilled water (Fig. 18 and Fig. 19). The etiolated stipes of PUK2-3 were longest and strongest of all (Fig. 19A). The cap of a few etiolated stipes of PUK1-4 developed also further and opened but within the cap there were only very few spores as judged by the lightbrown colour of the cap (Fig. 18B). The cap of a few of the etiolated stipes of PUK2-3 on YMG/T medium made up with tap water also developed further and showed production of black basidiospores (not photographed).

In the set of experiments described in Table 9, homokaryons 7K17, B-1918, PUK1-6, PUK2-6, PUK3 and PUK4 and in addition the wildtype homokaryon AmutBmut were cultured for 5 days at $37^{\circ} \mathrm{C}$ in constant dark on normal YMG/T medium made up with distilled water. Subsequently, plates were transferred into standard fruiting conditions at $28^{\circ} \mathrm{C}$. After 8 days of incubation at $28^{\circ} \mathrm{C}$, all mutant homokaryons formed 

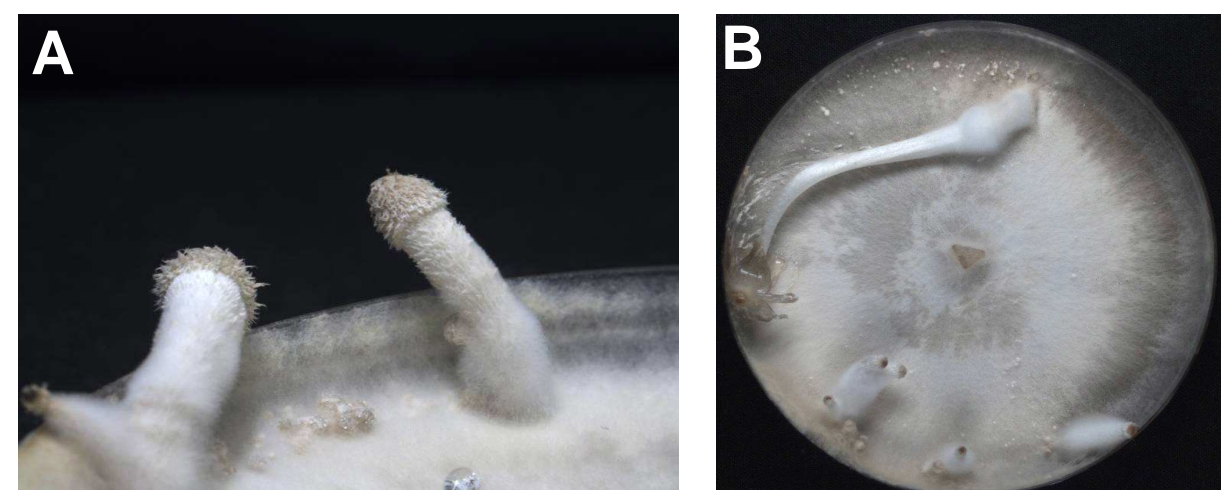

Fig. 18 dst1-2 mutant homokaryon PUK1-4 grown for five days at $37^{\circ} \mathrm{C}$ in constant dark on YMG/T medium made up with tap water upon which plates were transferred into standard fruiting conditions at $\mathbf{2 8}^{\circ} \mathbf{C}$. (A) Strong elongated stipes are formed with bigger rudimentary caps (photographed after 11 days of incubation at $28^{\circ} \mathrm{C}$ under standard fruiting conditions) whilst as shown in (B) some structures may also complete fruiting body development as documented by the mushroom with an up-normal etiolated stipe underneath the normally elongated stipe and the light brown opened and autolysing cap.

etiolated stipes and homokaryon AmutBmut formed mature fruiting bodies. Plates were then further incubated for seven days at $28^{\circ} \mathrm{C}$ at standard fruiting conditions. Next, plates were turned upside down and incubated for seven days at $28^{\circ} \mathrm{C}$ under standard fruiting conditions. In plates of homokaryon AmutBmut, likely due to the limited light illumination of the agar surface with the mycelium, the formation of small etiolated stipes was initiated (Fig. 20A). New formation of etiolated stipes were also seen in some plates of the mutants (e.g. see Fig. 20B, C and E). Of the mutant homokaryons, the etiolated stipes of strains PUK1-6 and PUK2-6 (Fig. 20B, C) already existing at the time of turning the plates over were dramatically elongated unlike structures seen in cultures of the mutants PUK3 and PUK4 that were already established previously to the turnover of the plates (Fig. 20D, E). In case of mutant PUK4, however, also in a few instances matured fruiting bodies were obtained in this series of experiments (Fig. 20E). Overall, etiolated stipes on plates of mutant homokaryons PUK3 and PUK4 had a very senescent appearance (Fig. 20D, E) which raises the idea that turning plates up-side down at an earlier time point (e.g. directly after they were fully established) might give rise to a more advanced development of many more of the structures as could be detected in this specific experiment.

In alike turning agar plates up-side-down upon appearance of etiolated stipes in cultures of mutant homokaryons under standard fruiting conditions, fruiting bodies were relatively easily obtained in cultures of the $d s t 3-1$ homokaryons 7 K17 and PUK3 and in 

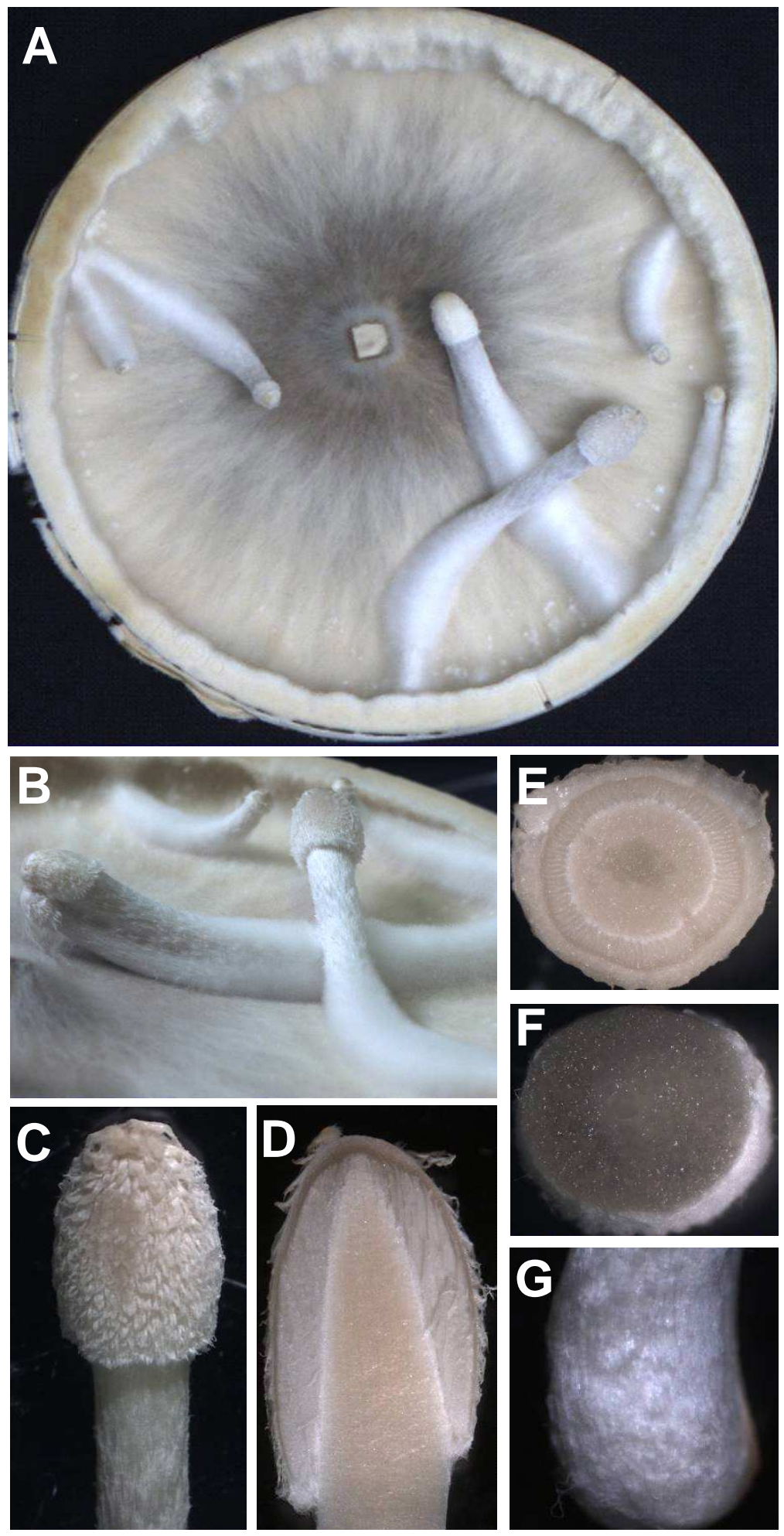

Fig. 19 dst2-1 mutant PUK2-3 grown for grown for five days at $37^{\circ} \mathrm{C}$ in constant dark on YMG/T medium made up with tap water upon which plates were transferred into standard fruiting conditions at $28^{\circ} \mathbf{C}$. (A) and (B) Strong and very long etiolated stipes are formed (photographed six days after transfer into standard fruiting conditions). The caps were further developed with well differentiated gills $(\mathbf{C})$ to $(\mathbf{E})$ corresponding to a development of mature primordia in the normal fruiting pathway of the wildtype homokaryon AmutBmut (stage 5 primordia; compare Fig. 1 in Chapter 2 of this thesis). (F) shows a cross section through the upper part of the stipe about $2 \mathrm{~cm}$ beneath the cap and $(\mathbf{G})$ an enlargement of the base of the etiolated stipe. 


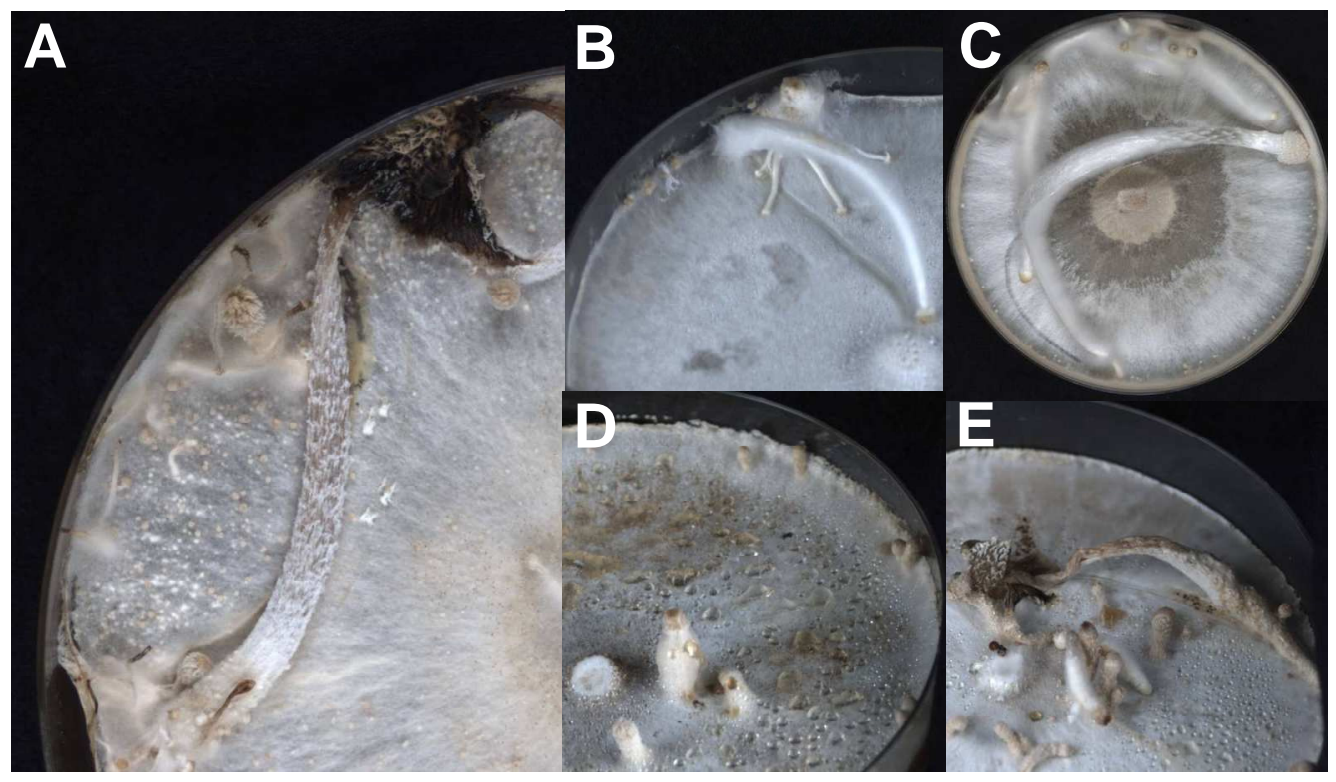

Fig. 20 " Turning plates upside-down experiment". Strains were cultivated on YMG/T medium for five days in constant dark at $37^{\circ} \mathrm{C}$ before transferring them to $28^{\circ} \mathrm{C}$ under standard fruiting conditions. Upon formation of fruiting bodies by homokaryon AmutBmut (A) and etiolated stipes by strains PUK1-6 (B), PUK2-6 (C), PUK3 (D) and PUK4 (E), plates were further incubated for seven days in normal way under standard fruiting conditions before they were turned upside-down for incubation for another seven days at $28^{\circ} \mathrm{C}$ under standard fruiting conditions upon which development on the plates was evaluated a second time.

the dst4-1 homokaryons B-1918 and PUK4 (Fig. 21) supporting the above given idea that with improving culture conditions for the upside-down type of experiments by putting less stress onto the strains (e.g. better hindering of drying out) more etiolated stipes might be forced to finally transform into mature fruiting bodies. In all instances where maturation of fruiting body development was observed in the upside-down experiments, the structure of an etiolated stipe was clearly visible underneath the elongated normal stipe of the mushrooms (Fig. 21). In very few instances, fruiting bodies were also observed in such experiments in cultures of dst1-2 homokaryon PUK1-3 and in cultures of $d s t 2-1$ homokaryon PUK2-3 (not photographed).

Both the results from the tap water experiments and from the upside-down experiments performed in this thesis suggest again that defects caused in the light regulation pathway of fruiting body development can partially be overcome by adding extra metals or minerals to the medium. Thus, there appears to be a connection between the signalling pathways of the environmental signals light and presence of metals and minerals. In this connection it is interesting to note that M. Navarro-González found that by copper addition to YMG/T medium, homokaryon AmutBmut is able to initiate 


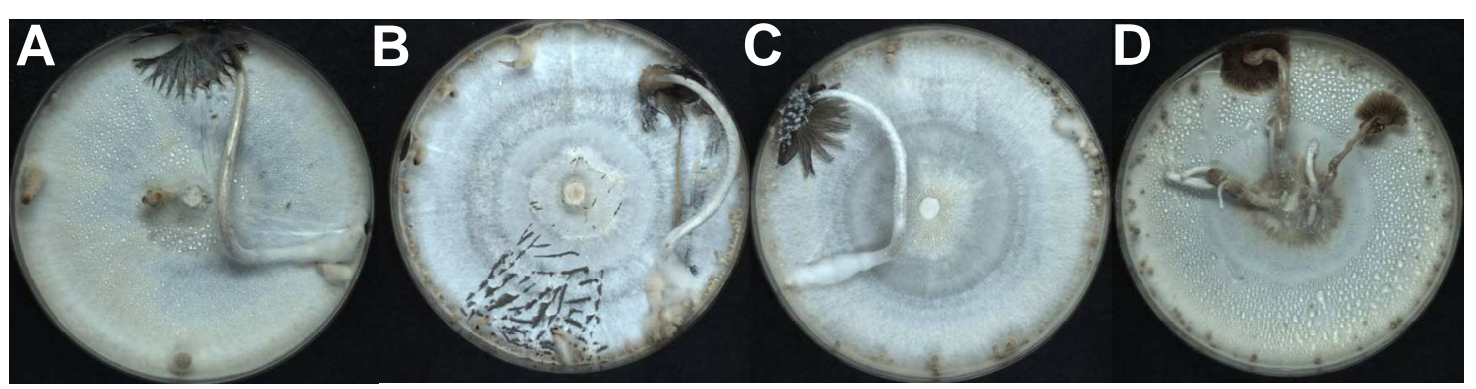

Fig. 21 Mutant homokaryons 7K17 (A), B-1918 (B), PUK3 (C) and PUK4 (D) were grown for five days on YMG/T plates at $37^{\circ} \mathrm{C}$ in constant dark, after which plates were transferred into standard fruiting conditions at $28^{\circ} \mathrm{C}$ and, after formation of etiolated stipes, were turned upside-down for additional seven days of incubation at $28^{\circ} \mathrm{C}$ under standard fruiting conditions. All plates were turned upside-down 7 days after formation of etiolated stipes, i.e. 14 days after transfer into standard fruiting conditions. Note in all cases the elongated stipes beneath the normal elongated stipes of the fruiting bodies.

fruiting body development at the unusual higher temperature of $37^{\circ} \mathrm{C}$ with formation of etiolated stipes in the dark and formation of abnormal mushrooms under day/light conditions at $37^{\circ} \mathrm{C}$ (Navarro-González 2008).

Fruiting body development of homokaryons PUK1-6, PUK2-6, PUK3 and PUK4 were finally tested at $28^{\circ} \mathrm{C}$ also under constant light illumination (Fig. 22). YMG/T plates were incubated directly after incubation also for growth at $28^{\circ} \mathrm{C}$. Results were quite interesting since PUK1-6 gave primordia that were blocked early in development at primordia stage 1 (Fig. 22D) and PUK3 and PUK4 gave primordia that were blocked later in primordia development at primordia stage 3 and 4. Primordia stages 3 and 4 are known from work presented in Chapter 2 of this thesis to require a dark phase for further development. Most interestingly, mutant PUK2-6 gave also under constant light illumination rise to formation of etiolated stipes (Fig. 22). Their morphology did not differ from etiolated stipes formed by the mutant in constant dark (Fig. 11) and not from etiolated stipes formed by the mutant under standard fruiting conditions with alternating dark/light cycles regardless of whether previously grown at $37^{\circ} \mathrm{C}$ in the dark (Fig. 13) or whether grown at $28^{\circ} \mathrm{C}$ under standard fruiting conditions directly toward from the point of illumination (Fig. 23). Unlike cultures that were grown at $28^{\circ} \mathrm{C}$ in constant light (not shown) or in constant dark (Fig. 24), under such growth conditions of alternating dark and light phases, mycelial colonies have a ringed structure due to the alternating light and dark phases and/or due to slight temperature differences caused locally on the mycelium by temporary heating through the direct light illumination. Different from cultures grown at $28^{\circ} \mathrm{C}$ under constant light illumination, etiolated stipes 


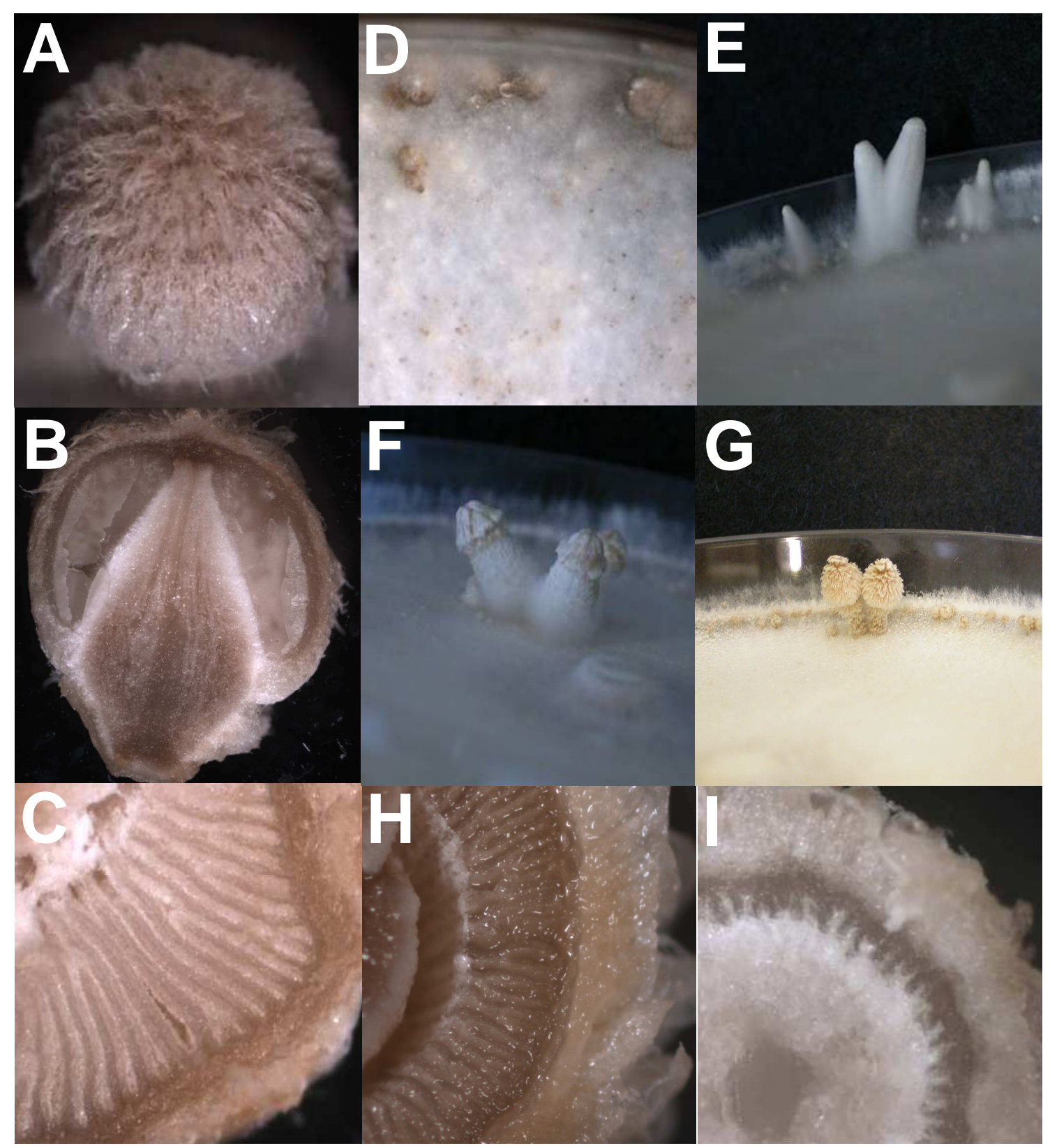

Fig. 22 Fruiting body development at $28^{\circ} \mathrm{C}$ under constant light illumination. YMG/T plates made up with distilled water were inoculated with the control homokaryon AmutBmut or with mutants PUK1-6, PUK2-6, PUK3 and PUK4 and incubated at $28^{\circ} \mathrm{C}$ under constant light illumination with an light energy 30-40 $\mu \mathrm{E} \mathrm{m}^{-2} \mathrm{~s}^{-1}$. Homokaryon AmutBmut formed under these conditions primordia that developed up to stage 5 (A) to (C), (compare structures and sections of structures shown in Fig. 1 in Chapter 2 of this thesis). Mutant PUK1-6 (D) stopped development at an early primordia stage which, judging from the outer morphology, correspond to primordia stage 1 (compare Fig. 1 in Chapter 2 of this thesis). Mutant PUK2-6 (E) formed abundant numbers of etiolated stipes (compare also Fig. 22). Mutants PUK3 and PUK4 formed normal primordia arresting at stage $3(\mathbf{F} ; \mathbf{H})$ and $4(\mathbf{G} ; \mathbf{I})$ respectively, in primordia development; compare also Fig. 1 in Chapter 2 of this thesis). 


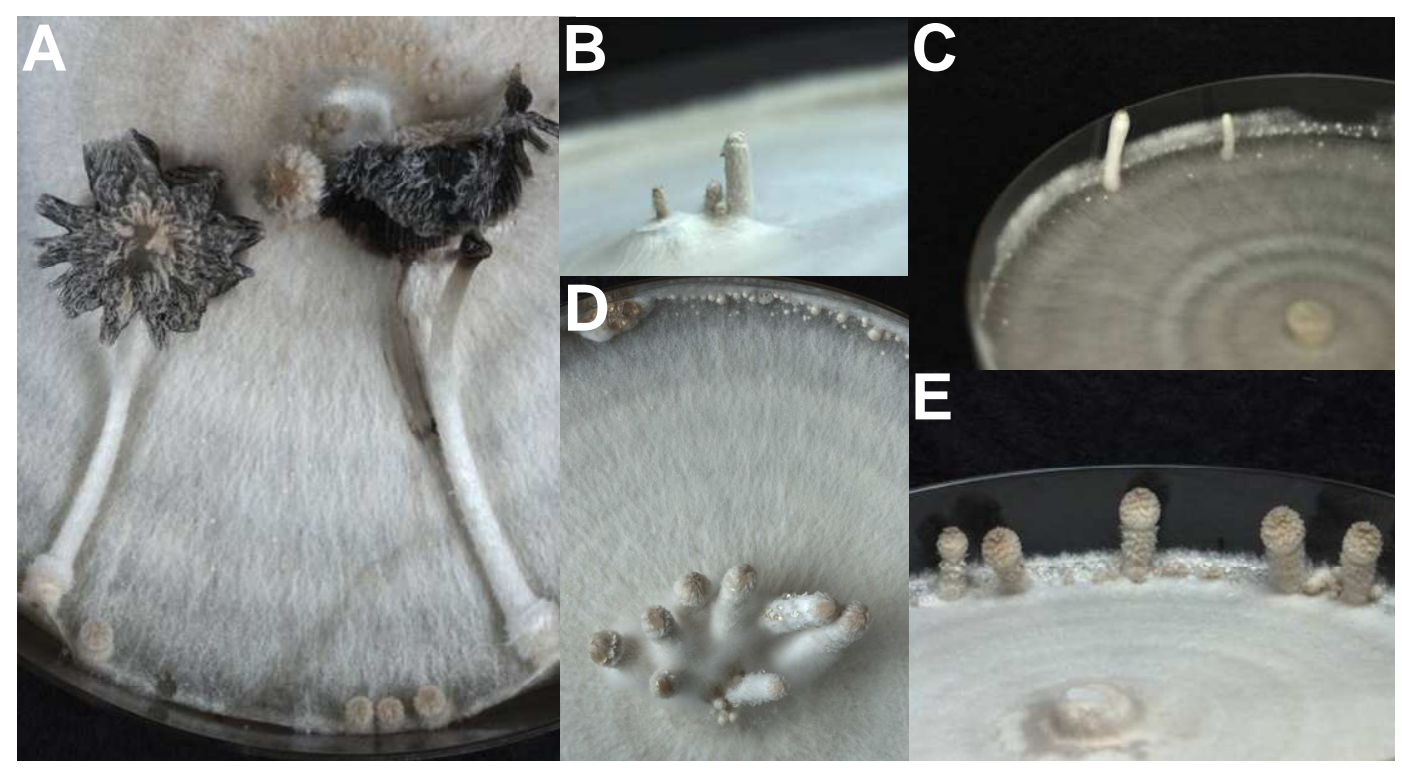

Fig. 23 Etiolated stipes formed by mutant homokaryons PUK1-6 (B), PUK2-6 (C), PUK3 (D) and PUK4 (E) in YMG/T cultures made up with distilled water that were incubated dirtectly upon inoculation at $28^{\circ} \mathrm{C}$ under standard fruiting conditions with alternating dark and light phases in comparison with the control homokayon AmutBmut (A).

appeared in cultures of all four mutants grown at $28^{\circ} \mathrm{C}$ under light/dark cycles (Fig. 23). Thereby, the structures formed by PUK1-6 and PUK2-6 were generally longer than the structures formed by mutants PUK3 and PUK4 that had only shortly elongated primordial shafts (compare Fig. 23B, C and Fig. 23D, E). The different results from cultivating at $28^{\circ} \mathrm{C}$ in constant light and in alternating dark and light phases suggest that there is a complex interplay in regulation of development in which also dark phases have an influence by induction of certain steps in development (compare also Chapter 2 of this thesis). Finally as another exception compared to the other mutant homokaryons, mutant PUK2-6 also formed etiolated stipes of alike morphology when incubated at $37^{\circ} \mathrm{C}$ in constant dark or in constant light (Fig. 25) unlike the three other mutants that never initiated fruiting body development at this higher temperature under constant illumination and in constant dark (10 plates per mutant strain were tested). Furthermore, mutant PUK2-6 formed etiolated stipes when inoculated on YMG/T plates made up with distilled water and kept directly at $28^{\circ} \mathrm{C}$ in constant dark also for growth without any in between exposure to a light signal. Plates were evaluated at 8 days of incubation (not photographed). Cultures of mutants PUK1-6, PUK3 and PUK4 incubated in parallel did not initiate fruiting body development during the incubation for 8 days at $28^{\circ} \mathrm{C}$ in constant dark. 

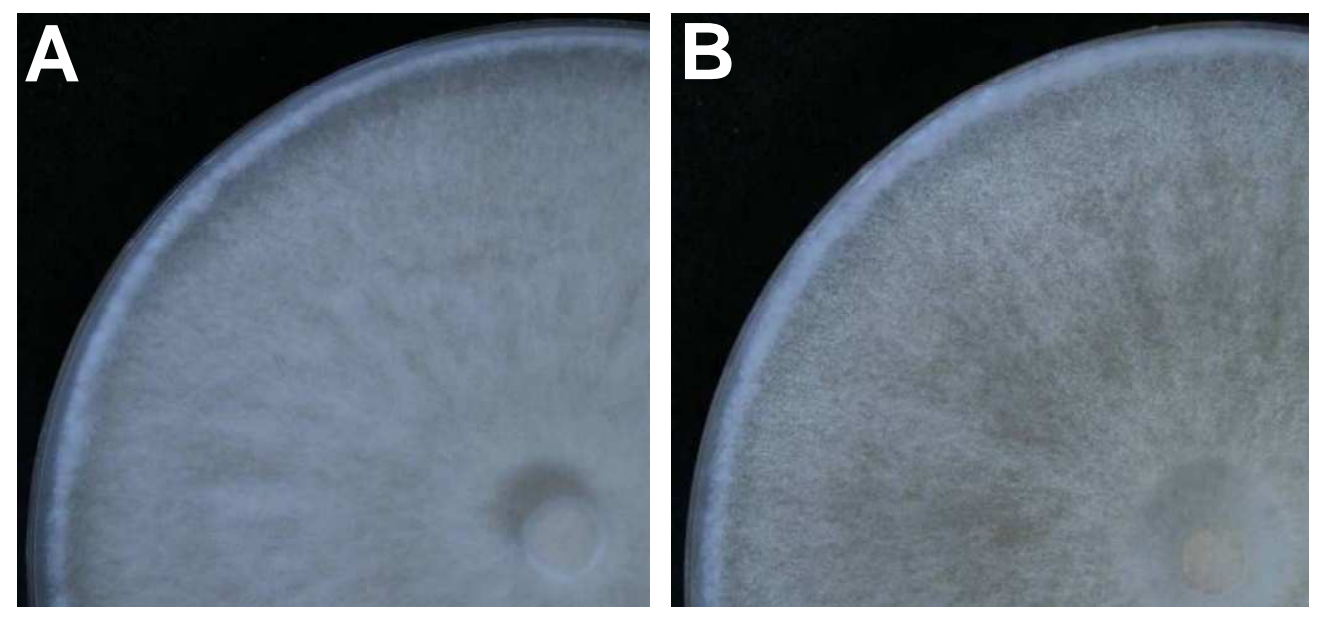

Fig. 24 Homokaryon AmutBmut (A) and mutant PUK2-6 (B) grown directly upon inoculation on YMG/T medium made with distilled water at $28^{\circ} \mathrm{C}$ in constant dark. Note that the cultures show no ring structure unlike cultures that were grown at $28^{\circ} \mathrm{C}$ under standard fruiting conditions.

\subsubsection{Other phenotypes influenced by the $d s t$ mutations}

Kertesz-Chalopková and colleagues had previously shown that asexual sporulation in the aerial vegetative mycelium (oidia formation, oidiation) is under light control once the $A$ mating type pathway is activated. This is also true for activation by mutation such as happened in the $A 43$ mating type locus to give $A 43 m u t$ whilst the mutation the $B$ mating type locus, B43mut, little influences this phenotype (Kertesz-Chalopková et al. 1998, Kües et al. 1998, 2001). Since another light-regulated phenotype, oidiation in dark and light was investigated for A43mut, B43mut homokaryons exhibiting the formation of etiolated stipes under standard fruiting conditions (Fig. 26, Fig. 27). Most interestingly, the tested $d s t 3-1$ and $d s t 4-1$ mutant homokaryons showed a light regulated control of oidia production comparable to the wildtype homokaryon AmutBmut unlike the $d s t 1-2$ and $d s t 2-1$ strains. The $d s t 1-2$ homokaryon PUK1-6 showed a very low increase in production of oidia per plate whereas the $d s t 2-1$ homokaryon PUK2-1 was totally blind (Fig. 26, Fig. 27).

Sclerotia development is another light-regulated feature in $C$. cinerea when the A mating type pathway is activated (Kertesz-Chaloupková et al. 1998). Normally, sclerotia development will happen in aging cultures in the dark but sclerotia development will be repressed when $C$. cinerea is incubated under constant light illumination (Kües et al. 1998). In this study, sclerotia development was observed in cultures of the $d s t 1-2$ and $d s t 2-1$ mutants PUK1-6 and PUK2-6 kept at $37^{\circ} \mathrm{C}$ for 25 days 
either in constant dark (Fig. 28 and Fig. 29) and in constant light (not photographed) and in cultures kept at $28^{\circ} \mathrm{C}$ for 25 days in constant light (not photographed). The $d s t 3-1$ and dst4-1 mutants PUK3 and PUK4 in contrast formed sclerotia only in the dark. Under incubation at $37^{\circ} \mathrm{C}$ in constant dark, there was a clear difference in sclerotia formation by the four different $d s t$ mutants compared to the wildtype homokaryon AmutBmut and the wildtype dikaryon PS001-1 x PS002-1. Whilst the wildtype strain both produces some number of sclerotia, the dst1-2 mutant PUK1-6 and the dst2-1 mutant PUK2-6 produced masses of sclerotia and the $d s t 3-1$ mutant PUK4 and the dst4-1 mutant PUK4 very few sclerotia (Table 11, Fig. 28 and Fig. 29). At $37^{\circ} \mathrm{C}$ under incubation for 25 days under constant light illumination, of all tested five strains (including homokaryon AmutBmut as control) only mutant PUK2-6 produced sclerotia, whereas at $28^{\circ} \mathrm{C}$ under incubation for 25 days under constant light illumination, in addition to mutant PUK2-6, mutant PUK1-6 also produced sclerotia.
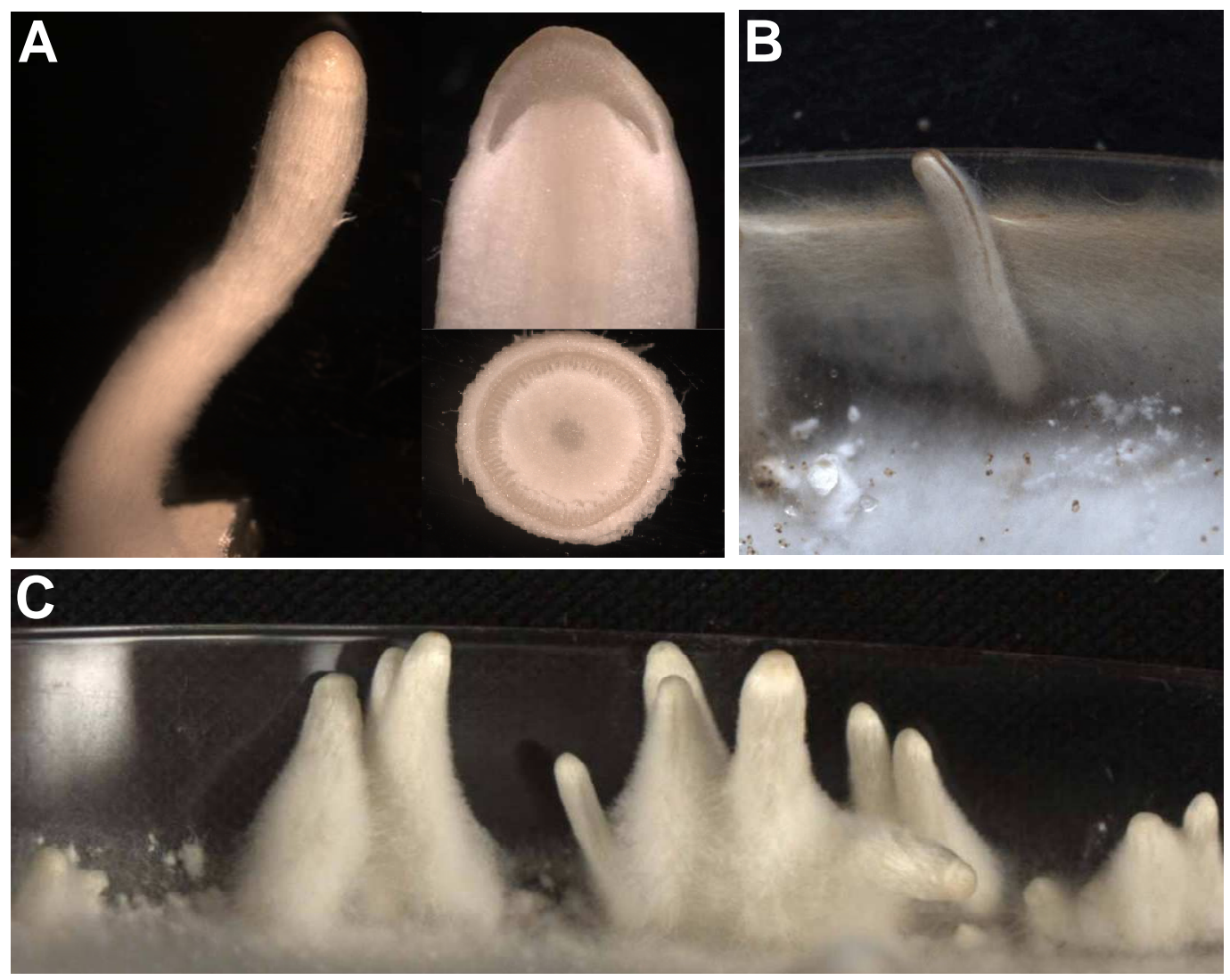

Fig. 25 Etiolated stipes formed by mutant PUK2-6 on YMG/T plates made with distilled water at $37^{\circ} \mathrm{C}$ incubated under constant light (A), (C) and constant dark (B). The etiolated stipes were morphological alike to those structures developed by the strain at $28^{\circ} \mathrm{C}$ under different types of cultivation (compare Fig. 11 and Fig. 13). Note the black spots in the mycelium shown in (B) are sclerotia. 


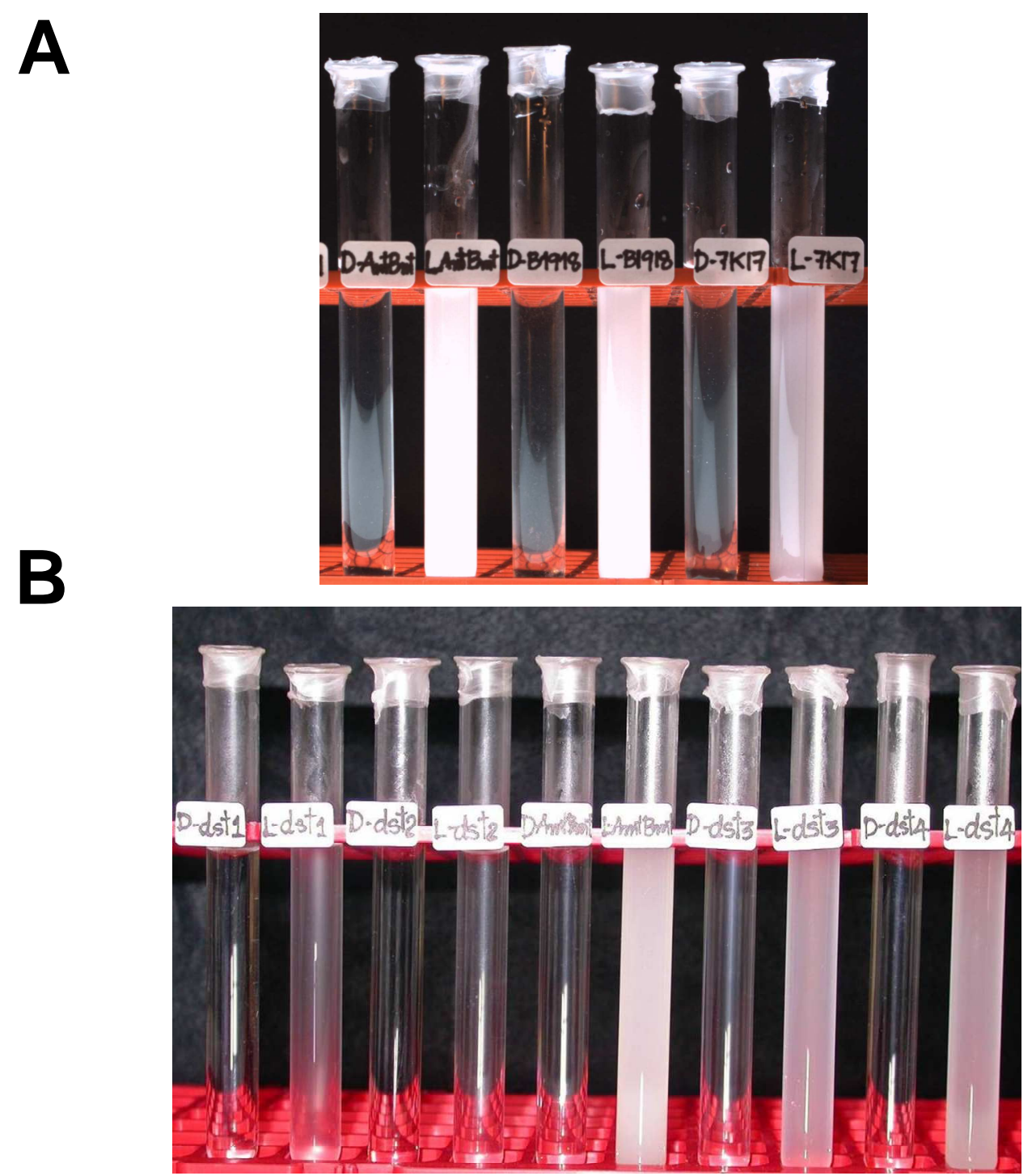

Fig. 26 Oidia suspensions (oidia scrapped from $9 \mathrm{~cm}$ in $\emptyset$ Petri dish in $10 \mathrm{ml}$ water) from YMG/T cultures made up with distilled water grown first at $37^{\circ} \mathrm{C}$ in the dark until the whole plates were covered with mycelium before either transferring them four 4 days at $37^{\circ} \mathrm{C}$ into constant light or keeping them for further four days at $37^{\circ} \mathrm{C}$ in constant dark. (A) Suspensions from left to right: Homokaryon AmutBmut incubated fully in the dark, homokaryon AmutBmut treated for 4 days with light, $d s t 4-1$ mutant B-1918 incubated fully in the dark, dst4-1 mutant B-1918 treated for 4 days with light, dst3-1 mutant 7K17 incubated fully in the dark, dst3-1 mutant 7K17 treated for 4 days with light. (B) Suspensions from left to right: dst1-2 mutant PUK1-6 incubated fully in the dark, dst1-2 mutant PUK1-6 treated for 4 days with light, dst2-1 mutant PUK2-6 incubated fully in the dark, dst2-1 mutant PUK2-6 treated for 4 days with light, homokaryon AmutBmut incubated fully in the dark, homokaryon AmutBmut treated for 4 days with light, dst3-1 mutant PUK3 incubated fully in the dark, $d s t 3-1$ mutant PUK3 treated for 4 days with light, dst4-1 mutant PUK4 incubated fully in the dark, dst4-1 mutant PUK4 treated for 4 days with light. 


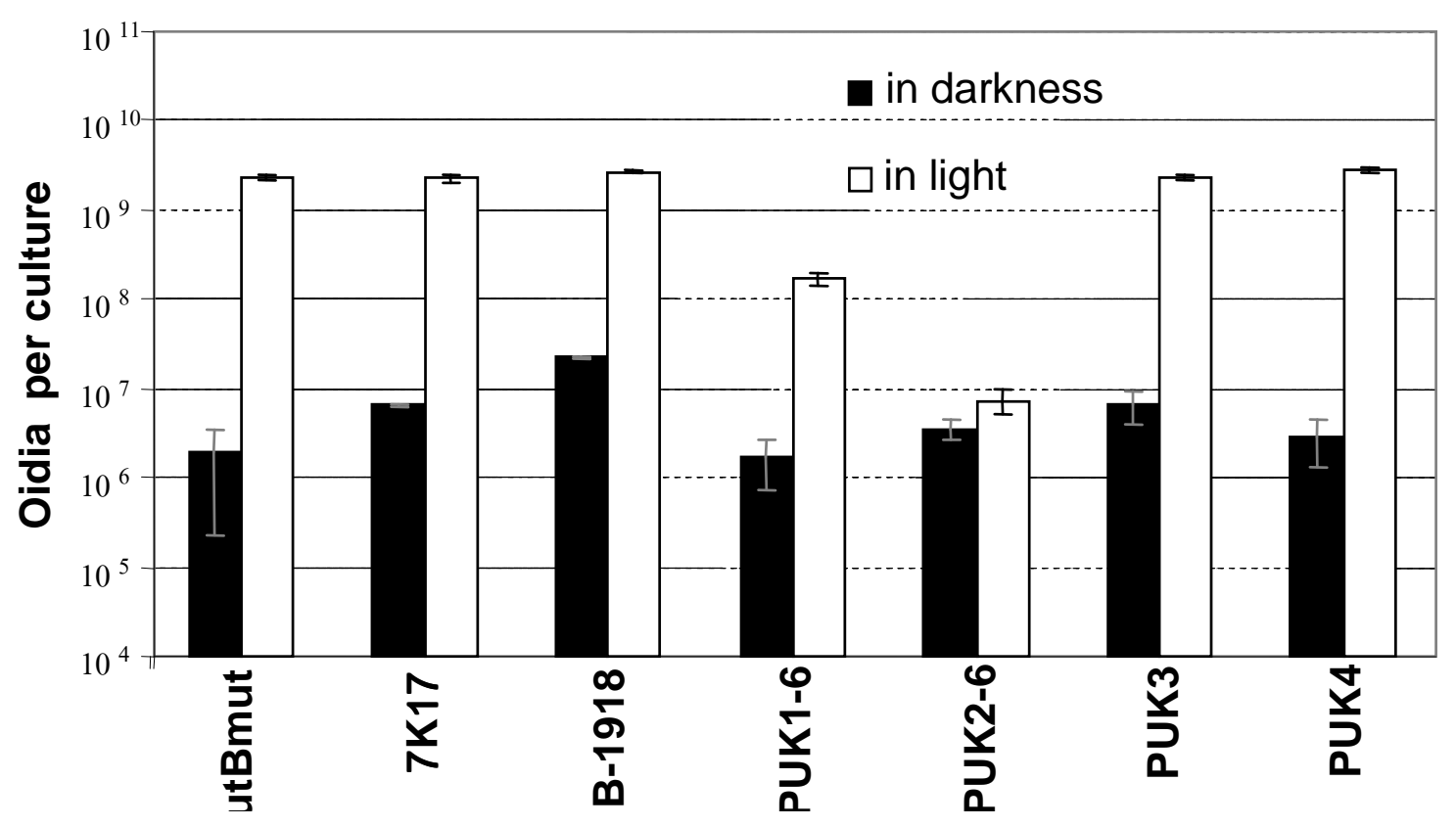

Fig. 27 Comparison of oidia production of mutant homokaryons with defects in fruiting with the wild type homokaryon AmutBmut. Oidiation was analyzed by harvesting and counting spores after incubating on YMG/T cultures for nine days at $37^{\circ} \mathrm{C}$ in light-proofed ventilated boxes in constant dark or after transferring 5 days old cultures from the dark for a 4 day-long incubation period into constant light (according to Kertesz-Chaloupková et al. 1998). 


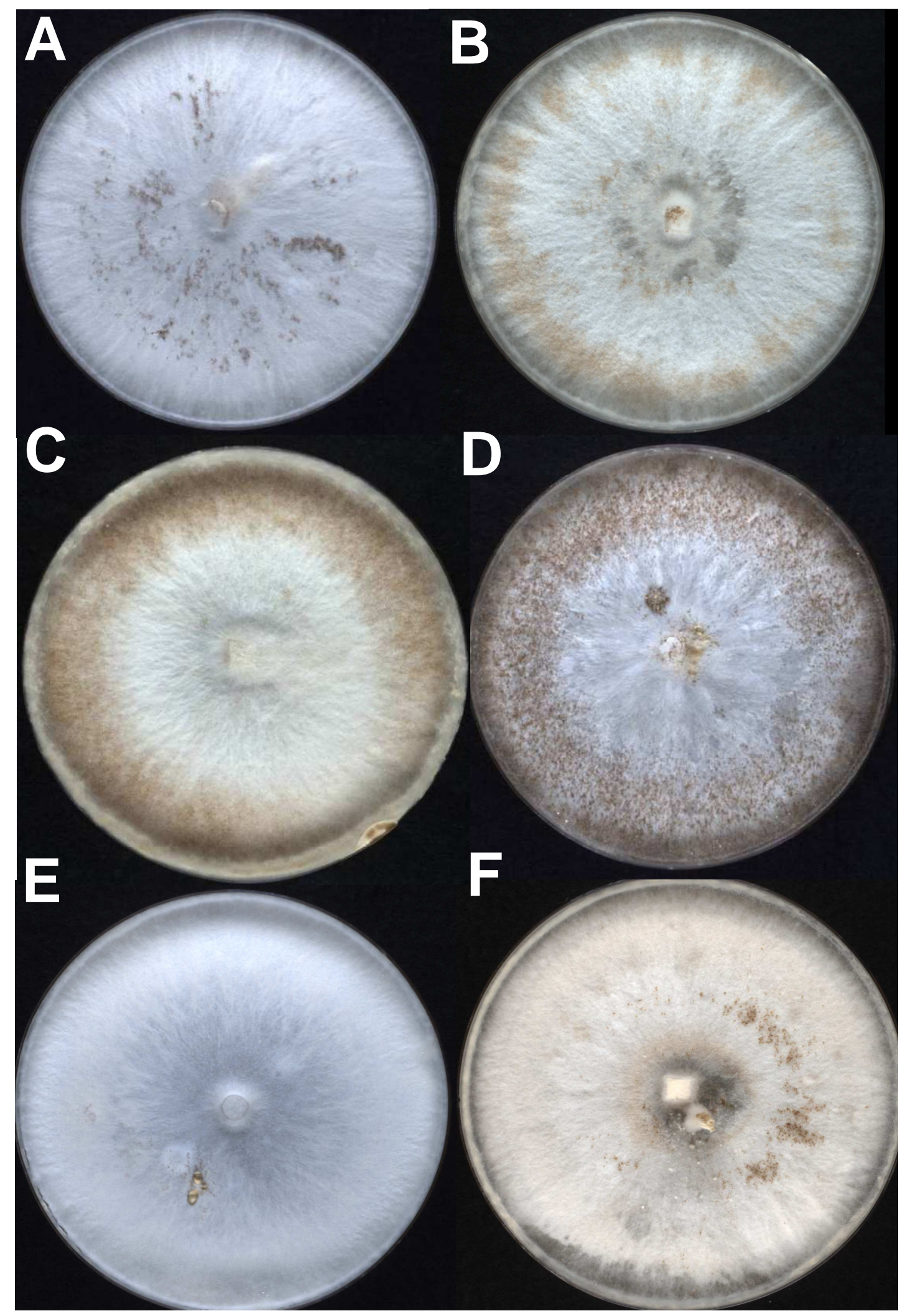

Fig. 28 Sclerotia development (to be recognized by the small brown spots in the mycelium; see Fig. 29 for a larger view) in cultures of the wildtype homokaryon AmutBmut (A), the wildtype dikaryon PS001-1 x PS002-1 (B), the dst1-2 mutant PUK1-6 (C), the dst2-1 mutant PUK2-6 (D), the dst3-1 mutant PUK3 (E) and the dst4-1 mutant PUK4 (F) after growth on YMG/T plates (made up with distilled water) for 25 days at $37^{\circ} \mathrm{C}$ in constant dark. 

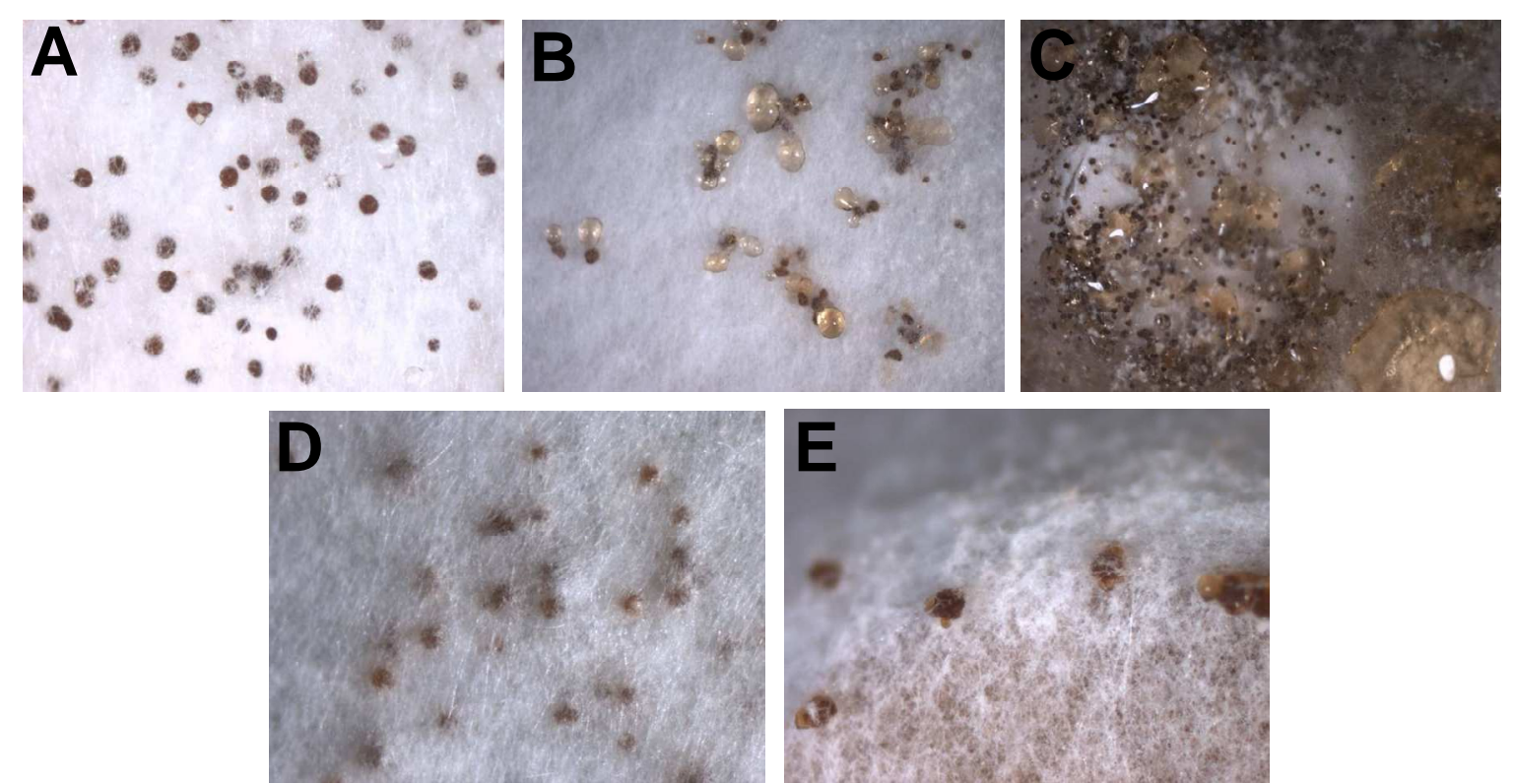

Fig. 29 Enlarged view on sclerotia development in cultures of the wildtype homokaryon AmutBmut (A), the wildtype dikaryon PS001-1 x PS002-1 (B), the dst1-2 mutant PUK1-6 (C), the dst2-1 mutant PUK2-6 (D), the dst3-1 mutant PUK3 (E) and the dst4-1 mutant PUK4 (F) after growth on YMG/T plates (made up with distilled water) for 25 days at $37^{\circ} \mathrm{C}$ in constant dark.

Table 11 Sclerotia production on YMG/T plates after incubation of $C$. cinerea strains for 25 days at $37^{\circ} \mathrm{C}$ in the dark.*

\begin{tabular}{|l|c|c|c|c|c|}
\hline \multicolumn{1}{|c|}{ Strains } & $\begin{array}{l}\text { Amut Bmut } \\
\text { wildtype }\end{array}$ & $\begin{array}{c}\text { PUK1-6 } \\
\boldsymbol{d s t 1 - 2}\end{array}$ & $\begin{array}{c}\text { PUK2-6 } \\
\boldsymbol{d s t 2 - 1}\end{array}$ & $\begin{array}{c}\text { PUK3 } \\
\boldsymbol{d s t 3 - 1}\end{array}$ & $\begin{array}{c}\text { PUK4 } \\
\boldsymbol{d} \text { st4-1 }\end{array}$ \\
\hline $\begin{array}{l}\text { Sclerotia } \\
\text { per circled area } \\
\mathbf{3} \text { cm apart from } \\
\text { the middle of the } \\
\text { plate }\end{array}$ & $\begin{array}{l}3.5 \times 10^{3} \pm \\
2.4 \times 10^{3}\end{array}$ & $\begin{array}{l}2.7 \times 10^{4} \pm \\
1.2 \times 10^{4}\end{array}$ & $\begin{array}{l}7.9 \times 10^{4} \pm \\
4.0 \times 10^{4}\end{array}$ & $247 \pm 126$ & $71 \pm 12$ \\
\hline $\begin{array}{l}\text { Sclerotia } \\
\text { per circled area } \\
\text { 1.5 cm apart from } \\
\text { the middle of the } \\
\text { plate }\end{array}$ & $529 \pm 236$ & $448 \pm 247$ & $2.4 \times 10^{4} \pm$ & $58 \pm 57$ & $4 \pm 2$ \\
\hline
\end{tabular}

* Sclerotia were counted in circled areas of $0.5 \mathrm{~cm}$ in $\varnothing$ at two different positions in the plates one being with its center $1.5 \mathrm{~cm}$ apart from the middle of a plate, the other being with its center $3 \mathrm{~cm}$ apart from the middle of a plate. Per plate, sclerotia were counted in each one area per distance; per strain, five different plates were analyzed for calculating average values and standard deviations. 


\subsection{Conclusions}

In this study, four different types of mutants $(d s t 1-2, d s t 2-1, d s t 3-1, d s t 4-1)$ were analyzed that formed elongated etiolated stipes by extending the primordial shaft when mutant cultures were kept at $28^{\circ} \mathrm{C}$ under standard fruiting conditions. Previously in Chapter 2 it was reported that in the wildtype such phenotypes occur only, when the wildtype strain is kept for longer periods in constant dark and it was concluded that light inhibits such phenotype. The four types of mutants were thus suspected to be blind. A blind phenotype implies that also other light-regulated characteristics of $C$. cinerea are not anymore underlying such light regulation. This was clearly found the mutant carrying defects in gene $d s t 1$ and in gene $d s t 2$ (Table 12). Next to the defect in light repression of formation of etiolated stipes, these mutants showed also aberrant regulation of oidia production and sclerotia production, both features known to be under light control in strains as the A43mut homokaryons where the $A$ mating type pathway has been actviated (Kertesz-Chaloupková et al. 1998, Kües et al. 1998). The product of gene $d s t 1$ is known since 2005 when Terashima et al. (2005) published that the gene encodes a white-collar 1 (WC1)-type of blue light receptor. This physiological function fits very well with a control of various morphological processes by light. Genetic analyses showed that all defects in $d s t$ genes were recessive and that all four defects analyzed relate to different $d s t$ genes. Whilst $d s t 2$ must be expected to also encode a product acting generally in the light-control pathway of developmental processes, genes $d s t 3$ and $d s t 4$ are much more specific (Table 12). The defects in light regulation by the $d s t 1$ and $d s t 2$ mutations are early in fruiting body development at time points of hyphal knot formations up to the primordia stage 1 . In contrast, $d s t 3$ and $d s t 4$ act at later stages of development, i.e. at primordia stage 3 and primordia stage 4, respectively. Work presented in Chapter 2 of this thesis revealed that progress of development at these stages does not need dark phases but light is required to repress etiolated stipe formation and, finally in primordia stage 4, for induction of karyogamy in the basidia (compare Chapter 2 of this thesis).

Other experiments presented in this chapter link light-regulation to temperature regulation as well as to regulation by metals or minerals present or absent in the environment (see the tap water and the turning plates up-side down experiments). Altogether, the results show that fruiting body development in C. cinerea is regulated by complex mechanisms in which light has a central but not an exclusive role. Signals from the environment for fruiting body induction can generally be seen as stress signals. 
Table 12 Summary of phenotypes affected by light in the homokaryon AmutBmut and in the four types of $d s t$ mutants in an A43mut, B43mut homokaryotic background.

\begin{tabular}{|c|c|c|c|c|c|}
\hline Incubation & $\begin{array}{l}\text { Amut Bmut } \\
\text { wildtype }\end{array}$ & $\begin{array}{l}\text { PUK1-6 } \\
\text { dst1-2 }\end{array}$ & $\begin{array}{c}\text { PUK2-6 } \\
\text { dst2-1 }\end{array}$ & $\begin{array}{l}\text { PUK3 } \\
\text { dst3-1 }\end{array}$ & $\begin{array}{l}\text { PUK4 } \\
\text { dst4-3 }\end{array}$ \\
\hline $\begin{array}{l}\text { Development at } \\
28^{\circ} \mathrm{C} \text { in standard } \\
\text { fruiting } \\
\text { conditions }\end{array}$ & $\begin{array}{c}\text { fruiting bodies } \\
\text { (2-5/plate) }\end{array}$ & $\begin{array}{l}\text { dark stipes } \\
(2-5 / \text { plate })\end{array}$ & $\begin{array}{c}\text { dark stipes } \\
(15-20 / \text { plate })\end{array}$ & $\begin{array}{l}\text { dark stipes } \\
(5-7 / \text { plate })\end{array}$ & $\begin{array}{l}\text { dark stipes } \\
(8-10 / \text { plate })\end{array}$ \\
\hline $\begin{array}{l}\text { Development at } \\
28^{\circ} \mathrm{C} \text { in constant } \\
\text { dark }\end{array}$ & $\begin{array}{l}\text { only vegetative } \\
\text { mycelium }\end{array}$ & $\begin{array}{l}\text { only vegetative } \\
\text { mycelium }\end{array}$ & $\begin{array}{l}\text { dark stipes } \\
(5-10 / \text { plate })\end{array}$ & $\begin{array}{c}\text { only } \\
\text { vegetative } \\
\text { mycelium }\end{array}$ & $\begin{array}{l}\text { only } \\
\text { vegetative } \\
\text { mycelium }\end{array}$ \\
\hline $\begin{array}{l}\text { Development at } \\
28^{\circ} \mathrm{C} \text { in constant } \\
\text { light }\end{array}$ & $\begin{array}{l}\text { abnormal } \\
\text { primordia } \\
(1-5 / \text { plate })\end{array}$ & $\begin{array}{c}\text { abnormal } \\
\text { primordia } \\
(15-20 / \text { plate }) \\
\text { some sclerotia } \\
\end{array}$ & $\begin{array}{c}\text { dark stipes } \\
\text { (15-20/plate), } \\
\text { some } \\
\text { sclerotia } \\
\end{array}$ & $\begin{array}{l}\text { dark stipes } \\
\text { (8-12/plate) }\end{array}$ & $\begin{array}{c}\text { dark stipes } \\
(15-20 / \text { plate })\end{array}$ \\
\hline $\begin{array}{l}\text { Development at } \\
37^{\circ} \mathrm{C} \text { in constant } \\
\text { dark }\end{array}$ & $\begin{array}{l}\text { medium amount } \\
\text { of sclerotia }\end{array}$ & $\begin{array}{l}\text { high amount of } \\
\text { sclerotia }\end{array}$ & $\begin{array}{c}\text { dark stipes } \\
\text { (rare), } \\
\text { high amount } \\
\text { of sclerotia }\end{array}$ & $\begin{array}{c}\text { minute } \\
\text { amount of } \\
\text { sclerotia }\end{array}$ & $\begin{array}{c}\text { minute } \\
\text { amount of } \\
\text { sclerotia }\end{array}$ \\
\hline $\begin{array}{l}\text { Development at } \\
37^{\circ} \mathrm{C} \text { in constant } \\
\text { light }\end{array}$ & $\begin{array}{l}\text { only vegetative } \\
\text { mycelium }\end{array}$ & $\begin{array}{l}\text { vegetative } \\
\text { mycelium }\end{array}$ & $\begin{array}{c}\text { dark stipes } \\
(15-20 / \text { plate }), \\
\text { some } \\
\text { sclerotia }\end{array}$ & $\begin{array}{c}\text { only } \\
\text { vegetative } \\
\text { mycelium }\end{array}$ & \begin{tabular}{l}
\multicolumn{1}{c}{ only } \\
vegetative \\
mycelium
\end{tabular} \\
\hline $\begin{array}{l}\text { Oidiation } \\
\text { repressed at } 37^{\circ} \mathrm{C} \\
\text { in constant dark }\end{array}$ & ++++ & ++++ & ++++ & ++++ & ++++ \\
\hline $\begin{array}{l}\text { Oidiation induced } \\
\text { at } 37^{\circ} \mathrm{C} \text { in } \\
\text { constant light }\end{array}$ & ++++ & + & - & ++++ & ++++ \\
\hline
\end{tabular}

In conclusion from this postulate, fruiting body development is to be seen as a very complex, but specific stress reaction.

At the start of this work, four different $d s t$ defects were available with monokaryons R1428F1\#74 (dst1-1), H1-1280F1\#5 (dst2-1), 7K17 (dst3-1) and B-1918 (dst4-1) but these differed in the genetic backgrounds by the origin of generation. Whilst observations presented in this chapter were therefore not always obtained from the same four co-isogenic dst1-2, dst2-1, dst3-1 and dst4-1 mutant strains, respectively, the overall observations on strains carrying the same defective gene follow a similar pattern. Since co-isogenic strains have been produced in this study, in the future, morphological effects due to the different $d s t$ mutations can be studied in a more targeted and defined way. 


\subsection{References}

Borriss H (1934) Beiträge zur Wachstums- und Entwicklungsphysiologie der Fruchtkörper von Coprinus lagopus. Planta 22:28-69.

Boulianne RP, Liu Y, Aebi M, Lu BC and Kües U (2000) Fruiting body development in Coprinus cinereus: regulated expression of two galectins secreted by a nonclassical pathway. Microbiol 146:1841-1853.

Brodie HJ (1931) The oidia of Coprinus lagopus and their relation with insects. Ann Bot 45:315-344.

Buller AHR (1910) The function and fate of the cystidia of Coprinus atramentarius, together with some general remarks on Coprinus fruit-bodies. Ann Bot 24:613-629.

Casselton LA and Kües U (2007) The origin of multiple mating types in the model mushrooms Coprinopsis cinerea and Schizophyllum commune. In: Sex in fungi: Molecular determination and evolutionary implications. (J Heitman, W James, JW Kronstad, JW Taylor, LA Casselton eds.), ASM Press Herndon, VA, USA, pp. 283-300.

Casselton LA and Olesnicky NS (1998) Molecular genetics of mating recognition in basidiomycete fungi. Microbiol Mol Biol Rev 62:55-70.

Cox RJ and Niederpruem DJ (1975) Differentiation in Coprinus lagopus. III. Expansion of excised fruit-bodies. Arch Microbiol 105:257-260.

Elliott CG (1994) Reproduction in fungi. In: Genetical and physiological aspects. (CG Elliott and C Elliott eds.), Chapman and Hall, London, UK, pp. 1-324.

Gooday GW (1974) Control of development of excised fruit bodies and stipes of Coprinus cinereus. Trans Br Mycol Soc 62:391-399.

Granado JD, Kertesz-Chaloupková K, Aebi M and Kües U (1997) Restriction enzymemediated DNA integration in Coprinus cinereus. Mol Gen Genet 256:28-36.

Gruen HE (1982) Control of stipe elongation by the pileus and mycelium in fruitbodies of Flammulina velutipes and other Aaricales. In: Basidium and basidiocarp. Evolution, cytology, function and development (K Wells and EK Ells, eds.) Springer-Verlag, New York, NY, USA. pp. 126-155.

Hammad F, Ji R, Watling R and Moore D (1993) Cell population dynamics in Coprinus cinereus: co-ordination of cell inflation throughout the maturing basidiome. Mycol Res 97:269-274. 
Kamada T (1994) Stipe elongation in fruit bodies. In: The Mycota, vol. I. Growth, differentiation and sexuality (JGH Wessels and F Meinhardt, eds.), SpringerVerlag KG, Berlin, Germany, pp. 367-380.

Kamada T, Kurita R and Takemaru T (1978) Effects of light on basidiocarp maturation in Coprinus macrorhizus. Plant Cell Physiol 19:263-275.

Kamada T, Miyasaki S and Takemaru T (1976) Quqntitqative changes of DNA, RNA and protein during basidiocarp maturation in Coprinus macrorhizus. Trans Myc Soc Jpn 17:451-460.

Kertesz-Chaloupková K, Walser PJ, Granado JD, Aebi M and Kües U (1998) Blue light overrides repression of asexual sporulation by mating type genes in the basidiomycete Coprinus cinereus. Fungal Genet Biol 23:95-109.

Kües U (2000) Life history and developmental processes in the basidiomycete Coprinus cinereus. Microbiol Mol Biol Rev 64:316-353.

Kües U, Granado JD, Hermann R, Boulianne RP, Kertesz-Chaloupkova K and Aebi M (1998) The $A$ mating type and blue light regulate all known differentiation processes in the basidiomycete Coprinus cinereus. Mol Gen Genet 260:81-91.

Kües U, James TY, Vilgalys R and Challen MP (2001) The chromosomal region containing pab-1, mip, and the $A$ mating type locus of the secondarily homothallic homobasidiomycete Coprinus bilanatus. Curr Genet 39:16-24.

Liu Y, Granado JD, Polak E and Kües U (1999) Crosses with Amut Bmut homokazons of Coprinus cinereus. Fungal Genet Newsl 46:16-20.

Liu Y, Srivilai P, Loos S, Aebi M and Kües U (2006) An essential gene for fruiting body initiation in the basidiomycete Coprinopsis cinerea is homologous to bacterial cyclopropane fatty acid synthase genes. Genetics 172:873-884.

Lu BC (1974) Meiosis in Coprinus. V. The role of light on basidiocarp initiation, mitosis and hymenium differentiation in Coprinus lagopus. Can $\mathrm{J}$ Bot 52:299-305.

Lu BC (2000) The control of meiosis progression in the fungus Coprinus cinereus by light/dark cycles. Fungal Genet Biol 31:33-41.

Lu BC and Jeng DY (1975) Meiosis in Coprinus. VII The prekaryogrammy S-phase and the postkaryogammy DNA replication in C. lagopus J Cell Sci 17:461-470.

Matthews TR and Niederpruem DJ (1973) Differentiation in Coprinus lagopus. II. Histology and ultrastructural aspects of developing primordia. Arch Mikrobiol 88:169-180. 
May GL, Chevanton Le and Pukkila PJ (1991) Molecular analysis of the Coprinus cinereus mating type $A$ factor demonstrated an unexpectedly complex structure. Genetics 128:529-538.

Miyake H, Tanaka K and Ishikawa T (1980) Basidiospore formation in monokaryotic fruiting bodies of a mutant strain of Coprinus macrorhizus. Arch Microbiol 126:207-212.

Money NP and Ravishankar JP (2005) Biomechanics of stipe elongation in the basidiomycete Coprinopsis cinerea. Mycol Res 109:627-634.

Moore D (1981) Developmental genetics of Coprinus cinereus: genetic evidence that carpophores and sclerotia share a common pathway of initiation. Curr Genet 3:145-150.

Moore D (1998) Fungal morphogenesis. Cambridge University Press, Cambridge, UK, pp. 1-469.

Moore D, Elhiti MMY and Butler RD (1979) Morphogenesis of the carpophore of Coprinus cinereus. New Phytol 83:695-722.

Muraguchi H and Kamada T (1998) The ichl gene of the mushroom Coprinus cinereus is essential for pileus formation in fruiting. Development 125:3133-3141.

Navarro-González M (2008) Growth, fruiting body development and laccase production of selected coprini. PhD thesis. Georg-August University of Göttingen, Göttingen, Germany.

Pukkila PJ and Lu BC (1985) Silver staining of meiotic chromosomes in the fungus, Coprinus cinereus. Chromosoma 91:108-112.

Reijnders AFM (1979) Developmental anatomy of Coprinus. Persoonia 10:383-424.

Srivilai P (2006) Molecular analysis of genes acting in fruiting body development in basidiomycetes. PhD thesis. Georg-August University of Göttingen, Göttingen, Germany.

Swamy S, Uno I and Ishikawa T (1984) Morphogenetic effects of mutations at the $A$ and $B$ incompatibility factors in Coprinus cinereus. J Gen Microbiol 130:3219-3224.

Terashima K, Yuki K, Muraguchi H, Akiyama M and Kamada T (2005) The dst1 Gene involved in mushroom photomorphogenesis of Coprinus cinereus encodes a putative photoreceptor for blue light. Genetics 171:101-108.

Tsusué YM (1969) Experimental control of fruit-body formation in Coprinus macrorhizus. Dev Growth Differ 11:164-178. 
Walser PJ, Hollenstein M, Klaus MJ, Kües U (2001) Genetic analysis of basidiomycete fungi. In: Molecular and cell biology of filamentous fungi: a practical approach. Practical Approach Series (Talbot NJ, ed.), IRL Press, Oxford, England, pp. 59-90.

Walser PJ, Velagapudi R, Aebi M and Kües U (2003) Extracellular matrix proteins in mushroom development. Recent Res Devel Microbiol 7:381-415. 
CHAPTER 4

\section{Grazing of the mite Tyrophagus putrescentiae in cultures of the basidiomycete Coprinopsis cinerea}

Dr. Mónica Navarro-González is greatly acknowledged for her initiative that we studied together relationships between the fungus Coprinopsis cinerea and the mite Tyrophagus putrescentiae and her kind help and participation in discussions of the work. I appreciate Dr. Prodepran Thakeow for her help in experimental tests of volatile organic compounds, 1-octen-3-ol and 3-octanone, in attraction of mites. Ulrike Eisenwiener and Dr. Pavel Plašil prepared the samples of mites for scanning electron microscopy in order to examine the morphology of the arthropods and in order to define their species names. I very much appreciate Dr. Pitipong Thobunluepop and Martin Rühl for their input in this chapter by helping in the statistical analysis to evaluate the results. 


\subsection{Abstract}

Mites are easily attracted to fungal cultures. In this study, the behavior of mites of the species Tyrophagus putrescentiae (Acari: Acaridida) in cultures of the basidiomycete Coprinopsis cinerea were observed. The mites invade cultures of C. cinerea in order to graze on the vegetative mycelium. They leave multicellular structures such as sclerotia and fruiting body primordia, fruiting body stipes and etiolated stipes aside but they are attracted to the caps of maturing caps where they graze on the gills including ingesting the mature basidiospores. Basidiospores are distributed by the animals externally when attached to their bodies and internally. After passing the digestion track of the mites, faecal pellets are excreted containing many spores that are able to germinate. Moreover, this study present evidence that the mites distribute the asexual spores (oidia) formed in high numbers in the aerial mycelium of monokaryotic strains. Mites were shown in this study to be attracted by the mushroom odor compounds 1-octen-3-ol and 3-octanone. Strain preferences in mite attraction were tested. Monokaryons appear not to differ from each other and there was neither a striking difference between monokaryons and dikaryons. However, a significant difference was seen when comparing young and old mycelium of the homokaryon AmutBmut. Mites clearly prefer young mycelium. Further to the observation on the behaviour of $T$. putrescentiae towards different $C$. cinerea strains (monokaryons PS001-1 and PS002-1, dikaryon PS001-1 x PS002-1, homokaryon AmutBmut, mutants PUK1-6, PUK2-6, PUK3 and PUK4), observations on reproduction and death of the animals in fungal cultures are presented.

Key words: Coprinopsis cinerea, Tyrophagus putrescentiae, mold mites, infestation, green house, allergen, fruiting body, dikaryon, homokaryon AmutBmut, mutants, pests, volatile organic compounds, 1-octen-3-ol, 3-octanone 


\subsection{Introduction}

Mites are Chelicerata, belonging to the class of Arachnida and the subclass of Acari (Asselt 1999). Mites are found in nature nourishing on wide variety of organic substrates such as litter, mosses, lichens, plants, and fungi, and also as parasites on some animals. Adult mites have four pairs of legs, measure usually less than $1 \mathrm{~mm}$ length, and have no antennae (Rees 2001). Chemical receptors are found in segments of the legs (palpi, tarsi, tibiae) with which chemical cues such as volatile organic compounds (VOCs) are perceived (Debruyne et al. 1991, Baker 1996, and Wijk et al. 2007). Many mites are attracted to a variety of stored products or food infesting the resources that the mites feed on such as barley, hay, cheese, and poultry food (Hughes 1976) and other grain-storage, as well as mushrooms (Okabe et al. 2001, Kheradmand et al. 2007a). Volatile compounds such as C8 compounds and mono- and sesquiterpenes are attractants (infochemicals) to the mites, amongst the mite Tyrophagus putrescentiae (Vanhaelen et al. 1978a, b, 1980, Skelton et al. 2007). T. putrescentiae (Acari: Acaridida) Schrank is known under different common names such as storage mite cheese mite, house dust mite and mould mite, reflecting the various economical and medical problems linked to this species of arthropods. The mite is attracted to grain storages and to food such as cheese and ham, distributes moulds and causes allergic and other negative health reactions in humans due to own faecal pellets as well as due to effects by moulds transferred by them (Stewart et al. 1991, Abdel-Sater et al. 1995, Asselt 1999, Franzolin et al. 1999, Okabe et al. 2001, Hubert et al. 2003a,b, 2004, Smrž 2003, Morgan and Arlian 2006). Environmental circumstances at which the mites reproduce best $\left(25-28^{\circ} \mathrm{C}\right.$, relative humidity of $60 \%$ humidity) are alike those required for fruiting body development of the mushroom Coprinopsis cinerea (Granado et al. 1997, Sánchez-Ramos and Castañera 2005, Sánchez-Ramos et al. 2007, NavarroGonzález 2008). Under best environmental conditions, population duplication times of the mites are as low as 1.75 days (Sánchez-Ramos and Castañera 2005) resulting theoretically in >130000 descendants per mite within one month (30 days). On mushrooms, population doubling times of 3.74 days (on Agaricus bisporus) and 5.62 days (on Pleurotus ostreatus) were measured (Kheradmand et al. 2007b).

Recent studies have shown that there is a close relationship between the mite, T. putrescentiae and the basidiomycete Coprinopsis cinerea in their life cycles (Navarro-González 2008). The mite nourishes from both vegetative and reproductive structures of the fungus. The mites also ingest the asexual and the sexual spores of 
C. cinerea (oidia and basidiospores, respectively). However, without digesting them, the dark-stained basidiospores are packed together in numbers of up to 400 and more into faecal pellets surrounded by a peritrophic membrane. High numbers of basidiospores within the faecal pellets germinate on suitable substrate and resulting monokaryotic hyphae will mate when of different mating type. The strategy of enclosing fungal spores into faecal pellets by the mites ensures the formation of dikaryons between germinated siblings from a same mushroom and favors thus inbreeding in a species that otherwise under free spore dispersal by wind, insects and other means is outbreeding. The normal outbreeding situation in this fungus is due to the development of a mating type system with over 12000 different mating type specificities that is controlled by two unlinked genetic loci, each with multiple alleles. For the mites in contrast, packaging of fungal spores in faecal pellets and their subsequent germination is of advantage when laying the eggs in close vicinity to the faecal pellets. When the young larvae hatch, the mycelial colonies formed after spore germination offers them directly sufficient fresh food (for further details see NavarroGonzález 2008).

C. cinerea is an excellent model for the homobasidiomycetous fungi that is used for studying developmental processes by classical and molecular genetic techniques (Kües 2000, Walser et al. 2001). The investigation of VOCs as marker compounds in the life cycle of the fungus revealed the emission of typical fungal odour compounds - C8 compounds and sesquiterpene (Thakeow 2008, see Chapter 4 of this thesis) that are attractive for mites (see above). In this chapter, further to the studies presented in Navarro-González (2008) experiments on the interactions between the mite T. putrescentiae and the fungus $C$. cinerea are described.

\subsection{Materials and methods}

\subsubsection{Organisms and culture conditions used in this study}

C. cinerea homokaryon AmutBmut (A43mut, B43mut, pab1) is a self-compatible homokaryon that forms fruiting bodies and oidia in a light-regulated manner (Swamy et al. 1984, May et al. 1991, Kertesz-Chaloupková et al. 1998). Mutants co-isogenic to homokaryon AmutBmut forming etiolated stipes under standard fruiting conditions are PUK1-6 (A43mut, B43mut, pab1, dst1-2), PUK2-6 (A43mut, B43mut, pab1, dst2-1), PUK3 (A43mut, B43mut, pab1, dst3-1) and PUK4 (A43mut, B43mut, pab1, dst4-1) (see 
Chapter 3 of this thesis) and co-isogenic monokaryons are strains PS001-1 (A42, B42) and PS002-1 (A3, B1) (Srivilai 2006). All strains were routinely grown on YMG/T medium (Granado et al. 1997) in the dark after placing small pieces of mycelium $\left(4 \times 4 \mathrm{~mm}^{2}\right)$ in the middle of $9 \mathrm{~cm} \varnothing$ Petri-dishes. Cultures were incubated at $37^{\circ} \mathrm{C}$ and $75-85 \%$ relative humidity in ventilated black boxes sized $27 \times 37 \times 13 \mathrm{~cm}^{3}$. A dikaryon was constructed by mating monokaryons PS001-1 and PS002-1 through placing mycelia plugs of the strains in close vicinity to each other onto fresh YMG/T plates before incubation at $37^{\circ} \mathrm{C}$ in the dark (Walser et al. 2001). For studying grazing effects by mites on fruiting bodies and primordia of fruiting bodies, fully grown plates of homokaryon AmutBmut or fully grown plates of the dikaryon (obtained by inoculation of YMG/T plates with the respective strains followed by incubation for 5 days at $37^{\circ} \mathrm{C}$ in the dark) were transferred into standard fruiting conditions (12 h light/12 h dark, $28^{\circ} \mathrm{C}$, humidity of $85-90 \%$ set by the computer of the climate chamber) for performance of fruiting body development (Granado et al. 1997). In some experiments as indicated in the results section, after growth of mutant PUK1-6 or PUK4 on YMG/T plates and their incubation at $28^{\circ} \mathrm{C}$ for seven days under standard fruiting conditions for production of etiolated stipes, plates were turned upside-down for seven days as described in Chapter 3 of this thesis before treating them with mites.

The $T$. putrescentiae mites used in this study were originally collected from infested cultures of C. cinerea strain PUK1-6. The species was identified by electron microscopy analysis by Dr. P. Plašil (Navarro-González 2008, P. Plašil, personal communication). Mites were further cultivated by transferring three pieces of mycelium $\left(4 \times 4 \mathrm{~mm}^{2}\right)$ with mites and with eggs of mites from infected cultures onto freshly grown cultures of homokaryon AmutBmut, thereby placing them in even distances to each other and in distances of about $1.5 \mathrm{~cm}$ from the outer edges of the Petri-dishes onto the agar upon which the Petri-dishes were sealed with Parafilm (PECHINEY, Chicago, USA). Petri-dishes were incubated in a greenhouse at $25-28^{\circ} \mathrm{C}$ and $40-70 \%$ humidity (measured as minimum and maximum levels over the incubation period by a hygrometer; average $60 \%$ humidity) in containers either covered with paper to reduce the amount of incoming light to intensities of $0.1-4.2 \mu \mathrm{E} \mathrm{m}^{-2} \mathrm{~s}^{-1}$ or the piles of Petridishes were wrapped with aluminium foil to keep light away from the animals. Petridishes with mites were kept for cultivation and proliferation for 3 weeks up to one month at $25-28^{\circ} \mathrm{C}$ and a humidity of $60 \%$ in the green house. In experiments with mutants PUK1-6 and PUK4, each 10 plates were cultivated for seven days in up-side- 
down position after formation of etiolated stipes (see above). For two weeks, all plates were subsequently incubated without closing them with Parafilm on a pile of three also not by Parafilm closed plates acting as stock cultures of mites fed on mycelium of homokaryon AmutBmut (see below for details on how to prepare the stock cultures). Furthermore, other two plates of such mite stock cultures were deposited for the same time on top of the pile. The piles were covered with aluminium foil and left in the greenhouse for seven days at $25-28^{\circ} \mathrm{C}$ and a humidity of $60 \%$. Similar pile experiments with Parafilm unlocked mite stock plates were performed with also unlocked AmutBmut cultures and with unlocked cultures of PUK1-6 and PUK3. In these cases, plates were cultivated after 5 days growth at $37^{\circ} \mathrm{C}$ for seven days in standard fruiting conditions before transferring them within the piles of mite stock cultures into the greenhouse at $25-28^{\circ} \mathrm{C}, 60 \%$ humidity for incubation of up to one month under a cover of aluminium foil. In all experiments using piles of plates which were unlocked by Parafilm, the piles were stored in a metal basket placed upon a plastic tray $(33 \mathrm{~cm} \mathrm{x} 40$ $\mathrm{cm} \times 15 \mathrm{~cm}$ ) which was filled about half with water in order to block migration of mites from the bench of the greenhouse into the Petri-dishes.

For observing grazing effects by mites on mycelium and on fungal higher order structures (primordia, fruiting bodies, sclerotia) under more defined conditions, 25 strong, agile, fast moving animals of mature size $(214.43 \pm 32.73 \mu \mathrm{m})$ were picked in fast sequence with a fine needle from infected mycelial cultures and placed onto a fresh YMG/T agar piece $(0.6 \mathrm{~cm}$ in $\varnothing)$ in the middle of Petri-dishes with a respective fungal strain and plates were sealed by Parafilm, covered with aluminium foil and incubated for the times needed in the greenhouse at $25-28^{\circ} \mathrm{C}$ and a humidity of $60 \%$. Observations on the fungal mycelium and structures were made after 14, 21 or 28 days of incubation after transfer of mites. T. putrescentiae was observed under a Stemi 2000C binocular (Carl Zeiss Mikroskopie, Göttingen, Germany). Digital photos were taken with a color chilled 3CCD camera (colorview soft imaging system) for image processing (analysis ${ }^{\circledR}$, Soft Imaging System GmbH, Münster, Germany).

\subsubsection{Competition test between different types of $C$. cinerea mycelia}

Agar plugs $(0.6 \mathrm{~cm}$ in $\emptyset)$ of freshly grown mycelium of different $C$. cinerea strains were taken with a cork borer from the edge of actively growing cultures and transferred either onto YMG/T agar plates solidified with $1 \%$ agar (experiment 1 and 2) or onto 
water agar solidified with $1 \%$ agar (experiment 3). In each experiment, 10 replications were done for each treatment. In experiment 1, 8 different agar plugs with fungal mycelium were positioned in alternating order (monokaryon - dikaryon - monokaryon etc.) in even distances to each other on a circle $3 \mathrm{~cm}$ apart from the center of the Petridish. In experiment 2 and 3, one agar plug with mycelium per strain ( 2 in total) were positioned onto agar in a Petri-dish $6 \mathrm{~cm}$ apart from each other, respectively $3 \mathrm{~cm}$ each apart from the center of the plate. In experiment 1 and 3, 25 mites were in fast sequence put onto a fresh YMG/T agar plug positioned in the middle of the agar plates, upon which Petri-dishes were sealed with Parafilm, covered with aluminium foil and incubated in the greenhouse at $25-28^{\circ} \mathrm{C}$ and $60 \%$ humidity for $20 \mathrm{~h}$ before evaluating the plates. In experiment 2, plates with mycelial agar plugs were first sealed with Parafilm, wrapped with aluminium foil and incubated for $24 \mathrm{~h}$ at $25-28^{\circ} \mathrm{C}$ and $60 \%$ humidity in the greenhouse, before a fresh YMG/T agar plug was positioned in the middle of the Petri-dishes onto which in fast sequence 25 mites were transferred. Directly after, plates were sealed again with Parafilm, wrapped with aluminium foil and incubated for $20 \mathrm{~h}$ in the greenhouse at $25-28^{\circ} \mathrm{C}$ and $60 \%$ humidity before further evaluation of the plates.

\subsubsection{Testing effects of volatile organic compounds (VOCs) on mites}

Typical mushroom odour 8-carbon compounds, 1-octen-3-ol (>98\%, Merck, Darmstadt, Germany) and 3-octanone (>96\%, VWR, Darmstadt, Germany) were investigated in attraction tests of mites. 1-octen-3-ol and 3-octanone, respectively, were mixed with paraffin oil (Uvasol, Merck, Darmstadt, Germany) at a dilution of $10^{-6} \mathrm{~g} / \mathrm{g}$. Round pieces $(0.6 \mathrm{~cm}$ in $\varnothing)$ of sterilized filter paper, $\varnothing 90 \mathrm{~mm}$ (Schleicher \& Schuell MicroScience GmbH, Dassel, Germany) were placed on YMG/T agar plugs $(0.6 \mathrm{~cm}$ in $\varnothing$ ) positioned $6 \mathrm{~cm}$ apart from each other on YMG/T agar plates (two plugs in total per Petri-dish), respectively $3 \mathrm{~cm}$ apart from the center of Petri-dishes. On one of the plugs per Petri-dish, either $20 \mu 1$ of the 1-octen-3-ol/paraffin solution were pipetted or $20 \mu \mathrm{l}$ of the 3-octanone/paraffin solution whereas the other plug on the Petri-dish was treated as a control onto which $20 \mu \mathrm{l}$ of the pure paraffin oil was pipetted. Subsequently, 25 mites were transferred in fast sequence onto a fresh YMG/T agar plug positioned in the middle of the Petri-dish, sealed with Parafilm, incubated first for 
$10 \mathrm{~min}$ at room temperature and secondly $20 \mathrm{~h}$ at $25-28^{\circ} \mathrm{C}$ at $60 \%$ humidity in the greenhouse, before plates were observed under a Stemi 2000-C binocular.

\subsection{Results and discussion}

\subsubsection{The origin of mites used in this study and their experimental handling and cultivation}

Aging cultures of $C$. cinerea are characterised by unpleasant, pungent smells that possibly attract mites to the cultures. Accordingly, in old plates of mutant PUK1-6 kept for longer times neglected on a bench in the laboratory, perforations in the layer of the aerial mycelium became obvious in which under the Stemi 2000-C binocular mites were found. Mites and eggs of mites were transferred from infected cultures onto fresh plates through agar plugs where they proliferated when transferring them into a greenhouse at $25-28^{\circ} \mathrm{C}$ and $60 \%$ humidity. They were identified by Dr. P. Plašil as T. prudescentiae. Initially, mites were kept in Parafilm-closed Petri-dishes on a bench in the greenhouse without any further protection but during the hotter summer month when temperatures increased in the greenhouse to $33-37^{\circ} \mathrm{C}$ with the higher light illumination through the glass windows of the greenhouse, it became quickly clear that mites were negatively influenced by too much light and the accompanying heat. Accordingly, Petri-dishes were covered with first paper and later then by standard with aluminium foil in order to keep cultures dark and in order to reflect any light-associated heat. Moreover, it was observed by Dr. P. Plašil and the technician U. Eisenwiener from the section Forest Zoology and Forest Conservation of the Büsgen-Institute of GeorgAugust-University of Göttingen that in older cultures larger predatory mites invaded the Petri-dishes through the Parafilm. In order to prevent unwanted migration of mites (from the outer environment into the mite cultures but also migration of mites away from the cultures), Petri-dishes should therefore be incubated either on flat dishes with a thick, un-interrupted line of vaseline around the fungal cultures in which the invading and evading mites will stick or the Petri-dishes should be incubated onto grids kept above bowls filled with water into which mites will not invade or evade. With increasing experiences in handling of cultures of mites, at later stages in this work the latter possibility was chosen to protect the cultures. 


\subsubsection{Grazing of mites in mycelial cultures of $C$. cinerea}

To study the grazing behaviour of $T$. prudescentiae on the vegetative mycelium of C. cinerea, each 25 mites were transferred onto a small agar plug in the middle of freshly grown mycelial cultures of different fungal strains (monokaryons PS001-1 and PS002-1, homokaryon AmutBmut, dikaryon PS001-1 x PS002-1). The mites distributed randomly over the different sectors of the plates starting grazing on the mycelium with certain preferences for the most outer, i.e. younger regions of the colonies and/or the most inner, i.e. older regions of the mycelia (Fig. 1). Grazing by mites was visible by perforations in the aerial mycelium revealing the agar underneath. Agar was not recognisably consumed by the mites as well as not sclerotia (dark, round cellular aggregates with a melanized rind serving as duration structures) (Waters et al. 1975, Kües et al. 2002) that developed manifold over the time in the aging cultures kept under dark conditions (Fig. 1 and Fig. 2A to D). Generally, the mycelium of the monokaryons PS001-1 and PS002-1 was faster consumed than that of homokaryon AmutBmut and the mycelium of homokaryon AmutBmut was faster consumed than that of dikaryon PS001-1 x PS002-1 (Fig. 1).

When testing in a similar experimental set-up mycelial cultures of the dst mutant homokaryons PUK1-6, PUK2-6, PUK3 and PUK4 forming under standard fruiting conditions etiolated stipes that typically in wildtype strains are only formed after obtaining an initial light signal with subsequent cultivation in constant dark (see Chapter 3 of this thesis), the mites distributed evenly over the sectors of the Petri-dishes (Fig. 3). However, in contrast to the experiments with the wildtype strains shown in Fig. 1, preferentially grazing was observed in somewhat more inner parts of the cultures, mainly at places where in closer vicinity over the time the likely nutrient-rich etiolated stipes appeared. Nevertheless, the etiolated stipes were not consumed by the mites (Fig. 3). Consumed were also not the sclerotia that appeared in the cultures over the time and not the agar appearing as a surface when the mycelial mat was consumed by the mites (Fig. 2E to $\mathrm{H}$ and Fig. 3).

In the experiment shown in Fig. 3, the etiolated stipes appeared after infestation of the plates with the mites. In contrast in the plates shown in Fig. 4, etiolated stipes were formed prior to infestation of the cultures with the mites. After growth of $d s t$ mutants for 5 days at $37^{\circ} \mathrm{C}$, plates were first kept for 7 days in normal position in standard fruiting conditions at $28^{\circ} \mathrm{C}$ and then for 7 further days in an up-side-down condition to allow the already developed etiolated stipes to improve in strength and length (compare 
for example Fig. 20 in Chapter 3 of this thesis). However, also these etiolated stipes were not consumed, as were also not normal fruiting bodies induced in some of the $d s t$ mutant cultures by turning plates up-side down (experimental set-up of fruiting body induction in $d s t$ mutant cultures resulting in normal fruiting body development
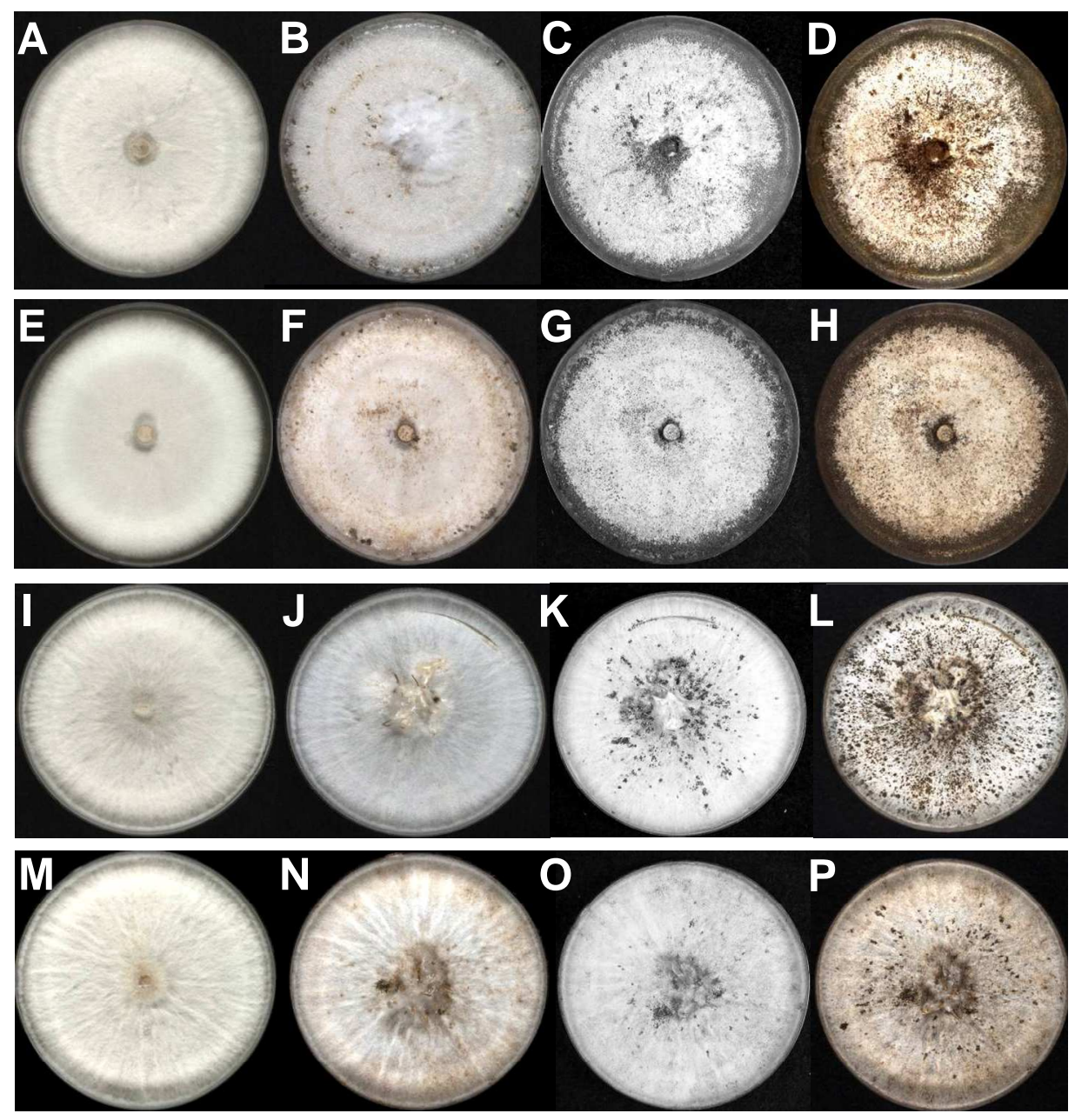

Fig. 1 Effects of grazing mites on fungal mycelium of Coprinopsis cinerea monokaryons PS001-1 (A)to (D) and PS002-1 (E) to (H), of homokaryon AmutBmut (I) to (L) and of dikaryon PS001-2 x PS002-1 (M) to (P). Mycelia were grown on YMG/T medium for 6 days (monokaryons PS001-1 and PS002-1), respectively 5 days (homokaryon AmutBmut and the dikaryon) at $37^{\circ} \mathrm{C}$ in the dark until the agar was covered by mycelium. Per strain, 3 different plates were inoculated with 25 mites each (as described in the methods), upon which they were transferred into darkened conditions (by covering with aluminium foil) into a greenhouse at $25-28{ }^{\circ} \mathrm{C}$ and $60 \%$ humidity and observed in parallel. Representative plates per strain are shown in the figure. The first plate of each strain (A), (E), (I) and (M), respectively) shows the freshly grown cultures at the time of transfer of the animals, the neighboured photos the same plates 14 days $(\mathbf{B}),(\mathbf{F}),(\mathbf{J})$ and $(\mathbf{N})$, respectively), 21 days $(\mathbf{C}),(\mathbf{G}),(\mathbf{K})$ and $(\mathbf{O})$, respectively) and 1 month after infection with the mites $(\mathbf{D}),(\mathbf{H}),(\mathbf{L})$ and $(\mathbf{P})$, respectively). Note the perforations in the mycelia indicating the places of grazing by the mites which tend to prefer the outer younger mycelium of the cultures as seen by the outer rings of free agar upon longer incubation and/or the region close to the fungal inoculi. Note also the formation of dark-brown stained sclerotia over the time (starting from day 7 after infestation with the mites) that were however neglected by the mites (compare Fig. 2 (A) to (D). 

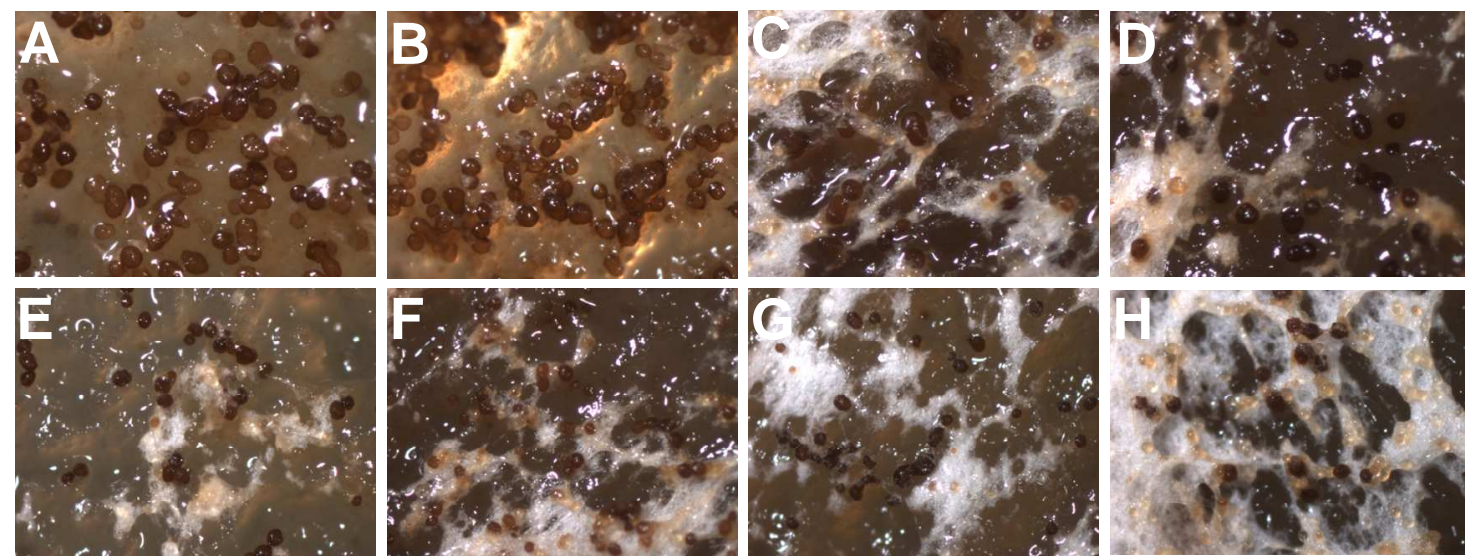

Fig. 2 Sclerotia and agar are neglected by the mites. Sclerotia of strains PS001-1 (A), PS002-1 (B), AmutBmut (C), PS001-1 x PS002-1 (D), PUK1-6 (E), PUK2-6 (F), PUK3 (G) and PUK4 $(\mathbf{H})$ are shown that are left on the agar surface in cultures (shown in full in Fig. 1 and in Fig. 3, respectively) after grazing by mites 1 month after infestation.

inclusively basidiospore formation were described previously in Chapter 3 of this thesis). Note that the plates shown in Fig. 4 were not directly infested with 25 mites as in all other experiments described in this chapter, but mites were given the free opportunity to migrate from infested mite stock cultures into the plates with the etiolated stipes. As can be seen from the perforations in the mycelial layers in the plates shown in Fig, 4, mites were attracted from the outside to the cultures.

\subsubsection{Grazing of mites in mycelial cultures of $C$. cinerea with fruiting bodies}

Subsequently, multi-cellular structures of homokaryon AmutBmut, of dikaryon PS001-1 x PS002-1 and of the different $d s t$ mutant homokaryons were analysed in more detail in terms of grazing preferences of mites (Fig. 5 to Fig. 8). In these experiments, cultures were allowed to produce multicellular structures (primordia, fruiting bodies, etiolated stipes) prior to infection with the mites. In all cultures, the vegetative mycelium was easily consumed by the mites - thereby note in Fig. 5 that again the mycelium of homokaryon AmutBmut was faster consumed than the mycelium of the dikaryon PS001-1 x PS002-1. The latter has a slightly different, somewhat chewinggum-like consistency compared to mycelia of the parental monokaryons and the coisogenic AmutBmut-type homokaryons and appears to age faster. Due to this different consistency, the mycelium of the dikaryon PS001-1 x PS002-1 might be less preferred 

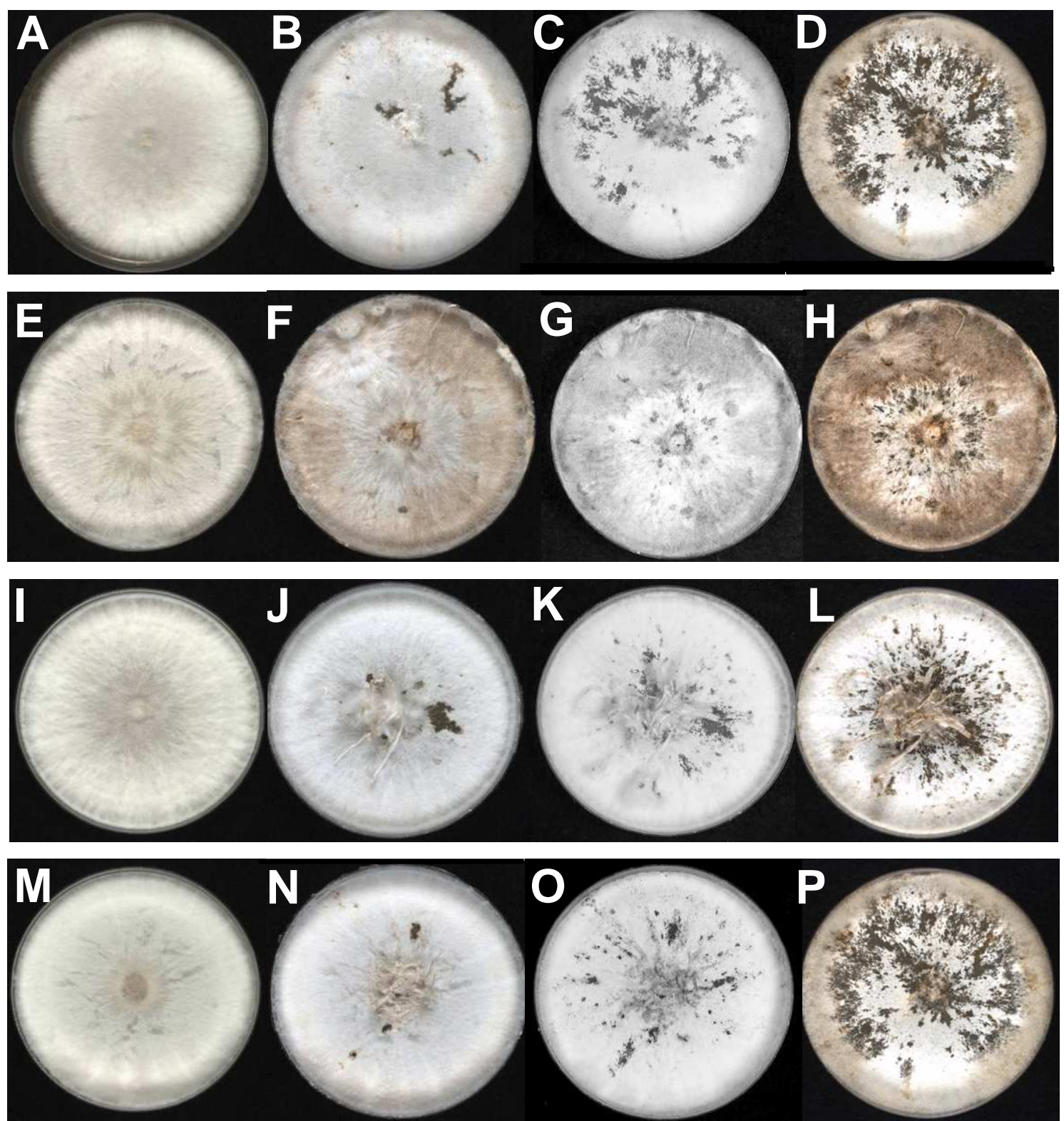

Fig. 3 Effects of grazing mites on fungal mycelium of Coprinopsis cinerea mutant homokaryons PUK1-6 (A) to (D) and PUK2-6 (E) to (H), PUK3 (I) to (L) and PUK4 (M) to (P). Mycelia were grown on YMG/T medium for 5 days at $37^{\circ} \mathrm{C}$ in the dark until the agar was covered by mycelium. Per strain, 3 different plates were inoculated with 25 mites each (as described in the methods), transferred into darkened conditions (by covering with aluminium foil) into a greenhouse at $25-28^{\circ} \mathrm{C}$ and $60 \%$ humidity and observed in parallel. Representative plates per strain are shown in the figure. The first plate of each strain $[(\mathbf{A}),(\mathbf{E}),(\mathbf{I})$ and $(\mathbf{M})$, respectively] shows the freshly grown cultures at the time of transfer of the animals, the neighboured photos the same plates 14 days $[(\mathbf{B}),(\mathbf{F}),(\mathbf{J})$ and $(\mathbf{N})$, respectively $], 21$ days $[(\mathbf{C}$, $\mathbf{G}, \mathbf{K}$ and $\mathbf{O}$, respectively] and 1 month after infection with the mites $[(\mathbf{D}),(\mathbf{H}),(\mathbf{L})$ and $(\mathbf{P})$, respectively]. Note the perforations in the mycelia indicating the places of grazing by the mites which tend to prefer regions in which etiolated stipes were forming. Note that etiolated stipes were neglected by the mites and also the sclerotia formed in the cultures over the time. 


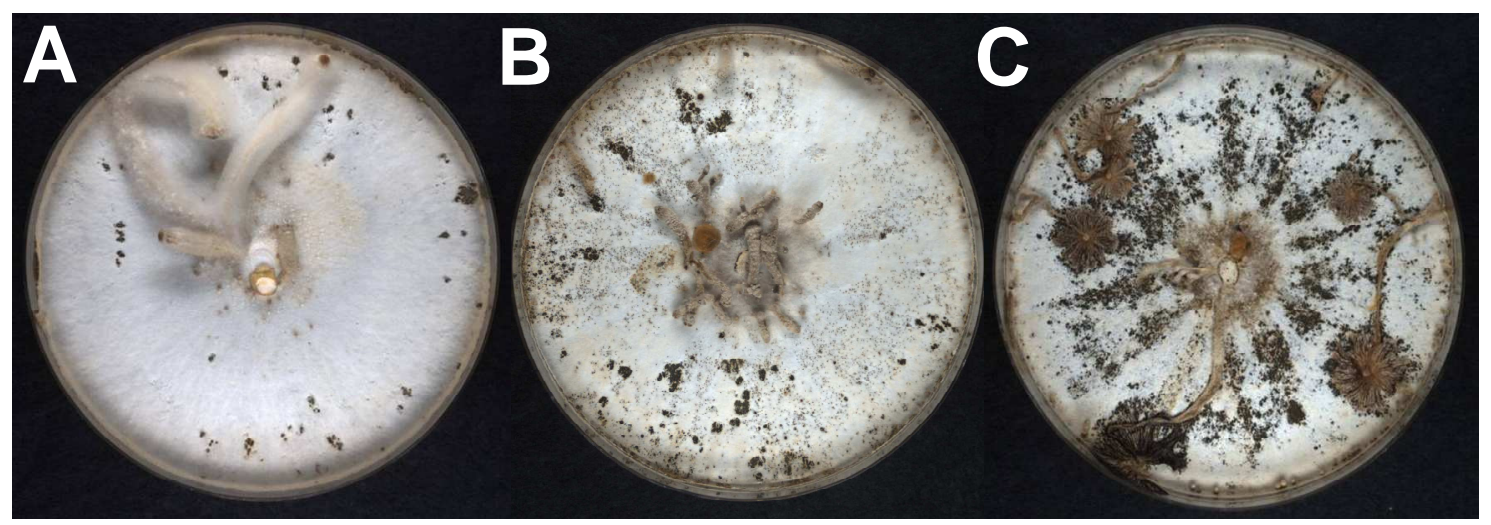

Fig. 4 Mites avoid grazing on etiolated stipes and fruiting bodies. Plates inoculated with the dst1-2 homokaryon PUK1-6 (A) and the dst4-1 homokaryon PUK4 (B), (C), respectively, were incubated for 5 days at $37^{\circ} \mathrm{C}$ in constant dark and then under standard fruiting conditions at $28^{\circ} \mathrm{C}$ until etiolated stipes were formed (day 5 of incubation at $28^{\circ} \mathrm{C}$ ). The plates were then further incubated for 7 days under standard fruiting conditions in an upside-down position, upon which they were installed in between a pile of 2 weeks-old mite stock cultures for free infestation by mites during a period of seven days of incubation in the greenhouse at $25-28^{\circ} \mathrm{C}$ under a humidity of $60 \%$ and shading of the plates by covering them with aluminium foil. None of the plates in these piles were locked with Parafilm. Plates were evaluated after 7 days incubation with the mites in the greenhouse. Perforations in the mycelial layer are seen indicating invasion of mites into the cultures and grazing by these mites.
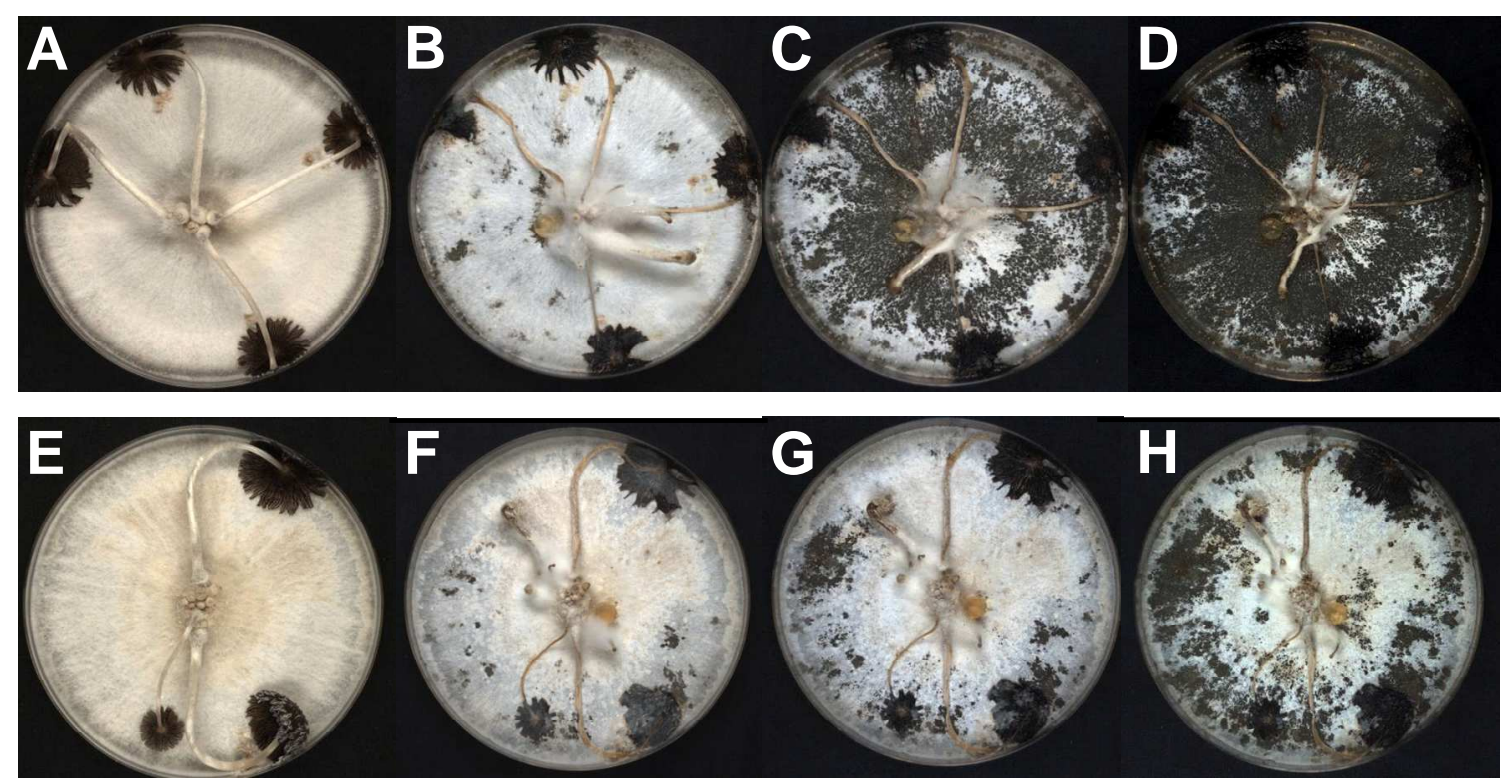

Fig. 5 Mites feed on the vegetative mycelium of Coprinopsis cinerea AmutBmut (A) to (D) and PS001-2 x PS002-1 (E) to (H) but not on stipes of fruiting bodies. Cultures were inoculated on the middle of YMG/T plates, incubated for 5 days at $37^{\circ} \mathrm{C}$ in the dark before transferring them into standard fruiting conditions at $28^{\circ} \mathrm{C}$ into a $12 \mathrm{~h}$ dark $/ 12 \mathrm{~h}$ light scheme at $85-90 \%$ humidity. After 7 days of incubation at $28^{\circ} \mathrm{C}$, mature fruiting bodies were grown on the plates. At this point, plates were infected with 25 mites per plate as described in the methods (3 repeats per strain). Representative plates are shown on day 7 of normal fruiting body development (A) and (E); compare Fig. 1 in Chapter 2 of this thesis) directly prior to infestation with 25 mites per plate by adding them into the middle of the cultures via a small agar block) and 14 days $(\mathbf{B})$ and $(\mathbf{F}), 21$ days $(\mathbf{C})$ and $(\mathbf{G})$ and 1 month after infestation with mites $(\mathbf{D})$ and (H), respectively. 

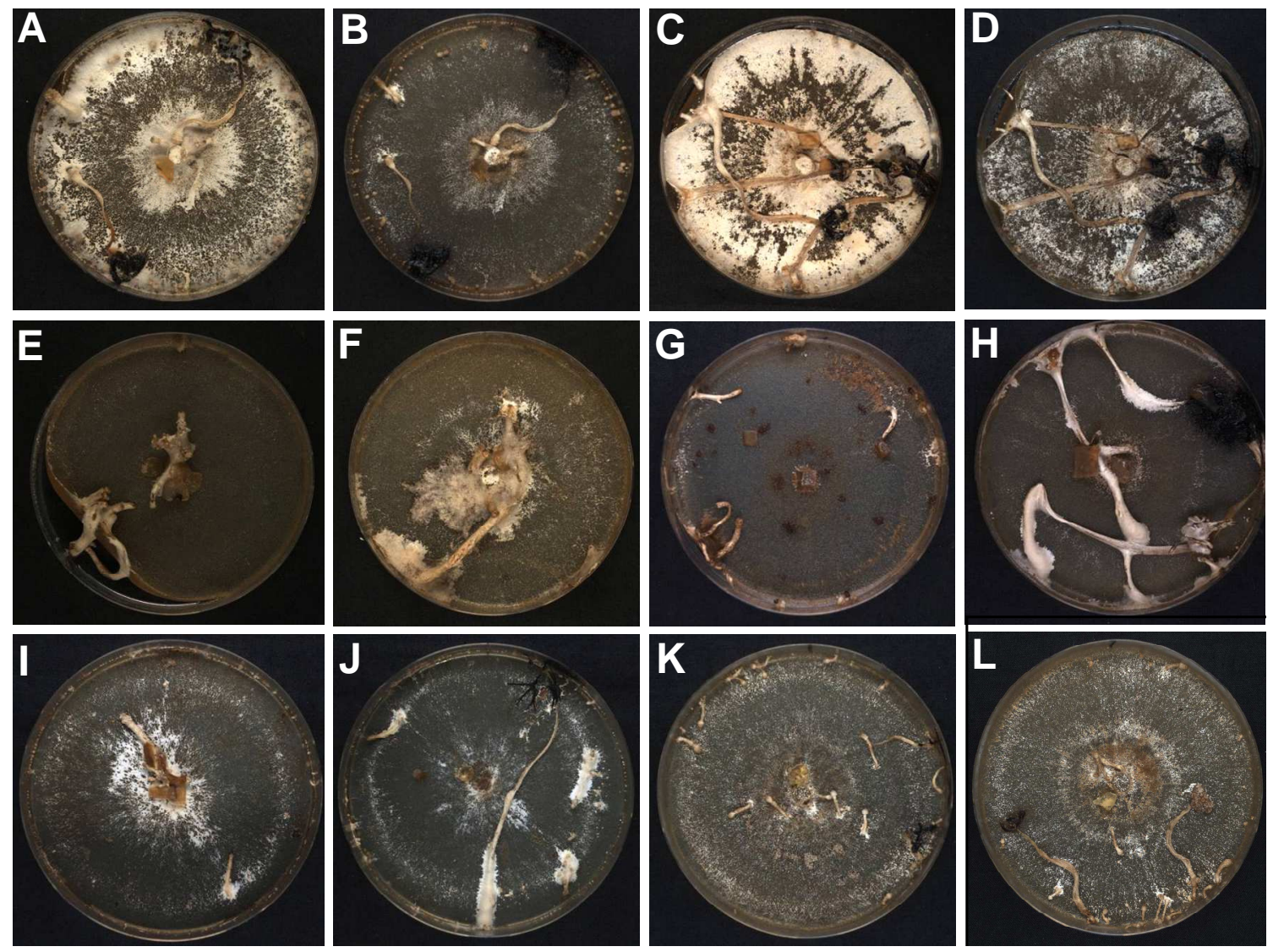

Fig. 6 Multi-cellular structures are avoided in grazing by mites. Plates of homokaryon AmutBmut (A), (B), the dikaryon PS001-1 x PS002-1 (C), (D), PUK1-6 (E), (F), PUK2-6 (G), (H), PUK3 (I), (J) and PUK4 (K), (L) were photographed after one (each time the left photo) and two month (each time the right photo) of incubation in a greenhouse after infestation with 25 mites per plate (see methods), respectively. Note that only in case of (A) and (B), respectively in case of $(\mathbf{C})$ and $(\mathbf{D})$, the same plate has been photographed at the two different time points.

by the mites as food or less easy to degrade. Moreover, in the cultures which underwent fruiting body development by incubation under standard fruiting conditions (Fig. 4 to Fig. 6), fewer numbers of sclerotia were observed compared to the cultures kept most of the time in dark conditions (Fig. 1 to Fig. 3). By impression from observations of the various cultures under the Stemi 2000-C binocular it appears that the mites prefer grazing on mycelial cultures lacking sclerotia and that the mites proliferated under these conditions in higher numbers (not further documented).

Whilst the mycelium was however in all cultures consumed over the time, the fruiting body primordia as well as the stipes of all fruiting structures were avoided by the mites for at least one month of incubation (Fig. 5). When prolonging incubations for two months, leaving the animals up to four weeks without any fresh nutrients, primordia and stipes of fruiting bodies were still avoided similarly like any etiolated 


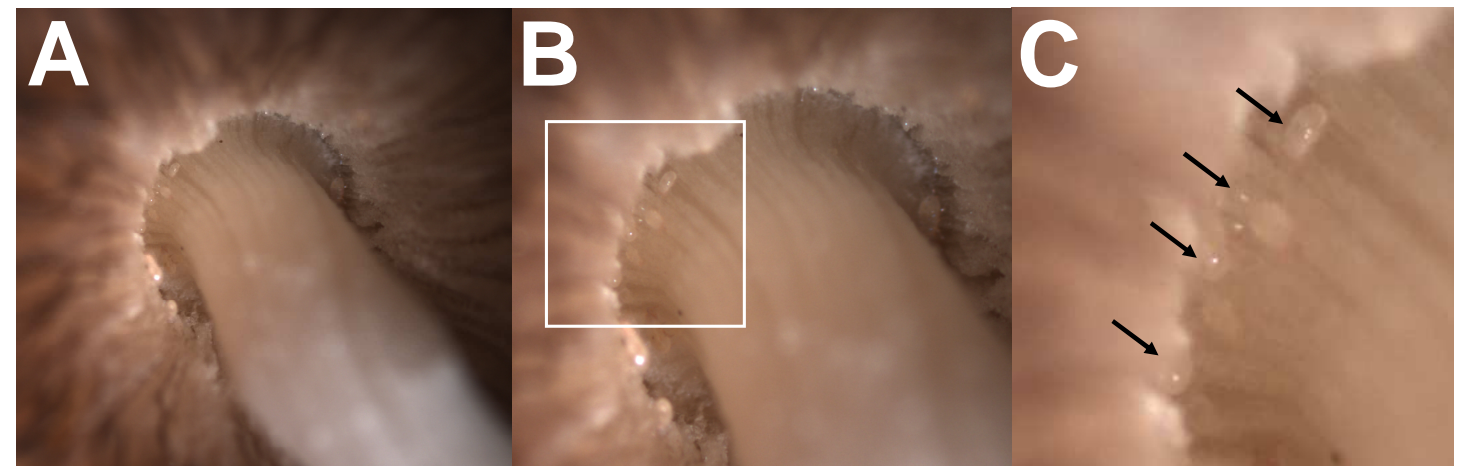

Fig. 7 Mites graze on issues of the cap of the fruiting body. The dikaryon PS001-1 x PS002-1 was grown on YMG/T medium for 5 days at $37^{\circ} \mathrm{C}$ in constant dark upon which the plate was transferred to $28^{\circ} \mathrm{C}$ into standard fruiting conditions. At day 6 of incubation at $28^{\circ} \mathrm{C}$ at the end of the $12 \mathrm{~h}$ light period (after $11 \mathrm{~h}$ of light incubation), fruiting body development reached the stage of basidiospore formation which parallels onset of rapid stipe elongation (see NavarroGonzález 2008 for a description of this stage of development). 25 mites were placed at the base of the elongating stipe and the Petri-dish was covered by a $600 \mathrm{ml}$ glass-beaker in order to avoid breakage of the upwards protruding fruiting body by the lid of the Petri-dish. The developing mushroom was incubated overnight for $12 \mathrm{~h}$ with the mites at $25-28^{\circ} \mathrm{C}$ in the greenhouse at $60 \%$ humidity, upon which the still standing mushroom was harvested and checked for mites. In total, 10 mites were still detected on the mushroom (see in $(\mathbf{A})$ to $(\mathbf{C})$ three different enlargements of the cap). All of them moved to the cap residing in the groove between the gills and the stipe formed by tearing apart the gills from the stipe (see Navarro-González 2008 for further information) allowing entry into the inner tissues of the cap. The 15 other mites all spread into the vegetative aerial mycelium around the base of the mushroom stipe in an area of a radius of about $1 \mathrm{~cm}$ and started grazing on the layer of aerial hyphae in a manner as documented in Fig. 9A leading to mycelial perforations.

stipes that appeared in cultures (Fig. 5 and Fig 6). Whilst mites did graze on cap tissues of mature fruiting bodies (Fig. 7 and Fig. 8A), there were however also hyphal cells in the cap giving the pileus shape and shape to the gills, respectively that were avoided even under long term of incubation with mites (Fig. 8B and C).

\subsubsection{Further observations on behaviour of the mites in young mycelial cultures}

In order to learn more about the grazing behaviour of mites on mycelium, fresh YMG/T cultures of homokaryon AmutBmut were infested with these animals by allowing them to invade from mite stock cultures into the by Parafilm unclosed Petridishes upon which they were observed under a Stemi 2000-C binocular with the mites. After seven days of incubation, first smaller perforations in the mycelial mat helped to easily detect the animals under the Stemi 2000-C binocular. Mites were observed to consume the mycelial mat from its surface into the direction of the agar (Fig. 9A). Once 


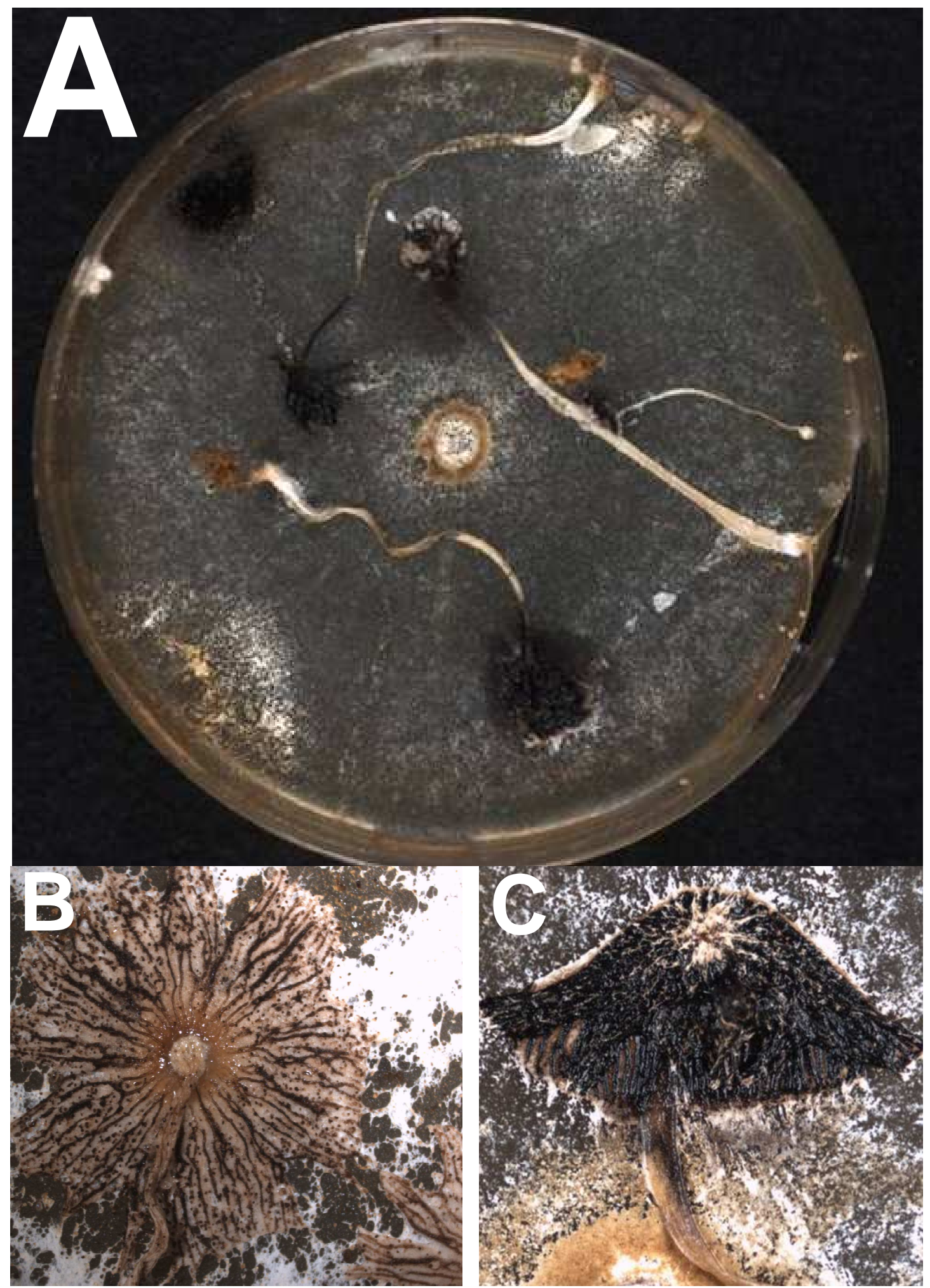

Fig. 8 Mites graze on certain issues of the cap of the fruiting body. (A) Plate of the dikaryon PS001-1 x PS002-1 from the same set of experiments as those shown in Fig. 6 (C) and (D) after incubation for two month with mites showing the neglected fruiting body stipes and remnants of the caps. (B) Cap of the mutant PUK4 after incubation for 7 days with mites. The strain was grown in three replicates for 5 days at $37^{\circ} \mathrm{C}$ in constant dark, upon which cultures were transferred at $28^{\circ} \mathrm{C}$ into standard fruiting conditions. Mature mushrooms were obtained at day 9 of incubation at $28^{\circ} \mathrm{C}$ (compare Fig. 14 and table 9 in Chapter 3 of this thesis) upon which cultures were infested by each 25 mites by placing them onto a fresh agar plug in the middle of 
the plates. Plates were sealed with Parafilm, wrapped in aluminium foil and incubated for seven days at $25-28^{\circ} \mathrm{C}$ and $60 \%$ humidity in the greenhouse. Upon incubation with the mites, certain outer tissues giving the pileus shape and the shape of the gills are still present. Note the high numbers of faecal pellets laid on the surface of the cap which were formed by ingesting but not digesting basidiospores by the mites (further information in Navarro-González 2008 and see below) indicating eager grazing of the mites on cells and tissues of the cap. (C) Cap of the homokaryon AmutBmut after incubation for 7 days with mites. The strain was grown in three replicates for 5 days at $37^{\circ} \mathrm{C}$ in constant dark, upon which cultures were transferred at $28^{\circ} \mathrm{C}$ into standard fruiting conditions. Mature mushrooms were obtained at day 7 of incubation at $28^{\circ} \mathrm{C}$ upon which cultures were treated as described under $(\mathbf{B})$ for the PUK4 plates. Note also here the high numbers of faecal pellets laid on the surface of the cap and on the surrounding agar. The remnants of the cap of homokaryon AmutBmut appear more black than in case of the PUK4 cap by the much higher amount of basidiospores produced by the fungus.

they reach the agar surface they bore tunnels in the mycelial mat through their grazing (not shown). The effect of this tunnelling was that the aerial mycelium could easily be lifted from the agar by a needle (Fig. 9B) which was not possible with the undamaged mycelium being firmly anchored into the agar. After 1 month of incubation with the mites, perforations in the aerial vegetative mycelium were manifold. In addition, it appeared that the mites brought bacteria in the fungal cultures that multiplied into a slimy mass attached to the mycelium (Fig. 9C). Upon further aging of the plates, much of the aerial mycelium is consumed and the mites also consumed the submerged mycelium present in the most upper regions of the agar (Fig. 9D). Once this myceliumcontaining agar is also eaten, mites stop to ingest agar (Fig. 9E).

In similar sets of experiments, mites were also observed in fully grown YMG/T cultures of the dst1 mutant homokaryon PUK1-6 (Fig. 10A) and the dst3 mutant homokaryon PUK3 (Fig. 10B, C). The behaviour of the mites were as in the cultures of the homokaryon AmutBmut: Mites started grazing of the mycelium from the surface down to the agar (Fig. 10A) or even into the agar possibly in order to consume the submerged mycelium (Fig. 10B) until all mycelium is eaten from the agar surface and the upper agar layer with the submerged mycelium (Fig. 10C). Upon consumption of all mycelium, the agar is not anymore further touched (Fig. 10C). Note that also in the cultures of the mutant homokaryons growth of slimy bacteria on the mycelial surface as well as on the agar surface was observed (Fig. 10B) and it is likely that the mites brought the bacteria with them into the formerly pure fungal cultures. 

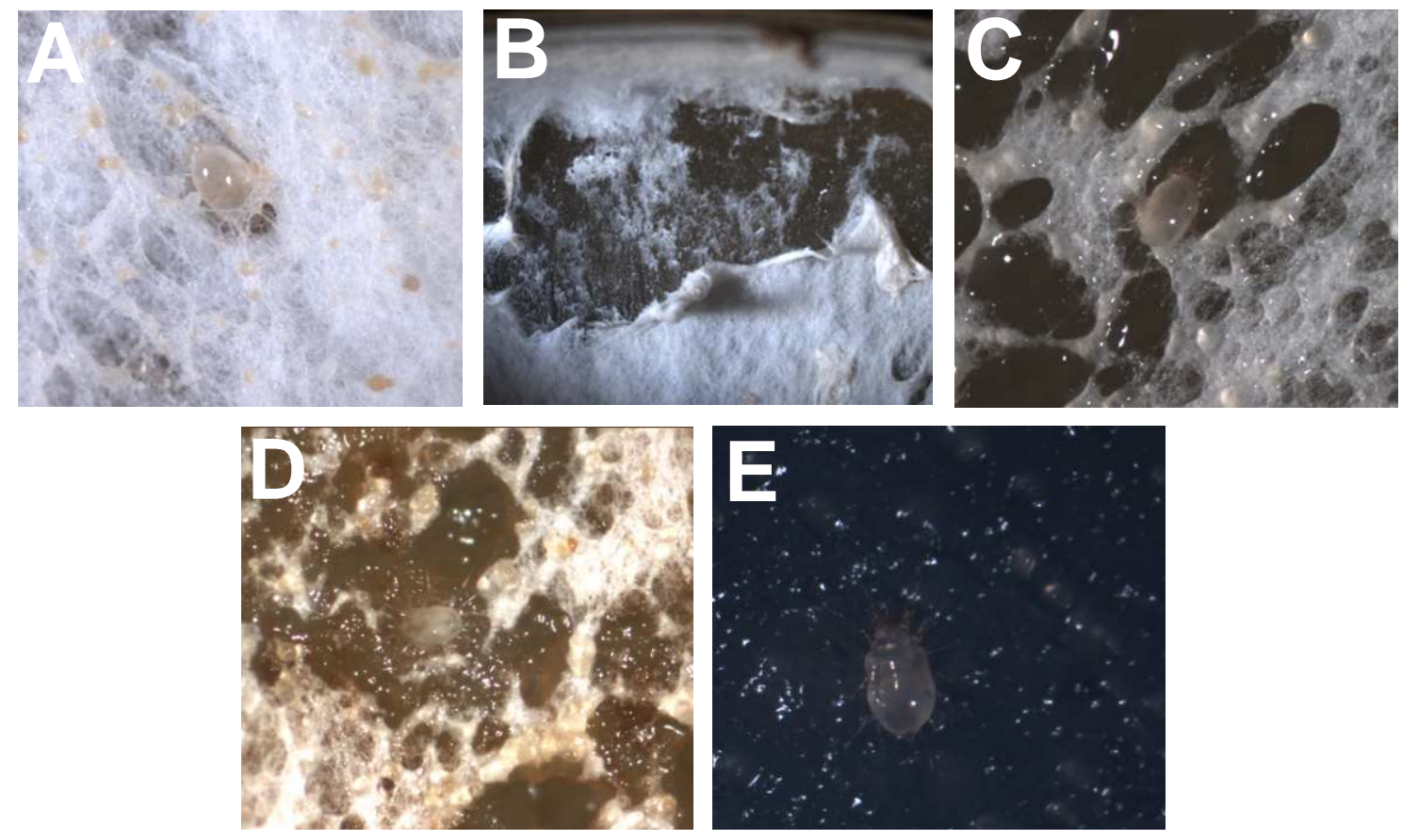

Fig. 9 Grazing behaviour of mites in the aerial mycelium of homokaryon AmutBmut. The strain was first grown for 5 days at $37^{\circ} \mathrm{C}$ in constant dark followed by 7 days of incubation under standard fruiting conditions at $28^{\circ} \mathrm{C}$, upon which plates unlocked by Parafilm were transferred in piles of also unlocked two weeks old mite stock cultures of homokaryon AmutBmut (two above and three below the non-infested homokaryon AmutBmut culture) into the greenhouse at $25-28^{\circ} \mathrm{C}$ and $60 \%$ humidity to be incubated under a cover of aluminium foil for 7 days $(\mathbf{A}),(\mathbf{B})$, respectively 1 month $(\mathbf{C}),(\mathbf{D}),(\mathbf{E})$ before evaluation of the mycelium with the mites were done underneath a Stemi 2000-C binocular.
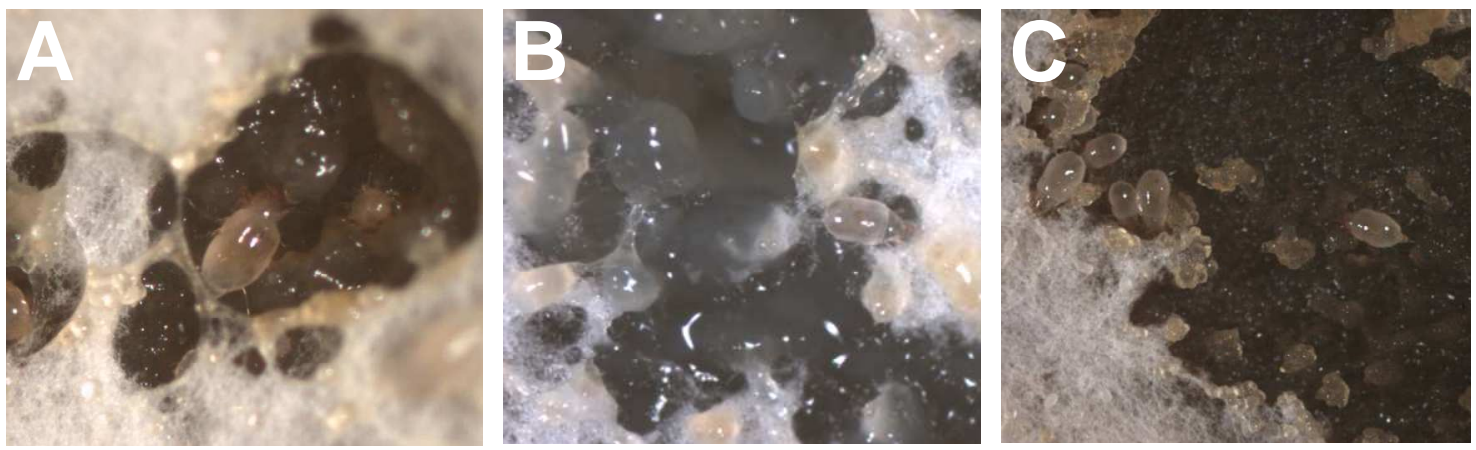

Fig. 10 Grazing behaviour of mites in the aerial mycelium of mutant homokaryon PUK1-6 (A) and PUK3 (B), (C). The strains were first grown for 5 days at $37^{\circ} \mathrm{C}$ in constant dark followed by 7 days of incubation under standard fruiting conditions at $28^{\circ} \mathrm{C}$, upon which plates unlocked by Parafilm were transferred in piles of also unlocked two weeks old mite stock cultures of homokaryon AmutBmut (two above and three below a plate with a non-infested mutant homokaryon culture) into the greenhouse at $25-28^{\circ} \mathrm{C}$ and $60 \%$ humidity to be incubated under a cover of aluminium foil for 7 days before evaluation of the mycelium with the mites were done underneath a Stemi $2000-\mathrm{C}$ binocular. 


\subsubsection{Further observations on grazing preferences and behaviour of the mites}

To further test the grazing behaviour of mites towards mycelium containing sclerotia, 8 other agar blocks $(0.6 \mathrm{~cm}$ in $\varnothing)$ with established mycelium containing numerous sclerotia were placed onto a YMG/T agar plate with homokaryon AmutBmut (Fig. 11A, B) grown in $28^{\circ} \mathrm{C}$ under constant light up to primordia stage P5 (from the same experiment presented in Fig. 18 in Chapter 2 of this thesis). These agar blocks with mycelium were harvested from an 1 month-old plate of homokaryon AmutBmut cultivated for the whole period at $28^{\circ} \mathrm{C}$ in constant dark. Afterwards, the plate (not sealed with Parafilm) was placed into a pile of 5 unsealed plates (two below, three above) of AmutBmut stock cultures containing populations of mites due to a 4-weeks incubation in the greenhouse at $28^{\circ} \mathrm{C}$ of the fully grown fungus after inoculation with 25 mites on agar blocks as described in the method section. The pile of plates was wrapped into aluminium foil and incubated for 28 days in the greenhouse as described in the method section before further evaluation. It was found that the mites consumed most of the aerial mycelium of the fungal culture but left the P5 primordia on the plate aside (Fig. 11A) as well as the sclerotia that in the meantime developed in the
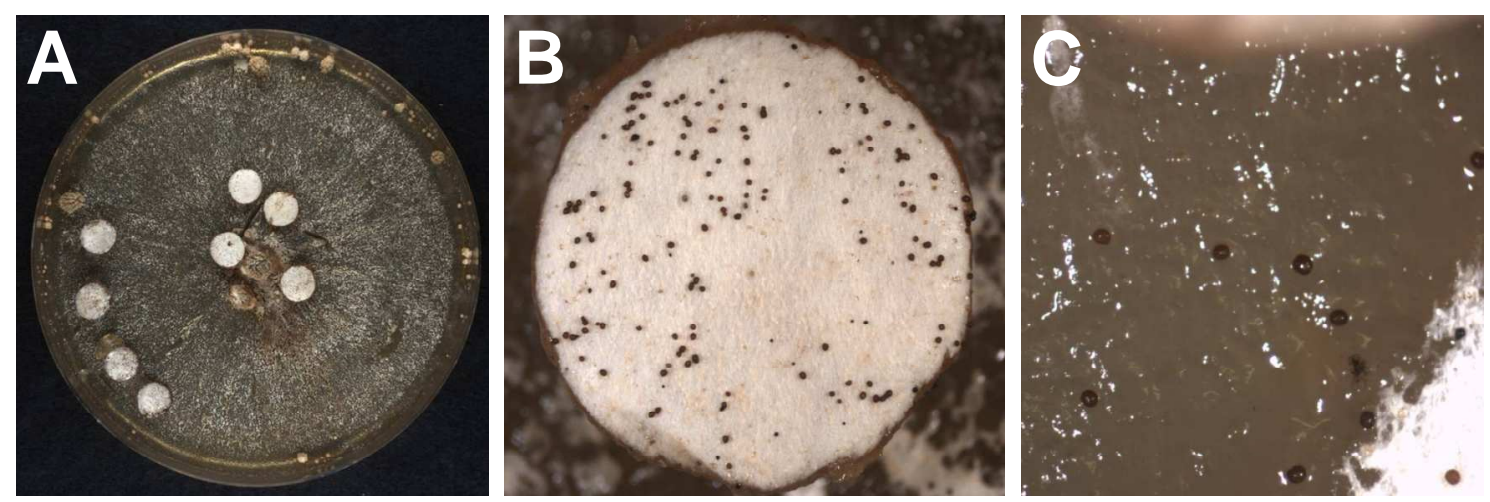

Fig. 11 Mites prefer fresh mycelium for grazing and avoid aged mycelium with sclerotia. (A) A still young mycelial YMG/T culture of homokaryon AmutBmut grown for 16 days at $28^{\circ} \mathrm{C}$ in constant light (compare Fig. 18 in Chapter 2 of this thesis) were taken at the primordia stage P5 onto which 8 mycelium-covered agar plugs from an aged culture of homokaryon AmutBmut grown for 28 days at $28^{\circ} \mathrm{C}$ in constant light were placed. Subsequently, the unsealed plate was placed in between 5 unsealed plates of homokaryon incubated previously for 4 weeks with mites for amplification of their populations. The pile of plates was wrapped by aluminium foil and incubated for 28 days in the greenhouse at $25-28^{\circ} \mathrm{C}$ and $60 \%$ humidity. After 4 weeks of incubation, the mycelium of the plate was mostly consumed but not that of the added agar plugs. (B) Enlarged view of an agar plug from the aged culture after incubation with the mites showing the untouched vegetative mycelia with the sclerotia that were already present on the plugs at the time of their transfer on top of the fresh culture. (C) Enlarged view onto the agar of the young culture after grazing of the vegetative mycelium by the mites. Note the sclerotia on the surface of the agar that were avoided by the mites. 

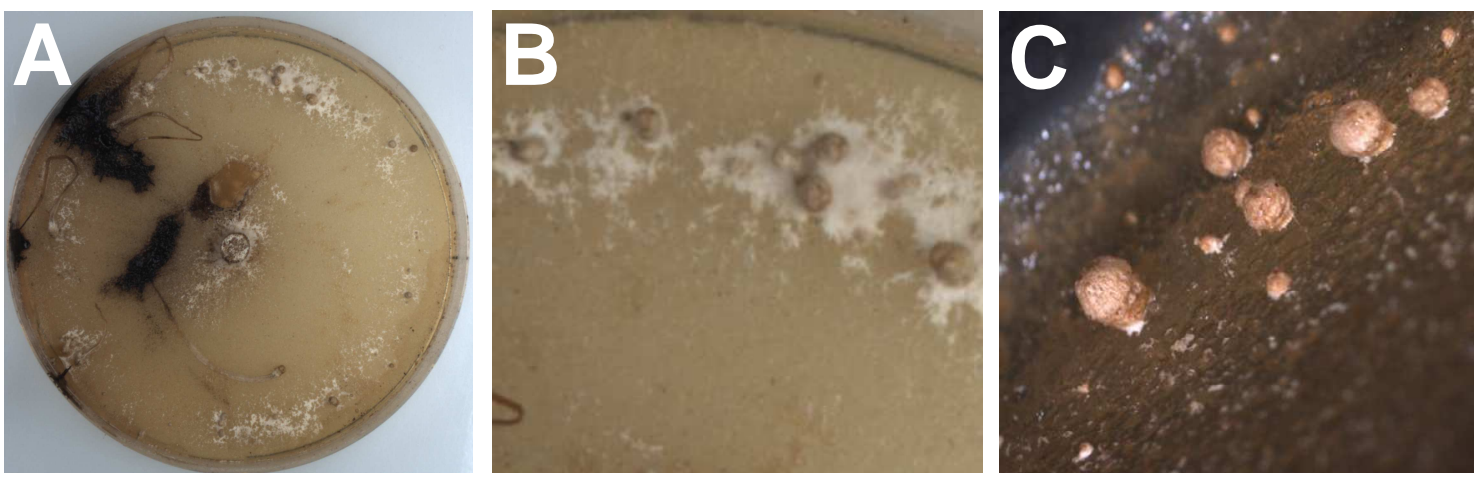

Fig. 12 Primordia and stipes of fruiting bodies are avoided by the mites. Homokaryon AmutBmut was grown for 5 days at $37^{\circ} \mathrm{C}$ in constant dark, upon which the cultures were transferred to standard fruiting conditions at $28^{\circ} \mathrm{C}$ in a $12 \mathrm{~h}$ light $/ 12 \mathrm{~h}$ dark regime. At day 7 of fruiting body development 8 hours after the light switched on (autolysed fruiting bodies, compare Fig. 1 in Chapter 2 of this thesis), 25 mites were placed on a fresh agar plug in the middle of the Petri dishes, which were then closed with Parafilm, wrapped with aluminium foil and incubated for 2 month in the greenhouse at $25-28^{\circ} \mathrm{C}$ under $60 \%$ humidity before further evaluation. (A) Complete culture showing primordia of stage P4 (compared Fig. 1 in Chapter 2 of this thesis), fruiting body stipes and dark areas of basidiospores and faecal pellets. (B) Enlargement of the same plate showing the aged and partially dried out primordia. (C) Primordia of stage P4 from another plate of the same age but not yet dried out.

aerial mycelium (Fig. 11C). Most interestingly, the mites did not attack the 8 agar blocks with the aged mycelium and the sclerotia that were placed on to of the vegetative mycelium of the fresh culture (Fig. 11 A, B).

Avoidance of primordia in cultures of homokaryon AmutBmut were regularly observed. Fig. 12 shows as examples primordia from stage P4 (compare Fig. 1 in Chapter 2 of this thesis) that were incubated with mites for 2 month without being through the animals, even though they must have been starving for at least weeks when the vegetative mycelium was fully consumed. Like primordia, the compact stipes of fruiting bodies were regularly neglected (Fig. 12A) as well as the etiolated stipes formed in cultures of the $d s t$ mutant homokaryons (Fig. 13). Obviously, the rigid structures of primordia, fruiting body stipes and etiolated stipes supported by outer dense, hard tissues are not attractive for the animals and can possibly not be utilized by them. This alters when such structures soften in consistency (Fig. 14). Aging fruiting body stipes over the time appear to undergo autolysis leading to their destabilization. Degenerating fruiting body stipes collapses and lie flat down onto the agar surfaces. When this happens, mites migrate to the degenerating stipes and nourish from the deliquescing stipe material. Occasionally, as long as they did not further harden due to 

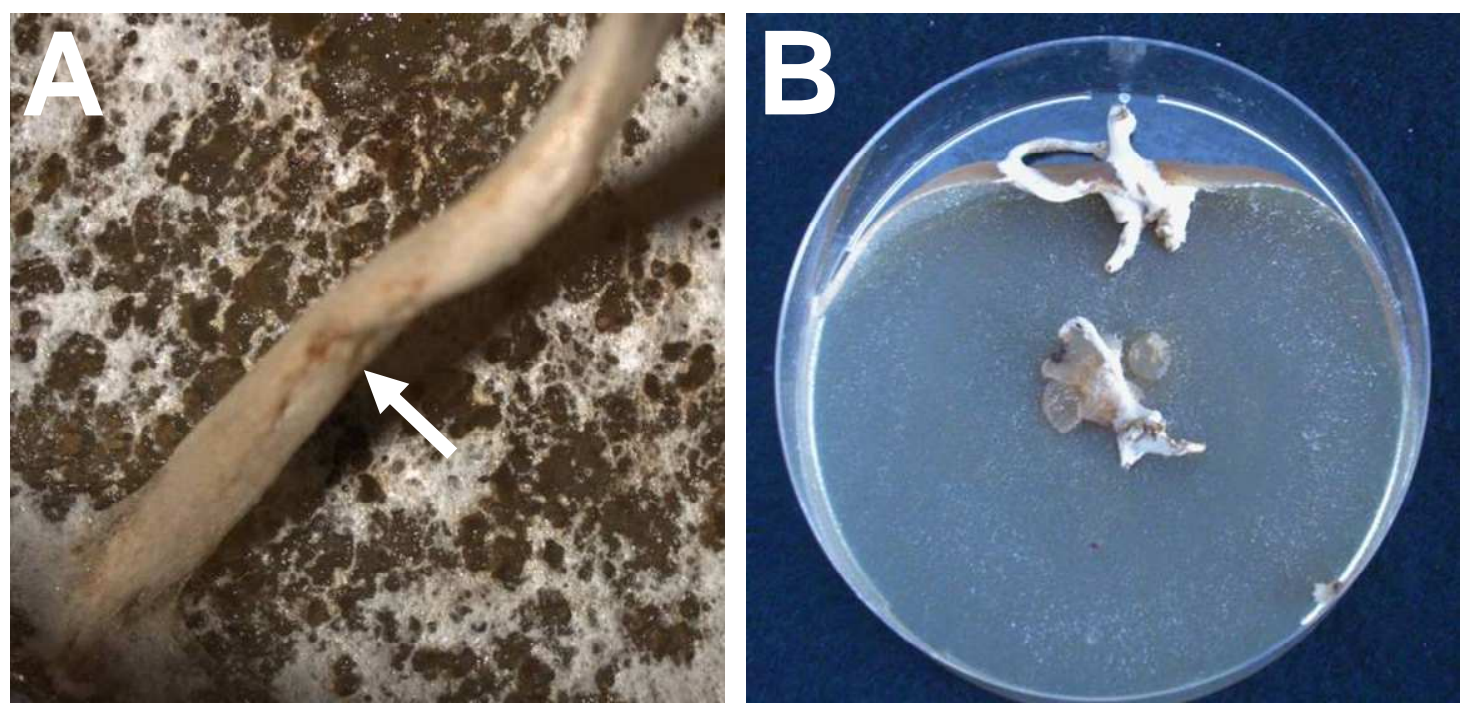

Fig. 13 Etiolated stipes from mutant PUK1-6 are avoided by mites until their decomposition through aging. Cultures of the dst1-2 homokaryon PUK1-6 obtained by incubating freshly inoculated $\mathrm{YMG} / \mathrm{T}$ plates for 5 days at $37^{\circ} \mathrm{C}$ in constant dark and subsequently for 11 days at $28^{\circ} \mathrm{C}$ under standard fruiting conditions were infested with 25 mites on fresh agar blocks placed in the middle of the plates. Plates were sealed with Parafilm, wrapped with aluminium foil and incubated for 14 (A), respectively 28 days (B) before further evaluation. Etiolated stipes are not consumed as long as their structure is compact [see (B)] but at places were tissues of the senescent structures soften due to degeneration, mites will use the chance of feeding on the material [see arrow in (A) pointing to a brown softened tissue area].

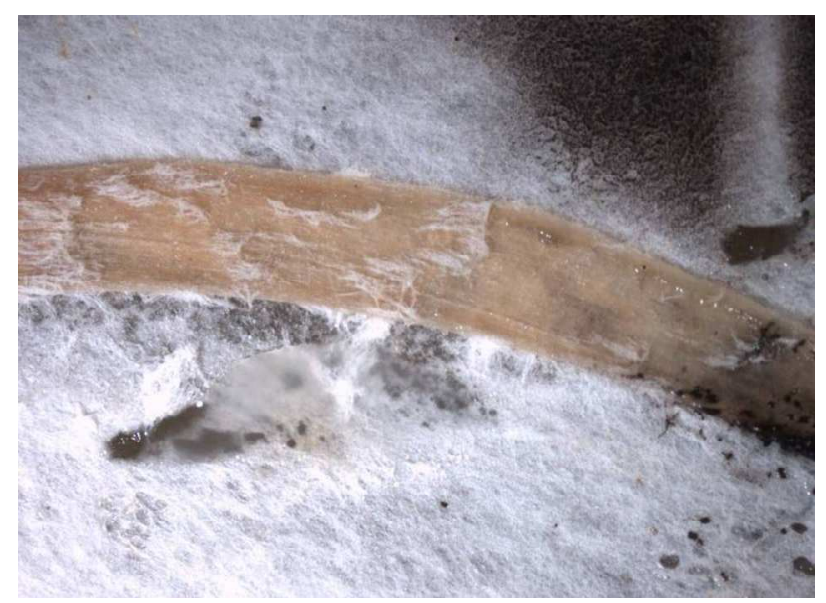

Fig. 14 Mites graze on softened tissues of the upper parts of senescent stipes of normal fruiting bodies. A stipe of a normal fruiting body obtained in an homokaryon AmutBmut culture grown for 5 days at $37^{\circ} \mathrm{C}$ in constant dark and cultivated for seven days at $28^{\circ} \mathrm{C}$ under standard fruiting conditions until fruiting body development was completed with cap autolysis at day 7 of development. Subsequently, 25 mites were transferred with a fresh agar block onto the middle of the plate, the Petri-dish was sealed by Parafilm, wrapped with aluminium foil and incubated for seven days at $25-28^{\circ} \mathrm{C}$ and $60 \%$ humidity in a greenhouse. The upper part of the stipe collapsed during this time in order to lay down flat the softened degenerating tissues at the surface of the vegetative mycelium. Using a Stemi 2000-C binocular, mites were observed grazing on the white floccose mycelium at the outer surface of the stipe (not shown). When the photo was taken, mites already disappeared due to the effect of the light binocular. 
desiccation, mites may attack also older softened etiolated stipes (Fig. 13A) but on aging primordia we never observed softening and mite attack.

\subsubsection{Consumption of basidiospores by the mites}

Mites appear to be specifically attracted by the caps of the fruiting bodies (Fig. 7) where they consume basidiospores (Fig. 8B, C, Fig, 15A, B). They have been seen to ingest basidiospores but not to digest these spores (Navarro-González 2008, Fig. 15). Spores pass the digestive tract of the about $450 \mu \mathrm{m}$ long and $210 \mu \mathrm{M}$ broad mites (compare Table 1) to be released in faecal spore pellets of a size of about $90 \mu \mathrm{M} \mathrm{x}$
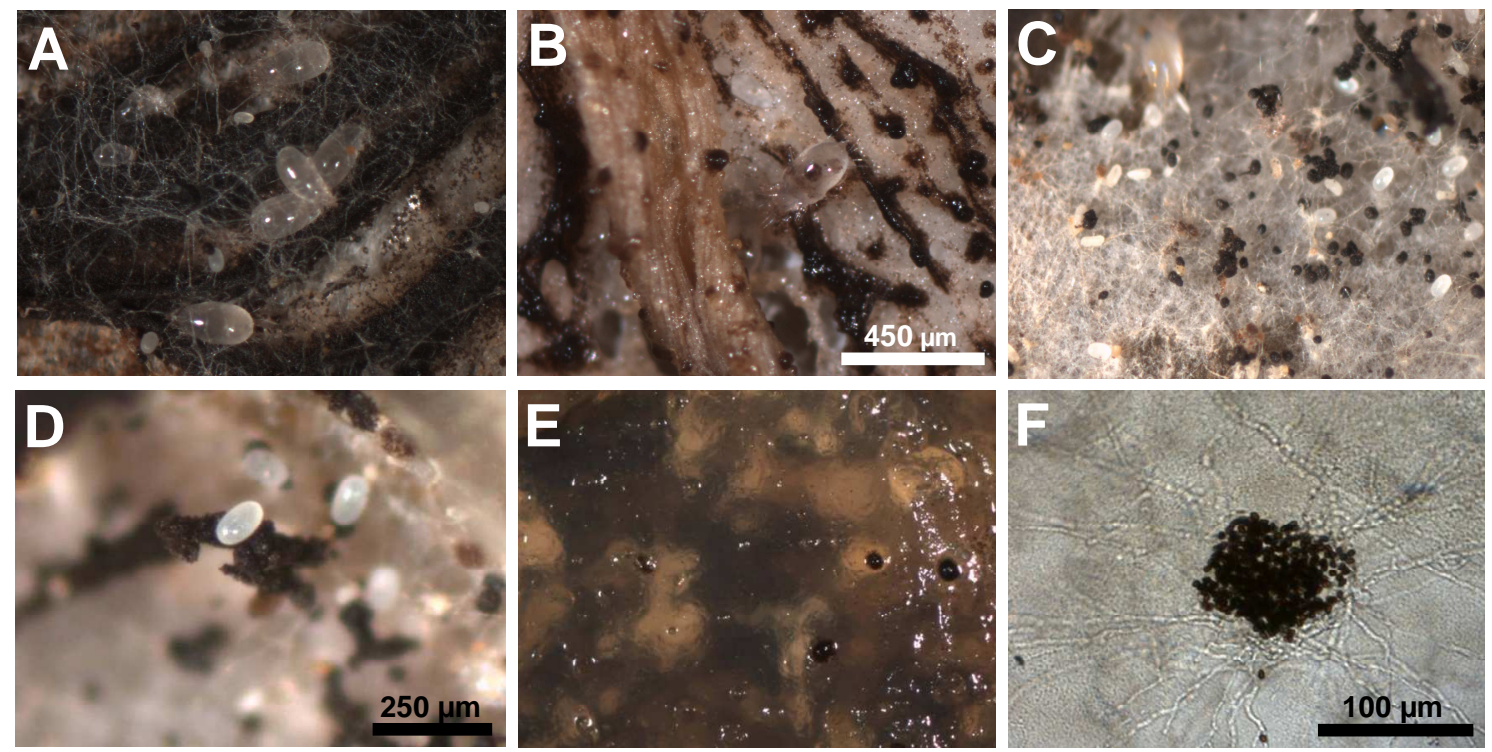

Fig. 15 Mites do ingest basidiospores but do not digest them in order to release them in special faecal pellets which on suitable substrate allows germination of the spores thereby providing mycelium as food for larvae hatching from eggs laid in close vicinity of the faecal pellets. Mites consuming spores formed on the gills of a 7 day-old fruiting body cap of homokaryon AmutBmut (A) respectively of the $d s t 4-1$ mutant $(\mathbf{B})$, releasing spores from the body in form of faecal pelltes and laying eggs in between $(\mathbf{C})$. Note in $\mathbf{B}$, that the formation of food bolis as a precursor of the faecal pellets in the mites body (Navarro-González 2008) is visible by the two round black spots shining through the clear body of the animals. Mites release their faecal pellets containing basidiospores and lay their eggs not only on cap tissues (A), (B) but when moving away from the cap also into the aerial vegetative mycelium of the 28 day-old cultures of homokaryon AmutBmut (C), (D) and onto the surface of agar (E). Spores in faecal pellets laid on consumed agar do not germinate at $25-28^{\circ} \mathrm{C}$ in the greenhouse at a humidity of $60^{\circ} \mathrm{C}$ but when the faecal pellets had been transferred onto fresh agar plates $(\mathbf{F})$. The faecal pellet shown in (E) was removed from the original culture of a culture of homokaryon AmutBmut after incubation for 28 days with mites at $25-28^{\circ} \mathrm{C}$ and $60 \%$ humidity in a greenhouse, indicating that the ability of germination of the spores remains over longer time periods. The faecal pellet with the germinated spores was incubated on YMG/T agar for $48 \mathrm{~h}$ at $37^{\circ} \mathrm{C}$ in the dark prior to taking the photograph. 
Table 1 Size determination of mites, hatched larvae, eggs and faecal pellets

\begin{tabular}{|l|c|c|c|}
\hline \multirow{2}{*}{ Object } & \multirow{2}{*}{$\begin{array}{c}\text { Number of } \\
\text { measurements }\end{array}$} & \multicolumn{2}{c|}{ Average size } \\
\cline { 3 - 4 } & 11 & $214.4 \pm 32.7$ & Length $(\boldsymbol{\mu m})$ \\
\hline Mature mites & 4 & $78.2 \pm 3.4$ & $140.7 \pm 37.3$ \\
\hline Hatched larvae & 21 & $75.8 \pm 5.7$ & $123.5 \pm 4.9$ \\
\hline Eggs & 3 & $89.7 \pm 20.9$ & $99.9 \pm 14.9$ \\
\hline Faecal pellets & &
\end{tabular}

$100 \mu \mathrm{M}$ (see Table 1) containing between 200 and 400 spores (Navarro-González 2008). Faecal pellets are released within the food resources such as the autolyzing cap tissues. Next to the faecal pellets the about $75 \mu \mathrm{M}$ x $125 \mu \mathrm{M}$ large eggs (see Table 1) are ovipositioned (Navarro-González 2008, Fig. 15A to D). In the closed system of the Petri-dish on used-up YMG/T agar, the basidiospores do not germinate (Fig. 15E), obviously by a lack of nutrients but possibly also by compounds or enzymes secreted either previously by the mycelium of the fungus, or by contaminating bacteria (see below) brought into the cultures by the mites or by faecal pellets from the mites (see conclusion). However, upon transfer of the faecal pellets onto fresh medium, there was germination (Navarro-González 2008, Fig. 15F). Mites can fast move (easily $50 \mathrm{~cm}$ in half an hour, Navarro-González 2008) and in nature, it is not unlikely that faecal pellets are laid by migrating mites onto fresh substrate where the spores will be able to germinate. If an egg is ovipositioned close to such faecal pellet, the small hatching larvae (about $140 \mu \mathrm{M}$ long, $80 \mu \mathrm{M}$ wide, see Table 1) is subsequently supplied with fresh fungal mycelium for feeding (Navarro-González 2008). Another way of spreading faecal pellets through mites is by transport through their bodies - faecal pellets easily attach to the outer surface of the body as shown in Fig. 16.

\subsubsection{Competition tests between different types of $C$. cinerea mycelia in attraction of mites}

The repeated occurrence of mites in plates stored for longer periods in the laboratory and the accumulation of mites observed underneath the cap at the place of tearing apart gills from the mushroom stipe suggest there are attractants such as organic volatile compounds emitted from fungal cells that serve as chemical signals to the animals (see also Chapter 5 of this thesis). Therefore, some experiments were performed to determine whether there are preferences by the animals to specific 


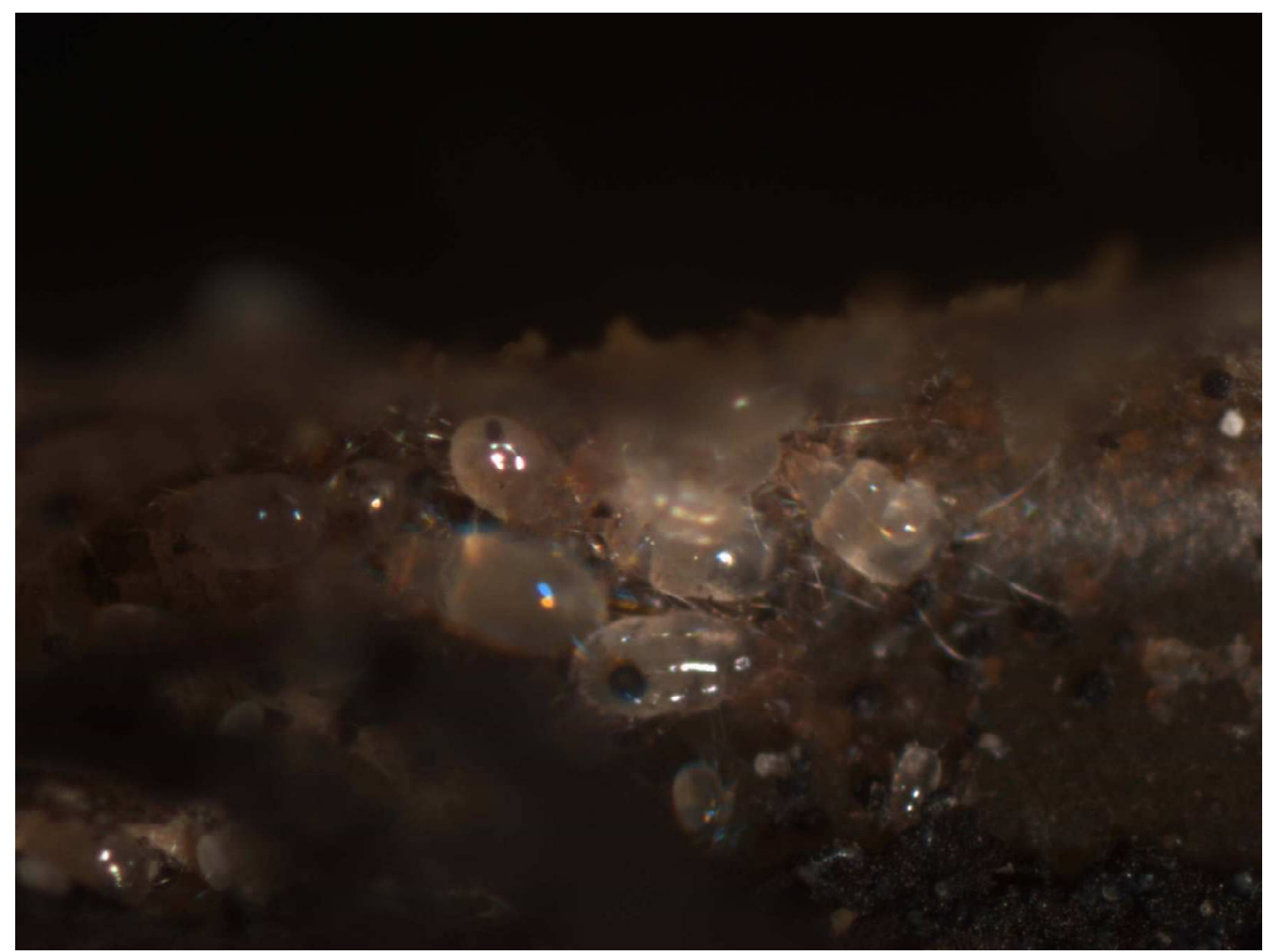

Fig. 16 Faecal pellets attach to the outer surface of the mites' bodies and are transported by them in such way (see black spots on the bodies of the mites).

mycelia of the fungus. Round mycelial plugs were cut with a cork borer (6 mm in $\varnothing)$ from the edges of actively growing YMG/T cultures cultivated at $37^{\circ} \mathrm{C}$ and placed onto fresh YMG/T plates (treatments 1 and 2 in Fig. 17) or fresh 1\% water agar (treatment 3 in Fig. 17). Per plate, either each four plugs of two different strains were positioned at even spacings onto the agar (treatment 1 of Fig. 17) or each one plug of two different strains were positioned at highest distance to each other onto agar plates (treatments 2 and 3 in Fig. 17). Compared were either the two monokaryons PS001-1 and PS002-1 or the monokaryon PS001-1 and the dikaryon PS001-1 x PS002-1 or the monokaryon PS002-1 and the dikaryon PS001-1 x PS002-1, respectively (see experimental setting in Fig. 17). Each 25 mites were placed onto a fresh $1 \%$ water agar plug in the middle of the plates and, after the plates were sealed with Parafilm and covered with aluminium foil, the mites were allowed for $20 \mathrm{~h}$ at $25^{\circ}-28^{\circ} \mathrm{C}$ in the greenhouse at $60 \%$ humidity to move within the plates (treatments 1 and 3 in Fig. 17). Plates in treatment 2 were first incubated for $20 \mathrm{~h}$ at $25^{\circ}-28^{\circ} \mathrm{C}$ in the greenhouse at $60 \%$ humidity before an $1 \%$ water agar plug was 25 mites were added in the middle of the plates, upon which 


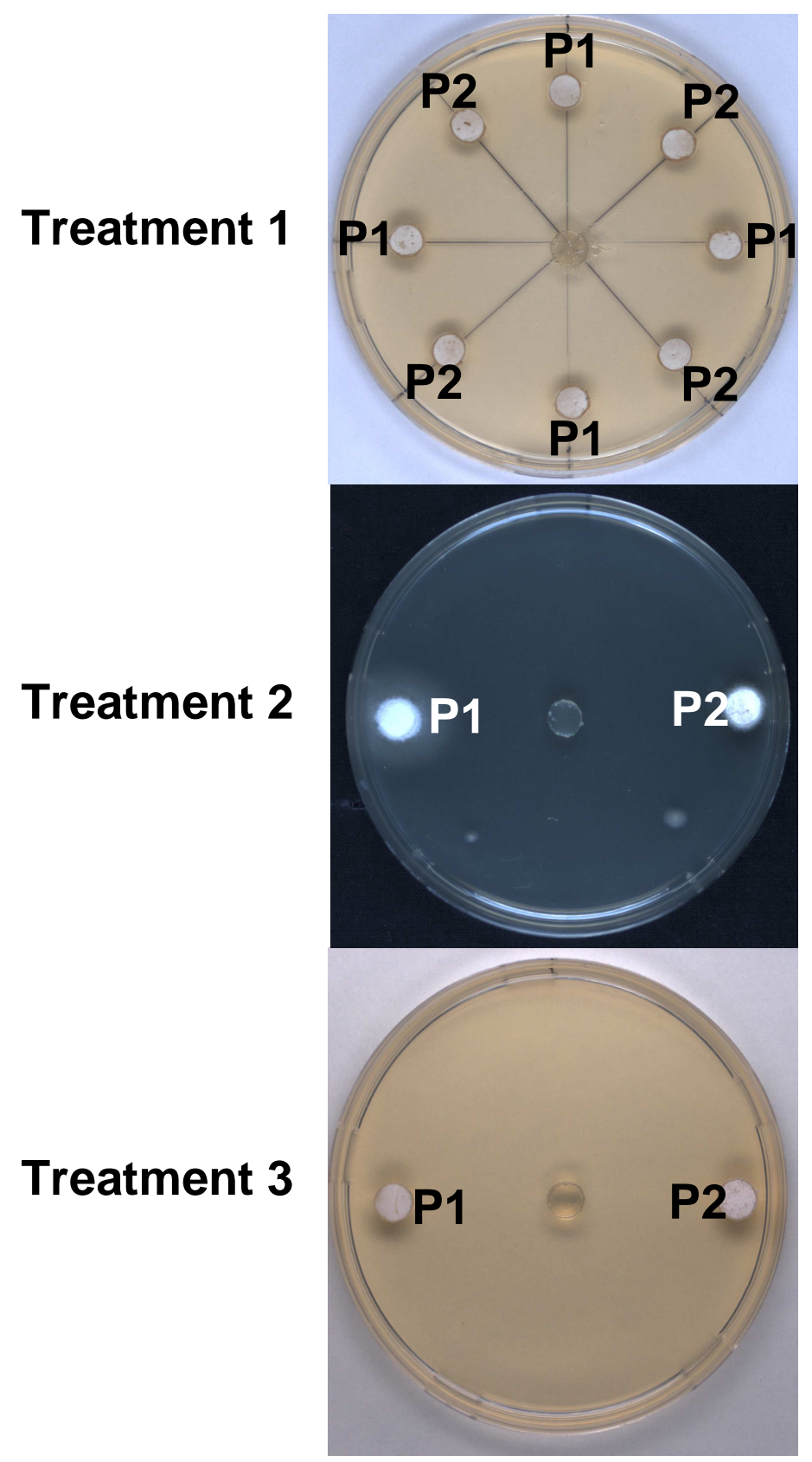

Fig. 17 Experimental design for competitive testes between each two types of mycelia in attraction of mites that were added to the plates in numbers of 25 on $1 \%$ water agar plugs in the middle of the plates. Combination of strains were as followed: combination 1: P1 = dikaryon PS001-1 x PS002-1; P2 = PS001-1; combination 2: P1 = dikaryon PS001- $\mathrm{x}$ PS002-1, $\mathrm{P} 2$ = PS002-1; combination 3: P1 = PS001-1, P2 = PS002-1). Mycelial plugs were cut from the edges of fresh, actively growing fungal cultures cultivated at $37^{\circ} \mathrm{C}$ in the dark and transferred in the respective patters shown in the figure onto fresh agar plates (YMG/T in treatments 1 and 2; $1 \%$ water agar in treatment 3 ). Mites were placed onto the agar plates into the Petri dishes either directly after transfer of mycelial plugs onto the agar (treatments 1 and 3) or after transfer of mycelium plugs, closing the plates with Parafilm, covering them with aluminium foil and incubating them first for $20 \mathrm{~h}$ at $25-28^{\circ} \mathrm{C}$ at a humidity of $60 \%$ in the greenhouse. After transfer of mites to plates, they were sealed with Parafilm, covered with aluminium foil and incubated for $20 \mathrm{~h}$ at $25^{\circ}-28^{\circ} \mathrm{C}$ in the greenhouse at a $60 \%$ humidity in order to allow the mites to walk on the agar. Per treatment and strain combination, 10 different plates were analysed. Plates were incubated with a random distribution of P1 and P2 positioned on the left or the right side in a pile. 
Table 2 Distribution of mites in numbers on mycelial plugs of different strains of C. cinerea and on the lids of the Petri-dishes at the end of the experiments explained in Fig. 17.

\begin{tabular}{|c|c|c|c|c|}
\hline \multirow{2}{*}{$\begin{array}{c}\text { Strain } \\
\text { combination }\end{array}$} & & \multicolumn{3}{|c|}{ Number of mites $^{2}$} \\
\cline { 3 - 5 } & Treatment $^{1}$ & at plug P1 & at plug P2 & $\begin{array}{c}\text { On the lid of } \\
\text { the Petri-dish }\end{array}$ \\
\hline 1 & 1 & $4.7 \pm 5.1$ & $12.5 \pm 6.4$ & $7.8 \pm 5.4$ \\
& 2 & $12.0 \pm 4.1$ & $10.5 \pm 4.4$ & $2.5 \pm 4.9$ \\
& 3 & $9.0 \pm 5.2$ & $4.1 \pm 4.5$ & $11.9 \pm 6.0$ \\
\hline 2 & 1 & $4.8 \pm 4.2$ & $10.3 \pm 7.1$ & $9.9 \pm 6.7$ \\
& 2 & $13.2 \pm 3.3$ & $11.1 \pm 3.1$ & $0.7 \pm 1.6$ \\
& 3 & $4.4 \pm 2.7$ & $4.5 \pm 3.6$ & $16.1 \pm 5.7$ \\
\hline 3 & 1 & $8.7 \pm 3.2$ & $11.6 \pm 4.4$ & $4.7 \pm 5.0$ \\
& 2 & $11.8 \pm 3.1$ & $9.6 \pm 4.9$ & $3.6 \pm 5.0$ \\
& 3 & $4.2 \pm 3.6$ & $5.4 \pm 3.9$ & $15.4 \pm 3.3$ \\
\hline
\end{tabular}

${ }^{1}$ Strain combination and treatment are as explained in Fig. 17

${ }^{2}$ Mites were counted per plate at the respective position(s) on each 10 different plates per strain combination and treatment. Averages and standard deviations were calculated with Excell software (Microsoft Office Excell 2003). Numbers highlighted in bold indicate conspicuous cases of an uneven distribution of mites on plugs between two strains tested (see however the statistical analysis performed on these data as presented in Table 3). Note that for the three different strain combinations, alike treatments were done in parallel but different series of treatments of the strains were done in different days.

the plates were sealed with Parafilm, covered with aluminium foil and incubated for $20 \mathrm{~h}$ at $25-28^{\circ} \mathrm{C}$ in the greenhouse at $60 \%$ humidity in order to allow the mites to migrate within the plates. Subsequently, mites were counted at positions found in the plates (Table 2).

In every plate, all the 25 mites were found back after the incubation. Mites were either detected on the mycelial agar plugs or on the plastic lids of the Petri-dishes but never on the pure agar surface (Table 2). The number of mites found in the lids of the Petri-dishes varied from experiment to experiment between nearly $0 \%$ to above $60 \%$ (compare Table 2). It appears that the number of mites found in the lids are possible linked to the type of treatment performed or to the individual round of experiments (see Table 2). To answer this clearly, repeats of the types of all treatments have to be performed in a single series of experiments and possibly, incubation times should be reduced in such experiments as discussed further below. A preference analysis of mites found in the lid versus mites on mycelial plugs (i.e. an analysis of avoidance of the agar and/or the mycelium) was not done. That many mites were however found on the mycelial plugs suggests that these were not avoided but is a good argument 
Table 3 Statistical analysis (paired T-test) of preferences of mites to migrate to a specific C. cinerea strain in the experimental set-ups described in Fig. 17, using the data presented in Table 2 and the software SX release version 8.00 (Analytical software, Tallahassee, USA)

\begin{tabular}{|c|c|c|c|c|c|c|c|c|c|}
\hline \multirow[t]{2}{*}{$\mathbf{T}^{1}$} & \multicolumn{2}{|c|}{$\begin{array}{l}\text { Number of mites } \\
\text { in strain } \\
\text { combination } 1\end{array}$} & \multirow[t]{2}{*}{$\begin{array}{c}\text { p- } \\
\text { value }\end{array}$} & \multicolumn{2}{|c|}{$\begin{array}{c}\text { Number of mites } \\
\text { in strain } \\
\text { combination } 2\end{array}$} & \multirow[t]{2}{*}{$\begin{array}{c}\text { p- } \\
\text { value }\end{array}$} & \multicolumn{2}{|c|}{$\begin{array}{c}\text { Number of mites } \\
\text { in strain } \\
\text { combination } 3 \\
\end{array}$} & \multirow[t]{2}{*}{$\begin{array}{c}\text { p- } \\
\text { value }\end{array}$} \\
\hline & P1 & $\mathbf{P 2}$ & & P1 & $\mathbf{P 2}$ & & P1 & $\mathbf{P 2}$ & \\
\hline 1 & $4.7 \pm 5.1$ & \pm 6.4 & $0.04 *$ & $4.8 \pm 4$ & +7 & & $8.7 \pm$ & $11.6 \pm 4.4$ & 0.15 \\
\hline 2 & $12.0 \pm 4.1$ & $10.5 \pm 4.4$ & 0.51 & $13.2 \pm 3.3$ & $11.1 \pm 3.1$ & 0.31 & $11.8 \pm 3.1$ & $9.6 \pm 4.9$ & 0.31 \\
\hline 3 & $9.0 \pm 5.2$ & $4.1 \pm 4.5$ & 0.08 & $4.4 \pm 2.7$ & $4.5 \pm 3.6$ & 0.91 & $4.2 \pm 3.6$ & $5.4 \pm 3.9$ & 0.59 \\
\hline
\end{tabular}

${ }^{1} \mathrm{~T}=$ treatment as explained in Fig. 17

*A p-value $<0.05$ was assumed to be statistically significant

for that the plugs had rather an attraction effect on the animals. Otherwise, one might have to expect to find a valid number of mites also on the pure agar.

Furthermore as seen in Table 2, the distribution of mites between the two types of plugs tested in most instances appeared to be more or less even with no preference for one specific strain. Leaving the mites that migrated into the lid aside (see Table 2), a statistical analysis was performed on migration preferences of mites to one or the other of two strains tested. Using A One-Way Analysis Of Variance (One-Way ANOVA) software SX release version 8.0 (Analytical software, Tallahassee, USA), a statistical paired T-test confirmed lack of preference of the mites for any given strain for all but one of the cases (see Table 3). In two further cases, were the average values of mites found at the two different types of plugs were quite different and thus showed high standard deviations resulting in statistically non-significant differences (Table 2 and Table 3).

Using One-Way ANOVA) software SX release version 8.0, next the three different treatments of individual strain combinations were compared (Table 4). The analysis revealed no statistical differences in between the three different treatments of the two monokaryons PS001-1 and PS002-1 (p-value =0.2054; see Table 4), an ambiguous situation for the strain combination dikaryon PS001-1 x PS002-1 versus monokaryon PS002-1 (p-value $=0.0504$, Table 4$)$ and a significant different situation for the strain combination dikaryon PS001-1 x PS002-1 versus monokaryon PS001-1 (p-value = 0.0067, Table 4). Altogether, the statistical results presented in Table 4 for the three treatments of a given strain combination are however reflecting three differently designed situations due to the usages of different media and the different number of plugs which of course is a reason to be careful about the statistical results shown here. 
Table 4 Analysis of Variance (ANOVA) of the three different treatments performed in preference analysis of mites for two individual strains of $C$. cinerea as described in Fig. 17 with the results presented in Table 2. ANOVA was performed with the software SX release version 8.0 (Analytical software, Tallahassee, USA)

\begin{tabular}{|c|c|c|c|}
\hline $\begin{array}{c}\text { Strain } \\
\text { combination }\end{array}$ & Treatment & Combined mite number ${ }^{1}$ & $\begin{array}{c}\text { Significant different } \\
\text { p-value }\end{array}$ \\
\hline $\mathbf{1}$ & $\begin{array}{l}1 \\
2 \\
3\end{array}$ & $\begin{array}{c}-0.3120 \pm 0.4117 \mathrm{~b} \\
0.0600 \pm 0.2766 \mathrm{a} \\
0.1960 \pm 0.3101 \mathrm{a}\end{array}$ & $\mathrm{p}=0.0067^{*}$ \\
\hline 2 & $\begin{array}{l}1 \\
2 \\
3\end{array}$ & $\begin{array}{c}-0.2200 \pm 0.3810 \mathrm{~b} \\
0.0840 \pm 0.2490 \mathrm{a} \\
-0.0040 \pm 0.1107 \mathrm{ab}\end{array}$ & $\mathrm{p}=0.0504$ \\
\hline 3 & $\begin{array}{l}1 \\
2 \\
3\end{array}$ & $\begin{aligned}-0.1160 & \pm 0.2305 \mathrm{a} \\
0.0880 & \pm 0.2584 \mathrm{a} \\
-0.0480 & \pm 0.2698 \mathrm{a}\end{aligned}$ & $\mathrm{p}=0.2054$ \\
\hline
\end{tabular}

${ }^{1}$ Note: combined mite number refers to an analysis of mites distribution determined by the formula $(1 \mathrm{x}$ number at $\mathrm{P} 1 / 25)+(0 \mathrm{x}$ number in lid/25) $+(-1 \mathrm{x}$ number at $\mathrm{P} 2 / 25)$

$1.0=100 \%$ of mites migrated to $\mathrm{P} 1$

$-1.0=100 \%$ of mites migrated to $\mathrm{P} 2$

$0=100 \%$ of mites migrated to the lid of the Petri dishes

Grouping of $a, b$ was done by LSD tests of means $(p<0.05)$ of all-pairwise comparisons of exp1. $\mathrm{a}=$ statistically alike, $\mathrm{b}=$ statistically different.

*A p-value $<0.05$ was assumed to be statistically significant

LSD $=$ Least significant difference

Mites when walking on the free agar will leave foot steps on the comparably soft surface that with appropriate contrasting can be followed up under a Stemi 2000-C binocular and photographed (Fig. 18A). Thus, principally the line of foot steps can be used to follow up on longer distances the way mites have been taken on the agar. However, technically it is difficult and tedious. As shown in Fig. 9 to Fig. 11, mites bring bacteria into fungal cultures. This feature can be made use off when analysing the walk ways of mites on the fresh nutrients-containing agar (such as YMG/T complete medium) in the Petri-dishes. Where mites walked, after prolonged incubation, slimy lines of bacterial colonies were visible regardless of whether one or more mites were applied to a plate (Fig. 18B, Fig. 19 to Fig. 21). The pictures from YMG/T plates infested with 25 mites from the experiments explained in Fig. 17 appear to show a tendency that mites move more or less targeted to the mycelial plugs but a difference between the two types of mycelia were not recognizable (Fig. 19 to Fig. 21). The same impression is given in addition by walk ways of mites that moved onto the plastic lids of the Petri-dishes. Here, walk ways are visible by clear lines when the lids 

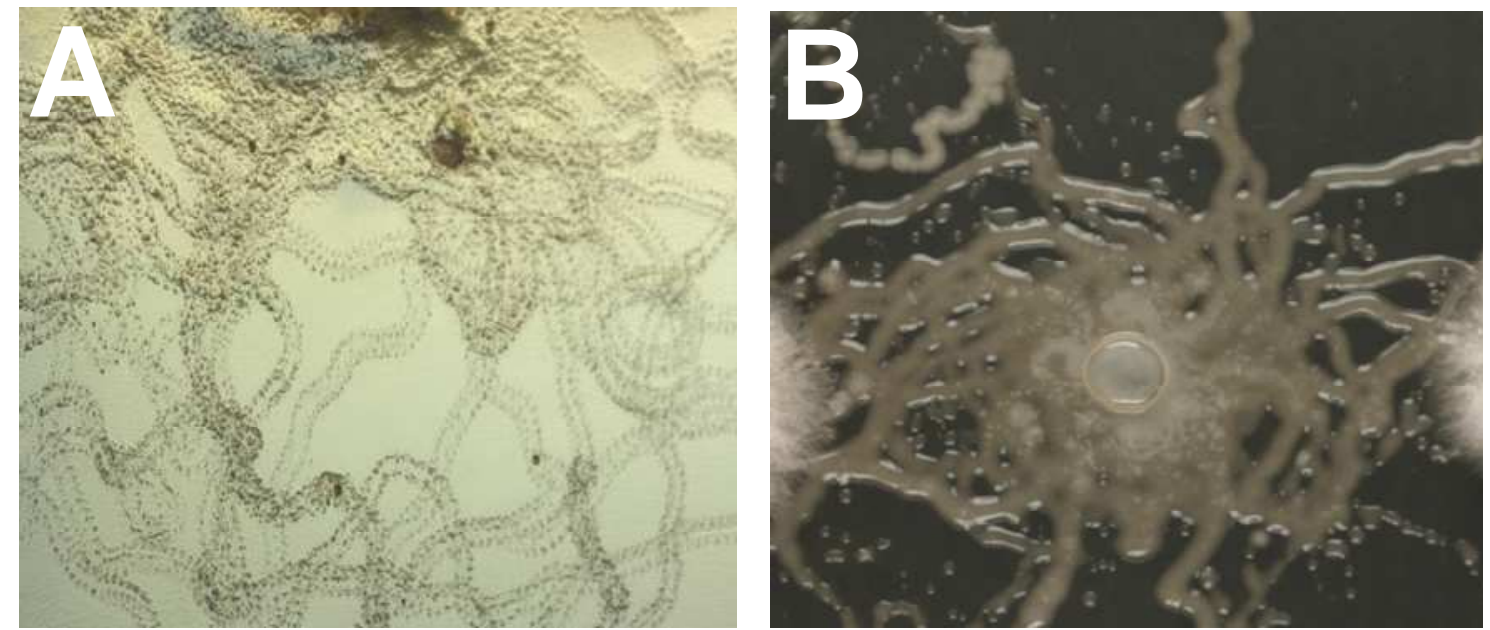

Fig. 18 Walk ways of mites are directly visible on the agar surface by foot step marks (A) and, after an appropriate time of incubation, by slimy lines of bacteria grown on top of the mites' walk ways. The plate shown in (A) originated from treatment 2 , strain combination 2 from the experiments explained in Fig. 17 and was incubated for $5 \mathrm{~h}$ with 25 mites at $25-28^{\circ} \mathrm{C}$ at a humidity of $60 \%$ in the greenhouse prior to photographing mites' foot steps in close vicinity to the fresh agar plug in the middle of the Petri-dish used to transfer the animals onto the plates. The plate shown in (B) was the same than in (A) but photographed after $20 \mathrm{~h}$ of incubation with the mites. Note that the photos were taken at different enlargements.

previous to mite migration were clouded by water condensation (Fig. 20B). Clearly as seen in Fig. 21, a single mite can cause the production of such lines of bacteria by migrating on the agar. Walk ways are not fully straight but mites appear to change regularly for short distances somewhat the momentary taken direction to another such as searching for something (Fig. 18A, Fig. 20), although an overall main direction appears to be kept for longer distances (Fig. 20). Future work will have to test the possible effect of mites being attracted to mycelial plugs in more detail, possibly with a lower number of mites per plate in order to avoid too high bacterial overgrowth of the walk ways of different animals. Moreover, the line of bacterial growth on the $9 \mathrm{~cm}$ in $\varnothing$ sized plate shown in Fig. 20, which reflects the walk of the mites within the 15 min of incubation (see experimental details in the legend to Fig. 20), indicates that an animal migrated $>1 \mathrm{~cm}$ in $3 \mathrm{~min}$ on the plate. A more extensive study by Navarro-González (2008) calculated a speed of migration for the mite $T$. putrescentiae of $0.6 \mathrm{~cm} / \mathrm{min}$. Thus, in future experiments an experimental set-up as described in the legend of Fig. 20 with a relatively short period of mite incubation might be chosen for experiments designed to determine whether mites are specifically attracted to fungal mycelia and whether mites might be attracted at the same time or later to enter the lid of the Petridishes as documented for the experiments compiled in Table 2. The results in Table 2 of 

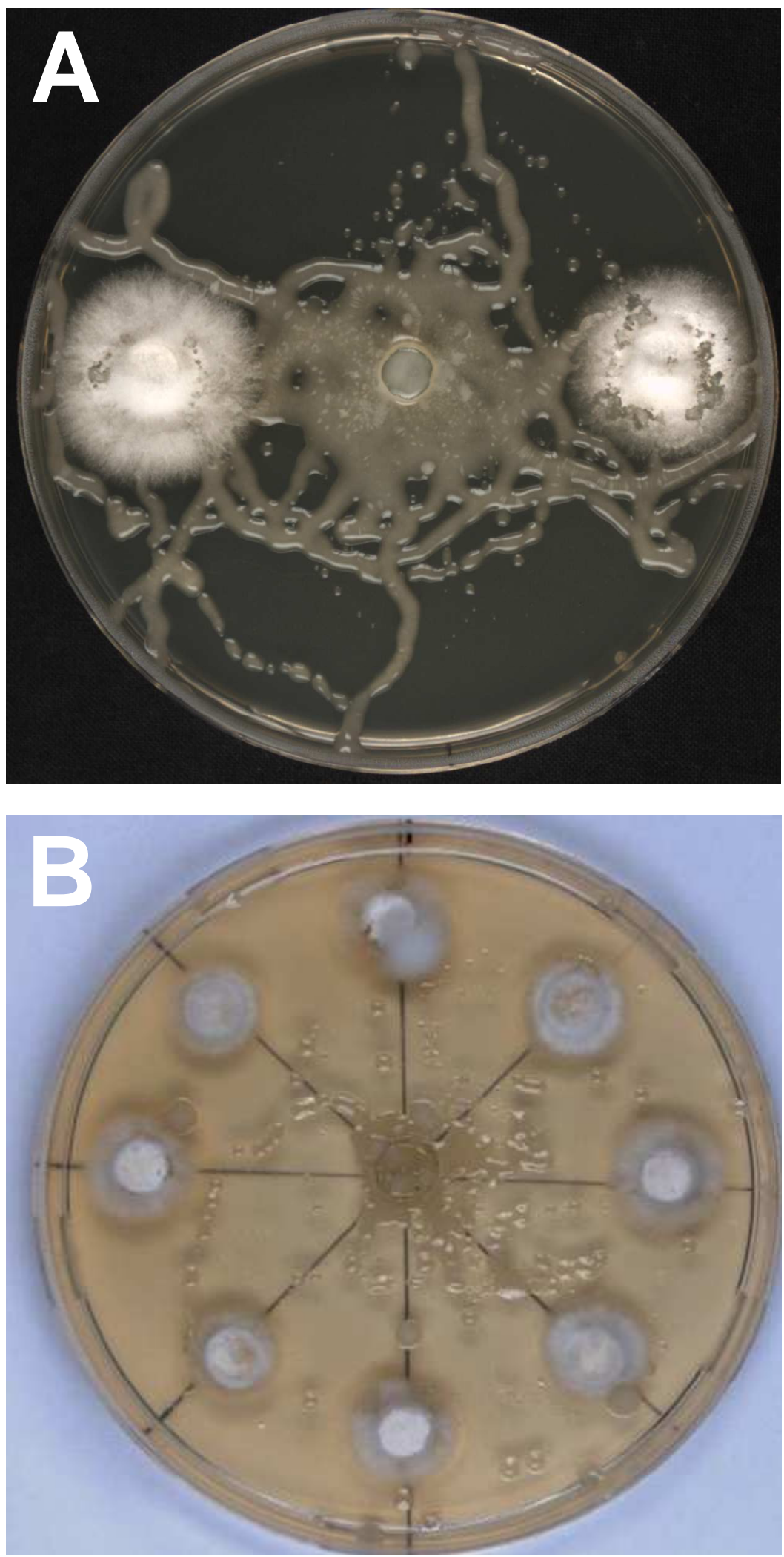

Fig. 19 Walk ways of mites become easily visible by growth of bacteria they distribute on their route over the agar. (A) A plate from treatment 2 (left plug: PS001-1 x PS002-1; right plug: PS002-1) and (B) a plate of treatment 1 (top plug: PS002-1; neighbored plugs: PS001-1 x PS002-1) of the experimental set-up explained in Fig. 17 photographed after $40 \mathrm{~h}$ of incubation with 25 mites at $25-28^{\circ} \mathrm{C}$ at a humidity of $60 \%$ in the greenhouse (analysis of mite migration as given in Table 2 was done in between at $20 \mathrm{~h}$ of incubation). 

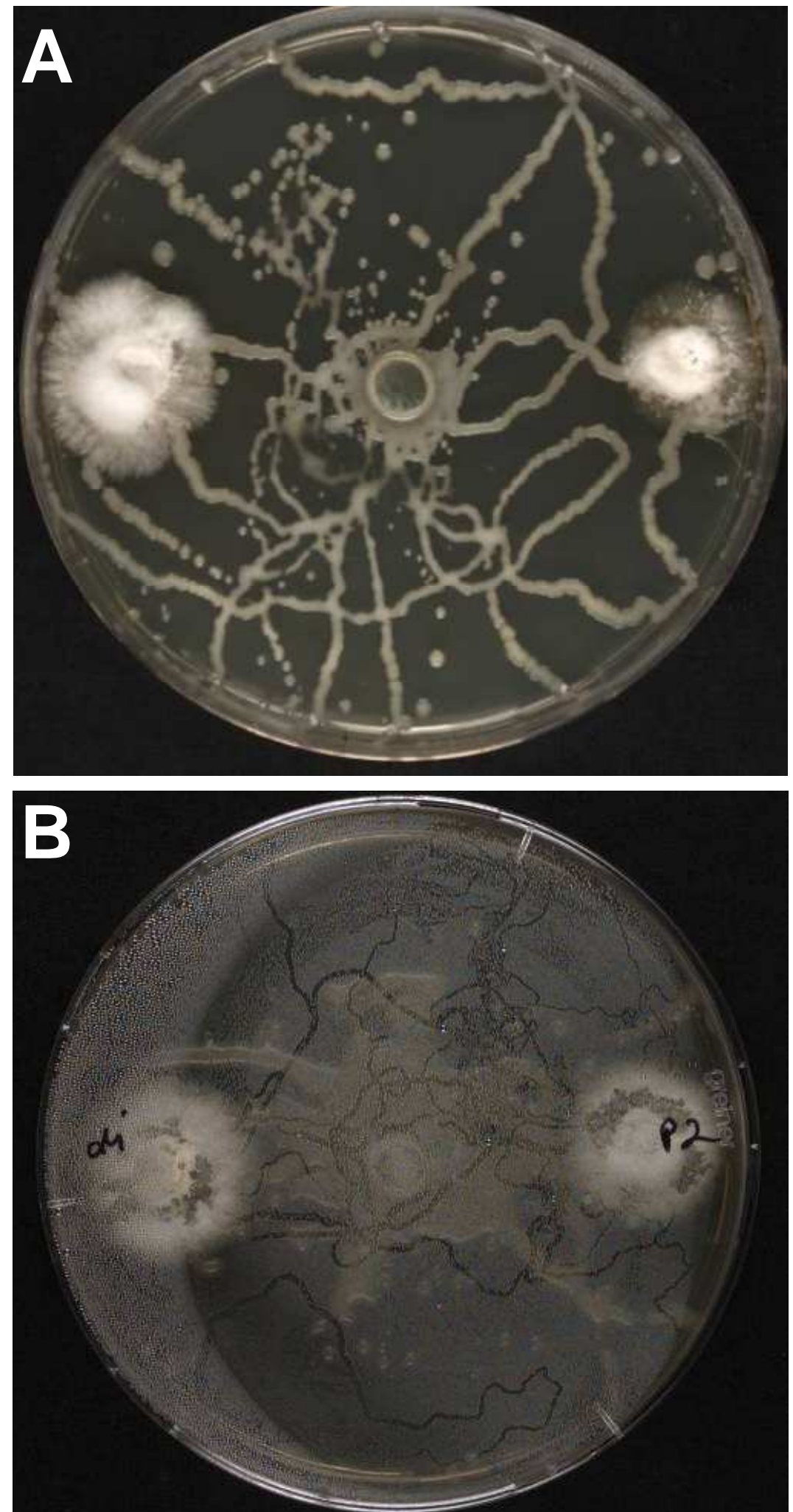

Fig. 20 Walk ways of mites become easily visible on agar by growth of bacteria the animals distribute on their route over the agar (A) and by clear lines on lids of the plastic Petri dish clouded by water condensation (B). Plates shown were from combination 2, treatment 1 (left plug: PS001-1 x PS002-1; right plug: PS002-1) of the experimental set-up explained in Fig. 17 photographed after $40 \mathrm{~h}$ of incubation with 25 mites at $25-28^{\circ} \mathrm{C}$ at a humidity of $60 \%$ in the greenhouse Note that the plate in $(\mathbf{B})$ is the same than shown without lid in Fig. 19A. The photo shown in (B) was taken before opening the lid to make the photo shown in Fig. 19A. 


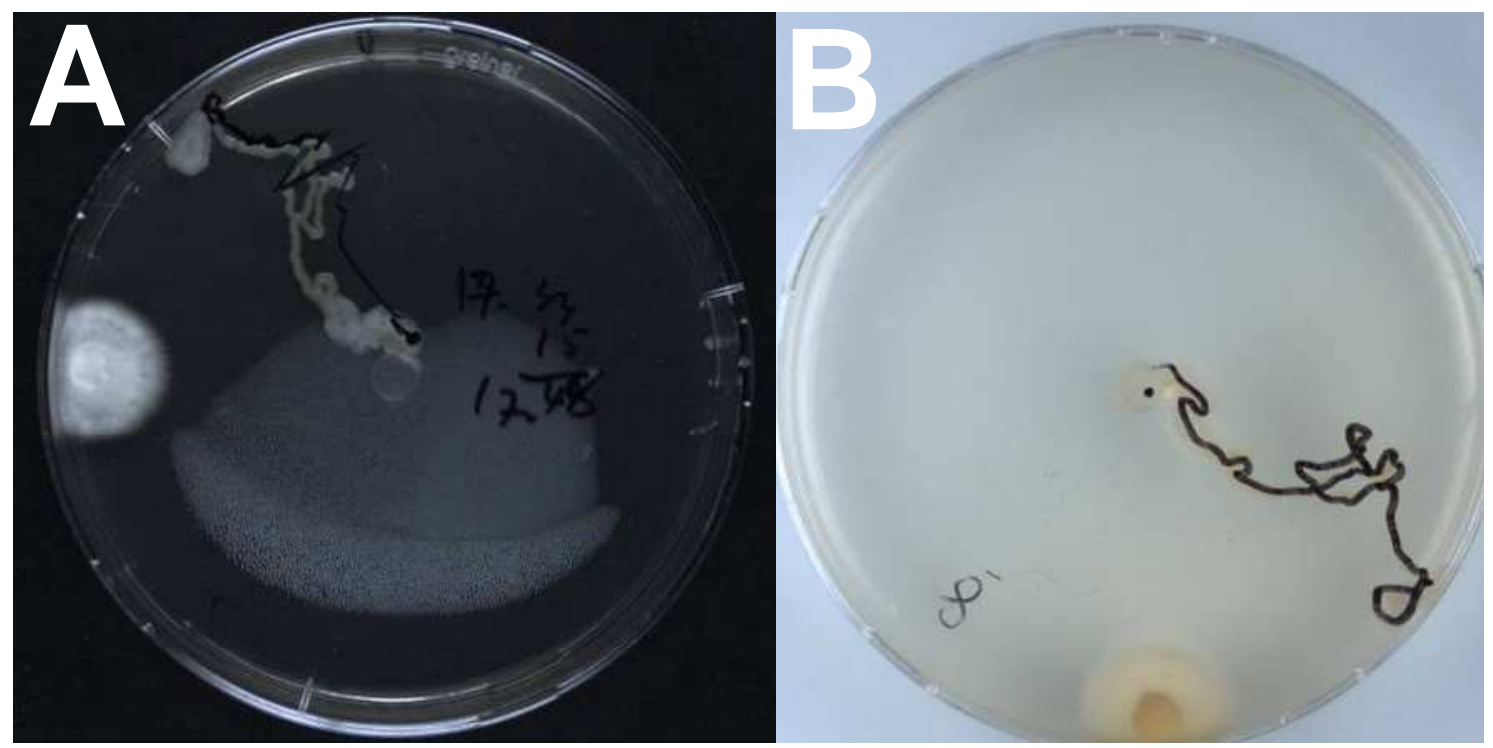

Fig. 21 In order to observe its walking behaviour, a single mite was positioned onto a fresh agar plug in the middle of a Petri-dish with YMG/T medium and let run for $15 \mathrm{~min}$ on the plate at $25^{\circ} \mathrm{C}$ at a humidity of $45 \%$ in the dark. Prior to infestation with the mite, a plug of freshly grown mycelium of dikaryon PS001-1 x PS002-1 was inoculated close to the edge of the Petri dish and the plate was incubated for $24 \mathrm{~h}$ at $37^{\circ} \mathrm{C}$ in the dark. Directly after infestation with the mite, the plate was closed with Parafilm and kept in the laboratory for $15 \mathrm{~min}$ at $25^{\circ} \mathrm{C}$ at a humidity of $45 \%$ in the dark during which the arthropod could freely walk within the plate. The plate was kept in the dark during this time also in order to calm down the light-sensitive mite from the possible light stress exerted on the animal by the two top halogen-light sources of the Stemi 2000-C binocular during the time of transferring the mite onto the agar block. Then after $15 \mathrm{~min}$, the mite was removed from the plate, the plate was closed with Parafilm, wrapped with aluminium foil and incubated for $20 \mathrm{~h}$ at $25-28^{\circ} \mathrm{C}$ at a humidity of $60 \%$ in a greenhouse in order to allow bacteria to grow. (A) and (B) show the same plate after the $20 \mathrm{~h}$ incubation period from photographed from the top (A) and the bottom (B), respectively. For better visualization, the bacterial line was marked with a black line on the lid of the Petri-dish (A), respectively from the bottom of the plate $(\mathbf{B})$.

the experiments from the set-up given in Fig. 17 together with the photos shown in Fig. 19 and the quick walking speed of the mites however suggest that mites were attracted to the mycelia and tend to stay there for longer times. When observing the plates of the experiments described in Fig. 17 under the Stemi 2000-C binocular after $20 \mathrm{~h}$ incubation for determining the positions of all the 25 mites on the plates, mites were observed to graze on the mycelial colonies. Holes in the mycelial carpet by grazing of mites were clearly visible (compare examples given in Fig. 19 and Fig. 22). Note that the transfer of bacteria onto the mycelial colonies causes that the aerial mycelium will collapse by the growth of the bacteria and will be hindered from further fast growth away from the plugs onto fresh agar (Fig. 22A and C). Mites were often found grazing at mycelium contaminated with bacteria but currently, it is not clear whether 

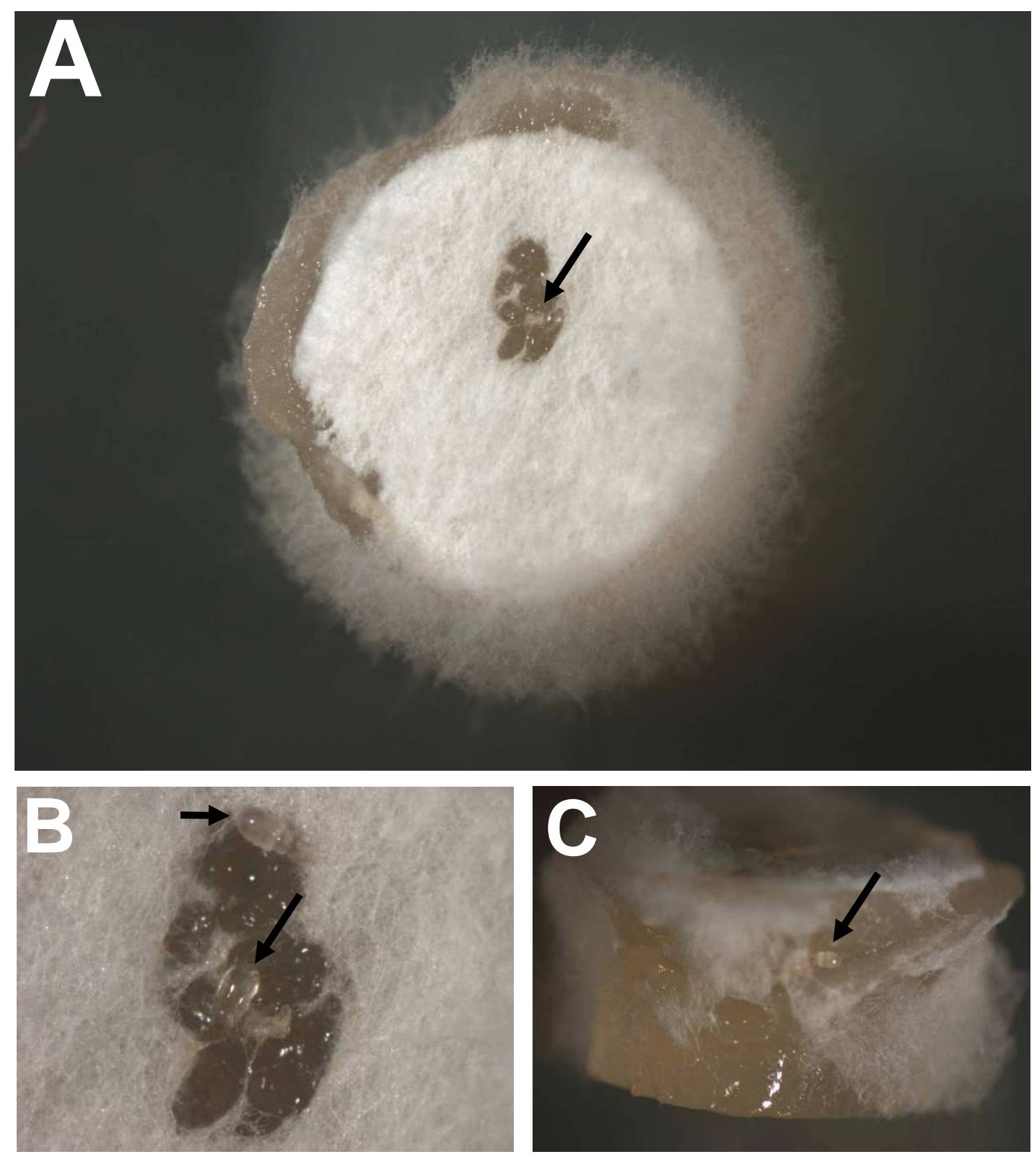

Fig. 22 Effects of grazing mites (see arrows) and transferred bacteria on mycelial plugs of dikaryon PS001-1 x PS002-1 originating from strain combination 1 of treatment 1 as described in Fig. 17. The photos were taken after $20 \mathrm{~h}$ of incubation with mites in the greenhouse as described in the experimental set-up in the legend of Fig. 17. (A) A view on the whole plug shows a hole in the carpet of the aerial mycelium in the middle of the plug due to grazing by a mite (seen enlarged in $(\mathbf{B})$ ) and the collapsed aerial mycelium at the upper left edge of the fungal colony which is due to bacterial growth and only partially due to grazing by mites - the place of grazing by a mite is seen by the sharp contours of holes in the mycelium at the lower quarter and at the upper quarter of the damaged half-moon-like region of aerial mycelium. (C) View on the side of a plug taken from the agar to be able to easily photograph it under a Stemi 2000-C binocular. Note that the fungus grew over the cut agar surface of the plug towards the fresh agar surface of the Petri dish and that part of the aerial mycelium was destroyed by grazing mite (see arrow), respectively by growth of bacteria that brought the aerial mycelium to collapse (lower part of the plug that appears shiny by the slimy bacterial layer covering the mycelium). 
they prefer bacteria contaminated mycelium for consumption (e.g. by support of bacterial enzymes helping with their enzymes to digest the chitin-containing fungal cell walls; in this connection compare references Smrž et al. 1991, and Smrž 2003) or whether the mites brought in the bacteria and did subsequently not move much further when the bacteria grow and which therefore would rather represent a coincidence unlinked to the direct grazing preference and an ease of digestion of fungal hyphae.

Similar negative effects by growth of bacteria on mycelial plugs were also seen in a series of experiments performed with $C$. cinerea homokaryon AmutBmut in which mycelium of different age was supposed to be compared (Fig. 23). Also in this experiment, 10 different plates were considered in which mycelial plugs of $C$. cinerea homokaryon AmutBmut were either inoculated on position P1 (older mycelium) or position P2 (fresh mycelium) on the Petri-dish (see Fig. 23; for further explanation on the experimental set-up, see Fig. 17 treatment 1). As in the previous experiments, positions of mites and the numbers of mites per position were determined. Also in this series of experiments, all 25 mites inoculated on a plate were found back at the end of the experiment. About half of them were found on the lids of the Petri-dishes and the remaining on the fresh mycelial agar. However, in this experiment, the mites on agar plugs were not evenly distributed (Table 5). A paired T-test was performed with the software SX release version 8.0 (Analytical software, Tallahassee, USA).

Fig. 23 (on next page) Comparison of mycelium of different age of Coprinopsis cinerea homokaryon AmutBmut in attraction of mites in an experimental set-up as given by treatment 1 in Fig. 17. (A) The P1 positions (top, bottom, outer left, outer right) were occupied by mycelial plugs from cultures of homokaryon AmutBmut grown for 28 days right from the beginning of inoculation at $28^{\circ} \mathrm{C}$ in constant light at $85 \%$ humidity. The $\mathrm{P} 2$ positions in between were occupied by mycelial plugs of homokaryon AmutBmut grown for 4 days at $37^{\circ} \mathrm{C}$ in the dark. On the $1 \%$ water agar plug in the middle, 25 mites were transferred before plates were sealed with Parafilm, wrapped with aluminium foil and incubated for $20 \mathrm{~h}$ in the greenhouse at $25-28^{\circ} \mathrm{C}$ at a humidity of $60 \%$. The plate was photographed after the $20 \mathrm{~h}$ incubation with the mites and makes obvious that plugs with fresh mycelium easily grew onto the fresh agar in contrast to plugs with old mycelium. Note the bacterial colonies indicating walk ways of mites. (B) An enlarged view on a plug from a young AmutBmut culture with mycelium growing from the plug onto the surface of the YMG/T agar plate. Note the bacterial colonies indicating walk ways of mites. (C) An enlarged view on a plug from an older AmutBmut culture that has sclerotia on its surface and did not start growth of fresh mycelium. Note also here the bacterial colonies indicating walk ways of mites. (D) to (F). Side views on separated plugs from a young AmutBmut culture with mycelium growing from the plug over the cut agar surface of the plug onto the surface of the fresh YMG/T agar plate (photographed under a Stemi 2000-C binocular). Note the mites on the plugs and the shiny areas representing bacterial growth on aerial mycelium of the fungus. 

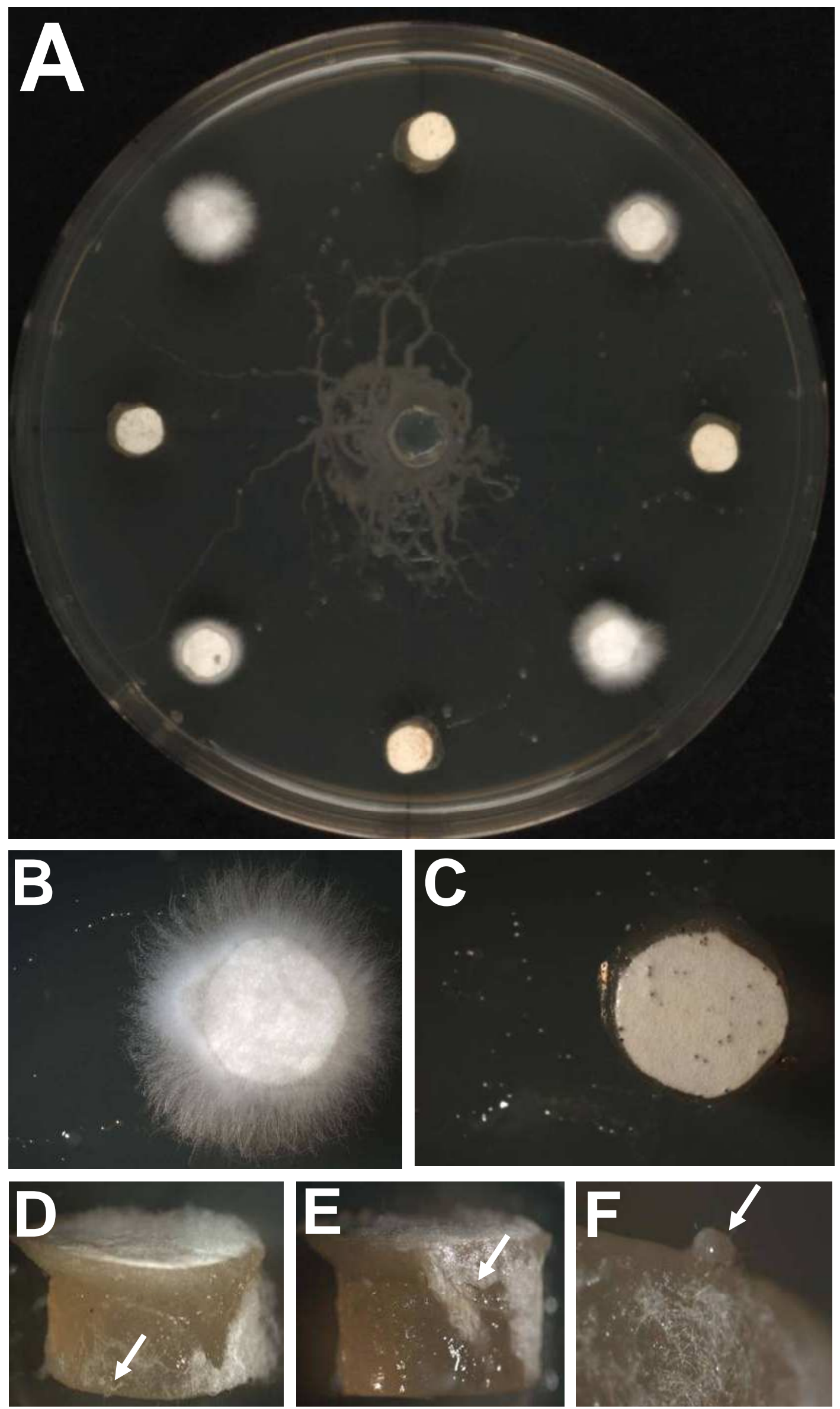

Fig. 23 (for description see previous page) 
Table 5 Preferences of mites to migrate to mycelium of $C$. cinerea homokaryon AmutBmut of a specific age in the experimental set-up described in Fig. 17 as treatment 1 as calculated by averages of number of mites at defined places and standard deviation using Excell software (Microsoft Office Excell 2003)

\begin{tabular}{|c|c|c|}
\hline \multicolumn{3}{|c|}{ Number of mites * } \\
\hline P1 (old mycelium) & P2 (fresh mycelium) & Lid of Petri-dish \\
\hline $1 \pm 1.3333$ & $11.4 \pm 4.7422$ & $12.6 \pm 5.3789$ \\
\hline
\end{tabular}

* 10 different plates were calculated

With an extreme high probability $(\mathrm{p}=0.0000)$, the analysis showed that mites clearly prefer the fresh growing mycelium and neglect the older one as suggested before from the experiments presented in Fig. 11.

As in previous experiments, walk ways of mites seen on the YMG/T agar by bacterial growth in the experiments with young and older mycelium of homokaryon AmutBmut suggest that mites are attracted to mycelial plugs since the walks ways appear not to be random on the plates (Fig. 23A). In this study, this was not further analysed but in the future such spatial orientation of the mites might be followed up by a computer-programmed photographic set-up as described by Kojima et al. (2003) who used such a set-up to observe the attraction behaviour of $T$. putrescentiae to olfactory fields presented to the animals on glass plates. With such computer-programmed photographic set-up one becomes independent from bacterial growth on nutrientcontaining medium, although the distances that can be follow up by such a camera is restricted by length and would need adjustments over the time in speed of the bacteria to follow their migration behaviour on Petri-dishes fully up.

On plates with $1 \%$ water agar, unless foot steps were seen, it was not possible in this work to determine the ways mites took on the surface of the agar after leaving the agar blocks on which they were set to the begin of experiments in treatment 3 described in Fig. 17. After $20 \mathrm{~h}$ of incubation at $25-28^{\circ} \mathrm{C}$ in the greenhouse at a humidity of $60 \%$, bacterial growth was not visible on respective plates (not shown). Parafilm sealed and aluminium wrapped plates from the series of experiments of treatment 3, strain combination 1 (P1: dikaryon PS001-1 x PS002-1; P2: PS001-1; see Fig. 17 for further explanations) were stored for 1 month further in the greenhouse at $25-28^{\circ} \mathrm{C}$ at a humidity of $60 \%$. Even after such long time, very little bacterial growth was visible on the nutrient-lacking agar (note some bacterial colonies of the right plug of used-up YMG/T medium transferred originally with mycelium from a fresh culture of 

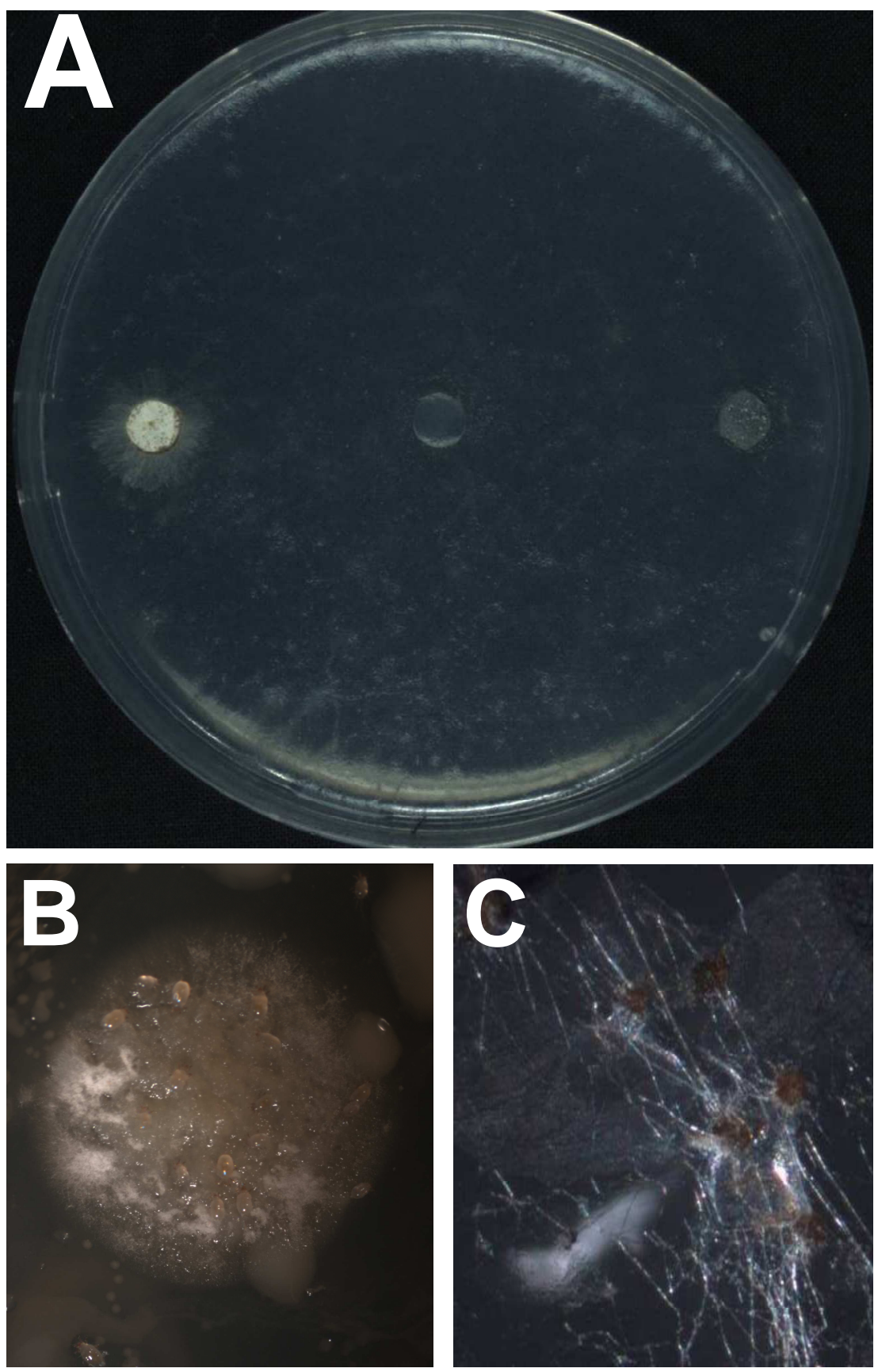

Fig. 24 A Petri-dish of treatment 3, strain combination 1 (P1: dikaryon PS001-1 x PS0021; P2: monokaryon PS001-1) of the experimental set-up explained in Fig. 17 after 1 month of incubation with mites in the greenhouse at $25-28^{\circ} \mathrm{C}$ at a humidity of $60 \%$. (A) Allover on the somewhat dried out agar, spores of Coprinopsis cinerea germinated giving rise to small thin colonies. Note the thin mycelium grown around the still with mycelium covered plug of the dikaryon PS001-1 x PS002-1, indicating that nutrients were supplied for fungal growth from the YMG/T agar block. In contrast, such thin mycelial ring where not seen around the plug of monokaryon PS001-1, which was fully free from mycelium due to grazing by the mites and after 1 month of incubation had some bacterial colonies on top. On top of the agar plug of the dikaryon, where in contrast vegetative fungal mycelium was still seen, also numerous by mites disliked sclerotia are visible explaining why mites did not fully consume the dikaryotic mycelium. (B) A fungal colony that arised on the water agar about $1.5 \mathrm{~cm}$ apart from the middle of the plate likely by germination of an oidium. Note the 15 different mites grazing on the colony and the small bacterial colonies attached to the fungal mycelium. (C) Sclerotia in fungal mycelium found attached to the lid of the Petri-dish. 
monokaryon PS001-1 onto the water agar plate!) that in the meantime was partially dried out as it is normal over the time (Fig. 24A). Most obvious at this point was that all over the plates, oidia, the asexual spores from the fungus (Polak et al. 1999, 2001, Kües et al. 2001), germinated on the water agar (Fig. 24). Oidia of C. cinerea are not distributed by wind but stay in sticky liquid droplets on the tips of the spore generating hyphae in the aerial mycelium until insects such as flies come along to which the spores stick and which distribute them to other places (Polak et al. 1999, 2001, Brodie 1931). In experiments performed in student courses with mycelial cultures of $C$. cinerea, similar observations of an insect-mediated transfer of the spores were done on various types of beetles (P.J. Hoegger, M. Navarro-González, unpublished observations).

In the experiments described here it appeared that over the time mites walked more happily over the dried and thus hardened surface than they did at the beginning of the experiment on the quite soft and humid surface of the agar. During their walks over the whole surface of the agar, the mites must have distributed the fungal spores taken previously up likely from the transferred YMG/T plugs with well-grown aerial mycelium (Fig. 24A). Mites were attracted for grazing to these new fungal colonies (Fig. 24B) and by the high numbers of mites seen on the germinated fungal colonies (e.g. 15 in total on the colony in Fig. 24B) it appeared that there was some reproduction within the mite population (not analysed in detail). The observations from the plates support the idea that mites distribute asexual fungal spores in order to provide their progeny food once larvae hatch from eggs laid by the mites [compare NavarroGonzález (2008), Duek et al. (2001) and above for discussion of sexual spores of C. cinerea and references Hubert et al. (2003a,b, 2004), Stewart et al. (1991), AbdelSater et al. (1995), Asselt (1999), Franzolin et al. (1999), Okabe et al. (2001), Smrž (2003) and Morgan and Arlian (2006) from the literature for fungal distribution of spores into food stores and reference Brust and House (1987) who reported a case in which mites laid their eggs close to eggs from the southern corn rootworm on which hatched larvae of the mite use as food source].

Finally in plates of this experiment, sclerotia formation was observed on fungal colonies germinated on the lids of the Petri-dishes where no nutrients were available unless mites left there faecal bodies or other material (e.g. egg shells, dead bodies of adult animals and larvae) that the fungus could have used for nutrition after germination. Otherwise, germination and sclerotia formation on the lid, where no other nutrients were available, must have fully been supported by nutritional material present 
in the spores themselves. By their small size ( $2 \mu \mathrm{m}$ x 4-6 $\mu \mathrm{m}$; Polak et al. 1999, 2001), this appears not as likely. As before with sclerotia, no mites were seen grazing on sclerotia also not when produced on the lid.

\subsubsection{Fungal odour compounds, 1-octen-3-ol and 3-octanone, in attraction of mites}

Since various experiments described above suggested that mites were attracted specifically to mycelium of $C$. cinerea it was of interest to perform experiments with typical fungal odours. Eight-carbon compounds such as 1-octen-3-ol and 3-octanone are typical fungal odours also produced by $C$. cinerea (Thakeow et al. 2007, Thakeow 2008; see also Chapter 5 of this thesis). In the literature, at least 1-octen-3-ol have been described to attract mites of the species T. putrescentiae and Halytedeus instructor (Vanhaelen et al. 1978a, b, 1980, Jiang et al. 1997). Here, experiments were performed to see whether the compounds have effects on T. putrescentiae.

In the experiments, in each 10 replications, either $20 \mu \mathrm{l}$ of an 1-octen-3-ol or a 3octanone in a paraffin oil solution at a dilution of $10^{-6} \mathrm{~g} / \mathrm{g}$ or, as a control, $20 \mu \mathrm{l}$ of pure paraffin oil were added on filter paper laid on round YMG/T agar blocks $(\varnothing 0.6 \mathrm{~cm})$ positioned at the outer edges on YMG/T agar plates shortly before transferring 25 mites onto small agar plugs in the middle of YMG/T agar plates (see Materials and methods).

The Parafilm sealed plates were evaluated first under a Stemi 2000-C binocular 10 min after mites had been transferred and stored in between in a dark box in the laboratory. Four mites in in total 10 plates were found close (i.e. an area of about $1 \mathrm{~cm}$ around the agar block with the filter paper) to the control filter (in average $0.4 \pm 0.5$ mites/plate) in the test with 1-octen-3-ol and 33 close to the filter onto which 1-octen-3ol was added (in average $3.3 \pm 1.2 \mathrm{mites} /$ plate). Likewise, 9 mites in in total 10 plates were found close to the control filter (in average $0.9 \pm 0.6$ mites/plate) in the test with 3octanone and 40 close to the filter onto which 3-octanone was added (in average 4.0 \pm 1.3 mites/plate). Both these data sets and statistical paired T-tests suggest that mites were attracted to mushroom odor compounds. The p-value for the 1-octen-3-ol situation was 0.0001 and the p-value for the 3-octanone situation was 0.0001 (see Table 6). Subsequently after this first evaluation, the Parafilm sealed and now in aluminium foil wrapped plates were transferred into a greenhouse at $25-28^{\circ} \mathrm{C}$ and a humidity of $60 \%$ and plates were further evaluated after $20 \mathrm{~h}$ and after another extra $20 \mathrm{~h}$ (40 h in total) of incubation in the greenhouse (Fig. 25). Again, bacterial growth indicating walk ways 
Table 6 Statistical analysis of preferences of mites for filters treated with eight - carbon compounds as determined by average values of mites found at a defined place and a standard deviation using Excell software (Microsoft Office Excell 2003) and applying paired T-test with the software SX release version 8.0 (Analytical software, Tallahassee, USA)

\begin{tabular}{|c|c|c|c|c|c|c|}
\hline \multirow[t]{2}{*}{$\begin{array}{c}\text { Time of } \\
\text { evaluation } \\
\text { after }\end{array}$} & \multicolumn{2}{|c|}{$\begin{array}{c}\text { Number of mites/tracks } \\
\text { of bacteria on/at filter } * \\
\text { with }\end{array}$} & \multirow[t]{2}{*}{ p-value } & \multicolumn{2}{|c|}{$\begin{array}{c}\text { Number of mites/tracks } \\
\text { of bacteria on/at filter * } \\
\text { with }\end{array}$} & \multirow[t]{2}{*}{ p-value } \\
\hline & Paraffin & 1-octen-3-ol & & Paraffin & 3-octanone & \\
\hline $10 \mathrm{~min}$ & $0.4 \pm 0.5$ & $3.3 \pm 1.2$ & $0.0001^{*}$ & $0.9 \pm 0.6$ & $4 \pm 1.3$ & $0.0001^{*}$ \\
\hline $\begin{array}{c}20 \mathrm{~h} \text { of } \\
\text { incubation }\end{array}$ & $1.1 \pm 0.6$ & $5.4 \pm 1.3$ & $0.0000^{*}$ & $1.5 \pm 0.8$ & $5.5 \pm 1.4$ & $0.0000^{*}$ \\
\hline
\end{tabular}

* 10 different plates were evaluated

of mites were used as an indication of where mites migrated. After $20 \mathrm{~h}$ of incubation, comparably fewer bacterial growth lines was seen on the sides with the control filters than on the sides with the eight carbon sources (see Fig. 25A and C). Under the Stemi 2000-C, positions of mites were tried to determine. Some of the animals were found on the lid (not properly counted!) but high amounts of animals were missing and not found back at this time point. This might be due to that the animals may have distributed randomly at this time over the agar surface, may be taken as a reaction of searching for missing food. On the agar surface, by a missing contrast, it would be quite difficult to find the animals if not aggregating at specific positions as seen previously at the evaluation $10 \mathrm{~min}$ after adding of the mites on the plates.

Since too many animals where missing in order to perform a valid evaluation, walk ways of mites visible by bacterial growth to the different filters (directly or to close vicinity) were counted and analysed (Table 6). As determined by the paired T-test, there were significantly more walk ways towards the filters with added 1-octen-3-ol (p-value $=0.0000)$ or added 3-octanone $(\mathrm{p}$-value $=0.0000)$, respectively (Table 6), suggesting a specific attraction of the mites to the mushroom odor compounds.

Following further incubation for an additional $20 \mathrm{~h}$ at $25-28^{\circ} \mathrm{C}$ in the greenhouse at an humidity of 60\%, as seen in Fig. 25B and Fig. 25D, lateron there appeared to be no obvious directional tendency visible in plates of these set of experiments, regardless of whether 1-octen-3-ol or whether 3-octanone was added. Bacterial colonies appeared to be more randomly distributed at this time point, suggesting that mites were visiting 

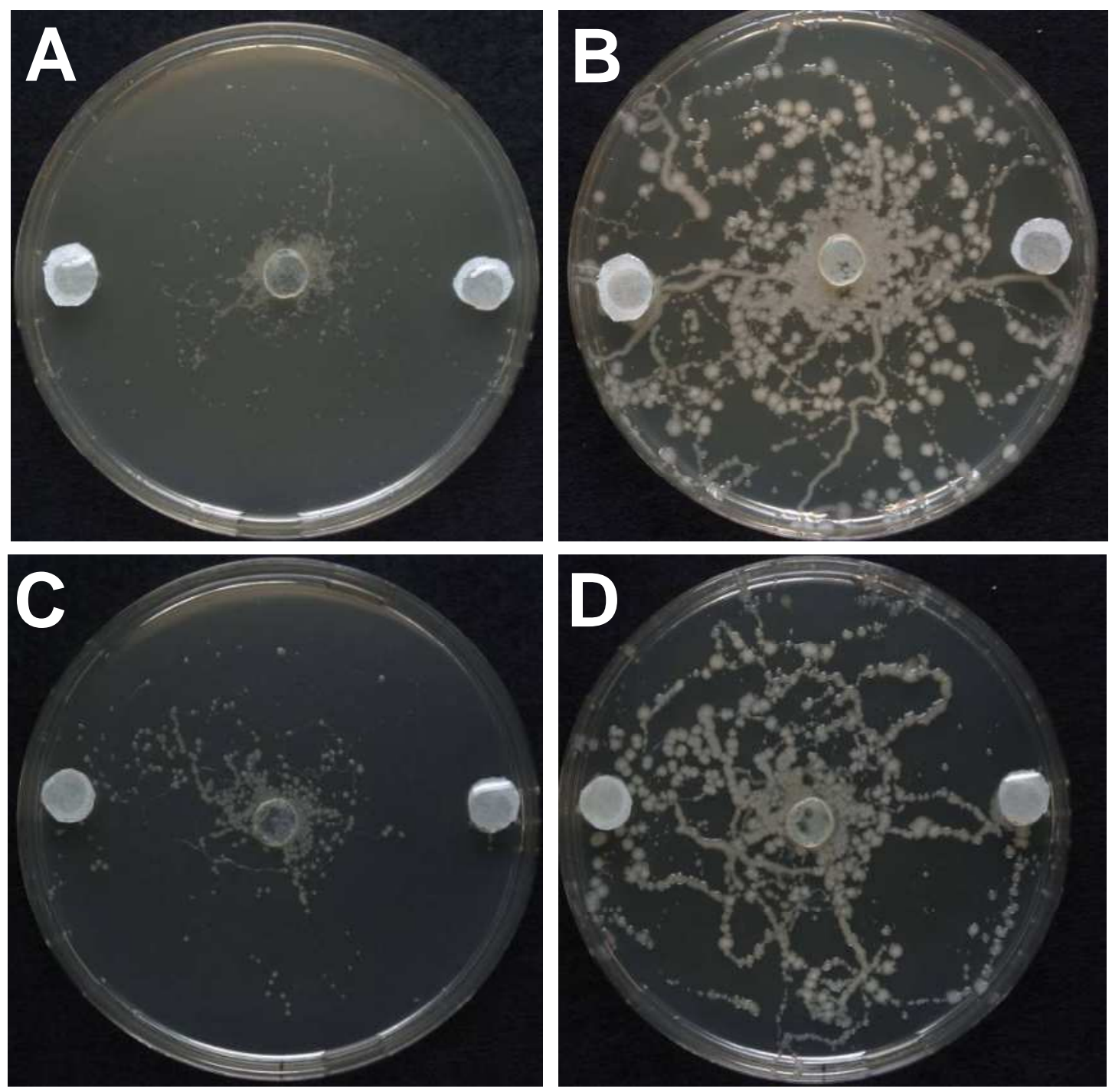

Fig. 25 Test for attraction of mites by 1-octen-3-ol (A), (B) and 3-octanone (C), (D). Paraffin oil solutions with an eight-carbon compound were added onto the filters shown at the right and pure paraffin oil solution onto the filters shown at the left. Plates were evaluated after $20 \mathrm{~h}$ with mites at $25-28^{\circ} \mathrm{C}$ in the greenhouse at a humidity of $60 \%$. (A, C) and after an additional $20 \mathrm{~h}$ of incubation at $25-28^{\circ} \mathrm{C}$ in the greenhouse at a humidity of $60 \%$ after the first evaluation at $20 \mathrm{~h}(\mathbf{B}),(\mathbf{D})$

places on the agar plates without any obvious preference. Bacterial colonies in the walk ways on the plates distinguished in size. Within a given walk way they were more or less even in size. Whether smaller and larger colonies being seen on the plates are due to different types of bacteria distributed by the mites or whether they are due to different timings of walking on top of the agar has however not been determined.

In conclusion from the preliminary experiments on mushroom odor volatile effects on mites, it appears that as in other cases of mites, the typical mushroom odor eight carbon components are used by the mites as a signal to direct them to food sources. 
In the experimental design used here, concentrations of volatiles are however difficult to control. Thus, in the future one might change the experimental set-up to a T-tube system (T-shape bridge system) or a similar Y-tube system in which mites have the choice to migrate into either a tube at the left or a tube at the right in dependence on attractive or repellent material situated in small containers at the end of the two tubes of choice [for further description see (Grostal and Dicke 1999, Gnanvossou et al. 2001, De Boer and Dicke 2004, Choh and Takabayashi 2007, Skelton et al. 2007 and ZahediGolpayegani et al. 2007)]. Moreover, such a T-tube or Y-tube system might be connected to a computer-programmed photographic set-up to obtain further results on spatial orientation of the mites (Kojima et al. 2003).

\subsubsection{Reproduction of mites in fungal cultures}

The total populations of mites within a culture depend on the rates of reproduction and of the death rate of the animals (Sánchez-Ramos and Castañera 2005, Kheradmand et al. 2007b, Sánchez-Ramos et al. 2007). Upon infestation of $C$. cinerea cultures with originally 25 mature mites, within 14 days an increase in numbers of animals became obvious, indicating strong reproduction activities. Apparent copulation activities of mature mites were repeatedly observed in populations on Petri-dishes without any obvious specific environmental conditions regarding presence and absence of abundant food sources (mycelium) as well as the age of the mycelium used as a food source (Fig. 26A, B).

In contrast, female mites laid their eggs usually under humid conditions (Fig. 27A to F), confirming previous reports from the literature (Sánchez-Ramos and Castañera 2001, 2005, Hart et al. 2007, Kheradmand et al. 2007a,b, Sánchez-Ramos and Castañera 2007). The process of oviposition was most easily observed in the lids of plastic Petridishes. Females discharged their eggs into water droplets on the plastic surface which evapourated within 5 min leaving thin films of material behind on the lids of the Petridishes (Fig. 27B, C). A female mite was capable to lay one egg at a time. Some mites died after finishing the egg laying process or possibly even during the process of oviposition. In such cases, the female bodies were repeatedly seen to be detoriated within a material left behind on the plastic surface after drying out (Fig. 28A, B). It is possibly the material that is related to that seen after oviposition surrounding the eggs likely released by the females in order to stick the eggs onto surfaces (see Fig. 27E and 

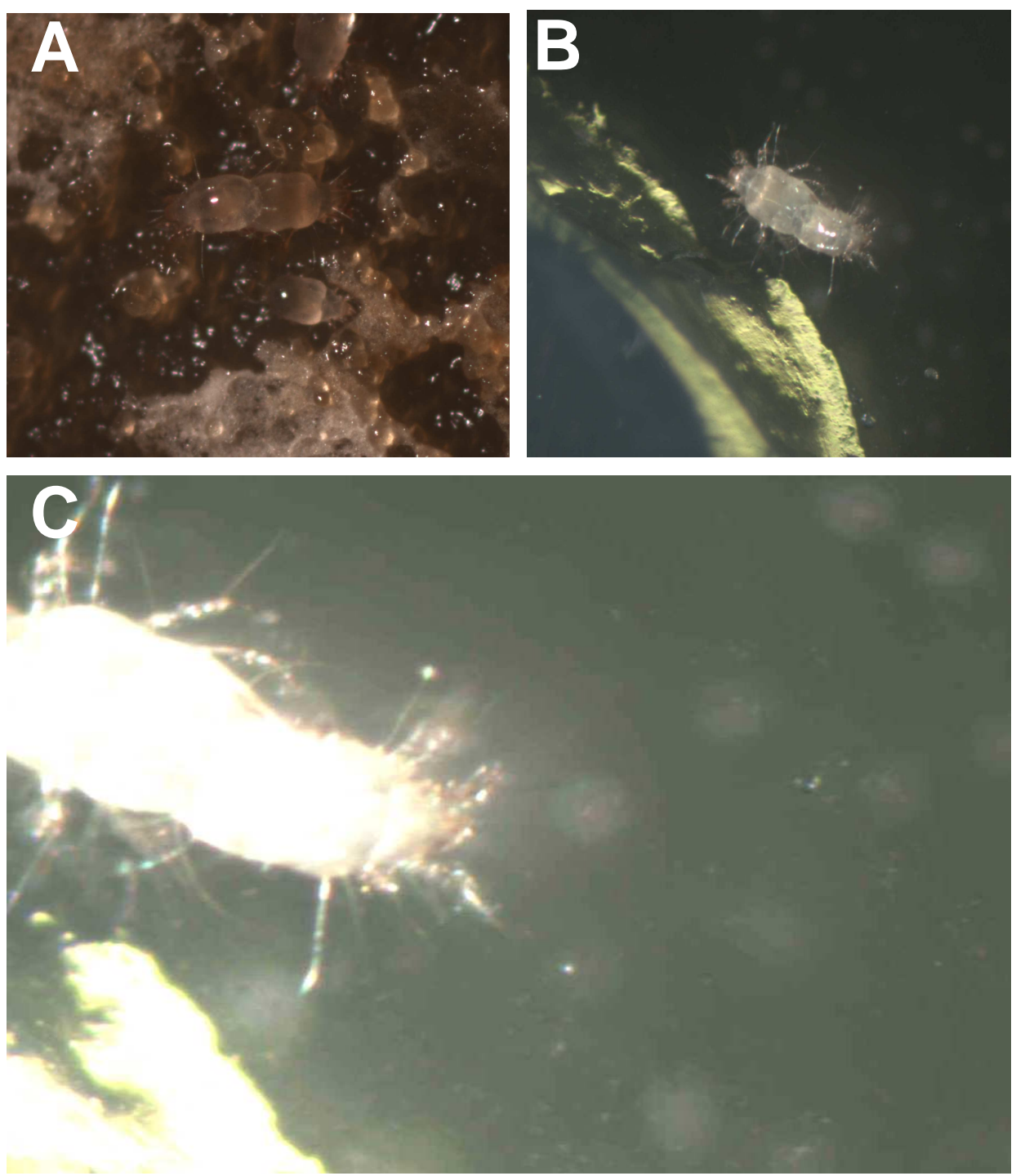

Fig. 26 Reproduction of the mite Tyrophagus putrescentiae in Petri-dish cultures. (A) Copulating mature mites found in older YMG/T cultures of homokaryon AmutBmut that were grown for 5 days at $37^{\circ} \mathrm{C}$ in the dark, upon which plates were first transferred for seven days to standard fruiting conditions Granado et al. 1997) at $28^{\circ} \mathrm{C}$ in a $12 \mathrm{~h}$ light/12 h dark regime at a humidity of $85-90 \%$ and then, after inoculation of 25 mites onto an fresh water agar block in the middle of the plate, sealing the plate with Parafilm and wrapping the plate with aluminium foil, plates were subsequently transferred for 1 month into a greenhouse at a temperature $25-28^{\circ} \mathrm{C}$ and a humidity of $60 \%$. (B) Copulating mature mites on $1 \%$ water agar (plate from treatment 3 from the experiment presented in Fig. 1, strain combination 1) after inoculation of the plate with 25 mites, sealing it with Parafilm and wrapping it in aluminium foil followed by two-weeks-incubation in the greenhouse at $25-28^{\circ} \mathrm{C}$ at a humidity of $60 \%$. Note the small lighter-grey spots on the agar surface [shown in (C) 3-fold enlarged and highly contrasted for better recognition] that represent fungal colonies originating from germination of oidia that were previously likely distributed by the animals.

Fig. 28B). As a further but still better to be followed up observation, mites appeared to lay eggs preferentially in close neighbourhoods where already one or more eggs were laid (e.g. see Fig. 27D to F and Fig. 28B). 

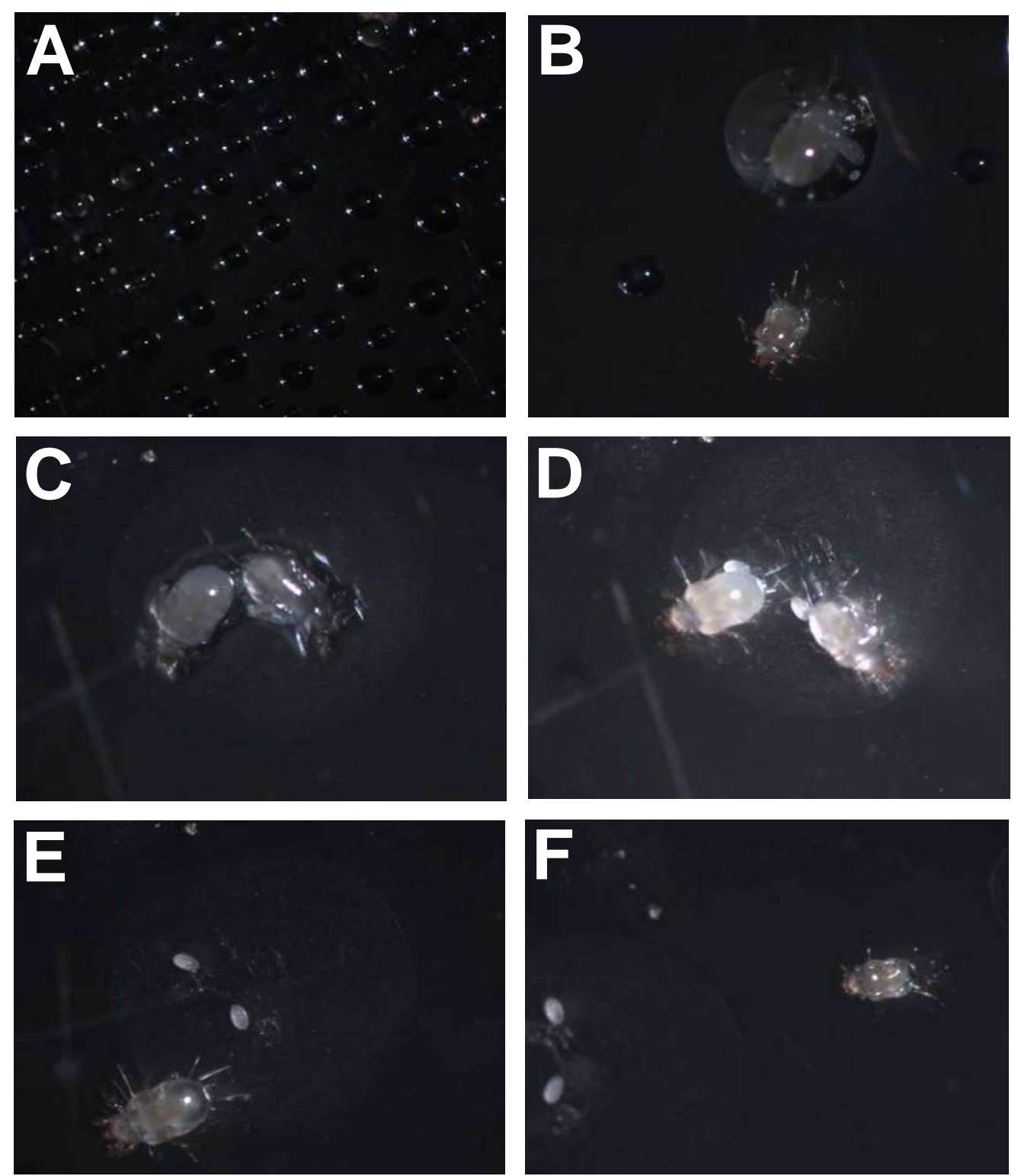

Fig. 27 The process of egg laying of the mites Tyrophagus putrescentiae as observed on the lid of a plastic Petri-dish. A YMG/T plate from the experiment presented in Fig. 17, treatment 1 and strain combination 1 was inoculated with 25 mites as described in the figure legend, sealed with Parafilm and wrapped in aluminium foil, upon which the plate was incubated for 2 weeks in a greenhouse at $25-28^{\circ} \mathrm{C}$ and a humidity of $60 \%$ before the observations shown were done with the lid of the Petri-dish under a Stemi 2000C binocular. At this time, mites undergoing oviposition were easily detected and all over the surface of the lid, there were many eggs. (A) From observations made, it appeared that mites preferred laying eggs into the lid that provided a certain degree of humidity by water condensed on the plastic surface. (B) to $(\mathbf{F})$ Females laying eggs within a liquid droplet released from their bodies $(\mathbf{B}),(\mathbf{C})$ that quickly evapourates within $5 \mathrm{~min}(\mathbf{D})$ to $(\mathbf{F})$ leaving a shadow of material behind on the agar surface. Moreover, it appeared that mites liked to aggregate together when laying eggs $(\mathbf{B})$ to $(\mathbf{F})$. Upon oviposition, mites quickly left the place where they laid their eggs $(\mathbf{E}),(\mathbf{F})$. Note in $(\mathbf{F})$ [view turned slightly in clock-wise direction compared to (D) and (E)] the body of a dead mite placed at some distance to the freshly laid eggs of the two mites that disappeared from the area of observation. Mites were seen to run away very fast but it can not be excluded that the light given from the Stemi 2000-C binocular had part in this. Photographing of picture (D) is arbitrarily set at $0 \mathrm{~min}$, and pictures $(\mathbf{C})$ to $(\mathbf{F})$ were taken $2 \mathrm{~min}, 1 \mathrm{~min}, 1 \mathrm{~min}$ and $1 \mathrm{~min}$ later, respectively. 

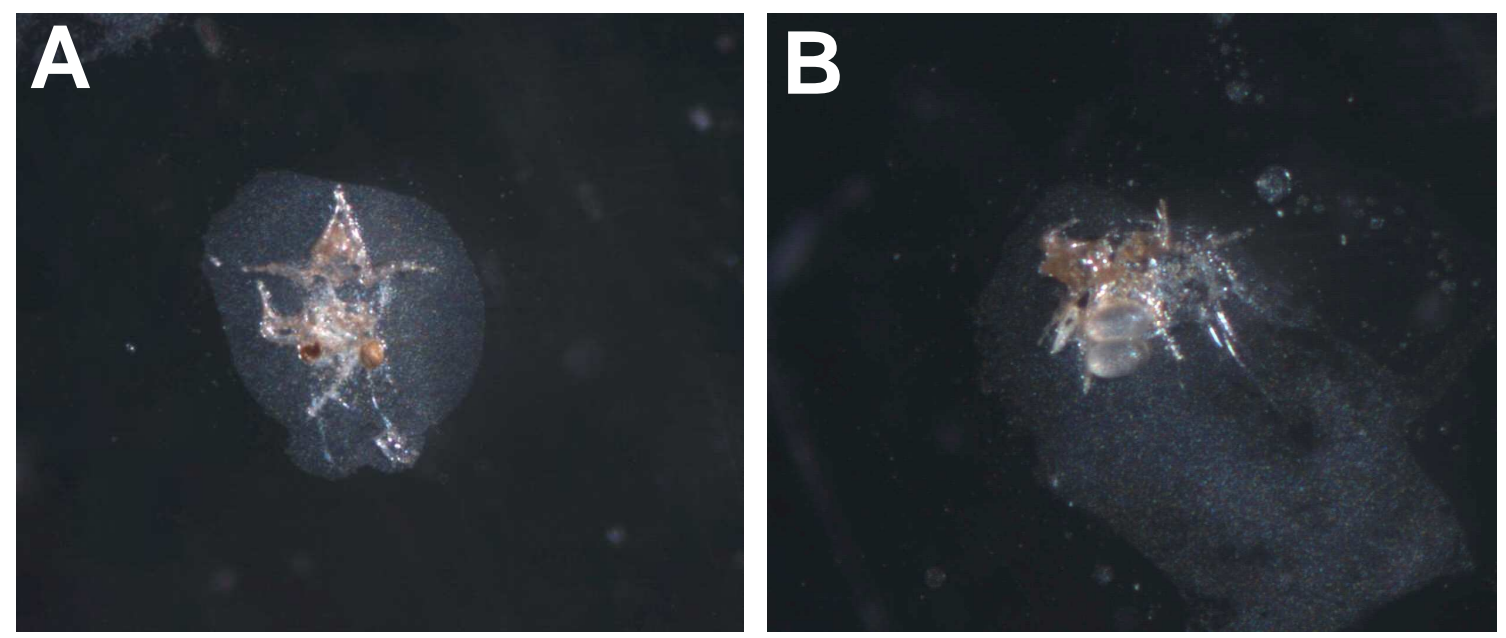

Fig. 28 Death of Tyrophagus putrescentiae mites in the reproductive state. (A) Dead female mite found attached by a dried material onto the surface of the lid of the same Petri-dish shown in Fig. 27 in which the observations on oviposition were made. The dried material appeared by look to be that what is released from the female bodies during laying eggs. An egg in this case was however not seen but it cannot be excluded that there was previously an egg from which a larvae hatched. (B) Another dead female mite on the lid of the same Petri dish that had died possibly during or shortly after the egg-laying process. Note the two eggs next to berthe destructed body.

Like oviposition of eggs by females, hatching of larvae can also be observed in the lids of Petri-dishes (Fig. 29A to D). In the observations shown here, eggs were identified under the Stemi 2000-C binocular on the lid of the Petri-dish shown in Fig. 27 and Fig. 28 and they were then marked on the outer surface of the lid by a circle drawn around the egg with a permanent marker, upon which the Petri-dish with its lids was incubated for another $24 \mathrm{~h}$ under humid conditions $(60 \%$ humidity to avoid drying out of the eggs) at $25-28^{\circ} \mathrm{C}$. The next day, the eggs were observed again, some of which were empty due to hatching of the larvae (not shown). In one instance, the hatching process was observed under the Stemi 2000-C binocular. The larva came out as quickly as within 3 min (Fig. 29A to D). 

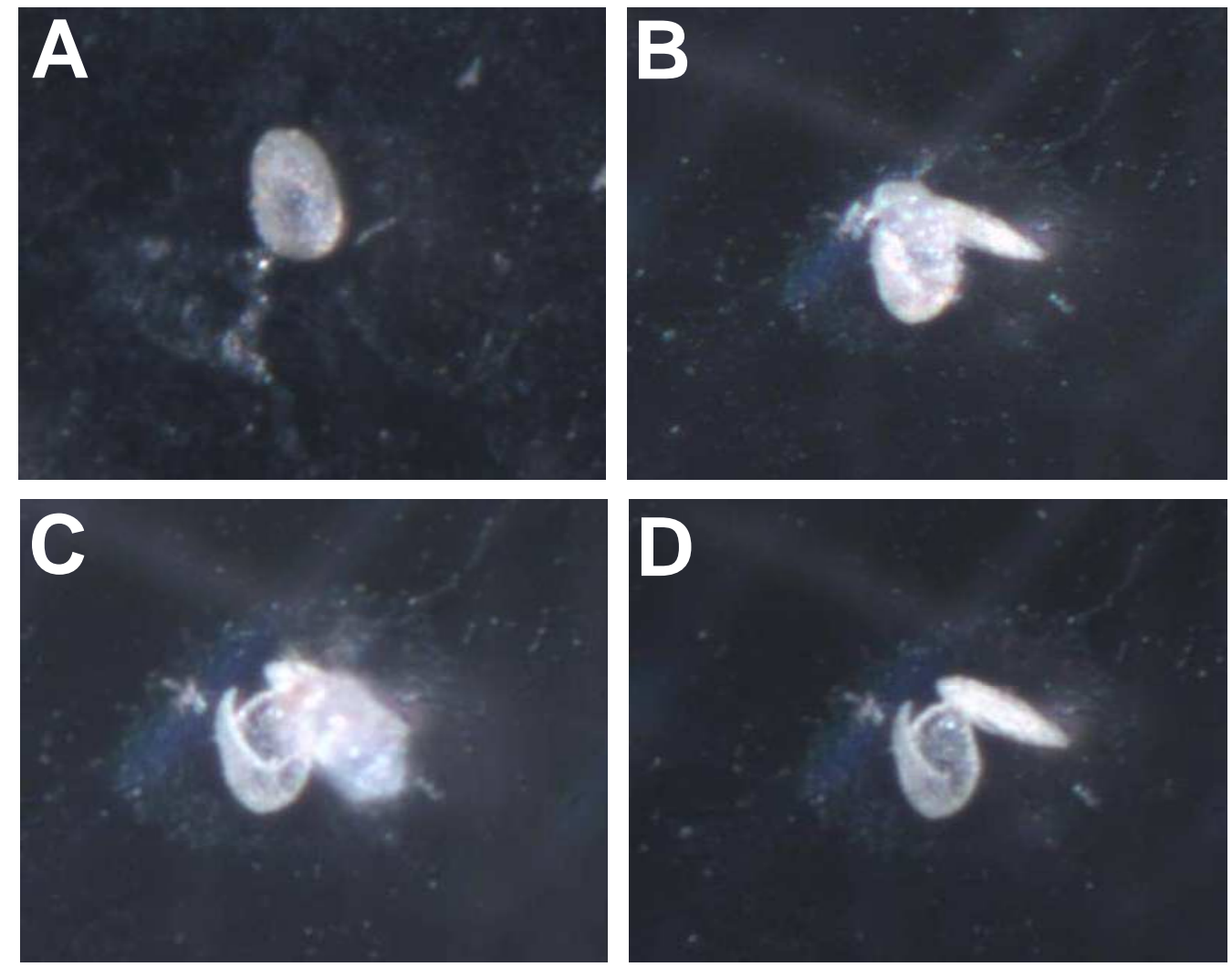

Fig. 29 Hatching of a larva from an egg in the lid of the same Petri-dish shown previously in Fig. 27 (A) Egg shortly before hatching to which attention was drawn by some movement within the egg, $(\mathbf{B}),(\mathbf{C})$ the process of hatching within $3 \mathrm{~min}$ from a break at a pole part of the egg and (D) the empty egg shell. Photographing of picture (A) is arbitrarily set at $0 \mathrm{~min}$, and pictures $(\mathbf{B})$ to $(\mathbf{D})$ were taken $1 \mathrm{~min}, 1 \mathrm{~min}$, and $1 \mathrm{~min}$ later, respectively.

\subsubsection{Death of mites in fungal cultures}

As already mentioned above (paragraph 4.4.1), the death of mites in cultures was generally increased when plates were kept at higher temperature and when plates were kept in light why dark culture conditions should be chosen with temperatures below $30^{\circ} \mathrm{C}$. In cultures where the fungal mycelium was fully consumed during incubation in the greenhouse at $25-28^{\circ} \mathrm{C}$ at a humidity of $60 \%$, mites appeared to decease but eggs may still be there which upon transfer to fresh medium with fresh mycelium may hatch to subsequently infest the fresh culture (not further studied). To test effects of lack of nutrients better, in ten repeats of the experiment a round piece of paper towel (about 9 $\mathrm{cm}$ in $\varnothing$ ) was transferred into a Petri-dish and wetted with $5 \mathrm{ml}$ of destilled water. Afterwards, a round piece of $1 \%$ water agar $(0.6 \mathrm{~cm}$ in $\varnothing)$ was put into the middle of the paper and 25 mites were added onto the agar. The plates were sealed with Parafilm, wrapped with aluminium foil and incubated for 1 month in the greenhouse at $25-28^{\circ} \mathrm{C}$ and a humidity of $60 \%$. After 1 month of incubation, the plates were opened and the 
piece of paper towel removed. The plastic surfaces of the bottoms of the Petri-dishes were checked for presence of mites. Only part of the mite populations were found back on the bottom of the Petri-dishes (approximately ten per plate). All mites found on the bottom of the plates were dead, most likely by starving due to a lack of fresh nutrient supply. However, dead mites' bodies still were complete in structure as indicated from observations under the Stemi 2000-C binocular (Fig.30A).
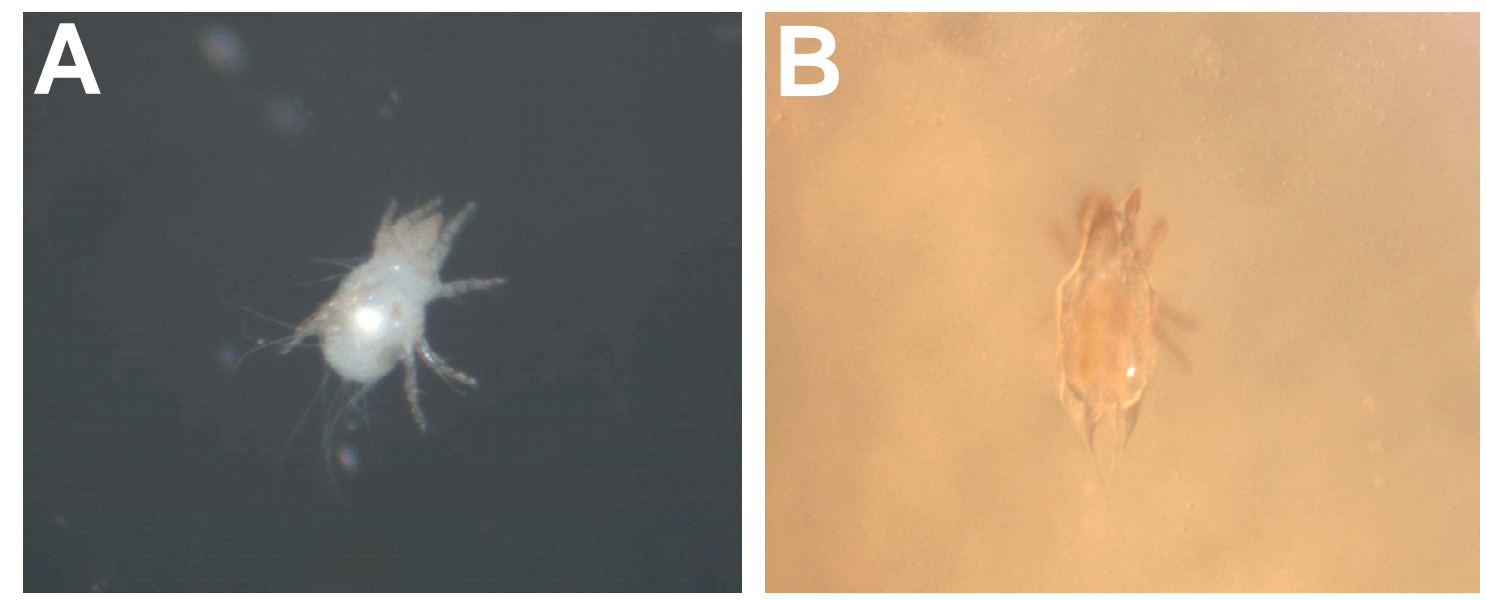

Fig. 30 Additional causes of death of mites. (A) A mite that died within 1 month incubation in a Petri-dish in which a piece of paper towel was laid and wetted by $5 \mathrm{ml}$ of distilled water before an 1 water agar plug with 25 mites were added onto the paper. The Parafilm-sealed plate was wrapped in aluminium foil and incubated for 1 month in a greenhouse at $25-28^{\circ} \mathrm{C}$ and $60 \%$ humidity. (B) A mite that was trapped and died in a slimy mass of a bacterial culture that grew on YMG/T agar on a plate from the experiment described in Fig. 17, treatment 2, strain combination 1. Upon infesting the plate with 25 mites, sealing the plate with Parafilm and covering it with aluminium foil, within $24 \mathrm{~h}$ of incubation at $28^{\circ} \mathrm{c}$ at an humidity of $60 \%$ in the greenhouse, the bacteria likely introduced by the mites themselves grew into the slimy colony in which overnight the mite was captured and died.

Death of mites were further observed during this work to be caused by bacterial contamination growing in Petri-dish cultures (Fig. 30B). Mites walking into slimy colonies of bacteria were captured and possibly suffocated within the bacterial cell masses. The higher the bacterial contaminations and the larger and faster growing the bacterial colonies were and how more slimy the consistency of the bacterial colonies were, the more mites appeared to become more fast killed in numbers (not further analysed). 


\subsection{Conclusions}

The ubiquitous mite $T$. putrescentiae is most frequently found in food and grain storages, as well as in beddings and dusts of houses nourishing from dead human and animal skin scales and in mushroom cultivations nourishing from the fungal biomass. T. putrescentiae has been reported previously to be attracted by fungi from ascomycetous and deuteromycetous genera such as Trichophyton, Penicillium and Alternaria (Duek et al. 2001, Hubert et al. 2004, Smrž and Norton 2004) and by basidiomycetes such as the mushrooms A. bisporus and P. ostreatus and Hypsozygus marmoreus (Okabe et al. 2001, Kheradmand et al. 2007b) and as seen in this study and in the study by Navarro-González (2008) now also by $C$. cinerea. The mites are shown to use the fungi as nutrients. The common environmental requirements of moderate temperatures and high relative humidities are considered to be important factors in the relationships of mites with the fungi (Asselt 1999). Mites were found to be very sensitive towards environmental conditions and at higher temperature and lower humidity and under too much light, populations of $T$. putrescentiae quickly die, respectively do not reproduce anymore. In contrast, although best conditions for fruiting body development of the fungus $C$. cinerea is at a temperature range of $25-28 \%$ and a humidity around 85-90\% (Granado et al. 1997, Kües 2000), conditions at which the mites apparently feel happy and reproduce (Ree and Lee 1997, Sánchez-Ramos and Castañera 2005, Aspaly et al. 2007, Hart et al. 2007, Kheradmand et al. 2007b, Sánchez-Ramos et al. 2007, Navarro-González 2008), the optimum conditions for mycelial growth is at $37^{\circ} \mathrm{C}$ and vegetative growth at that and other temperatures tolerates also lower humidity levels (Kües 2000 and pers. communication). The broader tolerance of environmental conditions will help the fungus in its survival in its natural habitats, i.e. in the relatively hot decomposing horse dung (Kües 2000), whilst the mites should be repressed under such conditions in order for them to re-appear once the microbial metabolic activities in the dung exhaust by complete consumption of nutrients that were present in the dung.

The study presented here performed in parallel to the work of Navarro-González (2008) advanced our knowledge on interactions of $T$. putrescentiae with a fungus with respect to the pure vegetative mycelia and with respect to the fungal sexual and asexual reproductive structures. The observations on feeding and attraction to different morphological structures of the fungus combined with an increasing knowledge on fungal VOCs acting as attractants or as repellents towards mites and also insects (My- 
Yen 1980, Ruther and Steidle 2000, Thakeow et al. 2007, Thakeow 2008) will help to understand the ecological relationships between the different types of organisms in the natural environment (Dusenbery 1992).

Whilst the work concentrated here on one mite, i.e. T. putrescentiae, and one fungus, i.e. C. cinerea, evidence for further organismal interactions in the interplay of the two named species came to light. Bacteria are distributed by the mites, possibly on the one hand by their feet as seen from the bacterial outgrowth of the walkways of the animals (see Fig. 19) as well as on the other hand by their faeces (Smrž et al. 1991, Smrž 2003; M Navarro-González unpublished observations). Bacteria appear to be needed in the digestion part of the mites to contribute enzymes for example for chitin and keratin degradation. In consequence, the prevailing diet will influence the type of bacteria found predominantly in the digestion part of the mites. Typical bacteria reported in faeces of mites are Serratia marcescens and Alcaligenes eutrophus (Smrž 2003, Smrž and Norton 2004) whereas bacteria isolated from T. putrescentiae-infected C. cinerea cultures according to their ITS (internal transcribed spacer)-sequences with about $85 \%$ and $88 \%$ sequence identity are distantly related to Ochrobactrum anthropi and Sphingobacterium multivorum, respectively, bacteria that are associated with various types of animals including man, often with symptoms of illness, and that can degrade amongst other compounds also chitin (Kleemann 2007). Without chitinolytic bacteria, the ingested fungal mycelium with its chitin-containing cell walls will likely only poorly or not at all be digested. Without opening the fungal cells, other nutrients, e.g. the precious trehalose used commonly as a storage sugar in fungi (e.g. see Koide et al. 2000, Beecher et al. 2001, Shi et al. 2002, Tereshina et al. 2004, Tsai et al. 2007) will not easily be accessible. Accordingly, chitinolytic bacteria in the mesenchymal tissues of the mite $T$. putrescentiae produce also high activities of trehalose (Smrž 2004).

Bacteria growing in excess in the environment are shown in this study to eventually kill the mites (observed also by M Navarro-González, unpublished observations). On the other hand, $C$. cinerea reacts upon bacterial overgrowth with laccase production and related to the enzymatic actions of laccases radical production, likely in order to defeat the bacteria (Rühl et al. 2007, Kleemann 2007; M Navarro-González unpublished observations). In this way, it helps obviously the mites in their survival. NavarroGonzález (2008) showed that the fungus has an advantage through the mites by distribution of fungal spores coming from the same mushroom in faecal pellets, thereby 
favouring inbreeding in an otherwise strongly outbreeding species. This gives much more genetic flexibility to the fungus in order to adapt as a species best to changing or maintaining environmental conditions. Distributing the fungal spores through their faeces has also advantages for the mites. Female mites lay eggs next to the faeces and hatching larvae are supplied directly with suitable food by the germination of the fungal spores into fast growing mycelium. In order for the fungus to survive, not all mycelium should be consumed by the mites prior to production of mushrooms or sclerotia ensuring sexual or asexual reproduction. In nature, the predatory mites observed by Dr. P. Plašil and U. Eisenwiener in fungal cultures (pers. communications) are likely a mean to keep the fungi-consuming mites into well balancing numbers allowing all organisms to benefit from each other without any one of being lost from their respective biotopes.

Next to a broader tolerance of environmental conditions in vegetative growth, the fungus has however also own means to keep the population numbers of mites lower. For example, the appearance of multi-cellular sclerotia acting as duration structures for asexual reproduction in colonies of $C$. cinerea (Waters et al. 1975, Kües et al. 2002) seems to negatively affect the speed of infesting fungal cultures by T.putrescentia, respectively the speed of fungal consumption by the mite. Sclerotia development has been described to occur under non-favorable environmental conditions in various fungi that belong to either to the Ascomycetes, the Deuteromycetes or the Basidiomycetes. Usually, they have a high resistance towards chemical and biological degradation (Georgiou 1997). In Sclerotium rolfsii, sclerotia differentiation is accompanied by a high degree of lipid peroxidation caused by oxidative stress due to adverse fungal growth conditions (Georgiou 1997, Ellil 1999, Ramos et al. 1999, Han et al. 2005, Ritchie et al. 2006). Moreover, in Penicillium sp. the production of sclerotia is a consequence of oxidative stress and it is accompanied by production of alfatoxins (Han et al. 2005). Production of aflatoxins from lipid degradation products (Maggio-Hall et al. 2005) is seen as a direct consequence of lipid peroxidation (Jayashree and Subramanyan 2000). A linkage between sclerotia and alfatoxin is also recognized by a shared nutritional control of their production-production of both increased after adding ammonium and urea to minimal medium (Chang and Hua 2007). Such secondary metabolites from the fungi resulting in production from lipid peroxidation can negatively influence grazing of small animals on fungal mycelium, for example by avoidance reactions (Rohlfs et al. 2007). We currently do not know whether any toxic 
compounds acting negatively against grazing arthropods are produced in parallel to sclerotia development in $C$. cinerea. In the future, the $T$. prudescentiae population rates should therefore be observed in relation to the chemical composition of the sclerotia of C. cinerea in order to find out whether production of any toxic compounds are a reason for avoidance of the mites of mycelium with sclerotia or whether the reduced production of VOCs in aging cultures (compare Chapter 5 of this thesis) just makes the animal to neglect such mycelium by lack of required signal molecules. VOCs from C. cinerea mycelium expected to react attractive to the mite $T$. putrescentiae are mainly 1-octen-3-ol and 3-octanone (compare Chapter 5 of this thesis). With mycelial aging there is a strong decrease in the production of these VOCs (see Chapter 5 of this thesis). Attraction experiments with small agar plugs covered by fresh $C$. cinerea mycelium performed in this study (Fig. 18) suggest that the mites find these due to emissions of VOCs. There was no preference for a specific type of mycelium. Possibly this is also because the mycelium was damaged when transferring the freshly cut mycelial agar blocks onto fresh agar for the attraction tests with the mites. As shown in Chapter 5 of this thesis, damaged mycelium produces rapidly high levels of VOCs of the C8compound types and it is these that are reported in the literature to be the attractant for the mites (Vanhaelen et al. 1978a, b, 1980, Jiang et al. 1997).

As the sclerotia, all developmental stages in the fruiting pathway up the mature fruiting body (see Fig. 1 in Chapter 2 of this thesis) are structures that are avoided by the mites. All these structures are protected by densely aggregated, robust and durable tissues that shape the respective structures (the melanized rind in case of the sclerotia and the outer stipe and cap tissues in case of the fruiting body primordia and etiolated stipes and, in the final stage of the development, also of the stipes of the matured fruiting bodies). When cultures with such structures were infested by mites, the mycelium quickly became perforated by grazing through $T$. putrescentiae whereas the higher order structures remained untouched. However, T. putrescentiae feeds on the fruiting body caps at the stages of maturation and autolysis, thereby ingesting the sexual basidiospores. Basidiospores of C. cinerea are black due to melanization (Kües 2000) and the melanization likely helps the spores to pass the digestion tract of the mites without any harm (Navarro-González 2008). Mites do transport the basidiospores not only by attachment on their bodies to new places but also by distribution of their faeces. Faecal pellets contain several hundreds of basidiospores that can germinate on suitable substrates (Navarro-González 2008). However, the spores in the faecal pellets of mites 
did not germinate in the old agar cultures (see Fig. 15E), most likely by lack of nutrients in the used-up medium or by effects of the $\mathrm{pH}$ that at end of vegetative growth periods at least in liquid cultures are known to increase into the alkaline range of $\mathrm{pH} 8$ to $\mathrm{pH} 9$ (Navarro-González 2008). Faeces of mites have been shown to contain various types of proteases such as trypsin, chymotrypsin, carboxypeptidase A and B, cathepsin B and aminopeptidase acitivities (Ortego et al. 2000, Sánchez-Ramos et al. 2004, Morgan and Arlian 2006). Activities of such digestive proteases might have an inhibitory effect on spore germination from the faecal pellets. However, since feacal pellets germinate on fresh medium (Navarro-González 2008), if there is any such postulated protease inhibition on germination it cannot be very strong. Another more likely explanation for the lack of germination of basidiospores within the faces on used-up medium is the presence of bacteria that might produce anti-fungal compounds. Strains of S. marcescens for example are said to produce anti-fungal compounds ( $\mathrm{Xu}$ et al. 2007) and chitinolytic bacteria attacking fungi often also produce anti-fungal compounds (De Boer 1988).

\subsection{References}

Abdel-Sater MA, Hemida SK, Eraky SA and Nasser MM (1995) Distribution of fungi on two mite species and their habitats in Egypt. Folia Microbiol 40:304-313.

Aspaly G, Stejskal V, Pekár S and Hubert J (2007) Temperature-dependent population growth of three species of stored product mites (Acari: Acaridida) Exp Appl Acarol 42:37-46.

Asselt LV (1999) Interactions between domestic mites and fungi. Indoor Built Environ 8:216-220.

Baker EW, Kono T, Amrine JW, Delfinado-Baker M and Stasny TA (1996) Eriphyoid mites of the United States. Indira Publishing House, West Bloomfield, Michigan, USA, pp. 1-394.

Beecher TM, Magan N and Burton KS (2001) Water potentials and soluble carbohydrate concentrations in tissues of freshly harvested and stored mushrooms (Agaricus bisporus). Posthar Biol Technol 22:121-131.

Brodie HJ (1931) The oidia of Coprinus lagopus and their relation with insects. Ann Bot 45:315-344. 
Chang PK and Hua SST (2007) Molasses supplementation promotes conidiation but suppresses aflatoxin production by small sclerotial Aspergillus flavus. Lett Appl Microbiol 44:131-137.

Choh Y and Takabayashi J (2007) Predator avoidance in phytophagous mites: response to present danger depends on alternative host quality. Oecologia 151:262-267.

De Boer JG and Dicke M (2004) The role of methyl salicylate in prey searching behavior of the predatory mite Phytoseiulus persimilis. J Chem Ecol 30:255-271.

De Boer R (1988) Reflections on the control of mites and mite allergens. Allergy $53: 41-46$.

Debruyne M, Dicke M and Tjallingii WF (1991) Receptor cell responses in the anteriortarsi of Phytoseiulus persimilis to volatile kairomone components. Exp Appl Acar 13:53-58.

Duek L, Kaufman G, Palevsky E and Berdicevsky I (2001) Mites in fungal cultures. Mycoses 44:390-394.

Dusenbery DB (1992) Sensory ecology: How organisms acquire and respond to information. WH Freeman, New York, USA, pp.1-558.

Ellil AHA (1999) Oxidative stress in relation to lipid peroxidation, sclerotial development and melanin production by Sclerotium rolfsii. J Phytopath 147:561-566.

Franzolin MR, Gambale W, Cuero RG and Correa B (1999) Interaction between toxigenic Aspergillus flavus Link and mites (Tyrophagus putrescentiae Schrank) on maize grains: effects on fungal growth and aflatoxin production. J Stored Prod 35:215-224.

Georgiou CD (1997) Lipid peroxidation in Sclerotium rolfsii: a new look into the mechanism of sclerotial biogenesis in fungi. Mycol Res 101:460-464.

Gnanvossou D, Hanna R, Dicke M and Yaninek SJ (2001) Attraction of the predatory mites Typhlodromalus manihoti and Typholodromalus aripo to cassava plants infested by cassava green mite. Entomol Experim ET 101:291-298.

Granado JD, Kertesz-Chaloupková K, Aebi M and Kües U (1997) Restriction enzymemediated DNA intergration in Coprinus cinereus. Mol Gen Genet 256:28-36.

Grostal P and Dicke M (1999) Direct and indirect cues of predation risk influence behavior and reproduction of prey: a case for acarine interactions. Behav Ecol 10:422-427. 
Han JR, Zhao WJ, Gao YY and Yuan JM (2005) Effect of oxidative stress and exogenous $\beta$-carotene on sclerotial differentiation and carotenoid yield of Penicillium sp. PT95. Lett Appl Microbiol 40:412-417.

Hart BJ, Crowther D, Wilkinson T, Biddulph, P, Ucci M, Pretlove S, Ridley I and Oreszczyn T (2007) Reproduction and development of laboratory and wild house dust mites (Acari: Pyroglyphidae) and their relationship to the natural dust cosystem. J Med Entomol 44:568-574.

Hubert J, Stejskal V, Kubatova A, Munzbergova Z, Vanova M and Zd'arkova E (2003a) Mites as selective fungal carriers in stored grain habitats. Econom Entomol 97:2144-2153.

Hubert J, Stejskal V, Munzbergova Z, Kubatova A, Vanova M and Zd'arkova E (2003b) Mites and fungi in heavily infested stores in the Czech Republic. J Econom Entomol 97:2144-2153.

Hubert J, Jarosik V, Mourek J, Kubatova A and Zdarkova E (2004) Astigmatid mite growth and fungi preference (Acari: Acaridida): Comparisons in laboratory experiments. Pedobiol 48:205-214.

Hughes AM (1976) The mite of stored food and houses. Ministry Agr Fish. and Food (London), Technical Bull. 9

Jayashree T and Subramanyam C (2000) Oxidative stress as a prerequisite for aflatoxin production by Aspergillus parasiticus. Free Radic Biol Med 29:981-985.

Jiang Y, Ridsdill-Smith TJ and Ghisalberti EL (1997) The effect of volatile metabolites of lipid peroxidation on the aggregation of redlegged earth mites Halotydeus destructor (Acarina: Penthaleidae) on damaged cotyledons of subterranean clover. J Chem Ecol 23:163-174.

Kertesz-Chaloupková K, Walser PJ, Granado JD, Aebi M and Kües U (1998) Blue light overrides repression of asexual sporulation by mating type genes in the basidiomycete Coprinus cinereus. Fungal Genet Biol 23:95-109.

Kheradmand K, Kamali K, Fathipour Y and Goltapeh EM (2007a) Development, life table and thermal requirement of Tyrophagus putrescentiae (Astigmata: Acaridae) on mushrooms. J Stored Prod Res 43:276-281.

Kheradmand K, Kamali K, Fathipour Y, Goltapeh EM and Ueckermann EA (2007b) Thermal requirement for development of Sancassania rodionovi (Acari: Acaridae) on mushrooms. J Econom Entomol 100:1098-1103. 
Kleemann F (2007) Interaction between Coprinopsis cinerea and other microorganisms: effects on the laccase production. Master thesis. Faculty of Forest Ecology and Forest Sciences, Georg-August University of Göttingen, Göttingen, Germany.

Koide RT, Shumway DL and Stevens CM (2000) Soluble carbohydrates of red pine (Pinus resinosa) mycorrhizas and mycorrhizal fungi. Mycol Res 104:834-840.

Kojima T, Sakuma M, Fukui M and Kuwahara Y (2003) Spatial orientation of the mould mite, Tyrophagus putrescentiae (Schrank) (Acarina: Acaridae), in the computer-programmed olfactory field. J Acarol Soc Jpn 12:93-102.

Kües U (2000) Life history and developmental processes in the basidiomycete Coprinus cinereus. Microbiol Mol Biol Rev 64:316-353.

Kües U, James TY,Vilgalys R and Challen MP (2001) The chromosomal region containing pab-1, mip, and the $A$ mating type locus of the secondarily homothallic homobasidiomycete Coprinus bilanatus. Curr Genet 39:16-24.

Kües U, Polak E, Bottoli APF, Hollenstein M, Walser PJ, Boulianne RP, Hermann R and Aebi M (2002) Vegetative development in Coprinus cinereus. In: Molecular Biology of Fungal Development (HD Osiewacz, ed.), Marcel Dekker, New York, USA, pp. 133-164.

Maggio-Hall LA, Wilson RA and Keller NP (2005) Fundamental contribution of beta oxidation to polyketide mycotoxin production in planta. Mol Plant-Microbe Interac 18:783-793.

May GL, Chevanton Le and Pukkila PJ (1991) Molecular analysis of the Coprinus cinereus mating type $A$ factor demonstrated an unexpectedly complex structure. Genetics 128:529-538.

Morgan MS and Arlian LG (2006) Enzymatic activity in extracts of allergy-causing astigmatid mites. J Med Entomol 43:1200-1207.

My-Yen LT (1980) Pheromone study on Acarid mites. V. Presence of critral as a minor component of the alarm pheromone in the mold mite, Tyrophagus putrescentiae (Schrank, 1781) (Acarina: Acaridae). Appl Ent Zool 15:474-477.

Navarro-González M (2008) Growth fruiting body development and laccase production of selected coprini. $\mathrm{PhD}$ thesis. Georg-August University of Göttingen, Göttingen, Germany.

Okabe K, Miyazaki K and Yamamoto H (2001) Population increase in mushroom pest mites on cultivated Hypsozygus marmoreus and their vectoring of weed fungi between mushroom cultivation media. Japan J Appl Entomol Zool 45:75-81. 
Ortego F, Sanchez R I, Ruiz M and Castanera P (2000) Characterization of proteases from a stored product mite, Tyrophagus putrescentiae. Arch Insect Biochem Phys 43(3):116-124.

Polak E (1999) Asexual sporulation in the basidiomycete Coprinus cinereus. PhD thesis. ETH Zürich, Zürich, Switzerland.

Polak E, Aebi M and Kües U (2001) Morphological variations in oidium formation in the basidiomycete Coprinus cinereus. Mycol Res 105:603-610.

Ramos AJ, Magan N and Sanchis V (1999) Osmotic and matric potential effects on growth, sclerotia and partitioning of polyols and sugars in colonies and spores of Aspergillus ochraceus. Mycol Res 103(2):141-147.

Ree HI and Lee IY (1997) Development of mass rearing technique of Tyrophagus putrescentiae (Acari: Acaridae) found in house dust. Korean J Parasitol 35: $149-154$.

Rees D (2001) Mangement: A range of control methods may beat grain pests. Farming ahead 111:45-46.

Ritchie F, McQuilken MP and Bain RA (2006) Effects of water potential on mycelial growth, sclerotial production, and germination of Rhizoctonia solani from potato. Mycol Res 110:725-733.

Rohlfs M, Albert M, Keller NP and Kempken F (2007) Secondary chemicals protect mould from fungivory. Biol Lett 3:523-525.

Rühl M, Kilaru S, Navarro-González M, Hoegger P, Kharazipour A and Kües U (2007) Production of laccase and other enzymes for the wood industry. In: Wood production, wood technology and biotechnological impacts (U Kües, ed.), Universitätsverlag, Göttingen, Germany, pp. 469-507.

Ruther J and Steidle JLM (2000) Mites as matchmakers: semiochemicals from hostassociated mites attract both sexes of the parasitoid Lariophagus distinguendus. J Chem Ecol 26:1205-1217.

Sánchez-Ramo I, Hernández CA and Castañera P (2004) Proteolytic activities in body and faecal extracts of the storage mite, Acarus farris. Med Vet Entomol 18:378-386.

Sánchez-Ramos I and Castañera P (2001) Development and survival of Tyrophagus putrescentiae (Acari: Acaridae) at constant temperatures. Environ Entomol 30:1082-1089. 
Sánchez-Ramos I and Castañera P (2005) Effect of temperature on reproductive parameters and longevity of Tyrophagus putrescentiae (Acari: Acaridae). Exp Appl Acarol 36:93-105.

Sánchez-Ramos I and Castañera P (2007) Evaluation of low humidity treatments to control Acarus farris (Acari: Acaridae) in Cabrales cheese. Exp Appl Acarol 41:243-249.

Sánchez-Ramos I, Álvarez-Alfageme F and Castañera P (2007) Reproduction, longevity and life table parameters of Tyrophagus neiswanderi (Acari: Acaridae) at constant temperatures. Exp Appl Acarol 43:213-226.

Shi LB, Guttenberger M, Kottke I and Hampp R (2002) The effect of drought on mycorrhizas of beech (Fagus sylvatica L.): changes in community structure, and the content of carbohydrates and nitrogen storage bodies of the fungi. Mycorrhiza 12:303-311.

Skelton AC, Birkett MA, Pickett JA and Cameron MM (2007) Olfactory responses of medically and economically important mites (Acari: Epidermoptidae and Acaridae) to volatile chemicals. J Med Entomol 44:367-371.

Smrž J (2003) Microanatomical and biological aspects of bacterial associations in Tyrophagus putrescentiae (Acari: Acaridida). Exp Appl Acarol 31:105-113.

Smrž J (2004) Microanatomical and biological aspects of bacterial associations in Tyrophagus putrescentiae (Acari: Acaridida). Exp App Acarol 31:105-113.

Smrž J and Norton RA (2004) Food selection and internal processing in Archegozetes longisetosus (Acari: Oribatida). Pedobiol 48:111-120.

Smrž J, Svobodová J and Čatská V (1991) Synergetic participation of Tyrophagus putrescentiae (Schrank) (Acari: Acaridida) and its associated bacteria on the destruction of some soil micromycetes. J Appl Entomol 11:206-210.

Srivilai P (2006) Molecular analysis of genes acting in fruiting body development in basidiomycetes. PhD thesis. Georg-August University of Göttingen, Göttingen, Germany.

Schiestl FP, Steinebrunner F, Schulz C, von Reuss S, Francke W, Weymuth C, and Leuchtmann A (2006) Evolution of 'pollinator'-attracting signals in fungi. Biol Lett 2:401-404.

Stewart GA, Lake FR, and Thompson PJ (1991) Faecally derived hydrolytic enzymes from Dermatophagoides pteronyssinus: Physicochemical characterization of potential allergens. Int Arch Allergy Immunol 95:248-256. 
Swamy S, Uno I and Ishikawa T (1984) Morphogenetic effects of mutations at the $A$ and $B$ incompatibility factors in Coprinus cinereus. J Gen Microbiol 130:3219-3224.

Tereshina VM, Kovtunenko AV, Memorskaya AS and Feofilova EP (2004) Effect of carbohydrate composition of the cytosol of Aspergillus niger conidia on their viability during storage. Appl Biochem Microb 40:454-459.

Thakeow P (2008) Development of a basic biosensor system for wood degradation using volatile organic compounds. $\mathrm{PhD}$ thesis. Georg-August University of Göttingen, Göttingen, Germany.

Thakeow P, Holighaus G and Schütz S (2007) Volatile compounds for wood assessment. In: Wood production, wood technology and biotechnological impacts. (U Kües, ed.), Universitäsverlagverlag, Göttingen, Germany, pp. 197-228.

Tsai SY, Tsai HL and Mau JL (2007) Nonvolatile taste components of fruit bodies and mycelia of shaggy ink cap mushroom Coprinus comatus (OF Mull: Fr.) pers. (Agaricomycetideae). Int J Med Mush 9:47-55.

Vanhaelen M, Vanhaelen-Fastré R and Geeraerts J (1978a) Volatile constituents of Trichothecium roseum. Sabouraudia 16:141-150.

Vanhaelen M, Vanhaelen-Fastré R and Geeraerts J (1980) Occurrence in mushrooms homobasidiomycetes) of cis-octa-1,5-dien-3-ol and trans-octa-1,5-dien-3-ol, attractants to the cheese mite Tyrophagus putrescentiae (schrank) (Acarina: acaridae). Experientia 36:406-407.

Vanhaelen M, Vanhaelen-Fastré R and Geeraerts J and Wirthlin T (1978b) Cis-and trans-octa-1,5-dien-3-ol, new attractants to the cheese mite Tyrophagus putrescentiae (Schrank) (Acarina, Acaridae) identified in Trichothecium roseum (Fungi Imperfecti). 23:199-212.

Walser PJ, Hollenstein M, Klaus MJ and Kües U (2001) Genetic analysis of basidiomycete fungi. In: Molecular and cell biology of filamentous fungi: A practical approach (NJ Talbot, ed.), Practical Approach Series, IRL Press, Oxford, England, pp. 59-90.

Waters H, Moore D and Butler RD (1975) Morphogenesis of aerial sclerotia of Coprinus lagopus. New Phytol 74:207-213.

Wijk M, Wadman WJ and Sabelis MW (2007) Morphology of the olfactory system in the predatory mite Phytoseiulus Persimilis. Exp Appl Acarol 40:217-229. 
$\mathrm{Xu}$ D, Xia XY, Xu N and An L (2007) Isolation and identification of a novel endophytic bacterial strain with antifungal activity from the wild blueberry Vaccinium uliginosum. Annals Microb 57:673-676.

Zahedi-Golpayegani A, Saboori A and Sabelis MW (2007) Olfactory response of the predator Zetzellia mali to a prey patch occupied by a conspecific predator. Exp Appl Acarol 43:199-204. 
CHAPTER 5

\section{Volatile production during \\ development of Coprinopsis cinerea}

I greatly appreciate Dr. Prodpran Thakeow for her kind co-operation in the identification of volatile organic compounds (VOCs) emitted during development of Coprinopsis cinerea by training me to analyse VOCs with a GC/MS and for teaching me how to transfer and present GC/DC data in chromatograms in the Excell programme. I very much appreciate Dr. Christof Köhler for his advice on how to present the results in curve diagrams. 


\subsection{Abstract}

Emission of volatile organic compounds (VOCs) during fruiting body development of Coprinopsis cinerea was examined in glass vials under standard fruiting conditions $\left(28^{\circ} \mathrm{C}, 85-90 \%\right.$ humidity, $12 \mathrm{~h}$ light $/ 12 \mathrm{~h}$ dark regime) after previous growth of the cultures at $37^{\circ} \mathrm{C}$. Cultures of $C$. cinerea homokaryon AmutBmut were grown on agar slants of YMG/T complete medium in 60-ml vials with loosely closed septum-caps allowing aeration. By headspace (HS) analysis, VOCs were collected under passive sampling with solid phase microextraction (SPME) to identify the VOCs emitted during the different stages in fruiting body development of $C$. cinerea. Rapid identification and characterization of volatiles were accomplished by using gas chromatography and mass spectrometry (GC/MS). Four odorous compounds were identified: the C8-compounds 1-octen-3-ol and 3-octanone and the sesquiterpenes $\beta$-himachalene and cuparene, respectively. The C8-compounds were produced in higher amounts during early stages of fruiting body development and their production decreased when the fruiting bodies maturated. In contrast, only tiny amounts of the sesquiterpences were detected during early stages of fruiting and their production increased at the stage of fruiting body maturation. Moreover, this study shows that intact vegetative mycelium of various C. cinerea strains produced only low amounts of the C8-compounds and tiny amounts of the sesquiterpenes whereas wounding causes a dramatic increase in the production of all four VOCs. Similarly, maceration of fruiting body stipes leads to a strong increases in production of the VOCs.

Key Words: Coprinopsis, Basidiomycetes, glass vial, odorous compounds, fruiting body VOCs, GC/MS (gas chromatography/mass spectrometry), SPME (solid phase micro extraction), abundance, TIC (total ion current), C8-compounds (carbon eightcompounds), 1-octen-3-ol, 3 -octanone, sesquiterpernes, $\beta$-himachalene, cuparene 


\subsection{Introduction}

Edible mushrooms are known to evapourate specific odors that make them appetizing and attractive as addendums for the tasting food (Kinderlerer 1989, Pfeil and Mumma 1993, Schnürer et al. 1999). Back to the 1950s, researchers attempted to determine the potential of natural flavors from fruiting body (mushroom) production (Sugihara and Humfeld 1954). Eventually, the main volatile flavor compounds of edible mushrooms such as Volvariella volvacea or Tricholoma matsutake as well of the vegetative fungal mycelium of edible species were found to be 1-octen-3-ol and other related eight-carbon aliphatic oxygenated compounds (Mau et al. 1997, Nidiry 2001, Wu et al. 2005, Combet et al. 2006, Cho et al. 2007, 2008). Other VOCs described from mushrooms include $p$-anisaldehydes as sweet flavor compounds in Pleurotus ostreatus (Okamoto 2002) as well as myrcene being a sexual hormone of mites (Krings et al. 2008), various sweet, floral, green and citrus compounds in T. matsutake (Cho et al. 2008), sulfur compounds in the garlic mushroom Marasmius alliaceus (Rapior et al. 1997), various types of terpenes that occur in species-specific distributions (Breheret et al. 1997) or benzaldehydes and aliphatic alcohols (Kawabe and Morita 1993). Production of volatile organic compounds (VOCs) were followed up by using an electronic nose system in Agaricus species and other homobasidiomycetes and found to discriminate the analysed species (Keshri et al. 2003). Moreover, production of VOCs can differ during development or even between stipe and cap tissues of the same mushroom (Cho et al. 2008). In the mycorrhizal ascomycete Tuber borchii, synthesis of specific VOCs is observed during fruiting body development. At a particular stage of maturation, 1-octen-3-ol, aromadendrene, $\alpha$-farnesene and other terpenoid compounds were detected giving particular information on progress in the life cycle of $T$. borchii (Zeppa et al. 2004, reviewed in Thakeow et al. 2007).

Here, the production of VOCs through the life cycle of the model basidiomycete Coprinopsis cinerea is analysed. C. cinerea is an easy to culture species that fruits easily in the laboratory and completes it whole life cycle within two weeks (Kües 2000, compare Chapters 2 and 3 of this thesis). Technically for determination of production of VOCs, volatiles need to be sampled without any other contaminating compound and analysed for rapid identification and characterization by using gas chromatography and mass spectrometry (GC/MS) (e.g. see Keshri et al. 1998, 2001). It was therefore necessary to establish a suitable method allowing $C$. cinerea to grow and fruit in specific vials that could serve in volatile sampling. VOCs released during fruiting body 
development of cultures in glass vials were then investigated by GC/MS in cooperation with P. Thakeow from the former Institute of Forest Zoology and Forest Conservation (now section Forest Zoology and Forest Conservation of the Büsgen-Institute).

\subsection{Materials and methods}

\subsubsection{Strains and growth conditions}

The self-compatible C. cinerea homokaryon AmutBmut (A43mut, B43mut, pab1-1) forming fruiting bodies without mating to another strain (Swamy et al. 1984, KerteszChaloupková et al. 1998, Boulianne et al. 2000) was used in this study on fungal VOCs as well as its co-isogenic monokaryons PS001-1 (A42, B42) and PS002-1 (A3, B1) (Srivilai 2006), the dikaryon PS001-1 x PS002-1 formed by mating of these two strains and the mutants UFO1 (A43mut, B43mut, pab1-1, eln) (Srivilai 2006) and PUK1-2 (A43mut, B43mut, pab1-1, dst1-2), PUK1-6 (A43mut, B43mut, pab1-1, dst1-2), PUK2-2 (A43mut, B43mut, pab1-1, dst2-1), PUK2-6 (A43mut, B43mut, pab1-1, dst2-1), PUK3 (A43mut, B43mut, pab1-1, dst3-1) and PUK4 (A43mut, B43mut, pab1-1, dst4-1) (Chapter 3 of this thesis).

For determinations of VOCs during fungal development, strain AmutBmut was first grown on $9 \mathrm{~cm}$ in $\varnothing$ Petri-dishes with YMG/T medium $(0.4 \%$ yeast extract, $1 \%$ malt extract, $0.4 \%$ glucose, $0.01 \%$ tryptophan, solidified by addition of $1 \%$ agar; Granado et al. 1997) under standard culturing ( 5 days at $37^{\circ} \mathrm{C}$ in the dark) and fruiting conditions (12 h light/12 h dark rhythm, $28^{\circ} \mathrm{C}, 85-90 \%$ humidity) (Granado et al. 1997, see Chapters 2 and 3 of this thesis). Subsequently, glass vials were chosen in order to avoid any VOCs that might be emitted from the plastic. Strain AmutBmut was inoculated on YMG/T agar slants in 60-ml glass vials having a diameter of $2.4 \mathrm{~cm}$ (CSChromatographie Service GmbH, Langerwehe, Germany). Vials were loosely closed with septum-caps allowing aeration during growth of the fungus. If not otherwise mentioned, $20 \mathrm{ml}$ agar medium was used to produce the agar slants within the glass vials. Upon filling the agar into the tubes, they were laid down onto a support (Fig. 1A) in an angle of 13 degree to allow by solidification of the agar under formation of a surface of agar being $11 \mathrm{~cm}$ in length. In experiments where $10 \mathrm{ml}$ of medium was used, the agar surface length was $8 \mathrm{~cm}$. Mycelial plugs $(4 \mathrm{~mm}$ x $4 \mathrm{~mm}$ ) from YMG/T pre-cultures serving as inoculi were placed at different positions onto the surface of YMG/T slants according to the need of experiment: when $20 \mathrm{ml}$ agar was used, plugs 


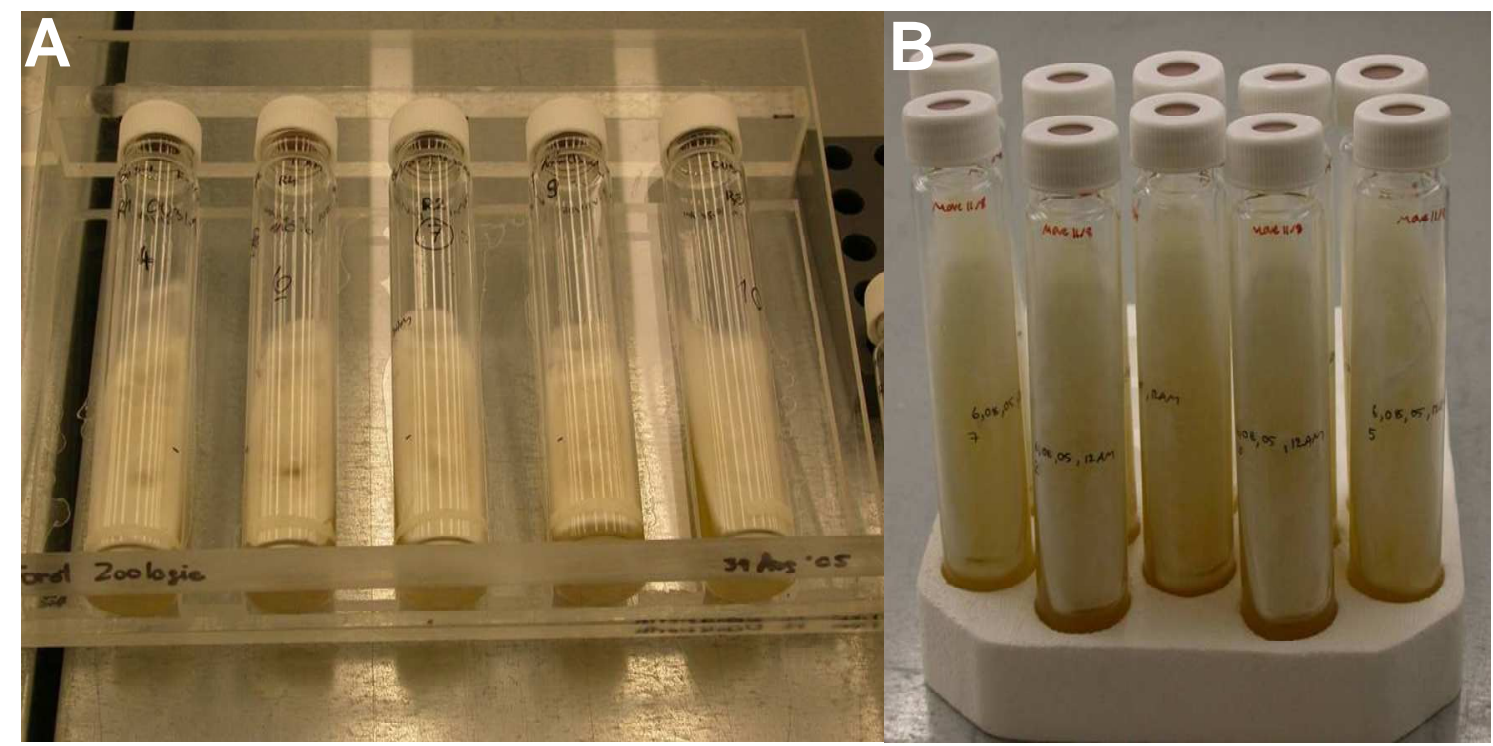

Fig. 1 Horizontal and vertical incubation of Coprinopsis cinerea homokaryon AmutBmut grown on $20 \mathrm{ml}$ YMG/T agar slants in glass vials first for 5 days at $37^{\circ} \mathrm{C}$ followed by incubation for about 13 to 21 days (horizontal incubation; (A) or 17 to 21 days (vertical incubation; (B) in standard fruiting conditions at $28^{\circ} \mathrm{C}$ until fruiting body development was completed. Note that the septum-caps of the vials were only loosely closed to allow oxygen supply for the fungus. Furthermore, note that the supply shown in (A) was also used for the preparing agar slants by cooling down after filling warm liquid agar into the vials.

were either deposited $1.5 \mathrm{~cm}$ apart from the outer bottom of the agar surface, or directly in the middle of the agar surface or $1.5 \mathrm{~cm}$ apart from the upper top of the agar surface; when $10 \mathrm{ml}$ was used, plugs were either deposited $1.5 \mathrm{~cm}$ apart from the outer bottom of the agar surface, or directly in the middle of the agar surface $(3 \mathrm{~cm}$ apart from the outer bottom) or $1.5 \mathrm{~cm}$ apart from the upper top of the agar surface $(4.5 \mathrm{~cm}$ apart from the outer bottom). Vials were first incubated for either 5 days ( $20 \mathrm{ml}$ agar experiments) or 4 days ( $10 \mathrm{ml}$ agar experiments) at $37^{\circ} \mathrm{C}$ in the dark before they were transferred into standard fruiting conditions ( $12 \mathrm{~h} \mathrm{light} / 12 \mathrm{~h}$ dark rhythm, $28^{\circ} \mathrm{C}, 85-90 \%$ humidity) into a climate chamber. Vials were incubated throughout the experiments either horizontally or vertically (Fig. 1A and B) to define the best way of fruiting body development within the narrow glass vials. Respective developmental stages in the fruiting body pathway were defined by outer morphological characteristics as described earlier (NavarroGonzález, 2008; see also Chapter 2 of this thesis). Per experiment, 3 to 5 different vials were analysed. Upon optimizing the growth and fruiting conditions in the glass vials, these optimized conditions were adopted also for VOC tests of other strains (see above). A final experiment with strain AmutBmut on $10 \mathrm{ml}$ agar slants in vials were performed 
with incubating the fungus in an incubator (Ernst Schütt jun., Laborgerätebau, Göttingen, Germany) first for four days at $37^{\circ} \mathrm{C}$ in constant dark and then for 7 days under fruiting conditions $\left(28^{\circ} \mathrm{C}, 12 \mathrm{~h}\right.$ light $/ 12 \mathrm{~h}$ dark rhythm). Moisture was kept high by putting a $60 \times 30 \mathrm{~cm}$ sized container into the incubator and filling it with water to a level of about $2 \mathrm{~cm}$ for evaporation of humidity.

\subsubsection{Volatile organic compounds (VOCs) sampling by solid phase micro- extraction (SPME) and gas chromatography/mass spectrometry (GC/MS)}

VOCs emitted during fungal development into the headspace of the glass vials were collected by SPME (solid phase micro extraction) using $85 \mu \mathrm{m}$ Carboxen ${ }^{\mathrm{TM}} /$ Polydimethylsiloxane (PDMS) StableFlex ${ }^{\mathrm{TM}}$ fibre type (Supelco, USA) housed inside a metal needle. Before usage, fibres were cleaned and sterilized by exposing the SPME needles into the injection port of a gas chromatograph at $250^{\circ} \mathrm{C}$ for $5 \mathrm{~min}$. Note, that in this study either one of two GCs of the model HP 6890N, Agilent Technologies, Paolo Alto, USA at the section Forest Zoology and Forest Conservation of the BüsgenInstitute of the Georg-August-University of Göttingen were used which in this thesis are arbitrarily called no. 1 and no. 2 since they slightly differ in the retention-times of a given compound: Within the GC no. 1, a GC column was separated in two capillaries, one leading to a mass spectrometer, the other to an EAG (electroantennogram) setup (for measurements with insect antennae). In contrast in GC no. 2, no EAG setup was installed and therefore, the flow conditions were slightly different altering somewhat the retention time of the spectrums. In both GCs, volatile compounds were detected with a 5973 mass spectrometer, Agilent Technologies.

After cleaning for capturing volatiles emitted by a fungal culture, SPME needles were then aseptically inserted through the septa of the caps of the glass vials which directly beforehand were tightly closed (Fig. 2). Needles were kept for exactly $24 \mathrm{~h}$ in the vials (in exceptional cases for $3 \mathrm{~h}$ as mentioned in the results) for subsequent chemical analysis of compounds bound. Each tube was only tested once for emission of VOCs. To follow up the complete fungal developmental pathway, per day new cultures were treated with cleaned and sterilized SPME needles. Per developmental stage to be analysed, three different vials were treated with SPME needles. Per day, each three vials with YMG/T agar without fungi were used in parallel for control. 


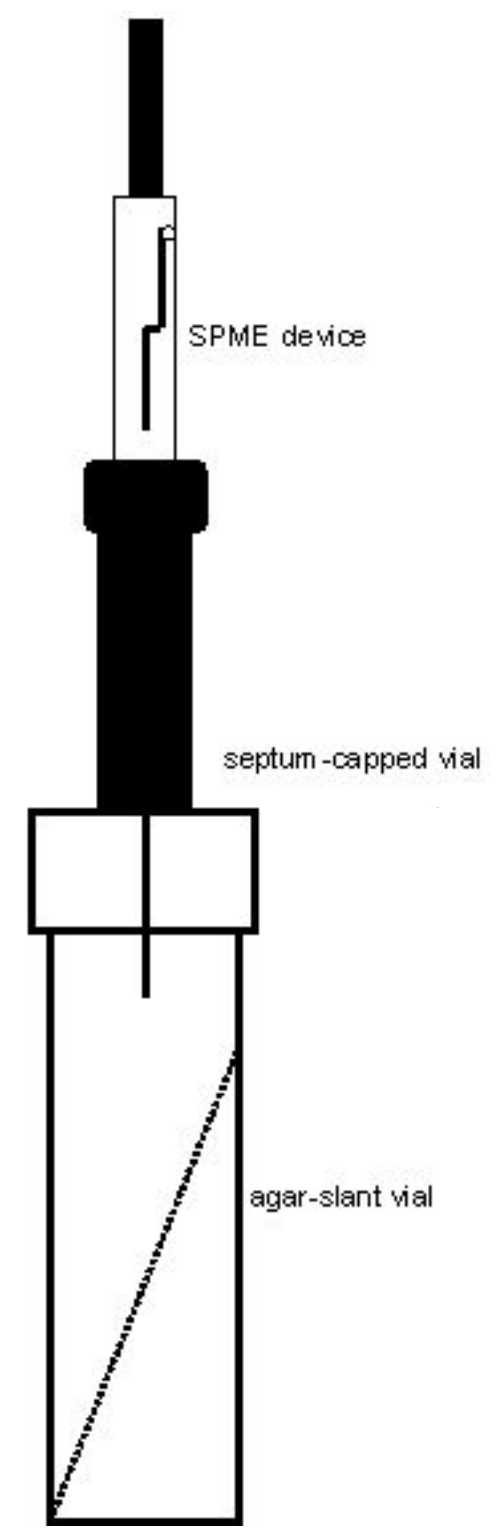

Fig. 2 SPME volatile sampling method. A needle with a SPME fibre $(85 \mu \mathrm{m}$ Carboxen $^{\mathrm{TM}} /$ Polydimethylsiloxane (PDMS) StableFlex ${ }^{\mathrm{TM}}$ fibre type) is injected with the help of a SPME device for a fixed time into the headspace of a glass vial in which Coprinopcis cinerea grow on an YMG/T agar slant. Diagram modified from Thakeow (2008).

Analysis of VOCs was performed with either one of the two MS-coupled HP 6890N GCs at the section Forest Zoology and Forest Conservation of the Büsgen-Institute of Georg-August-University of Göttingen. The column used for compound separation was every time a non polar type, HP-5MS column (Agilent Technologies, Paolo Alto, USA), $30 \mathrm{~m} \times 0.25 \mathrm{~mm}$ in $\varnothing, 0.25 \mu \mathrm{m}$ film thickness. The volatile-loaded SPME fibres were inserted into the injection port $\left(250^{\circ} \mathrm{C}\right)$ upon which the desorbed volatiles were run through thecolumn with helium as a carrier gas at a flow rate of $1.0 \mathrm{ml} \mathrm{min}^{-1}$. The temperature programme started at $40^{\circ} \mathrm{C}$, held for $1.5 \mathrm{~min}$, heated with a rate of 
$6.0^{\circ} \mathrm{C} \mathrm{min}^{-1}$ to $200^{\circ} \mathrm{C}$ and held at this temperature for $5 \mathrm{~min}$. The MS was operated in the scan mode in a range of 20-300 amu (atomic mass units), a source temperature of $230^{\circ} \mathrm{C}$, and $\mathrm{EI}$ (electron ionization) mode at $70 \mathrm{eV}$. A preliminary interpretation of the chromatograms were carried out by matching mass spectra with Enhanced Chemstation version D00.00.38 (Agilent Technologies, Paolo Alto, USA), the Mass Spectral Search library of the National Institute of Standards and Technology (NIST, Gaithersburg, USA), and the database of Massfinder version 3.0 software together with the library “Terpenoids and Related Constituents of Essential Oils"' (Hochmuth, König, Joulain, Hamburg, Germany). The interpretation was confirmed by evaluating mass spectra and retention times with those of authentic standards. The quantification of major constituents was done by five-point calibration of standard compounds and evaluation of peak areas in the selected ion monitoring mode.

\subsection{Results and discussion}

\subsubsection{Defining best conditions for fruiting of $C$. cinerea on glass vials}

First, VOC sampling tests were performed with strain AmutBmut grown on normal $9 \mathrm{~cm}$ in $\varnothing$ Petri-dishes (YMG/T medium, 5 days at $37^{\circ} \mathrm{C}$ in the dark) under standard fruiting conditions $\left(12 \mathrm{~h}\right.$ light/12 h dark rhythm, $28^{\circ} \mathrm{C}, 85-90 \%$ humidity; Granado et al. 1997, see also Chapters 2 and 3 of this thesis). The septum-caps were slightly opened and the SPME needles were inserted inside the plates. However, upon GC/MS analysis high levels of contaminants were encountered that were believed to come from the plastic material of the Petri-dishes. Accordingly, the standard set-up of fruiting experiments with $C$. cinerea was not applicable and new growth and fruiting conditions free of contaminating VOCs had to be determined.

Subsequently, glass vials were chosen in order to avoid as much as possible any VOCs that might be emitted from plastics. It had however to be noted that also the septum-caps of the glass vials were emitting some contaminating VOCs why first an empty vial had to be tested. Subsequently in SPME experiments with YMG/T agar slants with and without fungi, background VOCs coming from the septum-cap were then neglected and just VOCS coming from the agar and from the fungus were compared with each other. In a first larger set of experiments for determination best fruiting conditions in glass vials for detection of VOCs during the fruiting body 
development, $C$. cinerea homokaryon AmutBmut was grown on $20 \mathrm{ml}$ YMG/T medium in glass vials in a vertical direction (compare Fig. 1B) with loosely closed caps, thereby using and comparing three different positions of inoculation (top, middle, bottom of the agar slant). For each type of inoculation, five different tubes were prepared. All tubes were grown for 5 days at $37^{\circ} \mathrm{C}$ before transferring them into standard fruiting conditions (Fig. 3 and Fig. 4). Initially, there was no major difference in development between the different types of inoculations in glass tubes and on Petri-dishes over the time up to primordia stage 4 (compare Chapter 2 of this thesis) upon which development in all glass vials arrested (Fig. 3 and Fig 4). At a later stage (day 17 of incubation under standard fruiting conditions), finally mature mushrooms were observed in cultures, likely from newly formed primordia (Fig. 3 and Fig. 4). Comparison of the different types of inoculation (top, middle, bottom of the agar slant) suggested that inoculation in the middle could be best (Fig. 4). Primordia developed always closely around the inoculum when positioned at the top or at the middle of the agar slant (Fig. 4A, B, D and E). However, when the inoculum was positioned at the top of the agar slant, primordia easily aborted as a consequence of that the upper region in the tubes easily dried out due to the slim agar layer (Fig. 4A and D). When the inoculum was placed in the middle of the agar slant, the growth of mycelium occurred rather evenly over the agar slant (Fig. 4B) and developing mushrooms had enough air space to grow up to the septum-cap (Fig. 4E). When the inoculum was placed at the bottom of the agar slant, mycelial growth on the glass walls was encountered in parallel to the process of slowly covering the agar surfaces by the growing mycelium (Fig. 4C). Primordia development started at various places with favouring primordia at the top of the agar slant to develop further, although they also easily aborted due to drying out of the thin agar layer beneath (Fig. 4F).

In a second larger set of experiments of growing strain AmutBmut on YMG/T agar slants in glass vials, therefore only the middle place of inoculation was further considered. In this second experiment, horizontal and vertical positions of the glass vials during incubation were compared with each other as well as different amounts of agar medium (10 and $20 \mathrm{ml}$ ) combined with a different period of time for growth at $37^{\circ} \mathrm{C}$ (see scheme shown in Fig. 3). Generally, fungal development up to completion of fruiting body development was faster in horizontal incubation, regardless of the amount of medium used. Horizontal cultivation conditions were therefore chosen for all tests of VOC emissions during fruiting body development (see below). When using $10 \mathrm{ml}$ of 


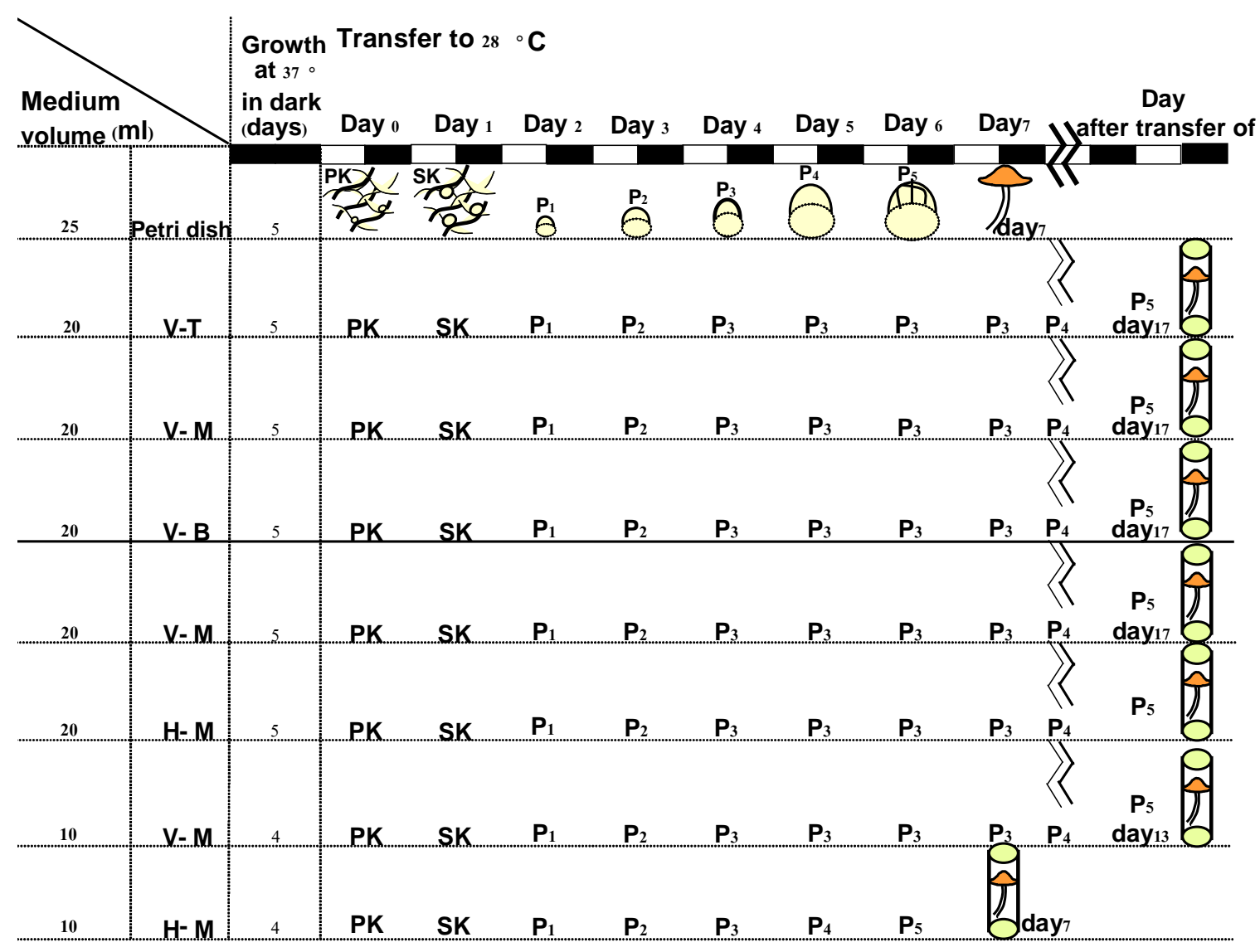

Fig. 3 Scheme explaining the progress in fruiting body development in initial experiments of keeping the Coprinopsis cinerea strain AmutBmut in a glass vial allowing a low level of aeration through a loosely closed cap. The broader black and white line at the top of the figure and the row below with the various symbols for developmental stages present the time course of events that is normally observed on Petri-dishes filled with $25 \mathrm{ml} \mathrm{YMG/T}$ plates under standard growth and fruiting conditions (compare Chapter 2 of this thesis) - dark phases in this time course are indicated by black boxes and light phases by non-filled boxes above the symbols. The next three lines document by abbreviations the progress in development over the time for the fungus when grown in glass vials containing $20 \mathrm{ml}$ YMG/T agar slants that were incubated in vertical direction throughout the experiment but inoculated at different positions on the agar slant. The last four lines compare the progress of development over the time of the fungus in a set of experiments where the vials were either kept horizontal and vertical throughout the incubation period and where either 20 or $10 \mathrm{ml}$ of YMG/T medium and different times of vegetative growth at $37^{\circ} \mathrm{C}$ were used. Abbreviations used for inoculation and incubation conditions: T, M, and B, inoculation at the top, the middle and the bottom of the agar slant, respectively; $\mathrm{V}$ and $\mathrm{H}$, vertical and horizontal incubation, respectively (see Material and methods). Abbreviations used for developmental stages: PK, primary hyphal knot; SK, secondary hyphal knot; P1 to P5, primordia stage 1 to primordia stage 5, respectively (compare Fig. 1 in Chapter 2 of this thesis). Mature fruiting bodies are indicated by the mushroom symbol, in cases of cultivation in glass vials by the mushroom symbol within a container. 

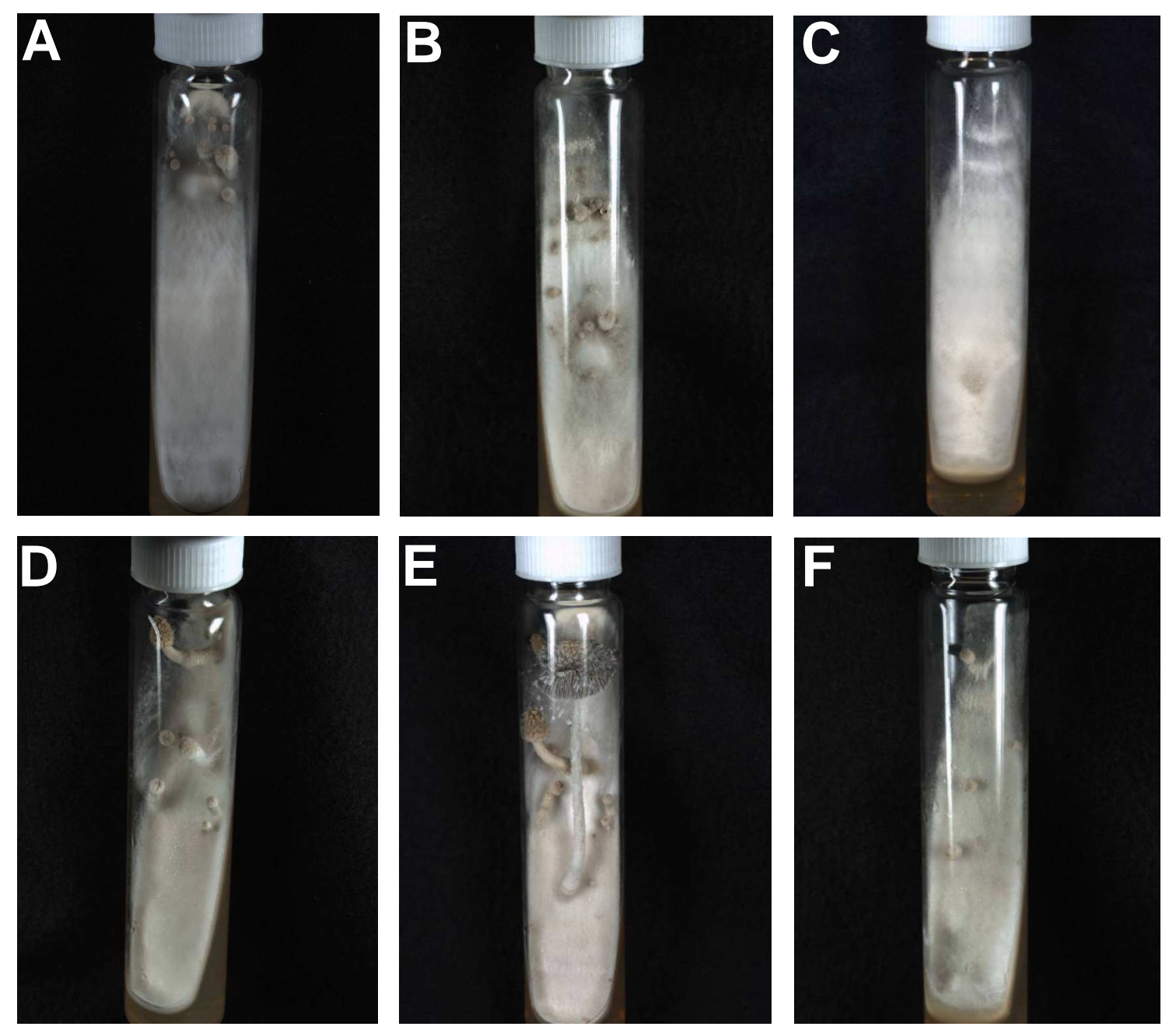

Fig. 4 Comparison of effects of the place of inoculation on YMG/T agar slants on fruiting body development of strain AmutBmut in glass vials. (A) and (D): inoculation at the top of the agar slant; $(\mathbf{B})$ and $(\mathbf{E})$ : inoculation at the middle of the agar slant; $(\mathbf{C})$ and $(\mathbf{F})$ : inoculation at the bottom of the agar slants. Upon inoculation, the cultures were first grown for 5 days at $37^{\circ} \mathrm{C}$ before transferring into standard fruiting conditions (compare lines 3 to 5 in the scheme given in Fig. 3). The culture shown in (A) was photographed on day 10 of cultivation after transfer into standard fruiting conditions, the cultures shown in $(\mathbf{B}),(\mathbf{C}),(\mathbf{D})$ and $(\mathbf{F})$ on day 12 of cultivation after transfer into standard fruiting conditions, and the cultures shown in (E) on day 17 of cultivation.

agar and an incubation period for 4 days at $37^{\circ} \mathrm{C}$, the pathway of fruiting body development was identical to that commonly seen on Petri-dishes with obtaining mature mushroom seven days after transfer into standard fruiting conditions (Fig. 3 and Fig 5). Fig. 5 and Fig. 6 document in photographs that under horizontal incubation mushrooms can mature with basidiospore formation. The frequency of primordia formation was better with only $10 \mathrm{ml}$ agar (Fig. 5A and B), probably because these tubes were only 4 days incubated at $37^{\circ} \mathrm{C}$ unlike the tubes with $20 \mathrm{ml}$ agar that were 5 days incubated at 

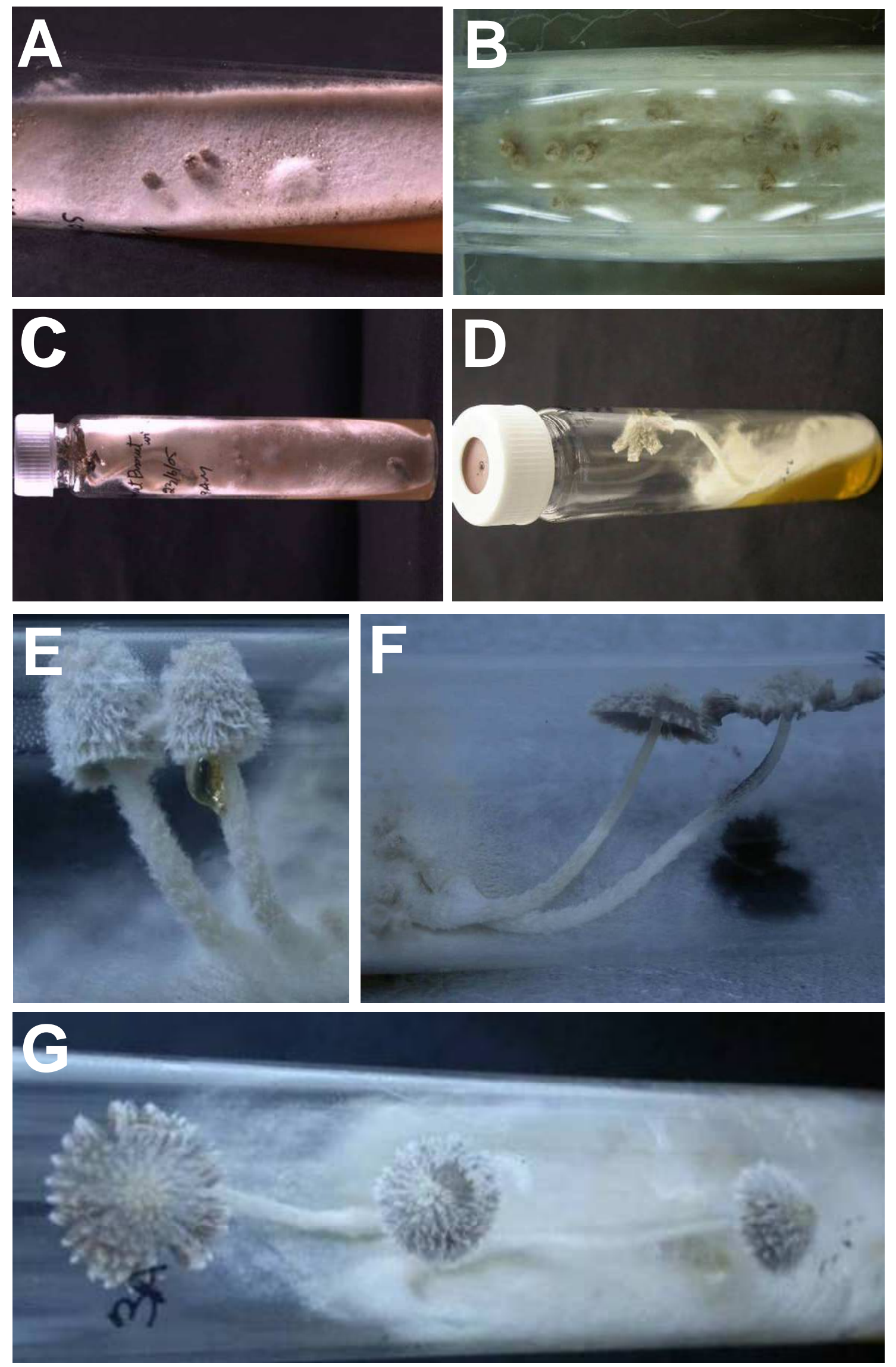

Fig. 5 Fruiting body development during horizontal cultivation in slant YMG/T agar cultures. (A), (C): $20 \mathrm{ml}$ agar and 5 days growth at $37^{\circ} \mathrm{C}$ prior to transfer into standard fruiting 
conditions; (B), (D) to (G): $10 \mathrm{ml}$ agar and 4 days growth at $37^{\circ} \mathrm{C}$ prior to transfer into standard fruiting conditions) in $60 \mathrm{ml}$ glass vials with loosely closed septum-caps allowing aeration. In every case, the inoculum was positioned in the middle of the slants. (A) Homokaryon AmutBmut stopped development at primordia stage 4 (compare Fig. 1 in Chapter 2) probably due to desiccation of the agar beneath at day 6 of cultivation under standard fruiting conditions (photographed in the morning at the start of the light period). (B) Primordia of stage 5 grown on $10 \mathrm{ml}$ agar on day 6 of cultivation under standard fruiting conditions (photographed in the morning at the start of the light period) - note the higher number of primordia that were likely formed by the shorter incubation time at $37^{\circ} \mathrm{C}$ causing less desiccation of the agar beneath. $(\mathbf{C})$ At day 13 of incubation under standard fruiting conditions, in 3 out of 5 tubes a mushroom developed following new primordia formation (photographed in the morning at the start of the light period). (D) At day 7 of development, mature mushrooms were observed in 5 out of 5 tubes filled with $10 \mathrm{ml}$ agar (photographed in the morning at the start of the light period). (E) Maturating fruiting bodies photographed at the end of the light period at day 6 of cultivation and $(\mathbf{F})$ and $(\mathbf{G})$ mature fruiting bodies with basidiospores at day 7 of incubation under standard fruiting conditions (photographed in the morning at the start of the light period).

$37^{\circ} \mathrm{C}$. With $20 \mathrm{ml}$ agar in the glass vials, mature fruiting bodies were obtained on day 13 of incubation after new primordia formation in some but not all inoculated tubes (Fig. 5A and C) whereas in all tubes containing only $10 \mathrm{ml}$ medium, mature mushrooms appeared already at day 7 of incubation under standard fruiting conditions (Fig. 5D to G, Fig. $6 \mathrm{~A}$ and B). Therefore, after a first set of experiments using cultures in glass vials with $20 \mathrm{ml}$ YMG/T agar, finally all further emission of VOCs experiments were performed with only $10 \mathrm{ml}$ of YMG/T agar. Furthermore, the established cultivation conditions with $10 \mathrm{ml}$ YMG/T agar in glass vials with loosely closed caps leading to reliable fruiting of homokaryon AmutBmut (4 days growth in the dark at $37^{\circ} \mathrm{C}, 7$ days growth under standard fruiting conditions) were successfully tested on mutants of the homokaryon having defects in fruiting body development. As on Petri-dishes (compare Chapter 3 of this thesis), mutants PUK1-2, PUK2-2, PUK3 and PUK4 formed etiolated stipes after mycelial growth for 4 days at $37^{\circ} \mathrm{C}$ and the transfer of the glass vials to standard fruiting conditions (Fig. 6C to F), whereas mutant UFO1 being defective in stipe elongation formed under such conditions of culturing dumpy mushrooms with short stipes (Fig. 6G and $\mathrm{H}$ ) as seen previously seen for the strain on Petri-dishes (Srivilai et al. 2005, Srivilai 2006, Kües et al. 2007). 

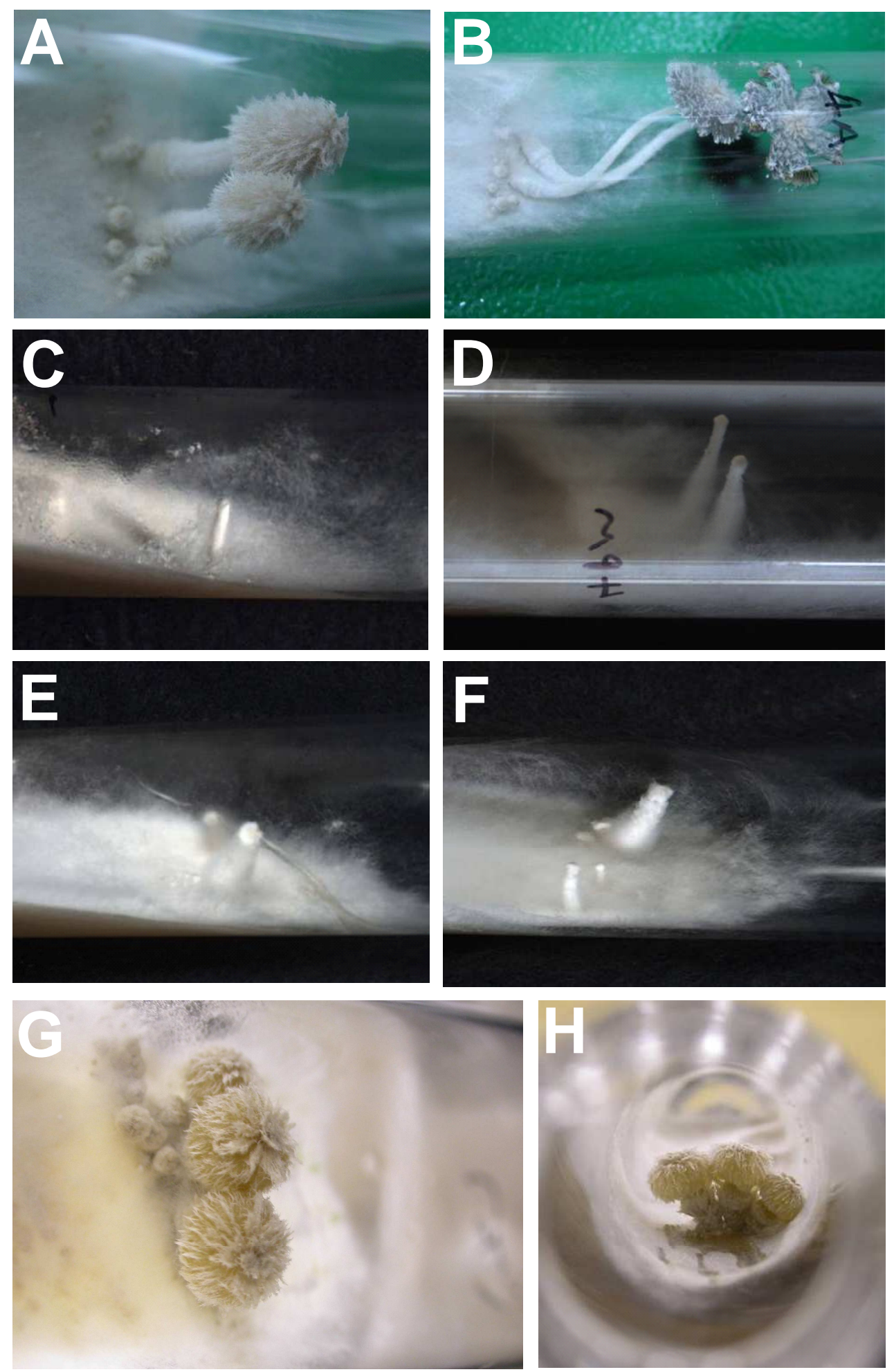

Fig. 6 Fruiting body development on $10 \mathrm{ml}$ agar in glass vials with loosely closed caps. (A) Homokaryon AmutBmut at the end of the light period at day 6 of cultivation after transfer into standard fruiting conditions and $(\mathbf{B})$ in the morning at the beginning of the light phase of day 7 of incubation under standard fruiting conditions. The same structures as in Fig. $5 \mathrm{E}$ and $\mathrm{F}$ are shown but from another view for better comparison with structures developing on agar slant cultures with various mutant strains. (C) Mutant PUK1-2 at day 5 of incubation after transfer into standard fruiting conditions, (D) mutant PUK2-2 at day 5 of incubation after transfer into standard fruiting conditions, and (E) mutant PUK3, (F) mutant PUK4 and (G) and (H) mutant UFO1 at day 7 of incubation after transfer into standard fruiting conditions. Note that in $(\mathbf{H})$ that the same culture shown in $(\mathbf{G})$ was photographed through the opening of the glass tube. 


\subsubsection{Identification of VOCs of homokaryon AmutBmut emitted during fruiting body development in glass vial cultures.}

Emissions of VOCs were determined in the year 2005 in a first set of experiments of cultures of homokaryon AmutBmut which were grown on $20 \mathrm{ml} \mathrm{YMG/T} \mathrm{slant} \mathrm{agar} \mathrm{in}$ glass vials in horizontal positions. After five days incubation at $37^{\circ} \mathrm{C}$ in the darkness, the cultures were transferred into standard fruiting conditions $(12 \mathrm{~h} \mathrm{light} / 12 \mathrm{~h}$ dark rhythm, $28^{\circ} \mathrm{C}, 85-90 \%$ humidity). All VOCs emitted by strain AmutBmut during fruiting body development were sampled by using the SPME technique as described in Materials and methods and the sampled VOCs were subsequently analysed by GC/MS. Fig. 7 shows the results of this analysis in form of GC-chromatograms for some of the developmental stages in fruiting body development (note that the process of fruiting body development in the glass vials was not as synchronous as described in Chapter 2 for fruiting body development in Petri-dishes - see Fig. 1 of the respective chapter; further information in the legend of Fig. 7). VOCs were detected throughout the whole fungal development but in changing amounts.

C8-compounds (identified by P. Thakeow as 1-octen-3-ol and 3-octanone, personal communication), being typical mushroom odour compounds (Ohta 1983, Rapior

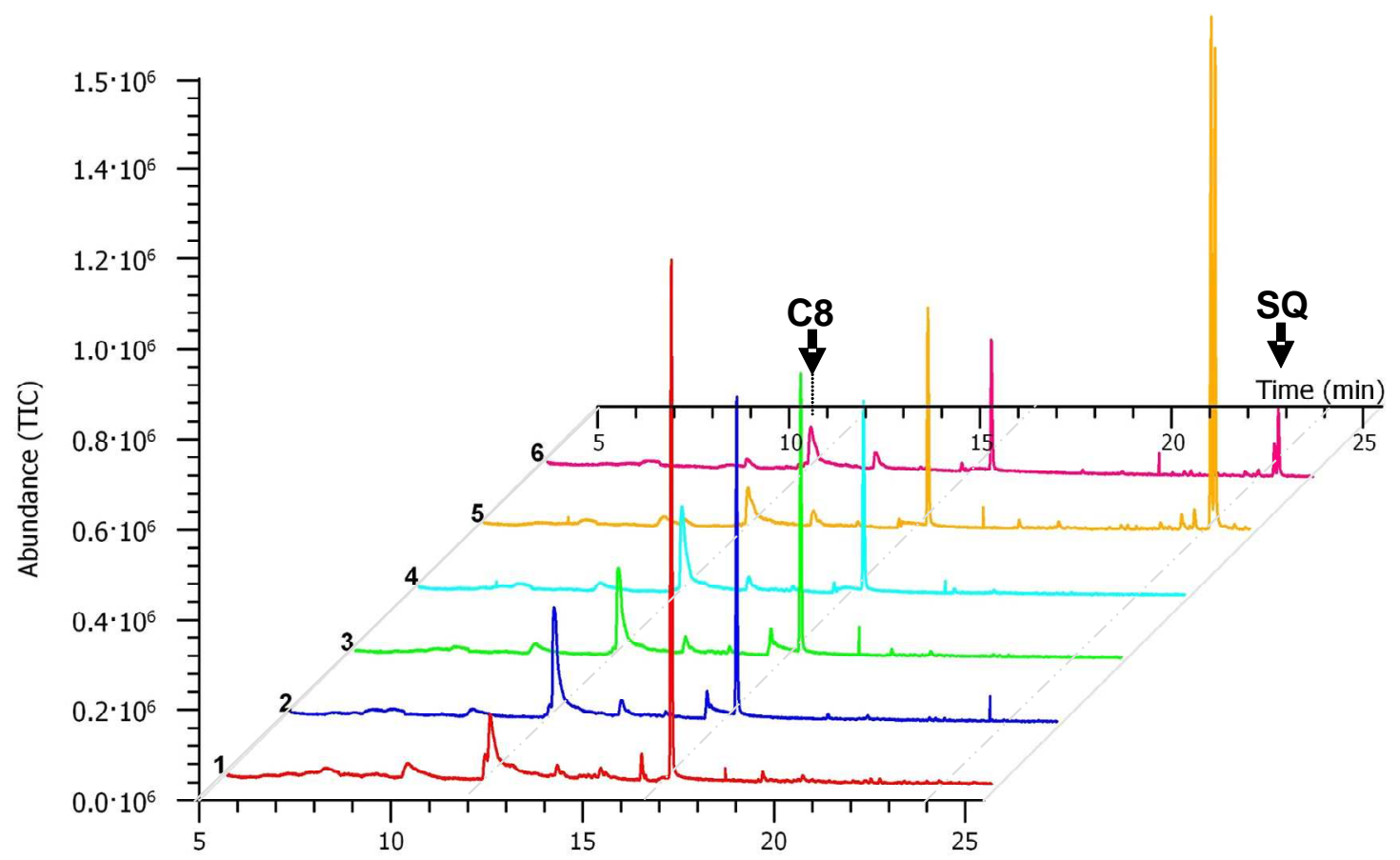

Fig. 7 Emissions of VOCs as sampled during the process of fruiting body development of homokaryon AmutBmut grown prior to transfer into a climate chamber with standard 
fruiting conditions ( $12 \mathrm{~h}$ light $/ 12 \mathrm{~h}$ dark, $28^{\circ} \mathrm{C}, 85-90 \%$ humidity) for 5 days in glass vials on $20 \mathrm{ml}$ YMG/T agar slants at $37^{\circ} \mathrm{C}$ in horizontal manner and as analysed by GC/MS (model HP 6890N gas chromatograph and 5973 mass spectrometer, Agilent Technologies, Paolo Alto, USA, GC no. 1 at the section Forest Zoology and Forest Conservation of the Büsgen-Institute of the Georg-August-University of Göttingen). In each case, a representative curve from one of three parallel measurements per developmental stage is shown. Note that every curve in this graph originated from another glass vial due to the fact that the vials had to be fully closed for $24 \mathrm{~h}$ for the measurements and since this might have negatively affected subsequent periods of measurements. Per time point, three different vials were analysed and the three respective curves obtained per time point were comparable to each other. Thus, only one representative curve per time point is shown in this figure. Curve 1: VOCs emitted from the mycelium of homokaryon AmutBmut from hour 9 at day 1 after transfer into standard fruiting conditions (obviously day 5 of total incubation) to hour 9 at day 2 after the transfer (obviously day 6 of total incubation). Curve 2: VOCs emitted from cultures containing primordia stage 2 of development from hour 9 likely at day 8 after transfer into standard fruiting conditions (day 12 of total incubation) to hour 9 at day 9 after the transfer up to primordia stage 3 (day 13 of total incubation). Curve 3: VOCs emitted from cultures containing primordia stage 3 of development from hour 9 at day 9 after transfer into standard fruiting conditions (day 13 of total incubation) to hour 9 at day 10 after the transfer up to primordia stage 4 (day 14 of total incubation). Curve 4: VOCs emitted from cultures containing primordia stage 4 of development from hour 9 at day 10 after transfer into standard fruiting conditions (day 14 of incubation) to hour 9 at day 11 after the transfer up to primordia stage 5 (stage of meiosis; day 15 of total incubation). Curve 5: VOCs emitted from cultures containing older stage 5 primordia being in the stages of meiosis II and at the beginning of rapid stipe elongation from hour 9 at day 13 after transfer into standard fruiting conditions (day 17 of total incubation) to hour 9 at day 14 after the transfer (day 18 of total incubation) including the developmental stages of fruiting body maturation and finally the autolysis of the fruiting body (for details of VOCs emitted throughout this time period, compare also Fig. 8). Curve 6: Fruiting bodies after cap autolysis (occurred in this tube likely in the morning at day 12 of incubation) from hour 9 at day 14 after transfer into standard fruiting conditions (day 18 of total incubation) to hour 9 at day 15 after the transfer (day 19 of total incubation). C8 = peak at about 11.8 and 11.9 min representing C8-compounds (1-octen-3-ol and 3-octanon, respectively); SQ = peak at about 23.7 and $23.8 \mathrm{~min}$ representing sesquiterpenes ( $\beta$-himachalene and cuparene, respectively); note that the peaks at 15.5 and $16.5 \mathrm{~min}$ are volatile contaminations also found in non-inoculated YMG/T controls (not shown). The sampling of the VOCs was performed by the author of this thesis and the GC/MS analysis and interpretation by P. Thakeow. Note that time values given in this figure for the experiment were adjusted from the notes in the laboratory book of P. Thakeow since no own record for the experiment is available. Note also that the normal, 7-day lasting time course of fruiting body development of C. cinerea (see Fig. 1 in Chapter 2 of this thesis) is not followed up in regular terms. This was likely due to the at this time point (in July 2005) not yet perfectly established growth conditions within the $20 \mathrm{ml}$ glass vials so that the events in fruiting body development were possibly less synchronized than expected. Also, because of water condensation at the round glass vials and because of still low levels of experience with defining stages in fruiting body development at the time point of the experiment, assignments of developmental stages might not have been perfect. It is possible that arrest in development and restart of development by the formation of new structures has been overlooked by lack of experiences at the time (year 2005) of performance of the experiment. Moreover, since mycelial age plays an important role in synchronized initiation of fruiting basically for best results, freshly growing mycelial tips are required that just reach the outer edge of the available still soft agar surface. If the latter is too dry, or if the mycelium is older at the point of transfer, either no fruiting will be induce or fruiting at irregular places and times (U. Kües, personal communication and own observations). 
et al. 2002, Fons et al. 2006 Cho et al. 2006, 2007, 2008, Wood and Lefevre 2007) were detected throughout the development (at about 11.8 and $11.9 \mathrm{~min}$ in the GC/MS curves shown in Fig. 7), within cultures with vegetative mycelium in which hyphal knot formation started (red line 1 in Fig. 7) throughout the whole process of fruiting body development up to maturation and autolysis of the fruiting bodies (curves 2 to 6 in Fig. 7). The height of the peaks possibly indicates a slight decrease in later stages of fruiting body development, i.e. when the fruiting bodies matured, were mature and when they autolysed (see orange and pink curves 5 and 6 in Fig. 7 and see Fig. 8). However, such conclusion has to be taken with caution, since for every measurement, another fresh tube had to be taken and as can be seen in Fig. 7, the peaks indicating the background VOCs coming from the septum-caps of the tube (peaks at $16.5 \mathrm{~min}$ ) vary in height although for every measurement an equal time has taken (always $24 \mathrm{~h}$ ).

In contrast to the $\mathrm{C} 8$-compounds, $\beta$-himachalene and cuparene (identified by P. Thakeow, personal communication), being antimicrobial sesquiterpenes (Abad et al. 1996, Jeleń HH 2002, 2003, Ho and Chein 2006), were detected only during later stages of fruiting body development (at $23.7 \mathrm{~min}$ and $23.8 \mathrm{~min}$, respectively, in the orange and pink curves 5 and 6 in Fig. 7 and in the curve shown in Fig. 8). These sesquiterpenes were emitted at comparably high amounts during the $24 \mathrm{~h}$ period from the start of maturation of a fruiting body in the glass vial (primordia stage 5 undergoing in the basidia the meiosis II in parallel to the start of fast stipe elongation, a process that judged from the outer appearance of the mature primordia occurred approximately at the hour 9 of day 13 of incubation in the glass vials under fruiting conditions), over maturation of the fruiting body (that should have occurred approximately at the end of day 13 and the start of day 14 of incubation under fruiting conditions) to autolysis of the fruiting body (that occurred during the following morning hours up to the hour 9 of day 14 of incubation under fruiting conditions), (orange curve 5 in Fig. 7 and Fig. 8). During a $24 \mathrm{~h}$ period subsequent to the rapid autolysis of a mushroom's cap, these compounds were still detected in a glass vial culture with an autolysed fruiting body, but apparently at much lower amounts (pink curve 6 in Fig. 7).

Fig. 9 presents a final summary of the results of this experiment together with the results obtained from further GC chromatograms not shown in Fig. 7. Of the C8compounds, it is mainly the mostly produced 3-octanone that changes in amounts over the time [maximum of about 350000 TIC (total ion current)] encountered during primordia development (stages 2 and 3, Fig. 7 and Fig. 9) whereas the less produced 


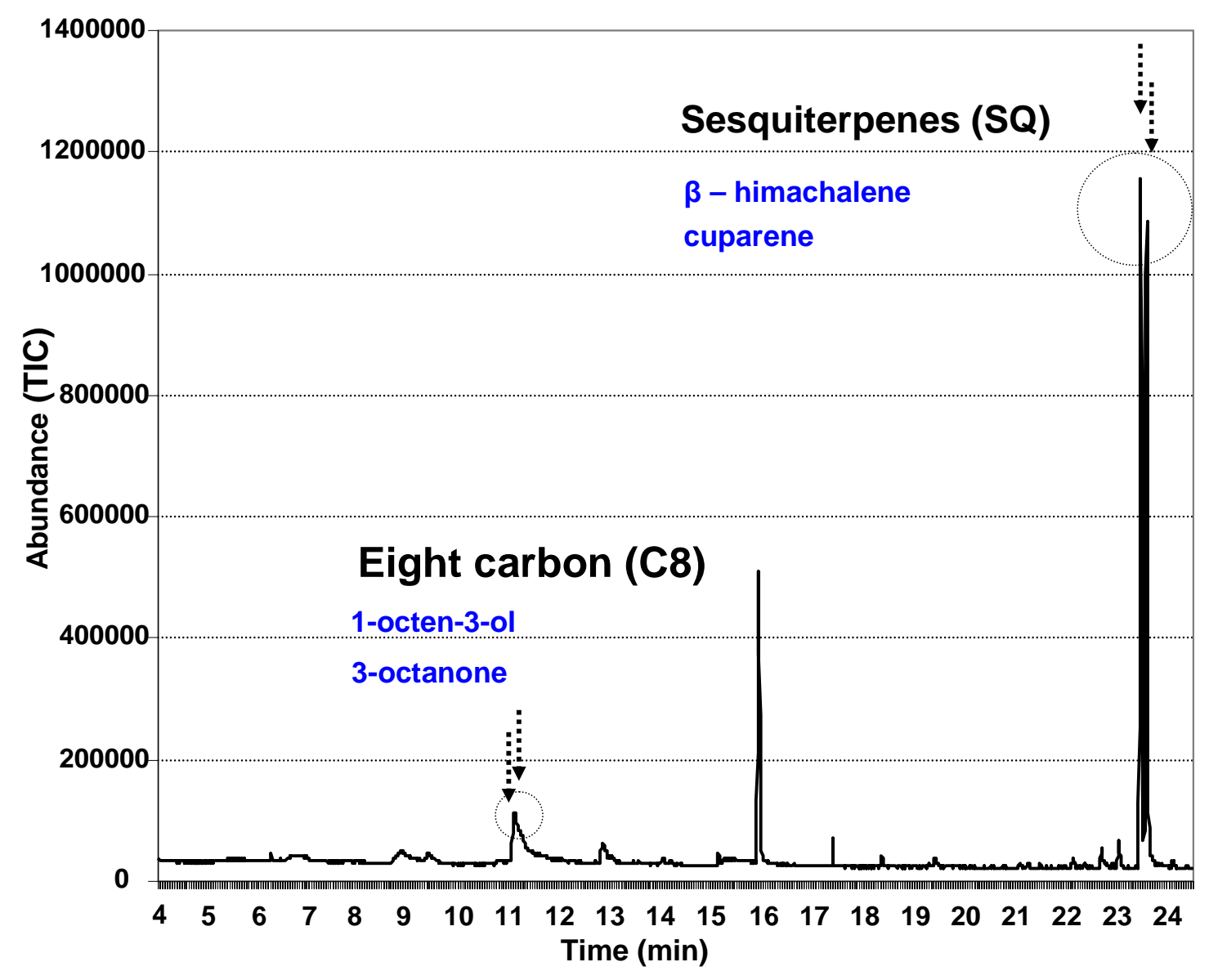

Fig. 8 Gas chromatogram of VOCs emitted by a culture of homokaryon AmutBmut with a first maturating, then mature and finally cap-autolysing fruiting body grown on a $20 \mathrm{ml}$ YMG/T slant agar (period in this specific experiment: day 13 to day 14 after transfer of the cultures into standard fruiting conditions). A representative curve from one of three parallel measurements is shown. This curve is an enlarged view on the results presented by curve 5 in Fig. 7 (for experimental details see the text to Fig. 7). VOCs emitted from cultures containing older stage 5 primordia being in the stages of meiosis II and at the beginning of rapid stipe elongation from hour 9 at day 13 after transfer into standard fruiting conditions to hour 9 at day 14 after the transfer including the developmental stages of fruiting body maturation and finally the autolysis of the fruiting body. The different retention times characterised the four mainly occurring VOCs as the C8-compounds 1-octen-3-ol (11.8 $\mathrm{min})$ and 3-octanone (11.9 min) and the sesquiterpenes (SQ) $\beta$-himachalene $(23.7 \mathrm{~min}$ ) and cuparene $(23.8 \mathrm{~min})$. The analysis of this curve was performed together with $\mathrm{P}$. Thakeow.

1-octen-3-ol (maximum of about 200000 TIC) encountered in the vegetative mycelium lacking still any fruiting structures (Fig. 7 and Fig. 9) shows only a smaller decrease in production with the proceeding in fruiting body development. After cap autolysis, there was for about the next 10 days no major change in C8-compound emission but finally, in the very old cultures (days 23 to 34 of incubation under standard fruiting conditions), the level of emitted C8-compounds dropped further to a very low abundance of 5000 TIC in case of 1-octen-3-ol and 10000 TIC in case of 3-octanone, respectively (Fig. 9). 


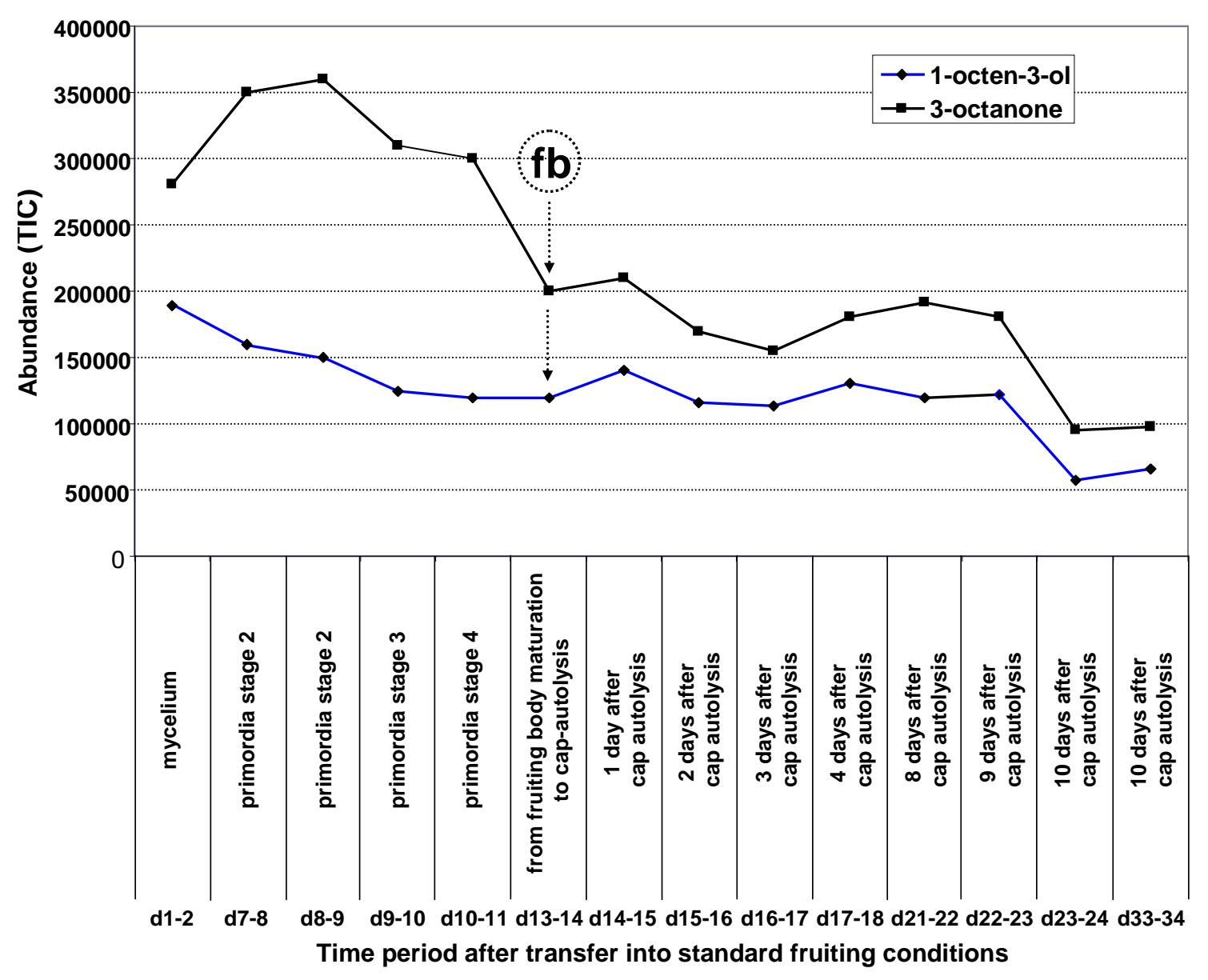

Fig. 9 Comparison of emission of the C8-compounds 1-octen-3-ol and 3-octanone over the time with progress in fruiting body development of homokaryon AmutBmut that after growth in glass vials on $20 \mathrm{ml}$ YMG/T agar slants for $5 \mathrm{~d}$ at $37^{\circ} \mathrm{C}$ in the dark was incubated under standard fruiting conditions $(\mathrm{d} 1=$ day of transfer into standard fruiting conditions). 1-Octen-3-ol and 3-octanone emissions were collected each time over $24 \mathrm{~h}$ (each time from hour 9 of incubation in light from one day to the following day up to hour 9) and measured by GC/MS. Averages of values from three parallel measurements per developmental stage are shown. For further details on the experiment, see legend of Fig. 7 and Fig. 8. Curves 1 to 6 in Fig. 7 correspond to the values given for d1-2 (curve 1), d8-9 (curve 2), d9-10 (curve 3), d10-11 (curve 4), d13-14 (curve 5) and d14-15 (curve 6) of incubation under standard fruiting conditions at $28^{\circ} \mathrm{C}$ and $85-90 \%$ humidity during a $12 \mathrm{~h} \mathrm{light} / 12 \mathrm{~h}$ dark cycle. The encircled label $\mathrm{fb}$ marks specifically the time period during which the mature fruiting body occurred. Note that the analysis shown in the figure obtained from GC/MS curves as presented in Fig. 7 has been performed together with P. Thakeow.

Subsequently in February 2007, emissions of VOCS from homokaryon AmutBmut were determined during fruiting body development on $10 \mathrm{ml}$ YMG/T agar slants in glass vials that were horizontally incubated (Fig. 10). In parallel, a Petri-dish with YMG/T agar was inoculated in the established way (compare Chapter 2 and Fig. 1 therein for standard inoculation and incubation conditions for fruiting body 


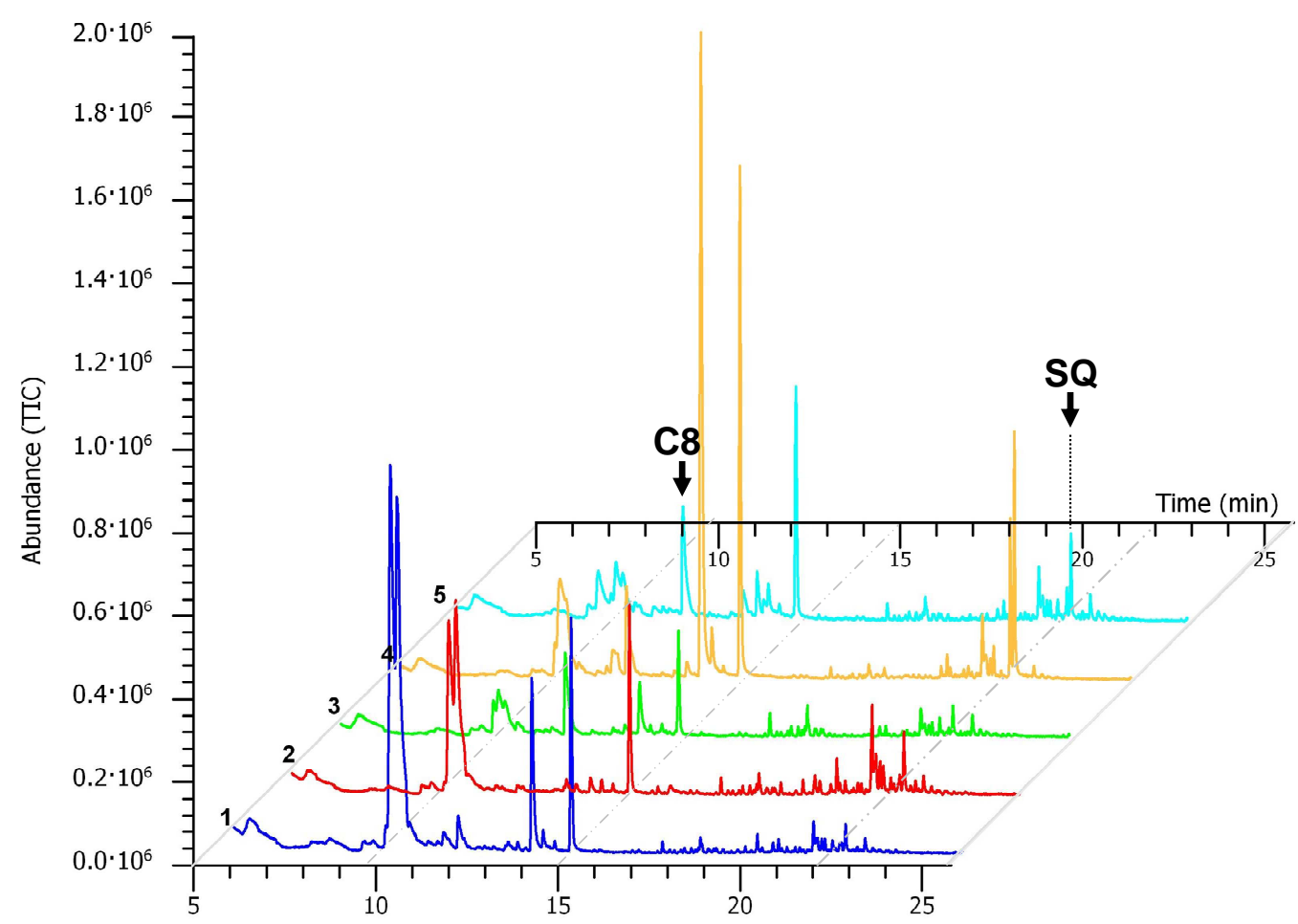

Fig. 10 Emissions of VOCs as sampled during the process of fruiting body development of homokaryon AmutBmut grown prior to transfer into standard fruiting conditions (12 h light/12 h dark, $28^{\circ} \mathrm{C}, 80-90 \%$ humidity) for 5 days in glass vials on $10 \mathrm{ml}$ YMG/T agar slants at $37^{\circ} \mathrm{C}$ in a horizontal manner and as analysed by GC/MS (model HP 6890N gas chromatograph and 5973 mass spectrometer, Agilent Technologies, Paolo Alto, USA, GC no. 2 at the section Forest Zoology and Forest Conservation of the Büsgen-Institute of the Georg-August-University of Göttingen). In each case, a representative curve from one of three parallel measurements per developmental stage is shown. Despite the different amount of agar, the experimental set-up was similar than described for the experiments in Fig. 7. However, the process of fruiting body development after transfer followed the normal 7-day scheme as previously established on Petri-dishes (compare Fig. 1 in Chapter 2 of this thesis). Per time point, three different vials were analysed and for every time period, the three respective samples behaved similar in the GC/MS analysis. Thus, per time point, only one representative sample is shown. Curve 1: VOCS emitted from the mycelium of homokaryon AmutBmut from hour 9 at day 1 after transfer into standard fruiting conditions to hour 9 at day 2 after the transfer during which secondary hyphal knots will have been developed on the mycelial mat. Curve 2: VOCS emitted from the cultures of homokaryon AmutBmut from hour 9 at day 2 after transfer into standard fruiting conditions to hour 9 at day 3 . At this time of incubation, primordia of stage 1 will have been present. Curve 3: VOCS emitted from the cultures of homokaryon AmutBmut from hour 9 at day 3 after transfer into standard fruiting conditions to hour 9 at day 4 . At this time of incubation, primordia of stage 2 will have been present. Curve 4: VOCS emitted from the cultures of homokaryon AmutBmut from hour 9 at day 4 after transfer into standard fruiting conditions to hour 9 at day 5. At this time of incubation, primordia of stage 3 will have been present. Curve 5: VOCS emitted from the cultures of homokaryon AmutBmut from hour 9 at day 6 after transfer into standard fruiting conditions to hour 9 at day 7 . At this time of incubation, one primordium per vial matured into a fully established fruiting body on which subsequently the cap autolyzed. The label C8 in the figure marks the peaks at about 9.6 and 9.8 min representing C8-compounds (1-octen-3-ol and 3-octanone) and the label SQ marks the peaks at about 21.8 and 21.9 min representing sesquiterpenes ( $\beta$-himachalene and cuparene); note that the peaks at 14,15 and $23 \mathrm{~min}$ are contaminations also found in non-inoculated YMG/T controls (not shown). Note further that the values in min in this experiment differed from those obtained in the previous one shown in Fig. 7 and Fig. 8 due to the change in the GC/MS machine. 
development on agar plates) to have a better control of the fruiting events. Inoculated vials were incubated for 4 days (due to the smaller agar surface compared to Petridishes) and control Petri-dishes respectively for 5 days (inoculated therefore one day earlier) at $37^{\circ} \mathrm{C}$ in the dark before transferring them into standard fruiting conditions (12 h light $/ 12 \mathrm{~h}$ dark, $28^{\circ} \mathrm{C}, 85-90 \%$ humidity). This time, the fruiting process in the vials followed obviously exactly the same pathway than that which was regularly observed in Petri-dishes and which was also again successfully reassessed in this experiment with the control plates. Accordingly, following the transfer from $37^{\circ} \mathrm{C}$ into $28^{\circ} \mathrm{C}$ at standard fruiting conditions (12 h light/12 h dark, 85-90\% humidity), mature fruiting bodies were obtained in the glass vials within 7 days of incubation. Although not checked in detail, all the required developmental stages prior to maturation should thus have been executed at the time points to be expected from the normal time course as presented in Fig. 1 in Chapter 2 of this thesis. For VOC measurements, each three vials were analysed per developmental stage (i.e. for the events occurring per $24 \mathrm{~h}$ time period) under the assumption that for every of the time points considered, the developmental processes in all three vials analysed reached the stages as expected from normal proceeding of fruiting body development.

Although more contaminations of VOCs were encountered in this second series of experiments making the analysis more difficult, the overall results were similar as before (compare Fig. 7 and Fig. 10). Also in the second set of experiments, mainly 4 different volatiles were detected during the process of fruiting body development, namely 1-octen-3-ol, 3-octanone, $\beta$-himachalene and cuparene. C8-compounds were produced to a larger extend in the beginning of the process of fruiting body development up to primordia stage 3 after which there was a comparably sharp decrease in production of these compounds (Fig. 10). This decrease was in the second set of experiments obviously more sharp than in the first experiment and it appeared to occur at a somewhat earlier stage (compare Fig. 7 and Fig. 10 - however, note that in the experiment shown in Fig. 7 the appearance of the different developmental stages spread over a longer time period which could have resulted in a misleading conclusion). As in the previous experiment presented in Fig. 7, production of the sesquiterpenes increased in later, easily to recognize stages of development during the time period in which the fruiting body maturated, in which the fully matured fruiting body established and in which the cap of the mushroom autolysed (compare Fig. 7 and Fig. 10). Future studies will have to repeat the experiments - as deduced here from the presented experiments 
best with $10 \mathrm{ml}$ agar in the vials - whereby sources of contaminations of VOCs however need to be better avoided. Unfortunately, the reason for the extra contaminations in the second set of experiment is not known. Compared to the first experiment where vials were incubated in the a climate chamber at the Büsgen-Institute used by standard for fruiting experiments of $C$. cinerea, the set of vials in the second set of experiments were cultivated in an incubator (Ernst Schütt jun. Laborgerätebau, Göttingen, Germany). It is possible that emissions in this incubator were the reason for the unwanted extended range of background VOCs.

\subsubsection{Comparison of VOCs emissions by mycelia of $C$. cinerea cultures with respect to wounding}

Emissions of VOCs by the mycelium of monokaryons PS001-1 and PS002-1 and their respective dikaryon PS001-1 x PS002-1 and of homokaryon AmutBmut and the related mutants PUK1-6 and PUK2-6 forming etiolated stipes under normal fruiting conditions were compared when unwounded and when wounded. To this purpose, all

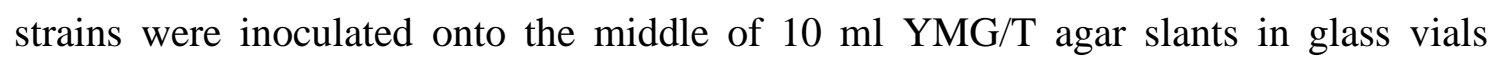
(3 vials per strain and treatment). The glass vials were horizontally incubated at $37^{\circ} \mathrm{C}$ in the dark for four days. After this time, the mycelium of all cultures had covered most of the agar surface leaving only a small agar surface area (about $5 \mathrm{~mm}$ in width) at both ends of the agar slants still free for further growth. VOC sampling was performed for 18 hours overnight from day 4 to day 5 of incubation. The SPME fibres used for VOC sampling were taken from the vials and the vials were incubated for three further hours at $37^{\circ} \mathrm{C}$ in the dark, thereby leaving the septum-cap loosely open. Afterwards, the mycelium mats were scratched with a sterile lancet needle, upon which the septum-caps were tightly closed and SPME needles were pressed through the cap in order to collect for a period of $3 \mathrm{~h}$ at $37^{\circ} \mathrm{C}$ the VOCs released by the fungal mycelia. Collected VOCs were analysed on a GC model HP 6890N gas chromatograph (GC no. 2 at the section Forest Zoology and Forest Conservation of the Büsgen-Institute of the Georg-AugustUniversity of Göttingen) and the coupled 5973 mass spectrometer (Agilent Technologies, Paolo Alto, USA). The results of these analyses are presented in Fig. 11, Fig. 12 and Table 1. Before wounding, all strains showed emission of the mushroomodour C8-compunds (1-octen-3-ol and 3-octanone) which was clearly visible in the 

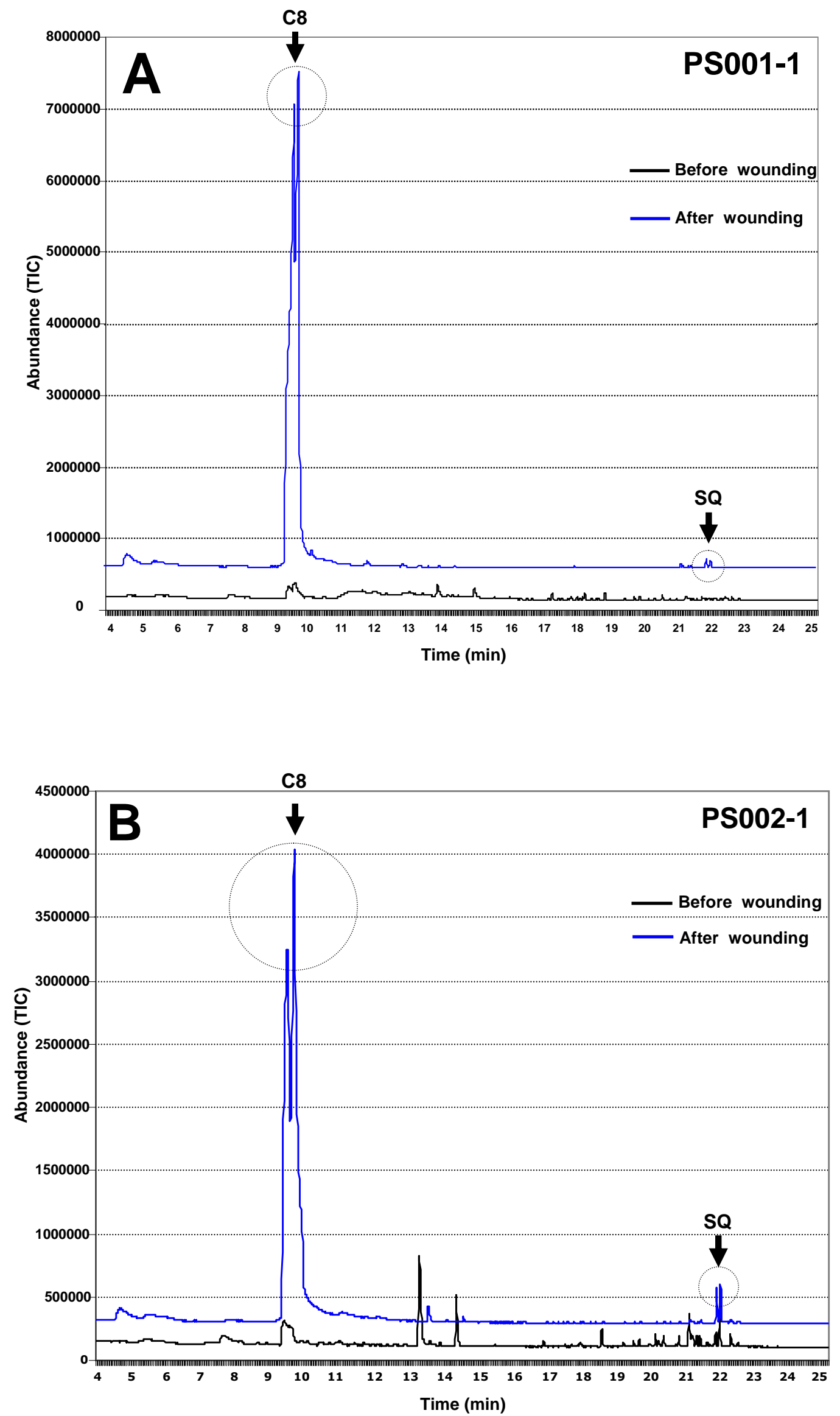

Fig. 11 (A) and (B) For description see the legend on p. 242. 

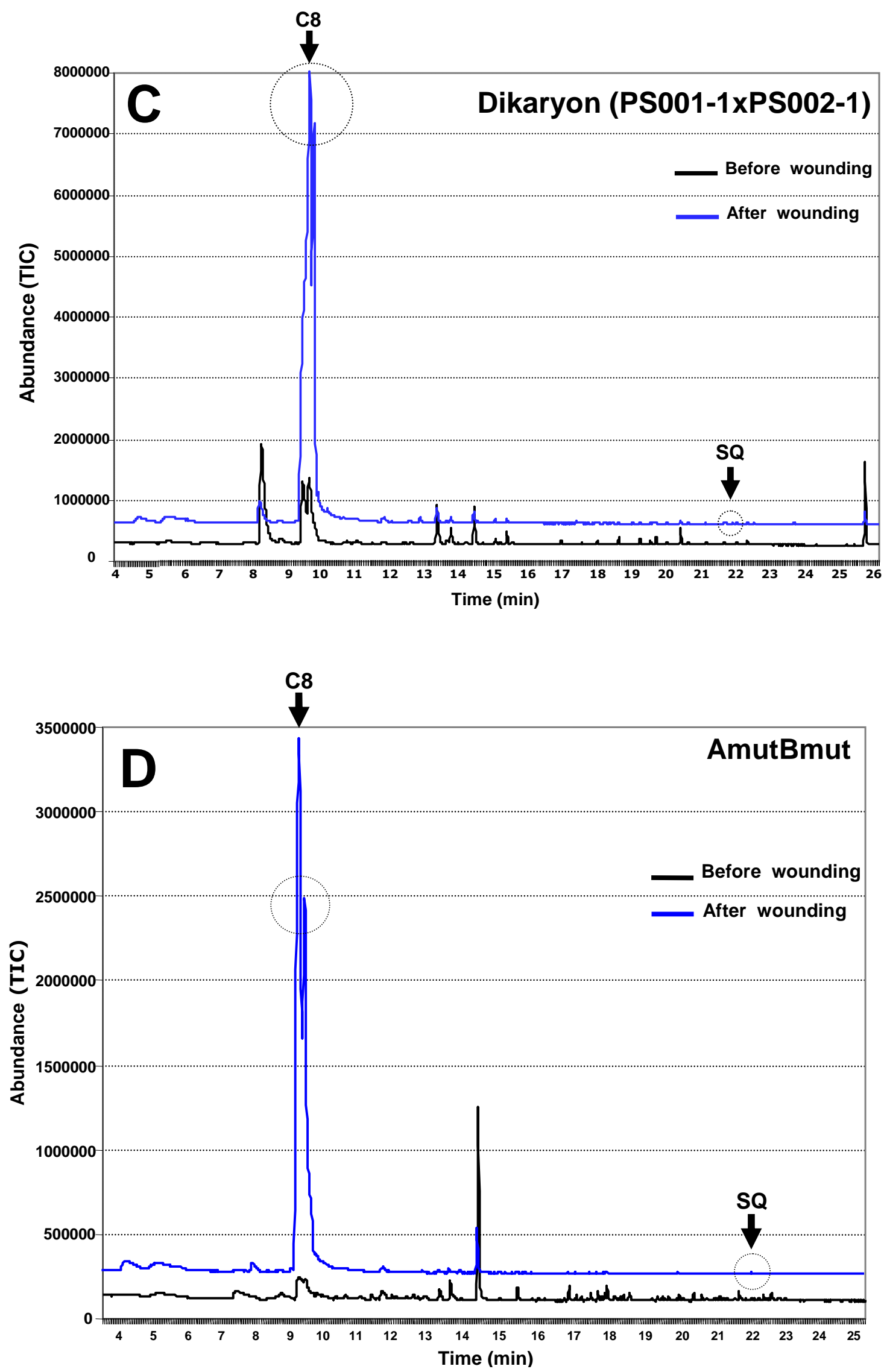

Fig. 11 (C) and (D) For description see the legend on p. 242. 

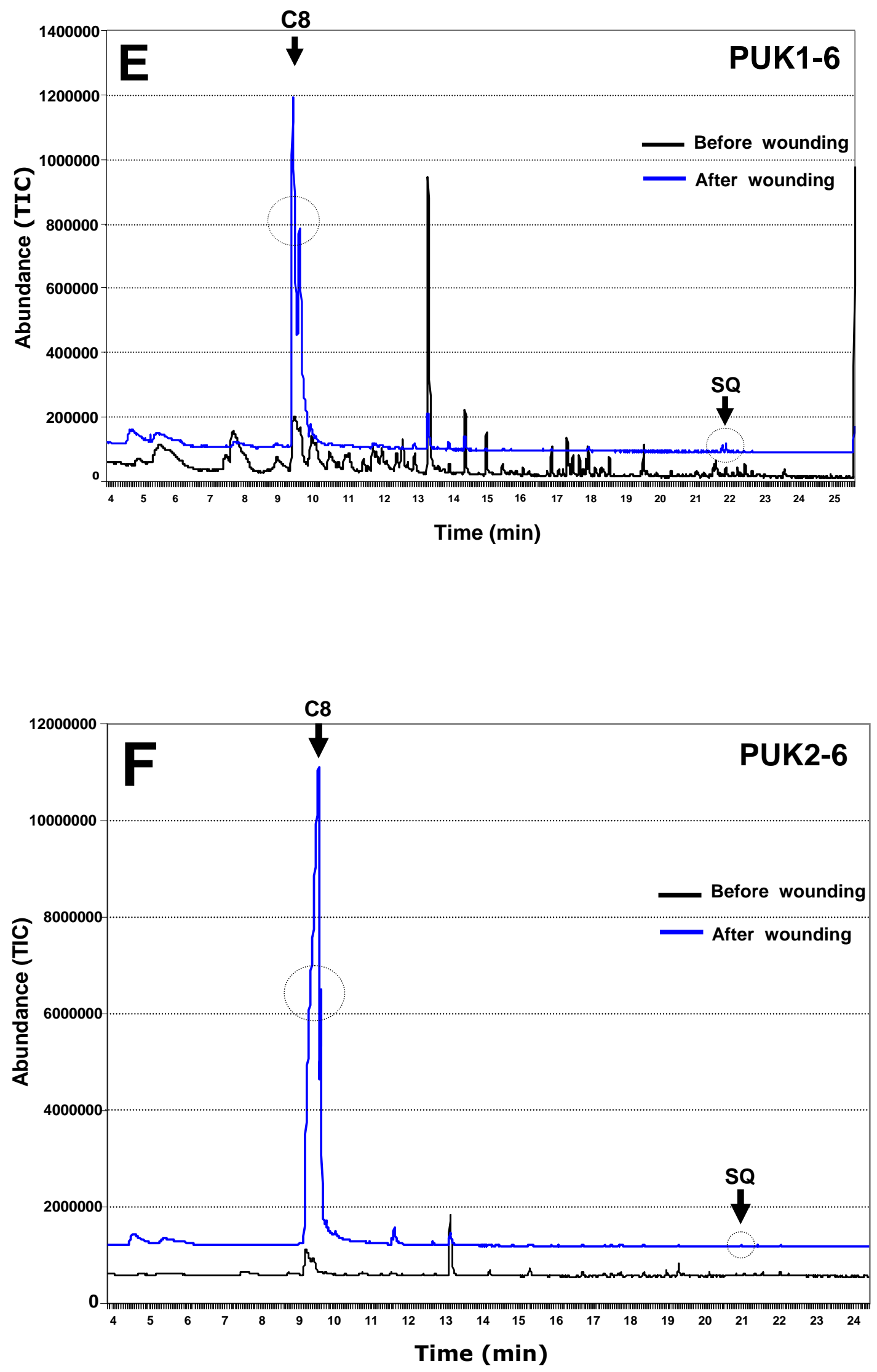

Fig. 11 (E) and (F) For description see the legend on p. 242. 
Fig. 11 Emissions of VOCs by healthy and by wounded cultures of Coprinopsis cinerea. Glass vials with $10 \mathrm{ml} \mathrm{YMG/T}$ agar slants were inoculated in the middle of the agar with either the monokaryon PS001-1 (A), the monokaryon PS002-1 (B), the dikaryons PS001-1 x PS002-1 (C), the homokaryon AmutBmut (D), the etiolated stipe mutant PUK1-6 (E) or the etiolated stipe mutant PUK2-6 (F) and the vials were incubated in horizontal manner for 4 days at $37^{\circ} \mathrm{C}$ in the dark with loose caps, upon which the caps were tightly closed for $18 \mathrm{~h}$ during which VOCs from the unwounded mycelial cultures were sampled at $37^{\circ} \mathrm{C}$ in the dark by SPME fibres as described in the methods. After sampling, the caps were loosened and the cultures incubated for $3 \mathrm{~h}$ at $37^{\circ} \mathrm{C}$ in the dark. Then, the mycelium was wounded by scrapping the mycelial surface with a lancet needle, upon which the caps were directly tightly closed and VOCs were sampled for $3 \mathrm{~h}$ at $37^{\circ} \mathrm{C}$ in the dark by SPME fibres as described in the methods. VOCs were analysed by GC/MS analysis as described (GC model HP 6890N gas chromatograph and 5973 mass spectrometer, Agilent Technologies, Paolo Alto, USA, GC no. 2 at the section Forest Zoology and Forest Conservation of the Büsgen-Institute of the Georg-August-University of Göttingen was used). Per strain, representative curves from one of three parallel measurements of vials with mycelium in the intact and in the wounded stage are shown. The retention times for the C8-compounds 1-octen-3-ol and 3-octanone (marked in the diagrams by C8) were 9.6 and 9.8 min, respectively and the retention times for the sesquiterpenes (marked in the diagrams by SQ) $\beta$-himachalene and cuparene were 21.8 and $21.9 \mathrm{~min}$, respectively. Circles were introduced into the diagrams to make better obvious peaks corresponding to either 3-octanone or peaks corresponding to the sesquiterpenes. The analysis of these curves was performed together with P. Thakeow.

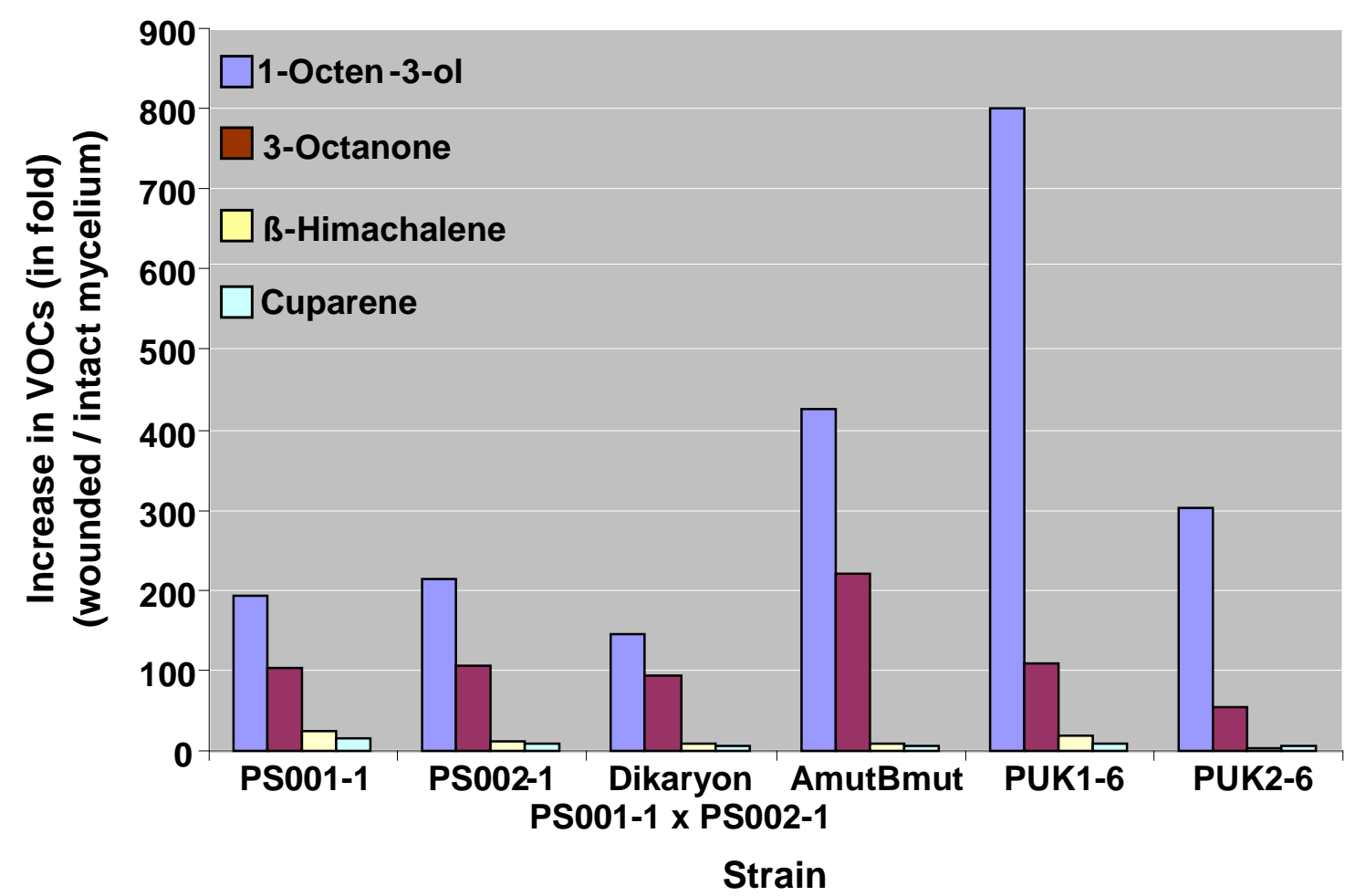

Fig. 12 Increase in emissions of VOCs by wounded cultures of different Coprinopsis cinerea strains compared to intact cultures. Increases in emissions of VOCs were calculated from the average values of three parallel treatments as listed in Table 1 and as described in the footnote of Table 1 . 
Table 1 Abundance of VOCs (in TIC, total ion current) emitted from fungal cultures with intact mycelium and after wounding as measured by GC/MS analysis (compare Fig. 11) and calculated as averages from three parallel treatments

\begin{tabular}{|c|c|c|c|c|c|}
\hline \multicolumn{2}{|c|}{ Culture of strain } & \multicolumn{4}{|c|}{ Abundance of VOCs (TIC) } \\
\hline & & \multicolumn{2}{|c|}{ C-8 compounds } & \multicolumn{2}{|c|}{ Sesquiterpenes } \\
\hline & & 1-Octen-3-ol & 3-Octanone & $\beta$-Himachalene & Cuparene \\
\hline \multirow[t]{3}{*}{ PS001-1 } & Intact & $\begin{array}{l}6.84 \times 10^{6} \pm \\
2.98 \times 10^{6}\end{array}$ & $\begin{array}{c}6.71 \times 10^{6} \pm \\
3.66 \times 10^{6}\end{array}$ & $\begin{array}{l}4.30 \times 10^{4} \pm \\
9.87 \times 10^{3}\end{array}$ & $\begin{array}{c}1.05 \times 10^{5} \pm \\
5.05 \times 10^{4}\end{array}$ \\
\hline & Wounded & $\begin{array}{c}2.21 \times 10^{8} \pm \\
3.21 \times 10^{7}\end{array}$ & $\begin{array}{c}1.14 \times 10^{8} \pm \\
7.22 \times 10^{6}\end{array}$ & $\begin{array}{c}1.67 \times 10^{5} \pm \\
2.45 \times 10^{5}\end{array}$ & $\begin{array}{c}2.52 \times 10^{5} \pm \\
3.06 \times 10^{5}\end{array}$ \\
\hline & Increase* & 194.16 fold & 101.86 fold & 23.32 fold & 14.33 fold \\
\hline \multirow[t]{3}{*}{ PS002-1 } & Intact & $\begin{array}{c}4.76 \times 10^{6} \pm \\
4.23 \times 10^{6}\end{array}$ & $\begin{array}{c}3.85 \times 10^{6} \pm \\
3.28 \times 10^{6}\end{array}$ & $\begin{array}{c}1.51 \times 10^{5} \pm \\
2.03 \times 10^{5}\end{array}$ & $\begin{array}{c}4.65 \times 10^{5} \pm \\
6.12 \times 10^{5}\end{array}$ \\
\hline & Wounded & $\begin{array}{c}1.70 \times 10^{8} \pm \\
5.6 \times 10^{7}\end{array}$ & $\begin{array}{c}6.75 \times 10^{7} \pm \\
2.23 \times 10^{7}\end{array}$ & $\begin{array}{c}3.36 \times 10^{5} \pm \\
5.58 \times 10^{5}\end{array}$ & $\begin{array}{c}6.19 \times 10^{5} \pm \\
8.22 \times 10^{5}\end{array}$ \\
\hline & Increase* & 214.26 fold & 105.11 fold & 13.35 fold & 7.99 fold \\
\hline \multirow{3}{*}{$\begin{array}{l}\text { Dikaryon } \\
\text { PS001-1 x } \\
\text { PS002-1 }\end{array}$} & Intact & $\begin{array}{r}9.49 \times 10^{6} \pm \\
7.23 \times 10^{6} \\
\end{array}$ & $\begin{array}{c}5.78 \times 10^{6} \pm \\
6.07 \times 10^{6}\end{array}$ & $\begin{array}{c}3.55 \times 10^{4} \pm \\
5.75 \times 10^{4}\end{array}$ & $\begin{array}{c}8.92 \times 10^{4} \pm \\
1.3 \times 10^{5}\end{array}$ \\
\hline & Wounded & $\begin{array}{c}2.27 \times 10^{8} \pm \\
5.22 \times 10^{7}\end{array}$ & $\begin{array}{c}9.10 \times 10^{7} \pm \\
3.75 \times 10^{7}\end{array}$ & $\begin{array}{c}5.03 \times 10^{4} \pm \\
3.42 \times 10^{4}\end{array}$ & $\begin{array}{c}1.09 \times 10^{5} \pm \\
8.04 \times 10^{4}\end{array}$ \\
\hline & Increase* & 143.58 fold & 94.40 fold & 8.50 fold & 7.32 fold \\
\hline \multirow[t]{3}{*}{ AmutBmut } & Intact & $\begin{array}{c}2.24 \times 10^{6} \pm \\
2.18 \times 10^{5}\end{array}$ & $\begin{array}{c}9.66 \times 10^{5} \pm \\
6.52 \times 10^{5}\end{array}$ & $\begin{array}{c}5.31 \times 10^{3} \pm \\
3.49 \times 10^{3}\end{array}$ & $\begin{array}{c}2.46 \times 10^{4} \pm \\
7.25 \times 10^{3}\end{array}$ \\
\hline & Wounded & $\begin{array}{c}1.59 \times 10^{8} \pm \\
5.93 \times 10^{7}\end{array}$ & $\begin{array}{c}3.60 \times 10^{7} \pm \\
1.04 \times 10^{7}\end{array}$ & $\begin{array}{c}8.49 \times 10^{3} \pm \\
2.69 \times 10^{3}\end{array}$ & $\begin{array}{c}2.20 \times 10^{4} \pm \\
1.37 \times 10^{4}\end{array}$ \\
\hline & Increase* & 426.92 fold & 221.50 fold & 9.60 fold & 5.37 fold \\
\hline \multirow[t]{3}{*}{ PUK1-6 } & Intact & $\begin{array}{c}9.64 \times 10^{5} \pm \\
8.01 \times 10^{5}\end{array}$ & $\begin{array}{c}1.08 \times 10^{6} \pm \\
8.11 \times 10^{5}\end{array}$ & $\begin{array}{c}1.40 \times 10^{4} \pm \\
7.30 \times 10^{3}\end{array}$ & $\begin{array}{c}5.49 \times 10^{4} \pm \\
4.42 \times 10^{4}\end{array}$ \\
\hline & Wounded & $\begin{array}{l}1.28 \times 10^{8} \pm \\
9.03 \times 10^{7}\end{array}$ & $\begin{array}{c}1.98 \times 10^{7} \pm \\
1.10 \times 10^{7}\end{array}$ & $\begin{array}{c}4.09 \times 10^{4} \pm \\
3.00 \times 10^{4}\end{array}$ & $\begin{array}{c}9.66 \times 10^{4} \pm \\
586 \times 10^{4}\end{array}$ \\
\hline & Increase* & 800.02 fold & 109.68 fold & 17.50 fold & 10.56 fold \\
\hline \multirow[t]{3}{*}{ PUK2-6 } & Intact & $\begin{array}{c}8.37 \times 10^{6} \pm \\
2.53 \times 10^{6}\end{array}$ & $\begin{array}{c}3.46 \times 10^{6} \pm \\
7.03 \times 10^{5}\end{array}$ & $\begin{array}{c}4.43 \times 10^{4} \pm \\
2.26 \times 10^{4}\end{array}$ & $\begin{array}{c}4.86 \times 10^{4} \pm \\
3.00 \times 10^{4}\end{array}$ \\
\hline & Wounded & $\begin{array}{c}4.20 \times 10^{8} \pm \\
5.78 \times 10^{7}\end{array}$ & $\begin{array}{c}3.15 \times 10^{7} \pm \\
3.24 \times 10^{6}\end{array}$ & $\begin{array}{c}2.38 \times 10^{4} \pm \\
3.72 \times 10^{3}\end{array}$ & $\begin{array}{c}5.34 \times 10^{4} \pm \\
1.55 \times 10^{4}\end{array}$ \\
\hline & Increase* & 301.39 fold & 54.70 fold & 3.23 fold & 6.58 fold \\
\hline
\end{tabular}

* Increase in VOC production was calculated by dividing the value after wounding with the value before wounding and multiplying the result by six in order to adjust the different time periods of measurements.

GC/MS diagrams (Fig. 11), However, as deduced from calculations of the Agilent computer programme Enhanced Chemstation version D00.00.38, there was also some low level of emission of the sesquiterpenes $\beta$-himachalene and cuparene (see Fig. 12 and Table 1). Strikingly, after wounding, the amounts of emitted C8-compounds raised dramatically in all cultures tested by about 50 to 800 fold (Fig. 11, Fig. 12 and Table 1). 


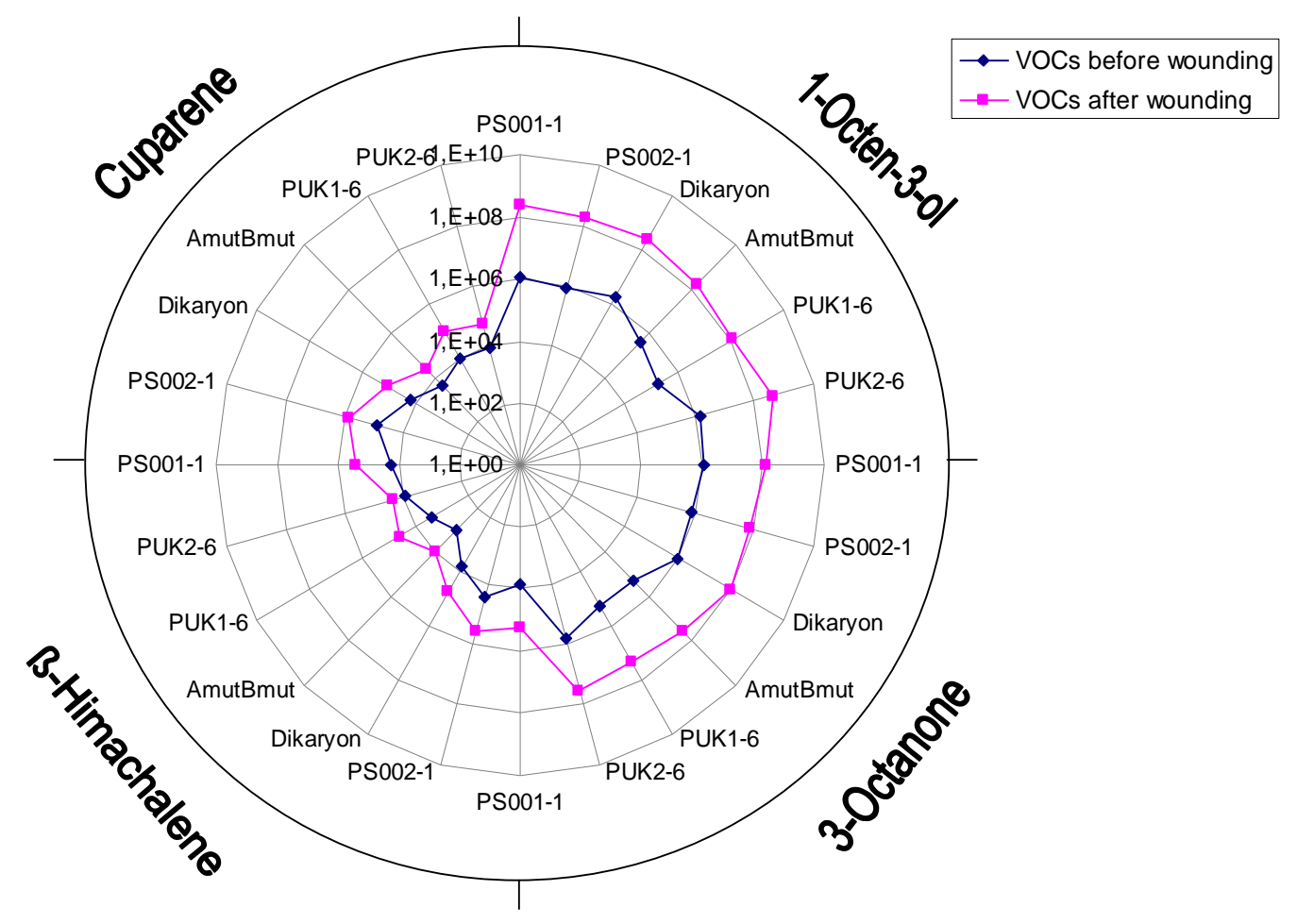

Fig. 13 Diagram showing that the six tested Coprinopsis cinerea strains (monokaryon PS001-1 and PS002-1, dikaryon PS001-1 x PS002-1), homokaryon AmutBmut and its mutants PUK1-6 and PUK2-6) were alike in their overall behaviour in emitting the four VOCs 1-octen-3-ol, 3-octanone, B-himachalene and cuparene from intact and from wounded mycelium. TICs from averages values are shown as calculated in each case from three parallel measurements (compare Table 1).

Also the amounts of the emitted sesquiterpenes $\beta$-himachalene and cuparene increased after wounding, but by lower factors of about 3 to 23 (Fig. 11, Fig. 12 and Table 1). The graph in Fig 13 nicely demonstrates this - as can be seen from the presentation, the overall behaviour of all the six different strains tested with respect of emitting increased amounts of the four different VOCs 1-octen-3-ol, 3-octanone, $\beta$-himachalene and cuparene after wounding were the same.

\subsubsection{Wounding effect emissions of VOCs from fruiting body stipes of $C$. cinerea}

Wounding was seen to have a clear effect on dramatically increasing the emissions of 1-octen-3-ol, 3-octanone, $\beta$-himachalene and cuparene from the vegetative mycelium (Fig. 11 to Fig. 13, Table 1). In a further final experiment in this thesis, the effect of wounding on an aggregated structure was tested. For this, six different stipes of 


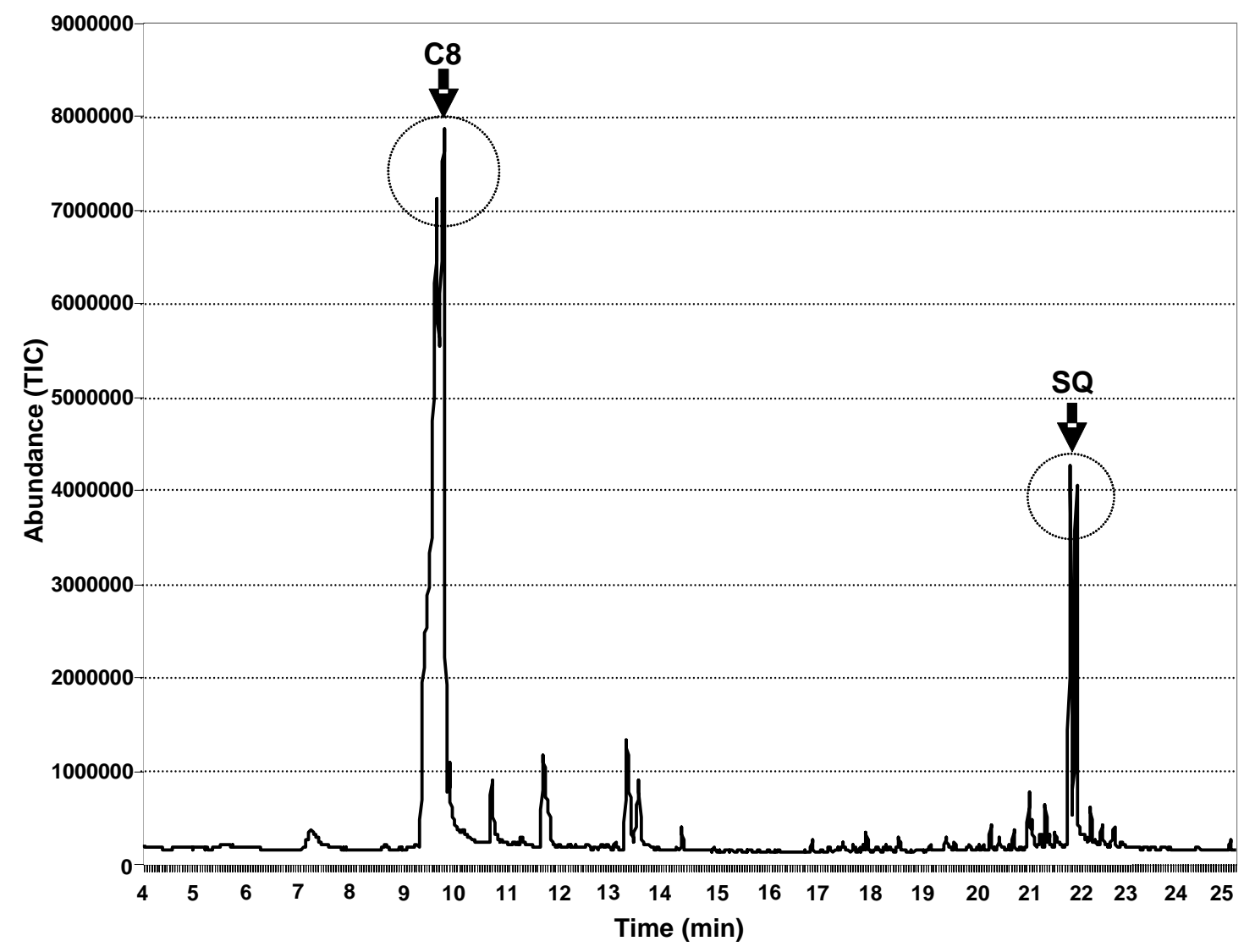

Fig. 14 Emissions of VOCs by macerated stipes of fruiting bodies of Coprinopsis cinerea homokaryon AmutBmut. A representative curve from one out of three parallel measurements is shown. Six different stipes from autolysing fruiting bodies were separated at day 7 of fruiting body development (compare Fig. 1 in Chapter 2 of this thesis), macerated in a sterile glass beaker and $0.6 \mathrm{~g}$ of the macerate (corresponding approximately to two full stipes) was filled into a glass vial for VOC sampling for 3 hours at $37^{\circ} \mathrm{C}$ in the dark and subsequent VOC detection by GC/MS analysis (GC model HP 6890N gas chromatograph and 5973 mass spectrometer, Agilent Technologies, Paolo Alto, USA, GC no. 2 at the section Forest Zoology and Forest Conservation of the Büsgen-Institute of Georg-August-University of Göttingen) as described in Material and methods (for further details see text of chapter 5..4.4). The retention times for the C8-compounds 1-octen-3-ol and 3-octanone (marked in the diagrams by $\mathrm{C} 8$ ) were 9.6 and $9.8 \mathrm{~min}$, respectively and the retention times for the sesquiterpenes (marked in the diagrams by SQ) $\beta$-himachalene and cuparene were 21.8 and $21.9 \mathrm{~min}$, respectively. Circles were introduced into the diagrams to make better obvious peaks corresponding to either 3 -octanone or peaks corresponding to the sesquiterpenes. The analysis was performed at the same time than the analysis of intact and wounded vegetative mycelium presented in Chpater 5.4.3. The analysis of these curves was performed together with P. Thakeow.

autolysing fruiting bodies of homokaryon AmutBmut (grown on a Petri-dish under standard cultivation and fruiting conditions: after inoculation incubation for 5 days at $37^{\circ} \mathrm{C}$ in the dark, then transfer of the plate into $28^{\circ} \mathrm{C}$ and $85-90 \%$ humidity in a $12 \mathrm{~h}$ light/12 h dark regime) was separated from the left cap tissue in the morning of day 7 of 
development (two hours after the light period started in the fruiting pathway as following up under standard fruiting conditions; see Fig. 1 in Chapter 2 of this thesis). The stipes were macerated in a sterile beaker thereby using a lancet needle and three samples of each $0.6 \mathrm{~g}$ of the macerate (corresponding approximately to two full stipes) were transferred into a glass vial that was tightly closed with a septum-cap for detection of VOCs with the help of a SPME fibre and GC/MS analysis as described in the Material and methods. The glass vials were incubated for three hours at $37^{\circ} \mathrm{C}$ in the dark with the SPME fibres injected into the glass vials through the septum-cap. Fig. 14 shows representatively the sampled VOCs from one out of the three analysed parallel macerate samples. Although not fully comparable since vegetative mycelium and a complete mushroom were analysed over $24 \mathrm{~h}$ during which a structure maturated into a fruiting body and a mature fruiting body was transiently present which within a few hours autolysed (the stage labelled in Fig. 9 from fruiting body maturation to capautolysis), respectively during which vegetative mycelium with an autolysed fruiting body was analysed (the stage labelled in Fig. 9 with 1 day after cap autolysis) a much higher amount of all for types of VOCs were emitted from the macerated stipes (Table 2). There was an approximate 1000 fold increase of emission of both C8compounds 1-octen-3-ol and 3 octanone, respectively and an approximate 100 fold increase of emission of both sesquiterpenes $\beta$-himachalene and cuparene, respectively, upon massively injuring the stipe tissues. That this higher emission of VOCs might not just be the result of degradation of dead cellular material is seen in Fig. 15 that shows active mycelial growth on the macerated stipe material after two days of incubation at room temperature of the glass vials after taking out the SPME fibres and loosening the septum-caps of the glass vials. In the future, one might repeat the result with the macerated stipes but, for better comparison, in parallel undamaged stipes should be analysed isolated from the vegetative mycelium. 
Table 2 Abundance of VOCs (in TIC, total ion current) emitted from macerated stipes in comparison with VOCs (in TIC) emitted from intact cultures at the stages from fruiting body maturation to cap-autolysis and from intact cultures 1 day after cap autolysis, respectively (compare Fig. 7 to 9) as calculated from three parallel treatments per sample type.

\begin{tabular}{|l|c|c|c|c|}
\hline \multirow{2}{*}{ Sample } & \multicolumn{4}{|c|}{ Abundance of VOCs (TIC) } \\
\cline { 2 - 5 } & \multicolumn{2}{|c|}{ C-8 compounds } & \multicolumn{2}{c|}{ Sesquiterpenes } \\
\cline { 2 - 5 } & $\mathbf{1 - O c t e n - 3 - 0 l}$ & $\mathbf{3 - O c t a n o n e}$ & $\boldsymbol{\beta}$-Himachalene & Cuparene \\
\hline Macerated stipes $*^{1}$ & $7.67 \times 10^{7} \pm$ & $5.99 \times 10^{7} \pm$ & $5.84 \times 10^{6} \pm$ & $9.05 \times 10^{6} \pm$ \\
& $2.90 \times 10^{7}$ & $9.60 \times 10^{6}$ & $2.47 \times 10^{6}$ & $2.62 \times 10^{6}$ \\
\hline $\begin{array}{l}\text { Intact culture at the } \\
\text { stages from fruiting } \\
\text { body maturation to } \\
\text { cap-autolysis*2 }\end{array}$ & $1.51 \times 10^{4} *^{3}$ & $2.50 \times 10^{4} *^{3}$ & $1.35 \times 10^{4} *^{3}$ & $1.35 \times 10^{4} *^{3}$ \\
\hline $\begin{array}{l}\text { Intact culture 1 day } \\
\text { after cap autolysis }\end{array}$ & $1.70 \times 10^{4} *^{3}$ & $2.64 \times 10^{4} *^{3}$ & $1.35 \times 10^{4} *^{3}$ & $1.33 \times 10^{4} *^{3}$ \\
\hline
\end{tabular}

* ${ }^{1}$ Averages in VOC production over $3 \mathrm{~h}$ of sampling time were calculated from three parallel samples, upon which the values were divided by two in order to obtain a value that would correspond to the VOCs emitted by just one stipe.

$*^{2}$ Averages in VOC production over $24 \mathrm{~h}$ of sampling time were calculated from three parallel samples, upon which the values were divided by eight in order to obtain a value that would correspond to the amount of emissions of VOCs during $3 \mathrm{~h}$.

$*^{3}$ Values are only deduced from one curve but they were also divided by eight in order to adjust for the different sampling times.
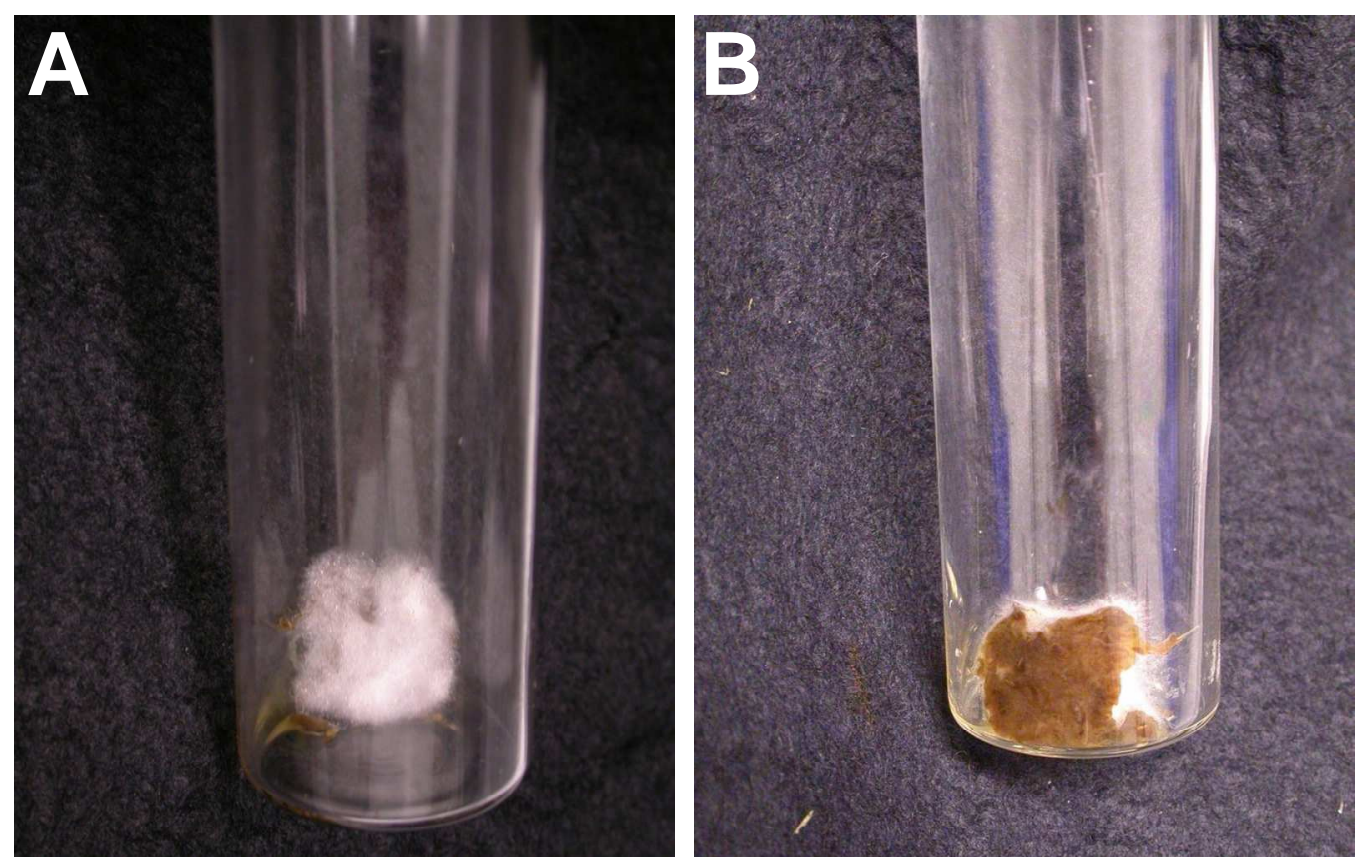

Fig. 15 Glass vials with $0.6 \mathrm{~g}$ of macerated stipe material of homokaryon AmutBmut incubated with loosened septum-caps for 2 days at room temperature after the SPME fibres used for VOC sampling as described in the text of Chapter 5.4.4 have been taken out from the septum-cap. (A) New mycelium was generated on the surface of macerated stipe material. (B) The same vial is shown photographed from behind showing the brown macerated stipe material attached to the glass surface surrounded by a ring of fresh mycelium that grew out of the material. 


\subsection{Conclusions}

Target of this study was to determine VOCs emitted during fruiting body development in order to see whether there are specific compounds that mark specific points in development such as the time point of initiation of fruiting body development or the time point of fruiting body maturation. To this end, first the best conditions for fruiting body development of $C$. cinerea on YMG/T agar slant cultures in $60 \mathrm{ml}$ glass vials had to be determined that allowed sampling of VOCs from the culture without a large contaminating background. $10 \mathrm{ml}$ agar slants inoculated in the middle with the fungus and incubated in horizontal manner turned out to be best. The technical details for rapid analysis of emission of VOCs during fruiting body development of $C$. cinerea by GC/MS analysis as a qualitative and a relative quantitative method has recently been described by Thakeow (2008). Quantitative statements with respect to an exact molecular amount of an emitted compound is however currently not possible since further analyses with pure reference compounds as a standard will have to be performed.

In this study and the study of Thakeow (2008), from the major peaks in GC/MS chromatograms the C8-compounds 3-octanone and 1-octen-3-ol and the sesquiterpenes $\beta$-himachalene and cuparene were identified as major volatiles compounds of C. cinerea. The C8-compounds were high in amounts at the beginning of fruiting body development and decreased at later stages of fruiting body development during fruiting body maturation and kept low in amounts after fruiting body autolysis. In contrast the sesquiterpenes occurred in increased amounts in later stages of fruiting body development at the stage of maturation and after maturation. Currently, it is however not clear whether they come from the mycelium, from the fruiting bodies or from both. In the future, developing primordia and after primordia maturation the maturating fruiting bodies need to be analysed in separated form without vegetative mycelium. Strikingly, after sufficient nutrients have been transported into the primordia, later stages in development (e.g. fruiting body maturation) can occur independently from a connection of the structures to a vegetative mycelium (Gooday 1974, Lu 1974, Moore 1979, Kües 2000).

The C8-compounds identified in this study and by Thakeow (2008) to be emitted from mushrooms are well-known typical fungal odours (FOs). 1-octen-3-ol recognised as a mushroom-like aroma (Vanhaelen et al 1978a, b, 1980, Tressl et al. 1982; Mau et al. 1997; Nidiry 2001, Sawahata and Shimano 2008) was found to be abundantly 
released in the mycelium stage of the fungi Trichothecium roseum and Tricholoma matsutake and it was found in these species to be gradually reduced in amounts during fruiting body formation. A similar phenomenon was observed regarding the occurrence of 3-octanone. There have been reports on the 1-octen-3-ol formation, e.g. in Agaricus campestris (Tressl et al. 1982), in Pleurotus pulmonarius (Assaf et al. 1997), in Volvariella volvacea (Mau et al. 1997), in Lentinus decadetes (Matsui et al. 2003) and in Lentinula edodes and T. matsutake (Akakabe et al. 2005).

For the production of these odours, different pathways from linoleic acid to 1-octen-3-ol have been proposed. For example, a hydroperoxide lyase enzymatic reaction on (10E,12Z)-9-hydroperoxyoctadeca-10,12-dienoic acid (9-HPOD) (Tressl et al. 1982) and on (8E,12Z)-9-hydroperoxyoctadeca-8,12-dienoic acid (10-HPOD) might occur (Wurzenber and Grosch 1982) or a homolytic cleavage of 10-HPOD (Combet et al. 2006).

In plants, the analogous 6-carbon (C6) containing compounds produced from $\alpha$-linolenic and linoleic acids by actions of lipoxygenases, hydroperoxide lyase are known as green leave volatiles (GLVs) (Visser 1979, Hatanaka 1993) are believed to function as intra- and interplant volatile signals (Matsui 2006). However, it is not fully established whether the C8-compounds have similar functions in the mushroom. Recently, it was found that 1-octen-3-ol in the ascomycete Penicillium paneum plays an important role in conidia germination as a volatile self-inhibitor (Chitarra et al. 2005). Such reports on the mushrooms are so far missing. However, in this study it was shown that wounding of the mycelium or of fruiting body structures causes an increase in the emission of the C8-compounds. Subsequently to heavy maceration, hyphal cells from stipe material were able to grow out quickly. From these observations, it rather appears that the $\mathrm{C} 8$-compounds do not have a negative effect on fungal growth of $C$. cinerea.

C8-compounds are prime candidates for mediating species specific interaction between fungi and insects (Fäldt et al. 1999; Thakeow et al. 2007, 2008). 1-Octen-3-ol has been shown to attract mites (Vanhaelen et al 1978a, b, 1980) and insects such as the phorid fly pest, Megaselia halterata (Pfeil and Mumma 1993). For 3-octanone, in the literature there are reports that they act as attractants for Tyrophagus putrescentiae (Vanhaelen et al 1978a ). In chapter 4 of this thesis, I showed for both compounds an attractant effect on the mite $T$. putrescentiae. It is possible that the mites use these compounds to identify mycelium of $C$. cinerea as food sources. Upon grazing on the mycelium, which is of course a type of wounding, deduced from experiments presented 
in this chapter (Fig. 11 and Fig. 14, Table 1 and Table 2), one might expect that the production of the C8-compounds might increase also due to grazing of mites. As a consequence, when the VOCs act as attractant, one should find mites in the fungal cultures clustered together in groups at places of grazing and not randomly distributed in the culture as single individuals. Such an effect was indeed repeatedly observed in mite-infested C. cinerea cultures and is documented in Fig. 10 and Fig. 22 in Chapter 4. An aggregation effect by mites within the mycelium can be of advantage when grazing on the aerial mycelium in which in the intact stages the mites cannot easily move. In contrast, once a hole is generated in the dense vegetative mycelium by mites's grazing, movement becomes easier for the mites and with the edges of the damaged mycelium, there is then an easier to attack surface for grazing of the mites (compare Fig. 22, Fig. 23 in Chapter 4 of this thesis). Interestingly, in the literature it is described that when $T$. putrescentiae is feeding on nematodes, mites of the same species are quickly attracted to the feeding site (Bilgrami 1994). However, there are other reasons for mites to aggregate, for example aggregation eases finding the partners for sexual reproduction (Muzaffar and Jones 2005). The density of local densities of mites determines their reproduction rates but availability of food sources and other endogenous factors such as humidity and temperature also play a role (Ferguson and Joly 2002).

Aggregation by mites might not only be influenced by VOCs being emitted from food sources as suggested in this study, but mites themselves produce VOCs acting as pheromones inducing aggregation of the animals (Royalty 1992, Mizoguchi et al. 2005, Raspotnig 2006, Yoder JA 2007). Amongst the VOcs acting as pheromones are sesquiterpenes such as monoterpenes citronellol and farnesol, and isoprenoids (Regev and Cone 1975, 1980, Royalty 1992, Kappers 2005). Some plant sesquiterpenes (e.g isoprenoids) have also been shown to act as attractants to mites (Phytoseiulus persimilis). In Chapter 4 of this thesis in Fig. 7 it was shown that T. putrescentiae mites are specifically attracted to the places where the caps of the maturating and mature mushrooms were previously attached to the fruiting body stipe. Interestingly, during the progress of these developmental stages, the sesquiterpenes $\beta$-himachalene and cuparene were detected in increased amounts. As C8-compounds, sesquiterpenes are prime candidates for mediating species specific interaction between fungi and insects (Fäldt et al. 1999; Thakeow et al. 2007, 2008). There appear to be no literature reports on effects of the two detected compounds $\beta$-himachalene and cuparene and attraction of mites. 
Future studies similar to those performed in Chapter 4 with the C8-compounds 1-octen3-ol and 3-octanone (see Fig. 25 and Table 6 in Chapter 4) need to show therefore whether these sesquiterpenes might act as attractants.

It was found however in the literature that cuparene-type sesquiterpenes from a mycelial culture of Flammulina velutipes proved to have an antimicrobial activity against the fungus Clodosporium herbarum and against the bacteria Becillus subtilis and Staphylococcus aureus (Ishikawa et al. 2001). Additionally, $\beta$-himachalene, as a component in essential oils of Vigna mungo and Chamaecyparis obtusa, showed antimicrobial activity as well (Abad et al. 1996, Singh and Tripathi 1999, Ho and Chein 2006, Yang et al. 2007). Thakeow (2008) therefore speculated that the two sesquiterpenes were produced during late stages of fruiting body development in order to protect the basidiospores formed at fruiting body maturation in the cap against a microbial attack. However, since the basidiospores are well protected by dense, melanin-pigmented spore wall layers (McLaughlin et al. 1985) they resist easily various adverse environmental conditions. This includes being consumed by mites and passing the digestive tract of the animals. Basidiospores are excreted in intact form in faecal pellets by the mites and the fully functional spores easily germinate from the pellets (see Fig. 15 in chapter 4 of this thesis and Navarro-González 2008). An extra protection by anti-microbial compounds appears therefore not necessary. Proposing that the production of the sesquiterpenes during the stages of basidiospore maturation and basidiospore release from the caps by autolysis acts in attraction of mites serving in spore distribution appears to be a more attractive hypothesis for a potential function of $\beta$-himachalene and cuparene in the life cycle of the fungus.

\subsection{References}

Abad A, Agullo C, Arno M, Cunat AC, Garcia MT and Zaragoza RJ (1996) Enantioselective synthesis of cuparane sesquiterpenes. Synthesis of (-)-cuparene and (-)-delta-cuparenol. J Organ Chem 61:5916-5919.

Akakabe Y, Matsui K and Kaiiwara T (2005) Stereochemical correlation between 10-hydroperoxyoctadecadienoic acid and 1-octen-3-ol in Lentinula edodes and Tricholoma matsutake mushrooms. Biosci Biotech Biochem 69:1539-1544. 
Assaf S, Hadar Y and Dosoretz CG (1997) 1-Octen-3-ol and 13-hydroperoxylinoleate are products of distinct pathways in the oxidative brake down of linoleic acid by Pleurotus pulmonarius. Enz Microb Technol 21:484-490.

Boulianne RP, Liu Y, Aebi M, Lu BC and Kües U (2000) Fruiting body development in Coprinus cinereus: regulated expression of two galectins secreted by a nonclassical pathway. Microbiology 146:1841-1853.

Breheret S, Talou T, Rapior S and Bessiere JM (1997) Monoterpenes in the aromas of fresh wild mushrooms (Basidiomycetes). J Agric Food Chem 45:831-836.

Chitarra GS, Abee T, Rombouts FM and Dijksterhuis J (2005) 1-Octen-3-ol inhibits conidia germination of Penicillium paneum despite of mild effects on membrane permeability, respiration, intracellular $\mathrm{pH}$, and changes the protein composition. FEMS Microbiol Ecol 54:67-75.

Cho IH, Choi HK and Kim YS (2006) Difference in the volatile composition of pinemushrooms (Tricholoma matsutake Sing.) according to their grades. J Agric Food Chem 54:4820-4825.

Cho IH, Lee SM, Kim SY, Choi HK, Kim KO and Kim YS (2007) Differentiation of aroma characteristics of pine-mushrooms (Tricholoma matsutake Sing.) of different grades using gas chromatography-olfactometry and sensory analysis. J Agric Food Chem 55:2323-2328.

Cho IH, Namgung HJ, Choi HK and Kim YS (2008) Volatiles and key odourants in the pileus and stipe of pine-mushroom (Tricholoma matsutake Sing.). Food Chem 106:71-76.

Combet E, Burton KS, Eastwood DC, Griffiths G and Henderson J (2006) Eigth-Carcon volatiles in mushrooms and fungi: properties, analysis, and biosynthesis Mycoscience 47:317-326.

Fäldt J, Jonsell M, Nordlander G and Borg-Karlsson AK (1999) Volatiles of bracket fungi Fomitopsis pinicola and Fomes fomentarius and their functions as insect attractants. J Chem Ecol 25:567-590.

Fan TY, Hwang DH and Kinsella JE (1976) Methyl ketone formation during germination of Penicillium roqueforti. J Agric Food Chem 24:443-447.

Fons F, Rapior S, Fruchier A, Saviuc P and Bessiere JM (2006) Volatile composition of Clitocybe amoenolens, Tricholoma caligatum and Hebeloma radicosum. Crypt Mycol 27:45-55. 
Gooday GW (1974) Control of development of excised fruit bodies and stipes of Coprinus cinereus. Trans Br Mycol Soc 62:391-399.

Granado JD, Kertesz-Chaloupková K, Aebi M and Kües U (1997) Restriction enzymemediated DNA intergration in Coprinus cinereus. Mol Gen Genet 256:28-36.

Hatanaka A (1993) The biogeneration of green odor by green leaves. Phytochemistry 34:1201-1218.

Ho TL and Chein RJ (2006) Total synthesis of (+)- $\beta$-himachalene. Helvet Chim Act 89:231-239.

Ishikawa NK, Kasuya MCM and Vanetti MCD (2001) Antibacterial activity of Lentinula edodes grown in liquid medium. Braz J Microbiol 32:206-210.

Jeleń HH (2002) Volatile sesquiterpenes hydrocarbons characteristic for Penicillium roqueforti strains producing PR Toxin. J Agric Food Chem 50:6569-6574.

Jeleń HH (2003) Use of solid phase microextraction (SPME) for profiling fungal volatile metabolites. Lett Appl Microbiol 36:263-267.

Kappers IF, Aharoni A, van Herpen TWJM, Luckerhoff LLP, Dicke $M$ and Bouwmeester HJ (2005) Genetic engineering of terpenoid metabolism attracts, bodyguards to Arabidopsis. Science 309:2070-2072.

Kawabe T and Morita H (1993) Volatile components in culture fluid of Polyporus tuberaster. J Agric Food Chem 41:637-640.

Kertesz-Chaloupková K, Walter PJ, Granado JD, Aebi M and Kües U (1998) Blue light overrides repression of asexual sporulation by mating type genes in the basidiomycete Coprinus cinereus. Fungal Genet Biol 23:95-109.

Keshri G and Magan N (2001) Detection and differentiation between mycotoxigenic and non-mycotoxigenic strains of two Fusarium spp. using volatile production profiles and hydrolytic enzymes. J Appl Microbiol 89:825-833.

Keshri G, Magan N and Voysey P (1998) Use of an electronic nose for the early detection and differentiaion between spoilage fungi. Lett Appl Microbiol 27:261-264.

Keshri G, Challen M, Elliott T and Magan N (2003) Differentiation of Agaricus species and other homobasidiomycetes based on volatile production patterns using an electronic nose system. Mycol Res 107:609-613.

Kinderlerer JL (1989) Volatile metabolites of filamentous fungi and their role in food flavour. J Appl Bacteriol Symp Suppl 67:133S-144S. 
Kinsella JE and Hwang DH (1976) Enzymes of Penicillium roqueforti involved in the biosynthesis of cheese flavour. CRC Crit Rev Food Sci Nutr 8:191-228.

Krings U, Hapetta D and Berger RG (2008) A labelling study on the formation of perillene by submerged cultured oyster mushroom, Pleurotus ostreatus. Appl Microbiol Biotech 78:533-541.

Kües U (2000) Life history and developmental processs in the basidiomycete Coprinus cinereus. Microbiol Mol Biol Rev 64:316-353.

Kües U, Mai C and Militz H (2007) Biological wood protection against decay, microbial staining, fungal moulding and insect pests. In: Wood production, wood technology and biotechnological impacts (U Kües, ed.), Universitätsverlag, Göttingen, Germany, pp. 273-294.

Liu Y, Srivilai P, Loos S, Aebi M and Kües U (2006) An essential gene for fruiting body initiation in the basidiomycete Coprinopsis cineerea is homologous to bacterial cyclopropane fatty acid synthase genes. Genetics 172:1-12.

Lu BC (1974) Meiosis in Coprinus. V. The role of light on basidiocarp initiation, mitosis and hymenium differentiation in Coprinus lagopus. Can $\mathrm{J}$ Bot 52:299-305

Matsui K (2006) Green leaf volatiles: hydroperoxide lyase pathway of oxylipin metabolism. Curr Opin Plant Biol 9:274-280.

Matsui K, Sasahara S, Akakabe Y and Kaiiwara T (2003) Linoleic acid 10-hydroperoxide as an intermediate during formation of 1-octen-3-ol from linoleic acid in Lentinus decadetes. Biosci Biotech Biochem 67:2280-2282.

Mau JL, Chyau CC, Li JY and Tseng YH (1997) Flavor compounds in straw mushrooms Volvariella volvacea harvested at different stages of maturity. J Agric Food Chem. 45:4726-4729.

McLaughlin DC, Beckett A and Yoon KS (1985) Ultrastructure and evolution of ballistosporic basidiospores. Bot J Linn Soc 91:253-271

Mizoguchi A, Murakami K, Shimizu N, Mori N, Nishida R and Kuwahara Y (2005) $\mathrm{S}$-isorobinal as the female sex pheromone from an alarm pheromone emitting mite, Rhizoglyphus setosus. Exp Appl Acarol 36:107-117.

Moore D, Elhiti MMY, Butler RD (1979) Morphogenesis of the carpophore of Coprinus cinereus. New Phytol 83:695-722. 
Navarro-González M (2008) Growth fruiting body development and laccase production of selected coprini. PhD thesis. Georg-August University of Göttingen, Göttingen, Germany.

Nidiry ESJ (2001) Structure-fungitoxicity relationships of some volatile flavour constituents of the edible mushrooms Agaricus bisporus and Pleurotas florida. Flavour Fragr J 16:245-248.

Okamoto K, Narayama S, Katsuo A and Shigematsu I (2002) Biosynthesis of p-anisaldehyde by the white-rot basidiomycete Pleurotus ostreatus. J Biosci Bioengin 93:207-210.

Ohta A (1983) Quantitative-analysis of odourous compounds in the fruit bodies of Tricholoma-matsutake. Trans Mycol Soc Jpn 24:185-190.

Pfeil RM and Mumma RO (1993) Bioassay for evaluating attraction of the phorid fly, Megaselia halterata to compost colonized by the commercial mushroom, Agaricus bisporus and to 1-octen-3-ol and 3-octanone. Applicata 69:137-144.

Rapior S, Breheret S, Talou T and Bessiere JM (1997) Volatile flavor constituents of fresh Marasmius alliaceus (Garlic Marasmius). J Agric Food Chem 45:820-825.

Rapior S, Breheret S, Talou T, Pelissier Y and Bessiere JM (2002) The anise-like odour of Clitocybe odora, Lentinellus cochleatus and Agaricus essettei. Mycologia 94:373-376.

Raspotnig G (2006) Chemical alarm and defence in the oribatid mite Collohmannia gigantea (Acari: Oribatida). Exp Appl Acarol 39:177-194.

Regev S and Cone WW (1975) Evidence of farnesol as a male sex attractant of 2-spotted spider-mite, Tetranychus urticae Koch. (Acarina: Tetranychidae). Environ Entomol 4:307-311.

Regev S and Cone WW (1980) Monoterpene citronellol, as a male sex attractant of the twospotted spider-mite, Tetranychus urticae (Acarina: Tetranychidae). Environ Entomol 9:50-52.

Royalty RN, Phelan PL and Hall FR (1992) Arrestment of male 2-spotted spider-mite caused by female sex-pheromone. J Chem Ecol 18:137-153.

Sawahata T, Shimano S and Suzuki M (2008) Tricholoma matsutake 1-octen-3-ol and methyl cinnamate repel mycophagous Proisotoma minuta (Collembola: Insecta). Mycorrhiza 18:111-114.

Schnürer J, Olsson J and Börjesson T (1999) Fungal Volatiles as Indicators of food and Feeds Spoilage. Fungal Gen Biol 27:209-217. 
Singh J, Tripathi NN (1999) Inhibition of storage fungi of black gram (Vigna mungo L.) by some essential oils. Flav Frag J 14:1-4.

Srivilai P (2006) Molecular analysis of genes acting in fruiting body development in basidiomycetes. PhD thesis. Georg-August University of Göttingen, Göttingen, Germany.

Srivilai P, James TY, Vilgalys R, Chaisaena W and Kües U (2005) Heterologous expression of mating type genes in basidiomycetes. In: VI Genetics and Cellular Biology of Basidiomycetes (AG Pisabarro and L Ramírez, eds.), Universida Pública de Navarra, Pamplona, Spain, pp. 139-150.

Sugihara, TF and Humfeld H (1954) Submerged culture of mycelium of various species of mushrooms. Appl Microbiol 2:170-172.

Swamy S, Uno I, and Ishikawa T (1984) Morphogenic effects of mutations at the $A$ and $B$ inconpatability factors in Coprinopsis cinereus. J Gen Microbiol 130:3219-3224.

Thakeow P (2008) Development of a basic biosensor system for wood degradation using volatile organic compounds. $\mathrm{PhD}$ thesis. Georg-August University of Göttingen, Germany.

Thakeow P, Holighaus G and Schütz S (2007) Volatile compounds for wood assessment. In: Wood production, wood technology and biotechnology impacts (U Kües, ed.), Universitätsverlag Göttingen, Germany, pp. 197-228.

Tressl R, Bahri D and Engel KH (1982) Formation of 8-carbon and 10-carbon components in mushroom (Agaricus campestris). J Agric Food Chem 30:89-93.

Vanhaelen M, Vanhaelen-Fastre R and Greeraerts J (1978a) Volatile constituents of Trichothecium roseum. Sabouraudia 16:141-150.

Vanhaelen M, Vanhaelen-Fastre R, Geeraerts J and Wirthlin T (1978b) Cis- and transocta-1,5-dien-3-ol, new attractants to the cheese mite Tyrophasus putrescentiae (Schrank) (Acarina: Acaridae) identified in Trichothecium roseum (Fungi Imperfecti). Microbios 23:199-212.

Vanhaelen M, Vanhaelen-Fastré R and Geeraerts J (1980) Occurrence in mushrooms (Homobasidiomycetes) of cis- and trans-octa-1,5-dien-3-ol, attractants to the cheese mite Tyrophagus putrescentiae (Schrank) (Acarina: Acaridae). Cell Mol Life Sci 36:406-407.

Visser JH (1979) Electroantennogram responses of the colorado beetle, Leptinotarsadecemlineata, to plant. Ent Exp Et Appl 25:86-97. 
Wu S, Krings U, Zorn H and Berger RG (2005) Volatile compounds from the fruiting bodies of beefsteak fungus Fistulina hepatica (Schaeffer: Fr.) Fr. Food Chem 92:221-226.

Wood WF and Lefevre CK (2007) Changing volatile compounds from mycelium and sporocarp of American matsutake mushroom, Tricholoma magnivelare. Biochem System Ecol 35:634-636.

Wurzenberger M and Grosch W (1982) The enzymic oxidative breakdown of linoleicacid in mushrooms (Psalliota bispora). Z Lebensm Unters-Forsch 175:186-190.

Yang JK, Choi MS, Seo WT, Rinker DL, Han SW and Cheong GW (2007) Chemical composition and antimicrobial activity of Chamaecyparis obtusa leaf essential oil. Fitoterapia 78:149-152.

Yoder JA, Mowrey DD, Rellinger EJ, Tank JL, Hanson PE and York RW (2007) Detection of the mite alarm pheromone neryl forimate in the velvet mite, Balaustium sp (Parasitengona: Erytihraeidae) Int J Acarol 33:73-78.

Zeppa S, Gioacchini MA, Guidi C, Guescini M, Pierleoni R, Zambonelli A and Stocchi V (2004) Determination of specific volatile organic compounds synthesised during Tuber borchii fruit body development by solid-phase microextraction and gas chromatography/mass spectrometry. Rapid Commun Mass Spectrom 18:199-205. 


\title{
Curriculum Vitae
}

Personal profile:

$\begin{array}{lll}\text { Name } & : & \text { Wassana Chaisaena } \\ \text { Date of birth } & : & 31^{\text {th }} \text { December } 1965 \\ \text { Place of birth } & : & \text { Bangkok, Thailand } \\ \text { Gender } & : & \text { Female } \\ \text { Nationality } & : & \text { Thai } \\ \text { Languages } & : & \text { Thai (native) and English }\end{array}$

Working place during the PhD study:

Address

\author{
Georg-August-University of Göttingen, Germany \\ Büsgen-Institute, Section Molecular Wood \\ Biotechnology and Technical Mycology \\ Büsgenweg 2, \\ D-37077, Göttingen, Germany
}

Permanent working place:

Prof. title

Assist.Prof. Wassana Chaisaena

Address

Rajamangala University of Technology Lanna

Phitsanulok Campus, Thailand

Faculty of Science and Agricultural Technology

$52 \mathrm{Mu}$ 7, Ban Krang, Muang District

65000, Phitsanulok, Thailand 


\section{Educational qualifications:}

PhD studies

(2004-2008)

\section{Master degree}

M.Sc.

(1988-1992)

\section{Bachelor degree}

B.Ed.Sc

(1985-1988)

\section{Scholarships}

(2004-2007)
PhD Program Wood Biology and Technology

Georg-August-University of Göttingen, Germany

Büsgen-Institute, Section Molecular Wood

Biotechnology and Technical Mycology

Dissertation: Light effects on fruiting body development of wildtype in comparison to light-insensitive mutant strains of the basidiomycete Coprinopsis cinerea, grazing of mites (Tyrophagus putrescentiae) on the strains and production of volatile organic compounds during fruiting body development Supervisor: Prof. Dr. Ursula Kües

Biological chemistry, Srinakharinwirot University, Bangkok, Thailand

Thesis: Study of esterase and alkaline phosphatase isozymes from hemolymph and gut of silkworm,

Bombyx mori

Supervisor: Assoc. Prof. Sumonta Promboon and Assoc. Prof. Arunee Ingkakul

Education (Science-Chemistry)

Srinakharinwirot University, Bangkok, Thailand

Rajamangala University of Technology Lanna Phitsanulok Campus granted for $\mathrm{PhD}$ studies at the Georg-August-University Göttingen, Germany 
(1988-1989)

(1985-1986)

Working experience:

1999,2003

1994-present

1990-1994

$1989-1990$

1988

Training course

20-27.09.2005

29-30.09.2003
Kao Essential Champoo Industry Scholarship for master studies at the Srinakharinwirot University, Bangkok, Thailand

King Bumipol scholarship for Bachelor studies at the

Srinakharinwirot University, Bangkok, Thailand

Tutor in chemistry (part-time), Tutor Academy, Bangkok, Thailand

Lecturer, Rajamangala University of Technology, Lanna Phitsanulok Campus, Thailand

Teacher at high school: Naenmaprangsuksavithaya School, Phitsanulok, Thailand

Practical student: Breeding and cultivation of the silkworm, Bombyx mori in Thailand, Kasetsart University, Thailand Practical student: Modification of seaweed to agarose production, Srinakharinwirot University, Bangkok, Thailand

Edible mushroom cultivation in Phitsanulok, Thailand TGIST web-based course offered by the National Science and Technology Development Agency, Thailand Graduate

Institute of Science Technology

\section{Publications}

Kües U, Navarro-Gonzaléz M, Srivilai P, Chaisaena W And Velagapudi R (2007) Mushroom biology and genetics. In: Wood production, wood technology and biotechnology impacts (U Kües, ed.), Universitätsverlag Göttingen, Germany, ISBN:13: 978-3-3-938616-84-0, pp. 587-607. 
Kharazipour A, Ludwig K, Chaisaena W, Polle A and Kües U (2007) Wood and other plant fibres in the production of peat substitutes and pot plant containers. In: Wood production, wood technology and biotechnology impacts (U Kües, ed.), Universitätsverlag Göttingen, Germany, ISBN:13: 978-3-3-938616-84-0, pp. 609-635.

Rühl M, Kilaru S, Majcherczyk A, Hoegger PJ, Navarro-González M, Chaisaena W, Naumann A, Peddireddi S, Malik I and Kües U, Biotechnological research on basidiomycete fungi. In: Review of Forests, Wood Products and Wood Biotechnology of Iran and Germany (Kharazipour A et al.,eds.), DAAD, Germany, pp. 58-69.

Srivilai P, Chaisaena W, and Kües U (2005a) Genetic analysis of Coprinopsis cinerea mutants with defects in fruiting body development. In: VI Genetics and Cellular Biology of Basidiomycetes (AG Pisabarro and L Ramírez, eds.), Universida Pública de Navarra, Pamplona, Spain, pp. $177-190$.

Srivilai P, James TY, Vilgalys R, Chaisaena W and Kües U (2005b). Heterologous expression of mating type genes in basidiomycetes. In: VI Genetics and Cellular Biology of Basidiomycetes (AG Pisabarro and L Ramírez, eds.), Universida Pública de Navarra, Pamplona, Spain, pp. 139150.

2003 Chaisaena P, Suksawat M, Chaisaena W and Singhadaung R (2003) The study on recycled paper to pot plant container of Kalanchoe coated with paraffin and glycerol. Research report to the Rajamangala University of Technology, Lanna Phitsanulok Campus, Thailand (in Thai).

Chaisaena W, Suksawat M, Saijeen S, Chaisaena P and Singhadaung R (2003) Study on Jiffy pot from banana leaf sheaths, water hyacinth, coconut dust and paper pulp for seed germination of Vinca. Research report to the Rajamangala University of Technology, Lanna Phitsanulok Campus, Thailand (in Thai).

2002 Chaisaena W, Chaisaena P Suksawat M, Raebroi A, and Singhadaung R (2002) The reused paper and paper pot which are made from paper pulp, fibre and water hyacinth and the soft herbaceous stalk of a banana tree. Research report to the Rajamangala University of Technology, Lanna Phitsanulok Campus, Thailand (in Thai).

Chaisaena W, Suksawat M, Treerat N, Chaisaena P and Singhadaung R (2001) Study on growth of Kalanchoe to grow in the reused paper pot which is made by a special machine. Research report to the Rajamangala University of Technology, Lanna Phitsanulok Campus, Thailand (in Thai). 
Kokthong A, Chaisaena W and Moopoung R (1999) Effects on chlorate in flowering of roses. Research report to the Rajamangala University of Technology Lanna Phitsanulok Campus, Thailand (in Thai).

Moopoung R, Chaisaena W and Kokthong A (1999) Effects of chlorate on amount of nitrate reductase activity in Logan. Research report to the Rajamangala University of Technology, Lanna Phitsanulok Campus, Thailand (in Thai).

1998 Chaisaena W, Suksawat M and Saijeen S (1998) Recycle of used paper for pot plant container which is composed of varied mixtures- effect to the growth and stability of Kalanchoe's containers. Research report to the Rajamangala University of Technology, Lanna Phitsanulok Campus, Thailand (in Thai).

\section{Conference contributions:}

Posters 2008
Navarro-González M, Chaisaena W, Sánchez-Hernández O, Plašil P, Schütz $\mathrm{S}$ and Kües U, Fungivorous mites promote inbreeding in Coprinopsis cinerea by distribution of basidiospores in faecal pellets. Multitrophic interactions Workshop. 6-7 March, Göttingen, Germany.

Chaisaena W, Navarro-González $M$ and Kües U, Defects in light regulation of sexual and asexual development in Coprinopsis cinerea. 24th Fungal Genetics Conference. 20-25 March, Asilomar, USA.

Navarro-González M, Chaisaena W, Sánchez-Hernandez O, Plašil P, Schütz $S$ and Kües U, Fungivorous mites promote inbreeding in Coprinopsis cinerea by distribution of basidiospores in faecal pellets. Molecular Biology of Fungi. 23-26 September, Hamburg, Germany.

Navarro-González M, Chaisaena W, Sanchez-Hernandez O, Schütz S and Kües U, Mites act in distribution of fungal spores in Coprinopsis cinerea. 24th Fungal Genetics Conference. 20-25 March, Asilomar, USA.

Chaisaena W, Navarro-González M, Srivilai P and Kües U, Coprinopsis cinerea mutants forming etiolated stipes under normal fruiting conditions. IXth International Fungal Biology Conference and $16^{\text {th }}$ New Phytologist Symposium. 18-20 September, Nancy, France.

Chaisaena W, Srivilai P, Navarro-González M and Kües U, Aberrant fruiting body formation in Coprinopsis cinerea: the etiolated stipe phenotype. $8^{\text {th }}$ European Conference on Fungal Genetics. 8-11 April, Vienna, Austria.

Navarro-González M, Chaisaena W and Kües U, Tissue development and differentiation during fruiting in the basidiomycete Coprinopsis 
cinerea. IXth International Fungal Biology Conference and $16^{\text {th }}$ New Phytologist Symposium. 18-20 September, Nancy, France.

Srivilai P, Kilaru S, Navarro-González M, Chaisaena W and Kües U, A constitutively activated Ras-GTPase alters mycelial growth in Coprinopsis cinereaand affects $B$ mating type regulated phenotypes in dikaryons and fruiting body development. $8^{\text {th }}$ European Conference on Fungal Genetics. 8-11 April, Vienna, Austria.

Chaisaena W, Navarro-González M, Srivilai $\mathrm{P}$ and Kües U, Light regulates fruiting body morphology in Coprinopsis cinerea. VAAMJahrestagung, 12-14 October, Frankfurt, Germany.

Chaisaena W, Srivilai P, Navarro-González M and Kües U, Aberrant fruiting body formation in Coprinopsis cinerea: the etiolated stipe phenotype. VAAM-Jahrestagung, 19-22 March, Jena, Germany.

Srivilai P, Kilaru S, Navarro-González M, Chaisaena W and Kües U, A constitutively activated Ras-GTPase alters mycelial growth in Coprinopsis cinerea and affects B mating type regulated phenotypes in dikaryons and fruiting development. $8^{\text {th }}$ European Conference on Fungal Genetics. 8-11 April, Vienna, Austria.

2005 Srivilai $P$, Chaisaena W and Kües U, Classical genetics in fruiting body development of Coprinopsis cinerea. $23^{\text {rd }}$ Fungal Genetics Conference Asilomar, 15-20 March, USA.

Srivilai P, Chaisaena W and Kües U, Mutants of Coprinopsis cinerea with defects in fruiting body development. 7th VAAM-Symposium Molecular biology of fungi, 3-7 September, Bochum, Germany.

Srivilai P, James TY, Vilgalys R, Chaisaena W and Kües U, Heterologous expression of mating type genes in basidiomycetes. Genetics and cellular Biology of Basidiomycetes VI. Pamplona, 3-6 June, Spain.

2004 Srivilai P, Navarro-González M, Chaisaena W and Kües U, Initiation of fruiting body development in the basidiomycete Coprinopsis cinerea. DBU Tagung, Osnabrück, 14-17 June, Germany. 


\section{Oral presentations:}

2007

Genetic analysis of mutants defective in fruiting body development. Seminar of the PhD program Wood biology and technology. June 20, 2007. Göttingen, Germany.

2006 Genetic analysis of mutants in mushroom development: Coprinopsis cinerea. Seminar of the $\mathrm{PhD}$ course: Wood structure, properties and biological degradation. PhD program Wood biology and Technology. May 8-13, 2006. Faculty of Forest Sciences Department of Wood Science, Swedish University of Agricultural Sciences, Uppsala, Sweeden.

Genetic analysis of mutants with defects in fruiting. Seminar of the $\mathrm{PhD}$ program Wood biology and technology. June 20, 2006. Göttingen, Germany.

2005 Products of lignocellulosic material to cultivate plants. Seminar of the PhD program Wood biology and technology. April 19, 2005. Göttingen, Germany.

Volvariella volvacea, mushroom cultivation in the tropics. Seminar of the PhD program Wood biology and Technology. October 18, 2005. Göttingen, Germany. 